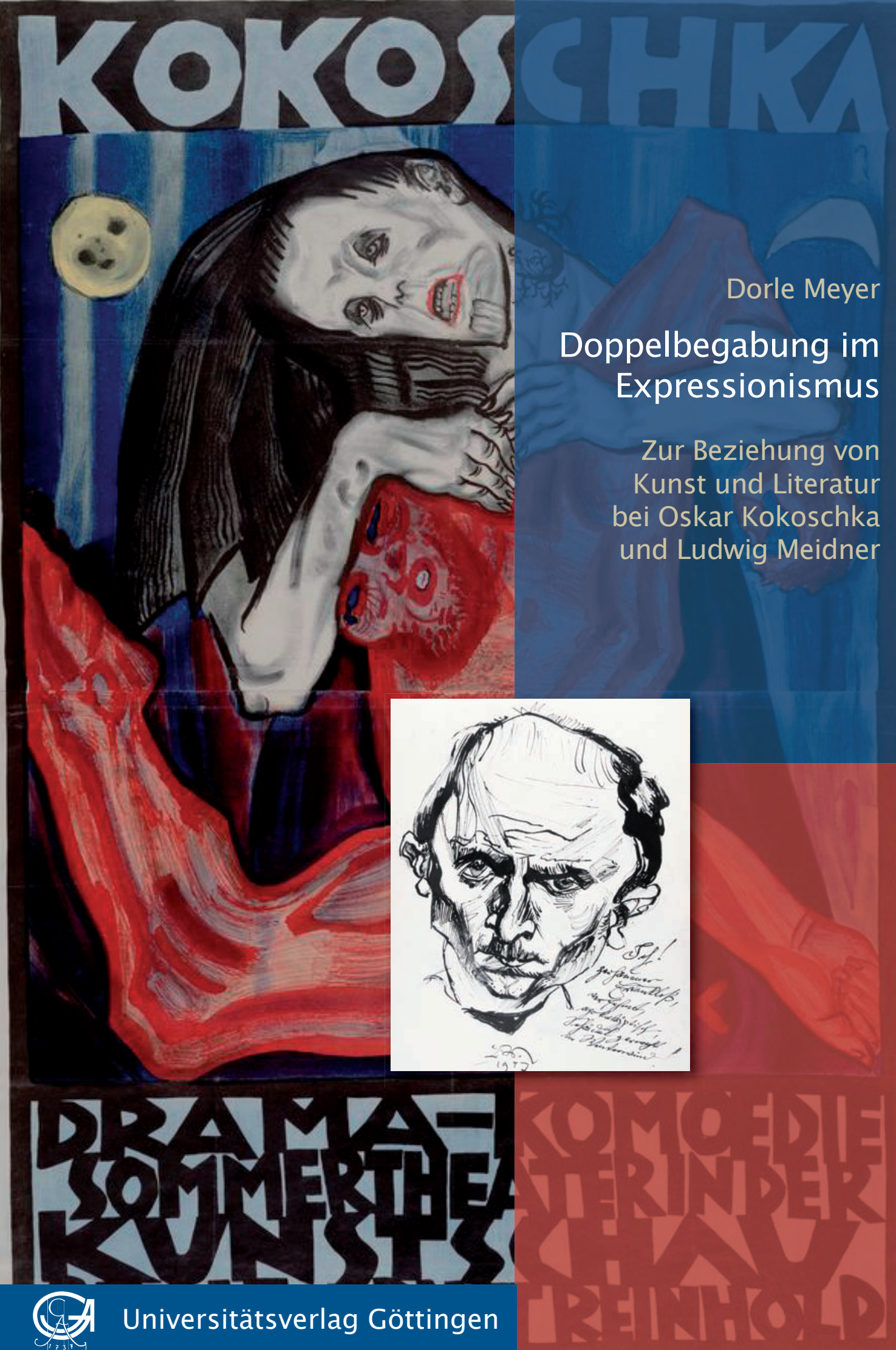

DRV CK VON AIEBERT BERG 



\section{Doppelbegabung im Expressionismus}

This work is licensed under the Creative Commons License 3.0 "by-nd", allowing you to download, distribute and print the document in a few copies for private or educational use, given that the document stays unchanged and the creator is mentioned.

You are not allowed to sell copies of the free version.

$$
\begin{array}{|c|}
\hline \text { CC) } \\
\text { SOREE RIGHIS RESERVED }
\end{array}
$$


erschienen im Universitätsverlag Göttingen 2013 
Dorle Meyer

Doppelbegabung im

Expressionismus

Zur Beziehung von

Kunst und Literatur bei

Oskar Kokoschka und

Ludwig Meidner

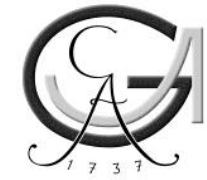

Universitätsverlag Göttingen 2013 


\section{Bibliographische Information der Deutschen Nationalbibliothek}

Die Deutsche Nationalbibliothek verzeichnet diese Publikation in der Deutschen Nationalbibliographie; detaillierte bibliographische Daten sind im Internet über $<$ http://dnb.ddb.de $>$ abrufbar.

\section{Autorenkontakt}

Dorle Meyer

e-mail: DorleMeyer@gmx.de

Dieses Buch ist auch als freie Onlineversion über die Homepage des Verlags sowie über den OPAC der Niedersächsischen Staats- und Universitätsbibliothek (http://www.sub.uni-goettingen.de) erreichbar und darf gelesen, heruntergeladen sowie als Privatkopie ausgedruckt werden. Es gelten die Lizenzbestimmungen der

Onlineversion. Es ist nicht gestattet, Kopien oder gedruckte Fassungen der freien

Onlineversion zu veräußern.

Satz und Layout: Dorle Meyer

Umschlaggestaltung: Franziska Lorenz

Titelabbildungen:

Hintergrund: Oskar Kokoschka: „Pietà“, Plakat für sein Drama „Mörder, Hoffnung der Frauen“ in der „Internationalen Kunstschau 1909“, 1909, Farblithografie, 125 x 81 cm, Leopold Museum, Wien.

(C) Fondation Oskar Kokoschka/ VG Bild-Kunst, Bonn 2013

Vordergrund: Ludwig Meidner: Selbstporträt (bez. u.r. mit den Worten: „Ich!

Zerhauener Erdenkloß, verfehmt, apokalyptisch, Schädel zerweht im Winterwind!“), 1917, Tusche/Rohrfeder, aus dem Skizzenbuch entstanden im Kriegsgefangenenlager Kottbus-Merzdorf im März 1917, Nachlass Ludwig Meidner Darmstadt.

(C) Ludwig-Meidner-Archiv, Jüdisches Museum der Stadt Frankfurt am Main

(C) 2013 Universitätsverlag Göttingen

http://univerlag.uni-goettingen.de

ISBN: 978-3-86395-107-8 


\section{Inhaltsverzeichnis}

Vorwort....... .7

1. Einleitung. 9

2. Doppelbegabung im Expressionismus ......................................................17

2.1. Definition von Doppelbegabung und historische Grundzüge bis zum Expressionismus.

2.2. Der Expressionismus als übergreifende Bewegung. 24

2.3. Doppelbegabung im Expressionismus - ihre Voraussetzungen und Vertreter 32

3. Fallbeispiele von doppelbegabten Künstlern des Expressionismus 43

3.1. Ludwig Meidner. 43

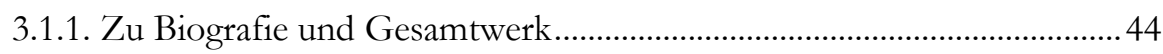

3.1.2. Bild- und Schriftwerke der expressionistischen Phase .............................. 51

3.1.3. Vergleichende formal-stilistische und inhaltliche Analyse.......................54

3.1.3.1. Die Großstadt als Erfahrungsraum ........................................54

3.1.3.2. Apokalypse - der Weltuntergang zur Welterneuerung?.....66 66

3.1.3.3. Der Krieg ................................................................................... 76

3.1.3.4. (Geistige) Revolution - der Wunsch nach Veränderung.... 91

3.1.3.5. Religion - der rote Faden in Meidners Schaffen ................100

3.1.3.6. Die Betrachtung des Menschen.............................................112

3.1.4. Zusammenfassung der Untersuchungen .................................................. 127

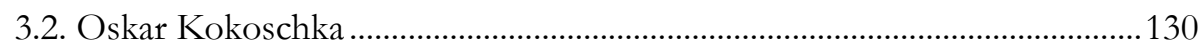

3.2.1. Zu Biografie und Gesamtwerk................................................................130

3.2.2. Bild- und Schriftwerke der expressionistischen Phase ...........................138

3.2.3. Vergleichende formal-stilistische und inhaltliche Analyse.....................142

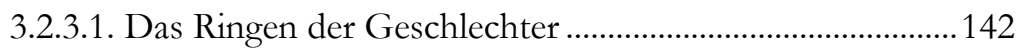

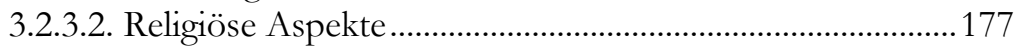

3.2.3.3. Der Mensch - Kokoschkas Porträts im Spiegel seines

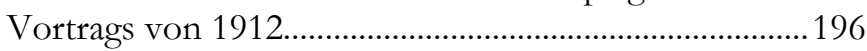

3.2.3.4. Krieg und politische Folgen....................................................223

3.2.3.5. Stilleben und allegorische Werke............................................236

3.2.4. Zusammenfassung der Untersuchungen ...................................................250 
3.3. Untersuchungen zur Entsprechung der Gestaltungsmittel...........................22

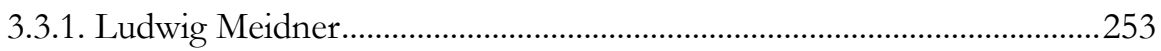

3.3.2. Oskar Kokoschka.............................................................................. 258

4. Ergebnisse und Schlussbemerkungen .........................................................265

A Quellen- und Literaturverzeichnis.............................................................273

B Textnachweis (Quellentexte) .....................................................................285

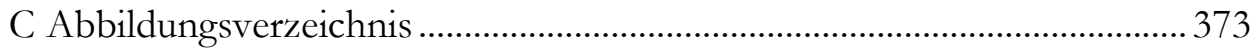




\section{Vorwort}

Bei der vorliegenden Arbeit handelt es sich um die leicht überarbeitete Fassung meiner Dissertation „Doppelbegabung im Expressionismus. Zum Zusammenhang von bildkünstlerischer und literarischer Aussage am Beispiel von Oskar Kokoschka und Ludwig Meidner", die im Winter 2011 von der Philosophischen Fakultät der Georg-August-Universität Göttingen angenommen wurde. Auf der Grundlage meiner Magisterarbeit über das expressionistische Schaffen Ludwig Meidners werden hierin die Forschungen zum Thema der Doppelbegabung im Expressionismus intensiv erweitert und maßgeblich vertieft.

Besonderer Dank gilt meinem Doktorvater Prof. Dr. Thomas Noll für seine stets unterstützende wissenschaftliche Betreuung, seine wertvollen Ratschläge und die hilfreiche konstruktive Kritik in allen Phasen der Arbeit, sowie meinem Zweitgutachter Prof. Dr. Carsten-Peter Warncke. Weiterhin sei der Graduiertenschule Geisteswissenschaften Göttingen (GSGG) gedankt, die mich durch Seminare, Summerschool und finanzielle Mittel während der Promotionszeit gefördert hat.

Von unschätzbarer Bedeutung für das Gelingen der Promotion war zudem die Unterstützung meiner Familie und meiner Freunde, die diese Phase intensiv und mit viel positiver Energie begleitet haben. Vor allem meinen Eltern sei dabei auf das Herzlichste gedankt, ohne deren stete mentale und finanzielle Hilfe diese Arbeit so nicht hätte entstehen können und denen darum die vorliegende Publikati- 
on gewidmet ist. Dr. Sarah Hoke sei für ihre kontinuierliche freundschaftliche Unterstützung durch hilfreiche Tipps, Korrekturvorschläge und motivierende Gespräche gedankt. Gleiches gilt für Dr. Stefan Christmann, insbesondere auch für seine Geduld und „Zauberei“ in jeglichen Computer- und Formatierungsfragen. Julia König und Katja Riemer als Freundinnen und „Büronachbarinnen“ danke ich für den Zusammenhalt insbesondere in der ersten Phase des gemeinsamen Projekts Promotion. Weiterhin sei meinen Freundinnen und Freunden - vor allem Martin und Eva Bender, Jörn Bünger, Sascha John, Anne Schneider, Friederike von Schwerin und Manuela Wengelnik - für die vielen guten Gespräche und insbesondere die abwechslungsreiche Zerstreuung in allen Lebenslagen gedankt.

Göttingen, im Februar 2013 


\section{Einleitung}

Fragestellung

Im Zentrum der vorliegenden Untersuchung über „Doppelbegabung im Expressionismus" über die Zusammenhänge zwischen bildkünstlerischem und literarischem Schaffen bei Oskar Kokoschka und Ludwig Meidner, steht die Frage nach dem formalen und inhaltlichen Zusammenhang zwischen diesen beiden speziellen künstlerischen Ausdrucksformen im Euvre expressionistischer, in diesem Sinne als in doppelter Hinsicht begabt zu bezeichnender Künstler. Es soll untersucht werden, in welchem qualitativen und quantitativen Verhältnis die beiden schöpferischen Potentiale im jeweiligen CEuvre zueinander stehen, wie sie einander in der Auseinandersetzung mit bestimmten Themen ergänzen können und welche unterschiedlichen oder vielleicht auch vergleichbaren Ausdrucksmittel im jeweiligen Medium entwickelt werden. Oder kürzer gefasst: Wie äußert sich Doppelbegabung? Dazu bedarf es einer eingehenden Betrachtung exemplarisch ausgewählter bildender Künstler, die sich zugleich auch durch ihr literarisches Schaffen hervor getan haben. Diese Eingrenzung begründet sich damit, dass es sich um eine kunstwissenschaftliche Dissertation handelt und das Thema der Doppelbegabung somit nicht mit dem Fokus auf künstlerisch tätigen Schriftstellern bearbeitet werden soll. Der Expressionismus eignet sich für die Betrachtungen besonders, da in 
dieser Phase viele bildende Künstler zusätzlich ihren Ausdruck in anderen Medien suchten. Zugunsten der Vergleichbarkeit bleibt die Auswahl der Künstler im Rahmen der Dissertation auf den deutschsprachigen Raum beschränkt.

Ausgehend von den Untersuchungen zur Wechselbeziehung von künstlerischem und schriftstellerischem Schaffen, die im Rahmen meiner Magisterarbeit „Ludwig Meidner - Werke seiner expressionistischen Schaffenszeit im Spiegel seiner Schriften" bereits am Beispiel Meidners vorgenommen wurden, möchte ich den Blick ausweiten, um das Phänomen der Doppelbegabung im Zeitraum zwischen ungefähr 1910 und 1920 genauer zu beleuchten. Zu fragen ist insbesondere nach den verschiedenen Ausprägungen von Doppelbegabung und nach den Gründen für ein verstärktes Ausdrucksverlangen in den unterschiedlichen künstlerischen Medien während des Expressionismus. Weitergehend sind anhand der einzelnen Künstler die konkreten Themenkreise und ihre Verarbeitung im jeweiligen Medium zu erörtern.

Die Grundlage für diese Untersuchungen bilden die Ergebnisse der Magisterarbeit, die, durch den Wunsch einer Zusammenführung meiner beiden Hauptfächer Kunstgeschichte und Deutsche Philologie motiviert, ebenfalls interdisziplinär ausgerichtet war. Sie zogen den Wunsch nach sich, weitere Erkenntnisse darüber zu erlangen, wie sich die Nähe zwischen den Künsten in anderen Fällen äußern mag. Damit stellen sich folgende Fragen: Welche weiteren Künstler waren neben Meidner in verschiedenen Bereichen schöpferisch tätig? Welche Gründe lassen sich für das Arbeiten in verschiedenen Medien bei expressionistischen Künstlern finden? Welche Überschneidungen in Themenwahl oder formaler Ausgestaltung lassen sich im konkreten Einzelfall erkennen? Und daraus resultierend: Wie ist die Beziehung zwischen bildkünstlerischem und schriftstellerischem Schaffen letztlich $\mathrm{zu}$ fassen?

Um Antworten auf diese Fragen zu finden, ist neben der Betrachtung der historischen Entwicklung künstlerischer Doppelbegabung sowie der Voraussetzungen dafür, explizit zu Beginn des 20. Jahrhunderts, vor allem die inhaltliche und formalstilistische Untersuchung einzelner Künstlerpersönlichkeiten und ihres Schaffens im Sinne von Fallstudien wichtig. Als zweiter Künstler, der neben Ludwig Meidner exemplarisch untersucht werden soll, ist Oskar Kokoschka vorgesehen. Dieser Künstler bietet sich an, insofern er nicht nur ein prominenter Vertreter des Expressionismus ist, sondern sich zudem kontinuierlich sowohl bildkünstlerisch, als auch schriftstellerisch betätigt hat. In dem schwerpunktmäßig zu untersuchenden Zeitraum zwischen 1910 und 1920, gleichsam der Kernphase expressionistischer Bestrebungen in allen künstlerischen Bereichen, haben beide genannten Künstler sich intensiv der Malerei oder Grafik einerseits, der Dichtung als Dramatiker, Lyriker oder Epiker andererseits gewidmet, was in solch ausgeprägtem Maße bei anderen mehrfach begabten Künstlern der Zeit nicht der Fall ist. Alfred Kubin beispielsweise, der neben seinem grafischen Schaffen ein bemerkenswert umfangreiches literarisches Euvre vorzuweisen hat, hat in besagtem 
Zeitraum allein ein Werk, wenn auch ein viel beachtetes - den Roman „Die andere Seite“ - veröffentlicht. Meidner und Kokoschka hingegen haben im zweiten Jahrzehnt des 20. Jahrhunderts in beiden Medien eine Vielzahl an Werken hervorgebracht, weshalb sich anhand ihrer Entwicklung und ihres Schaffens das Phänomen der Doppelbegabung am Lückenlosesten und damit am Repräsentativsten untersuchen lässt.

\section{Relevanz des Themas und Stand der Forschung}

Die Fokussierung auf das Thema der Doppelbegabung liegt neben einem interdisziplinär orientierten Interesse auch in der bislang unzulänglichen Berücksichtigung des Aspektes innerhalb der Forschung begründet. Dieses Defizit gilt es zu beheben, umso mehr als die Kunstgeschichte es sich aufgrund der großen Bedeutung der neuen Medien neuerdings zur Aufgabe gemacht hat, die Grundlagen sozialer Kommunikation mehr zu erforschen, wobei interdisziplinäre Beziehungen selbstverständlich von entscheidender Bedeutung sind. Gerade die zu Beginn des 20. Jahrhunderts entwickelten avantgardistischen Formensprachen, die vielfach durch ein spezielles Wort-Bild-Verhältnis geprägt sind, sind dabei durch ihre bis heute nachhaltige Wirkung von besonderem Interesse. Die Untersuchung von expressionistischer Doppelbegabung bietet sich indes an, da hier dieses Verhältnis besonders eng ist. Außerdem ist gerade sie von besonderer Bedeutung, da sie eng verknüpft ist mit der zu Beginn des 20. Jahrhunderts verstärkt hervortretenden Idee des Gesamtkunstwerks und der Zusammenführung von Kunst und Leben. ${ }^{1}$ Ideen, die auf so bedeutende Kunstströmungen wie das Bauhaus, Dada und, nach dem Zweiten Weltkrieg, in gewisser Weise auf die Fluxus-Bewegung ausstrahlen sollten.

Obwohl das Phänomen der Doppelbegabung nun zunehmend Beachtung findet - wenn auch mehr im Bereich der Vergleichenden Literaturwissenschaft - so hat es bislang nur selten eine genauere Behandlung erfahren. Als Ausnahmen sind die älteren Publikationen von Herbert Günther („Künstlerische Doppelbegabungen“, München 1960), Ernst Scheidegger („Malende Dichter - Dichtende Maler“, Zürich 1957) und Kurt Böttcher („Dichter als Maler“, Stuttgart 1980) zu nennen. Allerdings handelt es sich hierbei eher um Anthologien - als kritische Studien zum Phänomen der Doppelbegabung im Sinne wissenschaftlicher Forschung können sie nicht gelten und sind daher wenig erhellend. Darüber hinaus ist festzustellen, dass keine eingehendere Auseinandersetzung mit literarisch talentierten Künstlern erfolgt ist, sondern es bei einer undifferenzierten Parallelisierung derselben mit künstlerisch begabten Schriftstellern bleibt. Eine solche Gleichsetzung ist aber nicht zulässig, da der Umgang mit dem jeweiligen Medium dadurch geprägt ist, worauf der Schaffende seinen Hauptakzent gelegt hat. Bei Günther beispielsweise

${ }^{1}$ Näheres hierzu s. auch im Katalog der Ausstellung „Gesamtkunstwerk Expressionismus“ auf der

Darmstädter Mathildenhöhe 2010 (Beil/Dillmann (2010)), S. 12 ff. 
mangelt es ferner auch an einer genaueren Abgrenzung zwischen denjenigen mehrfach Begabten, die mit ihren Werken in die Öffentlichkeit getreten sind und denen, die bestimmte Bereiche ihres Schaffens mehr privat und tendenziell laienhafter verfolgt haben.

Andere Publikationen zum Thema Doppelbegabung beziehen sich auf deren Erscheinungsformen in anderen Kunstströmungen wie der Romantik. Hier können Georg J. Wolf („Deutsche Malerpoeten“, München 1934) und Heinz Stolz (,Sieben Malerpoeten“, Düsseldorf 1948) als Beispiele angeführt werden. Diejenigen, die sich tatsächlich mit expressionistischen bildenden Künstlern, die eine zusätzliche literarische Begabung offenbaren, beschäftigt haben, tun dies in Einzeluntersuchungen zu den entsprechenden Künstlern. Zu den doppelbegabten Künstlern ersten Ranges in dieser Zeit, wie Oskar Kokoschka, existieren Publikationen beispielsweise von Henry I. Schvey („Oskar Kokoschka. The Painter as Playwright“/1982) und Gerhard J. Lischka („Oskar Kokoschka: Maler und Dichter“/1972). Jedoch lassen diese Publikationen eine gleichwertige Verknüpfung beider Wirkungsbereiche vermissen oder sind thematisch beschränkt. So gehen Schveys sehr aufschlussreiche Untersuchungen zu Kokoschkas Dramen vor allem von den Texten aus und beziehen nur sporadisch bildkünstlerische Werke zum Vergleich mit ein. Lischka nimmt zwar eine tatsächlich interdisziplinäre Untersuchung zu Kokoschkas Doppelbegabung vor, doch bleibt diese auf den Themenkreis „Mann und Weib“ begrenzt. Eine eingehendere Betrachtung des Medienverhältnisses in Bezug auf andere von Kokoschka behandelte Themen steht damit noch aus. In heute minder populären Fällen wie dem Ludwig Meidners sind die Untersuchungen zu seiner Doppelbegabung noch begrenzter. Es gibt nur wenige Aufsätze, die den Blick überhaupt auf das schriftstellerische Euvre des Künstlers lenken (Michael Assmann „Literarische Werke und Briefe (Auswahl)“/1991; Michael Assmann „,Leg den Pinsel weg, Kleckser!' - Der Dichter und Schriftsteller Ludwig Meidner“/2001). Dementsprechend kurz und überaus unvollständig fallen die Bemerkungen aus, die auf die Relation zwischen literarischem und bildkünstlerischem Werk eingehen.

Es fehlen also generell für beide Künstler eingehendere Einzeluntersuchungen zum inhaltlichen, formalen und intentionalen Verhältnis ihrer Schrift- und Bildwerke. Es ist das Ziel der vorliegenden Studie diesem Mangel im Kapitel 3.) abzuhelfen. Was darüber hinaus fehlt, sind übergreifende Arbeiten zum Thema der Doppelbegabung im Expressionismus insgesamt. Im Folgenden soll eben diese, wenn auch nur exemplarisch angerissene Zusammenführung verschiedener Künstler, die unter den gleichen Vorzeichen - „Expressionismus“ und „Doppelbegabung" - gearbeitet haben, erreicht werden. Dabei soll auch die Frage geklärt werden, warum im Expressionismus eine Häufung von Doppelbegabung zu bemerken ist. ${ }^{2}$

${ }^{2}$ Darauf weist beispielsweise auch Henry I. Schvey in seinem Aufsatz „Doppelbegabte Künstler als Seher: Oskar Kokoschka, D. H. Lawrence und William Blake“ (In: Weisstein (1992), S. 73-85) hin. 
Methodische Überlegungen

Die Arbeit ist so aufgebaut, dass sie vom Allgemeinen ans Besondere heranführt. Zum besseren Verständnis des Hauptteils, wird zunächst in Kapitel 2.) eine Einführung gegeben, in der Grundlegendes geklärt werden soll. Dazu gehört vor allem eine genauere Definition der zu untersuchenden Form von Doppelbegabung und eine Eingrenzung des zu betrachtenden Zeitraums auf den Expressionismus. Hierbei soll auch kurz auf einige historische Aspekte eingegangen werden, wie beispielsweise die Verbreitung von Doppelbegabung und die soziologischen und politischen Hintergründe des Expressionismus. Darüber hinaus sollen anhand von verschiedenen zeitgenössischen Quellen Gründe für ein gesteigertes Ausleben von Doppelbegabung in dieser Periode benannt werden, auch um die im Hauptteil folgenden Beobachtungen besser kontextualisieren zu können.

Der Hauptteil im Kapitel 3.) ist in zwei umfangreiche Abschnitte gegliedert. Die Künstler Ludwig Meidner und Oskar Kokoschka, die als außerordentlich wichtige Vertreter und zentrale Beispiele ausgelebter Doppelbegabung gelten dürfen, sind in Einzeluntersuchungen zu fokussieren, um einen Überblick über ihr expressionistisches CEuvre zu erhalten und natürlich vor allem das Wechselverhältnis zwischen den jeweiligen Medien zu beleuchten. Hierbei wird der thematologische Ansatz - also eine nach Themen gegliederte Untersuchung - verfolgt, da die Bezüge zwischen den Medien, die als zwei verschiedene Mittel eines Ausdruckswillens genutzt werden, auf der inhaltlichen Ebene besonders deutlich sind.

Insgesamt ist das Vorgehen komparatistisch angelegt, wobei eine stärkere Konzentration auf die bildkünstlerischen Aspekte gelegt wird, da die Dissertation in erster Linie aus kunsthistorischer Perspektive motiviert ist. Die Werkanalysen und Vergleiche im Hauptteil der Arbeit werden vor allem der ikonografischikonologischen Methode beziehungsweise der literaturwissenschaftlichen Textuntersuchung verpflichtet sein. Der Schwerpunkt liegt somit auf der Deutung von Intention und Funktion der Werke und der Berücksichtigung ihrer formalen Umsetzung, welche über ausführliche Analysen nach kunsthistorischen und literaturwissenschaftlichen Gesichtspunkten herauszuarbeiten sein werden.

\section{Zur Vergleichbarkeit der Künste}

Der Vergleich der verschiedenen Künste untereinander ist in der Forschung nicht unumstritten. Schon in den vergangenen Jahrhunderten wurde das Verhältnis der Künste konträr diskutiert, wobei oftmals die Frage nach dem Wert und der Vorrangstellung einer der künstlerischen Disziplinen im Vordergrund stand (mehr dazu siehe Kapitel 2.1.). Im 20. Jahrhundert änderte sich das und so konzentriert man sich heute mehr auf die Fragestellung, ob und mit welchen Methoden die Künste miteinander verglichen werden können.

Wichtiger Ausgangspunkt hierfür war in Deutschland die 1917 von Oskar Walzel herausgegebene Schrift „Wechselseitige Erhellung der Künste: ein Beitrag 
zur Würdigung kunstgeschichtlicher Begriffe", 3 in der der Autor die von Heinrich Wölfflin aufgestellten kunstgeschichtlichen Grundbegriffe auf die Literatur anzuwenden versuchte. Weitere komparatistische Studien in dieser Richtung, die in Frankreich bereits im 19. Jahrhundert vorgenommen wurden $-z$. B. Jean-François Sobrys „Poétique des arts ou Cours de peinture et de littérature comparées“ (Paris 1810) oder Jean-Jacques Amperes „De la littérature française dans ses rapports avec les littératures étrangères au moyen age“ (Antrittsvorlesung an der Sorbonne, 1832) - hatten dem Künstevergleich nicht zur Etablierung verhelfen können. Die französische Schule der Komparatistik blieb daher lange Zeit ihrer traditionellen Ausrichtung auf die vergleichende Literaturgeschichte treu. Die wirklich ernsthafte literatur-wissenschaftliche Auseinandersetzung mit der „wechselseitigen Erhellung der Künste" erfolgte erst ab Mitte des 20. Jahrhunderts. Walzels Schrift wieder aufgreifend entwickelte sich dazu eine Diskussion zunächst im deutschen Sprachraum, die dann verspätet auch auf die USA übergriff. ${ }^{4}$

Die als „amerikanische Schule“ bezeichnete, neuere Komparatistik hat seitdem in sehr viel umfangreicherem Maße als die deutsche Forschung versucht, Methoden und Grundsatzfragen zu klären. Zu nennen sind hier unter anderem das Standardwerk „Theory of literature“ (1949) von René Wellek, „The Parallel of the Arts: Some Misgivings and a Faint Affirmation“ (1972/73) von James D. Merriman und die verschiedenen, auch in die jüngere Forschung reichenden Beiträge von Ulrich Weisstein. ${ }^{5}$ Wichtige Themen sind immer wieder die Prinzipienfrage ob und unter welchen Bedingungen die Künste verglichen werden können (z. B. auch dann, wenn Maler und Musiker verschiedener Epochen aus gleicher Inspirationsquelle schöpften?) - und die Methodendiskussion. Jedoch muss Ulrich Weissteins Feststellung zugestimmt werden, dass bislang nur Teilbereiche befriedigend untersucht worden sind, allgemein gültige Instrumentarien zur wechselseitigen Erhellung der Künste nach wie vor noch nicht gefunden sind und somit die Forschung der „Comparative Arts“ noch am Anfang steht. „Uns bleibt also nichts übrig als fallweise voryugehen und punktuelle Entscheidungen zu treffen."

Die Untersuchung des Wechselverhältnisses zwischen den Künsten liegt grundsätzlich nicht nur nahe, sondern ist durchaus gerechtfertigt, da ihre Verwandtschaft auf mindestens drei Ebenen anzuerkennen ist. ${ }^{7}$ Erstens ist jede Kunstäußerung „Ausdruck der Seele“. Literatur, Musik, Bildende Kunst, Tanz -

\footnotetext{
${ }^{3}$ S. Literaturverzeichnis.

${ }^{4}$ Vgl. Weisstein (1992), S. 18 f.

${ }^{5} \mathrm{~S}$. Literaturverzeichnis.

${ }^{6}$ Weisstein (1992), S. 31. Nähere Ausführungen zu den neueren Forschungen sollen hier nicht erfolgen, da sie nicht Gegenstand dieser Untersuchung sind und für die Betrachtung des doppelbegabten künstlerischen Schaffens wenig hilfreich sind.

${ }^{7}$ Vgl. dazu z. B. Wais (1992), S. 36. Nicht allen Erörterungen dieses Autors ist indes zuzustimmen. Sein Ansatz, die Beziehung der Künste aufgrund ihrer „Urbindung“ im Schöpfungsakt anhand der Entstehung eines Kunstwerkes zu untersuchen, erscheint vage, psychologisierend und nicht wirklich umsetzbar.
} 
jegliche Kunst ist kreatives Mittel des persönlichen Ausdrucks eines Menschen. Zweitens bedienen sich die verschiedenen Künste oftmals paralleler Ausdrucksformen. So spielen Gestaltungsmittel wie Leitmotiv, Symmetrie, Dynamik oder Symbolik in mehr als nur einer künstlerischen Disziplin eine entscheidende Rolle. Drittens manifestiert sich die enge Nähe durch eine Vielzahl von Grenzformen, die verschiedene Künste vermischen, wie beispielsweise die Oper Musik und dialogische Wortkunst, oder zusammenbinden, wie das Bildgedicht, die Ekphrasis, die Buchillustration und dergleichen mehr. ${ }^{8}$

Die Doppelbegabung zählt ebenfalls zu diesen Grenzformen, die im Rahmen der „wechselseitigen Erhellung der Künste“ (auch „Künstevergleich“ oder moderner: „Intermedialität") ins Blickfeld der Komparatistik gehören. Einzeluntersuchungen zu Künstlern, die sich in verschiedenen Medien ausdrücken - wie z. B. die bereits erwähnten Publikationen Henry I. Schveys zu Oskar Kokoschka oder, als weitere Beispiele im Bereich der klassischen Moderne, die Veröffentlichungen von Kent W. Hooper („Ernst Barlach’s literary and visual art: the issue of multiple talent“, 1987) und von Gabriele van Zon („Word and Picture: a Study of the double talent in Alfred Kubin and Fritz Herzmanovsky-Orlando“, 1991) - sind zwar vorhanden, nicht aber eine für diesen Bereich überzeugende einheitliche Theorie und Methode des Vergleichens. So bleibt es bei der oben zitierten Feststellung Weissteins, dass eine solche fallweise entwickelt werden muss.

Wichtige Voraussetzungen für die Vergleichbarkeit der Künste, die von Komparatisten immer wieder angeführt werden und in anderen Zusammenhängen und Teilbereichen Probleme bereiten, werden im Untersuchungsfeld „Doppelbegabung“ gleichsam automatisch erfüllt: zum einen der beiden Künsten (oder Medien) zugrunde liegende ähnliche Ausdruckswille und zum anderen das Prinzip der ungefähren Gleichzeitigkeit.

Da in der vorliegenden Untersuchung bildender Künstler und Schriftsteller ein und dieselbe Person sind, kann die Ähnlichkeit des Ausdruckswillens in den bildkünstlerischen wie literarischen Werken, auch bei unterschiedlicher Schwerpunktsetzung und Nuancierung, wohl kaum größer sein. Daraus ergeben sich gleichzeitig auch die Einheit von Ort und kulturellem Hintergrund. Durch die Eingrenzung auf das expressionistische Schaffen ist zugleich die zeitliche Übereinstimmung gegeben. Berührungspunkte müssen hier also nicht konstruiert werden, sondern sind von vornherein vorhanden. Darüber hinaus wird, wie bereits erwähnt, zugunsten der größtmöglichen Vergleichbarkeit eine Gliederung nach Themen vorgenommen. Insbesondere auch die Tatsache, dass gerade die Expressionisten selbst die Grenzen der Künste aufzulösen strebten und Gefühlen synästhetisch Ausdruck zu verleihen suchten (s. Kapitel 2.3.1) - legitimiert die in dieser Arbeit vorliegenden Untersuchungen.

\footnotetext{
${ }^{8}$ Eine übersichtliche Auflistung letzterer Phänomene, in denen das Wechselverhältnis von Literatur und Bildender Kunst zum Tragen kommt, findet sich bei Weisstein (1992), S. 20 ff.
} 



\section{Doppelbegabung im Expressionismus}

\subsection{Definition von Doppelbegabung und historische Grundzüge bis zum Expressionismus}

\footnotetext{
„Doppelbegabung“ - oder weitreichender „Mehrfachbegabung“ - als Begriff bezeichnet im Prinzip jegliche grenzüberschreitenden Betätigungen und dies nicht nur auf den in der vorliegenden Arbeit fokussierten, künstlerischen Bereich bezogen. Angewendet auf künstlerische Medien kann er nicht nur die Verbindung von Literatur und Kunst meinen, sondern auch deren jeweilige Verknüpfung mit der Musik. Oder er beschreibt im enger gefassten Sinne den künstlerischen Ausdruck in verschiedenen Gattungen, so z. B. einen Künstler, der als Maler und zugleich als Bildhauer tätig ist. Wichtig ist es auch zu beachten, dass im Grunde dieser Begriff irreführend ist, denn er impliziert, dass bei den sogenannten „doppelbegabten“ Künstlern, der schöpferische Ausdruck in den verschiedenen Medien gleich gewichtet sei. Zumeist jedoch wird eine der Disziplinen bevorzugt, überwiegt sowohl in Qualität als auch in Quantität, und wird daneben durch eine weitere ergänzt. Im Falle der in dieser Arbeit vorgenommenen Untersuchungen sind die exemplarisch betrachteten Personen, Ludwig Meidner und Oskar Kokoschka,
} 
entsprechend in erster Linie bildende Künstler und betätigen sich - in weniger ausgeprägter Weise - zusätzlich als Schriftsteller.

Das Phänomen der künstlerischen Doppelbegabung ist nicht nur gattungsübergreifend, sondern lässt sich auch nicht auf bestimmte Länder oder zeitliche Abschnitte festlegen. Es handelt sich um eine generelle Erscheinung, die sich mindestens bis ins Mittelalter zurückverfolgen lässt. ${ }^{9}$ In der historischen Rückschau wird deutlich, dass in Europa das Arbeiten in verschiedenen Medien eng mit der Bewertung der Kunstgattungen selbst verknüpft war. So unterschieden die Griechen in der Antike zwar zwischen mehreren von Musen beschützten Künsten und Tätigkeiten, zählten Malerei und Skulptur aber zum Bereich des Handwerks. Bis ins Mittelalter blieben die Bildenden Künste von den „Artes liberales“ und somit von den Lehrplänen der Scholastik ausgeschlossen, während die Musik und die Dichtung - letztere immerhin als Unterkategorie der Rhetorik - darin enthalten waren. ${ }^{10}$ Damit wurde im Verhältnis von Bildender Kunst und Poesie letzterer ein deutlich höheres Ansehen zuerkannt. Doppelbegabung, im heutigen Sinne verstanden, konnte mangels eines Selbstbewusstseins der Malerei und Skulptur als Künste so nicht bestehen. Allerdings gab es dennoch im Zuge einer langsamen Emanzipation der Literatur (gegenüber der Rhetorik), einer sich entwickelnden „Neuordnung des ästhetischen Kosmos"11 und einer davon abhängenden Aufwertung auch der Bildenden Künste, bereits in der Spätantike Mischformen aus Dichtung und Malerei. So beispielsweise das Bildgedicht, welches im zweiten Jahrhundert vor Christus unter anderem von dem Gelehrten Flavius Philostratus populär gemacht wurde. ${ }^{2}$ Und schon zuvor soll laut Plutarchs „Moralia“ (1. Jh. n. Chr.) der griechische Dichter Simonides von Keos (557-468 v. Chr.) die später seit der Renaissance in vielen Debatten aufgenommene Behauptung, Malerei sei stumme Dichtung und die Dichtung redende Malerei, aufgestellt haben, welche die enge Verwandtschaft der beiden Disziplinen zum Ausdruck bringt. ${ }^{13}$

Im Mittelalter blieben die Bildenden Künste weiterhin untergeordnet. Als bloBes „Handwerk“ betrachtet, sollten sie in erster Linie dem Ausdruck christlicher Botschaften dienen. Die Malerei wurde als das Medium, welches den Sehsinn anspricht, dabei in der Bewertung der Theologie besonders misstrauisch betrachtet. Das Auge, einerseits positiv als „Fenster der Seele“ bewertet, galt andererseits negativ als Spiegel der sinnlichen und somit sündigen Natur. Verknüpfungen der Künste gab es auch hier, z. B. in den mit Miniaturen versehenen Handschriften oder in Verbindung von Dichtung und Musik bei den Minnesängern - doch nach

\footnotetext{
${ }^{9}$ Eine Tendenz zum medienübergreifenden Schaffen war hier beispielsweise bei Heinrich Seuse bemerkbar, der seine theoretischen Ausführungen über das Verhältnis zwischen Gott und Kirche durch Skizzen ergänzt hat. Böttcher/Mittenzwei (Zwiegespräch, 1980), S. 10.

10 Zu den Artes liberales (Sieben freie Künste) zählten Grammatik, Dialektik, Rhetorik, Arithmetik, Geometrie, Musik und Astronomie. Vgl. Brockhaus (1987), Bd. 2, S. 154.

11 Weisstein (1992), S. 12

12 Weisstein (1992), S. $11 \mathrm{f}$.

13 Hagstrum (1987), S. 10 f.
} 
wie vor nicht gezielt und selbstbewusst im Sinne einer Doppelbegabung. Dies hängt zum einen, wie gesagt, mit der noch mangelnden Wertschätzung der Bildenden Künste zusammen, zum anderen geht damit gleichzeitig auch eine Geringschätzung des Künstlers einher. Als Handwerker wurde seiner Person keine gröBere Aufmerksamkeit zuteil. ${ }^{14}$

Erst im Zuge der italienischen Renaissance und des Humanismus, die das Interesse an den Werten und der Würde des Menschen in besonderer Weise schürten und eine Aufwertung der Künste betrieben, emanzipierten und verselbständigten sich auch die einzelnen Gattungen. Die Bildenden Künste sollten zwar weiterhin eine Welt vor Augen führen, die religiösen Maßstäben gerecht wird, jedoch wurde das Augenmerk nunmehr verstärkt auf die teils geradezu wissenschaftlich genaue Wiedergabe der Vielfalt der Natur gelegt, die Darstellung auch weltlicher Freuden verfolgt und insgesamt eine Tendenz zu mehr größerer künstlerischer Freiheit spürbar. Zugleich wandelte sich das Bild des Künstlers. Die Entwicklung von Kunstschulen und Kunsttheorie sowie die Spezialisierung der Einzelkünste führte letztlich ebenso zu einem höheren Ansehen wie zu einem neuen Selbstbewusstsein der einzelnen Künstlerpersönlichkeit, wie beispielsweise in Dürers Münchener Selbstbildnis ${ }^{15}$ in hervorragender Weise abzulesen ist. Maler und Bildhauer organisierten sich zunehmend in Akademien, statt in Handwerksgilden. Die Bildenden Künste gelangten damit zu einer, der Dichtung ebenbürtigen, Stellung. ${ }^{16}$

In Rückbesinnung auf die Antike begann man in der Renaissance zudem ernsthafte Diskussionen über die Unterschiede und die Rangfolge der Künste zu führen, welche bis ins 18. Jahrhundert hineinreichen sollten. Ausgehend von Simonides Äußerung (s. o.) und der ebenso häufig zitierten Formel „ut pictura poesis“, die fünfhundert Jahre später von dem römischen Dichter Horaz (65-8 v. Chr.) in seiner Schrift „De Arte Poetica“ geprägt wurde, wurde die Frage nach der Leistungsfähigkeit der Künste erörtert, wobei die Nachahmung der Natur als Maßstab angesetzt wurde. Dieses Zitat - übersetzt "wie in der Malerei, so in der Dichtung“stellt im Kontext von „De Arte Poetica“ eigentlich nur die Wirkungsweise der Dichtung vor, wurde nun aber als Postulat einer Gleichstellung der beiden Disziplinen interpretiert. Von manchen wurde die Malerei im Gegensatz zu der bis dahin geltenden Auffassung sogar höher eingestuft, so beispielsweise von Leonardo da Vinci (1452-1519). Dieser - selbst eine Universalbegabung - forderte vom Künstler, dass er möglichst alle Bereiche der Kunst beherrschen solle. Darüber hinaus aber lobte er an der Malerei besonders die Eigenschaft des Fortdauerns gegenüber der im Vortrag zeitlich begrenzten Disziplinen Dichtung und Musik. ${ }^{17}$ Die in der Renaissance spürbare Aufwertung der Künste und Künstler förderte auch deutlich

\footnotetext{
14 Vgl. Günther (1960), S. 15, Böttcher/Mittenzwei (Zwiegespräch, 1980), S. 11, Weisstein (1992), S. 13.

15 „Selbstbildnis im Pelzrock“, 1500, Öl auf Holz, Alte Pinakothek München.

16 Weisstein (1992), S. 12 f.; Böttcher/Mittenzwei (Zwiegespräch, 1980), S. 12 f.

17 Böttcher/Mittenzwei (Zwiegespräch, 1980), S. 11 f.; Weisstein (1992), S. 12 f.
} 
das schöpferische Arbeiten in verschiedenen Medien. Immerhin waren in Italien Persönlichkeiten wie Lorenzo Ghiberti (1378-1455), Benvenuto Cellini (15001571), Raffael da Urbino (1483-1520) und Michelangelo Buonarroti (1475-1564) neben ihrem bildkünstlerischen Schaffen zum Teil auch schriftstellerisch tätig. Im deutschsprachigen Raum verbanden einige Schriftsteller, z. B. Jörg Wickram (1505-1562) oder Thomas Murner (1475-1537), in der Illustrierung ihrer Werke Wort und Bild miteinander.

Im 17. Jahrhundert sind kaum bildkünstlerisch-literarisch tätige Persönlichkeiten in Erscheinung getreten und das, obwohl auch hier ein Neben- und Miteinander der beiden Künste postuliert wurde. John Dryden (1631-1700) beispielsweise beschrieb 1695 in seinem Vorwort „A Parallel of Poetry and Painting“ Malerei und Dichtung als zwei Schwestern, ähnlich wie hundert Jahre zuvor Giovanni Paolo Lomazzo (1538-1600) in seinem "Trattato dell'arte della pittura“ (1584) sie als Zwillinge (,quasi nate ad un parto ") bezeichnet hatte. Vor allem die Emblematik, beziehungsweise die in Mode gekommenen Emblembücher, sprechen für eine enge Verknüpfung von Wort und Bild im Barock.18

Im 18. Jahrhundert kam dann erneut Bewegung in die Diskussion um die Rangfolge der Künste und vor allem kamen hier Reflexionen über die Unterschiede der Künste zum Tragen. Auf der Grundlage Jean Baptiste Dubos’ „Reflexions sur la poésie et la peinture“ (1719) und unter Rückbezug auf Simonides wie auch Horaz, verfochten die Philologen Johann Jakob Bodmer (1698-1783) und Johann Jakob Breitinger (1701-1776) eine Gleichstellung von Malerei und Poesie und gleichzeitig deren Emotionalisierung. Kunst sollte nicht mehr der Vernunft folgen, wie es im Gegenzug der Schriftsteller Johann Christoph Gottsched (1700-1766) verlangte, sondern dem Gefühl. Insbesondere im Sujet der Landschaft - durch deren stimmungsvolle Beschreibung und Abbildung - wurde diesen Forderungen Rechnung getragen. Auch wuchs das Bestreben Maler und Dichter zugleich zu sein - Ludwig Meyer von Knonau (1705-1805) wurde von Bodmer dafür als Musterbeispiel angeführt - und in gesteigertem Maße verbanden sich Literatur und Malerei in Bildgedichten und Allegorien. Diesen Entwicklungen stellte sich der Dichter Gotthold Ephraim Lessing (1729-1781) im Zuge der klassizistischen Ablehnung von Mischformen vehement entgegen. In seiner, die Diskussionen zu diesem Thema nachhaltig prägenden Schrift „Laokoon oder Über die Grenzen der Malerei“ (1766) betonte er die Spezifika der beiden Künste und forderte deren strikte Trennung. Ausgehend von seinen Untersuchungen zu der als „LaokoonGruppe" bekannten antiken Marmorskulptur und ihrer Differenz zur poetischen Behandlung des Themas bei Vergil, markierte er zunächst die Grenzen zwischen Dichtung und Bildhauerei sowie weiterführend auch zwischen Dichtung und Malerei. Dabei stand vor allem der Aspekt der Raum-Zeitlichkeit im Mittelpunkt seiner Ausführungen, wonach die Malerei im Abbilden eines Augenblicks statisch,

18 Vgl. Weisstein (1992), S. 14 f. Genaueres zur Emblematik findet sich bei Warncke (2005). 
die Dichtung dagegen durch artikulierte Abläufe dynamisch geprägt sei. ${ }^{19}$ Er postulierte: „die Zeitfolge ist das Gebiete des Dichters, so wie der Raum das Gebiete des Malers ". ${ }^{20}$ Die Möglichkeit ein Thema auf einen Blick zu vermitteln, bewertet Lessing dabei als Vorteil der Bildenden Kunst. Aus der Erkenntnis über die Unterschiede der Künste leitet er schließlich auch ihre Abgrenzung ab:

„Zwei notwendig entfernte Zeitpunkte in ein und ebenddasselbe Gemälde bringen (...): beißt ein Eingriff des Malers in das Gebiete des Dichters, den der gute Geschmack nie billigen wird. (...) dem Leser nach und nach zuquä̈hlen, um ibm dadurch ein Bild von dem Ganzen machen zu wollen: heißt ein Eingriff des Dichters in das Gebiete des $\mathrm{Ma}$ lers, wobei der Dichter viel Imagination obne allen Nutzen verschwendet". ${ }^{21}$

Diese Auffassung teilte auch der französische Gelehrte Denis Diderot (17131784), der im gleichen Jahr in seiner Schrift „Essai sur la peinture“ zum gleichen Ergebnis kam und die Raum-Zeitlichkeitsthese blieb im Folgenden ein wichtiger Gesichtspunkt bei der Bestimmung der wechselseitigen Beziehung der Künste. ${ }^{22}$ Johann Wolfgang von Goethe (1749-1832) knüpfte an Lessing, Diderot und die Trennung der Künste an, stellte aber noch weitergehende Aspekte zur Debatte, indem er sich gegen die Tendenz der Vermischung auch von Kunst und Natur (wie bei Bodmer und Böttinger angestrebt) verwahrt. Auf der Grundlage älterer Konzepte legte er in seinem Aufsatz „Einfache Nachahmung der Natur, Manier, Stil“ (1789) drei Stufen künstlerischen Schaffens fest, wobei die Nachahmung am einfachsten und der Stil, welcher sich aus der tiefen Erkenntnis über das Wesen der Dinge bilde, am höchsten zu beurteilen sei. Er verfolgte damit eine Wendung der Kunst weg vom Gefühl und hin zum Objektiven. ${ }^{23}$

Entgegen Goethes und später auch Friedrich Schillers Bestrebungen theoretische Grundlagen für die Eigenbestimmung der Kunstdisziplinen zu etablieren, stieg die Tendenz zum künstlerischen Schaffen in mehreren, parallel genutzten Medien zunehmend. Insbesondere die Romantiker missachteten eine Abgrenzung der Künste und wendeten sich - ebenfalls entgegen den Forderungen der Aufklärung - von der Betonung des Geistes ab und stattdessen verstärkt dem Gefühl zu. Synästhesie und Symbiose waren die großen Schlagworte. Vielfach wollte man mittels Intuition ,,die Künste einander nähern und Übergänge aus einer in die andere suchen ${ }^{24}$. So gab es unter den Romantikern viele Dichter, wie beispielsweise Clemens Brentano (1778-1842), Achim von Arnim (1781-1831), Joseph von Eichendorff (1788-1857) und die Brüder Grimm (Jacob: 1785-1863, Wilhelm: 17861859), die auch malten oder zeichneten, oder Bilder als Anregung für ihre literari-

\footnotetext{
${ }^{19}$ Vgl. Wetzel (1997/98), S. 54, Weisstein (1992), S. 15.

${ }^{20}$ Lessing (1988), S. 119.

${ }^{21}$ Lessing (1988), S. 119 f.

22 Weisstein (1992), S. 15.

${ }^{23}$ Böttcher/Mittenzwei (Zwiegespräch, 1980), S. 16.

${ }^{24}$ Schlegel (1799 (1960)), S. 49.
} 
schen Werke nutzten. Theoretische Debatten, Gemäldegedichte und in herausragendem Maße die Künstlerromane eines August Wilhelm Schlegel (1767-1845), Ludwig Tieck (1773-1853) („Franz Sternbalds Wanderungen“ (1798) sei als Beispiel genannt) oder Eduard Mörike (1804-1875) sind einige der wichtigen Impulse in der neuerlichen Zusammenführung der Künste. In den Künstlerromanen schlägt ein gewisses Krisenbewusstsein nach der Enttäuschung der Französischen Revolution durch, denn hier wendet sich im Allgemeinen der Mensch von der Gegenwart ab und sucht in der Kunst, die das Universum zusammenbindende, gleichsam religiös aufgeladene, positive Gegenwelt zu finden. Insgesamt weist die Kunst in der Romantik tendenziell über sich hinaus, verfolgt oftmals die Auffassung einer von göttlichen Kräften durchdrungenen und beseelten Natur. Der Wunsch nach Zusammenbindung spiegelt sich vor allem auch in der Idee des Gesamtkunstwerks. Philipp Otto Runge (1777-1810) wollte in seinem unvollendeten Werk „Vier Tageszeiten“ (1803) eine malerische Dichtung mit Chören schaffen und Richard Wagner (1813-1883) ein Gesamtkunstwerk, das durch die Musik das Unbewusste anspricht. Synästhesie, also eine gleichsam intuitive, mit dem Gefühl erfasste Verknüpfung der Künste, war hierfür essentiell und zugleich ist dabei eine spezielle Betonung der Musik gegenüber den anderen Künsten festzustellen. ${ }^{25}$

Die ernsthaften und mit Vehemenz diskutierten, theoretischen Erörterungen über das Verhältnis von Kunst und Malerei erhielten im Laufe des 19. Jahrhunderts kaum weitere Impulse. Die Künste versandeten zum Gut des gebildeten Bürgertums und schienen zeitweise in einem Findungsprozess begriffen zu sein. Dennoch sind bedeutende Persönlichkeiten wie beispielsweise der zeichnende Schriftsteller Wilhelm Busch (1832-1908) in dieser Zeit der Verknüpfung der Künste zugetan und insbesondere Wagner verfolgte die Idee des Gesamtkunstwerks in seinen Opern und Dramen. Der Impressionismus brachte in seiner unliterarischen, nur optisch orientierten Ausdrucksweise, kaum Doppelbegabungen hervor. Im Jugendstil, der das Hässliche aus der Kunst zu verbannen und das Leben einem Gesamtkunstwerk gleich zu ästhetisieren suchte, beförderte mit dieser Einheit anstrebenden Programmatik wiederum die Verbindung von Bildender Kunst und Literatur, die allerdings meist im Illustrativen blieb. Bildende, bauende und angewandte Künste wurden dem Dekorativen, oftmals des in organischen Formen sich Äußernden angepasst. Holzschnitt und angewandte Kunst wurden neu belebt, handwerkliche Finesse und kostbares Material geschätzt. Die sich aus diesem gemeinschaftlichen ästhetischen Streben wieder verstärkende Zusammenbindung der Künste bereitete schließlich den Weg für den Höhepunkt literarisch-bildkünstlerischen Schöpfertums im Expressionismus. ${ }^{26}$

\footnotetext{
25 Vgl. Böttcher/Mittenzwei (Zwiegespräch, 1980), S. 16 f.; Weisstein (1992), S. 16 f.

${ }^{26}$ Böttcher/Mittenzwei (Zwiegespräch, 1980), S. 18 f.
} 
Der Expressionismus wies im Vergleich zu früheren Epochen eine besonders große Zahl von Doppelbegabten beziehungsweise in Bildender Kunst und Dichtung Tätigen auf. Sie waren mehr als je zuvor Träger der aktuellen Kunstbewegung. Künstler und Literaten schlossen sich zu einer geistigen Avantgarde zusammen, deren Ziel die gesamtkulturelle und auch gesellschaftliche Erneuerung war. Zeitschriften wie der „Sturm“ oder „Die Aktion“ wurden zu Foren, in denen diese Bestrebungen artikuliert wurden. In Schriften, wie dem Almanach „Der Blaue Reiter" (1912), wurde das bereits in der Romantik postulierte Ideal des Gesamtkunstwerks von Neuem belebt. Künstler wie zum Beispiel Oskar Kokoschka (1886-1980), Alfred Kubin (1877-1959), Ernst Barlach (1870-1938), Ludwig Meidner (1884-1966) oder Max Beckmann (1884-1950) widmeten sich neben ihren Bildern zumindest zeitweise auch dem Schreiben. Andere, wie beispielsweise Wassily Kandinsky (1866-1944) oder Arnold Schönberg (1874-1951), suchten Verknüpfungen zwischen Bildender Kunst und Musik. Das synästhetische Zusammenspiel von Formen, Farben und Klängen sollte zu einer Intensivierung des künstlerischen Ausdrucks führen. Insbesondere die Bühne sah man hierfür als geeignet an. Die künstlerisch-literarische Avantgarde mischte sich in ihrem alles umfassenden Erneuerungswillen zudem auch in politische Fragen ein. Man glaubte die bestehenden Zustände durch die Wirkung der Künste auf die Gesellschaft verändern zu können. Das enge Verhältnis der Künste hatte auch kunsttheoretische Auswirkungen: Mit seinem Vortrag über die „Wechselseitige Erhellung der Künste" von 191727 legte Oskar Walzel einen Grundstein für die sich später etablierenden Forschungen der Komparatistik. Die Vermischung der Künste ist seitdem nicht mehr abgebrochen, sondern hat sich im Gegenteil im Dadaismus und Bauhaus und nachfolgend gerade auch im Zuge neuer Medien wie Fotografie und Film immer weiter verstärkt. ${ }^{28}$

Es ist festzuhalten, dass es Doppelbegabung oder zumindest das Schaffen in mehreren Medien - wenn es auch vor der Emanzipation der Bildenden Künste und Künstler in der Renaissance anders zu bewerten ist - offenbar schon seit vielen Jahrhunderten gibt und die Intermedialität tendenziell zunimmt. In Abhängigkeit von der Beurteilung der verschiedenen Künste im jeweiligen zeitgenössischen Diskurs gibt es Phasen, in denen die Wertigkeiten der Disziplinen wechseln. So wurde in der Renaissance die Malerei, im 18. Jahrhundert eher die Plastik und Anfang des 19. Jahrhunderts die Musik als paradigmatische Kunst angesehen. Darüber hinausgehende theoretische Diskussionen über die Trennung oder Verschmelzung der Künste nehmen ebenso Einfluss. So war die Forderung nach Objektivität und strikter Trennung der Künste während der Aufklärung von bedeutender Vehemenz, wenn auch die entgegengesetzte Zielvorgabe des Gesamtkunstwerks in der Romantik sich in der Praxis letztlich stärker durchsetzen und die schöpferische Tätigkeit in verschiedenen Medien beflügeln konnte. Die Pro-

${ }^{27}$ S. auch erweiterte Publikation dazu im Literaturverzeichnis.

${ }^{28}$ Vgl. Anz (2001), S. 148 ff.; Schvey (1992), S. 77; Böttcher/Mittenzwei (Zwiegespräch, 1980), S. 19. 
grammatik des Gesamtkunstwerks und das Streben nach einer universellen Gestaltung des Lebens, wie sie für die Romantik und für den Expressionismus essentiell war, scheinen insgesamt die Symbiose der Künste und daraus resultierend die Doppelbegabung sowie deren Ausleben besonders zu begünstigen. ${ }^{29}$

\subsection{Der Expressionismus als übergreifende Bewegung}

Das Phänomen Expressionismus und seine Voraussetzungen

Der Expressionismus war nun also eine Strömung, in der besonders viele künstlerische Doppelbegabungen in Erscheinung traten und diese Bewegung entscheidend mittrugen. Darum bot es sich an, gerade im Kontext dieser Zeit die Frage nach dem Phänomen der Doppelbegabung zu stellen. Doch was war das eigentlich für eine Bewegung? Welche Voraussetzungen und Ziele standen damit in Verbindung? Um bei den späteren Untersuchungen Künstler und Werk angemessen beurteilen zu können, ist eine kurze Betrachtung ihres politischen und sozialen Umfeldes unerlässlich.

Expressionismus als Begriff ist eigentlich nur ein Notbehelf - eine Sammelbezeichnung für unterschiedlichste Vertreter der verschiedenen Künste, die unter dieser so genannten Stilepoche zusammengefasst werden. ${ }^{30}$ Die Differenzen in Weltsicht, Ausdrucksform und Themenauswahl zwischen den deutschen Künstlern und vor allem auch zwischen den Autoren sind groß. Der Expressionismus lässt sich deshalb am treffendsten als eine, geistige europäische Strömung des früben 20. Jabrbunderts" ${ }^{11}$ bezeichnen, die in Deutschland einen Umbruch in allen Künsten markiert. Der Begriff „Expressionismus“ wurde zuerst auf französische Maler angewendet, die man heute zwischen Fauvismus und Kubismus einordnet. 1912 waren im Katalog der Sonderbund-Ausstellung all jene Künstler damit gemeint, die über Realismus und Impressionismus hinausgingen. Bis heute werden Künstler wie Vincent van Gogh (1853-1890), Edvard Munch (1863-1944) und James Ensor (1860-1949) in der Forschung teilweise als Vertreter einer ersten Phase des Expressionismus angesehen, von anderen dagegen als dessen Vorläufer eingestuft. In jedem Fall etablierte sich zumindest für die Bildende Kunst die bis heute gültige Auffassung, als Expressionisten jene Künstler zu bezeichnen, die ,durch Verformung der sichtbaren Wirklichkeit ibre Gefüble oder Ideen in drastischer Weise bildlich ${ }^{\text {(32 }}$ dar-

\footnotetext{
${ }^{29}$ Vgl. Schvey (1992), S. 77; Böttcher/Mittenzwei (Zwiegespräch, 1980), S. 10.

${ }^{30}$ Knapp (1979), S. 13.

${ }^{31}$ Hoffmann (1985), S. 99.

32 Muller (1977), S. 6.
} 
stellten. ${ }^{33}$ Die Zeitspanne, in der die dem Expressionismus zugeordneten Werke entstanden, umfasst im Kern etwa die Zeit von 1910 bis 1925. Erste Anfänge lassen sich schon ab 1905 registrieren. Unter dem besonderen künstlerischen Einfluss von van Gogh, Munch und Paul Gauguin (1848-1903), sowie der Philosophie bzw. Lehre beispielsweise eines Friedrich Nietzsche (1844-1900) oder Sigmund Freud (1856-1939), formierte sich eine expressionistische Bewegung in Deutschland. Allerdings gab es ähnliche Tendenzen auch in anderen europäischen Ländern. Vornehmlich in der Bildenden Kunst fand eine solche Formierung ebenso in Frankreich, Russland, Tschechien, Ungarn und Polen statt. In verwandter Weise arbeitete man parallel dazu auch in Italien. ${ }^{34}$ „Die Brücke“ in Deutschland und die „Fauves“ in Frankreich waren die um 1905 zeitgleich entstehenden Keimzellen der sich anschließenden stufenweisen Entwicklung des Expressionismus. ${ }^{35}$ Innerhalb des wilhelminischen Deutschland war das gesellschaftliche und kulturelle Leben jedoch stärker von Widersprüchen und Problemen eines epochalen Umbruchs geprägt als in anderen europäischen Ländern. ${ }^{36}$ Hier war es die Stadt Berlin, die sich insbesondere seit 1910 als wichtigstes Zentrum der Bewegung etablierte. Andere Zentren waren München und Dresden - Ausgangspunkte für die Künstler des „Blauen Reiter“ und der „Brücke“. Grundsätzlich kennzeichnete das Opponieren gegen die herrschenden spätbürgerlichen Verhältnisse und die als bürgerlich verachtete Kunst des Impressionismus und Naturalismus den Umbruch. Doch dieses Verhalten war eine Reaktion auf vielschichtigste Gegebenheiten, fiel im Einzelnen denkbar unterschiedlich aus und bedarf daher einer Erklärung. Welche politischen und gesellschaftlichen Voraussetzungen in Deutschland waren es also, die das nach außen getragene Aufbegehren der Intellektuellen provozierten? Welches Umfeld bot den Nährboden für die Ideen einer so umfassenden Bewegung?

Die Zeit der Expressionisten war eine „Ära tiefer gesellschaftlicher Widersprüche und radikaler geschichtlicher Umbrüche ${ }^{637}$. Politisch gesehen befand man sich in dem neu gegründeten deutschen Kaiserreich zwar in einer Phase des Friedens, dennoch gab es gleichzeitig eine massive Militarisierung, die durch die Präsenz des Militärs in öffentlichen Bereichen und durch die Verherrlichung der eigenen Nationalgeschichte auch im Alltag spürbar war. Adelige nahmen nach wie vor die zentralen politischen Positionen ein und die Eliten setzten sich gegen neue gesellschaftliche Kräfte wie die Sozialdemokratie zur Wehr. Dem Adel stand das durch wirtschaftlichen Erfolg an Einfluss gewinnende Bürgertum gegenüber. Die Gesetzgebung des erneuerten Staates war zwar modernisiert worden, doch benachteiligte sie viele Bevölkerungsgruppen, beispielsweise dadurch, dass das Wahlrecht Jugendlichen

\footnotetext{
33 Muller (1977), S. 5 f.

34 Olbrich (2004), S. 406.

35 Hoffmann (1985), S. 99.

36 Jurkat (1993), S. 28.

37 Bogner (2005), S. 48.
} 
unter 25 Jahren, Frauen und Armen vorenthalten blieb. ${ }^{38}$ Dies vertrug sich in keiner Weise mit dem Wachstum eines städtischen Proletariats, einer Entwicklung die durch massive Umwälzungen insbesondere im technischen Bereich begünstigt wurde. Die sich schon seit Mitte des 19. Jahrhunderts verändernde Sozialstruktur in Folge der Industriellen Revolution hielt an. Mehr denn je wurden die Städte durch die Landflucht von Arbeitssuchenden überflutet, die vor allem in die Bereiche der Textilindustrie und des Bergbaus drängten. Daraus erwuchsen vornehmlich zwei große Probleme: zum einen sanken mit dem Überangebot an niedrig qualifizierten Arbeitskräften die Löhne und zum anderen machte das rapide Bevölkerungswachstum eine verstärkte Urbanisierung nötig. Wohnungen wurden schnell gebraucht und mussten mit niedrigen Mieten zu bezahlen sein. Neue Stadtviertel wurden deshalb ,aus dem Boden gestampft“, in denen die Bewohner ärmlich und auf engstem Raum lebten. Die Technisierung hielt mit Straßenbahn, Automobilen und elektrischer Beleuchtung Einzug in den städtischen Alltag und wirkte für viele durch Lärm, Schmutz und grell erleuchtete Nächte abschreckend und irritierend. ${ }^{39}$ Die durch die Industrialisierung bedingte Verstädterung führte auch zu einer Vermassung. Der Mensch geriet in eine anonymisierende Umwelt und fühlte sich seinen Mitmenschen durch die Hektik und Unübersichtlichkeit entfremdet. Dieses Gefühl wurde durch andere Umwälzungen noch verstärkt: Die Technisierung bot die Möglichkeit und förderte den Wunsch nach materiellem Wohlstand und neuen Perspektiven. Daraus erwuchs jedoch zugleich ein rücksichtsloses Gewinnstreben, der Verlust von Idealen und eine "mentale Verflacbung ${ }^{40}$. Neben all diesen politisch und gesellschaftlich problematischen Aspekten der Zeit, die später noch durch die negativen Erfahrungen des Ersten Weltkrieges ergänzt werden sollten, wirkten die Impulse neu aufkommender Ideologien in ebenso starkem Maße auf die Gemüter ein.

Von besonderer Bedeutung waren Sigmund Freuds Psychoanalyse und seine Zweifel an der Vernunftbestimmtheit des menschlichen Handelns. Vor allem in seiner Schrift „Das Ich und das Es“ (1923) unterschied er zwischen unbewusstinstinktivem und vernünftigem Verhalten wobei er das unterbewusst-triebhafte Verhalten des Menschen betonte. Einflussreich waren auch Maurice Maeterlincks (1862-1949) Widerstand gegen die Wissenschaftsgläubigkeit sowie Henri Bergsons (1859-1941) Ablehnung der entpersonalisierenden Maschinisierung und der steigenden Betonung der neueren naturwissenschaftlichen Erkenntnisse, wie sie beispielsweise auf dem Gebiet der Biologie insbesondere durch Charles Darwin (1809-1882) und dessen Evolutionstheorie ${ }^{41}$ vorangetrieben wurde. Bergson stellte dem in seiner lebensphilosophischen Schrift „L'evolution créatrice“ (1907) die These vom ständig im Fluss befindlichen und somit nicht völlig mit dem Verstand

\footnotetext{
38 Bogner (2005), S. 48 f.

${ }^{39}$ Bogner (2005), S. 50.

40 Jurkat (1993), S. 29.

${ }^{41}$ Darwins Hauptwerk dazu ist „Die Entstehung der Arten“ (1859).
} 
erfassbaren Lebensimpuls („élan vital“) entgegen. ${ }^{42}$ Die zentrale Rolle bei der Verankerung neuer Ideen spielte Nietzsche. Sein nihilistisches Postulat vom „toten Gott ${ }^{\text {"43 }}$, das den Verlust des Glaubens an ein höheres Wesen formulierte, die Kritik an Spießertum und körperfeindlichen Glaubensrichtungen und seine Bejahung des vitalen Menschen, die sich bis zur Verherrlichung eines Übermenschen ${ }^{44}$ steigerte, etablierte sich zu einer Art von Allgemeinwissen. Diese ideologischen und philosophischen Gedanken ,lagen in der Luft“ und waren selbstverständlicher Bestandteil intellektueller Diskussionen. Sie formulierten den Eindruck des Sinnverlusts und die Umwertung der Werte. Allen diesen Ideen waren einige Grundtöne gemein: Rationalismus und Wissenschaftseuphorie wurden darin ebenso angegriffen wie der Nützlichkeitswahn und die Technikversessenheit. ${ }^{45}$ Es handelte sich bei den Problemen zur Entstehungszeit des Expressionismus, wie Jurkat es zum Ausdruck bringt, also um einige, die zeitbedingt waren und um andere, die schon in der ,gesellschaftspolitischen und geistigen Auseinandersetzung seit der Aufklärung" ${ }^{46}$ wurzelten.

\section{Ideen und Entwicklung der expressionistischen Bewegung}

Welche Wirkung hatten all diese Einflüsse nun aber konkret auf die Künstler und Literaten der Zeit? Besser gefragt: Welche Sichtweisen, Ideen und Forderungen erwuchsen in den Köpfen der damaligen Intellektuellen aus diesen äußeren Bedingungen? Es gab, wie bereits gesagt, eine Fülle von Formen expressionistischen Ausdrucks - vielfältig nicht nur durch die Äußerung in den verschiedenen Kunstformen, wie Literatur, Musik, Theater, Film und Bildender Kunst, sondern eben auch innerhalb dieser Bereiche selbst. Es würde deshalb hier zu weit führen, die dem Expressionismus zugeordneten Erscheinungsformen auseinander zu dividieren, denn wie Bogner es in Bezug auf die expressionistische Literatur beschreibt, ist das Einheitliche der Expressionisten im Wesentlichen das Prinzip der Bewegung, also des ständigen Variierens. ${ }^{47}$ Darum sollen im Folgenden nur einige Grundlinien bezüglich der expressionistischen Ideen und ihrer Entwicklung aufgezeigt werden.

\footnotetext{
42 Dazu später mehr in den Kapiteln 3.2.3.2. und 3.2.3.3.

43 Als Motiv besonders in den Aphorismen in „Die fröhliche Wissenschaft“ (1882) und danach in „Also sprach Zarathustra“ (1883-85) zu finden.

${ }^{44}$ Vgl. Bogner (2005), S. 53 f.; Von besonderer Bedeutung war hier das Werk „Der Wille zur Macht“ (1906).

45 Bogner (2005), S. 52 f.

46 Jurkat (1993), S. 28.

47 Bogner (2005), S. 54.
} 


\section{„Unter der Oberfläche stilistischer Vielfalt findet sich (...) ein alle Expressionisten ver- bindendes Element: Sie bringen das Unbehagen einer jungen Generation zum Ausdruck, die sich in ibrer Ablehnung der herrschenden gesellschaftlichen und politischen Strukturen einig ist. " 48}

Das Stichwort ist: „Etwas zum Ausdruck bringen“! Grundsätzlich ging es darum, dem Empfänger - also z. B. dem Betrachter oder dem Leser - die Stimmung des Senders (Künstlers, Autors etc.) zu vermitteln. Der Sender legte sein Werk so an, dass es beim Empfänger die gleichen Empfindungen auslösen sollte, die den Sender beim Entstehungsprozess des Werkes bewegt hatten. ${ }^{49}$ Ziel war es demnach, das Gefühl mit künstlerischen Mitteln nach außen zu tragen. Dieser Wunsch sich mitzuteilen, ergab sich aus dem hohen Pathos, das bei den Expressionisten eine entscheidende Rolle spielte.

Aus den irritierenden Erfahrungen der Großstadt, ihrer Technisierung und den geradezu menschenfeindlichen Wirkungen wie Stress, Anonymisierung und Vereinsamung bezogen die Expressionisten überwiegend eine kritische und pessimistische Weltsicht. Dabei war das Verhältnis zur Großstadt durchaus paradox: zum einen wurde sie verurteilt, zum anderen bestand eine Abhängigkeit von ihrer Infrastruktur mit Cafés, Verlagen, dem Publikum und natürlich von ihren Wahrnehmungsreizen. ${ }^{50}$ Die wilhelminische Gesellschaftsordnung und die durch die Philosophie vermittelte „Entwertung der Werte“ waren weitere Faktoren, die die Intellektuellen zu pessimistischer Grundstimmung, Kritik und dem Streben nach Veränderung führten. So begann man Althergebrachtes überwinden zu wollen. Künstler verurteilten Impressionismus und Naturalismus als Instrumente des Spießbürgertums und suchten, ebenso wie die Autoren und Vertreter anderer Gebiete, nach Möglichkeiten, ihre Wahrnehmung, zunächst der Großstadt, angemessen zum Ausdruck zu bringen. Wilhelm Worringer (1881-1965) als Kunsthistoriker und Wassily Kandinsky (1866-1944) als Künstler wie auch Kunsttheoretiker waren es, die dabei die Abstraktion vorantrieben. ${ }^{51}$ Auch bezog man sich auf künstlerischer Ebene für die Überwindung des Naturalismus auf Vorbilder wie van Gogh, Ensor oder Gauguin. Darüber hinaus wollte man gegen die herrschenden Zustände protestieren. Die Revolte führte zu einem Riss, der in der Literatur häufig als Vater-Sohn-Konflikt verarbeitet wurde. Der Widerstand gegen die Vertreter der alten Ordnung - welche vor allem die ältere Generation, Eltern, Professoren, Armee und Kaiser umfasste - war dabei ein Faktor, ebenso wie die Solidarisierung mit gesellschaftlichen Randgruppen, wie Armen, Prostituierten, Irren oder Kranken. In Kunst und Literatur der Zeit sind Randgruppen deshalb vielfach

\footnotetext{
48 Jurkat (1993), S. 31.

49 Vgl. Hoffmann (1985), S. 100; Vgl. Kandinskys Konzept: „Emotion-Gefühl-Werk-Gefühl-

Emotion" bei Anz (2001), S. 161.

50 Bogner (2005), S. 50.

51 Bogner (2005), S. 63.
} 
thematisiert worden.52 Literaten regten darüber hinaus zum politischen Engagement an, wie beispielsweise Heinrich Mann (1871-1950) mit seiner Forderung nach Einheit von Geist und Tat, und strebten nach größerer öffentlicher Wirksamkeit. ${ }^{53}$ Neben diesen aktivistischen Tendenzen etablierte sich die insbesondere von Freuds Theorien sich ableitende Begeisterung für den Vitalismus, welcher den als herrschend wahrgenommenen übersteigerten Rationalismus ablehnte und dafür Körper, Gefühl, Rausch und Sexualität bejahte. Daran anknüpfend wandten sich die Expressionisten auch der Verarbeitung des Hässlichen und Grotesken zu, da sie der Auffassung waren, dass die Darstellung nur des Schönen und Guten der Erscheinungsvielfalt des menschlichen Seins nicht gerecht werden könne. ${ }^{54}$

„,Himmelfahrten“ oder ,Höllenstürze? - das sei unsere Losung. Seien wir hingerissen, leidenschaftlich, ,pathetisch'; ,ekstatisch', seien wir nur ,Flamme' und ,Brand', ,Durst' und ,Schrei"! (...) “.55 Diese „Wiederentdeckung des Ichs als menschliche Seele (...) subjektiv, ekstatisch, mit visionärem, spirituellen und religiösem Ethos'56 in der Frühphase des Expressionismus seit 1905 stellte also das Gefühl in den Vordergrund. Theorie war verpönt. Der Dichter Jakob van Hoddis (1887-1942) drückte das mit den Worten aus: „Wir füblen uns, obne uns zu definieren. "57 Diese Theoriefeindlichkeit führte zu der paradoxen Situation, dass Theoretiker im Nachhinein das in Theorien beschrieben, was in der Praxis schon vorhanden war. Auch ein Grund für die Schwierigkeit die expressionistische Bewegung zu umgrenzen, ist die Tatsache, dass sie bei ihrer Entstehung kein einheitliches Konzept hatte. Die zugleich als negativ und faszinierend empfundene Großstadt wurde von Dichtern und Künstlern gleichermaBen thematisiert. Das von Emilio F. T. Marinetti (1876-1944) verfasste Manifest der italienischen Futuristen, welches Dynamik, Geschwindigkeit und Technik feiert, übte, wenn auch nicht mit seiner Begeisterung für diese Dinge, doch Einfluss aus auf manchen deutschen Künstler und vor allem auf die deutschen Literaten. ${ }^{58}$ Es wurden neue Konzepte erarbeitet, um den neuen Sehgewohnheiten gerecht zu werden, auf die die Futuristen hinwiesen - Reihungsstil und Fragmentierung sind beispielsweise zu nennen. „Die Brücke“ und „Der Blaue Reiter“ als die beiden großen deutschen Künstlergruppen und die vielen einzeln arbeitenden Künstler suchten neben neuer Kunst auch eine neue Lebensform. Die Künstler der „Brücke“ beispielsweise entdeckten das freie und kollektive Zusammenleben mit ihren Modellen und Gefährtinnen für sich, während viele Künstler der Gruppe „Der Blaue Reiter“ sich programmatisch die Ursprünglichkeit primitiver Völker zum Vorbild erkoren. ${ }^{59}$

\footnotetext{
52 Richard (1980), S. 19. Vgl. Bogner (2005), S. 65 ff.

${ }^{53}$ Vgl. Anz (2001), S. 127 ff.

54 Bogner (2005), S. 54.

${ }^{55}$ Soergel (S. Grochowiak (1966), S. 30).

56 Hoffmann (1985), S. 100.

${ }^{57}$ Zitiert bei Hoffmann (1985), S. 101.

${ }^{58}$ Bogner (2005), S. 63.

${ }^{59}$ Olbrich (2004), S. 406.
} 
Aus der Großstadtthematik entwickelte sich bei nicht wenigen Expressionisten eine Tendenz zum Visionären mit negativer, gar apokalyptischer Tendenz. Georg Heym (1887-1912) als Dichter dämonischer Großstadt-Gedichte und Ludwig Meidner als Maler von Landschaften mit Weltuntergangsstimmung können hier als Beispiele genannt werden. Dieser Aspekt lässt sich bereits in den Werken der Vorkriegsjahre feststellen und spricht möglicherweise für den dringender werdenden Wunsch nach Veränderung. Zunehmend wurde als Weg zu dessen Erfüllung nur eine radikale Vernichtung aller bestehenden Zustände mit darauffolgender Erneuerung angesehen - ähnlich wie es die biblische Apokalypse verheißt.

Der im Sommer 1914 beginnende Erste Weltkrieg wurde daher von den meisten Expressionisten ebenso euphorisch aufgenommen, wie von der deutschen Bevölkerung insgesamt auch. Er wurde als reinigendes Ereignis und Möglichkeit zur Befreiung von den alten Werten begrüßt und durch zahllose freiwillige Meldungen zum Militär unterstützt. ${ }^{60}$ Zugleich war die Begeisterung auch vielfach in vitalistischem Denken begründet: Der Krieg wurde als neues Erlebnis, als Ausbruchsmöglichkeit aus der durch die gesellschaftliche Ordnung hervorgerufenen Langeweile gefeiert. ${ }^{61}$ Das klingt makaber, wird aber vor dem Hintergrund, dass alle an einen schnellen Sieg glaubten, etwas verständlicher. Nachdem es anfangs nur wenige kritische Stimmen gegeben hatte (Franz Pfemfert (1879-1954) und die „Aktion" wurden dabei noch am ehesten wahrgenommen) ${ }^{62}$, kam es bald zur Desillusionierung. Der Krieg zog sich länger hin, das Massensterben und die unerwartete Zerstörungskraft der neueren Kriegstechnik führten zur Einsicht in dessen Brutalität und zu einem Stimmungsumschwung hin zur Kriegskritik. Das Sehnen und Streben nach Gewaltlosigkeit und Menschenverbrüderung wurden die neuen Leitideen der „intellektuellen Kriegsopposition "63 und spiegeln sich auch in deren Werken wider. ${ }^{64}$ Eine Ahnung von der Vergeblichkeit dieser Hoffnung schwang aber nicht selten schon mit und wurde durch eine Flucht in parareligiöse Vorstellungen, wie sie sich z. B. bei Ludwig Meidner oder Franz Marc (1880-1916) abzeichnete, zu kompensieren versucht. ${ }^{65}$

Trotzdem erwuchs aus den neuen Ideen der letzte große Höhepunkt der expressionistischen Bewegung. Viele ihrer Anhänger sahen mit dem Ende des Krieges den Zusammenbruch der alten Ordnungen für vollzogen und nun die Möglichkeit durch eine Revolution die langersehnte Erneuerung des politischen und gesellschaftlichen Lebens zu verwirklichen. Es gab eine massive Verstärkung linksorientierter, politisierender Tendenzen. Kunst und Literatur stellten sich vielfach in den Dienst des politischen Engagements und viele Intellektuelle gefielen

\footnotetext{
${ }^{60}$ Anz (2001), S. 133.

${ }^{61}$ Anz (2001), S. 134 f.

62 Breuer (1991) 2, S. 20.

${ }_{63}$ Anz (2001), S. 138.

${ }^{64}$ Anz (2001), S. 137 f.

${ }^{65}$ Hoffmann (1985), S. 103. Siehe auch S. 24.
} 
sich als vermeintliche Mitwirkende am Neuaufbau des Staates. Diese Politisierung war eng mit den Ideen des Sozialismus verknüpft. Doch der Einfluss war in Wirklichkeit gering und ebenso wenig erfüllten sich die Vorstellungen einer neuen staatlichen Ordnung. Das endgültige Zerbrechen dieser Utopie markierten die Niederschlagung des Spartakusaufstandes mit der Ermordung von Karl Liebknecht (1871-1919) und Rosa Luxemburg (1870-1919) und das blutige Ende der Bayrischen Räterepublik. Die Resignation, die folgte, kennzeichnete auch das Sterben der überalterten expressionistischen Bewegung, deren Vertreter sich entweder jüngeren Strömungen anschlossen oder in traditionelle Gestaltungsweisen zurückfielen. ${ }^{66}$

\section{Verbreitung der Ideen}

Die expressionistischen Ideen waren einer ganzen Generation von Intellektuellen gemeinsam und traten um 1910 in steigendem Maße zu Tage. Die Mitglieder fanden sich in allen Teilen des Landes, wie beispielsweise „Der Blaue Reiter" in München und „Die Brücke“ in Dresden. Dazu gab es vornehmlich in Berlin eine große Anzahl literarisch geprägter Expressionisten. Berlin wurde sehr bald zum generellen Zentrum der gesamten expressionistischen Bewegung. Doch wie wurden deren Ideen transportiert, wie die großen Entfernungen überwunden, so dass die Bewegung sich ausbreiten, beziehungsweise vernetzen konnte?

Dieses Verdienst kommt neben den Galerien, die die innovativen Bilder ausstellten, vor allem auch den Schriftmedien zu. Um 1910 gab es eine große Menge Neugründungen von Verlagen und Zeitschriften, die in den meisten Fällen allerdings eher kurzlebig waren. Immerhin aber wurden dort die aufrüttelnden neuartigen Texte verlegt, die andere, traditionellere Verlage nicht drucken wollten oder denen man diese Aufgabe erst gar nicht anvertrauen wollte. Wichtige Foren waren vor allem die Zeitschriften. Herwarth Waldens (1878-nach 1930 verschollen) „Der Sturm“ und Franz Pfemferts „Aktion“ kommen dabei besonderes Gewicht zu. Im Gegensatz zu vielen anderen liefen deren Auflagen sehr erfolgreich.67 Im März 1910 gegründet, verbreitete der „Sturm“ die „Kenntnis der bestehenden Künstlerbewegungen, wie des Futurismus und des Kubismus und [rief] eine allgemeine Reflexion über ästhetische Probleme hervor"68. Hier wurden neueste Gedichte, theoretische Aufsätze und vielfach auch Grafiken abgedruckt und diskutiert. Die damit vorgenommene $\mathrm{Zu}$ sammenführung von Literatur und Bild und auch die von Walden immer weiter vorangetriebene Erweiterung seiner Institutionen, wie die „Sturm“-Galerie, Theater etc. zeugt von dem damals besonders ausgeprägten Wunsch nach dem Gesamtkunstwerk zur „Intensivierung des Ausdrucks“. Die Realisierung der Synthese verschiedener Künste wurde zur gegenseitigen Befruchtung angestrebt und war Teil des expressionistischen Programms. Außerdem waren die zentralen Elemente

\footnotetext{
66 Anz (2001), S. 142 ff.; Olbrich (2004), S. 406.

${ }^{67}$ Bogner (2005), S. 58.

${ }^{68}$ Richard (1980), S. 17.
} 
- radikaler Traditions- und Tabubruch, scharfe Abkehr von einer Wiedergabe nur der äußeren Wirklichkeit, das Prinzip der Abstraktion, die Betonung des Organischen, Lebendigen, Irrationalen und Emotionalen und der gesteigerte Einsatz wirkungsmächtiger, suggestiver und affekterregender Darstellungsmittel - überall gleichermaßen zu finden. ${ }^{69}$ Insgesamt ergab sich daraus ein verstärktes Auftreten und Fördern von Mehrfachbegabungen in der expressionistischen Bewegung. Die „Aktion“, die ein Jahr später auf den Plan trat, wurde zur größten Konkurrenzzeitschrift des „Sturm“, war jedoch in stärkerem Maße politisch orientiert. Beide Zeitschriften begleiteten die Vertreter des Expressionismus über einen Zeitraum von ungefähr zehn Jahren und spiegeln somit auch die Entwicklungen und Veränderungen der Bewegung.

Während des Krieges verfälschte die Zensur ,das Bild der bestehenden intellektuellen Kräfteverhältnisse "\%0, da sie die Möglichkeit zu kriegskritischen Äußerungen zu unterbinden oder wenigstens einzuschränken suchte. Vielfach wurde die Arbeit der Zeitschriften deshalb ins Exil verlagert - vor allem in die Schweiz. Andere entwickelten Strategien indirekter Kriegs- und Zensurkritik.711 Nach dem Krieg transportierten die Zeitschriften schließlich auch die Ideen für eine neue Gesellschaftsordnung und stellten sich dementsprechend die Aufgabe ihre Leser zu politisieren. So blieb das geschriebene Wort bis zum Auslaufen des Expressionismus ein wichtiges Medium.

\subsection{Doppelbegabung im Expressionismus - ihre Voraussetzungen und Vertreter}

Krisenbewusstsein, Gruppenbildung und Seelensuche

In den vorigen Kapiteln wurde bereits angedeutet, dass der Expressionismus das Ausleben von Doppel- und Mehrfachbegabungen in besonders hohem Ausmaß befördert hat. Nachfolgend soll nun noch einmal den genauen Gründen dafür nachgegangen werden.

Wesentlich für das Empfinden der gesamten Intellektuellenszene war vor allem ein Krisenbewusstsein, das sich, wie erwähnt, aus der politischen und sozialen Lage, aus den technischen Veränderungen und den wissenschaftlichen Umbrüchen ergab. Die vielen einschneidenden Neuerungen und Theorien - Nietzsches Nihilismus war nur eine davon - wirkten irritierend und führten zu einer Suche nach neuen Werten, aus der sich schließlich eine antithetische Vorstellungswelt

\footnotetext{
${ }^{69}$ Bogner (2005), S. 58 ff.

70 Anz (2001), S. 139.

71 Anz (2001), S. 139 ff.
} 
ergab. Der negativ empfundenen Wilhelminischen Patriarchalgesellschaft mit ihrem von Traditionen geprägten sozialen und kulturellen System, das nun zunehmend vom technischen und naturwissenschaftlichen Fortschritt bestimmt war, stellte man eine positive, wenn auch vage Vorstellung von einer neuen Welt gegenüber, in der die Menschen im freien Miteinander leben und zugleich alle ihr eigenes Selbst realisieren können sollten. ${ }^{72}$ Dem Gefühl in einer Krisenzeit zu leben, entsprang also das Bedürfnis nach Erneuerung der Gesellschaft sowie des Menschen, welches Ausgangspunkt für die Ideen des Expressionismus und zugleich für die Vereinigung der Künstler und Künste war. ${ }^{73}$ So schrieb denn beispielsweise Franz Marc in dem einflussreichen Almanach „Der Blaue Reiter“ von 1912, in dem verschiedene Autoren ihre Gedanken zu einer neuen Kunst bündelten, unter dem Titel ,Zwei Bilder“:

„,...) noch liegt das weite Land voll Trümmer, voll alter Vorstellungen und Formen, die nicht weichen wollen, obwohl sie schon der Vergangenheit gehören. Die alten Ideen und Schöpfungen leben ein Scheinleben fort, und man steht ratlos vor der Herkulesarbeit, wie man sie vertreiben und freie Bahn schaffen soll für das Neue, das schon wartet. Die Wissenschaft arbeitet negativ, au détriment de la religion - welches schlimme Eingeständnis für die Geistesarbeit unserer Zeit. Wohl fühlt man, dass eine neue Religion umgeht, die noch keinen Rufer hat, von niemand erkannt. (...) Es sind eigenwillige, feurige Zeichen einer neuen Zeit, die sich heute an allen Orten mehren. Dieses Buch soll ihr Brennpunkt werden (...). "74

Die „neue Religion“, die er hier anspricht und die bei der Bewältigung der Krise helfen sollte, sollte die Kunst sein - erneuert von Visionären, die „eigenwillige, feurige Zeichen" setzen. Elementar für diese neue Kunst war das Ziel, dem Inneren Ausdruck zu verleihen - die Kunst also gleichsam zur Sprache der Seele zu erheben und zugleich die Menschen zum gemeinschaftlichen Aufbruch zusammenzubinden. Der Wunsch das eigene Ich mehr in den Mittelpunkt zu stellen und gleichzeitig in eine Gemeinschaft mit anderen einzubringen, war Resultat der Krise. Diese nämlich bewegte die Künstler- und Literatenkreise dazu über das Sein des Menschen zwischen darwinistischer Evolutionstheorie (die das Recht des Stärkeren propagierte), einem nach Gottes vermeintlichen „Tod“ zur Emanzipation als Übermensch bestimmten Individuum (laut Nietzsche) und dem zerbröckelnden, bestehenden Sozialgefüge zu reflektieren und inmitten aller Umbrüche Halt in einer Gemeinschaft zu suchen, die zwar in ihren Äußerungen nicht homogen war, aber doch prinzipiell ähnliche Ideen ${ }^{75}$ vertrat. Und Träger dieser Ideen wurden in besonderem Maße die Intellektuellenzirkel aus Künstlern und Literaten, die ein einmalig enges Netzwerk entwickelten, um ihre Gedanken auszutauschen und sich

\footnotetext{
72 Anz/Stark (1982), S. 128.

$73 \mathrm{Vgl}$. Schober (1994), S. 14.

${ }^{74}$ Lankheit (1990), S. 34 f.

75 S. Kapitel 2.2.
} 
gegenseitig Inspirationen zu liefern. Mehr als je zuvor wurden „Künstlervereinigungen und Schriftstellerkereise, subpolitische Zirkel und programmatische Gruppierungen in der Zeit des Expressionismus zu kommunikativen Zentren" "\%. Sie schlossen sich zusammen zu einer künstlerisch-literarischen Avantgarde mit dem Ziel einer gesellschaftlichen Gesamterneuerung.

Eine der Formen, wie Teile der vielfach auch politisch interessierten Intellektuellenzirkel zur Erneuerung von Mensch und Gesellschaft gelangen wollten, war die Auflehnung gegen alles Bestehende durch revolutionäre Agitation, wie es sich beispielsweise in dem Aufruf von Erich Mühsam von 1913 spiegelt:

„Revolution entsteht, wenn ein Zustand unhaltbar geworden ist: mag dieser Zustand in den politischen oder sozialen Verbältnissen eines Landes, in einer geistigen oder religiösen Kultur oder in den Eigenschaften eines Individuums stabilisiert sein. Die treibenden Kräfte der Revolution sind Überdruß und Sebnsucht, ibr Ausdruck ist Zerstörung und Aufrichtung. (...) Einige Synonyma für Revolution: Gott, Leben, Brunst, Rausch, Chaos. Lasst uns chaotisch sein!" "77

Der rege Austausch zwischen Künstlern und Literaten, in dem die Ziele und Möglichkeiten ihrer Bewegung diskutiert wurden, trug nun entscheidend dazu bei, die Nähe zwischen den Künsten zu befördern. Das gilt ebenso für die Verknüpfung von Wort und Bild, also die gemeinsame Präsentation literarischer, wie bildkünstlerischer Produkte bei der Verbreitung der expressionistischen Ideen über die genannten, populären Zeitschriften Pfemferts und Waldens. So beschreibt Rudolf Blümner in seiner Einführung über Waldens 1910 gegründete Zeitschrift „Der Sturm“ die grenzüberschreitenden Bestrebungen der daran Beteiligten wie folgt:

„Der Sturm hat auf dem Gebiet der Dichtung, der Literatur, der Musik, der Zeichnung und des Holzschnittes stets nur die Arbeiten jener Jüngeren und Neuen veröffentlicht, die eine Entwicklung zu größerer Bedeutung erwarten ließen. (...) Um der heranwachsenden künstlerischen Generation Gelegenheit zu bieten, sich in den Anschaunngen des Expressionismus heranzubilden, wurde im Jahre 1916 die Kunstschule Der Sturm gegründet. Durch den Unterricht auf allen künstlerischen Gebieten bringt sie die innere Gemeinsamkeit der Künste zum Ausdruck. (...) Die Kunstschule Der Sturm lehrt die Bühnenkunst, Schauspielkeunst und Vortragskunst, die Malerei, die Dichtung und die Musik. Die Einheit der Kunst fordert die Kenntnis aller Künste und die Einheitlichkeit im Unterricht, die Verschiedenheit ibrer Ausdrucksmittel die Trennung in die einzelnen Kunstabteilungen der Schule. "78

Der Sturm vereinte somit in beispielhafter Weise, nicht nur durch die eigene Kunstschule, sondern auch durch eine eigene Bühne, Kunstabende, eine eigene

\footnotetext{
76 Anz/Stark (1982), S. 404.

77 Mühsam (1913), S. 2. Dieser Aufruf leitete die erste Nummer der Münchener Zeitschrift „Revolution" ein und erläutert damit programmatisch ihren Titel.

${ }^{78}$ Blümner (1917), S. 2 und S. 10-14.
} 
Buchhandlung und Ausstellungen, Künste aller Couleur. Sicherlich war es dieser nicht nur vom Sturm angeregte, enge Austausch zwischen den verschiedenen Künsten, der viele Künstler und Literaten ganz selbstverständlich sich auch im anderen Metier „,zu Hause“ fühlen und gegebenenfalls im anderen Medium Ausdruck suchen ließ.

Die Erneuerung der Künste in Abwendung insbesondere von ihrer akademischen Tradition und eine teilweise Wiederbelebung der romantischen Programmatik des Gesamtkunstwerks, waren ebenso wie die revolutionären Tendenzen Teil des Strebens nach gemeinschaftlichem Aufbruch. Dabei waren wie gesagt bei jeglichem künstlerischen Arbeiten vor allem das neue Ich-Bewusstsein und die Erforschung der eigenen Seele essentiell, wie es Ernst Ludwig Kirchner im Programm der „Brücke“ von 1906 knapp mit den Worten ,Jeder gehört zu uns, der unmittelbar und unverfälscht das wiedergibt, was ibn zum Schaffen drängt"79 ausgedrückt hat oder ausführlicher beispielsweise von dem Schriftsteller Richard Huelsenbeck formuliert wurde:

„Wir haben ganz tief in uns hinein zu sehen, um begreifen zu können, was sich aus Menschlichem machen lässt und wo die Synthese aller Fähigkeiten und Dinge des Menschen zu suchen ist. Wir müssen ganz ehrfürchtig werden vor der Gewalt unserer Seele, wenn wir die Erfahrung erreichen wollen, die uns sagt, dass das Imponderabil eines erhabenen Augenblicks eine bessere Beantwortung kompliziertester Fragen sein kann, als präziseste Berechnung. (...) Der neue Mensch findet sich selbst in ekstatischer Erlösung, er betet sich selbst an. "80

Die in Huelsenbecks Worten von 1917 mitschwingende, geradezu mystische Erfahrung der eigenen Seele in der Erforschung und Betonung der Gefühle, erinnert nicht wenig an Tendenzen der Romantiker und lässt sich vielfach auf zeitgenössische Ansätze wie Bergsons Lebensphilosophie, Nietzsches lebensbejahendes, dionysisches Prinzip oder Freuds Erforschung der menschlichen Psyche zurückführen.

Die Seele und damit den Menschen derart in den Mittelpunkt zu stellen, war ein wichtiger Faktor für das Ausleben von Doppelbegabung, denn dadurch wurde der Fokus in den expressionistischen Künsten neu gelegt - weg von der formalen Vollendung, hin zur Mitteilung von Seelenzuständen. Und dieser Ausdruck des eigenen Seelenlebens ließ sich vorzüglich in jeder der verschiedenen Medien realisieren. Dies wurde z. B. insbesondere durch Kandinsky und den „Blauen Reiter" propagiert. Nicht nur werden im Almanach unterschiedlichste bildkünstlerische Werke aus verschiedenen Epochen, Ländern und Lebensbereichen nebeneinandergestellt, sondern gleichermaßen wird darin versucht durch die Einbeziehung von Bühnenkompositionen Wassily Kandinskys, von Musikbeilagen Arnold Schönbergs, Alban Bergs (1885-1935) und Anton von Weberns (1883-1945) sowie

${ }^{79}$ Zitiert nach Anz/Stark (1982), S. 18.

${ }^{80}$ Huelsenbeck (1917), S. 2. 
von Aufsätzen insbesondere über das Verhältnis von Kunst und Musik, das Zusammenwirken der Künste zu beleuchten. Kandinsky betont zwar in seiner Publikation „Über das Geistige in der Kunst“" (1911) zunächst die Unterschiedlichkeit der einzelnen Disziplinen ${ }^{81}$ („So stellen sich allmäblich verschiedene Künste auf den Weg, das zu sagen, was sie am besten sagen können, und durch die Mittel, die jede von ibnen ausscbließlich besitzt" ${ }^{\prime \prime}$, doch unterstreicht er zugleich vehement ihre Nähe zueinander: „Und trotz oder dank dieser Absonderung, nie standen in den letżten Jahren die Künste, als solche, einander näher als in dieser letzten Stunde der geistigen Wendung".82 Ausgehend von den unterschiedlichen Möglichkeiten der Disziplinen, wie sie auch von Lessing erörtert wurden, ${ }^{83}$ kommt er zu dem Schluss: „So grenæt die Vertiefung in sich eine Kunst von der anderen ab, so bringt sie die Vergleichung wieder zueinander im inneren Streben "84. Dieses „innere Streben“ (auch „innere Notwendigkeit") ist Kern seiner Kunstauffassung, wie sie im besagten Aufsatz oder ebenso im Almanach vermittelt wird. So ist Kandinsky der Meinung, dass die Kunst nicht der Auffassung des „l'art pour l'art“ folgen, sondern dem Künstler als Mittel dienen solle, um das geistige Leben innerhalb einer Gesellschaft voranzubringen. Die geistige Leitung sei Pflicht des Künstlers und die Künste jede für sich mit ihren eigenen Möglichkeiten sein Mittel dazu. Insofern sei das Streben der Künste bei all ihrer sonstigen Unterschiedlichkeit dasselbe. Ihr Ziel müsse es sein, im Betrachter seelische Vibrationen hervorzurufen, um Wirkung auf ihn auszuüben. Diese Vibrationen könne die Kunst aber nur dann auslösen, wenn sie dem „Prinzip der inneren Notwendigkeit" folge. Um zu erkennen, was die innere Notwendigkeit und somit die vollkommene Wirkung eines Kunstwerkes ausmacht, müsse der Künstler seine eigene Seele erforschen. Anhand der Malerei führt er in seiner Schrift „Über das Geistige in der Kunst“" weiter aus, wie Farben und Formen mit ihren individuellen „Klängen" in unterschiedlicher Weise einen seelischen Ausdruck hervorbringen können, wie sie auch - und damit ebnet er der Abstraktion den Weg! - im Ungegenständlichen und assoziativ wirken können. Inhaltlich wie auch im Wortgebrauch (beispielsweise bringt er Farben mit Klängen in Verbindung) stellt Kandinsky dabei eine besonders große Nähe zwischen Musik und Malerei her, die auffällt, auch wenn er andere Künste ebenfalls zum Vergleich anführt.

Ähnliche Auffassungen über den Zusammenhang zwischen innerem Erleben und äußerem, künstlerischem Ausdruck spiegeln sich auch bei anderen Expressionisten, wenn beispielsweise August Macke (1887-1914) schreibt: „Der Mensch äußert sein Leben in Formen. Jede Kunstform ist Äußerung seines inneren Lebens. Das Äußere der Kunstform ist ibr Inneres. ${ }^{85}$ oder Arnold Schönberg überlegt, dass die Sprache der

\footnotetext{
${ }^{81}$ Ebenso wird es in Blümners obig zitierter Beschreibung der Sturm-Kunstschule konstatiert („Die Einheit der Kunst fordert die Kenntnis aller Künste und die Einheitlicbkeit im Unterricht, die Verschiedenheit ihrer Ausdrucksmittel die Trennung in die einzelnen Kunstabteilungen der Schule").

82 Beide Textstellen s. Kandinsky (1952), S. 54.

${ }^{83} \mathrm{Vgl}$. Kapitel 2.1.

${ }^{84}$ Kandinsky (1952), S. 56.

85 August Macke „Die Masken“ in: Kandinsky (2002), S. 56.
} 
Welt „nur füblbar sein soll“86. Im Almanach „Der Blaue Reiter“ und insbesondere bei Kandinsky finden die Ideen von der Zielgleichheit der Künste, vom seelischen Ausdruck und vom Aufbruch besonderen Ausdruck und dürften in ihrer geballten Prominenz von großer Bedeutung für viele Zeitgenossen gewesen sein. Auch wenn sich die Vertreter des „Blauen Reiter“ dagegen verwahrten, wurde der Almanach oft und gerne als programmatisch bezeichnet. In jedem Fall spiegelt er viele der von Expressionisten vertretenen und diskutierten Gedanken.

Die ebenfalls das Arbeiten in verschiedenen Medien inspirierende Idee eines die Künste vereinenden Gesamtkunstwerks, wie es die Romantiker zur Offenlegung der transzendentalen Identität von Mensch und Welt anstrebten, griff Mitte des 19. Jahrhunderts bereits Richard Wagner wieder auf, mit dem Ziel die Künste zu ihrer ursprünglichen Einheit zurückzuführen und die „vollendete menschliche $\mathrm{Na}$ tur" darzustellen. ${ }^{87}$ Expressionistische Künstler wie Kandinsky, oder im hier zu untersuchenden Fall Oskar Kokoschka, folgten diesem Beispiel und legten besagte Idee ihren Bühnenproduktionen zu Grunde. In Zusammenführung von Text, Bild und Musik in neuartiger Betonung bestimmter Faktoren wie Tanz oder z. B. bei Kokoschka insbesondere von Licht und Farbe, wollten sie auf multimediale Weise versuchen, durch das Miteinander der Kunstgattungen ein sinnlich erfahrbares Ineinander zu erreichen. Die Krise, die Suche nach dem Inneren, nach dem Ich und die durch das Aufbruchsstreben bedingte enge Verbindung von Künstler und Literaten sowie ihrer Medien waren wichtige Voraussetzungen für die Öffnung der Künste füreinander. Voraussetzungen, wie sie in dieser Konstellation und Ausprägung einmalig waren und den Weg für das auffallend verstärkte Ausleben von Doppelbegabung im Expressionismus ebneten.

Doppelbegabte während des Expressionismus - Einblick und Auswahl

Es gibt eine große Anzahl von Künstlern, die, inspiriert von den Möglichkeiten anderer Künste und angetrieben vom expressionistischen Ausdrucksstreben, sich zwischen 1910 und 1920 in verschiedenen Medien betätigten, von denen hier nur einige Beispiele genannt werden sollen. ${ }^{88}$ Ihre künstlerischen Grenzüberschreitungen waren durchaus von unterschiedlicher Intensität und Zielsetzung. Viele von ihnen waren in erster Linie Literaten und betätigten sich nur nebenbei im bildkünstlerischen Medium, wie beispielsweise Heinrich Mann, Franz Kafka, oder auch Else Lasker-Schüler ${ }^{89}$, deren dichterisches Werk von der Literaturwissenschaft zumindest teilweise in die Nähe des Expressionismus gerückt wird. Jede(r) von ihnen hat insbesondere über Zeichnungen und Illustrationen der eigenen

\footnotetext{
86 Arnold Schönberg „Das Verhältnis zum Text“ in: Kandinsky (2002), S. 60.

${ }^{87}$ Schober (1994), S. 26 ff.

${ }^{88}$ Bei Böttcher/Mittenzwei (1980; Zwiegespräch) und Günther (1960) sind hilfreiche Auflistungen dieser Mehrfachbegabten zu finden.

${ }^{89}$ Von ihr findet sich eine Vielzahl von Gedichten in der von Kurt Pinthus herausgegebenen, wichtigen Sammlung expressionistischer Lyrik mit dem Titel „Menschheitsdämmerung““
} 
Texte und Briefe das schriftliche Schaffen ergänzt, wenn dies auch nicht immer über das private Vergnügen hinausging. Bei den Mann-Brüdern ist das „Bilderbuch für artige Kinder“ zu nennen, das sie gemeinschaftlich 1895 in Rom schufen. Noch nicht in expressionistischer Manier führten sie hier Vers-Parodien, ironische Prosa und groteske Zeichnungen zu einem Buch zusammen, das nach Thomas Manns Aussage ,so hervorragend unpädagogisch und ungeeignet für Kinder war!'90 Heinrich Mann, der insbesondere in seiner Jugend dem Zeichnen und Malen nachging, gab einen dahingehenden Berufswunsch auf und schuf nach 1890 nur seltene Zeichnungen und Skizzen zu seinen Romanen. Franz Kafkas Zeichnungen, die er wohl als ,zweckfreie, spielerische Transponierung von Gedanken und Emotionen ins Figürliche ${ }^{\circ 1}$ schuf, wurden überwiegend von Max Brod gesammelt. Auch die Aquarelle und Zeichnungen der Lasker-Schüler sind als kleinere Ergänzungen ihres literarischen Schaffens zu sehen, deren bildkünstlerischer Eigenwert weit hinter dem dichterischen Werk zurückbleibt.92 Ambitionierter arbeitete der Schriftsteller und Zeichner Fritz von Herzmanovsky-Orlando in beiden Bereichen, der aber geringe Bekanntheit erlangte. Dies wird nicht zuletzt auf die zumeist erst posthum erfolgte Veröffentlichung der skurril-phantastischen Romane, Erzählungen, Dramen und Ballette und dazu ergänzender Grafiken des finanziell vom Kunstmarkt unabhängigen Ritters zurückzuführen sein..$^{93}$

Manche, wie zum Beispiel Wassily Kandinsky und Arnold Schönberg, widmeten sich, wie bereits erwähnt, mehr der Verbindung von Bildender Kunst und Musik, was sie durch theoretische Schriften untermauerten, wie sie unter anderem im Almanach „Der Blaue Reiter“ neben Texten des Malers Franz Marc zu finden sind. Schönberg, der als Komponist besonders durch seine 1921 entwickelte Zwölftonmusik hervorstach, fertigte zwischen 1906 und 1913 eine Vielzahl sehr ausdrucksstarker Bilder (rund 360). Insbesondere seine Porträts und „Visionen“ sind von expressiver Kraft. Daneben schuf er auch Landschaften und Bühnenentwürfe, wobei er sich in den verschiedenen bildkünstlerischen Techniken erprobte. Obwohl eher als Dilettant angesehen, war er bei mehreren Ausstellungen vertreten - darunter auch bei einer Schau des „Blauen Reiter“ in München 1911.94 Kandinsky konzentrierte sich neben seiner Malerei lieber auf theoretische Ausführungen. Als wirkliche, literarisch-bildkünstlerische Doppelbegabungen, die in beiden Medien annähernd regelmäßig und nicht nur zum privaten Vergnügen oder zu rein illustrativen Zwecken ihren Ausdruck suchten, können Alfred Kubin,

\footnotetext{
${ }^{90}$ Günther (1960), S. 172.

${ }^{91}$ Böttcher/Mittenzwei (1980; Zwiegespräch), S. 248.

92 Zu den Mann-Brüdern außer Günther (1960), S. 172 ff. auch Böttcher/Mittenzwei (1989; Zwiegespräch), S. 211 ff.; zu Kafka s. Böttcher/Mittenzwei (1980; Zwiegespräch), S. 246 ff., Günther (1960), S. 180; zu Lasker-Schüler s. Günther (1960), S. 173 f., Böttcher/Mittenzwei (1980; Zwiegespräch), S. $200 \mathrm{ff}$.

${ }^{93}$ Günther (1960), S. 176; Böttcher/Mittenzwei (1980; Zwiegespräch), S. 226 f.; Beispiele seiner Zeichnungen s. in: Flora (1974).

${ }^{94}$ Günther (1960), S. 169. Mehr zu den bildkünstlerischen Werken z. B. in: Hollein (2002).
} 
Ernst Barlach, Oskar Kokoschka und Ludwig Meidner genannt werden. Als Mitbegründer der „Neuen Künstlervereinigung München“ (1909) und zeitweise Mitglied des „Blauen Reiter“ (ab 1911), entwickelte Kubin (1877-1959) jedoch einen unabhängigen, individuellen Stil, der sich sowohl in seinem zeichnerischen als auch in seinem schriftstellerischen Schaffen niederschlug. Phantastisches, Traumhaftes und Gespenstisches wurden sein Hauptthema. Seine zumeist düsteren, dämonischen und skurrilen Zeichnungen haben ihm großes Ansehen verschafft, doch auch seine irrealen, die Grenzbereiche der menschlichen Seele tangierenden Schriften verdienen Beachtung. Die meisten davon sind allerdings erst nach dem Expressionismus entstanden - ausgenommen der eindrucksvolle Roman „Die andere Seite“ von 1909. ${ }^{95}$ Ernst Barlach (1870-1938) war als Bildhauer, Grafiker und Schriftsteller tätig. Er ist besonders bekannt für seine Holzskulpturen und Bronzen, die vor allem den Menschen und seine Lebensbedingungen beziehungsweise -einstellungen thematisieren. In seiner Berliner Zeit stellte er ab 1910 regelmäßig in Ausstellungen der Berliner Secession und bei Paul Cassirer aus. Der Anfang seines spät einsetzenden literarischen Schaffens fällt in diese Phase. In kurzen Abständen entstanden die Dramen „Der tote Tag“ (1912), „Der arme Vetter“ (1918), „Die echten Sedemunds“ (1920), „Der Findling“ (1922), die „Sündflut“ (1924) und „Der blaue Boll““ (1926). ${ }^{96}$

Für eine genauere Betrachtung und den Vergleich Doppelbegabter eignen sich nun Oskar Kokoschka (1886-1980) und Ludwig Meidner (1884-1966) in besonderer Weise. Anders als bei Kubin ist ihr schriftstellerisches Schaffen auch während des Expressionismus sehr ausgeprägt und beide waren als Maler und Grafiker tätig, während Barlach dagegen in hohem Maße als Bildhauer arbeitete. Ludwig Meidner ist heute ein eher in Vergessenheit geratener Künstler, was in Anbetracht seiner Bedeutung und Bekanntheit in damaligen expressionistischen Kreisen völlig zu unrecht der Fall ist. Trotz seiner Nähe zur expressionistischen Gesamtbewegung hat er individuelle Ausdrucksformen gefunden und vor allem als Maler apokalyptisch anmutender Landschaften bemerkenswerte bildkünstlerische Werke geschaffen. Gleichzeitig war er Verfasser von zumeist pathetischer Lyrik und Prosa - letztere wurde zum Großteil in den Anthologien „Im Nacken das Sterne-

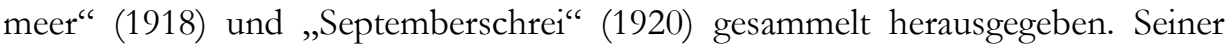
Doppelbegabung war sich Meidner durchaus bewusst, definierte sich selbst aber eher als Maler, wie in eigenen Aussagen deutlich wird: „Ihr Dichter seid gegrüsst. Der Maler grüßt Euch. ${ }^{~} 97$ oder:

\footnotetext{
95 Salzer (1986), S. 193 f.; Böttcher/Mittenzwei (1980; Zwiegespräch), S. 222 f.

${ }^{96}$ Salzer (1986), S. 190 ff., Böttcher/Mittenzwei (1980; Zwiegespräch), S. 202 ff.

${ }^{97}$ Aus „Gruß des Malers an die Dichter“ in: Meidner (1973), S. 75.
} 


\section{„Vor kurzem fand ich mich weinend neben meiner Staffelei, weinend, daß ich nicht mehr Schriftsteller sein kann (...) und bin überzengt, daß, wäre ich nicht Maler und wäre nicht Hitler gekommen, ich hätte mein Schreiben steigern können und wäre ein guter Schrift- steller geworden."98}

Durch die Zuordnung seiner Werke zur Entarteten Kunst und die Verfolgung durch die Nationalsozialisten sind verschiedene seiner Bilder vernichtet worden oder nach dem Krieg in Privatbesitz und Kunsthandel kaum mehr auffindbar. Bedeutende Werke sind in amerikanische und israelische Museen gewandert und Meidners Arbeiten in Deutschland heute kaum zu sehen; nur ein eher geringer Bestand ist in unseren öffentlichen Sammlungen ausgestellt. Dazu kommt die 1923 erfolgte, vehemente Absage Meidners an sein eigenes expressionistisches Schaffen, das seinen Ruhm als Künstler begründet hatte - die damit verbundene Abkehr von seinen Künstlerfreunden, Anhängern und Mäzenen dürfte sein unmerkliches Verschwinden aus dem Gedächtnis der Öffentlichkeit mitbegründet haben. Das durch die Judenverfolgung im Dritten Reich erzwungene Exil nahm ihm dann auch noch die letzte Möglichkeit, sich weiterhin als Künstler bemerkbar zu machen.

Dennoch gab es natürlich Kunsthistoriker und Museen, die seine Bedeutung anerkannten und sein Werk nach außen zu tragen versuchten, beziehungsweise dies nach wie vor tun. Beispielsweise Grochowiaks Monographie von 1966, die noch kurz vor Meidners Tod erschienen ist und von dem Kontakt des Autors zum Künstler profitiert, ist ein wichtiges Werk - das erste, das sich nach dem Krieg und nach Meidners Rückkehr nach Deutschland eingehend mit dessen Werdegang und seinem Oeuvre auseinandersetzt und dabei überhaupt das erste, das den Künstler derart umfassend würdigt. Aus den 1970er Jahren ist die Abhandlung Joseph Paul Hodins in den Darmstädter Schriften erwähnenswert, auch wenn sie etwas ausschweifend geschrieben ist. In den 1980er und 90er Jahren folgten weitere wichtige Veröffentlichungen, wie beispielsweise die Dissertation Gerhard Leistners von 1986 und der Katalog der Berlinischen Galerie, die im Frühjahr 1990 eine Ausstellung Meidners „Apokalyptische[n] Landschaften“ widmete, welche im Winter 1989 bereits im Los Angeles County Museum of Modern Art zu sehen war. Carol S. Eliel und Eberhard Roters befassen sich hier eingehend mit dieser Werkgruppe aus Meidners expressionistischer Schaffenszeit, die entsprechend ihrer Komplexität weiten Raum in der hier vorliegenden Arbeit einnehmen wird. Ebenso interessante Einblicke bietet der Ausstellungskatalog des Jüdischen Museums in Wien von 2001. Herausgegeben von Tobias Natter enthält er eine Vielzahl aufschlussreicher Beiträge, die die verschiedenen Facetten des Expressionisten Meidner und dabei auch das literarische Werk beleuchten. Die wertvollste Publikation allerdings ist der Katalog zu der im Winter 1991 auf der Mathildenhöhe in Darmstadt gezeigten Ausstellung, den Gerda Breuer und Ines

98 Meidner (1964). Zitiert bei Breuer (1991) 2, S. 32. 
Wagemann herausgegeben haben. Neben einer breit gefächerten Aufsatzsammlung zu den verschiedenen Bereichen von Meidners Gesamtschaffen bietet ein zweiter Band eine erfreulich qualitätvolle und großzügige Zusammenstellung von Bildern und Schriften. Auch über die wichtigsten und bekanntesten Zeugnisse des Künstlers und Autors Meidner hinaus bietet er einen breiten Überblick über die Primärquellen. Hervorzuheben ist, dass sich hier drei Beiträge explizit auf Meidners literarisches Wirken beziehen, wovon für die vorliegende Arbeit zwei sehr hilfreich sind. Zuletzt erschien ein Katalog zu der 2009 in Hamburg gezeigten Ausstellung „Unter unerforschlichen Meteoren: Ludwig Meidner - Ernst Barlach“. Dieses hoffentlich noch ansteigende Interesse für den Künstler besteht zu Recht, denn seine Werke spiegeln mit hoher Intensität die Stimmung der expressionistischen Zeit, stehen aber zugleich in der Umsetzung bestimmter Themen einzigartig da. ${ }^{99}$

Oskar Kokoschka gehört dagegen noch heute zu den bekannteren Vertretern des Expressionismus. Insbesondere seine psychologisierenden Porträts und seine damals noch als skandalös angesehenen Dramen verschafften ihm breite Aufmerksamkeit. Sich vom Vorbilde Gustav Klimts (1862-1918) und dem von ihm als konservativ empfundenen Wiener Künstlermetier lösend, arbeitete Kokoschka ebenso wie Meidner zwischen 1910 und 1920 viel in Berlin und Dresden, wo er Kontakte zu zentralen Persönlichkeiten der expressionistischen Bewegung im deutschsprachigen Raum, wie z. B. Paul Cassirer, pflegte. Seine frühen Dramen, wie beispielsweise „Mörder, Hoffnung der Frauen“ oder „Hiob“, sind anders als sein bildkünstlerisches Werk, heute kaum mehr im Gedächtnis, obschon sie durch ihre extreme Betonung des Visuellen und durch die Verarbeitung des Grotesken auf die damalige Bühnenliteratur großen Einfluss hatten. Auch schrieb Kokoschka Lyrik und theoretische Schriften. Ähnlich wie Meidner sah er sich selbst wohl in erster Linie als Künstler, wenn er - obwohl seine ersten Theateraufführungen und die Veröffentlichung der Dichtung „Die träumenden Knaben“ bereits hinter ihm lagen - in Erinnerung an abendliche literarische Diskussionen über die neueste Ausgabe der „Fackel“ mit Karl Kraus und anderen im Vorkriegs-Berlin äußert:

„Ich entschuldigte mich als einziger damit, dass ich diese Nummer nicht gelesen bätte. Ich hatte es natürlich getan, aber heimlich. (...) Hätte ich es zugegeben und durch Unverständnis einer Zeile mich vergangen (...) ich hätte mich des gröbsten Undanks gegenüber dem letzten Hüter der deutschen Sprache schuldig gemacht. Schließlich war ich nur ein Maler, und wie man im Orient einen Geistesschwachen für sakrosankt hält, war ich auch als „Stummer" berechtigt, mit den anderen am Tisch zu sitzen. "100

Wenn auch sein literarisches CEuvre heute fast nur noch in der Forschung Beachtung findet, Kokoschkas bildkünstlerisches Schaffen ist immer wieder Gegenstand internationaler Ausstellungen und umfangreicher Publikationen. Dass Kokoschka

\footnotetext{
${ }^{99}$ Genaue Angaben zu der genannten Literatur sind dem Literaturverzeichnis zu entnehmen.

${ }^{100}$ Kokoschka (1971), S. 81.
} 
im Gegensatz zu Meidner nicht in Vergessenheit geriet, dürfte im Wesentlichen darin begründet sein, dass die Unterstützung durch Freunde wie Förderer und die Kontakte zum Kunstbetrieb nie abrissen. Stets blieb Kokoschka aktiv. Selbst in den Jahren des Nationalsozialismus war er präsent, indem er sich von Wien und Prag aus gegen dessen Ideologie zu Wort meldete; im Londoner Exil engagierte er sich bei „Young Austria“ und im „Freien Deutschen Kulturbund“.

Die Liste der Äußerungen und Publikationen über Kokoschka ist lang. Als Beispiele seien hier deshalb nur einige der wichtigsten Werke herausgegriffen. Der ersten umfassenden Monographie über Leben und Schaffen des Künstlers von Edith Hoffmann aus dem Jahre 1947 folgten 1956 Überblickswerke Hans Maria Winglers über die Schriften und das malerische Cuvre Kokoschkas. Ernst Rathenau ergänzte dies 1961 mit einem Katalog der Zeichnungen. Mitte der 60er gaben Hans Schwerte und Horst Denkler in ihren Aufsätzen „Anfang des expressionistischen Dramas: Oskar Kokoschka“ und „Schauspiel“ und ,Der brennende Dornenbusch 'von Oskar Kokoschka" wichtige Denkanstösse zu den Dramen und damit zu Kokoschka als Schriftsteller. Lia Secci beschäftigte sich 1968 als erste mit seiner Lyrik. Außer ihr und Gerhard Lischka, der vier Jahre später die erste umfassende Untersuchung zu Kokoschka als Doppelbegabung vorgenommen hat, fehlt bis heute bedauerlicherweise eine übergreifende Studie zum dichterischen Werk und damit mehr als nur die Interpretation von „Die träumenden Knaben“. Lischkas Untersuchungen zu Kokoschka als Maler und Dichter sind ebenfalls nur wenige nachgefolgt. Hier ist vor allem Henry Schvey zu nennen, der 1982 eingehende und sehr wertvolle Überlegungen zu „Oskar Kokoschka - the painter as playwright" angestellt hat. Ein weiterer Essay von ihm ist in der von Erika Patka herausgegebenen Aufsatzsammlung abgedruckt, die anlässlich eines Symposions der Hochschule für Angewandte Kunst in Wien 1986 erschien. Gerade in den 1990ern hat sich das Interesse an Kokoschka noch einmal verstärkt, denn es erschienen so wichtige Kataloge wie derjenige der Gemälde von 1906-1929, herausgegeben 1995 von Johann Winkler und Katharina Erling oder der zur Ausstellung „Kokoschka und Dresden“ im Albertinum Dresden von 1996. 2002 widmete sich Tobias Natter mit dem Katalog „Oskar Kokoschka: das moderne Bildnis 1909 bis 1914“ umfassend dem Porträtschaffen des Künstlers. Ein Jahr später legte Heinz Spielmann, welcher zuvor bereits Beiträge zu den Schriften und den Fächern Kokoschkas veröffentlicht hatte, eine neue Monographie über den Künstler vor. Bis heute hat das Interesse an Kokoschkas Schaffen nicht nachgelassen. Davon zeugen auch die Ausstellungen in Wien 2008, die Früh- und Spätwerk des Künstlers detailliert in den Blick nahmen. Insbesondere der Katalog „Kokoschka: Träumender Knabe - Enfant terrible“ ergänzt bisherige Erkenntnisse und ist daher in manchen Punkten für die nachfolgenden Untersuchungen zu Kokoschkas expressionistischer Phase erhellend. Dennoch gibt es nach wie vor Forschungslücken auch bei diesem Künstler zu schließen. Gerade das hier zu verfolgende Schaffen als Doppelbegabter ist auch bei ihm noch nicht hinreichend behandelt worden. 


\section{Fallbeispiele von doppelbegabten Künstlern des Expressionismus}

\subsection{Ludwig Meidner}

Im zweiten Kapitel sind die Geschichte der Doppelbegabung und die Bewegung des deutschen Expressionismus überblickshaft skizziert worden, wobei nicht zuletzt auch ein Eindruck der damals bestehenden Verhältnisse in Deutschland vermittelt worden ist. Es ist dabei deutlich geworden, wie vielfältig Einflüsse und Erscheinungsformen dieser Strömung waren und dass die verschiedenen Künste in dieser Zeit häufig in engem Kontakt miteinander standen und Ideen austauschten. Ludwig Meidner war einer der Künstler, der diese Kontakte besonders intensiv pflegte. Keiner der großen oder kleinen Künstlergruppierungen zugehörig, fand er Gleichgesinnte eher in den Literatenzirkeln Berlins, wo er Inspiration und Unterstützung erfuhr und so tief in die Gedankenwelt von Dichtern und Autoren 
eintauchte, wie kaum ein anderer expressionistischer Maler. ${ }^{101}$ Es ist daher wenig verwunderlich, dass er, wie manch anderer Expressionist ebenso, sich nicht ausschließlich der Malerei verschrieb, sondern zudem seine schriftstellerischen Fähigkeiten auslebte, wenn auch in durchaus geringerem Ausmaß. Der Zusammenhang beider Begabungen beziehungsweise wie er sich in beiden Bereichen ausdrückte, was die vermittelten Intentionen sind und in welchem Verhältnis sie zueinander stehen, soll im Folgenden untersucht werden. Doch zuerst muss die Frage nach dem Menschen Ludwig Meidner selbst gestellt werden, nach seiner Entwicklung und seinem Gesamtwerk, um sein expressionistisches Schaffen vor diesem Hintergrund angemessen analysieren und bewerten zu können.

\subsubsection{Zu Biografie und Gesamtwerk}

Kindheit und Jugend

Ludwig Meidner wurde am 18. April 1884 in Bernstadt in Schlesien geboren. Die Eltern waren Inhaber eines kleinen Textiliengeschäfts. Meidner hatte noch zwei Schwestern und zwei Brüder. Bernstadt und seine Umgebung empfand er als prägend: ,,...) diese trübe Farbe, diese grämliche Enge und Erdschwere babe ich von meiner Heimat mitbekommen (...) ".102 Auch die Bevölkerung der Gegend hatte in ihrer Judenfeindlichkeit vermutlich Einfluss auf den jüdischen Künstler und seine Auseinandersetzung mit dem Glauben, die durch das Elternhaus wenig forciert wurde. In den Jahren seiner frühen Kindheit entwickelte er nach eigener Aussage zudem eine tiefe Liebe zur Natur und zum Zeichnen. ${ }^{103}$

An der Oberrealschule Kattowitz vernachlässigte er über seiner Vorliebe für Deutsch und Malen alle anderen Fächer so sehr, dass er drei Jahre in der Quarta zubringen musste. Er schwärmte für die Neu-Romantiker Arnold Böcklin (18271901) und Franz von Stuck (1863-1928) und beschäftigte sich beim Malen und Zeichnen mit verschiedensten und teils außergewöhnlichen Themen: mit Asketen und Säulenheiligen, mit dem Tod, mit Gespenstern aber auch mit der Darstellung der Natur. Meidner entschied, dass er Künstler werden wolle. Seine Bewerbung 1901 an der Breslauer Kunstschule wurde jedoch abgelehnt und seine Eltern, die dem Berufswunsch des Sohnes verständnislos gegenüberstanden, drängten ihn zu einer Maurerlehre. Weiterhin nutzte Meidner jedoch jegliche freie Zeit zum Zeichnen und brach seine Lehre schließlich ab, um 1903 nach einer erneuten Bewerbung an der „Königlichen Kunst- und Kunstgewerbeschule“ in Breslau aufgenommen zu werden. ${ }^{104}$

\footnotetext{
101 Breuer (1991) 2, S. 17.

102 Meidner (1930), S. 368.

103 Breuer (1991) 2, S. 11 f.; Grochowiak (1966), S. 16.

${ }^{104}$ Breuer (1991) 2, S. 12 f.; Grochowiak (1966), S. 16 ff.; Hodin (1973), S. 27.
} 
Aufbruch zur Malerprofession - Breslau, Berlin, Paris

Das Studium dort stellte sich für ihn allerdings als Enttäuschung heraus: die Schule war sehr akademisch und konventionell. Er bemängelte die Geistlosigkeit und das pedantische Nachzeichnen langweiliger Gegenstände. Neben den von ihm bevorzugten, auf Religion, Einsamkeit und Armut bezogenen Bildthemen entwickelte Meidner auch ein Interesse für gesellschaftspolitische Lehren und die Schriften führender Philosophen. Da er in Breslau ebenso wenig die künstlerischen Impulse fand, die er suchte, entschied er sich 1905 die Breslauer Kunstschule $\mathrm{zu}$ verlassen und beinahe mittellos in die lebendige und aufblühende Reichshauptstadt Berlin zu gehen. ${ }^{105}$

Er sah dort in Ausstellungen Bilder von van Gogh, Paul Cézanne (1839-1906), Wilhelm Leibl (1844-1900) und Carl Schuch (1846-1903), die ihn sehr beeindruckten. Hauptsächlich aber war er mit dem Problem seiner Existenzsicherung beschäftigt, weshalb er eine Anstellung als Modezeichner im Atelier WulfSchwertfeger annahm, wo er Pelze für Zeitschriften möglichst getreu nachzuzeichnen hatte. Nebenbei malte er nachts für sich selbst, besuchte weiterhin Ausstellungen und nahm Unterricht im Radieren bei Hermann Struck (1876-1944), durch den er in Kontakt mit anderen Künstlern und Intellektuellen kam - unter anderem zum Beispiel mit Max Liebermann (1847-1935) und den späteren Mitgründern der „Pathetiker“.106

1906 erhielt Meidner seine große Chance, als eine Tante väterlicherseits ihm die Finanzierung eines Auslandsaufenthalts anbot. Im Juli 1906 bis zum April des folgenden Jahres ging er nach Paris, wo er am Montmartre wohnte und die populären Kunstschulen „Cormon" und „Julien“ besuchte. Er kehrte sich von beiden Schulen jedoch bald ab - wegen ihrer rüpelhaften Atmosphäre und ihrer Ablehnung Édouard Manets (1832-1883), den Meidner überaus schätzte. Im Eigenstudium erprobte Meidner in den Straßen der Stadt die impressionistische Bildbehandlung, obwohl die Impressionisten im Allgemeinen gar nicht mehr im Zentrum der Aufmerksamkeit standen, sondern die „Fauves“. Diese faszinierten ihn ebenfalls, doch konnte er sich nicht dazu entschließen ihre Malweise zu übernehmen. ${ }^{107}$

Durch seine vielen Aufenthalte in den Künstlerlokalen und dabei besonders im „lapin agile“ lernte er schließlich Amedeo Modigliani (1884-1920) kennen und es entstand eine intensive Freundschaft, in der Meidner in vielem von seinem Freund inspiriert wurde. Laut Meidners eigenen Aussagen will er in Paris die Anfänge seiner expressionistischen Ausdrucksweise gefunden haben. Doch vermutlich handelte es sich nur um erste Versuche in dieser Richtung, denn seine Bilder

\footnotetext{
105 Breuer (1991) 2, S. 14; Grochowiak (1966), S. 20.

106 Breuer (1991) 2, S.14 f.; Grochowiak (1966), S. 21.; Hodin (1973), S. 32.

107 Breuer (1991) 2, S. 15; Grochowiak (1966), S. 21 ff.; Hodin (1973), S. 32.
} 
verweisen auf den spezifisch deutschen Expressionismus und insbesondere auf die Berliner Szene. ${ }^{108}$

1907 musste Meidner dann bereits wegen eines Musterungsbescheids nach Deutschland zurückkehren, wurde allerdings zunächst vom Militärdienst zurückgestellt. Dennoch zog es ihn nicht wieder nach Paris, denn er hatte diese Stadt im Großen und Ganzen als Enttäuschung empfunden. Berlin dagegen entdeckte er nun neu für sich, war von der aufgeblühten Metropole begeistert und setzte seine Hoffnungen auf ein Leben und Arbeiten in dieser Stadt. Da er in Paris gelernt hatte, die Freiheit zu schätzen und notfalls dafür auch zu hungern, nahm er seine Arbeit als Modezeichner in Berlin nicht wieder auf und führte in der Folgezeit ein sehr ärmliches Leben. In Lesehallen verbrachte er seine Zeit; er beschäftigte sich u. a. mit Nietzsche, Baudelaire, Schiller und Hölderlin. 1908/09 hielt er sich kurzzeitig in Kattowitz auf, wo er eine Zeichenschule leiten sollte, doch scheiterte diese Unternehmung und er ging nach Berlin zurück. ${ }^{109}$

Am Vorabend des Ersten Weltkrieges

Erst 1911 rettete ihn ein Glücksfall aus der Not: „Ein unbekannter Gönner hatte für junge Künstler ein Stipendium von monatlich 100 Mark zur Verfïgung gestellt. Ein Scbüler von Max Beckmann (1884-1950) hatte dafür Meidner vorgeschlagen. "110 Meidner erhielt durch Beckmann das nötige Gutachten dafür. Es erwuchs daraus auch ein freundschaftlicher Kontakt zwischen den beiden Malern. In dieser Zeit, um 1910/11, entwickelte Meidner seinen Stil sichtbar weiter. In seinen Darstellungen der städtischen Peripherie wurde sein Pinselstrich vergleichsweise temperamentvoller, die Formen waren weniger steif und entfernten sich vom Naturvorbild. Zugleich erweiterte Meidner in dieser Phase seine Kontakte. Er tauchte ein in die Expressionistenkreise Berlins und entdeckte die Literatencafés für sich, wie vor allem das "Café des Westens", das sich am Kurfürstendamm befand. Hier begründete er seine Freundschaften zu den Schriftstellern Kurt Hiller (1885-1972), Alfred Döblin (1878-1957), Heym, van Hoddis und vielen andern, die größtenteils Mitglieder des „Neuen Clubs“ und des sich daraus entwickelnden „Neopathetischen Cabarets" waren. Meidner dürfte von den neuen, aggressiven und dynamischen Ausdrucksformen der Literatur, insbesondere nach all den negativen Erfahrungen an Schulen und Akademien, sehr angezogen worden sein. Folglich haben sie sich auch in seinem eigenen Werk niedergeschlagen. Meidner transportierte das literarische Gefühl durch eine ,intensive, unbesonnene, die Objekte mit großer Heftigkeit an sich beranreißende Darstellung ${ }^{\text {" } 111}$ in die Malerei. ${ }^{112}$

\footnotetext{
108 Breuer (1991) 2, S. 16; Grochowiak (1966), S. 23; Hodin (1973), S. 33.

${ }^{109}$ Breuer (1991) 2, S. 16; Grochowiak (1966), S. 23 ff.

110 Grochowiak (1966), S. 25.

111 Breuer (1991) 2, S. 17 (dort zitiert aus: Ludwig Meidner: Bernstadt in Schlesien. Manuskript aus dem in Darmstadt befindlichen Nachlass des Künstlers).

112 Breuer (1991) 2, S. 17; Grochowiak (1966), S. 25.
} 
Das Jahr 1912 wurde einschneidend. Nicht nur, dass in diesem Jahr neue Manifeste und Dichtungen für Aufruhr sorgten, die Bilder der „Fauves“ skandalträchtig über Berlin hereinbrachen und die Wellen der expressionistischen Bewegung hochschlugen, sondern gerade auch Meidner durchlebte in diesen Monaten eine überaus kreative und intensive Schaffensphase. Es entstanden die ersten der bis heute unter dem Oberbegriff „Apokalyptische Landschaften“ geführten Gemälde. Zugleich gründete er gemeinsam mit den Künstlern Jakob Steinhardt (1887-1968) und Richard Janthur (1883-1956) die Künstlergruppe „Die Pathetiker“. Im November 1912 hatte die Gruppe dann bereits ihre erste und einzige Ausstellung in Waldens „Sturm“-Galerie, wo vor allem Meidners Bildnis des Schriftstellers Alfred Mombert ${ }^{113}$ (1872-1942) Beachtung fand. Die Presse allerdings schwieg sich über diese Ausstellung aus, nur Kurt Hiller schrieb einen Artikel dazu, in welchem er Meidner besonders hervorhob. „Die Pathetiker" trennten sich daraufhin, aber immerhin hatte Meidner einen gewissen Bekanntheitsgrad erreicht. Er fertigte Illustrationen für so wichtige Zeitschriften wie „Die Aktion“ und „Der Sturm“, besuchte die aktuellen Ausstellungen der „Fauves“ und der Futuristen, malte seine bedrohlichen Landschaften und portraitierte mit Vorliebe seine Freunde aus dem „Café des Westens“.114

Im Dezember 1912 hatte Meidner laut eigenen Aussagen dann das Schlüsselerlebnis seines Lebens: „Ich konnte nicht malen. Dann plötzlich gelang es mir in einem Maße, dass ich meinem eigenen Malen zuschaute. (...) Dann kam etwas über mich: Der Heilige Geist." 15 Viele seiner in der Folgezeit entstehenden Bilder, die düster wirkende Vorahnungen enthalten, malte er in ähnlich ekstatischen Zuständen. 1913 war Meidner kurzzeitig mit der Gründung der Zeitschrift „Das Neue Pathos“ beschäftigt, deren Herausgabe jedoch aus Geldmangel nach nur wenigen Ausgaben eingestellt werden musste. Zusätzlich zu den Treffen der expressionistischen Intellektuellen in den entsprechenden Cafés fand sich ein Kreis von befreundeten Dichtern und Künstlern im Sommer und Herbst dieses Jahres regelmäßig zu einem Jour Fix am Mittwochabend in Meidners Atelier ein. 1914 folgte das für das ganze Land so einschneidende historische Ereignis des Kriegsbeginns. Meidner war mit seinem engen Freund Ernst Wilhelm Lotz (1890-1914) nach Dresden gezogen, um dort eine neue Zeitschrift zu gründen. Ein Mäzen namens Kochmann hatte ihnen eine lithografische Anstalt gekauft, die sie zum Druck und zur Herausgabe von Zeitschriften und lithografischen Mappen nutzen wollten. Hier erlebten die beiden Freunde den Ausbruch des Ersten Weltkrieges - für Meidner ein unheilvolles Ereignis, wie es beispielsweise in dem Text „Erinnerung an Dresden“116 deutlich wird, während Lotz sich dagegen begeistert zum freiwilligen Militärdienst meldete. Er fiel schon in den ersten Wochen seines Einsatzes. Meidner betrauerte ihn mit

\footnotetext{
113 Heute verschollen.

114 Breuer (1991) 2, S. 18 f.; Grochowiak (1966), S. 30 ff.

115 Zitat nach Meidner. Vgl. Grochowiak (1966), S. 119.

116 Textnachweis, Text LM I.
} 
größtem Schmerz und verließ Dresden sogleich wieder, um nach Berlin zurückzukehren. Sein Mappenwerk mit dem Titel „Krieg“ stellte er direkt nach Lotz' Tod zusammen. Auch sonst beschäftigte Meidner der Krieg als Thema, neben seinen Gemälden besonders auch in der Grafik, längere Zeit, doch wandte er sich in Zeichnungen bald auch religiösen Themen zu. ${ }^{117}$

\section{Literarische Anfänge im Militärdienst}

Unter den Künstlern und Literaten, die noch nicht einberufen und nun ebenso wie die übrige Bevölkerung durch die fortwährenden Kämpfe hinsichtlich des Krieges desillusioniert worden waren, herrschte derweil eine ängstliche Stimmung. Auch Meidner hoffte darauf, vom Militärdienst verschont zu bleiben. Schließlich erfolgte der Einberufungsbefehl zur Infanterie 1916 aber doch und er wurde in Crossen an der Oder ausgebildet und anschließend als Französisch-Dolmetscher im Kriegsgefangenenlager in Merzdorf bei Cottbus eingesetzt. Dort wurde er sehr grüblerisch, konnte nicht malen und wendete sich ersatzweise dem Schreiben zu. Seine während dieser Militärzeit entstehenden, stark autobiografisch geprägten Texte sind später in zwei kurz nacheinander herausgegebenen Anthologien - „Im Nacken das Sternemeer“ (1918) und „Septemberschrei“ (1920) - beim Kurt Wolff Verlag in Leipzig und bei Paul Cassirer in Berlin erschienen. Diese Werke sind wie seine Gemälde von hoher Expressivität und zudem zumeist in einer Form hymnischen Pathos' formuliert. Sie fanden trotz einiger Kritik allgemein viel Anklang. Die Phase der zuvor in einer Fülle ekstatisch anmutender Nächte entstandenen Gemälde mit apokalyptischem Hintergrund war beendet. Dafür hielt Meidner seine Eindrücke von den Geschehnissen im Lager in der expressionistischen Prosa und in Zeichnungen fest. Darin sind Tendenzen von Religiosität und der Sehnsucht nach einer alle Menschen umfassenden „Bruderliebe“ bemerkbar. ${ }^{118}$

1917 erhielt Meidner ein Vertragsangebot der Galerie Cassirer für eine Retrospektive seines Werkes bis 1916 für das darauffolgende Jahr. Diese Ausstellung verlief sehr erfolgreich, hatte eine große Resonanz und viele Bildverkäufe zur Folge. Als Meidner 1918 an der Ardennefront eingesetzt werden sollte, rettete ihn eine am Abmarschtag ausbrechende Bartflechte, die seine Einweisung zuerst ins Würzburger, dann ins Aschaffenburger Lazarett bewirkte. ${ }^{119}$

\section{Politische Aktivität}

Nach dem Kriegsende kehrte Meidner bald wieder nach Berlin zurück. Hier wurde er von den politischen und aktivistischen Tendenzen erfasst und schloss sich der „Novembergruppe“ an, die sich 1918 infolge der Novemberrevolution konstituiert hatte. Es wurde der Ruf nach einem nach dem Krieg auf Grundlage sozialis-

\footnotetext{
117 Breuer (1991) 2, S. 17 und 20 f.; Grochowiak (1966), S. 99 ff.

118 Breuer (1991) 2, S. 21 ff.; Grochowiak (1966), S. 108 ff.; Soergel (1925), S. 553 f.; Hodin (1973), S. $52 \mathrm{f}$.

119 Breuer (1991) 2, S. 24 f.; Grochowiak (1966), S. 115 ff.
} 
tischer Ideen neu zu organisierenden Staat laut. Mit seinem Engagement war für Meidner das politische Ziel einer Einheit von Sozialismus und Religion verbunden. Er schrieb verschiedene politische Aufrufe, wie beispielsweise den in der Broschüre der Gruppe 1919 abgedruckten „An alle Künstler, Dichter, Musiker“120 und beteiligte sich zudem am „Arbeitsrat für Kunst“ - einem Zusammenschluss von deutschen Künstlern, die sich und die Intellektuellen insgesamt als „geistige Arbeiter" für die Mitgestaltung der Revolution und des Neuaufbaus des Staates verantwortlich sahen. Im gleichen Jahr erschien bei Brieger die erste Monographie über den Maler Meidner. Bald jedoch distanzierte Meidner sich wieder von allen politischen Bewegungen und versenkte sich verstärkt ins Religiöse. ${ }^{121}$

\section{Abkehr vom Expressionismus}

1923 erschien eine zweite Auflage von Meidners Monographie bei Brieger, diesmal jedoch völlig verändert. Den Hauptteil bildeten nun eigene Reflexionen Meidners über sein bisheriges Schaffen und zum größten Entsetzen seiner Freunde, Anhänger und Förderer distanzierte er sich nun vehement von seinen Arbeiten und vom Expressionismus im Allgemeinen. Dieser Wandel markierte das Ende von Meidners expressionistischer Phase und rührte vermutlich von den Enttäuschungen des Ersten Weltkriegs, dem Überdruss am expressionistischen Stil und seinem immer noch als unzureichend empfundenen gesellschaftspolitischen Engagement her. Vielleicht war er auch durch Meidners Kritik an seinem persönlichen, insbesondere durch Alkoholgenuss rauschhaften Lebenswandel bedingt. Ein Gesinnungswandel jedenfalls erfolgte, wie er beispielhaft für viele Expressionisten dieser Zeit war. Verbunden mit der Abkehr vom Expressionismus war die innerliche Abkehr von Berlin. Meidner sehnte sich nach Natur, Ruhe, Bürgerlichkeit und Religion. Im Gegensatz zu anderen Künstlern fand er keinen Anschluss an die neuen Strömungen. Er bemühte sich um eine Anstellung in den Charlottenburger Studienateliers, wo er in seiner Schülerin Else Meyer (1901-1987) seine spätere Frau fand, die er im Februar 1927 ehelichte. Zwei Jahre später wurde ihr Sohn David geboren. 1929 gab sein Buch „Gang in die Stille“ Einblick in seine religiöse Suche und seine entschiedene Hinwendung zum Judentum, die er nun mit intensiven Studien und Einhaltung der strengen Rituale unterstrich. Weitere religiöse Bücher hatte Meidner in Arbeit, doch sind diese wegen der Inflation nicht erschienen, während verschiedene Essays und Glossen zu Religion und Kunst in der Tagespresse veröffentlicht wurden. Meidner erkannte selbst, dass der innere Frieden, den er gefunden hatte, ihn eine weniger qualitätvolle Kunst hervorbringen ließ als früher. Er verbitterte über diese Erkenntnis und darüber, dass seine Kunst immer weniger geschätzt und wahrgenommen wurde. ${ }^{122}$

\footnotetext{
${ }^{120}$ Vgl. Textnachweis, Text XI.

121 Breuer (1991) 2, S. 24.

122 Breuer (1991) 2, S. 25 f.; Grochowiak (1966), S. 179 f.; Hoffmann (1985), S. 111 f.; Assmann (2001), S. 52.
} 


\section{Jahre im Exil}

Sein Bekenntnis zum konservativen Flügel des Judentums bereitete Meidner bei der Machtübernahme der Nazis große Probleme. Die Werke seiner expressionistischen Phase wurden der Öffentlichkeit als Entartete Kunst vorgeführt. Seine gesammelten Feuilletons konnte er wegen antisemitischer Vorbehalte nicht in Buchform herausgeben und er war nur noch auf zwei kleinen Ausstellungen $1934 \mathrm{zu}$ sehen; danach musste er sich nach Köln zurückziehen, wo er als Zeichenlehrer an einer jüdischen Schule arbeitete. Verschiedene Ansätze zur Emigration nach Südamerika, Israel oder die USA scheiterten - zumeist aus finanziellen Gründen. Erst das Erlebnis der Reichskristallnacht und die Zerstörung der Kölner Synagoge bewegte Meidner und seine Frau endgültig dazu nach England zu emigrieren. Sie wohnten in London, fühlten sich dort aber nicht wohl. Ludwig Meidner verfiel in Depressionen, nicht zuletzt wegen fast vollkommener Isolation durch fehlende Kontakte und die schlechte finanzielle Lage, die ihm das Malen wieder sehr erschwerte. Meidners Verhaftung und Internierung in Huyton bei Liverpool im Jahr 1940 verbesserten daher seinen emotionalen Zustand, denn dort traf er viele Künstler und Intellektuelle und konnte Zeichenunterricht geben. Nach mehrmaliger Verlegung und Freilassungsbemühungen von Freunden war es Meidner selbst, der gar darum bat länger im Lager bleiben zu dürfen - er fürchtete die Armut und Isolation außerhalb. Schließlich kehrte er dann aber 1941 doch nach London zurück. Das mühselige Leben der folgenden Jahre finanzierte er als Porträtist. Häufig musste er auch andere Arbeiten annehmen, um finanziell notdürftig versorgt zu sein. In schriftstellerischer Hinsicht hat Meidner während seiner Exilzeit nichts hervorgebracht, was zur Veröffentlichung bestimmt war. Nach der Kapitulation scheiterte auch seine Rückkehr nach Deutschland an den fehlenden finanziellen Mitteln. Erst eine Ausstellung des Ehepaars Meidner in der Ben Uri Art Gallery, die wohlwollend aufgenommen wurde und einige Bilderverkäufe erzielte, machte ein etwas angenehmeres Leben möglich. Als David 1951 nach Israel auswanderte, schmiedete Meidner neue Emigrationspläne. Trotz der negativen Erfahrungen im Nazi-Deutschland und dem für sein Empfinden nach wie vor schlechten geistigen Klima wollte er im Gegensatz zu seiner Frau Else in sein Heimatland zurückkehren - wegen der Kontakte, der besseren Arbeitsbedingungen und nicht zuletzt wegen der Sprache, in der er dann wieder uneingeschränkt schreiben zu können hoffte. ${ }^{123}$

Rückkehr nach Deutschland - die letzten Jahre

Alte Kontakte und Freundschaften waren es dann vornehmlich, die zu Meidners Rückkehr nach Deutschland führten. Ernst Buchholz lud ihn im September 1951 nach Hamburg ein, wo er von Stadt und Presse wohlwollend begrüßt wurde. Während seines Aufenthaltes bekam er verschiedene Aufträge für Porträts be-

${ }^{123}$ Breuer (1991) 2, S. 27 ff.; Assmann (2001), S. 54 f. 
kannter Persönlichkeiten und war von dieser Aufmerksamkeit euphorisiert. Er musste jedoch noch einmal nach London zurückreisen, da er in Hamburg keine Wohnung fand, stellte aber sofort den Wiedereinbürgerungsantrag, obwohl klar war, dass Else ihn nicht begleiten würde. Ab 1953 war Meidner dann endgültig wieder in Deutschland, wo er in ein jüdisches Altersheim in Frankfurt einzog. ${ }^{124}$

Er bekam weiterhin Porträtaufträge, ließ alte Kontakte - auch zu Freunden der expressionistischen Zeit - wiederaufleben und erlebte verschiedene Ausstellungen seiner Werke, beispielsweise in Hamburg und Darmstadt. Er sehnte sich verstärkt nach der Natur, so dass er im April 1955 nach Marxheim bei Hofheim im Taunus zog, wo er sich eine alte Klempnerwerkstatt im Grünen als Atelier einrichtete. Er lebte dort in einfachen Verhältnissen mit seinem Schüler und Freund Jörg von Kitta-Kittel $(* 1940)$ zusammen. Es folgten noch einige Ausstellungen und Ehrungen seiner Werke, dazu genügend Bildverkäufe vor allem an amerikanische Käufer, um seine Versorgung zu sichern und doch konnte Meidner nicht mehr recht heimisch werden in seinem Heimatland. Es betrübte ihn, dass er nicht mehr zum Schreiben kam und er spürte, dass er trotz mancher Aufmerksamkeit, wie beispielsweise die Erwähnung seines 75. Geburtstags im Fernsehen, weitestgehend in Vergessenheit geraten war. 1963 bewegten Freunde ihn dazu, das unbeheizte, karge Marxheimer Atelier zugunsten einer Wohnung in Darmstadt aufzugeben. Im darauffolgenden Jahr erlebte er dort die Eröffnung einer bedeutenden, von Grochowiak organisierten Ausstellung anlässlich seines 80. Geburtstags, die groBen Anklang fand. Es folgten weitere Ehrungen, die Meidner, inzwischen schwach geworden, nicht mehr persönlich annehmen konnte, und eine große Monographie Grochowiaks zu seinem 82. Geburtstag. Am 14. Mai 1966 starb Ludwig Meidner in Darmstadt und wurde auf dem dortigen jüdischen Friedhof begraben. ${ }^{125}$

\subsubsection{Bild- und Schriftwerke der expressionistischen Phase}

Ludwig Meidner ist in Deutschland stark in Vergessenheit geraten. Das liegt vor allem an der mangelnden Publizität seiner Kunst und Person. Dieses Versäumnis erklärt sich aus Meidners Isolation, die in der Abkehr von seinem expressionistischen Schaffen und dem vierzehn Jahre währenden Exil begründet liegt. Trotzdem ist es bis heute aber gerade seine expressionistische Phase, mit der er am ehesten identifiziert wird.

Nach den Erläuterungen zur Biografie, die einen Überblick über den Menschen Ludwig Meidner und sein Werk verschafft haben, sollen nun die Jahre insbesondere zwischen 1910 bis 1920 beziehungsweise bis 1923 genauer in den Blick genommen werden. Es sind die Jahre, die Meidners expressionistisches Werk umspannen. Diese Phase spiegelt Meidners kreativste und fruchtbarste Schaffenskraft, den frühen Höhepunkt seiner künstlerischen Laufbahn.

\footnotetext{
124 Breuer (1991) 2, S. 29 ff.
}

125 Breuer (1991) 2, S. 32 f. 
Zeitgeist, äußere Gegebenheiten und prägende Ereignisse als Hintergrund der expressionistischen und auch Meidners persönlicher Entwicklung sind bereits erläutert worden und bieten die Grundlage für Verständnis und Einordnung der folgenden Untersuchungen. Wie ist Ludwig Meidner nun mit diesen Einflüssen umgegangen - mit dem Großstadterlebnis, der Aufbruchstimmung, den Ideen seiner Dichterfreunde und anderer Künstler, den Ängsten und dem Krieg? Spiegeln sie sich in seiner Themenauswahl? Welche Themen sind es überhaupt, die ihn beschäftigten? Und - das soll im Folgenden die zentrale Frage sein - in welcher Art und Weise werden die Themen innerhalb der besagten Zeitspanne in Bild und Text variierend, differierend oder übereinstimmend verarbeitet?

\section{Erste Schritte}

Es ist interessant zu sehen, wie Meidner um 1909/10 den ruhigen, glatten Malstil und die von Stille geprägten Motive, die Ruhe ausstrahlen, in eine bewegtere Formensprache überführt und schließlich zugunsten expressiver Gestaltung ganz aufgibt. Aufgrund dieser zu beobachtenden Entwicklung ist es zweifelhaft, ob Meidner wirklich erst durch eine plötzliche Eingebung des Heiligen Geistes zu seinem expressiven Stil gelangt ist, wie er selbst es behauptet. Vielmehr machen sich die Anfang des neuen Jahrzehnts auf ihn einwirkenden äußeren Einflüsse bemerkbar. Nicht nur die bereits erwähnten gesellschaftspolitischen und philosophischen Tendenzen, sondern vor allem die Werke von Fauvisten, Futuristen und expressionistischen Dichtern, denen Meidner eine starke Neigung entgegenbringt, haben ihre Wirkung auf den jungen Künstler, wie im Folgenden zu zeigen sein wird. Sie bewegen Meidner zu einer Auseinandersetzung mit den bereits erwähnten Problemen, die für den Expressionismus typisch sind und spiegeln auch philosophisches und politisches Gedankengut der Zeit.

Expressionistische Bilder

Meidners expressionistisches Werk umfasst neben Selbstbildnissen und Porträts von Freunden und Bekannten vor allem einen zentralen Komplex von Gemälden, der schon lange mit dem Schlagwort „Apokalyptische Landschaften“ belegt ist, was sich häufig auf die Benennung der darin enthaltenen Bilder ausgewirkt hat. Es ist aber Schmids Auffassung zuzustimmen, dass diese Klassifikation mehr als undifferenziert ist und aufgrund ihrer bislang noch ungeklärten Entstehung eigentlich auch keine Berechtigung hat. Auch wenn im Folgenden nicht nach der Kategorisierung Schmids vorgegangen wird, so soll ihren Untersuchungen insoweit Beachtung gezollt werden, dass die von ihr ermittelten Originaltitel einiger Gemälde zum Zwecke ihrer Re-Etablierung mitverwendet werden. ${ }^{126}$

Die so genannten „Apokalyptischen Landschaften“ behandeln in verwandter Weise die thematischen Werkgruppen Stadt, Apokalypse, Krieg und Revolution.

${ }^{126}$ Schmid (1991), s. Literaturverzeichnis. 
Dies sind vier der sechs Kategorien, die nachfolgend analysiert und zu Texten Meidners in Beziehung gesetzt werden sollen. Sie verweisen inhaltlich deutlich auf die Themenfelder der expressionistischen Bewegung insgesamt. Es bleibt dabei zu erwähnen, dass die Übergänge zwischen den Themen fließend sind und eine eindeutige Zuordnung unter den jeweiligen Oberbegriff deshalb unter objektiven Gesichtspunkten nicht immer möglich ist. Die hier vorgenommenen Einteilungen sind daher nicht mit der Absicht der absoluten Verbindlichkeit zu sehen, sondern berücksichtigen, dass die meisten Bilder mehrere thematische Aspekte auf einmal aufgreifen. Aus einer Menge von verwandten Bildern können nur einige wenige exemplarisch den Themenkreisen zugeordnet und mit entsprechenden Texten in Beziehung gestellt werden. Die religiöse Thematik wird ebenso wie die Bildnisse, die zusammen mit Darstellungen der menschlichen Kreatur in anderen Zusammenhängen unter der Kategorie „Mensch“ abgehandelt werden wird, zuletzt Beachtung finden. Alle Themenbereiche sind nicht nur in Öl, sondern vielfach auch in Meidners grafischem Werk der Zeit behandelt worden, weshalb dieses in die folgende Betrachtung ebenso miteinbezogen werden soll wie die Gemälde.

Expressionistische Texte

Schriftstellerisch sind vor allem die zwölf Texte, die zusammen in „Im Nacken das Sternemeer" 1918 herausgegeben wurden und die einundzwanzig Texte der 1920 erschienenen Anthologie „Septemberschrei“ von Belang. Wie Soergel schreibt, kommen darin die Zerrissenheit und Widersprüchlichkeit Meidners und seiner Zeit durch „aufsteigende Imperative; versinkende Fragen; Satzmelodien, Satzgepolter und Sätzegeschrei" zum Ausdruck. ${ }^{127}$ Es ist natürlich zu berücksichtigen, dass Meidner diese hymnischen, insbesondere Autobiografisches verarbeitenden Texte zu einer Zeit geschrieben hat, da die meisten seiner dem Expressionismus zuzurechnenden Bilder bereits fertig gestellt sind und er selbst in einen neuen Lebensabschnitt getreten ist. Er schreibt sie während seines Militärdienstes nieder, wo er wenig Zeit und Material zum Malen hat und zudem von den kriegsbedingten Erfahrungen bedrückt ist. Es wird deshalb hier, wie auch bei anderen Texten (s. u.) zu untersuchen sein, ob sie dem künstlerischen Werk dennoch im Ausdruck ähneln oder ob sich Veränderungen wahrnehmen lassen. Dass die Illustrationen der beiden Bücher wenig Beachtung finden werden, geschieht mit der Absicht, die Texte als Referenz für Meidners gesamtes expressionistisches Schaffen als Künstler zu nutzen, statt sie nur auf Darstellungen anzuwenden, zu denen sie absichtlich in Beziehung gesetzt wurden. Es geht schließlich darum Tendenzen und Themen im expressionistischen Gesamtwerk des Malers und Schriftstellers Meidner aufzuzeigen und zu beleuchten. Weiterhin sollen kunsttheoretische und politische Manifeste und die Lyrik Meidners zum Vergleich herangezogen werden.

127 Soergel (1925), S. 553 f. 


\subsubsection{Vergleichende formal-stilistische und inhaltliche Analyse}

\subsubsection{Die Großstadt als Erfahrungsraum}

Die ersten Bilder, die Meidner nach seiner Rückkehr aus Paris in Berlin gemalt hat, beschäftigen sich mit verschiedenen Aspekten der Großstadt: Baustellen, Vorstadtödnis, oder Gasometer (z. B. Abb. 1). Sie sind noch nicht expressiv, aber es ist deutlich, wie sehr die Stadt auf ihn gewirkt haben muss - insbesondere die von Fortschritt und Industrie gekennzeichneten Orte scheinen ihn fasziniert zu haben. Grasskamp hat in seinem Aufsatz darauf hingewiesen, dass die Beliebtheit dieser Motive - die beispielsweise auch bei Max Beckmann, Erich Heckel (18831970) und Lyonel Feininger (1871-1956) Beachtung finden - sich vor allem in der darin verbildlichten unterirdischen Vernetzung des städtischen Lebens durch Gas-, Strom- und Wasserleitungen und die U-Bahn begründete. Zudem schreibt er, dass das künstliche Licht den Künstlern ,ibren Wabrnehmungshorizont um die Nacbt" erweitert habe, der Gasometer den Turmbau zu Babel versinnbildliche und darum so wichtig gewesen sei. ${ }^{128}$ Prägnanter gesagt bewirkte die Zerschneidung des Stadtraums neue Wahrnehmungsakzente. Das Gemälde „Gasometer in BerlinWilmersdorf" (Abb. 2) ${ }^{129}$ von 1911 wird allgemein als dasjenige angesehen, das zu Meidners expressiven Bildern überleitet. Hier versucht Meidner durch dynamische Pinselstriche Bewegung zu erzeugen, was sich speziell im wolkenverhangenen Himmel nachvollziehen lässt. Zugleich entsteht der Eindruck einer gewissen Instabilität durch das trapezförmige Auseinanderstreben des Gebäudes und das perspektivisch verfremdete Gelände im Vordergrund.

\section{Zuordnung}

Dem Thema „Großstadt" sind überwiegend Zeichnungen mit Bleistift, Tusche oder Kreide aus den Jahren 1913 bis 1915, teilweise auch die noch als Übergang zu bewertenden Zeichnungen von 1911/12, und die Lichtdrucke des Mappenwerks „Straßen und Cafés“, welches 1918 herausgegeben wurde, zuzurechnen. Unter den Gemälden sind „Landschaft: Landhaus in Dresden“ (= „Das Eckhaus") und auch „Apokalyptische Landschaft - Bahnhof Halensee“ diesem Thema zugehörig. Andere Gemälde - und es gibt viele weitere, die die Stadt wiedergeben - sind aufgrund eindeutiger Symbole, wie Feuersäule oder Kometen, eher der „Apokalypse“ zuzuordnen. Aufgrund des Titels „Ich und die Stadt", welcher vor allem die Beziehung zwischen Künstler und Urbanität in den Vordergrund stellt, scheint es gerechtfertigt auch in diesem Bild das Thema "Stadt" als domi-

\footnotetext{
128 Grasskamp (1992), S. 265 ff. Zum Turmbau zu Babel und seine Parallelisierung mit der Zivilisation findet sich auch ein Hinweis bei Meidners „Im Nacken das Sternemeer“, S. 14 (Text „Anrufung des süßen, unersättlichen Züchtigers“ = Textnachweis, Text VII).

129 Vgl. z. B. Leistner (2001), S. 10; Roters (1990), S. 78.
} 
nant zu werten. Wie sieht nun Meidner die Stadt? Welche Verarbeitung erfährt sie in seinem expressionistischen Werk und welche Auffassung spiegelt sich darin wider?

Die ambivalent wahrgenommene Stadt

Beispiel eines großstädtischen Ortes, der bei Meidner sowohl im Bild, als auch im Text Beachtung findet, ist die Alaunstraße in Dresden. Es handelt sich dabei um eine bis heute belebte schmale Straße in der Neustadt Dresdens, die den Albertsplatz mit der Luisenstraße verbindet. Ludwig Meidner hat 1914 einige Monate mit seinem Freund Ernst Wilhelm Lotz in Dresden verbracht. Sie haben zunächst bei ihrem Mäzen Kochmann und schließlich in einer Wohnung in der Bautzener StraBe gewohnt. Meidners Buch „Septemberschrei“ enthält den Text „Erinnerung an Dresden“130, worin gleich zu Beginn die von beiden bewohnte Bautzener Straße der Alaunstraße vergleichend gegenüber gestellt wird. Erstere schneidet dabei durchaus negativ ab, denn Meidner empfindet sie als von einem Dämon beherrscht. Nicht so dagegen die Alaunstraße:

„(...) der kosmopolitische Zug der Alaunstraße (...): das Weltausschreitende und unermesslich Wallende. Ein zweiter, schmaler, doch menschlicherer Elbstrom - ein Hineinrufen in den Himmel. (...) Man wehte so, ledig aller irdischen Schwere, mit dem erschütternden Gesang durch diesen Engpaß hin und ward ein wilder, turbulenter Narr (...). "

Es wird hier deutlich, dass Meidner von der Alaunstraße offensichtlich angezogen wurde und diese Tatsache liefert auch den Grund für seine Beschäftigung mit ihr. Er assoziiert mit diesem Ort Weltoffenheit - angedeutet z. B. durch Begriffe wie „das Weltausschreitende“ oder „unermesslich" - und mit den dort spazierenden Menschen das wirbelnde Spiel fließenden Wassers („,menschlicher Elbstrom “), das einen mit sich zieht und aus ihm einen ,wilde[n], turbulente $[n]$ Narr" macht - gedanken-, ja sorgenlos. Mit „Alaunstraße Dresden“ (Abb. 3) ist auch eine Tuschezeichnung von 1914 betitelt, die sich in den Staatlichen Kunstsammlungen Dresden befindet. Vom linken vorderen Bildrand läuft die Straße in einer leichten, Steigung andeutenden Kurve und in perspektivischer Verjüngung bis knapp in die obere Bildhälfte hinein. Links und rechts wird sie von mehrstöckigen Häusern flankiert, deren Silhouetten merkwürdig wankend und instabil wirken. Die Linien streben zuweilen auseinander, knicken ein, oder bezeichnen berstende Formen, so dass sich Mauern und Fenster zu wölben scheinen oder sich bedrohlich der Straße zuneigen, als könnten sie in sich zusammenfallen. Statische Gesetze herrschen hier nicht. In den Formen wie in den dynamisch gesetzten Schraffuren, die zudem einen ständigen, unruhigen Gegensatz heller und dunkler Bildteile erwirken, drücken sich Bewegung und Unruhe aus. Die Straße selbst ist zusätzlich belebt. Viele kleine Tuschepunkte und -striche deuten Personen an, wie jenen laufenden Mann

130 Textnachweis, Text I. 
mit Hut rechts vorne. Auffallend prominent sind eine Straßenlaterne und ein darüber befindliches Schild in Form eines rennenden Schweins (vermutlich die Reklame eines Metzgerladens) in die obere Bildhälfte gesetzt, die durch ihre Größe im Vergleich zu den übrigen Bildgegenständen besonders in den Blick fallen. Es ist nicht ganz deutlich, welche Stimmung die Zeichnung vermitteln soll. Im Zusammenhang mit dem Schild könnte Meidner zunächst einfach eine lebendige und dies auch im eigentlichen Sinne des Wortes - Straßenansicht mit einer auf das Groteske zielenden Nuance beabsichtigt haben: die Alaunstraße als lebendig, vielseitig und irgendwie amüsant, ähnlich wie in den oben zitierten Erinnerungen. Allerdings fällt auf, dass eine Großzahl der Figuren im schnellen Lauf gezeigt ist, sofern die Kleinteiligkeit eine solche Behauptung zulässt. Auch dazu könnte das laufende Schwein in Beziehung stehen, jedoch wäre die Intention des Bildes dann bedrohlich gefärbt - es würde fliehende Menschen und erschütterte Gebäude zeigen. ${ }^{131}$ Die Zeichnung wäre dann im Vergleich zum zitierten, positiv zu lesenden Textausschnitt Indiz einer veränderten Wahrnehmung Meidners.

Michael Becker hat in seinem Aufsatz ${ }^{132}$ allerdings nachgewiesen, dass „Erinnerung an Dresden" ein stark durchgestaltetes Prosastück ist, in welchem Großstadtdarstellung und Apokalypse zusammengeführt werden und dass die positiven Passagen nur Atempausen in einem ansonsten verhängnisvoll gezeichneten Verlauf von Geschehnissen sind. Drei katastrophische Ereignisse des Sommers 1914 führt Meidner darin zusammen, nämlich eine seiner künstlerischen Schaffenskrisen, den Kriegsausbruch und den Verlust seines Freundes Lotz. Im Verlauf des Textes schildert Meidner das Sich-Ausbreiten des Dämons der Bautzener Straße auf die Menschen und schließlich den Kriegsausbruch, welchen er wie ein apokalyptisch anmutendes Ereignis darstellt, der von einem Großteil der Bevölkerung jedoch zunächst begeistert aufgenommen wird. Auf diese negativen Aspekte im Text soll aber an entsprechender Stelle zum Thema Krieg in Kapitel 3.1.3.3. genauer eingegangen werden. Wichtig ist es hier nur festzuhalten, dass im Text nicht nur eine schwärmerische Stadtsicht gegeben ist, sondern durch die unheilvoll erscheinende Bautzener Straße auch ein Gegenpart existiert. Die Stadt wird also gegensätzlich wahrgenommen. Beckers Ausführungen beleuchten, wie der Kriegsbeginn Meidners Wahrnehmung von Dresden verändert. Vor diesem Hintergrund lässt sich die Zeichnung „Alaunstraße in Dresden“ auch als ein Zeugnis der auf Meidner bedrohlich wirkenden Stimmung bei Kriegsausbruchs lesen. Im Gegensatz zu der schwärmerischen Sicht auf die Alaunstraße, wie sie in der Anfangspassage des Textes gegeben wird, die die Anfangszeit in Dresden reflektiert, würde die Zeichnung eine Vorahnung der Kriegsschrecken andeuten, dem Textende vergleichbar.

\footnotetext{
131 Ähnlich schwierig verhält es sich mit „Apokalyptische Landschaft - Bahnhof Halensee“, wo die Menschen ebenfalls im Laufen dargestellt sind.

132 Becker (1991): Ludwig Meidner und die frühexpressionistische Großstadtlyrik. (s. Literaturverzeichnis).
} 
Nun lässt sich hier allerdings einwerfen, dass eine Wahrnehmung unter dem Einfluss des Krieges eine Sondersituation ist und keine Rückschlüsse auf Meidners grundsätzliche Stadtwahrnehmung zulässt. Und selbst wenn man sich für die erste Lesart des Bildes als Darstellung einer lebendigen Straße ausspricht, so sind darin die wankenden Häuser als Unsicherheit vermittelnde Faktoren und die laufenden Menschen als Ausdruck von Hektik zu deuten. Auch in diesem Fall lässt sich keine eindeutige Beurteilung der Straße als Teil der Stadt erschließen. Darum soll zur Überprüfung noch ein weiterer Text herangezogen werden: das Gedicht „Alaunstraße in Dresden“, welches 1915 in „Die Aktion“ erschienen ist. ${ }^{133}$

Hier wird das Bild einer lebendigen Geschäftsstraße gezeichnet, die den Besucher mit einer Flut an Reizen überschwemmt. Bewegung und Gleichzeitigkeit von Eindrücken verarbeitet Meidner zum einen durch einen Reihungsstil, wie ihn auch seine expressionistischen Dichterfreunde genutzt haben ${ }^{134}$ und zum anderen durch eine „synästhetische Verknüpfung akustischer und optischer Reize" "135. So „hauen" „Fubrwerksstimmen" „um Aug und Mund" und werden im gleichen Atemzug mit „ABC der Schilder, Schnellzugeile... " ergänzend hintereinandergereiht. Ebenso unvermittelt stehen andere Satzteile zusammen wie beispielsweise „Unter uns die schwarzen Hosen schlenkern,/ Tabakpfeife, Käfig, Wildbrethasel durch die Himmelsweiße schwimmen (...)." oder „Aus Budiken, Milchgeschäften/ wirbelt Heringswonne in mein Ohr./ Aus den Betten zwanzigstöckiger Häuser,/ aus den Läden, Truben, Käfigen der Menschen/ hauchen Winde diese Wellenbahn vorüber (...). "

Gebäude rahmen das gesamte im Gedicht erzeugte Straßenbild: „Häuser“ oder „Häuserreihen“, „Essen, Türme“ werden zu Beginn und am Ende angeführt und vermitteln eine in die Höhe strebende Dynamik. ${ }^{136}$ Gleichzeitig wird die Straße auch personifiziert - also wie ein Mensch aktiv agierend gezeigt - , denn die „Н̈̈userreiben“ „schreien“ und der „Asphalt“ „sprüht die Kinder hoch“. Sie wirkt dadurch noch bewegter und von Eigenleben erfüllt. Die gesteigerte Lautstärke wird durch das Schreien, ebenso wie durch die bereits erwähnten „hauen[den] " „Fubrwerksstimmen“ assoziiert. Der Dynamik der Höhe, die zusätzlich zu oben genannten Begriffen auch durch „Wellenberge" und „Gotik steilt"vermittelt wird, wird jene der Weite von Straße und Eisenbahn (,Schnellzugeile ") an die Seite gestellt. Der „Schnellzugeile“ wird die Passage „O Choral der Fernen,/ wo Kasernen blauen,/ wo sich Gotik steilt." nachgeschoben, die Fernweh assoziiert, welches mit der Farbe Blau in Verbindung gebracht wird. Interessant ist vor allem die Gegensätzlichkeit der hier gegebenen lyrischen Stadtdarstellung: einerseits wird die Sehnsucht nach der Ferne formuliert, die als Wunsch gedeutet werden kann der Stadt zu entfliehen, auch werden die Häuser mit „Käfigen“ in Verbindung gebracht. Andererseits wird das Treiben auf der Straße wie eine beglückende Wellenbewegung beschrieben, in der das

\footnotetext{
133 Aus dem Darmstädter Nachlass, vgl. Assmann (1991), S. 381. Textnachweis, Text II.

${ }^{134}$ Hoffmann (1985), S. 101; Anz (2001), S. 106.

135 Becker (1991), S. 65.

136 Becker (1991), S. 65.
} 
lyrische Ich „durch die Himmelsweiße schwimmend“ sich bewegt, „Heringswonne in mein Obr" ",wirbelt" und „Winde diese Wellenbahn" „vorüber",,hauchen". Auch lässt sich der Satz "Nimm Gerassel mich/ in dein Schicksal ein,/ trag mich Wellenberge hoch/ und Täler nieder." als Wunsch nach Eingebundenheit in dieses städtische Treiben deuten. Himmel, Wind, Wellen und die Farbe Weiß sind in diesem Zusammenhang positive Symbole des Freiheitsgefühls, das in Opposition zu Eindrücken des Eingesperrt-Seins steht. Diese Symbole sind ähnlich auch in „Erinnerung an Dresden“ zu finden. Demnach ist diesem Gedicht keine wirklich bedrohliche Darstellung der Stadt zu entnehmen, sondern ein Wechsel von faszinierenden Eindrücken positiver wie negativer Art.

Becker hat darauf hingewiesen, dass die Zeile „Unter uns die schwarzen Hosen schlenkern" ein Indiz dafür ist, dass „Alaunstraße in Dresden“ einen gemeinsamen Spaziergang Meidners und Lotz' durch jene Stadt festhalten könnte. Des Weiteren wertet er beispielsweise wegen der Verwendung der Farben Blau, Weiß und Schwarz das Gedicht zu Recht als lyrische Umsetzung von Meidners Manifest „Anleitung zum Malen von Großstadtbildern“.137 Nun ist die Wahrnehmung und Beurteilung einer einzelnen Straße nicht repräsentativ für Meidners Gesamtauffassung von „Stadt", was auch die Gegenüberstellung der Alaunstraße zur Bautzener Straße in den „Erinnerungen an Dresden“ beweist. Darum sollen weitere Beispiele wie das besagte Manifest „Anleitung zum Malen von Großstadtbildern“ und „Landschaft: Landhaus in Dresden“ ebenfalls zum Vergleich herangezogen werden.

Das Gemälde „Landschaft: Landhaus in Dresden“ von 1913 (Abb. 4) zeigt die Villa des Mäzens Franz Kochmann, der Meidner und Lotz nach Dresden geführt hat und bei dem sie zu Beginn ihres Aufenthaltes in der Stadt einige Zeit gelebt haben. Die gesamte Leinwand einnehmend ist die Ecke des Hauses aus der Gründerzeit mit den sich links und rechts erstreckenden Hausseiten dargestellt. Es sind Kellergeschoss, zwei Stockwerke darüber und das Dach mit mehreren Schornsteinen und einer links befindlichen Gaube erkennbar. Die Fensterreihen sind von Dreiecks- oder Blendgiebeln bekrönt. Dabei sind die Architekturteile verformt, so dass die Linien den Eindruck erwecken als würden sie zusammenstürzen. Die verzerrten Achsen dynamisieren das Gebilde. Die Zergliederung in prismatisch geometrische Elemente erwirkt eine Multiperspektivität und unterzieht das Motiv der bürgerlichen Villa einem Auflösungsprozess. Die dominant verwendeten Blautöne changieren von dunklem Blaugrau und Grünblau zu aufgehelltem Blau mit Gelb und sind durchweg unrein. Bei der Aufhellung einzelner Gebäudeteile lässt sich nicht von natürlicher Beleuchtung sprechen, vielmehr dient sie zur Unterstützung des Eindrucks von prismatischer Zersplitterung. Der Ausdruck des Bildes ist schwer zu bestimmen. Zwar wirkt die Farbpalette eher düster und die Instabilität des Gebäudes hat einen halb bedrohlichen, halb grotesken Charakter, wie auch

${ }^{137}$ Becker (1991), S. 65. 
schon die Häuserfronten in der Zeichnung „Alaunstraße in Dresden“, dennoch ist es fraglich, ob dies die Intention Meidners gewesen ist, denn es gibt keine inhaltlichen Hinweise auf eine bedrohliche Situation. Hauptanliegen scheint es vielmehr gewesen zu sein Bewegung und Dynamik zu verbildlichen. Dies lässt sich auch an Meidners theoretischen Ausführungen über das Malen von Städten ablesen.

Verschiedene Autoren haben die Wichtigkeit von Meidners „Anleitung zum Malen von Großstadtbildern"138 herausgestellt und es ist offenkundig, wie nahe dieser Text und verschiedene Gemälde des Künstlers, dabei auch „Landschaft: Landhaus in Dresden“, miteinander zusammenhängen. ${ }^{139}$ Meidner hatte dieses Manifest als Antwort auf die Umfrage der Zeitschrift „Kunst und Künstler“ - in der es 1914 auch erschienen ist - im Hinblick auf ein „neues Kunstprogramm“ verfasst. Es ist dies vor allem ein Aufruf an eine neue Künstlergeneration sich verstärkt dem Thema Großstadt zuzuwenden. Dies wird zu Beginn postuliert -

„Wir müssen endlich anfangen unsere Heimat zu malen, die Großstadt, die wir unendlich lieben. Auf unzähligen, freskengroßen Leinwänden sollten unsere fiebernden Hände all das Herrliche und Seltsame, das Monströse und Dramatische der Avenüen, Babnhöfe, Fabriken und Türme hinkritzeln. "

zwischendurch betont -

„Denn darauf kommt es an, dass morgen Hunderte von jungen Malern voller Enthusiasmus sich auf dieses neue Gebiet stürzen. Ich habe hier nur einige Hinweise und Andeutungen gegeben. Man könnte es ebenso gut auch anders machen, vielleicht besser und überzengender. Aber die Großstadt muß gemalt werden!"

und am Ende noch einmal bekräftigend aufgenommen:

„Malen wir das Nabeliegende, unsere Stadt-Welt! Die tumultuarischen Straßen, die Eleganz eiserner Hängebrücken, die Gasometer, welche in weißen Wolkengebilden hängen, die brüllende Koloristik der Autobusse und Schnelliuglokomotiven, die wogenden Telephondrähte (sind sie nicht wie Gesang?), die Harlekinaden der Litfaß-Säulen, und dann die Nacht...die Großstadt-Nacht..."

Allein aus diesen Textpassagen wird wieder deutlich, was in den bisherigen Betrachtungen zu Meidners Behandlung des Großstadt-Themas bereits anklang: die Stadt mit all ihren anziehenden und abschreckenden Facetten ist für ihn nicht abzulehnen, sondern als faszinierendes Stimulans aufzunehmen und künstlerisch $\mathrm{zu}$ verarbeiten. Diese Einstellung bringt weder eine klare Ablehnung, noch eine deutliche Befürwortung der städtischen Gegebenheiten zum Ausdruck, sondern ein ambivalentes Verhältnis des Künstlers dazu. ${ }^{140}$ Dass im ersten Satz die Großstadt durch den Nebensatz ,die wir unendlich lieben “ ergänzt wird, ist dabei als Pro-

\footnotetext{
138 Textnachweis, Text III.

139 Z. B. Schmid (1991), S. 85; Leistner (2001), S. 10.

140 Diese Annahme stützt z. B. auch Eliel (1990), S. 23.
} 
vokation und als Ausdruck einer Hassliebe zu verstehen, die beispielsweise in den Gegensätzen der Aufzählung ,all das Herrliche und Seltsame, das Monströse und Dramatische "deutlich wird. Es geht Meidner in seinem Manifest aber vor allem darum die Notwendigkeit der Überwindung des Impressionismus zugunsten einer neuen Ausdrucksweise zu postulieren. Die Grundlagen sind dabei seines Erachtens die Fähigkeit zu richtigem Sehen und zur Wiedergabe der damit verbundenen Eindrücke. So solle man die Großstadt nicht im Freien malen, sondern im Atelier, wo man vollgesogen von den städtischen Eindrücken wohlüberlegte Kompositionen formen könne. Dabei sei es wichtig die Wirklichkeit tiefer zu durchdringen und nicht „eine rein dekorativ-ornamentale Füllung der Fläche a la Kandinsky oder Matisse“ vorzunehmen. Er nennt drei Aspekte, die bei der Gestaltung des Bildes beachtet werden sollten: Licht, Blickpunkt und die Anwendung der geraden Linie.

Es ist interessant, wie genau Meidner seine theoretisch formulierten Ansprüche in „Landschaft: Landhaus in Dresden“ umsetzt. Das Licht, welches er als fließend bezeichnet, soll in Streifen, Bündeln und Fetzen die Dinge zerreißen, Konturen grell zum Wanken bringen und durch Formung geometrischer Figuren Rhythmus und Bewegung erzeugen. Im Blickpunkt sollen die Dinge ,scharf und unmystisch" sein, doch ,je weiter vom Blickpunkt entfernt, desto mehr neigen sich die Linien (...) “ - „(...) die Häuser neben uns - wir füblen sie nur mit balbem Auge - scheinen zu wanken und zusammenzubrechen (...). "Die gerade Linie soll nicht starr wirken, sondern, indem sie an- und abschwillt, expressiv erscheinen. All diese Anweisungen hat Meidner im besagten Bild selbst befolgt und sogar wie im Manifest empfohlen die Farbpalette im Wesentlichen auf Schwarz, Weiß, Blau und Brauntöne reduziert. Es sind die Farben, die in seinen Augen die Stimmung der Stadt sichtbar machen. Über diese praktischen Ratschläge hinaus enthält die Anleitung auch Hinweise darauf, dass Meidner beispielsweise das futuristische Manifest als Vorbild im Kopf hatte und sowohl den Impressionismus, als auch die Rückbesinnung auf den Primitivismus, wie sie vor allem „Die Brücke“ betrieb, strikt ablehnte.

Ähnliche Darstellungen wie die Straßenszene oder das Gebäude in Dresden gibt es von Meidner als Zeichnungen vielfach - insbesondere natürlich von Berlin und auch als Nachtansichten, wie beispielsweise „Süd-Westkorso in BerlinFriedenau“, „Mond über Berliner Stadtbahnbrücke“ oder „Potsdamer Platz“ (Abb. 5-7). Die eher wahrnehmende als wertende Behandlung, beziehungsweise der eher unterschwellige Ausdruck des ambivalenten Verhältnisses zur Stadt ist ihnen allen gemeinsam.

\section{Das Caféhaus als städtischer Bestandteil}

Etwas außer der Reihe sind die Caféhausszenen zu sehen, die im Mappenwerk „Straßen und Cafés" enthalten sind und gleichfalls das Leben der Großstadt, wie Meidner es wahrnahm, wiedergeben. Im Text ,...im Nacken das Sternemeer..." ${ }^{141}$,

141 Textnachweis, Text IV. 
welcher gleichsam Meidners nächtlichen Weg durch die Stadt zum Caféhaus beschreibt, wird es wie eine Oase in den Wirrungen der Stadt dargestellt:

„Du Café voll Wonne - o zaubrische Helle - du Paradies der Lebendigen. Du Seele der Zeit. Du schwingende Glocke des Diesseits. Du Schule hoher Geister. Du beschwingter Kämpfer Rendezvous. Du tumultuarische Arche der Dichter. "

Das Caféhaus fungiert als ein Vitalismus freisetzender Ort und der „hymnische Tonfall vermittelt den Eindruck von unzensierter Spontaneität und Pathos“. ${ }^{142}$ Der um 1917 entstandene Gesamttext allerdings ist kriegsbedingt deutlich geprägt von negativen Empfindungen Meidners gegenüber der Stadt, aber dazu unter 3.1.3.3. mehr.

Bei „Vorzeichnung: Caféhaus in Berlin“ von 1913 (Abb. 8) aus „Straßen und Cafés“" ist eine solche Tendenz nicht feststellbar. Hier herrscht ein ,wildgebrochenes Schwarzweiß ein sich Verkrallen von Tischen und Menschen"143. Im Mittelpunkt des Geschehens sind drei Herren über ein kleines Tischchen geneigt, die Köpfe dicht beisammen und scheinen heftig zu diskutieren - die geöffneten Münder, das starre, feindselige Fixieren des Gegenübers, die abwehrende Gestik vorn und die unruhigen Linien wie auch die hier besonders starke, dramatisch wirkende, prismatische Zergliederung der Gestalten sprechen dafür. Pärchen, Bedienung, freundlich lächelnde Damen und ausdruckslos blickende Gesichter sind an den Nebentischen und auf der Balustrade erkennbar. Das Café in seiner Funktion als Anlaufpunkt für Diskussionen der Intellektuellen wird im Text von Meidner gefeiert. Die Zeichnung vermittelt durch die aggressiven Nuancen der Diskussion eine gespannte Stimmung - allerdings nur an dem hier in den Mittelpunkt gerückten Tisch. Auch Freude oder Nachdenklichkeit spiegeln sich schließlich in den umgebenden Gesichtern wider. Meidner zeigt hier also eine wohl alltägliche Caféhausszene. Bewegung, sowie Gleichzeitigkeit des Handelns an verschiedenen Plätzen innerhalb des Cafés und die Gegensätzlichkeit der anwesenden Personen und ihrer Verhaltensweisen hat er demnach beobachten und festhalten wollen, wobei die Diskussion als Teil seines eigenen Alltags im Vordergrund steht.

Nur eine einzige, ihrerseits bewegte Personengruppe zeigt das Blatt „Stammtisch- $\$ 11^{“}$ (Abb. 9). Fünf Männer sitzen debattierend um einen Tisch herum. Der Mittlere von ihnen, mit grimmigem Gesichtsausdruck unter einem Kronleuchter positioniert, hat seine rechte Hand im Redegestus erhoben, während die beiden Herren seitlich hinter ihm gebannt zuzuhören scheinen. Die zwei äußeren Personen heben sich durch ihre Physiognomie von den anderen ab - ihre Gesichter sind zu tierähnlichen Schnauzen verfremdet und erinnern mit den abstehenden Barthaaren und der langgezogenen Nasenpartie an Ratten oder Schweine. Zwei Details helfen diese Szene zu entschlüsseln. Auf der Tischdecke ist der stilisierte Adler als Wappentier und Hinweis auf den preußischen Staat zu erkennen. Auf

142 Breuer (2001), S. 26.

143 Willi Wolfradt zitiert in: Flammann (1994), S. 32. 
der Bierschaumkrone des rechten Stammtischbruders prangt das Kürzel „\$11“. Damit dürfte sich Meidner auf den entsprechenden Paragraphen des Reichsbeamtengesetzes bezogen haben, der in der Fassung von 1873 die Pflicht des Beamten zur Verschwiegenheit und Loyalität festlegte. Der Künstler stellt hier also die Vertreter des zu Redlichkeit und Stillschweigen angehaltenen Beamtenschaft in Bierlaune schwatzend dar und deutet durch ihre tierhaften Züge - Ratten und Schweine sind im Allgemeinen negativ konnotiert - ihr im Widerspruch dazu stehendes, eben unredliches Verhalten an. ${ }^{144}$ Für Meidner ist dies eine ungewöhnlich politische Note.

Vergleicht man weitere Caféhausdarstellung miteinander, die der Künstler bevorzugt im grafischen Medium ausführte, so finden sich auch weniger hitzige Szenen ohne Debatten, wie z. B. „Die Bar, Wilmersdorf“ von 1915 (Abb. 10). Hier herrscht ein dichtes Gedränge von Caféhausbesuchern, in dem vorwiegend eine große Menge von Köpfe und einzelne Tische erkennbar sind. Meidner geht es in dieser Zeichnung nicht wie in den anderen beiden Beispielen um eine spezielle Gruppe im großen Treiben des Cafés, sondern um die belebte Gesamtatmosphäre. Die Komprimierung der Personen auf kleinstem Raum, sowie die dynamischen Linien, Formen und Schraffuren sind bildkünstlerische Mittel, die hier aber genauso zur Anwendung kommen, wie in den anderen beiden Darstellungen des Caféhauses. Die schwärmerisch-fröhliche Beschreibung dieser Einrichtung in seinem Text vermag Meidner in den Grafiken weniger zum Ausdruck zu bringen. Hier dominieren der Ausdruck beziehungsweise die Beobachtung von Debatten, die neben Dynamik auch eine gewisse Aggressivität transportieren oder die eher schlichte Fixierung von Massenszenen.

\section{Meidners „expressiver Naturalismus“}

Es erscheint etwas merkwürdig wiederholt davon zu sprechen, dass Meidner (zumindest in seinen Bildern) teilweise einfach festhielt, was er sah. Aber tatsächlich deckt sich das mit seiner eigenen Einschätzung, dass er zeitweise „expressiven Naturalismus“ ${ }^{\text {“145 }}$ betrieben habe ${ }^{146}$ und mit seinem in der „Anleitung zum Malen von Großstadtbildern" formulierten Anspruch richtig sehen zu wollen, was eben auch die korrekte Wiedergabe der Linienverkrümmungen an Gegenständen bedeutet, die nur im Augenwinkel wahrgenommen werden. Brieger erklärt in der ersten Meidner-Monographie von 1919, dass die Bilder des Künstlers als Produkte des Kampfes zwischen Naturalist und Visionär zu bezeichnen seien. ${ }^{147}$ Zumindest für die Großstadtthematik soll in diesem Zusammenhang festgehalten werden, dass Meidner hier tendenziell vor allem die - für seine Begriffe naturalistische Verarbeitung neuer Wahrnehmungsphänomene interessierte, wie er sie in Straßen

\footnotetext{
144 Vgl. Flammann (1994), S. 35.

145 Meidner (1934). Zitiert bei Breuer (1991) 2, S. 20.

146 Auch bei Berankova (2001), S. 41.

147 Brieger (1919), S. 7.
} 
und Cafés fand. Die Wahrnehmung konnte auch durch rauschhafte Zustände erweitert werden, wie beispielsweise die Zeichnung „Betrunkene Straße mit Selbstbildnis“ (Abb. 11) von 1913 zeigt. Weiterhin ist festzuhalten, dass er dabei das Ambivalente der Großstadt, wie er es wahrnahm, auch in seine literarischen und bildnerischen Werke überführte.

\section{Doppelverwendung des Motivs „Stadt“}

Nun hieß es, dass es viele Zeichnungen Meidners gäbe, die die Stadt selbst thematisieren - was aber ist mit den Gemälden? In diesem Zusammenhang ist es wichtig, sich daran zu erinnern, dass die Themen „Großstadt“, „Apokalypse“, „Krieg“ und „Revolution“ in der Sekundärliteratur allgemein häufig unter dem Oberbegriff „Apokalyptische Landschaften“ zusammengefasst werden. Wenn diese Bezeichnung hier, wie gesagt, wegen ihrer Undifferenziertheit vernachlässigt werden soll, so verweist ihre Existenz doch auf die enge Verbindung zwischen den Themenbereichen und darauf, dass die Grenzen dazwischen fließend sein können. Auch Briegers Aussage, Meidners Bilder seien Produkte des Kampfes, den Naturalist und Visionär miteinander ausfechten, ist noch einmal ins Gedächtnis zu rufen.

Die bisher untersuchten Bilder behandeln die Stadt an sich und spiegeln ein ambivalentes Verhältnis des Künstlers zu ihr. Daneben hat die Stadt bei Meidner aber auch noch in ganz anders zu deutenden Bildern motivische Verwendung gefunden, nämlich in jenen, die mehr dem Themenkreis von Apokalypse und Krieg zuzurechnen sind. Es ist darin weniger eine Entwicklung hin zu einer rein negativen Sichtweise zu sehen, sondern vielmehr eine Doppelverwendung des Motivs Stadt. Gegensätzlich wie es ist, konnte es Meidner auch zu seinen apokalyptischen Visionen dienen, denn als Ballungsort menschlichen Lebens konnte kein anderes Motiv besser zur Darstellung der Zerstörung der Menschheit benutzt werden. In Bezug auf Briegers Ausspruch ist in solchen Bildern nun vermutlich der „Visionär“ Meidner - der „Seher“ bevorstehenden Leids - zu finden. Es soll im Folgenden noch ein Bild betrachtet werden, das nicht eindeutig zum Thema „Stadt“ gehört. Es könnte ebenso gut beim Thema „Mensch“ untersucht werden und auch Hinweise auf die Apokalypse sind gegeben. Doch ist die Stadt darin ein wichtiger Faktor und verbunden mit den dargestellten zerstörerischen Tendenzen kann es an der Schwelle zur apokalyptischen Thematik gesehen werden. Seine Betrachtung wird erste Schlüsse über die Zweitverwendung des Stadtmotivs geben und zum Themenkreis „Apokalypse“ überleiten.

Die Rede ist von dem Gemälde „Ich und die Stadt“ von 1913 (Abb. 12). Es handelt sich dabei um die Verbindung eines Selbstbildnisses mit einer Darstellung des Stadterlebnisses. Meidners sorgenvoll verschrecktes Gesicht taucht überdimensioniert in der unteren Bildhälfte auf. Ängstlich hat er seine klauenhaft verkrampften Finger zum Mund geführt, wobei die Lippen geöffnet, die Zähne aber aufeinandergepresst sind. Aufgerissene Augen sitzen in dieser zerfurchten und verwölkten Physiognomie des Künstlers, die eine Vielzahl von Gefühlen zum 
Ausdruck bringt. Dahinter ist die Sicht auf eine Stadt und einen entfernten Horizont gegeben. Die Häuser stehen dicht an dicht, sind aber schwankend, bald in Ober-, bald in Untersicht dargestellt und sind so um den Kopf des Künstlers angeordnet, dass die Wirkung entsteht, sie würden ihn bedrängen oder ihm im wahrsten Sinne des Wortes über den Kopf wachsen. Verlebendigung war ein schon genanntes Stilmittel bei Meidner, das bei den Expressionisten weithin beliebt war. Dazwischen sind eine Kirche und eine Fabrik auszumachen; Straßen, eine Brücke und schwarz hingetupfte menschliche Silhouetten sind erkennbar. Über allem dräut ein wolkenverhangener Himmel. Rechts ergießt sich ein eigentümlicher, bedrohlich wirkender Strahl aus rötlich-violetter Farbe aus den Wolken herab auf einige Häuser. Es ist dies der Anklang eines apokalyptischen Geschehens. Links dagegen ist ein entschwebender gelber Heißluftballon abgebildet. Unreine, blaue, graue und violette Farbtöne dominieren und unterstreichen die bedrohliche Stimmung im Bild. Helleres Aschfarben in der oberen Bildzone kennzeichnet ein diffuses Licht. Selbst das Porträt ist in unnatürlichen Violettnuancen gezeigt, die durch schmutzig-weiße Flächen aufgehellt werden. Der Pinselduktus ist bald schnell, aber dabei genau, bald unruhig und expressiv - besonders in Meidners Antlitz. Die Stadtlandschaft folgt keinen Gesetzen der Statik, sondern wirkt wie ein durcheinanderwirbelndes Häusermikado, in dem manche Einzelheiten nicht einwandfrei zu identifizieren sind.

Der Künstler zeigt sich hier selbst in Konfrontation mit der Stadt, zugleich aber scheint „das eher herausfordernde Gesicht, mit dem Meidner dem Betrachter in die Augen sieht, (...) anzudeuten, dass diese Stadtansicht das Spiegelbild seiner selbst ist, das Chaos seiner Seele. "148 Die Stadt ist also deutlich in einen bedrohlichen Zusammenhang gebracht, sie ist Schauplatz eines katastrophischen Geschehens. Die Feuersäule, ein beispielsweise bei Nietzsche aufgegriffenes Motiv, ${ }^{149}$ das auch durch den 1910 sichtbar gewordenen Halleyschen Kometen an Bedeutung gewann, ${ }^{150}$ transportiert den Gedanken an ein überirdisches zerstörerisches Ereignis, welches Stadt und Menschen bedroht. Zugleich kann sie das Verhältnis des Künstlers zur Stadt meinen und die negativen, auf Meidner von außen eindringenden Eindrücke unterstreichen. In diesem Fall geht die Vernichtung von der Stadt selbst aus. Das Bild kann also sowohl einen äußeren als auch einen inneren Zustand zum Ausdruck bringen, ist somit bald als apokalyptische Darstellung und bald als Großstadterlebnis zu lesen. Der gelbe Ballon steht vielleicht für den Wunsch nach Flucht. ${ }^{151}$

\footnotetext{
148 Hülsewig-Johnen (1992), S. 259.

149 Z. B. Schmid (1991), S. 86.

150 Eliel (1990), S. 31.

151 Vgl. Leistner (2001), S. 11.
} 
Dass das ambivalente Verhältnis zur urbanen Umwelt bei Meidner durchaus stärker in die Ablehnung schlagen kann, lässt sich ebenfalls aus dem Text „,...im Nacken das Sternemeer..." "152 ablesen:

„W as peitscht mich denn so in die Stadt hinein? W as ras' ich verrückt heerstraßenlang?! Pfähle blutig anrempelnd, Schädel zertrümmernd an feisten Stämmen und meine stadtgeilen Füße zerreißen am Gestein der Nacht...(...). Bist du so fern von mir du StadtStadt-Stadt??!! (...) Es nabt die Stadt. Es knistert schon an meinem Leibe. Auf meiner Haut brennt ibr Gekicher. Ich böre ibre Eruptionen in meinen Hinterkopf echoen. "

Aus dieser Passage wird deutlich, wie stark die Stadt den Künstler emotionalisiert. Wieder einmal ist sie wie ein Lebewesen beschrieben, das direkt angesprochen wird, das näher kommt und kichert. Und obwohl sie ihm Schaden zufügt - seine Füße ,zerreißen am Gestein“ und er rempelt sich blutig - wird er in die Stadt ,hineingepeitscht" und seine Füße sind „stadtgeil", so dass er sich ihr nicht entziehen kann. Es klingt wie ein Zwang, wie eine selbstzerstörerische Sehnsucht.

Diese im Anfangsteil des Textes stehenden Sätze leiten zu weiteren Stadtwahrnehmungen Meidners über, die zum einen das Herrschen von Hektik, Lärm, Unzucht und Hunger festhalten und zum anderen auch das heuchlerische Verhalten der Menschen kritisiert, die das alles gut zu heißen scheinen. „Koblrübengestank“" und „Ein Feldgrauer ruft die Parole: ,Maul halten, enger schnallen, durchbalten!!"“ sind dabei Hinweise auf Kriegsumstände. Trotzdem soll auch noch die Abschlusspassage der Stadtbeschreibung zitiert werden, denn auch sie vermittelt einen Eindruck von Meidners Wahrnehmung der Stadt als einem unheilvollen Ort:

„Die Stadt kreischt auf. Steilgetürmt und weltenhoch. Sie dehnt sich krokodilisch lang, schnellt wie ein Fenerwerk in alle vier Winde. Sie bestürzt mich mit ibren Balkonen. Sie knattert in meinen Eingeweiden."

\section{Ergebnis}

Meidners Stadtwahrnehmung ist insgesamt ambivalent. Es gibt Texte und Bilder, die sich schwärmerisch oder beobachtend mit der Stadt befassen, die Angstzustände zum Ausdruck bringen, welche durch die Stadt ausgelöst werden, oder die in sich selbst schon teilweise widersprüchliche Eindrücke verarbeiten. Diese Schwankungen werden zum einen durch Meidners eigene impulsive Gefühlswelt begünstigt - sein späterer Schüler Jörg von Kitta-Kittel bestätigt, dass Meidner eine Art Phantasietrunkener war, der zu einer übersteigerten Wahrnehmung neigte. ${ }^{153}$ Zum anderen werden äußere Gegebenheiten, wie beispielsweise erste Kriegsanzeichen, ausschlaggebend gewesen sein. Neben der Stadtdarstellung, die sich eher beobachtend dem Thema widmet, dient das Motiv „Stadt“ also auch zur „Darstellung der unterschwelligen Zerstörungs- und Selbstzerstörungskräfte, die

\footnotetext{
152 Textnachweis, Text IV.

153 Natter (2001), S. 195.
} 
den Städten innewohnen und sie in apokalyptische Landschaften zu verwandeln

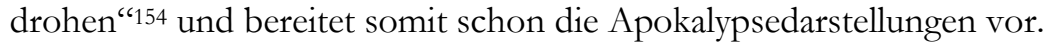

Festzuhalten ist die Tatsache, dass die Texte und Bilder in ihrer Aussage über die Großstadt im Wesentlichen übereinstimmen: Die Stadt ist faszinierender Quell künstlerischer Motivfindung und es ist Meidners intensivstes Anliegen die Bewegung, Gleichzeitigkeit, Mannigfaltigkeit und gegebenenfalls Gegensätzlichkeit von Eindrücken in Text und Bild festzuhalten. Im Bild sucht er dies durch Multiperspektivität, prismatische Zergliederung in geometrische Formen, aggressiven Lichteinsatz und „wankende“ Linien umzusetzen. Im Text arbeitet er unterschiedlich: im Gedicht mit Reihungsstil, Verlebendigung, Symbolen und Metaphern, in der Prosa schwärmerisch beschreibend mit gewählt assoziativen Worten und einem weniger prägnanten Reihungsstil, der nur Sätze aneinander hängt. Theoretische Äußerungen sind sowohl analysierend wie postulierend. Seine Lieblingsmotive sind dabei die Straßen, Häuser und Cafés.

\subsubsection{Apokalypse - der Weltuntergang zur Welterneuerung?}

Wie kommt es nun zu der zweiten, deutlich negativen Facette bei Meidners Stadtdarstellungen, die im gleichen Zeitraum wie die bereits untersuchten Stadtbilder entstanden sind? Meidner selbst meint, eine unerklärliche Angst habe ihn zur Anfertigung solcher Bilder getrieben. ${ }^{155}$ Angesichts von „Ich und die Stadt" stellt sich die Frage, ob, beziehungsweise inwiefern eine Auseinandersetzung mit religiösen Schriften eine Rolle spielte - der biblische Ursprung der apokalyptischen Tradition und das auffällige Nebeneinander von Kirche und Feuersäule im Bild liefern dafür erste Anhaltspunkte. Eine genauere Untersuchung des Themenbereichs „Apokalypse“ soll weiteren Aufschluss über die Hintergründe geben.

Vondung verweist innerhalb der Publikation „Die Modernität des Expressionismus" von Anz/Stark darauf, dass die Tradition des apokalyptischen Denkens durch die Offenbarung des Johannes angestoßen wurde und dass dort mit der Apokalypse Untergang, zugleich aber auch die darauffolgende Erneuerung gemeint gewesen sei. In diesem Sinne ist sie zumeist auch im Expressionismus begriffen worden - in ersten Vorstellungen Lust an Gewalt aufzeigend und später die gesteigerte Erwartung des direkten Untergangs spiegelnd, dem eine sozialistisch erneuerte Welt folgen sollte. ${ }^{156}$ Zwar ist Vondungs Ansatz auf die literarische Apokalypse bezogen, trotzdem: Lässt sich dies auch bei Meidner beobachten, welcher zum einen, wie bereits mehrfach erwähnt, stark unter dem Einfluss zeit-

\footnotetext{
154 Jurkat (1993), S. 60.

155 Maas (1965), S. 145 f.

156 Vondung (1994), S. 142 ff.
} 
genössischer Dichter stand und zum anderen eben auch selbst geschrieben hat? Und wie verarbeitet er apokalyptische Aspekte in Texten und Bildern?

\section{Zuordnung}

Das Thema „Apokalypse“ umfasst bei Meidner verschiedene Darstellungsweisen. So kann man zwischen der Lokalisierung des Geschehens in der Stadt einerseits und in der Landschaft andererseits unterscheiden, wobei das Urbane in der letzteren im Hintergrund steht. Demgemäß können die Münsteraner „Apokalyptische Stadt“, die zwei Varianten von „Brennende Stadt“, die zu beiden Seiten einer Leinwand im Saint Louis Art Museum zu finden sind, die „Landschaft: Hafen-

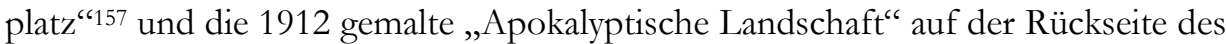
Bildes ,Junger Mann mit Strohhut" als Beispiele für die erste Darstellungsvariante genannt werden. Für die zweite sind beispielsweise die „Apokalyptische Landschaft" jeweils aus Berlin, Stuttgart und Wisconsin, sowie die Regensburger „Mondsichellandschaft" ${ }^{\prime 158}$ anzuführen. Die Katastrophe wird durch wechselnde Motive gekennzeichnet: Feuer, Feuersäule, Komet, Sintflut, Erdbeben. Entscheidend ist dabei der Charakter der „Weltlandschaft" ${ }^{\text {"159 }}$ - d. h., dass das gezeigte drohende oder ausbrechende Unheil als stellvertretend für ein globales Geschehen aufzufassen ist. Es gibt auch einige Grafiken, die sich aufgrund dieser Merkmale recht gut in den Themenbereich einpassen, wie „Blick in ein Flußtal“" von 1914 oder die Bleistiftzeichnung „Apokalyptische Szene“ von 1912. Insgesamt jedoch dominieren die Gemälde diesen Bereich deutlich, weshalb hier auch nur solche zur Betrachtung herangezogen werden sollen.

\section{Stadtapokalypsen}

Den zuvor behandelten Großstadtdarstellungen stehen jene apokalyptischen Bilder am nächsten, die das Geschehen in der Stadt lokalisieren. Besonders verwandt erscheint dabei die „Landschaft: Hafenplatz“ (Abb. 13), weil sie ebenso einen eher konkreten Ort - nämlich innerhalb Berlins - zeigt und wie „Landschaft: Landhaus in Dresden“ in engem Bezug zu den in der „Anleitung zum Malen von Großstadtbildern“ gegebenen maltechnischen Hinweisen steht. Über einer Kreuzung, von der drei Straßen abzweigen - auf der einen scheint der Betrachter selbst zu stehen und auf die Szene vor sich zu blicken, während eine gerade in den Bildhintergrund fluchtet und die letzte nach rechts abbiegt - ,zerstrablt das Metallgefüge der Hochbahn zischend im weißBlauen Licht eines grelle Blitze schleudernden elektrischen Gewitters "' ${ }^{\prime 60}$. Der zuweilen ausdrücklichen Identifikation des Gerüsts als Hochbahn ist

\footnotetext{
157 Originaltitel nach Schmid (1991). In der Sekundärliteratur sonst auch: „Apokalyptische Landschaft - Spreehafen Berlin“.

158 Originaltitel nach Schmid (1991). In der Sekundärliteratur sonst auch: „Apokalyptische Landschaft".

${ }^{159}$ Leistner (2001), S. 12.

160 Roters (1990), S. 81.
} 
allerdings eher nicht zuzustimmen - vielmehr mutet es wie ein Verladekran an. ${ }^{161}$ Die Straße selbst zerbricht in Zickzack-Flächen und die Gebäude am Straßenrand geraten aus den Fugen. Die Häuser und Lagerhallen an der etwas rechts der Bildmitte liegenden Straßenecke schimmern rötlich violett. Dagegen läuft die gerade Straße auf einige Gebäude zu, die von einer gelben Lichtsäule aus den Wolken angestrahlt werden. Einige wenige menschliche Schemen in Schwarz und Blaugrau hetzen auf die links vorne aus dem Bild laufende Straße zu oder auf der nach rechts abbiegenden davon, wobei ihnen eine vereinzelt dastehende Straßenabsperrung kaum im Wege ist. Einige grün-gelbe Pinselstriche kennzeichnen einzelne Bäume und eine größere Baumgruppe am linken Bildrand, auf die auch der aus den Wolken brechende Lichtstrahl abzustrahlen scheint.

Das hohe schwarze Metallgerüst beherrscht in seiner Größe die ganze in Aufruhr geratene Szene und verbindet sich mit den Wolken des Himmels. Dieser wird von zuckenden Formen aufgepeitscht, welche auch die Einzelteile des Gerüsts zerteilen und auflösen. Das Hauptaugenmerk gilt dem Kran, der zugleich mit dem Lichtstrahl die Vertikale betont. Die Waagerechte wird durch die Anordnung der Häuser und die horizontalen Bauteile der Verladevorrichtung dagegen gestellt. Die dominierende Farbe ist ein helles Blau, das ebenso wie Rot, Gelb und Grün im Bild ins Pastellfarbene tendiert. Diese freundlich wirkende Farbgebung steht in Opposition zum Bildinhalt und zu den Formen. Erdbebenhaft gerät die Straße in Bewegung und versetzt die Menschen in Schrecken und Flucht. Das Revoltieren des Erdbodens spiegelt sich im stark bewegten Himmel wider und der Lichtstrahl scheint beide Ebenen unheilvoll zu verbinden. Die scharfen Konturen und die mit expressivem Pinselstrich gesetzten spitzen Formen wirken aggressiv und unterstreichen die katastrophische Stimmung.

Ganz wie in der „Anleitung zum Malen von Großstadtbildern“162 gefordert, setzt Meidner hier seine Lichtstrahlen und -bündel ein und zersplittert die Formen. Die Passage:

\section{„Sind nicht unsre Großstadtlandschaften alle Schlachten von Mathematik! Was für Dreiecke, Vierecke, Vielecke und Kreise stïrmen auf den Straßen auf uns ein. Lineale sausen nach allen Seiten. Viel Spitzes sticht uns. Selbst die herumtrabenden Menschen und Viecher scheinen geometrische Konstruktionen zu sein."}

macht die Entsprechung Text - Bild deutlich. Nur mit der Anwendung der Farben hält Meidner es anscheinend nicht immer so genau. Im Manifest spricht er sich dafür aus in Berlin-Darstellungen viel Umbra zu verwenden, doch das fehlt hier gänzlich. Analog zum Manifest beschreibt eine Passage aus „Vision des apokalyptischen Sommers“163 aus dem Buch „Septemberschrei“ Meidners apokalyptische Gesichte:

\footnotetext{
161 Vgl. auch Bartmann (1987), S. 289.

162 Textnachweis, Text III.

163 Textnachweis, Text V.
} 
„So hab ich den Hochsommer vor dampfenden Leinwänden geschlottert, die in allen Flächen, Wolkenfetzen und Sturzbächen die künftige Erdennot abnten. (...) und ein schmerahbafter Drang gab mir ein, alles Geradlinig-Vertikale zu zerbrechen. Auf alle Landschaften Trümmer, Fetzen und Asche zu breiten. Wie baute ich immer auf meine Felsen die Häuserruinen, klagevoll gespalten, und der Weheruf der kablen Bäume zackte zu den keächzenden Himmeln binauf. Wie rufende, warnende Stimmen schwebten Berge in den Hintergründen; der Komet lachte beiser, und Aeroplane segelten wie böllische Libellen im gelben Nachtsturm."

Wie im Manifest ist hier die Rede von der Formzersplitterung oder auch der veränderten Perspektive. Zugleich greift die Beschreibung einige bereits festgehaltene Motive auf, wie Landschaft, zerstörte Stadt, Komet und die Luftschiffe, die innerhalb dieses Themenbereichs als charakteristisch einzustufen sind. Es ist auffällig, wie Meidner die Sätze mit assoziativen Worten anfüllt. Bilder der Zerstörung werden im Geiste ausgelöst. Beinahe jedes Adjektiv, jedes Verb und viele der Nomen verweisen schon auf etwas Bedrohliches: „Trümmer, Fetzen und Asche“, „Häuserruinen, klagevoll gespalten", und „Weheruf der kablen Bäume zackte zu den krächzenden Himmeln binauf" sind aufwühlend negativ angereicherte Satzteile. Und wieder nutzt Meidner das Dynamische und in diesem Zusammenhang Alptraumhafte der belebten Umgebung: Den Häuserruinen wird ein klagendes, den Bäumen ein rufendes und den Himmeln ein krächzendes Potential zugesprochen; dazu noch der lachende Komet - das alles sind Tätigkeiten, die nur Menschen oder eventuell Tiere ausführen können. Die Berge werden mit Stimmen und die Aeroplane mit höllischen Libellen verglichen - eine unheimliche zweite Ebene wird hinter allem forciert. Schmerz, Klage und Warnung beschreiben auch hier den zum Ausdruck gebrachten Stimmungscharakter.

„Vision des apokalyptischen Sommers“ ist einer der aufschlussreichsten Texte Meidners innerhalb seiner expressionistischen Prosa. Ausgehend von einer in der Kriegszeit liegenden Gegenwart, in der sich für ihn ein heißer Sommer ankündigt und er im Wald Trost für seine Seele sucht, erinnert sich der Künstler an den Sommer 1912. Detailliert und dabei aber immer lebhaft und voll explodierender Emotionalität schildert Meidner seine Arbeit in jenen Sommermonaten, die von Hunger, Krankheit, Unglauben und Einsamkeit geprägt war. Die Düsterkeit der Lebensumstände wird mit den apokalyptischen Visionen in direkten Zusammenhang gebracht und bestätigt, dass Meidner wohl weniger von politischen Geschehnissen, als vielmehr von den eigenen armseligen Verhältnissen bedrückt und von den negativen Erfahrungen der vorhergehenden Notjahre bei einem derart pessimistischen Weltbild beeinflusst worden ist. ${ }^{164}$ Angesichts seiner aktuellen Situation ergeht er sich auch in einigen Beschreibungen der vom Krieg geprägten Stadt.

164 So deutet es z. B. auch Roters (1990), S. 68 f. 
Ein Text, der konkret mit der in apokalyptisches Geschehen involvierten Stadt in Bezug zu setzen wäre, ist neben der genannten Schlusspassage in „Vision des apokalyptischen Sommers“ das Prosastück „Erinnerung an Dresden“ - doch wird dort die geschilderte Szenerie noch ausdrücklicher mit dem Kriegsbeginn in Zusammenhang gebracht, weshalb darauf erst bei der Behandlung des entsprechenden Themenbereichs eingegangen werden soll.

Einige Passagen, wie beispielsweise in „Nächte des Malers“"165, enthalten zumindest teilweise städtische Visionen:

„Ein Steamer treibt den Strom entlang. Dünn hängt der silberne Steg über dem Gewoge.

Das Menschenschwein trabt drüber (...) Häuserungetüme biegen sich und schütteln man-

chen Selbstmörder ab. Kathedrale purzelt nach links in die Landschaft hinein."

Es bleibt aber festzuhalten, dass die Beschreibung apokalyptischer Städte im Text, anders als die früher entstandenen Darstellungen des Themas im Bild, immer im Kontext des Krieges steht. Das ist nicht verwunderlich, wenn man sich in Erinnerung ruft, dass die meisten von Meidners expressionistischen Schriften erst nach Kriegsbeginn entstanden sind. Sie sind dementsprechend natürlich durch die Erfahrung des Krieges geprägt. Die der apokalyptischen Thematik zuzuordnenden Bilder mit dem Fokus auf dem Motiv der „Stadt“ dagegen sind zu einem Großteil im Jahr 1913 - also vor dem Krieg - entstanden.

Die Apokalypsen, in denen die Landschaft dominiert, wurden vielfach vom Künstler parallel zu den „Stadtapokalypsen“ oder schon 1912 geschaffen, stammen aber auch teilweise aus dem Jahr 1915. Eine direkte zeitliche Abhängigkeit vom Kriegsgeschehen ist demnach nicht auszumachen - apokalyptische Darstellungen sind bereits davor und ebenso währenddessen präsent. Dass nun manche Bildinhalte sich in den Texten stärker widerspiegeln und andere weniger, ist nur so zu erklären, dass Stadtwahrnehmung, apokalyptische Visionen und Kriegseindrücke in enger emotionaler Abhängigkeit zueinander stehen und literarisch dementsprechend oft von Meidner kaum differenzierbar miteinander verschmolzen wurden. Viel wichtiger ist es jedoch festzuhalten, dass die Stadtapokalypsen durchaus in ihrer pessimistischen Aussage miteinander übereinstimmen und eine hoffnungslose Endzeit zeigen.

\section{Landschaftsapokalypsen}

Kommen wir zur Betrachtung der Landschaftsapokalypsen. Wie gesagt, lässt sich der oben zitierte Abschnitt aus den „Visionen eines apokalyptischen Sommers“ besser mit den Bildern vergleichen, die die Apokalypse in die Landschaft transportieren. Schmid weist ganz zu Recht darauf hin, dass damit auch eine andere Aussage verbunden ist. 166 War die Stadt im Untergangsszenario gezeigt, ließ das nach

\footnotetext{
165 Textnachweis, Text VI.
}

166 Schmid (1991), S. 90. 
dem Vorbild von „Ich und die Stadt“ auch die Deutung zu, dass die Stadt selbst zerstörerisch agiert und durch apokalyptische Symbole nur ihre deshalb dem Untergang geweihte Lebenswelt unterstrichen wird. In der Landschaft dagegen kann nur eine weltumfassende Zerstörung intendiert sein.

Eines der Bilder, welches ein solches Szenario zeigt, ist die „Apokalyptische Landschaft" (Abb. 14) von 1912/13 aus der Neuen Nationalgalerie in Berlin. Es zeigt eine trostlos wirkende Landschaft. Im Hintergrund entlang dem Horizont sind einzelne Häuser zu sehen - teils ruinenhaft aufragend oder unsicher am Felsabgrund stehend. Im Mittelgrund der rechten Bildhälfte öffnet sich eine Schlucht. Schwarze Farbkleckse vor den darin stehenden Häusern deuten fliehende Menschen an. Hinter ihnen türmen sich riesige Flutwellen auf, sogar Schiffe sind darauf zu erkennen. Die obere Bildhälfte wird von einem unwetterdurchpeitschten Himmel dominiert, über den dunkle, blitzdurchzuckte Wolken rasen. Am linken Bildrand ballt sich die Dunkelheit nachtschwarz vor einem schwefeligen Mond und ein apokalyptisches Licht braust in breiten Strahlen auf die Erde. In der unteren Bildhälfte ist zerstörtes Land zu sehen: tote Bäume und im Vordergrund ein nackt auf dem Rücken liegender Mann zwischen einzelnen Gräsern. Neben ihm steigt Rauch von einem Lagerfeuer auf und an der rechten unteren Bildecke drängen sich einige Zelte. Auch hiervor stehen tote Baumstümpfe.

Die linke Bildhälfte dominiert das Gemälde. Während sich hier im Hintergrund das Zentrum des Unwetters in Licht und Regen entlädt, präsentiert sich im Vordergrund der nackte männliche Körper in zweifelhafter Pose. Ist er tot oder liegt er wie ein neuer Adam am Lagerfeuer und ist dem Untergangsszenario entkommen? Die in schrägen Farbflächen angedeuteten Regenfälle und Blitze scheinen in ihrer Verlängerung auf ihn zu deuten. Sein nach rechts ausgestreckter Arm wiederum lenkt den Blick in die andere Bildhälfte, auf das Feuer und die Zelte. Der Hintergrund ist von verschiedenen Blauschattierungen und Schwarz gekennzeichnet, was durch die Farben Gelb und Weiß ergänzt wird, die für Blitze, Mond und apokalyptisches Leuchten verwendet wurden. Im Vorder- und Mittelgrund dominieren erdige Farbtöne. Verbrannt wirkender ockriger Boden, dazu die beigefarbenen Zelte und der mit Rotnuancen versehene menschliche Leib zwischen einigen moosgrünen Halmen - insgesamt eine eher düstere und leblos wirkende Farbgebung.

Das meiste erscheint eckig - auch wenn die Stämme der Bäume und die Körperrundungen mit bogenförmigen Pinselstrichen ausgemalt sind, so werden sie dennoch häufig durch kantige Konturlinien wieder aufgehoben $-z$. B. an den Beinen des Mannes. Die Landschaft und die Wolken weisen weiche, runde Wölbungen auf und doch werden sie von den zackigen Linien der Häuser und den schräg verlaufenden Farbflächen, die sich zuweilen fächerartig ausbreiten, verdrängt. Auffällig ist im Vergleich zu „Landschaft: Hafenplatz“, dass hier viel weniger mit Formzersplitterung gearbeitet wurde und auch das Mittel der Multiperspektivität diesmal keine direkte Verwendung gefunden hat. Die Reduzierung 
dieser Mittel ist übrigens bei fast allen Gemälden des apokalyptischen Themenkreises zu bemerken. Es gibt verschiedene Lichtquellen, die aber wenig Widerschein in ihrer Umgebung finden - nur auf dem nackten Körper schimmert ein orangefarbener Hauch. Ansonsten ist die Landschaft in ein eher diffuses Licht getaucht.

Die Zerstörung der Welt durch eine Naturkatastrophe ist angedeutet: das im Expressionismus durch aktuelle Kometensichtung vielfach aufgenommene Thema des niedersausenden Kometen ist auch hier vermutlich der Hintergrund der Darstellung. Es scheint dabei Überlebende in dieser trostlosen Welt zu geben: Zelte und Menschen deuten das an. Aber es ist trotzdem nichts eindeutig Hoffnung Gebendes im Bild zu finden. Kein neuerwachtes Leben von Pflanzen, Tieren oder Menschen - nur ein nackter Leib, dessen Zustand ungewiss ist. Mager und zerfurcht hingestreckt wirkt er nicht wie ein Mann, der nur ausruht. Allerdings verrät das Lagerfeuer an seiner Seite, dass er zumindest bis vor kurzem lebendig gewesen sein muss. Unabhängig davon, ob er lebt oder tot ist, er symbolisiert durch seine klägliche Erscheinung das Leid in Person und lässt für das Szenario keinen positiven Ausgang erwarten.

\section{Religiöser Gehalt}

In der Einleitung zum Thema „Apokalypse“ wurde angedeutet, dass Meidner durch die Beschäftigung mit religiöser Literatur von der ambivalenten Stadtdarstellung zur „Stadtapokalypse“ und zur „Landschaftsapokalypse“ gekommen sein könnte. Tatsächlich waren auch andere Faktoren von Bedeutung. Schon Roters weist darauf hin, dass die Straße die Apokalypse in sich trage. Analog zu Meidner sei die Verschiebung der Stadt zum Apokalyptischen hin bei dem Dichter Georg Heym zu sehen. ${ }^{167}$ Becker hat diesen Zusammenhang ebenfalls erkannt und Heyms Gedichtzyklus „Berlin I-VIII“ ausführlich auf die Steigerung der Dämonisierung der Stadt hin untersucht. ${ }^{168}$ Meidner dürfte sich also auf die Apokalypse verlegt haben, nicht nur weil die Stadtdarstellungen darauf angelegt sind, sondern auch weil in seinem literarischen Umfeld dieser Schritt vollzogen wurde. Dennoch spricht vieles dafür den Einfluss religiöser Komponenten in seinen Apokalypsen ebenfalls hoch einzuschätzen. Wenn es auch zweifelhaft ist, dass Meidner durch eine plötzliche Eingebung zu seiner Malweise ab 1912 gelangte, so macht seine Schilderung dieses Ereignisses doch darauf aufmerksam, dass er spätestens ab jenem Zeitpunkt sich wieder der Religion zugewandt haben dürfte. Schmid hat an mehreren Bildern aufschlussreich Hinweise aufgezeigt, die auf den religiösen Gehalt insbesondere der „Landschaftsapokalypsen“ Meidners hindeuten. ${ }^{169}$ Wichtig ist insgesamt die Nähe der Darstellungen zu den Apokalypse-Schilderungen bei Jesaja 24,1 ff. oder Jeremia 4,23 ff.:

\footnotetext{
167 Roters (1990), S. 72 und S. 88.

168 Becker (1991), S. $59 \mathrm{ff}$.

${ }^{169}$ Schmid (1991), S. 87 ff.
} 
„Seht her! Der Herr verheert und / verwü̈tet die Erde;/ er verändert/ ibr Gesicht/ und zerstreut ihre Bewohner. "(Jesaja, 24,1)

„Ich schaute die Erde an: Sie war wüst/ und wirr./ Ich schaute zum Himmel: er/ war obne sein Licht./ Ich schaute die Berge an: Sie wank-/ ten,/ und alle Hügel bebten." (Jeremia, 4,23-24)

Hier wird vor allem auch die öde Landschaft als Endzeit-Motiv gebraucht. Zudem kündigt sich die Apokalypse nach dem jüdischen Glauben über kosmische Prozesse, also über Naturumwälzungen, an. Dazu zählen Erdbeben, Sintflut und Kometeneinschlag. Diese Erscheinungen sind ebenso in den Stadtapokalypsen zu finden, wobei Kometen oder himmlisches Licht als eindeutigste und unmissverständliche Kennzeichnen fungieren, wie zum Beispiel in dem oben besprochenen Bild „Landschaft: Hafenplatz“. In „Apokalyptische Landschaft“ der Berliner Neuen Nationalgalerie sind auf jeden Fall der Kometeneinschlag und die verwüstete Landschaft zur Darstellung gebracht. Auch eine Flutwelle ist angedeutet. Wie in den alttestamentlichen Bibelstellen ist eine Ödnis Schauplatz der Vernichtung und wie bei Jeremia 4,23 beschrieben wird, dass der Himmel ohne sein Licht sei, herrscht merkwürdige Dämmerung. Aus Deutungsversuchen der Forschungsliteratur wird die Wahrscheinlichkeit religiöser Nuancen im Bild ebenfalls deutlich so wird der nackte Mann im Vordergrund bald als „Neuer Adam“, bald als Abel oder als Christus, der vom Kreuze abgenommen wurde, gedeutet. ${ }^{170}$ In Anbetracht der Hoffnungslosigkeit der Situation, wie sie oben beschrieben wurde, sind die beiden Neuanfang verheißenden Deutungen allerdings fraglich. Der Mann verkörpert mutmaßlich Tod und Ende ohne Neubeginn.

Außer der „Vision des apokalyptischen Sommers“ gibt es anscheinend keine expressionistischen Texte zum apokalyptischen Thema, die frei vom Eindruck des Krieges sind. Das gilt auch für „Anrufung des süßen, unersättlichen Züchtigers" 171 . Hier wird aber besonders in einer Passage deutlich, wie sehr Meidner bei seiner Entstehung von einem göttlichen Einfluss hinter den ihm apokalyptisch erscheinenden Geschehnissen ausgegangen sein muss:

„Du, Gott, triebst uns in unsere Sünden hinein, um dann gewaltig auszuholen mit der Racherute. Du schickest wiederum zehn Plagen über uns und deine Geschöpflein krümmen sich wie Späne vor dir. Du rissest ibre Leiblein auf. Blutige Furchen grubst du in die Rücken. Hacktest Bein und Füße ab. Und in zerfleischten Schenkeln sieht man deine Fingermale sitzen. Du Heimsucher warfest alle Leiden tausendfach auf uns in dreien Jahren. Wir schreien jetzt vergeblich zu dir auf, Bedränger, Peitscher, Nimmersatt. Ach, du bist schrecklich. Wer kann vor die stehen, wenn du qürnest? Wenn du das Urteil lässest hören vom Himmel, so erschrickt das Erdreich und wird still. (...) Hilf, hilf, denn die Jauche gehet uns bis an die Seele. Hilf uns, denn das Land steht in Flammen. (...)

${ }^{170}$ Eliel (1990), S. 31.

171 Textnachweis, Text VII. 


\section{Mit deinem Lächeln stürzen Tausende tot hin. Durch einen kleinen Ruffliegen volkrei- che Städte in Scherben. Deine Atemzüge sind Erdbeben und Zyklone. Und wenn du schläfst, verdunkelt sich der Mond und viele Sterne wanken tosend in dem ewigen Raum."}

Dieser Abschnitt, der gegen Ende des Textes steht, beschreibt Gott als die vernichtende Kraft, als jene Macht, die das Schicksal der Menschen bestimmt. ${ }^{172}$ Die Bilder der Zerstörung, die jene Sätze assoziieren, sind analog zu verschiedenen Apokalypsen Meidners. Namentlich in der bereits besprochenen Berliner „Apokalyptische Landschaft“ kann man den hingestreckten Mann als einen blutig von Gott Niedergeworfenen lesen, Land und Stadt zerstört sowie den Mond verdunkelt sehen. Der fürchterliche Gott, den Meidner hier anruft, erinnert an jenen aus dem Alten Testament. Gerade die beiden zuerst zitierten Sätze lassen daran denken; von einem Gott ist die Rede, der zu Sünden verlockt, straft und Katastrophen schickt. Hier werden in Anlehnung an die Geschichte von Mose und dem uneinsichtigen Pharao aus Exodus 7,1-11,10 oder auch an die Offenbarung des Johannes die Plagen angeführt. Die Menschen werden dagegen als klein und unbedeutend dargestellt und als „Geschöpflein“ und „Späne“bezeichnet. Bald ist es der leblose Gegenstand, bald die durch die Verniedlichung unbedeutend erscheinende Kreatur, mit denen der Mensch gleichgesetzt wird. Grotesk erscheint die Beschreibung der einzelnen misshandelten Körperteile: „Du rissest ibre Leiblein auf. Blutige Furchen grubst du in die Rücken. Hacktest Bein und Füße ab. Und in zerfleischten Schenkeln sieht man deine Fingermale sitzen. " Gott andererseits ist „Bedränger, Peitscher, Nimmersatt" und ,schrecklich“. Und im Vergleich zu den Menschen gewaltig groß kleinste Gesten von ihm genügen, um alles zu zerstören: „Mit deinem Lächeln stürzen Tausende tot hin. Durch einen kleinen Ruffliegen volkreiche Städte in Scherben. Deine Atemzüge sind Erdbeben und Zyklone." Trotzdem ist er es zugleich, der in der Textstelle auch um Hilfe angerufen wird. Das erklärt sich aus dem Textzusammenhang, in dem sich insgesamt diese Ambivalenz hindurchzieht. Angeregt durch ein Begräbnis beginnt Meidner als lyrisches Ich nach Gott zu suchen. Er behauptet, dass dieser existiere, aber er zwischendurch immer wieder an ihm zweifle und ihm dabei auch die religiösen Schriften nicht weiterhülfen. Und obwohl er Gott negativ darstellt, stellt er dem doch immer dessen Fähigkeit zum Erbarmen entgegen und gibt zu verstehen, dass er selbst ohne den Glauben an Gott verzweifeln müsse. Soviel soll an dieser Stelle genügen, denn es wird auch eine gesonderte Betrachtung des religiösen Themas geben.

Ein vermutlich ebenfalls stark religiös intendiertes Beispiel der Apokalypse bei Meidner ist die „Apokalyptische Landschaft“ (Abb. 15) der Stuttgarter Staatsgalerie von 1912/13. Inmitten einer in Ocker, Schwarz und Weiß gehaltenen Landschaft erheben sich drei wankend wirkende Gebäude und eine kleine Kapelle. Am rechten Bildrand stehen zwei kahle Bäume als Gegenstücke zu zwei weiteren, die

\footnotetext{
172 In anderen Teilen des Textes wird dem eine Beschreibung Gottes als Helfer gegenüber gestellt.
} 
links im Bild liegen. Ein Tümpel ist zu erkennen und Risse scheinen sich durch die Erde zu ziehen, was im Vordergrund zu einem undeutlichen Nebeneinander trister Farbflächen und Linien zusammenläuft. Nur ein einzelner Ast rechts vorne reckt sich wie eine Hand in die Höhe. Hinter der Kapelle verbindet eine Brücke zwei Hügel miteinander und am Horizont hebt sich dunkel eine Bergkette vom schwach erleuchteten Nachthimmel ab. Ein paar lockere gelbe Pinseltupfer deuten links oben die Sterne an. Am Auffälligsten sind die verschiedenen hell strahlenden Himmelserscheinungen. Links über den Bergen leuchten drei Kometen - zwei, die wie flammende Feuerkugeln aussehen, von denen ungleichmäßige Strahlenschleier herabfallen und einer, der in einem breit gefächerten, nach unten spitz zulaufenden gelben Band niedersaust und in kleinere Einzelteile zu zerfallen scheint. Auf der Mittelachse, fast direkt über den Häusern, ist eine kreisförmige Himmelserscheinung zu sehen. Wie eine schwarze Sonne mit rotem Feuerkranz lugt sie über den Berg und erleuchtet in einem unregelmäßig gerundeten und blassen Strahlenkreis Teile des Himmels. Zuletzt werden diese kosmischen Zeichen noch durch einen weiteren großen und breit gefächerten Kometen ergänzt, der von rechts auf die Erde fällt. Farblich ist die Palette fast gänzlich auf Schwarz, Weiß, Ocker und Gelb reduziert. Zackige Linien und Umrisse verleihen dem Bild einen unruhigen Charakter. Der horizontalen Dreiteilung in Vorder-, Mittel- und Hintergrund stehen vertikale Elemente wie mahnend aufragende Äste und Bäume entgegen.

Für dieses Gemälde gilt eine ähnliche Deutung wie für die Berliner Apokalypse. Eine öde Landschaft mit zerstörter Zivilisation und unheilverkündende Himmelszeichen verweisen auf die Endzeit. Auch hier ist ein Neuanfang der Welt nicht zu vermuten. Anders als in der Berliner Landschaft sind entsprechende Zeichen nicht zweifelhaft, sondern gar nicht gegeben. Kein einziges Lebewesen scheint in diesem Szenario noch zu existieren, die Farbigkeit ist noch finsterer, das viele Weiß erweckt gar den Eindruck, ein ewiger Winter würde jegliches Leben ersticken. Ganz wie bei dem vorigen Gemälde, lassen sich die Ödnis und die Kometen mit den bereits angeführten biblischen Apokalypse-Vorstellungen in Beziehung setzen.

Allerdings ist auch ein besonderes Motiv hervorzuheben, das so nur noch in einem einzigen anderen Gemälde Meidners zu finden ist - nämlich in der 1913 entstandenen „Apokalyptischen Landschaft“ (Abb. 16) aus der Sammlung von Janet und Marvin Fishman in Milwaukee/Wisconsin. Gemeint ist die runde, sonnenähnliche Himmelserscheinung. Schmid folgend ist diese entweder als Saturn oder als verfinsterte Sonne zu interpretieren. ${ }^{173}$ Der Saturn wird schon von alters her als unheilbringendes Gestirn erachtet, ${ }^{174}$ die verfinsterte Sonne wird in der Offenbarung des Johannes 6,12 beschrieben: „Als er das sechste Siegel auftat, da ward ein großes Erdbeben und die Sonne ward finster wie ein schwarzer Sack und der Mond ward wie

\footnotetext{
173 Schmid (1991), S. 87.

${ }^{174}$ Lexikon der Astrologie (s. Schmid (1991), Anm. 15).
} 
Blut. "Ganz gleich, auf welche Quelle Meidner sich bezogen hat, mit Sicherheit ist ein mystisch-religiöser Gehalt festzustellen.

Ergebnis

Dass Meidner nun zu den apokalyptischen Bildern kam, lässt sich nur als Folge verschiedener Faktoren, wie persönliche Erfahrungen und Erlebnisse, die Wiederentdeckung der Religion und der direkte Einfluss seines Dichterumkreises, verstehen. Je nach Verfassung sah er die Welt weniger bedrohlich und schuf ambivalente Stadtdarstellungen, oder er war aufgewühlt ängstlich und verarbeitete dies in apokalyptischen Szenen.

Wichtig ist die Feststellung, dass für Meidner zwei Varianten der Apokalypse eine Rolle spielten. Der im Urbanen angesiedelte Untergang verweist nicht nur auf die Zerstörung durch höhere Mächte, sondern auch auf die der Stadt inne wohnenden, zerstörerischen Kräfte. Die Landschaftsapokalypse dagegen meint die globale Vernichtung, ist noch stärker von biblischen Texten inspiriert und ist ein von Meidner entwickeltes Novum.

Der religiöse Gehalt der Meidnerschen Apokalypsen ist mit Schmid besonders stark hervorzuheben. Religion und persönliches Leid werden später vor allem auch in Meidners expressionistischer Prosa gespiegelt. Das bedeutet, dass sich die Auseinandersetzung mit Religion, die sich in den apokalyptischen Landschaftsdarstellungen schon deutlich manifestiert, auch in Meidners Militärzeit fortsetzt, beziehungsweise sich dann sogar noch steigert - Religion bleibt für ihn ein wichtiges Thema. Dazu wird im Kapitel 3.1.3.5. Weiteres zu sagen sein.

Vondungs zu Beginn des Kapitel erwähnte Feststellung, dass bei den Expressionisten insbesondere in einer zweiten Phase der Beschäftigung mit apokalyptischen Themen die Hoffnung zum Ausdruck gebracht wurde durch die Apokalypse eine Erneuerung zu erreichen, lässt sich für Meidners betrachtete EndzeitBilder nicht bestätigen. Der pessimistische Charakter überwiegt ohne Zweifel, denn es sind eher Aspekte des Untergangs beziehungsweise der Strafe als der Erneuerung beziehungsweise der Rettung zu beobachten. ${ }^{175}$ In den Texten ist jedoch etwas mehr Ambivalenz zu bemerken - jedenfalls wenn man den hier zum Ausdruck gebrachten Glauben an Gott und an dessen Barmherzigkeit berücksichtigt.

\subsubsection{Der Krieg}

Nun folgt die Betrachtung des letzten kritischen Themenbereichs - kritisch deswegen, weil auch hier häufig keine eindeutigen Abgrenzungen zu den beiden vorherigen Themenkreisen möglich sind. Jedoch gilt für die folgenden Untersuchun-

175 So bewertet es auch Schmid (1991), S. 91. 
gen ebenso, dass sich trotzdem einige Werke finden, die aus der Menge der in der Literatur pauschal so benannten „Apokalyptischen Landschaften“ zu selektieren und mit guten Gründen der Kategorie „Krieg“ zuzurechnen sind.

\section{Zuordnung}

Die Darstellungsvarianten zum Thema „Krieg“ sind in Meidners CEuvre breiter gefächert als die der Apokalypse. An unkonkreten Örtlichkeiten findet durch entsprechende Merkmale wie Uniformen und Waffen deutlich als solches gekennzeichnetes Kriegsgeschehen statt. Vertriebene, Verletzte, Gefangene oder Tote werden fokussiert oder es wird kritisch die gesellschaftliche Stimmung festgehalten. Das Hauptmedium ist hier ganz eindeutig die Grafik. So sind neben vielen Einzelblättern in unterschiedlicher Technik - von Tempera und Tuschzeichnungen mit Feder oder Pinsel bis zu Bleistiftzeichnungen und Kohlezeichnungen vor allem jene Tuschfederzeichnungen anzuführen, die als Lichtdrucke im Mappenwerk „Krieg“ 1914 im A.R. Meyer Verlag in Berlin-Charlottenburg'176 herausgegeben worden sind. Auch sollten die Blätter dazugezählt werden, die Meidner in einem unvollendet gebliebenen Zyklus mit dem Titel „Europa 1914/15“ veröffentlichen wollte. ${ }^{177}$ Von den Gemälde sind nur zwei diesem Themenkreis zuzusprechen: „Der Jüngste Tag“ von 1916, der laut Schmid eventuell ursprünglich „Große Landschaft mit Vertriebenen“ betitelt war ${ }^{178}$ und „Die Abgebrannten“ von 1912 - beides Bilder, die Menschen in einer verzweifelten Situation zeigen. Um einen kleinen Überblick über die verschiedenen Darstellungsvarianten geben zu können, werden für diesen Themenbereich einige Beispiele mehr herangezogen, deren einzelne Analysen aber dann nicht ganz so viel Raum einnehmen können, wie in den anderen Bereichen.

\section{Darstellung von Toten oder Verletzten}

Schon lange bevor der Krieg Deutschland heimsuchte, setzte Meidner sich mit ihm auseinander. Erste Beispiele sind „Die Gestrandeten“ und „Schrecken des Krieges“ von 1911. Im Letzteren werden grauenvoll Verstümmelte gezeigt. Diese frühe Beschäftigung mit dem Thema lässt sich wohl auf die außenpolitischen Geschehnisse jener Jahre zurückführen. Obwohl Meidner den Krieg nicht selbst erfahren hatte, zog sich dessen Verarbeitung im Bild schon vor dem Ausbruch des Ersten Weltkrieges im Sommer 1914 durch sein Schaffen und bezeugt, welche ängstliche Vorahnung ihn erfüllt haben muss.

In „Schlachtfeld“ (Abb. 17), einer links unten explizit so bezeichneten Kohlezeichnung von 1912, erstreckt sich ein weites karges Feld bis zum Horizont. Beinahe mittig befindet sich ein Pfahl, an den angelehnt ein fast unbekleideter, in sich

\footnotetext{
176 Breuer (1991) 2, S. 21.

177 Leistner (1986), S. 155. Leistner schreibt über sie, dass sie „Meidners Parifismus und kritische Haltung gegenüber dem blinden Patriotismus "bezeugen.

178 Schmid (1991), S. 94.
} 
zusammengesunkener Mann sitzt. Sein Kopf ist unnatürlich nach hinten gebogen und lässt vermuten, dass es sich um einen Toten handelt, zumal unterhalb seiner knochigen breiten Brust eine große Wunde klafft. Sein rechtes Bein ist lang ausgestreckt, wirkt aber durch die separierende Wiedergabe der Einzelteile, wie Fuß, Unterschenkel und Knie, wie die Extremität einer Gliederpuppe. Man könnte dabei auch an metallische Beinschienen denken. Das andere Bein ist angewinkelt. Zur Linken lehnt ein großer runder Schild am Pfahl und verdeckt halb einen danebenliegenden Speer. Im Mittelgrund liegen gekrümmte oder langgestreckte Leiber - teilweise ebenfalls neben ihren Waffen. Weitere einzelne Pfähle stehen wie Grabsteine im Hintergrund verteilt. Ein bewölkter Himmel überspannt diese traurige Landschaft.

Die Zeichnung ist ohne großen Aufwand mit wenigen Einzelheiten und geringen Hell- Dunkelkontrasten ausgeführt. Auffallend ist jedoch die Dreieckskomposition der Vordergrund-Gruppierung aus Mann, Pfahl und Schild, deren unruhige Wirkung durch die Hinzufügung des Speers und der daraus insgesamt resultierenden Rechteckform wieder beruhigt erscheint. Im Gegensatz zu vielen der bisher betrachteten Bilder Meidners sind die Bildgegenstände nicht verzerrt dargestellt. Durch die Darstellung des unmodernen Kriegsgeräts wird klar, dass es sich nicht um eine vom Künstler selbst gesehene, sondern um eine fiktive Situation handelt. Gerade deshalb ist das Bild sicher als kritische Stellungnahme zum Krieg zu beurteilen, denn wenn nicht das Interesse getreuer Wiedergabe eines Beobachters dahinter steckt, muss es als Mahnung hinsichtlich der verheerenden, Tod und Verderben bringenden Folgen des Krieges verstanden werden. Durch die Historisierung der Szene wird die Allgemeingültigkeit der Kriegsablehnung zum Ausdruck gebracht.

In dem stark autobiografisch geprägten Text „In den weißen Windhimmel lauf ich binein"179, der Bestandteil des Buches „Septemberschrei“" ist, wird in einem verzweifelt wirkenden Selbstgespräch unter anderem die Erinnerung an den Krieg wachgerufen. In erster Linie wird allerdings die reuige Suche nach Gott thematisiert. Worüber Meidner als das lyrische Ich einst verfügte - über „Gottversunkenbeit", "Sicherheit, Weltinbrunst und tiefe Macht" - das kam von Gottes Gnade. Doch hat er diese durch Hochmut verspielt und erkennt nun in Reue die Lieblosigkeit seiner Seele und fragt sich, wer er sei. In diesen Rahmen sind Erinnerungen an verschiedene Glaubenszustände zu unterschiedlichen Lebensstationen eingestreut.

„Da horch, horch! Gewinsel aus dem Erdreich rinnt, Gemordeter Weherufe...vorbei ist dein winzig Leid und der Erde Leid, dieser Jahre Blutröcheln wirft sich schmerzhaft an deine Brust. Verdorrtes Bruderblut - Krieg, Krieg! - der heiseren Hassenden Würgebände noch immer, noch immer im Land. Blutlachen auf der weiten, keuschen Erde. An den Schienensträngen lang schleift mich Novemberwind. An Kanalufern, Böschungen,

179 Textnachweis, Text VIII. 
Hügelhängen stammelt erschauernd mein Tritt. An die Stadtkirchen klatscht mich, an Kasernen, Gefängnisse pfercht mich der rote Tod. Man mablt mich in allen Mühlen..."

Diese Beschreibung von Kriegserfahrung weckt wahrlich keine positiven Assoziationen. Der Krieg wird vor allem mit Blut in Verbindung gebracht, was auf dessen schreckliche Folgen hinweist: „Blutröcheln“, „Bruderblut“, und „Blutlachen“ stehen explizit dafür. Diese Nomen metaphorisieren zudem die Qual und die Ausmaße des großen Mordens zum einen, aber auch die Solidarisierung mit den Toten zum anderen. „Bruderblut" ist durchaus als Hinweis auf Meidners Sehnsucht und die vieler Expressionisten nach der Menschenverbrüderung zu sehen. Die Wiederholungen von „,horch", „Krieg" und „noch immer" als Spontaneitätsgesti erzeugen den Eindruck von Aufgeregtheit, wirken aber auch besonders betont und eindringlich. Das Leidvolle der Kriegserfahrung steht in dieser Passage im Vordergrund. Neben den bereits erwähnten Wortverbindungen mit dem Segment „Blut“, verdeutlichen „Gewinsel“, „Weherufe“ und vor allem der zuletzt zitierte Satz „Man mahlt mich in allen Müblen... "mit seiner sehr anschaulichen Metapher, wie schmerzlich und emotional belastend Meidner die Situation empfindet. Im Vergleich dazu erscheint ihm alles bisher gefühlte Leid als „dein winzig Leid“. Deutlich wird auch die Klage über die Dauer des Krieges durch das „noch immer", „dieser Jahre Blutröcheln" und das Verdorrtsein des Blutes. Doch anscheinend sind die Eindrücke ohnehin nicht zu verdrängen, wenn selbst die bislang Getöteten noch als unter der Erde winselnd wahrgenommen werden - dieser Abschnitt scheint auf die Ungerechtigkeit des Todes anzuspielen und darauf, dass dafür das schlechte Gewissen die Lebenden mit Wahnvorstellungen plagt.

Besonders augenscheinlich ist die Aversion gegen den Krieg durch zweierlei Faktoren: einmal dadurch, dass eine zwar anonyme, dafür aber deutlich negativ spezifizierte Gruppe von Menschen für sein Voranschreiten verantwortlich gemacht wird, zum zweiten durch das Symbol der entweihten Erde. Es sind die „,heiseren Hassenden“, die mit ihren „Würgehänden “das Land malträtieren. Damit sind wohl Menschen gemeint, die nur aus Hass oder vielleicht auch aus anderen niederen Gründen weiter morden, sich nicht aufhalten lassen und in Anbetracht all der Gräuel gefühllos sein müssen. Diese Äußerung geht in ihrer Sinnhaftigkeit sogar noch tiefer und spielt im Zusammenhang mit dem folgenden Satz auf die Gottlosigkeit dieser Menschen an. „Blutlachen auf der weiten, keuschen Erde. “Diesem Satz ist ein religiöser Gehalt zuzusprechen - gerade auch aufgrund von Meidners zunehmender Religiosität, die in Gesamtbetrachtung seiner Texte zu beobachten ist. Er erinnert an die Geschichte von Kain und Abel, in welcher Kain durch die Ermordung seines Bruders Neid und Hass in die Welt trägt und das erste Mal Menschenblut auf der von Gott geschaffenen Erde vergießt. ${ }^{180}$ In gewissem Maße jungfräulich war diese Erde und sie wurde entweiht. Dieser Gedanke wird hier in Meidners Text aufgenommen und mit den vorher genannten „Hassenden“ kontex-

180 Nachzulesen in der Genesis 4, 1-16. 
tualisiert. Analog zu der oben besprochenen Zeichnung wird in diesem Text die Vorstellung von Schlachtfeldern und Getöteten evoziert. Natürlich ist diese Parallelisierung absichtsvoll forciert worden, denn sie ermöglicht den Vergleich der beiden jeweils intendierten Aussagen. Daraus ergibt sich die Feststellung, dass in beiden Medien eine recht ähnliche Auffassung des Krieges gegeben wird, nämlich eine deutlich ablehnende Haltung, die durch das Aufzeigen des blutigen Verlusts von Menschenbrüdern zum Ausdruck gebracht wird. Der Text ist offenbar im Vergleich zu der Zeichnung noch tiefergehend angelegt, indem er religiöse Untertöne ins Spiel bringt.

\section{Darstellung gesellschaftlichen Verhaltens}

Ähnlich kriegskritisch sind die Darstellungen derjenigen, die die allgemein herrschende, unreflektierte Kriegsbegeisterung spiegeln, wie es in der Tuschezeichnung „Am Vorabend des Krieges“ (Abb. 18) von 1914 der Fall ist. Eine eng zusammengedrängte Menschenmenge ist in einer einheitlichen Vorwärtsbewegung nach rechts vorne gezeigt, so dass die meisten Gesichter im Dreiviertel-Profil zu sehen, beziehungsweise angedeutet sind. Aufgrund des Gedränges verdecken die vorderen die dahinter auftauchenden Köpfe. Die Menschen tragen Straßenbekleidung, was sich an den Hüten festmachen lässt. Ebenso kann man an ihren Formen ablesen, dass hier hauptsächlich Männer unterwegs sind. Die Mimik drückt vor allem Grimm aus: wütend verzogene Augenbrauen und Zornesfalten sind über mancher Nasenwurzel sind zu entdecken. Doch sind dazwischen auch durchaus besorgt und ängstlich blickende Gesichter, wie beispielsweise der Herr ganz vorne links, dessen Mund und Augen weit aufgerissen sind. Auffällig ist auch der vorne rechts dominant gegebene Mann, von dem nur Kopf und Hände gezeigt sind und der halb rückwärts zur Menge gewandt und mit geballten Fäusten den Aufmarsch hinter sich dazu aufzufordern scheint ihm zu folgen. Zwischen beiden steht ein Herr, der ernst zu seinem linken Nachbarn hinüber schaut - damit wird auch der Blick des Betrachters auf jenen gelenkt. Im Mittelgrund schlieBen eine Reihe gehobener Arme die Menge nach hinten ab. Etwas nach rechts versetzt stehen dem einige ziellos in die Luft greifende Arme entgegen - vielleicht gehören sie den ersten Freiwilligen, die sich zum Kriegsdienst melden. Dahinter steht in großen Lettern das Wort „Ultimatum“ an einer Bretterwand. Im Hintergrund, dessen räumliche Strukturen aufgrund der dem ganzen Bild fehlenden Tiefenwirkung unklar bleiben, deuten fensterstarrende Häuserfronten eine städtische Umgebung an.

Es erfolgt eine leicht schräg verlaufende horizontale Dreigliederung des Geschehens in Vorder-, Mittel- und Hintergrund. Auffällig ist, dass eine durchgehende Zickzack-Form vorhanden ist. So ist die Anordnung der Köpfe diagonal zur Mitte des rechten Bildrandes hin angelegt, wo sie mit einer durch die Arme zu ziehenden Linie zusammentreffen, woraus sich eine spitz zulaufende Form ergibt. Diese wird von dem Schriftzug verstärkt, der von links oben nach rechts unten 
und ebenfalls zur rechten Bildmitte hin verläuft. In Verbindung mit der darüber gezeigten, nach rechts oben weisenden Fensterreihe ergibt sich dann eine Form, die ein wenig an ein spiegelverkehrtes „Z“ erinnert. Diese Komposition und die emotionalisiert dargestellten Gesichter erzielen eine dynamische, fast aggressive Wirkung.

Diese Zeichnung entstand Anfang August 1914, also zu einem Zeitpunkt, als der Erste Weltkrieg seinen Anfang nahm: „Es ist tatsächlich das ,Ultimatum' eingetreten, der Punkt, an dem es kein Zurück mehr gibt: Am 1. August erklärte Deutschland Russland den Krieg und zwei Tage später Frankreich. "181 Meidner skizziert in „Am Vorabend des Krieges" die Entschlossenheit der Bevölkerung, mit der sie sich dem Krieg anschließt. Doch durch das Groteske der wie abgehackt erscheinenden Arme und der eingestreuten ohnmächtigen Mienen verdeutlicht er auch das Schreckliche dieser Situation. Der mittig stehende Herr ganz vorne, dem eine gewisse Ähnlichkeit zu Meidner zuzusprechen ist, ${ }^{182}$ scheint ein wenig zwischen der Entschlossenheit des Mannes rechts von ihm und der Angst des Mannes zu seiner Linken zu schwanken, doch sein verstohlener Blick nach links verweist auf die zweite Alternative.

Im Kapitel 3.1.3.1. wurde bereits erwähnt, dass das expressionistische Prosawerk ,...im Nacken das Sternemeer..." ${ }^{183}$ - gemeint ist der Text und nicht das Buch - zeitlich wie auch inhaltlich im Kriegsdeutschland zu verorten ist. Wie die Menschen hier das städtische Leben akzeptieren, so nehmen sie auch den Krieg hin:

„Ein Feldgrauer ruft die Parole: ,Maul balten, enger schnallen, durchbalten!!’ Maul halten, enger schnallen, durchbalten!! Braust es von Mensch zu Mensch. Aus Giebeln, Torbogen, Kirchenfenstern; von Balkonen, Häuserdächern, Nachtstüblen schallt's wieder. Aus allen guten Stuben, Pbilharmonien und Kreditanstalten heraus: ,Maul halten, enger schnallen, durchbalten!!' Es klatscht auf die bohen Fronten der Postämter, zischt aus den Feueressen, fällt auf die dicken Türme. Die Bürger machen loyale Gesichter und werfen sich das Wort zu wie saft'ge Würschte. Der Junge nebenan konjugiert das Verbum ,durchbalten" und das Küchenfräulein wickelt es in ibre Tasche ein."

Was hier beschrieben wird, ist zwar eine spätere Situation als die in „Am Vorabend des Krieges“, dennoch hält der Text den Zeitgenossen kritisch den Spiegel vor. Wie die Papageien plappern sie die Parole nach, die hier bezeichnenderweise auch noch von einem Vertreter des Militärs ausgegeben wird. Die Reihung der Örtlichkeiten legt nahe, dass diese Durchhalteeinstellung eigentlich überall zu finden ist und allgemein sogar mit Enthusiasmus geteilt wird. Letzteres kommt besonders gut im zuletzt zitierten Satz zur Geltung - „Der Junge nebenan konjugiert das Verbum ,durchbalten" und das Küchenfräulein wickelt es in ihre Tasche ein.", und vor

${ }^{181}$ Eliel (1990), S. 59.

182 Vgl. auch Grochowiak (1966), S. 102.

183 Textnachweis, Text IV. 
allem auch in dem Halbsatz davor ,[sie] werfen sich das Wort zu wie saft'ge Würschte". Dass diese Haltung aber vermutlich nicht von einer inneren Überzeugung herrührt, belegt die Aussage „Die Bürger machen loyale Gesichter" - das impliziert die Unaufrichtigkeit dieses Verhaltens. Es handelt sich dabei nur um eine Maske. Was in dieser Textpassage somit angesprochen wird, ist nicht wie bei der Zeichnung die begeisterte Kriegsbefürwortung, sondern das heuchlerische Mitläufertum. Explizit wird ein Anklagen dieses Verhaltens allerdings nicht zum Ausdruck gebracht, stattdessen könnte der Abschnitt auch „nur“ spöttisch gemeint sein. Die Kritik ist dann nicht so deutlich wie in der betrachteten Zeichnung, dennoch ist sie vorhanden. Dies kommt auch durch den Befehlscharakter der Parole zum Ausdruck, worin das "Maul balten“ besonders diktatorisch wirkt und das ,enger schnallen" auf die schwierigen Lebensumstände im Krieg aufmerksam macht.

Kriegsvorstellungen

\section{„Am 28. Juni 1914 fallen die Schüsse von Sarajevo, am 18. Juli erklärt Österreich- Ungarn Serbien, und am 1. August das Deutsche Reich Russland und am 3. August Frankereich den Krieg (...) “.'184}

Der Erste Weltkrieg nimmt seinen Anfang und Meidner erlebt dessen Ausbruch gemeinsam mit dem befreundeten Dichter Lotz in Dresden. Bei dem Maler löst dieses Ereignis große Ängste aus, wie es beispielsweise aus „Erinnerung an Dresden“ ablesbar ist, der Dichter dagegen ist begeistert, meldet sich als Kriegsfreiwilliger und fällt schon nach wenigen Wochen. Für Meidner ist dieser Verlust ein Schock, einer, der wohl auch seine Sicht des Krieges weiterhin prägt. Obwohl er vorerst selbst keine Erfahrungen an der Front macht, wirft er sich in die Erarbeitung des Mappenwerks „Krieg“ und verarbeitet dort seine Vorstellungen vom Kriegsgeschehen. Dieser grafische Zyklus, bestehend aus acht Lichtdrucken einem Titelblatt und sieben weiteren Blättern -, die auf Tuschfederzeichnungen basieren, ist 1914 im Verlag A. R. Meyer in Berlin-Wilmersdorf herausgegeben worden. Die Darstellungen selbst sind allerdings noch in Dresden entstanden. Thesing weist darauf hin, dass allen Blättern das Thema „Energie der Zerstörung“ zu Grunde liegt. 185

„Die Bombe“ (Abb. 19), ein in der Mappe enthaltener Lichtdruck der Zeichnung „Brückenexplosion“ von 1914, ist Ergebnis einer solchen eher unkonkreten Kriegsphantasie. Ohne räumliche Struktur und Tiefenwirkung sind verschiedene Situationen wie Momentaufnahmen kaleidoskopartig zu einem Bild zusammengefügt, wobei sie jedoch einer horizontalen Dreiteilung des Blattes unterliegen. Relativ zentral ins Bild gesetzt und auch kompositorischer Brennpunkt ist die gerüstartige Konstruktion einer Brücke, die von einer Explosion mitten entzweigerissen in sich zusammenfällt. Staubwolken, Qualm und Brückenteile sind zu erkennen.

\footnotetext{
184 Breuer (1991) 2, S. 20.

185 Thesing (1991), S. $96 \mathrm{ff}$.
} 
Eine im oberen Bildabschnitt gezeigte Stadt scheint ebenso von der Zerstörung bedroht zu sein: Sturmwolken peitschen durch den Himmel, die Häuser scheinen zu wanken und das Dach eines auf der Mittelachse angeordneten Eckhauses ist von Rauch und Flammen verhüllt. Menschen laufen fliehend durch die Straßen. Im unteren Bilddrittel sind verschiedene Figurengruppen gezeigt. Ganz rechts steht vom Rand überschnitten ein volluniformierter Soldat frontal zum Betrachter, aber den Kopf zur Explosion hingewendet. In seiner Rechten hält er eine Muskete, sein Gesichtsausdruck bringt durch das weit geöffnete Auge und einen unnatürlich verzogenen Mund Erschrecken zum Ausdruck. Links liegt zu seinen Füßen ein Totenschädel, dessen Augenhöhlen auf den Betrachter gerichtet sind und der Zeigefinger einer daneben aus dem Boden ragenden Totenhand weist mahnend auf das kriegsbedingte Chaos in den oberen Bildsphären hin. Links vorne sind über Signatur und Datum die Köpfe und Hände zweier Fliehender in Nahsicht gezeigt. Vorwärts aus dem Bild strebend werfen sie ängstliche Blicke zurück auf das Geschehen und auf eine Gruppe von Soldaten, die als Halbfiguren angedeutet und durch Pickelhauben kenntlich gemacht sind. In militärisch strammer Haltung stehen sie diszipliniert da, als ob sie unbeeindruckt der Explosion beiwohnen würden. Die Physiognomien der beiden flüchtigen Männer sind stark herausgearbeitet, allerdings auch fratzenhaft übertrieben. Während der rechte von ihnen mit in die faltendurchfurchte Stirn gezausten Haaren und stoppeliger Oberlippe verzweifelt einen prüfenden Blick auf das Kriegsgeschehen hinter sich wirft, scheint der linke mit dem kahleren Kopf, den ausgeprägten Wangenknochen und dem schmalen Bärtchen vielmehr zu dem mahnenden Totenkopf hinüberzuschielen. Bang hat er seine rechte Hand an die Wange gelegt und gleichzeitig den linken Arm abwehrend seitlich vor das Gesicht gehoben.

In der Komposition ist eine gewisse Ordnung zu beobachten: die horizontale Gliederung, deren drei Abschnitte nach oben hin jeweils etwas schmaler werden, und eine ziemlich genau axiale Anordnung von brennendem Dach, der Wolke inmitten der berstenden Brücke und der Soldatengruppe, geben der Zeichnung eine dem dargestellten Chaos entgegenstehende klare Grundstruktur. Dadurch werden alle Wahrnehmungseindrücke, auch jene, die nur durch zersplitternde, berstende oder bewegt geschwungene Formen angedeutet sind und insgesamt die Wirkung starker Dynamik erzeugen, zusammengehalten. Anscheinend sind hier, wie schon bei der Großstadtthematik festzustellen war, verschiedene Wahrnehmungsmomente desselben Geschehens dargestellt. Wenn die Einzelszenen wohl auch fiktiv sind, so ist ihre Gleichzeitigkeit vermittelnde Zusammenführung doch ausdrucksstark. Durch die Hell-Dunkel-Kontraste wird der Eindruck des Explosiven, den schon die Formen und expressiven Schraffuren und Linien vermitteln, verstärkt.

In dieser Zeichnung ist die Kontextualisierung von Krieg und Tod ganz explizit. Deutlicher als durch den auf die Kriegsgeschehnisse hindeutenden Totenschädel hätte Meidner diesen Bezug nicht herausstellen können. Dass für ihn der Tod 
in diesem Zusammenhang, gerade auch nachdem sein Freund Lotz gefallen war, ein Hauptaspekt des Krieges ist, lässt die Behauptung zu, dass der Krieg für Meidner vor allem ein Negativum darstellt.

Bruchstückhaft lässt Meidner seine Erfahrungen und Vorstellungen vom Krieg in seinen expressionistischen Prosatexten immer wieder durchschimmern. Oft jedoch beschreibt er hauptsächlich seine Verzweiflung und Gottessuche - versucht seine überschäumenden Emotionen in Worten hinzuschleudern, wie er es als Maler mit der Farbe tut - und dabei ist der Krieg als Auslöser seiner Situation und Empfindung häufig nur zwischendrin angedeutet und dann zwischen den Zeilen zu lesen. Eine der etwas deutlicheren Passagen ist in „Malers TagGesang "'186 zu finden:
„Maler, träume nicht, da die Erdreiche grollen, Jabrtausende vor deiner Zeit erschre- cken....sei auf deiner Hut. Stelle dich gegen die Zeit, schrei' ibr meuternd ibre Verbrechen 2u. Maler, straucble nicbt, ob auch die Leichen schrein. Der Schall der Minen dein Ge- birn zerreißt. Reiß von den blutigen Fabnen das Tuch. Kochend, in weißer Glut spann es auf und mal' das Leid. Mal' dein Menschenherz auf das blutige Tuch..."

Der gesamte „Gesang“" ist durchlaufend in diesem beschwörenden Tonfall geschrieben, der Appell eines Malers an sich selbst. Ein Selbstaufruf zu Stärke, zum Festhalten an seinem Arbeiten und dazu sich durch die Geschehnisse der Zeit und die inneren Gesichte nicht aufhalten zu lassen. In den Schlusssätzen wird gar deutlich, dass er sich als ein Werkzeug Gottes betrachtet: „bist ja der Griffel unerforschlichen Gottes". Entsprechend der in der Literatur formulierten Auffassung, dass die expressionistischen Schriften Meidners einen stark autobiografischen Charakter aufweisen, ${ }^{187}$ ist sicher auch dieser Text auf Meidner persönlich zu beziehen. Im zitierten Absatz ist die Aufforderung an sich selbst, die Eindrücke malend zu verarbeiten, deutlich herausgestellt: ,mal' das Leid. Mal' dein Menschenherz". Und diese zu malenden Eindrücke stehen hier in direktem Zusammenhang mit einem kriegerischen Hintergrund: ,Maler strauchle nicht, ob auch die Leichen schrein. Der Schall der Minen dein Gebirn zerreißt. Reiß von den blutigen Fabnen das Tuch." „Leichen", „Minen" und ,blutige[ ] Fahnen" sind unmissverständliche Hinweise auf den Krieg. Und dass dieser verurteilt wird, lässt sich daran ablesen, dass „die Erdreiche grollen, Jahrtausende vor [dieser] Zeit erschrecken", und vor allem daran, dass sich der Maler gegen diese Zeit stellen und ,ihr menternd ibre Verbrechen " zurufen will. Das bedeutet im übertragenen Sinne, dass die Kriegsgeschehnisse von lauter anzuklagenden Verbrechen geprägt sind und sich sogar die schon ewig existente Natur, die demnach schon viele schlechte Zeiten „erlebt“ hat - hier ist wieder eine Verlebendigung angedeutet - angesichts dessen revoltiert.

Der Text wurde zu einem Zeitpunkt verfasst, als Meidner mehr als bei den zuvor genannten Zeichnungen in die Realität des Krieges involviert war - durch

186 Textnachweis, Text IX.

187 Z. B. Soergel (1925), S. 553; Assmann (2001), S. 50; Breuer (1991) 2, S. 23. 
seine Arbeit im Gefangenenlager. Dennoch war er nicht an der Front und selbst in Gefechte verwickelt. So bleibt der Text trotz seiner im Vergleich zum Bild stärkeren Intensität doch eher unkonkret, denn es werden Gefühle und Sinneseindrücke, nicht aber genaue Situationsbeschreibungen gegeben. Trotzdem ist tendenziell die Unterschiedlichkeit der beiden hier angeführten Medien festzustellen. Der groteske Charakter der Zeichnung ist so im Text nicht gegeben, stattdessen findet darin eine Dramatisierung der Eindrücke insbesondere durch Verwendung aggressiver Verben wie „schreien" und „zerreißen“ statt, die eine Wirkung von größerer Unmittelbarkeit des Leids hervorruft.

\section{Darstellung Gefangener im Lager}

Einen konkreteren Bezug zur Realität als all seine anderen Kriegsdarstellungen haben Meidners Zeichnungen aus dem Lager bei Merzdorf, wo er 1916 nach seiner doch noch erfolgten Einberufung als Dolmetscher eingesetzt wurde. In der Folgezeit begann er wie bereits erwähnt aus Mangel an Möglichkeiten zum Malen mit dem Schreiben von Texten - es entstanden jene, die später in „Septemberschrei“ und „...im Nacken das Sternemeer...“ zusammengestellt und herausgegeben wurden. Ein wenig konnte er aber auch künstlerisch tätig sein. In drei 1917 erworbenen Skizzenbüchern schuf er neben Zeichnungen von Propheten auch Studien von den Lagerinsassen. ${ }^{188}$ „W Wen die Zeichnungen vor der Einberufung wenig realitätsbezogen und allegorisch überhöht, so wählte Meidner jetzt für seine Skizzenbücher unmittelbar Erlebtes: Menschengesichter aus denen Kriegsschicksale sprechen (...). "189

Eine davon ist die Tuschezeichnung „Verwundeter“ (Abb. 20) von 1917. Gezeigt ist ausschließlich der Kopf eines Mannes im Dreiviertelprofil. Die rechte Gesichtshälfte ist bandagiert, wobei sich die Verbände quer über Nasenwurzel und Stirn ziehen und so auch den Großteil des restlichen Schädels verhüllen. Nur Ohr, Auge und Wange der linken Seite, ein bartumstandener Mund, Kinn und Nase sind freigelassen. Das sichtbare Auge ist mit ernstem Blick auf den Betrachter gerichtet - insgesamt einen verhärmten Eindruck vermittelnd. Um Mund und Nase spielt ein Zug von Bitterkeit.

Meidner hat hier einen der Eindrücke festgehalten, die er während seiner Tätigkeit im Gefangenenlager Merzdorf erhalten hatte. Dahinter steckt vielleicht nur das Interesse eines Beobachters an einer Physiognomie, beziehungsweise an einem vom Krieg geprägten Gesicht, sicherlich bringt aber die Wahl dieses Motivs hier ebenso wie in den bereits angeführten Beispielen Meidners pazifistische Grundhaltung zum Ausdruck. Analog dazu ist die Beschreibung des Merzdorfer Lagers im Text „Septemberschrei““190, nach dem das 1920 erschienene Buch benannt ist, zu lesen:

\footnotetext{
188 Grochowiak (1966), S. 108-113.

189 Thesing (1991), S. 104.

190 Textnachweis, Text X.
} 
„Über dem Gefangenenlager zu M. dampft Geschrei und Schwermut des Kerkers. (...) Menschengesichter, tief zerfressen von Sebnsüchten. Von Hunger und Kränklichkeit Zernagte, gedemütigt und bespieen von Menschenbrüdern. Menschenantlitze mit SlavenNasen bleckend. Schiefe, sengende Augen-Fratzen. Immer lauernde Mäuler. Rasierte, zerfetzte Schädel voll Zweideutigkeit und Verrücktheit in den Wangen. Da flammt auf einer Maske Güte auf und gottseliges Lächeln. Da gehen zarte Händedrücke um. Und manche sind versunken in ihr Nichts und ferne Heimatlieder. "

Der Gesamttext ist an sich eine Proklamation der Menschheitsverbrüderung. Meidner beschreibt im Anschluss an die zitierte Passage Menschen verschiedener Nationalitäten und anerkennt sie als seine Brüder, doch darf er dieses Gefühl nicht zum Ausdruck bringen. Im Gegenteil: Klimax der expressiven Darlegungen ist seine Beteiligung an einem Henkerkommando, das auch Auslöser für den Text gewesen sein mag. Anschließend geht alles wieder seinen gewohnten Gang. Meidner jedoch spiegelt hier seine Verwirrung und Aufgewühltheit:

„Mich bedrängt der große Welt-Unsinn. In mir weint es schon tagelang. Ich will Haß in mir entfachen! Aber das nützt nichts. Ich will webklagend mich in den Aschen der Traurigkeit wälzen! Aber das nützt nichts. Ich muß ein langes Messer an der Seite tragen und meine Menschenbrüder mit zynischem Gleichmut bedrohen."

Bei der hier deutlich werdenden Menschenliebe des Künstlers ist es nicht verwunderlich, dass er sich interessiert der Darstellung dieser „Brüder“ zuwendete, für die er Mitleid empfand und deren Gesichter so sehr von den negativen und gar widersprüchlichen Erfahrungen des Krieges gezeichnet sind. Die hier angeführte Zeichnung wie auch der Text zeugen von einer scharfen Beobachtungsgabe Meidners, der wie mit einem Röntgenblick die Emotionen und innere Wesensart seines Gegenübers zu ergründen sucht. Zugleich erscheint darin eine versteckte Kritik, die in seinen Worten auch noch offensichtlicher zu Tage tritt als in der Zeichnung. Es ist erschreckend, wie entstellt die Gefangenen vom Krieg sind und das nicht nur äußerlich, wie es die Zeichnung zeigt, sondern auch innerlich, wie Meidner es in ihren Zügen lesen kann und im Text festhält. „Zerfressen“, „zernagt" und „Fratzen“ sind die Attribute, die Meidner ihren Gesichtern zuspricht und die zum Ausdruck bringen, wie zerstörerisch die Zeit auf sie gewirkt hat. Sie haben „sengende Augen" und „lauernde Mäuler" - Angst und Misstrauen stehen dahinter. „Zweidentigkeit" und „Verrücktheit" sind weitere Aspekte, die verdeutlichen, wie negativ die Folgen des Krieges zu beurteilen sind. Die Bezeichnung des Krieges als „Welt-Unsinn" und der Gefangenen als „Menschenbrïder" sind ebenso Indizien einer antikriegerischen Haltung.

Krieg als Gottes Strafgericht

Die Betrachtung des Themas Krieg soll mit einem Gemälde abschließen, das andere Autoren zumeist dem apokalyptischen Kreis zuordnen. Die Rede ist von „Jüngster Tag“ (Abb. 21) von 1916, welches zugleich das letzte Gemälde ist, das 
Meidner vor seinem Militärdienst gemalt hat. Es wird vermutlich aufgrund des Titels im allgemeinen als Apokalypse gewertet, doch da der Titel laut Schmid wahrscheinlich nicht authentisch ist und im Bild keine eindeutigen Hinweise auf kosmische Zerstörung gegeben sind, kann es auch eine Kriegsszene zeigen, zumal es kurz vor Meidners Kriegsdienst entstanden ist und ursprünglich „Große Landschaft mit Vertriebenen“ betitelt gewesen sein soll. ${ }^{191}$

Eine hügelige karge Landschaft ohne Baum und Strauch in Ocker- und Umbratönen erstreckt sich bis zum Horizont, der von einem schmalen, von Wolken fast schwarz verfinsterten Himmelsstreifen überspannt wird. Auf den entfernteren Hügelkuppen deuten gräuliche Quader und andere senkrecht aufstrebende, flächige Formen die Überreste von Gebäuden an. Auf der Mittelachse ist eine Mulde zu sehen, deren blaugraue Färbung vielleicht auf Wasser hinweist. An seinem Rand sind ein Totenkopf und eine Schlange zu erkennen. ${ }^{192}$ Vereinzelt oder in kleineren Gruppen drücken sich Menschen kauernd an die Erde. Ihre Körper sind vielfach nur kleine, düster gehaltene Farbflächen und ihre Gesichter muten maskenhaft an.

In einem schmalen Vordergrundstreifen sitzen bildparallel aufgereiht und ängstlich zusammengedrängt weitere Personen in einer größeren Gruppe zusammen am Boden. Alter und Geschlecht sind gemischt. Ihre Angst äußert sich in unterschiedlicher Weise: mancher hockt nur mit leerem Blick apathisch da, wie jener schnurrbärtige Mann ganz rechts; eine Figur hat ihren Arm um die Schultern eines Kindes gelegt, doch gleichzeitig verzweifelt das eigene Gesicht zwischen den Knien verborgen. Hinter ihr haben zwei Frauen klagend Hände und Blicke zum Himmel erhoben - die eine hält dabei gar ein kleines schwarzes Kreuz, während weiter links andere betend die Hände gefaltet haben. Mehrere schauen aus dem Bild heraus den Betrachter an: die beiden Männer in der Mitte, von denen der vordere animalisch verfremdete Gesichtszüge trägt, und jener halbverdeckte Glatzkopf, der mit Frau und Kind ganz links kauert und mit seiner Rechten in den Himmel zeigt.

Die Stimmung ist sehr düster. Nicht nur durch inhaltliche Aspekte wie die verzweifelten und hoffnungslosen Menschen, die Ödnis, Zerstörung und Dunkelheit wird diese Wirkung erzielt, sondern auch formal - vor allem durch die Farbgebung, die auf das Spektrum dunkler Töne beschränkt ist. Schwarz, Blaugrau und Umbra sind es, die das Bild dominieren. Die Dreiteilung gibt der Landschaft den größten Raum. Wie Furchen ziehen sich Schatten zwischen den Hügeln hindurch, die den düsteren und bedrohlichen Charakter des Gemäldes unterstreichen.

Wie bei den Landschaftsapokalypsen ist auch hier die Deutung der Ödnis als biblisch inspirierte apokalyptische Landschaft denkbar. Zugleich ist mit Rücksicht auf die Entstehung des Bildes während des Krieges auch die Lesart möglich, dass es sich um eine Darstellung Heimatloser in der vom Krieg zerstörten Umwelt handelt. Es ist zu vermuten, dass Meidner diese Dualität sogar beabsichtigt hat,

191 Schmid (1991), S. 93.

192 S. auch Leistner (1986), S. 157. 
denn weder hat er die bei den Apokalypsen häufig genutzten unzweifelhaften Symbole, wie beispielsweise den Kometen verwendet, noch hat er das Bild durch Darstellung von Waffen, Soldaten oder ähnliches als eindeutige Kriegsszenerie kenntlich gemacht. Diese Verschmelzung von Krieg und Apokalypse, wie sie vielleicht auch für andere Bilder Meidners zu konstatieren ist, ist in seiner Vorstellung vom Krieg als Strafe Gottes begründet. Im Bild wird sie durch die verschiedenen Gesten der vorderen Figuren offenbar: durch zum Beten gefaltete und zum Himmel gestreckte Hände, durch das Halten des Kruzifixes, durch Tod und Sünde symbolisierende Motive wie Totenschädel und Schlange. Ganz unmissverständlich wird dies auch durch den zum Himmel zeigenden Mann links deutlich gemacht, der dabei den Betrachter ansieht, um ihn nachdrücklich auf seine Geste aufmerksam zu machen.

In Worten formuliert Meidner diese Auffassung zum Beispiel in einem Brief an die Freundin Rose Friedrich vom Juli 1918:

„Ich habe Angst vor der Zukunft, vor meiner eigenen und vor unser Aller Morgen. Was
wird noch werden? Eigentlich verdient die europäische Civilisation den Untergang, den
ein vierjähriger Krieg am Ende zeitigt. Aber Gott sollte noch einmal Nachsicht üben.
Die Menschbeit war auf falscher Bahn und der vierjährige Krieg schon würde ein furcht-
barer Denkzettel gewesen sein. Die Umkeehr und moralische Wiedergeburt würde auch so
unbedingt erfolgen. Aber wer weiß? Vielleicht sind wir noch nicht reif für den Frie-
den?!!"'93

Meidner legt dar, warum Gott Nachsicht üben und dem Krieg ein Ende bereiten sollte. Hieraus geht hervor, dass er glaubt, Gott habe den Krieg zur Züchtigung der Menschheit geschickt - als Strafe für ihre vorherigen Vergehen. Was ebenfalls mitschwingt, ist ein Gefühl großen Zweifelns an einer besseren Zukunft, denn er spricht von Angst und stellt die skeptische Frage, ob die Menschheit für den Frieden überhaupt schon reif sei. Die darin sich spiegelnde Niedergeschlagenheit lässt sich als düstere Stimmung auch in „Jüngster Tag“ finden. Zwar flehen die Menschen Gott um Hilfe an, doch ob er sie erhören wird oder ob tatsächlich das Ende der Zeit bevorsteht, da er über sie richten wird, ist durch keinerlei Hinweise ersichtlich. Kein Hoffnungsschimmer ist in diesem Bild zu sehen.

Der Glaube an den Krieg als göttliche Strafe, ${ }^{194}$ die Verschmelzung von Krieg und Apokalypse und die Frage nach einem besseren Morgen sind auch in dem Prosatext „Erinnerung an Dresden“ ${ }^{195}$ verarbeitet. Schon beim Thema „Stadt" wurde darauf hingewiesen, dass der politische Hintergrund des Textes der Ausbruch des Krieges war, den der Künstler in Dresden erlebte. Er ist 1917 verfasst

\footnotetext{
193 Brief von Ludwig Meidner an Rose Friedrich vom 7.7.1918. Bayerische Staatsbibliothek, München. Zitiert bei Thesing (1991), S. 103 f. Drei weitere Briefe sind bei Assmann (1991) auf S. $463 \mathrm{ff} . \mathrm{zu}$ finden.

194 S. Thesing (1991), S. 102.

195 Textnachweis, Text I.
} 
und 1918 separat das erste Mal veröffentlicht worden. ${ }^{196}$ Schaffenskrise, Kriegsausbruch und Freundesverlust werden darin thematisiert und abermals findet sich hier statt einer Vision die Wiedergabe einer realen Katastrophe, eines konkreten eigenen Erlebens. Der Text beschreibt zunächst die frohe Beschwingtheit der Freunde Meidner und Lotz, die die gemeinsame Zeit genießen, Dresden erkunden und inspiriert ihr Arbeiten vorantreiben. Wie auch Becker feststellt, wird allerdings schon gleich zu Beginn ein Dämon eingeführt, der in der Straße lauert, in der sie wohnen. ${ }^{197}$ Das Gefühl einer Bedrohung wird schleichend in die folgenden Textabschnitte eingestreut, beispielsweise durch das Todesmal, das Meidner auf der Stirn seines Freundes wahrzunehmen meint. Obwohl in dem Text generell eine Steigerung des Geschehens angelegt ist, beinhaltet er auch wiederkehrende schnelle Wechsel von Emotionsbeschreibungen. Daraus entsteht der Eindruck, der Künstler unterliege vielfachen Gefühlsschwankungen - eine für Meidners expressionistische Prosa typische Eigenart, die Expressivität und Spontaneität vermittelt. Bald laufen die Freunde schwelgend durch die Stadt, dann quält den Maler eine Ahnung, bald zerstört Meidner aus Zorn seine Bilder, dann gibt es wieder Momente tief empfundener Freundschaft. Man sollte diese Emotionswechsel aber vermutlich nicht nur als künstlerisches Mittel begreifen, sondern ebenso als tatsächliche Brüche in Meidners Stimmung, die für sein Wesen und letztendlich damit auch für sein Werk bestimmend sind.

Das „Finale furioso“ in „Erinnerung an Dresden“ ist dann schließlich das Aufspringen des Dämons - der Ausbruch des Krieges und der Verlust Lotzens sind die Folgen:

„Aber Gott der Herr fand, dass die Zeit reif war. Er bedeckte sein unerforschliches Angesicht und holte gewaltig aus in seinem Zorn. Und aus den Schlünden der Erde stiegen entsetəliche Unholde, setzten sich in alle Hirne breit hin...und der Dämon der Bautzener Straße sprang auf, wuchs riesengroß über den Kontinent. Da tat die Stadt Dresden hunderttausend Mäuler auf zu Lästerung und grenzenlosem Hohn. Sie schäumte auf und das Gift stieg bis an die Dächer. Und sie entblößten ibre Scham, und ibre geheimen Schwären zeigten sie unter dem offenen Himmel. Und in ibrem Wabn logen sie die Zuchtrute zu einer Festfreude um und priesen den einzigen Tag, und ibre heiseren Gesänge verdunkelten das Firmament. Ach, ach, ach! Wir wissen alle noch, wie jene Tage uns gegeißelt haben, und es war hier wie dort das Gleiche. - Viele Wochen lag ich brach wie ein Klumpen heißer, schmerzenreicher Erde. Da im Beginn des Herbstes, als meine Hand vermeinte, wieder in die Weite langen zu können, kam mir die Kunde von des Freundes frühem Tod. (...) Tagaus, tagein noch wehrte ich mich gegen das große Gericht und geiferte über Gottes heilige Hand. Und Jahre vergingen, ehe ich zum Sinn des Un-

\footnotetext{
196 Becker (1991), S. 67.

197 Becker (1991), S. 68. Es ist ihm wohl zuzustimmen, dass Meidner das Motiv des Dämons von Heym übernommen haben wird.
} 
wetters gelangte: denn es muß viel Trübsal, Verzweiflung und leibliche Not in die Welt kommen, auf dass ein besserer Morgen tage."

Es ist der Dämon, der das Unheil bringt - Becker hat nicht Unrecht dieses Motiv als Anlehnung an Heyms Gedichte zu werten -, aber es ist Gott, der ihn freigesetzt haben muss, wie aus dem zuerst zitierten Satz offenbar wird. Dresden erscheint dadurch wie ein von der Apokalypse heimgesuchter biblischer Ort, erinnert gar an die „Hure Babylon“ - eine in der Johannes-Offenbarung beschriebene, prächtige, aber sündhafte und daher von Dämonen bewohnte Stadt. ${ }^{198}$ Auch der biblisch anmutende Sprachduktus unterstreicht diesen Eindruck und erzielt dabei eine gewisse Dramatik. ${ }^{199}$ Anklagend deutet Meidner das stupide Verhalten der Kriegsbegeisterten an, die anscheinend besessen sind und ,in ibrem $W a b n$ " „die Zuchtrute zu einer Festfreude“ „logen“. Metaphorisch sind es „entsetzliche Unbolde“, die „sich in alle Hirne breit" hinsetzen - diese „Besessenheit" im wahrsten Sinne des Wortes verursacht den Krieg. Der Glauben an Gottes Einfluss wird auch gegen Ende des Absatzes wieder aufgenommen, wenn Meidner sich ,gegen das große Gericht" zur Wehr setzte und „über Gottes heilige Hand" „geiferte".

Hier wie in ,Jüngster Tag“" werden Krieg und Apokalypse miteinander verschmolzen und sowohl im Bild, als auch im Text ist Gott der Richter - wenn auch im letzteren offensichtlicher. Leicht variiert aber wird hier im letzten Satz die Zukunft gezeichnet: „(...) es muß viel Trübsal, Verzweiflung und leibliche Not in die Welt kommen, auf dass ein besserer Morgen tage. "Im übertragenen Sinne heißt dies, dass der Krieg und seine Folgen auf dem Weg zu einer besseren Welt vonnöten sind. Die Option eines Neuanfangs ist somit eröffnet. Mit dieser Idee nimmt Meidner allerdings sehr spät - doch noch den Gedanken auf, den schon die kriegseuphorischen Expressionisten einige Jahre zuvor geäußert haben.

\section{Ergebnis}

Es wurden nun verschiedene Facetten in Meidners Kriegsdarstellungen beleuchtet. Dabei ist deutlich geworden, dass dieses Thema ihn stark beschäftigt und zu unterschiedlichen Schwerpunkten geführt hat. In Abhängigkeit von seiner Biografie werden die Motive mit der Zeit konkreter. Texte und Bilder transportieren trotz zeitlicher Differenz in ihrer Entstehung weitestgehend gleiche Inhalte und Intentionen. Es bleibt dabei festzuhalten, dass dominierend eine ablehnende Haltung dem Krieg gegenüber zum Ausdruck gebracht wird. 200 Thesings Deutung der Bilder als Zeugnisse eines ambivalenten Verhältnisses zum Krieg, die die Darstellung wirklichen Leids vermissen lassen, 201 ist so nicht zustimmen. Es sind durchaus auch rein leidvolle Bilder wie z. B. „Schlachtfeld“ zu finden. Es muss berück-

\footnotetext{
198 Vgl. insbesondere Offenbarung des Johannes, 17,1-18 und 18,1-8.

199 Becker (1991), S. 68.

200 So auch bei Grochowiak (1966), S. 102.

201 Thesing (1991), S. 102.
} 
sichtigt werden, dass Meidner selbst zumindest bis zu seiner Einberufung nicht mit den Kämpfen in Kontakt gekommen ist und der Eindruck des Grotesken daher auch von der Fiktivität des Dargestellten herrühren dürfte. Gerade auch die Auffassung vom Krieg als göttlicher Strafe belegt Meidners kritische Haltung gegenüber dem Kriegsgeschehen.

Diese Auffassung kommt in erster Linie und eindeutiger als in den Bildern in Meidners zitierten expressionistischen Texten zum Ausdruck. Überhaupt ist der Glaube an Gottes schicksalhaftes Wirken in der Welt in vielen dieser Texte verarbeitet. Hoffnung auf Erlösung beziehungsweise einen positiven Ausgang ist in den meisten Kriegsdarstellungen, gleich ob schriftlicher oder bildlicher Art, nicht zu finden. Erst in „Erinnerung an Dresden“, als der Krieg weit fortgeschritten ist, deutet er die Möglichkeit einer dadurch zu erreichenden besseren Welt an. Wenn Meidner demnach auch, ähnlich wie seine Zeitgenossen, an die Notwendigkeit einer Erneuerung glaubte, sind es doch immer Angst und Leid, die überwiegen. So spiegelt sich in den Bildern Meidners Auffassung, dass der Krieg nicht der richtige Weg zu dieser angestrebten Erneuerung sein kann oder wenigstens, dass er sehr schreckenerregend auf ihn wirkte.

Bemerkenswert ist bei den herangezogenen Beispielen die Entwicklung des Stils. Meidner beginnt mit eher ruhigen Kompositionen zu diesem Thema um 1911/12, steigert sich zu sehr expressiven Bildern, in denen insbesondere durch eine Formzersplitterung Dynamik erzeugt wird und kehrt zurück zu beruhigteren Darstellungen, in denen er das Explosive zurücknimmt.

\subsubsection{4. (Geistige) Revolution - der Wunsch nach Veränderung}

Trotz seiner pazifistischen Tendenzen hat sich Ludwig Meidner dem Gedankengut der erneuerungsemphatischen, expressionistischen Strömungen nicht gänzlich verschlossen. Hätte er dies tun wollen, hätte er nicht so häufig die Apokalypse thematisiert, die nach allgemeiner Auffassung die Welt für eine neue Zukunft reinigt. Nur war er offensichtlich eher Pessimist - seine Ängste und Zweifel überwogen. Seine Auseinandersetzung mit den geforderten politischen Umwälzungen ist ebenfalls deutliches Kennzeichen für die damit verbundene Auseinandersetzung mit zukunftsgestaltenden Ideen. Dies manifestiert sich in seinen Bildern und Schriften, die sich dem Thema der Revolution widmen.

\section{Zuordnung}

Diesen Themenbereich hat Meidner bildkünstlerisch nicht so umfassend behandelt wie beispielsweise die Kriegs- oder Apokalypsedarstellungen. Es gibt aber einige vom Wunsch nach Veränderung getragene gesellschaftskritische Grafiken, die als Illustrationen zu politischen Zeitschriften und Texten zeitgenössischer 
Dichter dienen. Als einziges unter den Gemälden ist „Barrikade“ zu nennen. Schriftlich hat sich Meidner zu seinen Vorstellungen von einer neu aufzubauenden Gesellschaft erst nach dem Krieg konkreter geäußert. Seine Aufrufe „An alle Künstler, Dichter, Musiker“ und „Bruder, zünd’ die Fackel an“ sowie seine Vorschläge zu einem neuen Kunstprogramm an den Arbeitsrat für Kunst sind grundsätzlich von der Idee der Menschheitsverbrüderung getragen, die zu dieser Zeit so vielen Expressionisten ein Anliegen war.

\section{Vor dem Krieg}

„Bereits vor dem Krieg bekundet Meidner ein starkes Solidaritätsgefübl mit dem ,vierten Stand: “202 Die Zeichnung „Das schwarze Revier“ (Abb. 22), welche als Illustration zu einem so genannten „Lyrische[n] Flugblatt“ fungiert und Gedichte von Paul Zech (1881-1946) ergänzt, ist 1913 entstanden. ${ }^{203}$ Vor einer Bergwerkslandschaft mit Fördertürmen und rauchenden Schloten steht dichtgedrängt eine Gruppe von Zechenarbeitern in geschwärzten Kitteln. Ihre Gesichter wirken alt und müde, sorgenzerfurcht und ausgemergelt. Ihr ausdrucksloser Blick unterstreicht die Tristesse der Szene. So vor die Industriearchitektur gesetzt, scheint es, als würden sie von ihr erdrückt und gleichzeitig als seien sie selbst ein Teil in jenem Getriebe. Auffällig ist hier, dass Meidner entgegen seiner sonstigen Eigenart um 1913 ,auf jedwedes Zersprengen architektonischer Bestandteile oder auf jedwede Auflösung der Bildordnung '204 verzichtet. Der Ausdruck der Bedrängnis ist in dieser Komposition sein Ziel.

Die Zeichnung zeigt, dass sich Meidner spätestens zu diesem Zeitpunkt mit der sozialen Frage auseinander setzte. Die Kritik, die die Darstellung an den Verhältnissen und Lebensumständen der Arbeiterklasse übt, entspricht der Intention der Zech-Gedichte, die dem „Lyrische[n] Flugblatt“ beigegeben sind. Das Elend der europäischen Kohlenreviere schildernd, ist daraus Zechs Wunsch nach einer Veränderung dieser Missverhältnisse abzulesen. Armut und Ausbeutung werden thematisiert. Leistner hält jedoch fest, dass die Zeichnung Meidners mehr Anklage enthalte als Zechs Gedichte. ${ }^{205}$ Meidner klagt die Verhältnisse an, aber zeigt er auch Lösungen auf? Das mit Öl auf die Rückseite der „Apokalyptischen Landschaft" der Berliner Nationalgalerie gemalte Bild „Barrikade“ (Abb. 23) von 1912 erweckt auf den ersten Blick den Anschein. In Anlehnung an „Die Freiheit führt das Volk“ (Abb. 24) von Eugène Delacroix (1798-1863) ist eine revolutionsartige Szene gezeigt. Ein Gewirr von Menschen agiert zwischen Trümmern vor einem Hintergrund, der durch Häuserfronten und Fenster Urbanität andeutet. Rechts, auf der Höhe des Goldenen Schnitts, wird der Vordergrund von einem einzelnen Mann dominiert. Mit einem Kopfverband, eine rote Schärpe quer über der Brust,

\footnotetext{
202 Leistner (1986), S. 170.

203 Leistner (1986), S. 171.

204 Leistner (1986), S. 171.

205 Leistner (1986), S. 171.
} 
stürmt er mit einer Stange, die wohl als Halterung einer Fahne fungiert, welche durch einen roten, über seinem Kopf wehenden Stoffzipfel angedeutet ist, nach vorne rechts. Seine Beine werden allerdings vom Bildrand überschnitten. Er ist mit einem schwarzen Mantel bekleidet und hat seinen Kopf seitlich über die Schulter gewandt. Sein weit geöffneter Mund, die verkniffene Mimik der zusammengezogenen Augenbrauen und die Zornesfalte an seiner Nasenwurzel lassen einen wütenden Ausruf vermuten. Die Farbe seines Gesichts und seiner beiden die Stange umklammernden Hände ist aschgrau.

In dem Gewirr von vagen Formen, die Schüsse, Rauch und Chaos andeuten, sind einzelne Figuren auszumachen. Zum Teil sind sie nur schemenartig erkennbar, wie die schattenhaften Personen, die rechts oben durch ein Fenster einem brennenden Haus zu entfliehen versuchen, und Einzelpersonen, die zu ihnen hinaufschauen. Manche sind aber auch deutlicher zu sehen, wie Gesicht und Oberkörper eines Mannes rechts neben dem Anführer, der hinter den zur Barrikade aufgeschichteten Trümmern steht. Links im Bild scheint ein Schusswechsel stattzufinden. Ein schwarzbekleideter Mann steht dort mit erhobenen Händen. Sein zurückgeworfener Kopf und rote Fontänen auf gleicher Höhe zeigen an, dass er von einer Kugel getroffen wurde. Rechts unterhalb von ihm ist ein anderer Mann mit einem angelegten Gewehr zu erkennen. Am linken unteren Bildrand sind zwei angeschnittene Köpfe abgebildet. Vom linken ist nur eine blutige Stirn $\mathrm{zu}$ sehen. Der andere ist nach rechts gewandt, jedoch blicken seine geweiteten Augen zurück.

Den Vordergrund beziehungsweise die untere Bildhälfte dominieren Schwarzgrau und unreines Weiß. Nur wenig Rot und das Braun der Fahnenstange fließen zusätzlich mit ein. Der Hintergrund ist hauptsächlich bläulich und weiß gehalten. Beinahe wie eine Trennlinie zwischen Vorder- und Hintergrund fungieren rote Farbflächen und -linien, die für Feuer und Blut stehen und sich in Schärpe und Fahne des Anführers wiederfinden. Nur in den brennenden Häusern lässt sich auch Orange erkennen.

Die Formen richten sich kaum nach geometrischen Mustern. Gerade und gerundete Linien an Häusern oder Personen, die ruhiger wirken, werden von fächerartig aufgetragener Farbe und einzelnen Farbtupfern oder aggressiv geschlängelten Linien verdrängt oder überlagert. Der expressive Farbauftrag vermittelt assoziativ Geräusche von berstendem Holz, klirrendem Glas und lässt Chaos und Panik spürbar werden. Wenn auch teilweise prismatisch anmutend, so fallen doch vor allem die fächerartigen Farbflächen, die wie Fontänen oder Lichtstrahlen kraftvoll von einem Punkt weg expandieren und die wolkigen Gebilde ins Auge. Die Komposition ist bestimmt durch die Veranschaulichung von „Tumult“ und mittendrin befindet sich der Anführer, in dessen rechter Schulter sich die beiden Diagonalen kreuzen.

Licht und Schatten werden nicht konsequent im Bild verteilt. Zwar erwecken die Lichtflecken in den Gesichtern der im Vordergrund befindlichen Figuren den 
Eindruck, als komme das Licht von links, jedoch wird dies im Hintergrund nicht eindeutig wieder aufgenommen. Stofflichkeiten sind nur angedeutet, wie beispielsweise die Textilien durch ihren Faltenwurf; es dominiert eine expressive Faktur.

Zusammenfassend lässt sich sagen, dass in „Barrikade“ eine tumultartige Szene gegeben ist, die keinem konkreten Ort oder Ereignis zuzuordnen ist. Der Kampf wirkt hoffnungslos, brutal und chaotisch. Dem Anführer folgt niemand, vielleicht ist auch niemand mehr im Stande dazu. Jeder scheint um sein eigenes Leben besorgt und mehr mit Verteidigung als mit Angriff beschäftigt. Statt Euphorie und Mut ist in Meidners Gesichtern nur Wut und Verzweiflung zu lesen. Es handelt sich mehr um eine Flucht als um tatkräftiges Voranstürmen. Die Zentralfigur steht nicht für Sieg, sondern für Leid. ${ }^{206}$ Das rot-weiß-blaue Kolorit und das Thema verweisen auf das französische Vorbild Delacroix. Meidner wird sein Gemälde „Die Freiheit führt das Volk an“ ganz sicher während seines ParisAufenthaltes im Louvre gesehen und bei Anfertigung des eigenen nur wenige Jahre später vor Augen gehabt haben. Parallelen sind in Thema, Bildaufbau und Kolorit gegeben. Jedoch differieren die Aussagen der beiden Gemälde erheblich: während die Ausführung bei Delacroix mitreißend, glorifizierend und von Hoffnung auf Erfolg geprägt ist, ist bei Meidners „Barrikade“ die Hoffnungslosigkeit spürbar. Die jeweilige Stimmung wird auch durch die Komposition unterstrichen: bei Delacroix bewirkt die Dreiecksanordnung eine statuarische, beinahe monumentale Wirkung - dagegen vermittelt die chaotische Szene bei Meidner den Eindruck einer unkontrollierbaren Zerstörung. Der entscheidende Unterschied ist die zeitliche Verortung. „Die Freiheit führt das Volk an“ nimmt durch die getreue Darstellung von Kleidung und Waffen Bezug auf ein konkretes historisches Ereignis: die Aufstände vom 18. Juli 1830 in Paris gegen die Erlasse König Karls X. (1757-1836). ${ }^{207}$ Meidner hat dagegen ein Revolutionsbild geschaffen, das zeitlich und örtlich unabhängig ist und daher als grundsätzliche Stellungnahme verstanden werden kann. ${ }^{208}$

Das mutmaßliche Selbstporträt Meidners in dem überschnittenen Gesicht links unten bleibt in seinem Ausdruck unbestimmt. Die Augen auf den Schusswechsel hinter ihm gerichtet, klingt darin ein gewisser Zweifel an Sinn und Zweck einer Revolution an. Das Bild ist demnach nicht als „Propaganda“ für gewaltsame Umstürze zu verstehen. Wie auch in den Kriegsszenen und Apokalyptischen Landschaften ist Angst das Leitmotiv. Meidner beschränkt sich abermals auf die Anklage beziehungsweise auf die Verdeutlichung der Notwendigkeit eine Veränderung herbeizuführen, ohne dafür aber eine konkrete Lösung anzubieten. Mehr noch: er stellt den damals vielfach herbeigesehnten Umschwung durch eine Revo-

\footnotetext{
206 Vgl. auch Zitat bei Grochowiak (1966), S. 73.

207 Sérullaz/Pomarède (2004), S. 11 f.

208 Vgl. Eliel (1990), S. 31.
} 
lution als Lösung in Frage, wodurch der Eindruck entsteht, seine persönliche Lösungssuche stagniere - als wisse er selbst keinen Ausweg.

\section{Nach dem Krieg}

Interessanterweise wandelt sich diese offensichtlich ängstliche Ratlosigkeit und schlägt nach dem Krieg für kurze Zeit in politisches Interesse um. Wie bereits in der Einführung über den Expressionismus in Kapitel 2.2. erläutert, gab es nach dem Krieg eine Welle der Politisierung von Kunst und anderer Medien, beziehungsweise eine intellektuelle Bewegung, die den Anspruch erhob an der Neugestaltung von Staat und Gesellschaft mitzuwirken. Meidner schloss sich dieser Bewegung an, kandidierte für den Arbeitsrat für Kunst, nahm an einer von der Novembergruppe initiierten Ausstellung teil und schrieb einige Pamphlete, in denen er seine Vorstellungen von Kunst und Politik äußerte. ${ }^{209}$ Diese Facette seines Werks offenbart die Kunst als Agitationsmittel.

In seinem Aufruf „An alle Künstler, Dichter, Musiker“210 spricht sich Meidner sehr deutlich für den Sozialismus aus. Grundtenor ist hier die Betonung der Verantwortung der geistigen Elite für dessen angemessene Umsetzung. Als Hauptanliegen wird die Unterstützung der Arbeiter durch die Künstler gegen die bourgeoisen Ausbeuter formuliert:

„Damit wir uns nicht mehr vor dem Firmament zu schämen haben, müssen wir uns endlich aufmachen und mithelfen, dass eine gerechte Ordnung in Staat und Gesellschaft eingesetzt werde. Wir Künstler und Dichter müssen da in erster Reibe mittun. Es darf keine Ausbeuter und Ausgebeuteten mehr geben! Es darf nicht länger sein, dass eine gewaltige Mehrheit in den kümmerlichsten, unwürdigsten und entehrendsten Verhältnissen leben muß, während eine winzige Minderheit am übervollen Tisch vertiert. Wir müssen uns zum Sozialismus entscheiden: zu einer allgemeinen und unaufhaltsamen Vergesellschaftung der Produktionsmittel, die jedem Menschen Arbeit, Muße, Brot, ein Heim und die Ahnung eines höheren Zieles gibt. Der Sozialismus soll unser neues Glaubensbekenntnis sein!"

Die Ausdrucksweise ist hier im Gegensatz zu den bisher untersuchten Texten nicht hymnisch und emotional, sondern engagiert und fordernd: müssen, sollen und „es darf nicht", beziehungsweise „es darf keine "sind sehr bestimmte Verben und Verbkonstellationen. Bei der inhaltlichen Betrachtung dieses Einstiegs werden zwei Aspekte deutlich: zum einen ist es Meidners Anspruch vor allem Gerechtigkeit zu schaffen, um ein ausgewogenes gesellschaftliches Gleichgewicht herzustellen, und zum anderen scheint Meidner zu dieser Utopie religiös motiviert zu sein, denn er fordert diese Wandlung, um sich ,vor dem Firmament" nicht „schämen“ zu müssen - dies ist ein Hinweis auf einen göttlichen Beobachter. Merkwürdig mutet

\footnotetext{
${ }^{209}$ Leistner (1986), S. 169 f.

210 Textnachweis, Text XI.
} 
denn auch der hier zuletzt zitierte Satz an. Was hat denn der Sozialismus mit einem Glaubensbekenntnis zu tun? Diese Frage beantworten am Besten die letzten beiden Sätze des Manifests:

„Mit Leib und Seele, mit unseren Händen müssen wir endlich mittun. Denn es geht um den Sozialismus - das heißt: um Gerechtigkeit, Freibeit und Menschenliebe - um Gottes Ordnung in der Welt!"

Der Sozialismus ist also in Meidners Augen ein System, das auf religiösen Grundwerten basiert. ${ }^{211}$ Leistner hat darauf hingewiesen, dass Meidner die politischen Begrifflichkeiten wenig differenziert, was die Unausgereiftheit seines politischen Verständnisses bezeugt, und dass die Verschmelzung von religiösen und sozialistischen Ideen ein Gedanke ist, den der Künstler bei Tolstoi finden konnte. ${ }^{212}$ Religiöse Verknüpfungen tauchen im Text immer wieder auf:

„Wir sind leicht und wissend und müssen wie Führer-Fabnen vor unsern schweren Brüdern wehen. Maler, Dichter...wer sonst sollte für die gerechte Sache kämpfen als wir? In uns pocht noch mächtig das Weltgewissen. Die Stimme Gottes in uns facht immer von Neuem unsere Empörerfäuste an. "

In diesen Worten steckt zugleich die alte Vorstellung vom göttlich inspirierten Künstler, die Meidner zu der fragwürdigen Überzeugung bringt, dass die Verbindung zu Gott den Künstler auch in dieser politischen Frage zum richtigen Handeln führe und autorisiere. Welches Handeln fordert Meidner denn aber in diesem Aufruf überhaupt? Ausgehend von der Polarisierung ,guter Arbeiter" versus „schlechtem Bourgeois“ ist es die Bekämpfung des letzteren, die er für notwendig erachtet:

„Maler, Dichter! Scharen wir uns mit unseren eingeschüchterten, wehrlosen Brüdern um den Geist! Der Arbeiter achtet den Geist. Er bemüht sich mit kräftigem Eifer um Erkenntnis und Wissenschaft. Der Bourgeois ist ehrfurchtslos. Er liebt nur Spielerei und ästhetisch verbrämte Stupidität und haßt und fürchtet den Geist - denn er füblt, dass er von ihm entlarvt werden könnte. Der Bourgeois kennt nur eine Freibeit, seine eigene d. h. die Anderen ausbeuten zu können. Das ist der bleiche Terror, der geht schweigend um und Millionen sinken hin und verwelken früh. Der Bourgeois kennt keine Liebe nur Ausnutzung und Übervorteilung. Auf, auf, zum Kampf gegen das hässliche Raubtier, den beutelïsternen, tausendköpfigen Kaiser von morgen, den Gottesleugner und Anti-Christ!"

\footnotetext{
${ }^{211}$ Leistner spricht sogar davon, dass Meidner Sozialismus und christliche Werte verschmelzen wollte (Leistner (1986), S. 170), was allerdings aufgrund von Meidners jüdischem Glauben - der sich spätestens ab 1915 in religiösen Kompositionen sehr deutlich manifestiert (s. Kapitel 3.1.3.5.) - unbedingt in Frage zu stellen ist. Da der Künstler aber zum Beispiel auch über den „AntiChrist" schreibt, vermischen sich hier mutmaßlich einige religiöse Vorstellungen und er könnte somit insgesamt einen Gott jenseits einzelner Religionen gemeint haben.

${ }^{212}$ Leistner (1986), S. 170.
} 
Reißerisch und hetzerisch zeichnet er dabei das Bild des Bürgerlichen: „hässliche [s] Raubtier", „beutelüstern“, „Gottesleugner und Anti-Christ". Er wird zum Bestandteil einer ,vertierten Gesellschaft ${ }^{` 213}$ stilisiert. Auch ist hier wieder der religiöse Bezug hergestellt - wer nicht sozialistisch denkt, verinnerlicht nicht die dem Christentum vergleichbaren Werte, bezeichnet also den „Anti-Christ“. Dies ist eine durchaus radikale Einstellung.

Nun beinhaltet dies alles aber keine konkreten Forderungen; in dem Text ergeht sich Meidner überwiegend in allgemeinen Ausführungen ohne präzise Zielsetzungen. Es gibt nur eine Passage, die drei Punkte formuliert, deren Erfüllung er von seinen kunstsinnigen Mitstreitern erwartet:

„Wir wollen keinen blutbefleckten Lohn mehr. Wollen frei sein, zu unsrer und der Menschheit Lust uns hinströmen. Kameraden höret weiter: wir müssen wahre Sozialisten sein - die höchste sozialistische Tugend in uns entfachen: Menschenbrüderlichkeit. Das heißt: Güte, Freundlichkeit füreinander und Einsicht in das, was uns allen nottut. Höret weiter: Wir müssen Ernst machen mit unserer Gesinnung, dem neuen, wundersamen Glauben. Wir müssen uns der Arbeiterpartei anschließen, der entschiedenen, unzweideutigen Partei. “

Mit anderen Worten: der Künstler soll sich aus der Abhängigkeit vom Geld und Wohlwollen des reichen Bürgertums befreien, da dieser es durch Ausbeutung der Arbeiter erlangt hat. Wie die Künstler aber ihren Lebensunterhalt verdienen und ihr Überleben sichern sollen, darüber schweigt Meidner. Die anderen zwei Forderungen sind da etwas einfacher zu handhaben: zum einen die sozialistischen, beziehungsweise gleichzeitig ja auch religiösen Werte zu verinnerlichen und zum anderen den Anschluss an die Arbeiterpartei zu suchen, um diese Werte auch nach außen zu tragen.

Insgesamt erscheinen Meidners Ausführungen hier etwas widersprüchlich: bald sagt er dem Bürgertum mit durchaus aggressivem Vokabular den Kampf an, bald spricht er davon, dass es am Wichtigsten sei „Güte, Freundlichkeit füreinander und Einsicht in das, was uns allen nottut", walten zu lassen. Zwei unvereinbare Gegensätze, die er hier auch nicht auflöst. Wieder strebt er Veränderung an, ohne über Worthülsen hinaus zu kommen.

Ähnlich verhält es sich mit dem Titelbild zu dem Gedicht „Ewig im Aufruhr“ (Abb. 25) von Johannes R. Becher (1891-1958), das als propagandistisches Flugblatt 1920 herausgegeben wurde. Bechers Verse sind in hetzerischem Tonfall an das Volk gerichtet und lassen einen geistigen Führer vom Untergang der Ungerechten sprechen. ${ }^{214}$ Die Zeichnung selbst stammt von 1919, wie aus der Datierung links unten ersichtlich ist, und bezieht sich nur insoweit auf das Gedicht, als es dessen Stimmung widerspiegelt. Über einem in Aufsicht gezeigten Gewirr von Gesichtern erscheint in der rechten oberen Bildecke maskenhaft und überdimen-

${ }^{213}$ Leistner (1986), S. 170.

${ }^{214}$ Becher (1971), S. 52 f. 
sioniert der Kopf eines Rädelsführers, dessen Wortschwall durch einen ihm aus dem Mund fliegenden Schwarm von Fledermäusen verbildlicht wird. Mit weit aufgeblasenen Backen erinnert er an die personifizierten Darstellungen der Winde in der älteren Kunst. Mit seiner rechten Hand gestikulierend unterstreicht er seine Rede. Er scheint über den Köpfen der Menge zu schweben - eine Bühne ist nicht vorhanden oder ist als vom Bildrand überschnitten zu denken. Die in der Nähe einiger Häuser stehenden Zuhörer wirken ähnlich grotesk mit fast lächerlich verformten Gesichtern, aufgerissenen Augen, die hoffnungsvoll zu dem Redner aufschauen, und vielen kampfbereit emporgereckten Händen.

Mit schnellen Strichen und einer Aufruhr vermittelnden Unübersichtlichkeit hat Meidner hier eine vom Revolutionsgeist getragene Situation skizziert. Jedoch wird nicht richtig ersichtlich, welche Intention dahinter steckt. So nimmt die Zeichnung die Stimmung des Titels auf: Unruhe, Aufruhr, nicht nachlassendes Revoltieren. Es erscheint allerdings merkwürdig, dass der Rädelsführer wie ein unsteter Luftgeist in der Ecke schwebt und dass seine Worte ausgerechnet in Form von Fledermäusen verbildlicht werden, die zumeist eher negativ konnotiert sind. ${ }^{215}$ Auch die grotesken menschlichen Erscheinungen der Anhänger wirken eher so, als würden sie stupide und aufgebracht einem willkürlich erwählten Anführer folgen. Möglicherweise spiegelt sich in dieser Ambivalenz ein innerer Gegensatz zwischen Meidners eigener kämpferischer Hoffnung und den leisen Zweifeln am Erfolg der gesellschaftlichen Umstrukturierung. Das Scheitern der sozialistischen Idee und damit auch der expressionistischen Bewegung kündigte sich um 1920 bereits an und Meidner war einer der ersten, der die Vergeblichkeit der utopischen Programme erkannte. ${ }^{216}$ Unabhängig davon, welche Auffassung diese Titelzeichnung nun transportiert, ist auch aus ihr keine Lösung erkennbar, sondern nur der Wille zur Veränderung manifest.

Der Aufruf „Bruder zünd’ die Fackel an“217, den der Künstler 1919 nach der Ermordung Karl Liebknechts und Rosa Luxemburgs verfasst hat, mag vielleicht noch einmal verdeutlichen, wieso Meidner in seinem Aktivismus so unbestimmt bleibt. In der Tat scheint er fest daran zu glauben, dass Gott alles richten werde. Wenn auch die Menschen durch Befolgung der christlichen Gebote den Weg zum Sozialismus beschreiten sollen, so ist es doch vor allem Gott, der, auf welche Weise auch immer, die Welt zum Guten führen wird. Zunächst ruft er seine geistigen Brüder an: ,, $-Z u$ den Waffen! $Z u$ den Menschbeitswaffen! Liebe und Fanatismus heißen sie! Geist sei unser Pulver. Begeisterung unsere Lebne und Freibeit das Ziel."

\footnotetext{
${ }^{215}$ Henkel/Schöne (1967), Sp. 899 - 902. In Spalte 901 wird die Fledermaus sogar im Zusammenhang mit frevelhaften Worten genannt, allerdings ist nicht klar, ob das auf Meidners Zeichnung zu beziehen ist.

216 Leistner (1986), S. $173 \mathrm{ff}$.

217 Textnachweis, Text XII.
} 
Hier kommt einmal mehr die angestrebte Gewaltlosigkeit des Kampfes zum Ausdruck. Positive Gefühle, die abermals die Menschheitsverbrüderung implizieren und der Verstand - der Intellekt - sollen geeignet sein, die Welt vom Sozialismus zu überzeugen, denn:

„Ich weiß, ich hab' es erlebt als Soldat: wir sind alle gleich! (...) In uns allen rubt das Edle verborgen, und Sehnsucht zutiefst in unser aller Brust. Man muß euch nur richtig anzufassen verstehen, um die Schätze ans Licht zu fördern."

So ist es eigentlich nur der Weg der Liebe und Erkenntnis, den die Menschen nach Meidners Meinung beschreiten und weitervermitteln müssen, damit sich das Gute in allen Menschen herauskristallisiert. Und es ist Gottes Wille, dass dies geschieht:

„Doch höret: Gerechtigkeit regiert die Welt. Noch seht ihrs nicht, Gott ist euch fern. Ihr glaubet nur fest an den blauen Kassenschein, und zur Beschönigung habt ibr eine buntbemalte Kulisse vor eure gemästeten Bäuche bingestellt, die nennt ibr frech ,Kultur' und lügt die großen Dichter und Propheten in eure Wortemacher um. - Noch sebt ibr ihn nicht. Dennoch: Gott lebt. Ich hab' ibn gesehen. Er schickt einen besseren Tag hinauf, den sozialistischen Tag."

Mit diesen an das Bürgertum gerichteten Worten stellt er sich gegen den von den Expressionisten lange Zeit hoch verehrten Nietzsche und sein Postulat „dass Gott todt ist!' 218 .

\section{Ergebnis}

Es ist nicht von der Hand zu weisen, dass sich Meidner nach dem Krieg den politisch engagierten, aktivistischen Strömungen für einige Zeit angeschlossen hat und dass er in dieser Phase seine Umbruchswünsche auch in seinen Bildern und Texten zum Ausdruck gebracht hat. Herauszustellen bleibt dabei aber das konstante Festhalten an seiner pazifistischen Überzeugung. Weder vor noch nach dem Krieg ist seinen Werken eine andere Intention zu entnehmen als die des gewaltlosen Umschwungs. Insbesondere in seinen nach dem Krieg entstandenen Schriften ist eine stark zunehmende Religiosität zu bemerken, die in gravierendem Maße seine politische Überzeugung prägt und die bald, gerade nach den Frustrationen der gescheiterten Revolutionierung, sein gesamtes Werk beherrschen wird.

Abschließend kann man von den bislang behandelten Themenbereichen, die wie gesagt vielfach unter dem Begriff der „Apokalyptischen Landschaften“ subsumiert werden, noch einmal einen Bogen zurück zu der in Kapitel 3.1.3.2. wiedergegebenen Behauptung Vondungs schlagen. Dieser hatte konstatiert, dass in der Literatur die Apokalypse zunächst aus Begeisterung für die Gewalt verarbeitet wurde und später als Möglichkeit gewertet wurde einen Neuanfang zu initiieren

${ }^{218}$ Nietzsche (1925), S. 8. 
und die Gesellschaft im Sinne des Sozialismus zu erneuern. ${ }^{219}$ Bei Meidner ist das Gewaltsame sowohl in den Apokalypse-Darstellungen, wie auch in den Kriegsbildern negativ gemeint. Diese pazifistische Haltung ist auch in den Bildern und Schriften des Themenbereichs „Revolution“ zu finden und steigert sich hier insbesondere in seinen nach dem Krieg entstandenen Schriften. Was die Apokalypse als Weiche zur Veränderung anbelangt, so hat sich Meidner offenbar viel mit dem Gedanken beschäftigt - in den Katastrophenbildern wird der hoffnungsvolle Teil dieser Idee allerdings vernachlässigt und im Text nur vage angedeutet. Erst die revolutionär angehauchten Texte, die er verfasst, nachdem er sich von dem Alpdruck des Krieges erholt zu haben scheint, propagieren den hoffnungsvollen Neuanfang und bilden in ihrem Aktivismus einen Gegenpol zu den düsteren Apokalypsedarstellungen. Doch endet diese Phase innerhalb von zwei Jahren wieder. ${ }^{220}$ Somit steht Meidner den übergreifenden expressionistischen Idee nahe, beschreitet aber eigene Wege in Verarbeitung und Umsetzung.

\subsubsection{Religion - der rote Faden in Meidners Schaffen}

Religiöse Tendenzen spielen in Meidners Euvre eine eminent wichtige Rolle. Bald unterschwellig, bald dominant fließt seine Auseinandersetzung mit dem jüdischen und christlichen Glauben in seine Werke mit ein und ist, wenn auch nicht vordergründig thematisiert, sehr häufig präsent, wie es an besprochenen Beispielen aus anderen Themenkomplexen bereits deutlich geworden ist. Neben den versteckten Konnotationen in Apokalypse- und Kriegsdarstellungen, existiert eine große Zahl von Darstellungen mit explizit religiösen Motiven, die in Meidners Gesamtschaffen immensen Raum einnehmen. Interessanterweise ist es gerade seine frühexpressionistische Phase, die den direkten Niederschlag religiöser Vorstellungen am ehesten vermissen lässt. Sowohl das Frühwerk, als auch das gesamte Schaffen nach dem Krieg sind dagegen von religiösen Anschauungen geprägt.221 Wichtig für das richtige Verständnis der Werke ist die Tatsache, dass Meidners Glaube lange nicht eindeutig definiert ist, sondern verschiedene religiöse Tendenzen miteinander vermischt. Erst durch den Krieg scheint Meidner sich allmählich dem jüdischen Glauben zuzuwenden. Ganz explizit bekennt er sich dazu erst 1923 in „Eine Autobiografische Plauderei"“222 durch die Selbstbezeichnung als Israelit. ${ }^{223}$

\footnotetext{
219 Vondung (1994), S. $142 \mathrm{ff}$.

220 Schmid (1991), S. 92.

${ }^{221}$ Vgl. auch Ulmer (1991) und Heuberger/Riedel (2001).

222 Vgl. Text XV.

${ }^{223}$ Heuberger/Riedel (2001), S. 33 ff.
} 


\section{Zuordnung}

Innerhalb der zu betrachtenden expressionistischen Phase Meidners vollzieht sich eine Wende. Während der Künstler sich zu Beginn noch Darstellungen von Stadt und Stadtperipherie ohne jegliche Hinweise auf religiöse Bezüge zuwendet, zeugen vor allem die symbolisch behafteten Apokalypsen von der Auseinandersetzung insbesondere mit dem Alten Testament. „Der Jüngste Tag“ ist ein späteres Beispiel, in welchem Krieg, Untergang und Gott als Weltenrichter thematisch miteinander verschmolzen werden. Der Krieg als einschneidendes Ereignis scheint auch die anschließende neuerlich verstärkte Hinwendung Meidners zu religiösen Motiven zu bewirken. 1915/16 entstehen großformatige Tuschezeichnungen, die er mit „,50 Blätter religiöse Kompositionen“ betitelt. Diese zumeist keine konkreten biblischen Inhalte transportierenden Blätter zeigen überwiegend Einzelfiguren oder kleinere Personengruppen in Kutten gehüllt, die durch ihre gewundene Körperhaltung religiöse Ekstase vermitteln. Sie sind teilweise auch in der ebenfalls stark religiös geprägten expressionistischen Schrift „Im Nacken das Sternemeer“ als Illustrationen zu finden. Weiterhin behandeln die Skizzen aus den ab 1917 im Gefangenenlager Merzdorf entstehenden „Psalmenbücher[n]“ Motive des religiösen Bereichs und auch weitere, Büßer und Propheten darstellende Einzelblätter der nachfolgenden Jahre sind dem Thema Religion zuzuordnen.

\section{Erstes Suchen nach dem Glauben}

Meidners Suche nach einem eigenen Glauben vollzieht eine interessante Entwicklung und es erscheint daher unerlässlich, auch die vorexpressionistische Zeit kurz zu beleuchten. Schon im Alter von siebzehn bis neunzehn Jahren bringt er erste noch ungelenke Tuschezeichnungen zu Papier, die vor allem Mönche, Flagellanten, Asketen und Märtyrer zeigen (Abb. 26-28). Ulmer wertet in ihrem Aufsatz über Meidners religiöse Kompositionen die extreme Vorliebe Meidners für die Darstellung der Selbstgeißelung als Mittel zu Sündenvergebung und Erlösung überzeugend als Weg des jungen Künstlers eigene emotionale Zustände zu verarbeiten: „Neben der intellektuellen Auseinandersetzung mit der Religion und ihrer Geschichte sowie dem künstlerischen Interesse an Bewegungs- und Körperstudien spielt hier die Bewältigung beziehungsweise Sublimierung sexueller Obsessionen und der damit verbundenen Angst- und Schuldgefühlen eine nicht unwesentliche Rolle. "224 Heuberger und Riedel unterstreichen durch den Hinweis auf die in diesen frühen Bildern mehrfach verwendete Signatur „L.B. Meidner“, worin das „B“ für seinen jüdischen Vornamen „Baruch“ steht, dass Meidners spätere Beschäftigung mit Religion keine plötzliche Eingebung, sondern als Entwicklungsprozess schon angelegt war. ${ }^{225}$ Nach eigenen Aussagen Meidners waren es die Bekanntschaft eines Zimmernachbarn in Kattowitz, der ihn mit politischen,

224 Ulmer (1991), S. 108.

${ }^{225}$ Heuberger/Riedel (2001), S. 32 f. 
atheistischen Schriften in Berührung brachte, und der vehemente Atheismus seines Kattowitzer Schuldirektors, die ihn lange Zeit von weiteren religiösen Studien Abstand nehmen ließen.226

Das Schlüsselerlebnis, das ihn nach vielen Jahren wieder zur Auseinandersetzung mit der Religion zurückführt, ereignet sich am 4. Dezember 1912:

„Ganz plötzlich, während ich eines Abends malte, merkte ich, dass mir nichts gelang. Ich konnte nicht malen. Dann plötzlich gelang es mir in einem Maße, dass ich meinem eigenen Malen zuschaute. Mein Arm scbrieb von selbst, und ich war in böchstem Maße überrascht. Dann kam etwas über mich: Der Heilige Geist. Das Merkwürdige war: ich glaubte nicht an Gott. (...) Dies wiederbolte sich Abend für Abend, so dass ich schon darauf wartete. (...) Ich hatte zu Hause ein Neues Testament, das ich aber eigentlich immer nur aus antireligiösen Gründen benutzte. Plötzlich schlage ich einen Psalm auf und stelle fest: das babe ich ja erlebt; und in wenigen Sekunden wusste ich: das ist die Wabrbeit!'227

Vermutlich wollte Meidner sich mit dieser Aussage nur als göttliches Medium inszenieren. Möglicherweise hatte er dieses ekstatische, visionäre Erlebnis - oder ein ähnlich einflussnehmendes - tatsächlich. Tatsache ist jedenfalls, dass sich schon bald Veränderungen in seinem Werk zeigten. Er war zur Lektüre weiterer philosophischer und religiöser Schriften angeregt.228 Diese mögen ihn dann in den folgenden Apokalypse-Darstellungen inspiriert haben, die, wie Schmid zeigen konnte, durchaus religiöse Bezüge aufweisen. An dieser Stelle ist deshalb Ulmer auch zu widersprechen, die die „Apokalyptischen Landschaften“ nicht deutlich der religiösen Thematik zurechnen möchte. 229

\section{Wiederentdeckung der eigenen Religiosität}

Die subtileren religiösen Bezüge sind in den entsprechenden Themenbereichen bereits untersucht worden und sollen darum hier nicht wiederholt werden. Die wirkliche Wende zur konkreten Behandlung religiöser Motivik vollzieht sich bei Meidner allerdings erst mit dem Erlebnis des Krieges und vermutlich auch mit dem Verlust des Dichterfreundes Lotz. „Der Jüngste Tag““230 (Abb. 21) von 1916 führt zusammen, was Meidner innerlich beschäftigt: Er empfindet den Krieg als Strafe Gottes, die den Menschen den Untergang bringt. Er überhöht somit das reale Ereignis zum göttlichen Strafgericht. Darin unterscheidet sich dieses Gemälde von den vorherigen Apokalypsen, die nur allgemein als Visionen vor dem Krieg entstanden sind:

\footnotetext{
226 Ulmer (1991), S. 107 f.; Breuer (1991) 2, S. 14.

227 Zitat bei Grochowiak (1966), S. 119.

228 Grochowiak (1966), S. 120.

229 Vgl. Ulmer (1991), S. 109.

230 S. Analyse S. 86 f.
} 
„Meidners Untergangsvisionen der Vorkriegsjahre wurden 1914 von den zeitgeschichtlichen Ereignissen eingeholt. Die daraus resultierenden Konsequenzen (...) gaben diesem letzten der ,apokalyptischen' Bilder eine ganz eigene, gegenüber den vorausgegangenen Darstellungen veränderte inhaltliche Dimension (...). "231

Die zeittypische Vorstellung vom sündhaften Menschen, der nur durch Leiden erlöst werden kann, schwingt hier mit und erinnert an die Antizipation dieses selben Grundgedankens im oben angerissenen Frühwerk des Künstlers. Ähnliches wird auch in dem beim Thema Apokalypse ebenfalls bereits betrachteten Text „Anrufung des süßen unersättlichen Züchtigers“232 durch die dort erwähnte göttliche Racherute angedeutet.

„Der Jüngste Tag“ steht mit seiner kausalen Verknüpfung von Kriegserfahrung und religiös verstandener Vision somit an der Schwelle zu einem neuen Schwerpunkt in Meidners Werk. Er wendet sich in der Folgezeit ab 1915/16 ganz verstärkt wieder explizit religiösen Motiven zu: Gestalten des Alten Testaments, Propheten, Sibyllen, demutsvolle oder betende Figuren werden zu präferierten Bildinhalten.

Die neu aufgekeimte Überzeugung von der Existenz Gottes propagiert er in „Anrufung des süßen unersättlichen Züchtigers“ auch ganz deutlich: „Hört es, hört es, ibr Ermatteten alle! Ihr Wimmernden unten! Gott lebt! Lebt. Er ist, der lebendige Gott. Ich ahnte ihn, wusste ihn, liebte ihn immer (...). "Und er stellt sich damit gegen Nietzsches Postulat „dass Gott todt ist “. 233 Aber:

„,...) diese Weisheit habe ich nicht alle Tage. (...) Und morgen werde ich wieder verzweifelt sein. Morgen kommt der Zweifel in meine Brust ein tiefes Loch aufreißen und das bilflose Herz hinzerren aufs Schafott. (...) Was nützt mir jetzt die beilige Schrift und die Bücher der frommen Magier, die ich mit mir herumschleppe den ganzen Tag. Sie lassen sich nicht entsiegeln und ibre tieffsten Sprüche bleiben hart und gleichgültig auf dem Papier stehen. (...) Warum schweigst du und enthüllst dich nicht, Gnadeschenker, Taubringer, Nährer Gott? War ich schlecht? (...) Mein Gott, allersüßester Gott: dich, dich such ich wieder. Wonnefunken in meiner Brust, spring auf und lass mich nicht verdorren."

Diese bald pathetisch, bald gebetsartig anmutende Hin- und Hergerissenheit zwischen Überzeugung und Zweifel ist, wie bei der Textanalyse im Zusammenhang mit der Untersuchung des religiösen Gehalts der Apokalypsen bereits angedeutet wurde, der Grundton des Textes. Deutlich lehnt dieser Sprachduktus an die Sprache der Psalmen an. Die Frage „War ich schlecht?", die am Anfang einer Reihe von Fragen steht, in denen das lyrische Ich verschiedene Vergehensmöglichkeiten aufzählt, impliziert wieder die Auffassung vom Menschen als sündhafter Kreatur

\footnotetext{
231 Ulmer (1991), S. 107.

232 Textnachweis, Text VII.

233 Nietzsche (1925), S. 8.
} 
und von einem Gott, der diese für ihre Laster bestraft oder im Stich zu lassen scheint.

Die Zerrissenheit zwischen Glaube und Zweifel, flammender Hingezogenheit zu Gott und ängstlichem Bewusstsein der eigenen Sündhaftigkeit, die zu einem Verlust göttlicher Liebe führen könnte, birgt das emotionale Potential für die erwähnten expressiven Figuren der „50 religiösen Kompositionen“, mit denen die konkrete Darstellung religiöser Motive um 1916 bei Meidner seinen Neuanfang nimmt. Dabei handelt es sich um großformatige Tuschezeichnungen mit Pinsel und Feder auf Karton, die in Berlin entstanden sind. Zumeist sind einzelne Personen, seltener kleinere Gruppen zur Darstellung gebracht. In ihrer Überdimensioniertheit scheinen sie beinahe das Bild zu sprengen. Meidner bevorzugte, wie bereits erwähnt, vor allem den Figurentypus von Propheten, Büßern, Betenden und Sibyllen. Ihnen allen ist eine starke Expressivität gemein, die durch dramatische Bewegungen und suggestive Gebärden erzielt wird. Es ist auffällig, wie allgemein ihre Titel und Inhalte gehalten sind - es werden keine konkreten biblischen Geschehnisse im Bild umgesetzt. ${ }^{234}$

Als Beispiel kann jene männliche Prophetenfigur (Abb. 29) herangezogen werden, die, laut Bezeichnung unten rechts bereits 1915 entstanden, als Illustration dem Prosatext „Anrufung des unersättlichen Züchtigers“ beigegeben wurde. Meidner nutzte wie gesagt verschiedene der „,50 Blätter religiöse Kompositionen“ in dieser Weise für die große expressionistische Anthologie „Im Nacken das Sternemeer". ${ }^{235}$ Die Figur des Mannes mit dem langen Bart füllt das Blatt fast zur Gänze aus und ist vollständig in eine Kutte gehüllt - sogar die Kapuze ist bis in die gerunzelte Stirn gezogen. In gekrümmter Haltung steht er da, mit starrem Blick und halb gesenktem Kopf etwas fixierend, auf das er mit dem linken ausgestreckten Zeigefinger hindeutet, was sich aber außerhalb des Bildgeschehens befindet. Die rechte Hand hat er zu einer beschwörenden Geste erhoben. Der Gesichtsausdruck ist ernst und konzentriert, zeigt aber auch fanatische Züge. Meidner hat hier mit ausholenden, energischen Linienschwüngen gearbeitet und damit eine dramatische Bewegtheit erzielt. Die unnatürliche Haltung - halb hockend, halb stehend, die beinahe eine spiegelverkehrte S-Form bezeichnet - verstärkt diesen Eindruck. Arme, Kopf und Rumpf stechen durch ihre stärker ausgearbeiteten Schattierungen hervor, wobei der halbkreisförmige Bogen, den die Arme bilden, besondere Spannung erzeugt. Am Eindringlichsten ist die Mimik: die in Falten geworfene Stirn, die Adlernase und vor allem die stechenden Augen im stark verschatteten Gesicht implizieren eine heftige, vielleicht gar zornige Emotionalität des Dargestellten. Beine und rechte Hand sind nur flüchtig modelliert, eine nicht bestimmbare Umgebung ist nur in schnellen Parallelschraffuren und wolkigen Formen angedeutet. Ohne szenischen Zusammenhang oder ikonografisch deutbare Attribute ist die Identität der Figur unbestimmt. Auch scheint die Darstellung

${ }^{234}$ Grochowiak (1966), S. 120; Ulmer (1991), S. 109 f.; Heuberger/Riedel (2001), S. 33.

235 Ulmer (1991), S. 109. 
nur bedingt Bezug zum Text zu haben, dem sie beigefügt wurde, vornehmlich verbildlicht sie den dort gegebenen Stimmungsgehalt von religiös bedingter Aufgewühltheit und beschwörendem Pathos. Vermutlich handelt es sich um einen Propheten, der, durch göttliche Eingebung inspiriert, zornig schwere Heimsuchungen als Strafe für die Frevel der Menschen weissagt, ganz wie es Meidner in „Anrufung des süßen, unersättlichen Züchtigers“ gegen Ende hin tut, bevor seine schrecklichen Gesichte allmählich nachlassen.236 Er parallelisiert sich auf diese Weise mit den alttestamentlichen Sehern. Die in dieser Zeichnung zu beobachtende Darstellungsweise bleibt auch in den folgenden Jahren charakteristisch, wie an weiteren Beispielen zu sehen sein wird. Merkmal der religiösen Motive ist beinahe immer ihre durch Mimik und Gestik erreichte Dramatik, die extreme Nahsicht und die Unbestimmtheit des genauen biblischen Zusammenhangs.

Betrachtet man die 1916 gefertigte Zeichnung „Die Sibylle“ (Abb. 30), so fällt auch hier die „Prägnanz eines mittelalterlichen Holsschnitts“237 auf. Aus Untersicht und in extremer Verkürzung der Körper ist eine Sibylle - eine Seherin - an der Seite eines Propheten gezeigt. 238 Die Sibylle ist, dem Betrachter näher stehend, größer dargestellt und dominiert das Bild, indem sie es fast zur Gänze ausfüllt. In eine Kutte gehüllt kniet sie im Vordergrund, während vom Propheten hinter ihr nur Kopf und Hand zu sehen sind. Beide Figuren beschatten ihre Augen mit der rechten Hand und scheinen in die Ferne zu blicken, wobei der Seher allerdings die Augen mehr gen Himmel gerichtet hat und die Sibylle seitlich geradeaus schaut. Dass ihre Geste mehr als Andeutung inneren Schauens - also als Vergegenwärtigung visionärer Gesichte - zu verstehen ist, verdeutlicht nicht nur diese Differenz der Blickwinkel, sondern auch die Tatsache, dass es Nacht ist, wie die Mondsichel in der rechten oberen Bildecke verheißt. In ihrer verdreht auf die Knie gesunkenen Linken hält die Sibylle daher auch eine brennende Kerze. Der Blick des Mannes scheint ängstlich, die Zähne im bartumrahmten Mund hat er aufeinandergepresst. Ihr Gesichtsausdruck ist undurchdringlich, auch deswegen, weil Mund und Nase nur flüchtig skizziert sind. In dynamischen Schwüngen sind Faltenwurf und Körperkonturen behandelt. Aus diesem kompakten Kleidergewirr ragen nur Hände, Gesichter und die Füße der Seherin heraus. Auch bei diesen beiden Figuren ist nicht klar, welchem konkreten Kontext sie zuzuordnen sind. Ulmer bezeichnet sie daher überzeugend als „Prototypus des religiösen Sehers"239 Zugleich weist sie auf den historischen Hintergrund der antiken Seherinnen hin, deren unheilverkündende Prophezeiungen in Büchern gesammelt wurden und in der Tradition der hellenistisch-jüdischen Missionsliteratur standen. ${ }^{240}$

\footnotetext{
236 Vgl. Betrachtungen des Textes (VII) beim Thema Apokalypse.

237 Ulmer (1991), S. 109.

${ }^{238}$ Nach einer spätmittelalterlichen Bildtradition - s. Ulmer (1991), S. 110.

239 Ulmer (1991), S. 110.

240 Ulmer (1991), S. 110.
} 
Mindestens bis 1919 blieben die namenlosen Propheten und Sibyllen ein Hauptthema bei Meidner. Ulmer folgend kann dieses auffallende Interesse als Resultat einer verstärkten Auseinandersetzung mit der Bewegung des Chassidismus gedeutet werden, in der die religiöse Ekstase und die damit verbundene Erweckung durch Gott - im Übrigen die Zustände, die eben ein Prophet erlebt - eine zentrale Rolle spielen.241 Als Quelle der Inspiration dienten Meidner für seine Darstellungen die biblischen Psalmen und Prophetenbücher. Dies wird auch aus dem „Aschaffenburger Tagebuch“242, Bestandteil der Anthologie „Septemberschrei“, deutlich, in welchem er sich erstmals öffentlich über seine religiöse Entwicklung äußert: ${ }^{243}$

„Auch ich war lange obne Trost (...) bis mich eines Nachts eine innere Stimme wunderbar getröstet hat... Von da an ging es aus den hoblen Gassen wegsam auf eine strablende Ebene binaus. Ich schlich mich verstoblen in alte, mystische Bücher, und eines Tages ward mir inne, dass jene totgesagte Heilige Schrift ein unerschöpflicher Freudenborn und Quelle tiefer Wahrbeit ist. Hatte ich früber mit Missverstehen und Überhebung darinnen geblättert, so packten mich jetż mit Allgewalt die besänftigenden Verse der Psalmen oder die schrecklichen Reden des Jesaja; (...) - so floß jetzt sachte eine reinere Sehnsucht in meine Linie ein. (...) Da ich aber älter wurde, genügte mir irgendeine Zeile von Paulus, um mich innen zu entzünden und zur Tat zu stacheln.(...) Ja, ich hab' den großen Trost und diese Hoffnung, dass ich dir, o Herr, zum Preise unaufbörlich schaffen, trachten, beten, jubeln werde (...). ."

Die in diesem tagebuchartigen Text enthaltenen, inhaltlich differierenden Passagen stammen aus Meidners Zeit im Lazarett von Aschaffenburg, wohin er im August 1918 nach einigen Wochen Aufenthalt im Würzburger Lazarett verlegt wurde, nachdem er wegen einer Bartflechte nicht mit einem Reserveregiment zum Einsatz aufgebrochen war. ${ }^{244}$ Wie der Titel andeutet, handelt es sich um eine kleine Zusammenstellung verschiedener Beschreibungen und Gedankengänge aus diesen Monaten, deren Niederschriften durch Absätze voneinander abgesetzt sind. $\mathrm{Zu}$ Beginn beschreibt Meidner den Alltag im Lazarett und seine Beobachtungen von Kranken, wobei Gedanken an das Geschick und die damit im Zusammenhang stehende Sündhaftigkeit der Menschen mitschwingen. An anderer Stelle wünscht er endlich wieder als Künstler arbeiten zu können oder ergeht sich in enthusiastischen Beschreibungen der Stadt Aschaffenburg oder der Natur. Dabei bindet er häufig auch religiöse oder kunstkritische Bemerkungen mit ein. Auch der zitierte Abschnitt entstammt einem Absatz, der mit einer kritischen Auseinandersetzung Meidners mit dem Kunstbetrieb der Vorkriegszeit beginnt.

\footnotetext{
241 Ulmer (1991), S. 112.

242 Textnachweis, Text XIII.

243 Heuberger/Riedel (2001), S. 34.

244 Breuer (1991) 2, S. 24.
} 
„Wir waren verwirrt, überspannt und gereizt." stellt er über die Künstler dieser Phase fest und bemängelt die Sündhaftigkeit des Geld- und Erfolgsstrebens - deren Motivation zum Malen. Hier ist schon deutlich seine Hinwendung zum Glauben spürbar. Er verstärkt diesen Eindruck durch seine nachfolgende Forderung:

„Wir müssen bessre Wege zeigen und das alte Ideal, die alte Reinheit, Gottesklarheit, die Macht der Seele unvergänglich hinstellen in jauchzenden Flächen. Wir werden fürderhin nicht mehr dem mörderischen Kopfe folgen, dem alten Kirchendogma, einem politischen Ziel oder einer Tagesmeinung zuliebe malen - aber aus unseren urtiefen Herzen, aus den urplötzlichen Gesichten, ja! - aus unserm geistlichen Leib, dem seligen Bereich des Jenseits wollen wir unsere Eingebungen heraufholen und auf tönende Tafeln hauen."

Mit expressiver Eindringlichkeit und Spontaneitätsgestus (,aus den urplötzlichen Gesichten, ja!") bringt er sein Anliegen zum Ausdruck. Er will sich völlig von den äußeren Ansprüchen an seine Kunst befreien und sich nur noch auf sein Inneres konzentrieren. Soweit für einen Expressionisten kein ungewöhnliches Postulat. Der zuletzt zitierte Satz allerdings deutet an, was er in seinem Selbst zu finden meint: „Eingebungen“ aus „,dem seligen Bereich des Jenseits“. Hier spielt wieder die Idee des göttlich inspirierten Künstlers eine Rolle. Da nun alle Künstler seinem Wunsch entsprechend zu dieser „Reinheit" und „Gottesklarheit“"zurückfinden sollen, kann man durchaus von einer von Meidner angestrebten Missionierung der Kunst sprechen. Er begründet dieses Anliegen durch seine eigene Erfahrung mit religiösen Schriften, die ihn tief beeindruckt und getröstet haben, wie es dem oben zitierten Abschnitt zu entnehmen ist. Es ist dies eine Wiederaufnahme seiner bei Grochowiak wiedergegebenen Aussagen über seine 1912 erlebten Visionen vom Heiligen Geist und der darauffolgenden erleuchtenden Beschäftigung mit religiöser Literatur. ${ }^{245}$ „....) so packten mich jetzt mit Allgewalt die besänftigenden Verse der Psalmen oder die schrecklichen Reden des Jesaja. (...) “ - ,packten“ und „Allgewalt" sind die hier verwendeten Worte Meidners um die suggestive Kraft, die jene Bibeltexte auf ihn ausüben, zum Ausdruck zu bringen. Er nennt somit selbst explizit die wichtigsten Bezugspunkte für seine religiösen Kompositionen, wie zu Beginn der Textanalyse bereits ausgeführt wurde. Eine der zentralen Leitfiguren war für Meidner der Prophet Jeremia. Wie auch die Bücher der Propheten Jesaja und Ezechiel enthalten dessen Weissagungen Visionen von Krieg, Untergang und Weltgericht und mahnen die Menschen - konkret das Volk Israel - zur Umkehr zu einem gottgefälligen Leben. Zum einen knüpft Meidner mit der Darstellung dieser Propheten indirekt an seine apokalyptischen Szenen und Kriegsdarstellungen an. Zum anderen mochten diese Propheten als Außenseiter der Gesellschaft für Meidner Identifikationsfiguren gewesen sein, da er mit seiner, in seinen zuvor geschaffenen Bildern gespiegelten pazifistischen und mahnenden Grundhaltung die Meinung einer Minderheit vertrat und sich daher unverstanden gefühlt haben dürfte. ${ }^{246}$

245 Grochowiak (1966), S. 119.

246 Ulmer (1991), S. 112 f. 
Die als Darstellung des Jeremia zu deutende Zeichnung „Trauernder Prophet“ (Abb. 31) stammt aus einem der beiden so genannten „Psalmenbücher“. Es handelt sich dabei um Skizzenbücher, die Meidner während seines Aufenthaltes im Kriegsgefangenenlager Merzdorf ab September 1917 angefertigt hat. ${ }^{247}$ Der bärtige Prophet sitzt barfüßig, mit nicht gänzlich durchgestreckten Beinen vor einem kahlen Strauch auf der Erde zwischen einigen Grashalmen. Mit weit vorgebeugtem Oberkörper weint er still auf seine Knie. Während die linke Hand sich in den Erdboden krallt, rauft er sich mit der Rechten die Haare. Seine Augenlider sind fast geschlossen und das Gesicht ist von tiefer Trauer gezeichnet - schmerzlich sind die Augenbrauen in die Höhe gezogen. Wieder ist der Prophet nur in eine Kutte gehüllt, wieder ist der Fokus auf Gestik und Mimik gelegt. Hände und Füße bilden ein gleichschenkliges Dreieck, doch betrachtet man die ganze Figur, bildet sie eine Art liegendes U, dessen Rundung das Dreieck durchbricht. Dadurch wird die beruhigte Komposition durchbrochen, aber nicht völlig aufgehoben. Ebenso entgegengesetzt ist die Anspannung vermittelnde Geste des Haareraufens zur stillen Verschlossenheit der gesenkten Augenlider. Wie „zusammengeklappt“ im doppelten Sinne wirkt dieses Häuflein Elend. Diese Darstellung folgt der ikonographischen Tradition, in der wiederholt der Prophet Jeremia über die Zerstörung Jerusalems trauernd vor Augen geführt wird. Jeremia, der aufgrund seiner kontinuierlichen Unheilsverkündungen von seinem Volk bald als Gotteslästerer geschmäht wurde und darum großes Leid erfuhr und gar nach Ägypten fliehen musste, muss Meidner fasziniert haben, denn er widmete zahlreiche Zeichnungen dem Martyrium dieses Propheten. Nach Grochowiak sind die Jeremiaden in dieser Zeit gar „Meidners schöpferischste Domäne“248.

Trotz dieser starken Anziehungskraft der alttestamentlichen Texte ließ Meidner sich auch von verschiedenen anderen Schriften begeistern und inspirieren. Dabei waren konfessionelle Abgrenzungen weitestgehend unerheblich, wie beispielsweise aus der Aufzählung von Verfassern in „Gruß des Malers an die Dichter ${ }^{\text {‘249 }}$ deutlich wird:

„Komm doch, komm, du Naher und ewriger Tröster in mir, göttlicher Psalmist, du David! Dein Gesang umtönt noch die Verdammten des jüngsten Tags! Und du zorngeballter Jeremia und du unnabbar Vervückter, Jesaja. Woge christlicher Dicbter, umsinge mich und zertrete mich: Augustinus, Thomas a Kempis, Francois de Sales, Madame Guyon! Ibr Gottnahen Jan van Ruysbroeck, Seuse, Böhme, Silesius! Du Zions-Sänger Jehuda Halevi, und du bimmlischer Springer Israel Baalschem! Ist nicht auch Luther einer der Größten und Zartesten?! Und Paul Gerhardt, Spee, und du Jesu-Sänger Novalis und ibr Lieblinge meines Tages, du unvergesslicher, wogender Franz Werfel und du sehr innig-beglückter Nadel!!"

\footnotetext{
247 Ulmer (1991), S. 113; Breuer (1991) 2, S. 184.

248 Grochowiak (1966), S. 122.

${ }^{249}$ Textnachweis, Text XIV.
} 
Um 1919 tritt die Beschäftigung mit der paulinischen Theologie etwas in den Vordergrund, wie in dem oben bereits zitierten Satz aus dem Aschaffenburger Tagebuch anklingt („Da ich aber älter wurde, genügte mir irgendeine Zeile von Paulus, um mich innen zu entž̈unden und zur Tat zu stacheln. ") und es entstehen einige Farbkompositionen zu diesem Themenkreis. ${ }^{250}$ Doch hält diese Phase nicht allzu lange an.

\section{Resignation und Besinnung}

„Wenn [Meidner] jemals von der Hoffnung getragen war, ein Krieg könne am Ende eine ,moralische Wiedergeburt' zur Folge haben, so ist diese nach den gemachten Erfahrungen der Skepsis, ja der Resignation gewichen. Von nun an wurde die Weltsicht des Künstlers zunehmend durch den Glauben an die schicksalhafte Fügung Gottes bestimmt (...). '251

Meidner hat im Aschaffenburger Tagebuch durchblicken lassen, dass er sein Werk in den Dienst Gottes stellen wollte und ganz unterschwellig ist auch eine Tendenz zur Beruhigung des Künstlers und seines Stil vorauszuahnen, wenn er schreibt: „(...) - so floßjetzt sachte eine reinere Sehnsucht in meine Linie ein. "Waren für die religiösen Darstellungen bis dato der kräftige Duktus, Expressivität und Dramatik von Gestik und Mimik, aber auch der Gesamtkomposition charakteristisch, so erfolgte ab etwa 1920 eine Formberuhigung als Ausdruck der inneren Einkehr des Künstlers. Vom Krieg, den anschließenden, revolutionären Erhebungen und den fruchtlos gebliebenen expressionistischen Ideen frustriert, verschloss sich Meidner mehr und mehr in sich selbst und intensivierte dabei seine Hinwendung zur Religion, die sich ab 1920 verstärkt am orthodoxen Judentum orientierte. ${ }^{252}$ Damit einher ging auch eine entschiedene Abkehr von den revolutionären Ideen, die er kurz zuvor mit seinen eigenen Schriften noch unterstützt hatte. Die großformatigen Fettkreidezeichnungen des geplanten Mappenwerks „Moses“ zum Kapitel „Rotte Korach“ (Abb. 32) von 1920 zeugen sowohl von dieser Abkehr als auch von der Stilberuhigung. Die Rotte Korach war eine Gruppe von Verschwörern unter Korachs Leitung, die sich gegen Mose und Aaron auflehnten und die von Gott für ihr aufständisches Gebaren bestraft wurden, indem sie verbrannt und von der Erde verschluckt wurden. Die von Meidner halbfigurig gezeigten Männer im Tallith können als Warnung vor weiteren Umsturzversuchen verstanden werden. ${ }^{253}$

Der Bruch mit den expressionistischen Ideen und seinem bisherigen Stil erfolgte bei Meidner endgültig mit dem Widerruf seines expressionistischen Schaffens in der zweiten völlig veränderten Auflage der Monographie von Brieger, die harmlos mit „Eine autobiografische Plauderei“ ${ }^{254}$ betitelt ist. In den einleitenden Ausführungen über sein Künstlertum betont Meidner seine Dankbarkeit als Maler

\footnotetext{
250 Ulmer (1991), S. 112.

251 Thesing (1991), S. 104.

252 Heuberger/Riedel (2001), S. 34; Ulmer (1991), S. 113 f.

${ }^{253}$ Leistner (1986), S. 178; Grochowiak (1966), S. 127.

${ }^{254}$ Textnachweis, Text XV.
} 
tätig sein zu können, formuliert seinen Wunsch durch seinen Beruf Gott zu dienen und stellt einige Vergleiche an, um den Wert eines Kunstwerks festzustellen. Er kommt in einer Gegenüberstellung von Peter Cornelius (1783-1867) und Auguste Renoir (1841-1919) zu dem Ergebnis, dass letzterer zwar der größere Künstler sei, aber Cornelius' Werke im Gegensatz dazu von heiligem Geist verklärt und damit der unvergänglichen Welt zugehörig seien. Meidner stellt die große Bedeutung und Vorbildlichkeit verschiedener ,geistlicher“ Künstler, wie er sie nennt, heraus. Der Gedanke, dass diese gottgefällige Kunst wertvoller und beständiger sei, manifestiert sich in abfälligen Aussagen über anders ausgerichtete Kunst, wenn es etwa heißt:

„,...) die letzten Jahrbunderte, sind eine laute und schreiende Heidenzeit geworden, und die rationalistische und gänzlich entgottete Welt der Impressionisten und alles das, was jüngsthin die Malerei geleistet hat, wird, wie ich sagte, zu leicht befunden werden am Tage des letzten Gerichts. "

oder:

„Der zerknirschte, der reuevolle, der bußfertige Mensch, der Sünder, der die Bekehrung erharrt, der einsame Beter, der Zwiesprache bält und der entrückte Beter, der lächelnde Fromme in der Freude des Geistes und der Verzückte, der im Lichtglanz der Gottesberrlichkeit sich tummelt -: das sind die Gegenstände, die ich immer wieder zu gestalten suche. Mag auch in meinen Blättern viel Bizarres sein und wenig von jener Hoheit und Reinheit der geistlichen Welt, so muß man bedenken, dass auch ich ein Kind der Zeit bin und Anteil habe an ibren Krankheiten und Hässlichkeiten und soeben erst hob ich meinen Fuß auf zur Pilgerschaft in das Reich der Wabrheit - denn gestern war ich noch wie die anderen und trieb es nicht besser als sie."

Ganz deutlich äußert Meidner hier die Vorstellung, dass die Kunst der vergangenen Jahre verwerflich und gottlos gewesen sei. Für seine Zeitgenossen und Freunde muss es schockierend gewirkt haben, dass er sein eigenes expressionistisches Werk aus negativen Einflüssen („Krankheiten und Hässlichkeiten “) heraus geschaffen haben will. Die Aussage, dass er gerade erst in das „Reich der W abrheit" aufgebrochen sei, macht unmissverständlich klar, dass alles zuvor Entstandene demnach unwahr gewesen sein muss. Und das eben nicht nur auf sein eigenes Schaffen bezogen - denn wenn Meidner davon spricht in früherem Wirken von seiner Zeit beeinflusst gewesen zu sein, so muss damit in logischer Konsequenz gemeint sein, dass der von ihm als negativ angesehene Einfluss auch bei allen anderen expressionistischen Künstlern zu bemerken ist. Auffällig ist in dem zweiten Zitat auch der Bescheidenheitsgestus: „Mag auch in meinen Blättern viel Bizarres sein und wenig von jener Hoheit und Reinheit der geistlichen Welt (...). " Im gesamten Text ist dieser demütige Habitus spürbar. Er erklärt sich aus Meidners starker Hinwendung zur Religion, beziehungsweise zum Judentum, die ihn zum einen die Darstellung Gottes oder seiner in der Bibel geschilderten Wundertaten vermeiden lässt, wie er in diesem 
Text selbst erklärt, und zum anderen die Tilgung seiner Schuld ersehnen lässt. Diese Schuld sieht Meidner eben in seinem eigenen bisherigen Schaffen.

Die 1929 erschienene Textsammlung „Gang in die Stille“, die Meidner aber schon Ende des Krieges begonnen haben muss, wie aus einem Brief an den Verleger Kurt Wolff (1887-1963) von 1917 ersichtlich ist, ${ }^{255}$ ist aus Meidners eigener Perspektive eines seiner Mittel zur Sühne: „(...) ich glaube mit jenen kleinen Werken die Gemeinheit getilgt zu haben, welche ich mit meinen früheren Prosaschriften und mit hässlichen demagogischen Pamphleten anstiftete (...). "

Künstlerisch wie schriftstellerisch entfernte Meidner sich in den folgenden Jahren immer mehr von dem expressionistischen Schaffen, für das er bekannt geworden war. Die Religion sollte künftig sein Schaffen bestimmen, doch ganz ohne die Dramatik der frühen Jahre. Er hielt das für richtig, auch wenn er damit nicht mehr die Erwartungen der Kunstfreunde erfüllte:

„Künstlerische Arbeit ohne Besinnung und Rechenschaft kann nicht das Richtige sein, und es war schließlich ein Glück, dass ich vor einigen Jahren fast völlig die Fähigkeit der Ekstase verlor und mich allmählich einrichten musste, mit klarem Kopf und rubigem Herzen arbeiten zu lernen. So mache ich nun unauffällige, aber geformtere Arbeiten und schreibe eine stille und besonnene Prosa und obwobl ich jetzt schon jabrelang bürgerlichem Herkommen entsprechend schaffe, heißt es noch immer unter den Leuten ,Meidner, der Ekstatiker' - der Zuname bedeutet bier fast einen Schimpf, zumindest ein Naserümpfen. Wenn ich aber denen, die so reden meine neweren Bilder zeige, dann äußern sie enttäuscht: ,Herr M. Sie haben ja ibre ganze Eigenart eingebüßt. Ihr Schwung, Ihre Ekstase sind ja völlig dabin." 256

Ergebnis

Zwischen den religiös ausgerichteten Bildern und den ebenso geprägten Textteilen besteht eine enge inhaltliche Verknüpfung. Sie ist wahrscheinlich die engste zwischen beiden künstlerischen Begabungen Meidners in seinem expressionistischen CEuvre. Die Bejahung von Gottes Existenz und die damit verbundene Hoffnung auf Erlösung, der jedoch gleichzeitig nicht gänzlich zu verdrängende, schmerzliche Zweifel, die Suche und die Vorstellung von einem Weg zur Erlösung durch Leiden sind Grundtendenzen in beiden Bereichen. Neben dem „Aschaffenburger Tagebuch“ spiegeln beispielsweise auch „Septemberschrei“ oder „Dankgebet, dass ich lebe“ diese emotional schwierige Auseinandersetzung. Ergänzend zu den Darstellungen verweisen mehrere Texte auf die verschiedenen biblischen Figuren als Bezugspunkt. Weiterhin ist festzuhalten, dass die im Text nachweislich enthaltene Idee vom göttlich inspirierten Künstler mit der Nennung der ihrerseits göttlichen Eingebungen gehorchenden Propheten und Sibyllen und ihrer Darstellung korrespondiert. Die beabsichtigte Parallelisierung seiner eigenen Person mit diesen

255 Assmann (2001), S. 52.

256 Meidner (2003): „Vision zur Ekstase“; Textnachweis, Text XVI. 
ebenso mit Gott in Verbindung stehenden Gestalten ist hier gleichfalls zu vermuten und bindet Bild und Text auch in dieser Beziehung weiter zusammen. In den Bildern arbeitet er in der Hauptphase mit stark dramatisierendem Habitus, in den Texten mit eindringlicher Expressivität und häufig in hymnisch-biblischem Stil. Vor allem fällt auf, dass sich in beiden Bereichen vielfach derselbe Stimmungsgehalt findet. „Er gestaltete keine biblischen Historien oder Begebenbeiten, sondern Glaubenserlebnisse. ${ }^{257}$ - eben dieses Erleben versucht Meidner auch in den Texten spürbar zu machen.

Die Nähe von Text und Bild erklärt sich vor allem aus der Gleichzeitigkeit ihrer Entstehung, beziehungsweise ihrer mehrere Jahre währenden, parallel verlaufenden Behandlung. Anders als bei den anderen betrachteten Themenbereichen war Meidner hier eine lange Phase hindurch - mehr oder weniger die letzte seines expressionistischen Schaffens nämlich - sowohl schriftstellerisch als auch bildkünstlerisch gleichzeitig tätig. Ganz wichtig ist dabei auch die Berücksichtigung der Aussage Ulmers, dass für Meidner die Religion eine Art von Schutz bot - eine Möglichkeit zur Verarbeitung und Kompensation seiner Erfahrungen. Die Hinwendung zu Gott ist als Ausweg Meidners aus „Verzweiflung und den Gefährdungen des tagtäglichen Lebens" zu sehen. 258 Sowohl im Text, als auch im Bild hat er die Erlebnisse der vergangenen Jahre durch Rückzug und religiöse Besinnung zu verarbeiten versucht. Die Religion wird zum Maß aller Dinge.

\subsubsection{Die Betrachtung des Menschen}

Als letzter Bereich des expressionistischen Werkkorpus Meidners ist die Behandlung des Themas „Mensch“ zu untersuchen. Dies ist kein Thema, das sich zeitlich einem bestimmten Zeitraum zuordnen lässt, denn der Mensch ist als Protagonist oder Staffage in vielen Werken Meidners zu finden. Gerade als integrativer Bestandteil in Bildern anderer Themenbereiche ist er ein vielfältiger Bedeutungsträger. Durch die Darstellung seiner Reaktion können Wirkungsweise und Bewertung des gezeigten Geschehens intensiviert und deutlich gemacht werden. Solche Personendarstellungen im Kontext von Stadt, Krieg oder Apokalypse sind in den entsprechenden Untersuchungen der verschiedenen Themenbereiche erwähnt worden und ihre Deutung ist in die Interpretation eingeflossen, so zum Beispiel in der „Apokalyptischen Landschaft“ von 1912/13 aus der Berliner Nationalgalerie,

\footnotetext{
257 Ulmer (1991), S. 110.
}

258 Ulmer (1991), S. 116. 
in „Die Bombe“, „Jüngster Tag“ oder „Barrikade“. Sie sollen darum hier nicht wiederholt untersucht werden. ${ }^{259}$

Es gibt aber auch zwei Werkgruppen, die ausschließlich der Behandlung des Menschen gewidmet sind: die Selbstbildnisse und die Porträts von Personen aus Meidners literarisch-künstlerischem Umfeld. Diese Darstellungen nehmen bei Meidner zeitlebens eine wichtige Stellung ein - besonders auch in der expressionistischen Phase. Die daraus resultierende Werkgruppe ist die größte in seinem Schaffen überhaupt. Beide Bereiche beschäftigen sich mit dem Menschen als ausdrucksstarkem Motiv, dennoch müssen sie natürlich einzeln untersucht werden, um ihrer Differenziertheit gerecht zu werden. Wie also stellt Meidner Menschen dar? Was spiegeln ihre Antlitze wider, welche Aussagen lassen sich über die mögliche Intention der Darstellungen sagen? Drücken die Schriften dasselbe aus?

\section{Zuordnung}

Die Selbstbildnisse, deren erste Versuche schon um 1905 zu datieren sind, zeugen in ihrer Entwicklung bis 1925 vom Prozess der Identitätsfindung Meidners. ${ }^{260}$ Neben einigen Gemälden in Öl ist es vor allem die Zeichnung, die er sich dabei als Technik erwählt hat. In den expressionistischen Jahren ist deshalb eine große Anzahl von Darstellungen der eigenen Person in Bleistift oder Tusche vorhanden. Es handelt sich dabei um lauter Einzelblätter, die vermutlich auch ohne konkrete Bestimmung erstellt wurden - also nur für die Zwecke des Künstlers selbst. Als Bildnisse in Öl sind drei Gemälde zu nennen, die 1912 entstanden sind - im Übrigen die ersten Selbstdarstellungen Meidners in dieser Technik - eines befindet sich im Landesmuseum Darmstadt, eines gehört der Privatsammlung Fishman in Wisconsin und das dritte gilt bis heute als verschollen. Darüber hinaus sind „Mein Nachtgesicht" von 1913 und ein in der Berliner Nationalgalerie befindliches Selbstbildnis von 1915 in Öl ausgeführt. Die Porträts befreundeter Künstler und Literaten nehmen im CEuvre Meidners ähnlich viel Raum ein wie seine Selbstbildnisse. Ab 1913, zu einem Zeitpunkt zu dem Meidner sich in die Expressionistenzirkel eingefunden hatte und eigene Diskussionsrunden bei sich zu Hause einberief, begann er seine Bekannten bildlich festzuhalten - vornehmlich in Zeichnungen. Darunter sind Bildnisse Max Herrmann-Neißes (1886-1941), Bechers und Lotz' mehrfach zu finden, aber auch andere Dichter wie van Hoddis, Zech und Alfred Wolfenstein (1888-1945) und Künstler wie Wilhelm Lehmbruck (18811919) und Conrad Felixmüller (1897-1977) sind von ihm porträtiert worden. Dar-

\footnotetext{
259 Zwei Anmerkungen dazu: Angst, Leid oder Hilflosigkeit sind häufig Leitmotive dieser Darstellungen. Möglicherweise steht diese Tatsache im Zusammenhang mit Meidners Auffassung vom Menschen als sündiger Kreatur, die durch den Weg des Leidens Erlösung suchen muss. Eliel weist auch noch darauf hin, dass Meidner inspiriert und beeinflusst von Nietzsche in den integrierten Personendarstellungen die Idee vom Gegensatz zwischen dem dionysischen und dem apollinischen Menschen verarbeitet haben könnte. (Eliel (1990), S. 17).

260 Marquart (1991), S. 28.
} 
über hinaus hat Meidner in seiner expressionistischen Phase Kunsthistoriker, Journalisten, Galeristen, Kritiker und Musiker porträtiert, deren namentliche Erwähnung hier den Rahmen sprengen würde.

Selbstbildnisse

Bis 1925 entstanden bereits weit über fünfzig Selbstbildnisse, wobei jene zwischen 1910 und 1920 dominieren. ${ }^{261}$ Die ersten Porträts, die Meidner von sich selbst anfertigte, stammen bereits aus seiner ersten Berlin-Zeit, vor seinen Erfahrungen in Paris und seinem mühsamen Aufstieg in die Berliner Bohème und in den Jahren danach bis 1910. Doch sie verraten wenig über die gezeigte Person, sondern sind vorwiegend eine Wiedergabe der Physiognomie des jungen Künstlers (Abb. 33). Die Bildnisse der 1910er bis 20er Jahre jedoch sollten Ausdruck einer starken Auseinandersetzung mit seinem Selbst sein - eine Art psychologisierende Selbstbefragung. Diese Suche nach der eigenen Identität durch den künstlerischen Prozess brachte Porträts hervor, in denen dem Betrachter der innere Zustand der dargestellten Person äußerlich ablesbar gemacht wurde. Während die frühen Bildnisse eher als akademische Übungsstücke zu bezeichnen sind, vollzog Meidner, wohl beispielsweise durch van Gogh inspiriert, wenig später den großen Sprung zu einer expressiven Porträtauffassung. ${ }^{262}$ Diese kennzeichnet eine besondere, aber kurze Phase. Bereits um 1918 wandelte sie sich erneut, verlor ihre Expressivität und ging in den Naturalismus über.

Erste expressive Selbstdarstellungen finden sich bei Meidner 1912. In diesem Jahr entstehen auch gleich drei davon in Öl, was für die Aufwertung des Sujets innerhalb von Meidners Schaffen sprechen dürfte. ${ }^{263}$ Wenn er anfangs also womöglich aus Mangel an Modellen, beziehungsweise an finanziellen Mitteln dafür, sich selbst dargestellt hat, so wird dieses Sujet doch bald zu einem wichtigen Experimentierfeld für ihn. Entscheidender Zweck ist und bleibt aber wohl die Möglichkeit zur Auseinandersetzung des Künstlers mit dem eigenen Ego. In den daraus resultierenden künstlerischen Selbstanalysen spiegeln sich auch die durch die äußeren Gegebenheiten evozierten Gefühle.

Eines der frühen expressionistischen Beispiele ist das Selbstporträt von 1912 (Abb. 34) aus dem Hessischen Landesmuseum Darmstadt. Meidner hat sich hier halbfigurig dargestellt. Im Dreiviertelprofil sitzt er in einem dunklen Kittel nach links gewendet auf einem Stuhl, dessen Lehne rechts zu erkennen ist. Mit einem breiten Grinsen schaut er aus dem Bild heraus zum Betrachter, wobei sein kugeliger, von links unten infernalisch rot angeleuchteter Kopf etwas oberhalb der Bildmitte das Bildzentrum bildet. Seine linke, einen Pinsel haltende, ausgestreckte Hand ist links unten vom Bildrand überschnitten, während er seine Rechte quer über die Brust zur linken Schulter geführt hat. Stuhl und Künstler sind schräg in

\footnotetext{
261 Leistner (2001), S. 17.

262 Breuer (1991) 2, S. 38.

263 Marquart (1991), S. 30.
} 
die Bildebene, möglichst nah in den Vordergrund gerückt. Der Hintergrund ist nicht genauer definiert, sondern nur als rötlich-braune Fläche mit vager räumlicher Wirkung gegeben. Ein längliches, mehrfarbiges Gebilde findet sich dazu hinter Meidners Kopf, das rechts einer Papyrusstaude ähnlich in die Höhe strebt. Leistner hat dies als Schlange gedeutet, wie aus seiner Bezeichnung „Selbstbildnis mit Schlange" hervorgeht, ${ }^{264}$ jedoch scheint es sich den gleichsam zerfasernden Formen nach eher um eine Pflanze zu handeln, die unheilvoll, wie greifende Hände in Szene gesetzt, zu beiden Seiten des Kopfes hervorragt.

Die Lichtführung lässt auf zwei Lichtquellen schließen, die beide außerhalb des Bildes zu denken sind. Von oben rechts wird Meidners Glatze, ein Teil seiner linken Gesichtshälfte und seine linke Schulter angestrahlt. Dagegen steht ein rötlicher Lichtstrahl von unten links, der den übrigen und größeren Teil des Gesichtes und den rechten Arm beleuchtet und auch den Hintergrund in diffuses Rot zu tauchen scheint. Im gesamten Bild erzeugen diese verschieden positionierten Lichtquellen ein wildes Spiel von erleuchteten Partien und Schatten. So ergeben sich beispielsweise schlängelnde Linien auf dem linken Ärmel, eine knöchrig kontrastierte rechte Hand oder rhythmisierte Bewegungen der Farbe in der Gesichtslandschaft. Die Wirkungsweise der Farbe vermischt sich dabei stark mit dem Lichtspiel - allein schon durch das Rot der unteren Lichtquelle, aber auch durch die typisch expressive farbige Behandlung der Schatten. In zuckenden, ungestümen Bewegungen scheint die Farbe nass in nass aufgetragen worden zu sein und ergibt „ein spannungsgeladenes Schlachtfeld der Farben, Linien und Formen, das ganze Strecken lang im Chaos unterzugehen scheint, am Ende aber sowverän in die Ordnung gefübrt wird '265. Die Farbflecken, beispielsweise der Lichtreflexe in Beige, Gelb und Weiß sind pastos aufgetragen. Das Rot der Umgebung bildet einen Komplementärkontrast mit der grünen Farbe des Malerkittels.

Auffällig ist die Spannung der Gegenbewegungen sowohl des Lichtes als auch innerhalb der Körperhaltung. Die Haltung von Kopf und Schultern erscheint etwas angespannt gegeneinander verschoben, geradezu verrenkt und wird in ihrer verkrampften Wirkung noch durch den über die Brust geführten Arm unterstrichen. Spannungsgeladen ist vor allem auch das zentral in den Blick gerückte Gesicht mit den großen Augen, dem vom Grinsen verzerrten Mund und der durch einen Lichtfleck hervorgehobenen Nase. Als sei es eine zerfurchte Landschaft ziehen sich Linien und Falten über Stirn und die Wangen und spielen Schatten um Nase und linkes Auge.

Nun hat Meidner sich hier zwar durch den Pinsel als Maler ausgewiesen, jedoch scheint der Hinweis auf die Profession eigentlich nebensächlich zu sein. In erster Linie wird wohl Meidners innerer Gemütszustand zum Gegenstand der Darstellung gemacht. Wie in anderen Themenbereichen auch (z. B. Religion) sind es die ausdrucksstarke Gestik und Mimik, auf die es Meidner dabei ankommt. Der

${ }^{264}$ Leistner (1986), S. 191.

265 Grochowiak (1966), S. 43. 
Eindruck stark erregter Gefühle wird durch die unruhigen Linien und das wechselvolle, intensiv betriebene Spiel von Licht und Farben evoziert. Dabei vermittelt der unausgewogene Komplementärkontrast von Grün und Rot Spannung, ebenso wie die verkrampfte Haltung des Künstlers. Man fragt sich, wozu er seinen rechten Arm quer über die Brust führt - es wirkt beinahe wie eine schützende Geste. Zumindest bildet sie eine Abgrenzung zwischen Porträtiertem und Betrachter. Gespenstisch und bedrohlich sehen auch die links und rechts vom Kopf hervorstehenden Pflanzenteile aus, die beinahe aus dem Kopf selbst zu wachsen scheinen. Welche Stimmung das Bildnis auch genau wiedergeben will, der diabolischbedrohliche Charakter ist ihm nicht abzusprechen. Der verzerrte Gesichtsausdruck scheint zugleich eine gewisse Selbstironie des Künstlers zu spiegeln. Insgesamt entsteht der Eindruck eines verunsicherten Menschen, der seine Angst durch Ironie zu kaschieren sucht. ${ }^{266}$

Wie ist nun eine solche Selbstdarstellung zu verstehen? Das soeben untersuchte Bild ist nicht nur ein momentanes Psychogramm, sondern es verdeutlicht die Selbstwahrnehmung unter dem Einfluss der äußeren Gegebenheiten. Der Kontext der Entstehung ist hier wie auch bei Meidners anderen expressionistischen Selbstporträts mitentscheidend. So lässt sich das Gemälde also nicht nur als ein Spiegelbild eines vielleicht nur kurz andauernden negativ gefärbten - hier eben ängstlichen und selbstironischen - inneren Seelenzustands lesen, sondern kann auch als allgemeingültigere Aussage des Künstlers über sein generelles Befinden verstanden werden. Allein die 1912 zunehmende Beschäftigung mit der eigenen Person und die damit einhergehende isolierende Selbstbezogenheit „,kann zum einen als Reaktion auf das ,Ich'-dissoziierende Pbänomen Großstadt interpretiert werden, zum anderen als Anzeichen einer berufsbedingten Identitätskrise ${ }^{267}$. Die von den Expressionisten kritisierten Bedingungen der entfremdenden Großstadt und Meidners Existenzängste als Maler dürften also für die alptraumhafte Stimmung des Gemäldes eine Rolle gespielt haben. Jedenfalls lässt sich dies unter Berücksichtigung der Tatsache, dass er zur selben Zeit die Großstadtthematik behandelt hat, annehmen. Die Selbstironie des schiefen Grinsens deutet auf Meidners kritische Wahrnehmung seiner eigenen Person hin. Er hat sich nicht ideal oder naturalistisch dargestellt, auch dient das Bild wie gesagt nicht dazu ihn als Künstler abzubilden, sondern Meidner versucht hier sein Inneres zu ergründen, sich selbst zu analysieren. Dabei scheint er einen eher skeptischen Eindruck von sich zu gewinnen.

Aus dem ambivalenten Lebensgefühl, das sich aus seinem Bekenntnis zum Künstlertum und den dazu im Gegensatz stehenden Existenzängsten ergibt, und dem Gefühl der Entwurzelung resultiert Meidners innerliche Zerrissenheit, die er in vielen seiner expressionistischen Selbstporträts zum Ausdruck bringt und durch diese künstlerisch umgesetzte Identitätssuche zu kompensieren versucht. Ähnliches ist auch in den wenigen Textstellen zu beobachten, in denen Meidner mit

${ }^{266}$ Vgl. auch Marquart (1991), S. 31.

267 Marquart (1991), S. 32. 
Worten ein Bild von sich entwirft, wie beispielsweise in der in „Septemberschrei“ enthaltenen „Hymne an mich selbst“"268:

„Da, da---bineingewebt in den Alltag - sebt den Glatrkopf, Kablbauch - ibn den eulenängigen, gestiefelten Kater, Anfeuerer der Petroleusen und aller Stiefsöhne des Mondes. Hineinragend bis in die siebente Region des Weltalls - sich skeptisch schnäuzend und immerfort wehlachend - fragt er, kleiner Däumling, nach des Weltalls Wieso und Warum. Sapperment! Auf seinen langen Obren Störche nisten. Gänsegeier und Bussarde um seine Augenbrauen wehn. Sein asphaltierter Rachen schreit heisere Sarkasmen. Seine Backen voll Fliegenschiß. Spinnen wimmeln um seine Hoden. Dromedare taumeln aus seinen Lenden. Aus seinem Bauche Wölfe und Füchse eilen. Und der große Bär spiegelt sich eitel auf der Glatze, mitten in rotbrauner, feilschender Nacht."

Ein merkwürdiges Fabelwesen, das Meidner hier zusammendichtet! Viele Elemente werden assoziationsreich zu einer kritischen Selbstbetrachtung zusammengeführt. Zum einen wird die Vorstellung einer abstoßenden Kreatur erzeugt, die voller Exkremente und Ungeziefer ist, mit auffälligen Attributen versehen wird und mit Raubtieren in Verbindung gebracht eine bedrohlich-abschreckende Erscheinung sein muss. Zum anderen können die Tierbezeichnungen und ungewöhnlichen Adjektive im Einzelnen ausgedeutet werden und lassen damit auch Rückschlüsse auf Meidners Selbsteinschätzung seines Aussehens und seinen charakterlichen Eigenschaften zu. Schon der erste Satz nennt Meidner einen „Glatrkopf, Kablbauch" und „eulenängigen, gestiefelten Kater". Dabei beziehen sich die beiden ersten Bezeichnungen auf sein Äußeres und beschreiben jenes vermutlich einfach wahrheitsgetreu - zumindest die Glatze ist auch in den gemalten und gezeichneten Porträts zu finden. Der andere Teil der Beschreibung ist etwas tiefgründiger aufzufassen. Wenn auch das „eulenängig“ wiederum auf das Äußere des Künstlers anspielt, so muss man bei der Gleichsetzung mit Grimms Märchenfigur allerdings fragend inne halten. Zieht man die Quintessenz aus diesem Charakter, so ist der Gestiefelte Kater listenreich in der Not, dabei aber als sprechendes und sich wie ein Mensch bewegendes Tier ein absonderliches Unikum. Es ist recht wahrscheinlich, dass Meidner insbesondere den zweiten Aspekt für sich zutreffend fand und sich aufgrund des zeitlebens anhaltenden Gefühls ein Außenseiter zu sein mit dieser Figur identifizierte.

Im zweiten Satz verdichtet sich die Vorstellung von einem aufrührerisch Veranlagten durch die Satzteile „sich skeptisch schnäuzend und immerfort weblachend" und "fragt er (...) nach des Weltalls Wieso und Warum". Er kennzeichnet sich damit als jemanden, der hinterfragt und mutmaßlich ,wehlachend" kritisiert, doch spiegelt die Selbstbezeichnung als „kleiner Däumling“ auch die Erkenntnis der eigenen Naivität und Unbedeutendheit. Der zuletzt zitierte Textteil zeichnet ein bizarres Bild, wie aus einem Traum, in dem physiognomische Details durch Tiere ergänzt und cha-

268 Textnachweis, Text XVII. 
rakterisiert werden sollen. Interessant ist dabei die Verknüpfung einiger davon mit bestimmten Sinnen: „Auf langen Ohren Störche nisten. Gänsegeier und Bussarde um seine Augenbrauen wehn (...)" oder „Dromedare taumeln aus seinen Lenden" beispielsweise. Die „, lange[n] Ohren “ könnten Aufmerksamkeit signalisieren, also dafür sprechen, dass Meidner ein interessierter Zuhörer ist - bezogen auf seinen Bekanntenkreis oder auch auf den gesellschaftspolitischen Bereich, während die beiden Raubvögel den scharfen Blick symbolisieren mögen. Meidner würde sich demnach selbst als kritisch genauen Beobachter kennzeichnen wollen. Die Anspielung auf seine Lenden jedoch ist zugleich ein beispielhafter Hinweis auf eine andere Seite des Künstlers sie verweist auf die Wollust, derer er sich in den zwar expressionistischen, aber schon spürbar religiös geprägten Texten seiner beiden großen Textkonvolute häufiger anklagt. Auch die ausgeschrieenen ,heisre[n] Sarkasmen" und die Passagen über Spinnen und Fliegendreck, die Assoziationen von Ungepflegtheit und Verlotterung hervorrufen, klingen selbstkritisch an. Zudem gibt der auf das Zitierte folgende Teil der Hymne weiterhin einen Eindruck von Meidners Selbstbild. Indem er darin seine unterschiedlichen Gefühlswallungen im rhythmischen, hymnischen Tonfall sowie im Spiel ausdrucksstarker Worte wiedergibt und damit zugleich sein wechselvolles Verhalten, das etwas wild und irr erscheint, spinnt er die Vorstellung von seinem gegensätzlichen und komplexen Wesen weiter.

Nach 1912 bereits folgt eine Zeit weniger intensiven Schaffens im Bereich der Selbstdarstellung als eigenes Bildthema. Stattdessen wird Meidners Porträt häufiger integrativer Bestandteil in Bildern anderer Themenbereiche. ${ }^{269}$ So taucht seine Physiognomie in den Bildern der Folgejahre immer wieder in anderen Zusammenhängen auf - beispielsweise in „Barrikade“, in der Apokalyptischen Landschaft von 1913 aus der Sammlung Fishman oder in verschiedenen Blättern der Mappe „Krieg“. Ebenso hat Meidner sich selbst in Großstadtdarstellungen eingebaut, wie in „Betrunkene Straße mit Selbstbildnis“. Sie alle offenbaren Meidners Beziehung zu dem jeweils gezeigten Umfeld und vermitteln dabei zumeist Entfremdung, Not oder auch sein Aufbegehren. ${ }^{270}$ Das wohl eindrucksvollste Bildbeispiel, in dem Meidner die Synthese des Sujets Selbstporträt mit einem anderen vornimmt, ist das bereits untersuchte Gemälde „Ich und die Stadt“. Der Künstler zeigt sich hier selbst in Konfrontation mit der Stadt, wobei ja festzustellen war, dass das Bild sowohl einen äußeren als auch einen inneren Zustand zum Ausdruck bringen kann: seelisches Chaos oder zerstörerisch wirkende Stadt. Vermutlich ist es gar so gemeint, dass letzteres ersteres bewirkt.

Erst 1916 nimmt Meidner das Porträtieren seiner eigenen Person als eigenständigen Bildgegenstand wieder häufiger auf. Eine Fülle von Zeichnungen belegt dies. Zugleich werden ihn insbesondere die religiösen Darstellungen zunehmend beschäftigen, was sich auch in den Schriften aus der Zeit der erzwungenen „Malabstinenz“ im Kriegsgefangenenlager niederschlägt. In „Im Nacken das Sterne-

\footnotetext{
${ }^{269}$ Marquart (1991), S. 33.

${ }^{270}$ Leistner (1986), S. 187.
} 
meer“ und in der kurz darauf 1917 entstehenden Anthologie „Hymnen, Gebete und Lästerungen" "271 sind entsprechend in erster Linie religiöse Figuren als Illustrationen enthalten. Doch finden sich auch hier Beispiele dafür, dass Meidners Auseinandersetzung mit seinem Selbst nach wie vor kritisch und expressiv zum Ausdruck kommt. So fragt er in „Mündung, du böse bleckende, schweig, schweig!“‘272, dem letzten Text aus „Im Nacken das Sternemeer“:

„Warum bier zu sein, du lichte Seele, verbannt in einen trägen, zerbrechlichen Leib?! (...) Warum auf diesen runden, behaarten Beinen stehen, herumgehen, wackeln, wiegen?! Warum diesen Bauch, diese überflüssigen Schultern, die verzweifelten Arme tragen?! Warum diese unerklärlichen Augen, Obren, die dünnen Lippen, die infernalische Zunge mitten in dem schrecklichen Kugelkopf?!"

Anders als in der „Hymne an mich selbst“ handelt es sich hierbei um keine generelle Betrachtung, beziehungsweise Hinterfragung der eigenen Person, sondern um von Verzweiflung über eine bestimmte Situation geprägte Fragen. Meidner hat im Gesamttext die Empfindung der Sinnlosigkeit seines Tuns als Soldat beklagt. Als Nachtwache auf einem Damm postiert, verabscheut er sein Gewehr und wird durch quälende Fragen nach dem Sinn des Krieges und der Welten Lauf zum Gotteszweifler, der gar vor den Gedanken an Selbstmord nicht zurückschreckt. Selbstmord stellt er hier nicht zum ersten Mal als Lösung in Aussicht. Bereits 1912 schuf er ein Gemälde, das einen Selbstmörder zeigt und als ein Selbstbildnis von ihm angesehen wird (Abb. 35). Auch die oben zitierte Passage hängt mit diesem Gedanken zusammen, denn darin äußert sich implizit der Wunsch nach Befreiung der Seele aus dem als hässlich (z. B. „schrecklichen Kugelkopfr) und unnütz (z. B. „überflüssige Schultern") empfundenen Leib. Meidner beschreibt seinen Körper als nutzlose, gar hinderliche Hülle, die die Seele gefangen hält und beengt - wie es die Frage „W arum hier zu sein, du lichte Seele, verbannt in einen trägen, zerbrechlichen Leib?!“ vermittelt. Der Selbstmordgedanke spiegelt hier ,ein zutiefst romantisches Lebensgefühl, nämlich durch den Tod zur Freibeit und zum neuen Leben zu gelangen. '273 Ganz ähnlich wie in der „Hymne an mich selbst“ geht Meidner mit der eigenen Person höchst skeptisch um und betrachtet, hier allerdings stärker von der Seele abgetrennt, seinen Körper als kritikwürdig. Das Hinterfragen der bestehenden Zustände, was bereits im zuerst betrachteten Text angeklungen war, wird zum Hauptthema und führt zu einer gesteigerten, verzweifelten Selbstbeurteilung. Auch in den Bildern bleiben die kritische Innenschau und Expressivität Tendenzen mit großer Kontinuität. Bald ängstlich, bald abweisend blickt Meidner mit durchdringendem Blick aus den Porträts heraus und reflektiert damit immer auch ein Stück weit seinen inneren Zustand (z. B. Abb. 36).

\footnotetext{
2711920 dann ergänzt als „Septemberschrei“ publiziert.

272 Textnachweis, Text XVIII.

${ }^{273}$ Leistner (2001), S. 17.
} 
Seine Hinwendung zur Religion scheint jedoch nach und nach auch seine Selbstwahrnehmung zu beeinflussen. Bleibt er in den Bildern wie in den Schriften dem expressiven Element erst noch verhaftet, verlieren die Selbstbildnisse mit Fortschreiten des Krieges ihren Schwung, ihre Dynamik. Die Entstellungen und perspektivischen Verzerrungen der Physiognomie lassen nach. Dieser Wandel steht in engem Zusammenhang mit Meidners Forderung nach einer dem Glauben dienenden Kunst, die nur durch die Rückbesinnung auf die Werke alter Meister und mit einem davon inspirierten ,inbrünstigen Naturalismus" zu erreichen sei. Mit dieser Darlegung hat Meidner schon 1918 in seinem „Aschaffenburger Tagebuch“274 die Grundlage seiner neuen Kunstauffassung formuliert. Die Selbstbildnisse der kommenden Jahre insbesondere dann ab 1920 setzen diesen neuen Anspruch um und sind entsprechend tendenziell in naturalistischer Manier behandelt (z. B. Abb. 37). Sie entbehren der psychischen Durchdringung und kritischen inneren Selbstanalyse. Meidner scheint durch seinen Glauben sein neues Ich gefunden und somit die Identitätssuche abgeschlossen zu haben. Die Abbildung des Äußeren bekommt wieder mehr Gewicht. Daran wird er mehr oder minder zeitlebens festhalten. ${ }^{275}$

Die Intention von Meidners expressionistischer Selbstdarstellung ist im Bild wie im Wort die gleiche: der Künstler reflektiert seinen inneren Zustand, für den äußere Bedingungen ausschlaggebend sind. Wenn sich auch die Faktoren ändern, deren Einwirken Meidner verarbeiten muss - seien es Großstadterfahrung, persönliche Not oder der Krieg - so tut er dies immer in einer kritischen Selbstbefragung - vor dem Spiegel malend oder in sein Notizbuch schreibend. Der Übergang vom Malen zum Schreiben ist dabei fließend und Meidner legt in beides gleichermaßen viel Emotionalität hinein. Er hat die Vorstellung in seinen Bildern und Schriften durch Expressivität und Spontaneitätsgebaren einen unvermittelten, unverstellten Eindruck seines Selbst einzufangen. ${ }^{276}$ Es ist allerdings zu berücksichtigen, dass die bildlichen Darstellungen für sich allein sprechen ohne konkreten Hinweis auf die von außen auf die dargestellte Person einwirkenden Faktoren. Sie lassen sich nur mit Hilfe biografischen Wissens deuten. Es sei denn, es handelt sich um Bilder, die eine Verknüpfung des Selbstporträts mit einem anderen Sujet zeigen. Die Textausschnitte dagegen sind zumeist etwas eindeutiger in einen bestimmten Kontext gestellt. Aus dem Gesamttext lassen sich die Bezüge leichter erfassen. Zudem bringt die spätere Entstehungszeit während Meidners Militärdienst wieder die religiösen Untertöne mit sich und tendenziell den Bezug zum Krieg. Es ist im Übrigen Grochowiaks Aussage beizupflichten, dass Meidners Darstellungen der inneren Zerrissenheit beispielhaft als Widergabe des Zustands vieler deutscher Expressionisten gelesen werden können. ${ }^{277}$

\footnotetext{
${ }^{274}$ Textnachweis, Text XIII. Ausführungen dazu im Kapitel 3.1.3.5.

275 Marquart (1991), S. 35 f.

276 Vgl. Breuer (1991) 2, S. 38.

277 Grochowiak (1966), S. 45.
} 
Porträts befreundeter Künstler und Literaten

„Zeit seines Lebens ist das Porträt eines der wichtigsten Themen im künstlerischen Schaffen Ludwig Meidners. Besonders in seiner expressionistischen Phase stebt dabei die intensive Auseinandersetzung mit dem Gegenüber im Vordergrund. '278

Nach seiner Rückkehr nach Berlin 1907 gelang Meidner nach längerer Zeit der Not und Isolation langsam eine Verbesserung seiner Lage. Zu Beginn des neuen Jahrzehnts konnte er seine Kontakte ausbauen und fand Anschluss in der Künstler- und Literatenszene im Café des Westens, das auch unter dem Namen „Café Größenwahn“ bekannt war. Hier verkehrten Else Lasker-Schüler (1869-1945), Max Oppenheimer (1885-1954), Walden und viele andere, die damals ihre Grundhaltungen, ihren noch geringen Bekanntheitsgrad und zumeist auch die Armut teilten. Meidner fand sich meistens am Literaten-Stammtisch ein, wo unter anderem René Schickele (1883-1940) und Otto Flake (1880-1963) zu finden waren. Von den dort stattfindenden hitzigen Debatten und erregten Gesprächen innerhalb einzelner Cliquen und zwischen den Gruppen nahm Meidner häufig die ihn aufwühlenden Eindrücke mit nach Hause und hielt sie in den schon erwähnten Caféhaus-Darstellungen fest. ${ }^{279}$

Aus diesen Kontakten und Freundschaften entwickelte sich schließlich der 1913 jeden Mittwochabend stattfindende Jour Fix in Meidners bescheidenem Atelier in der Wilhelmshöher Straße in Berlin-Friedenau, wo er zugleich auch wohnte. Jakob van Hoddis, Alfred Wolfenstein, Paul Zech, Kurt Hiller, René Schickele, Max Herrmann-Neiße, Kurt Pinthus (1886-1975) und Erwin Loewenson (1888-1963) waren dabei häufige Gäste. Andere wie Johannes Baader (18751955) und Raoul Hausmann (1886-1971) kamen gelegentlich. ${ }^{280}$ Durch diese enge Eingebundenheit Meidners in die Bewegung des literarischen Expressionismus erklärt sich, dass so viele Porträts von Personen dieses Kreises von seiner Hand entstanden sind. Es ist Leistner zuzustimmen, dass daraus auch die zeittypische Verbrüderung von Künstlern und Literaten abzulesen ist..281 Dieser Verbrüderungsgedanke war nicht nur Theorie, sondern alltägliche Praxis. Meidner ist dafür ein besonders gutes Beispiel. Häufig hat Meidner die Gelegenheit genutzt, seine Modelle gleich während eines Besuches bei sich zu Hause zu rekrutieren, wie eine Aussage Paul Westheims (1886-1963) bestätigt: „Wenn man zu Meidner ins Atelier kommt, wird man gezeichnet."282 Und dies geschah während der expressionistischen Phase meist in einer karikierenden Weise, die die charakteristischen Eigenheiten der porträtierten Person herausstellen sollte.

\footnotetext{
278 (Wagemann in) Breuer (1991) 2, S. 206.

${ }^{279}$ Grochowiak (1966), S. 137 f.

280 Breuer (1991) 2, S. 17.

${ }^{281}$ Leistner (1986), S. 187.

282 Vgl. Padberg (2004), S. 34.
} 
Vor allem interessierten Meidner Modelle mit ausgeprägten Physiognomien oder mit körperlichen Auffälligkeiten. Ein gutes Beispiel hierfür ist Max HerrmannNeiße. Dieser war Meidner durch die gemeinsame jüdische Abstammung, schlesische Herkunft und besondere Freundschaft verbunden. Als studierter Kunsthistoriker und Germanist wurde er ein bedeutender Kulturkritiker, Essayist und Schriftsteller. Dass er für verschiedene expressionistische Künstler ein beliebtes Motiv war, erklärt sich aus seiner Verkrüppelung, die er schon von Geburt an hatte. ${ }^{283}$ Wie eingangs erwähnt, war Krankheit und darunter eben auch die körperliche Behinderung ein zentrales Thema des Expressionismus, denn die durch Krankheit erzwungene Leidensfähigkeit wurde als Voraussetzung gesehen, um Sehnsucht nach Erlösung empfinden zu können. Und Erlösung im übertragenen Sinne, als Ausdruck für Erneuerung und Veränderung, war ja wesentlicher Bestandteil des expressionistischen Strebens.

Dass Meidner Herrmann-Neiße mehrfach - in zwei Gemälden, Zeichnungen und einer Radierung - porträtiert hat, zeugt von der Bedeutung dieser Werke innerhalb von Meidners expressionistischer Porträtmalerei. Heusinger von Waldegg bezeichnet sie deshalb als einen ihrer Höhenpunkte, aus der auch die Idee der Gemeinschaft von Künstlern und Literaten abzulesen sei. ${ }^{284}$ Das erste Gemälde, welches Meidner von seinem Freund anfertigt, ist das Bildnis „Max HerrmannNeiße“ (Abb. 38) von 1913. Der Porträtierte sitzt mit einem dunkelgrünen Anzug in einem großen Lehnstuhl, der sich in einem undefinierten Raum befindet. Das Bild zeigt den Porträtierten frontal und aus großer Nähe. Durch den gewählten Ausschnitt werden die übergeschlagenen Beine unterhalb der Knie vom unteren Bildrand überschnitten. Herrmann-Neiße hält seinen Kopf leicht zur Seite geneigt und schaut durch die Gläser seiner runden Brille mutmaßlich in Richtung des Betrachters. Seine knochig gestalteten Hände sind übereinander gelegt und ruhen auf dem rechten Oberschenkel. Oberhalb der Weste und an den Ärmeln schaut ein rot-blau kariertes Hemd heraus. Die Umgebung ist nur durch eine unbestimmte ockrig-braune Fläche angedeutet, so dass nichts vom zentralen Motiv des Schriftstellers abzulenken vermag. Sein Gesicht ist dementsprechend detailliert: ein klein wirkender, rundlicher Kopf mit abstehenden Ohren, starker Nase und rötlichem kurzem Haar, in das Geheimratsecken weit hineinragen. Der Mund ist weit geschwungen mit großen, wulstig hervortretenden Lippen und eckig hervorstehenden Kieferknochen. Die tiefliegenden kleinen Augen werden von ausgeprägten Augenwülsten mit nur dünnen Brauen überfangen. Das rechte Auge erscheint etwas gerötet. Darüber schließt sich eine zerfurcht anmutende, knochige Stirn an.

Im Ganzen scheint das Bildnis dezenter gehalten als beispielsweise das Darmstädter Selbstporträt Meidners aus dem Jahr davor (Abb. 34), in welchem er mit ausdrucksstarkem roten Licht, ausgeprägtem Licht- und Schattenspiel und Kom-

${ }^{283}$ Leistner (1986), S. 193 und Heusinger von Waldegg (1991), S. 70.

${ }^{284}$ Heusinger von Waldegg (1991), S. 70. 
plementärkontrast gearbeitet hatte. Hier dagegen erscheint die Beleuchtung eher ausgeglichen, so dass nur aus einigen Lichtflecken in der hohen Lehne und am Anzug zu erahnen ist, dass sich die Lichtquelle links oben befinden muss. Der relativ harmonisch und beruhigt wirkende, dunkle Ton des Blaugrüns von Anzug, Hemd und Stuhl wird nur etwas durch Hintergrund, Hände, Gesicht und rotem Schopf aufgehellt. Insbesondere durch den unruhigen Pinselduktus erscheint das Bildnis expressiv.

Entscheidend ist aber die Frage, welchen Eindruck das Porträt beim Betrachter hinterlässt. Meidner hat durch keinerlei Attribute Hinweise auf HerrmannNeißes Profession als Schriftsteller gegeben. Auch verzichtet er darauf das körperliche Gebrechen des Literaten in den Vordergrund zu stellen. Nur dessen etwas verkrümmte Haltung und die im Anzug klein und zerbrechlich wirkende Statur verraten andeutungsweise die körperliche Anomalie. Worum ging es Meidner also? Ähnlich wie bei seinen eigenen Bildnissen ist der Fokus der Darstellung darauf gelegt, das Innere der Person zu erfassen. In psychologischer Durchdringung versucht Meidner hier den Gemütszustand - einen, der für den Freund charakteristisch sein mag - festzuhalten. Kopf und Hände sind hervorgehoben und sprechen eine subtile Sprache. So scheinen die knochig übereinandergelegten Hände auf den gleichfalls gekreuzten Knien in ihrer Verkrampftheit eine gewisse Verhaltenheit oder unterdrückte Nervosität anzudeuten. Der geneigte Kopf und der nicht ganz direkte melancholische Blick vermitteln den Eindruck einer eher gehemmten, vorsichtigen Person. ${ }^{285}$ Dazu passt denn auch die Ruhe der dunklen Farbtöne, die diesem Charakter mehr angemessen scheint als die furiose Farbwucht in dem genannten Selbstbildnis Meidners. Die Wahl dieser feinfühligen Darstellungsweise weist auf das enge und freundschaftliche Verhältnis der beiden Expressionisten hin und zeugt zugleich davon, dass es Meidner darauf ankam im Hässlichen die Schönheit der Seele menschlich und ergreifend ins Bild zu bringen. 286

Unverblümt, aber mit Worten, die zugleich die Nähe der beiden spüren lässt, äußert Meidner über den Schriftsteller deutlich:

„(...) mein langjähriger Freund, ein gebrechliches Wrack, ein eckiger Totenschädelkopf

voll Schwermut, ein unglücklich Verwachsener, der auf fast unerschöpfliche Weise seine zarten und ergreifenden Gedichte verfasste. '287

Wie viel Mühe und emotionalen Einsatz ihn das Hineinfühlen in den Freund und das Porträtieren gekostet haben mag, deutet die ironische, doch prägnante Aussage Herrmann-Neißes zum Entstehungsprozess an: „(...) er, besessen vom Dämon seiner

\footnotetext{
$285 \mathrm{Vgl}$. auch Heusinger von Waldegg (1991), S. 72.

286 Vgl. Hoffmann (1985), S. 114.

287 Meidner: Dichter, Maler und Cafés (bei Kunz, 1973), S. 21.
} 
Kunst, tobte um mich herum und focht sichtlich mit allen Teufeln, die ihm nicht wohl wollten, einen Kampf auf Sein oder Nichtsein aus. "288

Das Hineindenken und Erfassen des Inneren seines Gegenübers, ganz wie er es an sich selbst immer wieder erprobt hat, ist ein Anspruch an seine Porträts, den Meidner auch in seinem Text „Vom Zeichnen“"289 formuliert, der 1917 zuerst in „Das Kunstblatt“ und danach in der Anthologie „Im Nacken das Sternemeer“ veröffentlicht wurde. Dort heißt es in einer Passage:

„Fürchte dich nicht vor dem Antlitz des Menschen, das ein Abglanz bimmlischer Herrlichkeit ist, aber noch häufiger ein Schlachtfeld mit blutigen Fetzen. Nimm Runzelstirne, Nasenwurzel und Augen eng zusammen. Bobr dich wie ein Wühltier in den unerklärlichen Pupillengrund und das Augenweiß deines Gegenübers und lass' deine Feder nicht rasten, bis du deines Gegenübers Seele mit der deinen zu einem pathetischen Bunde vermählt hast. Versenke dich in die Innigkeit, in die feuchte und schreckliche Innigkeit eines Lippenpaares. Beachte die Spitze oder zernarbte Weichbeit des Kinns. Das Ornament des Ohrs soll dich immer wieder entzücken und die lodernden Haare, die Haarwellen, die Haar - Asche um dürre Wangen, die stechenden Borsten, die Härlein um den Mund seien ein Woblgeschmack für deine flitzende Feder. "

Der Satz „Bohr dich wie ein Wühltier in den unerklärlichen Pupillengrund und das Augenweiß deines Gegenübers und lass' deine Feder nicht rasten, bis du deines Gegenübers Seele mit der deinen zu einem pathetischen Bunde vermählt hast" bringt in aller Deutlichkeit zum Ausdruck, wie ernst es Meidner mit seinen Porträts ist. Er will seine Modelle nicht abbilden - er will ein Stück weit von ihrer Seele Besitz ergreifen zu dem Zwecke das Sein des Gegenübers besser fühlen und ins Bild bringen zu können. Die Leidenschaftlichkeit, mit der er die Beachtung der Details empfiehlt, verrät den genauen Beobachter, während der zuerst zitierte Satz den Gedanken der Menschenbrüderlichkeit transportiert, indem jeder Mensch in göttliche Nähe gerückt wird. Zugleich bezeichnet Meidner dort das Gesicht als „Schlachtfeld“ - darin mag sich die Vorstellung äußern, dass das menschliche Antlitz von den Spuren des Lebens gezeichnet ist. Die im Text geäußerten Vorstellungen decken sich recht genau mit dem, was aus einem Bild, wie z. B. demjenigem von Max Herrmann-Neiße, ablesbar ist.

Ein anderes Beispiel, das hier für Meidners expressionistisches Porträtschaffen angeführt werden soll, ist die Kaltnadelradierung „Ernst Wilhelm Lotz“ (Abb. 39). Wie Herrmann-Neiße stand Lotz Meidner freundschaftlich besonders nahe; es gibt sogar Vermutungen über eine homoerotische Beziehung der beiden. ${ }^{290} \mathrm{Im}$

\footnotetext{
${ }^{288}$ Herrmann-Neiße, M.: Meine Erlebnisse mit der bildenden Kunst. (1929)

289 Textnachweis, Text XIX.

290 Vgl. z. B. Thesing (1991), S. 100 und Natter (2001), S. 195. Anzeichen homoerotischer Empfindungen enthalten beispielsweise der Text „Fragment von der Winterqual“ und „Du loderndes Haupt“ aus „Im Nacken das Sternemeer“ (dort vermutlich bezogen auf einen befreundeten bayrischen Soldaten - vgl. Grochowiak (1966), S. 116 und „Tagebuches letzte Winterseiten“ aus „Septemberschrei“, S. 4 f.).
} 
Dreiviertelprofil nach links ist der Kopf des expressionistischen Schriftstellers gegeben, den er leger und zugleich nachdenklich auf den Rücken der rechten Hand gestützt hat. Die Hand ragt aus einem Ärmel mit Manschettenknopf; die feingliedrigen Finger, die in nervösen Linien angedeutet sind, hängen locker herab und sind vom unteren Bildrand überschnitten. Aus dem rundlichen Gesicht ragen markant die Wangenknochen hervor und die seitlich gescheitelten Haare fallen dicht und wellig. Am ausdrucksstärksten sind die Partien von Augen, Nase und Mund behandelt. Die melancholisch auf den Betrachter gerichteten Augen liegen etwa auf Höhe der Bildmitte, wobei das linke Auge durch die leichte Neigung des Kopfes etwas höher angeordnet ist. Sie werden von ausladenden Brauenschwüngen überfangen und unterhalb haben sich tiefe Linien eingegraben. Die Nasenlöcher sind groß, wie aufgebläht. Die Lippen sind um eine Zigarette zusammengepresst, deren Rauch links neben dem Gesicht aufsteigt. In dem stark schattierten Feld zwischen Nasenwurzel und dem linken Auge ist der Bildmittelpunkt.

Der Hintergrund ist unbearbeitet belassen, so dass der auf der Hand ruhende Kopf ganz für sich steht. Einzeln zusammengefügte Linien konturieren das Gesicht auf der linken Seite, rechts werden die Begrenzungen durch Schattierungen modelliert. Überhaupt unterstützen die Schattierungen der linken Gesichtshälfte die Spannung, die durch die dynamische Strichführung erzeugt wird. Der etwas betrübt wirkende und grüblerische Blick des ,unerklärlichen Pupillengrund[es] " - wie Meidner es formuliert - ist sehr eindringlich und ergreifend und wird durch die auf die Hand aufgestützte Geste in seiner Nachdenklichkeit noch unterstrichen. Die Augen sind, wie Hoffmann ausführt, für das expressionistische Porträt von elementarer Bedeutung, denn sie werden von den Künstlern dieser Zeit besonders ausdrücklich als Spiegel der Seele gewertet. Durch Herausheben von Größenunterschieden und Versetzen der Augen gegeneinander soll die innere Verzerrung, das emotional in Bewegung befindliche Sein der Porträtierten zum Ausdruck gebracht werden. ${ }^{291}$ Diese Behandlung lässt sich auch bei Meidners Porträts und Selbstbildnissen feststellen und ist stellvertretend an dieser Darstellung von Lotz zu beobachten.

Im Text „Erinnerung an Dresden“292 ist eine Beschreibung Meidners von seinem Freund Lotz enthalten, die mit fast noch höherer Intensität die Eigenheiten des Schriftstellers, so wie Meidner sie sah, darzulegen versucht:

„Lot2, Ernst Wilhelm -: Deutscher Schwärmer, Romantiker, verliebt in Wolken und

Wind. Schmal und lang, mit weiten Schritten durchs Gewühl der Straßen flammend.

Immer straßenfroh und bändehoch und beschwingter Besinger des Städtemeeres. Immer Tänzer, Schwimmer, Segler durch die blauen Gassen. Von seinen Hïften glitt ibm alle

Traurigkeit der Welt. Mit vorgeneigtem, verhalten-fieberndem Gesicht, mit beschwingten

Lungen atmete er ein den ungestïmen Tag, horchte beherzt auf seine Impulse bin und riß

${ }^{291}$ Hoffmann (1985), S. 114.

292 Textnachweis, Text I. 
die Inspiration, wenn sie kam so stürmisch wie ein Mädchen in die Arme. Melodienreicher Dichter in vierundswanzigjäbriger Jugend und Erdenseligkeit - immer zugetan dem heiß schwärmenden, begehrenden Blut - und das Herz, hochbaltend und die Vernunft wie eine Schnupftabakdose in der Rocktasche zu seltenem Gebrauch. "

Merkwürdigerweise ist dies ein ganz anderes Bild von Lotz, als das in sich versunkene Gesicht der Radierung. Ein „Schwärmer, Romantiker", „das Herz hochbaltend und die Vernunft wie eine Schnupftabakdose in der Rocktasche zu seltenem Gebrauch" soll Lotz sein - einer, der ,beherzt auf seine Impulse "hört - dieser mögliche Widerspruch zum Bildnis lässt sich nur so auflösen, dass die Melancholie der Augenpartie in der Radierung nicht die Nachdenklichkeit im eigentlichen Sinne meint, sondern eine vielleicht vergeistigte, schwärmerisch umherschweifende. Lotz scheint demnach keinesfalls eine von „Ratio“ beherrschte Person zu sein. Thesing betont auch, dass Lotz für Meidner das genaue Gegenteil seiner selbst verkörperte, nicht nur äußerlich, sondern vor allem in seiner Unbeschwertheit. ${ }^{293}$ Möglicherweise erklärt sich die Differenz des Ausdrucks auch aus der Differenz der Wahrnehmung Meidners. Der später aus der Erinnerung geschriebene Text wird angesichts der Kriegszeiten voller Schwärmerei und Überhöhung des gemeinsamen Glücks festgehalten worden sein. Die Monate in Dresden, wo er zusammen mit Lotz eine Zeitschrift gründen wollte, waren für Meidner auf jeden Fall eine wichtige und in vielen Teilen glückliche Zeit, auch wenn es wohl Auseinandersetzungen wegen ihrer unterschiedlichen Auffassung vom Krieg gegeben hat. Der Tod des Freundes, der sich als Kriegsbefürworter freiwillig zum Einsatz gemeldet hatte und gleich in den ersten Wochen fiel, war daher für Meidner ein tiefer Verlust. Auch das lässt sich aus Äußerungen in „Erinnerung an Dresden“ erkennen.

Unabhängig davon, welchen Eindruck Meidner von Lotz jeweils festgehalten hat, so ist doch die Übereinstimmung in der expressiven Behandlung im Text ebenso wie im Bild bemerkenswert. Sie lässt den Schluss zu, dass die psychologisierende Analyse des Gegenübers und ihre expressive Umsetzung für Meidner in beiden Bereichen kennzeichnend war, beziehungsweise als Anspruch in beiden Bereichen von ihm zum Ausdruck gebracht worden ist. Im Bild nutzt Meidner die Spannung der Linie, der Farbe und des Hell-Dunkel-Kontrasts und legt besondere Aufmerksamkeit auf die Ausarbeitung der Augen-Nase-Mund-Partie. Im Text sind es wie sonst auch die Auswahl ausdrucksstarker, assoziations- und emotionsreicher Wörter und hymnischer Tonfall, beziehungsweise ein melodischer Rhythmus, deren der Künstler sich bedient.

\section{Ergebnis}

Es ist in diesem Themenbereich aufgezeigt worden, dass das Motiv des Menschen bei Meidner einen großen Raum einnimmt. Seine Verwendung betrifft ganz unterschiedliche Lebens-, beziehungsweise Schaffensbereiche des Künstlers, die hier ob

${ }^{293}$ Thesing (1991), S. 100. 
ihrer Fülle nur angerissen werden konnten. Die anonymen Personendarstellungen innerhalb größerer Zusammenhänge konnten nur erwähnt bleiben, um zu viele Wiederholungen der Aussagen aus den entsprechenden anderen Themenbereichen zu vermeiden.

Die Porträts, die Meidner von sich selbst und von Menschen aus seinem Bekanntenkreis angefertigt hat, zeugen gleichermaßen von einer Porträtauffassung, die das Innere der Person nach außen zu kehren versucht, ihre Stimmung, ihre Eigenart analysierend zu erfassen und bildnerisch einzufangen sucht. Dafür nutzt Meidner das ganze Spektrum der malerischen, beziehungsweise zeichnerischen Mittel, die einem Expressionisten zur Verfügung stehen. Die Basis dieser Arbeiten ist der Gedanke der Menschenbrüderlichkeit, die alle Menschen, und auf den kleineren Rahmen von Meidners Lebensbereich übertragen, Künstler und Literaten miteinander verbindet. Aus diesem Gefühl der Verbundenheit begründet sich auch Meidners Anspruch, die Schönheit des Gegenübers nicht am Äußeren zu messen, sondern in dessen Seele zu suchen. Diesen Anspruch formuliert er auch im Traktat „Vom Zeichnen“ und versucht ihn als Dichter umzusetzen. Ob ihm die Umsetzung auch bei sich selbst gelingt, bleibt in seinen Selbstbildnissen etwas zweifelhaft, denn ganz ähnlich wie in den Textstellen spiegelt sich in ihnen ein innerlich zerrissener Künstler.

Das Leiden, das in den Selbstbildnissen (und häufig auch in den mit anderen Themen verknüpften Personendarstellungen) thematisiert wird, ist ein Gefühl, das sich durch große Teile von Meidners gesamtem Schaffen hindurchzieht. Es ist sein Lebenselixier, denn wie viele Expressionisten glaubte er an die Idee, dass es ihn - den Menschen überhaupt - der Erlösung näher bringen könne. Diese Idee ist hier genauso manifest, wie z. B. in den Apokalypsen oder den religiösen Kompositionen. Der Maler und der Dichter Meidner haben diese verschiedenen, grundlegenden Gedanken und Ansprüche gleichermaßen aufgenommen.

\subsubsection{Zusammenfassung der Untersuchungen}

Eines der in der Einleitung formulierten Hauptanliegen der Arbeit ist es, herauszustellen, welche Themen die hier exemplarisch untersuchten Doppelbegabten Ludwig Meidner und Oskar Kokoschka beschäftigten, welche Intentionen sich in ihren Werken ausdrücken, wie sie die Themen im jeweiligen Medium - Text und Bild - verarbeitet haben und in welchem Verhältnis die aus beiden Begabungen resultierenden Arbeiten zueinander stehen. Was ist nun die Quintessenz der Untersuchungen zur Doppelbegabung Meidners?

Etwas problematisch war zunächst die konkrete Abgrenzung der einzelnen Themenblöcke. Dies betrifft vornehmlich die drei zuerst untersuchten Bereiche „Stadt“, „Apokalypse“ und „Krieg“. Die Bilder behandeln häufig mehrere Aspek- 
te, weisen also Merkmale auf, die beispielsweise sowohl für die Auseinandersetzung mit der Großstadt, als auch für die mit der Apokalypse sprechen. Oder es werden apokalyptische und kriegbezogene Tendenzen miteinander vermischt. Auch gibt es Bilder, die in allen drei Kategorien einen Platz finden würden. Zusätzlich ließen sich nicht immer ganz passende oder eindeutige Texte zum Vergleich finden, denn auch in ihnen werden oft verschiedene inhaltliche Aspekte aufgegriffen. Diese Schwierigkeiten sind an entsprechender Stelle benannt worden. Und wenn auch versucht wurde, die vorgenommenen Zuordnungen argumentativ zu rechtfertigen, ist die Mehrdeutigkeit der Bilder und Texte dabei nicht unberücksichtigt geblieben, denn sie verdeutlicht wie eng diese Themen für Meidner beieinander lagen.

Die Darstellungen der Stadt zeugen von einer großen Ambivalenz zwischen der Wahrnehmung des urbanen Lebensraumes als Quelle faszinierender Inspirationen und zugleich in seinem zerstörerischen Einfluss auf den Menschen, wie es insbesondere das Gemälde „Ich und die Stadt" eindrucksvoll vor Augen führt. Die Bewegtheit und Dynamik der Großstadt spiegelt sich in der Expressivität von Sprachduktus und Malweise wider. Das apokalyptische Geschehen stellt Meidner in den zwei Varianten „Stadt-“ und „Landschaftsapokalypse“ dar und steht mit dieser pessimistischen Weltsicht in deutlichem Gegensatz zu den Erneuerungshoffnungen anderer Expressionisten. Wichtig sind hier die starken Bezüge zu biblischen Untergangsvorstellungen, die sich über Motive insbesondere von Naturkatastrophen, wie Ödnis, Flut, Feuer und ungewöhnliche Himmelserscheinungen manifestieren, wie beispielsweise „Apokalyptische Landschaft“ (Berlin) oder im Text „Anrufung des süßen, unersättlichen Züchtigers“. In den Themenbereichen Krieg und Revolution ist die Gewalt ablehnende Haltung elementar. Die kurzzeitige revolutionäre Euphorie, die sich z. B. in dem Aufruf „An alle Künstler, Dichter, Musiker" ausdrückt, ist ziellos und so bleibt es bei Meidners Skepsis, die beispielsweise im Gemälde „Barrikade“ deutlich wird. In der Behandlung des Menschen geht es dem Künstler vorrangig um die psychologische Erfassung des Inneren seiner Modelle, wie auch seiner eigenen Person, was sich in ähnlicher Weise z. B. auch in der Selbstbeschreibung in „Hymne an mich selbst" niederschlägt.

Allgemein lässt sich feststellen, wie groß die Nähe Meidners zur Literatenbohème war, die ihn bei der Auswahl seiner Themen und wohl auch in ihrer inhaltlichen Bewertung stark beeinflusst hat. ${ }^{294}$ Auffallend ist zudem seine hohe Sensibilität, die sich in Bildern und Texten gleichermaßen niederschlägt. Unter welch starkem Einfluss äußerer Gegebenheiten und innerer Bewegtheit er stand, zeigen beispielsweise die in beiden Medien zu findenden vielfältigen Kriegsschilderungen und eindrucksvollen Selbstbildnisse. Der Vergleich ergab, dass Meidners Schriften und bildnerische Werke in ihrer Intention vielfach übereinstimmen oder wenigs-

${ }^{294}$ Mehr dazu s. beispielsweise bei Becker (1991). 
tens denselben Grundtenor haben, obwohl sie in den meisten Fällen nicht im gleichen Zeitraum entstanden sind. Eigentlich war nur für die Aktivismus versprühenden revolutionären Aufrufe eine Differenz zu den zurückhaltenderen, pessimistischen Bildern des Themas „Revolution“ festzuhalten. Für beide Medien gilt, dass sie einen herausragenden Pazifismus und eine versteckte Menschenliebe zum Ausdruck bringen, die sich in gewaltablehnenden Apokalypse- und Kriegsdarstellungen, der Idee der Menschheitsverbrüderung und durchdringenden Freundesporträts manifestieren. Der religiöse Glaube scheint dafür prägend und überhaupt unterschwellige Isotopie im gesamten Schaffen zu sein, wenn es Meidner vielleicht auch nicht bewusst war.

Im bildkünstlerischen Bereich dominieren die Grafiken, im literarischen Bereich die Prosatexte. Beiden Medien ist auch eine hohe Expressivität gemeinsam, die sich in den Grafiken in einer schwungvoll-schnellen Pinsel- oder Federführung, abstrahierter Darstellung, unruhiger Komposition, aggressiver Gestaltung und in den Gemälden zusätzlich in einer ausdrucksstarken Farbpalette äußert. In den Schriften arbeitet Meidner vielfach mit Spontaneitätsgesti, Parataxe, Verlebendigung und insbesondere mit einer kreativen und assoziationsreichen Wortwahl. Deutlich differierend sind aber die Ausgeprägtheit beider Medien und ihre inhaltlichen Prioritäten. Das künstlerische Werk ist eindeutig von höherer Qualität und Quantität als das literarische. Tatsächlich war Meidner in erster Linie Maler und erst in zweiter Linie Schriftsteller. Während bei den Bildern die Auseinandersetzung mit aktuellen Themen, Ereignissen und Ideen im Vordergrund steht, dominieren in den Texten die autobiografischen Tendenzen. Kaum eine Passage über Gottesreflexion oder nach außen gerichteter Beobachtung kommt ohne Verweise auf den Künstler und sein persönliches Empfinden dabei aus. Von der starken Auseinandersetzung mit der eigenen Person zeugen bildnerisch nur die Selbstporträts - allerdings nehmen diese wie gesagt auch einen großen Raum im Schaffen des Künstlers ein.

Trotz dieser unterschiedlich ausgeprägten Ausübung seiner beiden Begabungen, sind sie beide lebenslang Teil seines Wesens und Meidners individuelle Möglichkeit, seine Wahrnehmung der Welt in und um sich herum in zwei verschiedenen Medien auszudrücken. Das war ihm ein Bedürfnis, das Hans Sahl, der ihn einmal in seinem Marxheimer Atelier besuchte, mit folgenden treffenden Worten beschrieb:

„(...) wieder spürte ich, während wir uns unterbielten, wie in ihm das Gewissen der Kunst arbeitete, der Trieb, sich Rechenschaft zu geben über das, was er sah und las und börte, in Sprache und Bildern zu formulieren, ein Literat und Künstler zugleich, ein Augenmensch und Wortmensch, ein zeichnender Schriftsteller und ein schreibender Seher, mit dem Lächeln der Weisheit und dem forschenden, ein wenig pfiffigen Gesicht. "295

295 Zitiert bei Grochowiak (1966), S. 217. 


\subsection{Oskar Kokoschka}

Oskar Kokoschka ist der zweite Künstler, der im Rahmen dieser Arbeit stellvertretend für die im Expressionismus bildkünstlerisch wie schriftstellerisch Tätigen untersucht wird. In den Betrachtungen zu Ludwig Meidner konnte bereits gezeigt werden, wie die politischen, soziologischen und künstlerischen Einflüsse der Zeit ihren Niederschlag im Schaffen des Künstlers gefunden haben und auf welche Weise - mit welchen Themen, welcher Gewichtung und welchen Ausdrucksmitteln - Meidner zugleich das allgemeine Streben nach der Zusammenführung der Künste als Maler, Grafiker und Dichter in individueller Weise umsetzte. Anders als Meidner, dessen literarisches Schaffen überwiegend in die Zeit seines Kriegsdienstes fällt, begann Kokoschka seine schriftstellerische Tätigkeit schon früh. Durch seine Auftragsarbeiten an den Wiener Werkstätten wurde er noch vor der Ausprägung seines expressionistischen Stils zu literarischer Produktion angeregt. Die Märchendichtung „Die träumenden Knaben“ stand dabei am Anfang dieser Entwicklung und die Mitarbeit als Schüler der Gewerbeschule an der Gestaltung des neu errichteten „Kabarett Feldermaus“ 1907 hat Kokoschka den ersten Kontakt mit der Bühne verschafft, für die er kurze Zeit später seine innovativen expressionistischen Dramen verfasste. Schriftstellerisches und bildkünstlerisches Schaffen in expressionistischer Manier verlaufen in der Folgezeit parallel. Doch in welchem Zusammenhang und Verhältnis stehen sie zueinander? Die folgenden Untersuchungen sollen diese Frage klären und weiteren Einblick in die individuelle Ausgestaltung expressionistischer Doppelbegabung geben. Für das Verständnis der Werke und ihrer Analysen, ist auch bei Kokoschka zunächst eine kurze Hinführung über die Biografie unerlässlich.

\subsubsection{Zu Biografie und Gesamtwerk}

Kindheit, Jugend und erste Künstlerjahre in Wien 1886-1909

Oskar Kokoschka wurde am 1. März 1886 als zweites von vier Kindern in Pöchlarn an der Donau in Niederösterreich geboren. Seine Mutter Maria Romana Loidl war eine energische Frau aus einem österreichischen Bauerngeschlecht. Väterlicherseits war die Familie von künstlerisch-handwerklichen und bäuerlichen Komponenten geprägt. Oskars Vater Gustav Kokoschka folgte seinem Vater (Wenzel Kokoska) als Goldschmied nach. Wenzel hatte sich in diesem Kunsthandwerk etabliert und gehörte zu den intellektuellen, sowie künstlerisch-musikalisch interessierten Kreisen Prags. Jedoch war Gustav Kokoschka nach dem Tode seines Vaters unstet, konnte seine Familie daher nur schlecht ernähren und verließ diese mehrfach, um der Misere zu entfliehen. ${ }^{296}$

296 Spielmann (2003), S. 11 f. 
Von seines Vaters Seite glaubte Oskar daher sein Streben nach Unabhängigkeit übernommen zu haben, während er seine visionäre Gabe und die Naturliebe der Familie mütterlicherseits zuordnete. So liebte er die Berge und Seen der Alpen, wo er oft die Ferien bei Verwandten verbrachte und sich außer mit den Ahnen seiner Mutter mit Flößern und Jägern identifizierte. Selbst die Heimatstadt Wien nahm er - im Vorort lebend - lange wie ein in Natur eingebundenes Dorf wahr, weshalb seine Kindheitsgeschichten um wenige, dörflich geprägte Orte kreisten. Auch wenn seine Erinnerungen an die Kindheit anscheinend positiv waren, so gab es doch auch verstörende Faktoren. Der Tod seines älteren Bruders und die ständig sich wiederholende Abwesenheit seines Vaters sind besonders zu nennen. ${ }^{297}$

1895-1904 besuchte Kokoschka die Staatsrealschule. In seiner Tätigkeit als Chorknabe der Wiener Piaristenkirche lernte er dort die expressiven, spätbarocken Deckenmalereien von Franz Anton Maulbertsch kennen, die ihn in seinem späteren Schaffen angeblich beeinflussen sollten. Kokoschka beschloss Zeichenlehrer zu werden und erhielt 1904 ein Staatsstipendium für die Kunstgewerbeschule des Österreichischen Museums für Kunst und Industrie. Dort stand er zunächst stark unter dem Einfluss der Wiener Secession, da mehrere ihrer Vertreter hier als Lehrer tätig waren. Als wichtigster Beitrag zur Wiener Werkstätte entstand 1905 sein märchenhaftes Bilderbuch „Die träumenden Knaben“ in einer Auflage von 500 Stück, in dem er seine Kindheit und die unerfüllte Liebe zu einer Kommilitonin verarbeitete. Zwar war es noch Gustav Klimt gewidmet und dem Jugendstil verhaftet, doch ist Kokoschkas Loslösung von den Wiener Werkstätten hier schon zu bemerken. ${ }^{298}$

1908 schrieb Kokoschka bereits auch seinen ersten Einakter: „Sphinx und Strohmann“. Im gleichen Jahr konnte er erstmals seine Werke in der von der Wiener Werkstätte und der Klimt-Gruppe veranstalteten „Kunstschau“ ausstellen. Als einziger junger Künstler wurde er neben den ehemaligen Secessionisten erwähnt, doch meistens eher ablehnend. Nur Wenige erkannten sein Talent an. Der Schriftsteller Ludwig Hevesi (1843-1910) prägte hingegen Kokoschkas legendären Titel als „Oberwildling“, woraufhin dieser sich als Zeichen des Protestes den Schädel kahl rasierte - das Stigma des Ausgestoßenen. Auf der Kunstschau lernte der Künstler in dem Architekten Adolf Loos aber auch seinen wichtigsten Mentor der folgenden Jahre kennen, der ihm Porträtaufträge verschaffte und in den Literatenkreis um Karl Kraus und Peter Altenberg einführte. Immer mehr kehrte er sich im Folgenden vom Ästhetizismus der Wiener Werkstätten ab. Im Jahr 1909 hatte Kokoschka weitere Erfolge zu verzeichnen. Er war Teilnehmer der „Internationalen Kunstschau“ in Wien und sein Stück „Sphinx und Strohmann“, sowie „Mörder, Hoffnung der Frauen“ von 1907 wurden im Gartentheater der Kunstschau aufgeführt. Außerdem löste Kokoschka sich durch den Einfluss von Loos

${ }^{297}$ Spielmann (2003), S. $12 \mathrm{f}$.

298 Schröder/Winkler (1991), S. 213. 
gänzlich von der Kunstgewerbeschule und den Wiener Werkstätten, so wie er überhaupt das Kunstklima in Wien als lähmend abzulehnen begann. ${ }^{299}$

Berlin, Wien, Kriegsdienst 1910-1917

Weiterhin schuf Kokoschka viele Porträts, wie beispielsweise „Conte Verona“ oder das Bildnis „Lotte Franzos“. Ab 1912 war er Mitarbeiter beim „Sturm“ und stand unter Vertrag bei Herwarth Walden, den er im März 1910 zum ersten Mal in Berlin besuchte. Berlin gab ihm das Gefühl in eine neue Zukunft aufzubrechen vielfältige Kontakte zu anderen Künstlern und ein exzessives Boheméleben folgten. Der weitgehend unbeachteten Ausstellung seiner Werke bei Cassirer schloss sich immerhin der erste Museumsankauf durch das Museum Hagen an. In diesem Jahr wurde auch sein Stück „Mörder, Hoffnung der Frauen“ publiziert, das entscheidenden Einfluss auf die frühexpressionistische Bühnenliteratur ausüben sollte. 1911 kehrte der Künstler nach Wien zurück, wo er jedoch tiefen Kränkungen ausgesetzt wurde: seine bei der Künstlervereinigung „Hagenbund“ ausgestellten Gemälde und Aktzeichnungen wurden als ,ekelhafte Pestbeulen“300 verurteilt und es sollten 13 Jahre vergehen bevor Kokoschka wieder bereit war, in Wien auszustellen. In den folgenden Monaten ist mit einer Gruppe religiöser Bilder, wie der „Kreuzigung“ und der „Verkündigung“, die Erschließung eines neuen Themenfeldes zu bemerken. 301

Das Jahr 1912 wurde für Kokoschka von besonderer Bedeutung. Zum einen wurde sein Name in dieser Zeit über die Landesgrenzen hinaus bekannt und er war an Ausstellungen in Budapest, und vor allem der „Internationalen Kunstausstellung des Sonderbundes“ in Köln beteiligt. Zum anderen begegnete er im April zum ersten Mal der Stieftochter des Malers Carl Moll und Witwe Gustav Mahlers: Alma Mahler, mit der ihn in der Folgezeit eine prägende und spannungsreiche Beziehung verband. Kokoschka hielt in Wien außerdem einen Vortrag mit dem Titel „Von der Natur der Gesichte“, worin er seine frühe Porträtkunst zu erklären sucht und die Wirklichkeit in Frage stellte - doch wurden seine Ausführungen vehement abgelehnt. Ende des Jahres erhielt er eine Assistenzstelle für Allgemeines Aktzeichnen an der Kunstgewerbeschule Wien, die sein finanzielles Auskommen absicherte. Dennoch geriet er in den nächsten Monaten in finanzielle Bedrängnis, hatte eine längere Krankheit zu überstehen und konnte seine Familie in Wien nicht wie sonst unterstützen. Immerhin stammen aus dieser Zeit die drei Doppelbildnisse mit Alma, die in eine Hochzeit mit dem Künstler einwilligte und ein gemeinsames Haus bauen ließ. Nach einer gemeinsamen Italienreise im Frühjahr 1913 begann Kokoschka mit dem bedeutenden Werk „Die Windsbraut“, welches mehrere Überarbeitungen erfuhr und ursprünglich „Tristan und Isolde“

\footnotetext{
299 Schröder/Winkler (1991), S. 214.

300 So der Wiener Kunsthistoriker Josef Strzygowski (zitiert bei Lachnit (2005), S. 117).

301 Schröder/Winkler (1991), S. 214 f.
} 
heißen sollte. Durch seine Beteiligung an weiteren Ausstellungen entwickelte sich Kokoschka zu einem der namhaftesten deutschen Expressionisten.

Es folgten für den Künstler schwere Jahre. Die Beziehung zu Alma war von Konflikten bestimmt. Als sie 1912 sein Kind abtreiben ließ, verarbeitete Kokoschka das in dem Gemälde „Stilleben mit Putto“. Auch die Dichtung, die 1915 unter dem Titel „Allos Makar“ (Anders glücklich) publiziert wurde, sowie die Lithografien zur Bach-Kantate sind von dem schwierigen Verhältnis der beiden geprägt. Nach Almas Auffassung hatte Kokoschka versucht sie von der Gesellschaft zu isolieren, weil er diese selbst nicht mochte; demgegenüber warf er ihr vor, sie habe ihn zu sehr mit ihrem berühmten und vermögenden ersten Mann verglichen. ${ }^{302}$

Als am 1. August 1915 der Erste Weltkrieg begann, meldete sich Kokoschka freiwillig. Möglicherweise tat er dies, weil das Ende der Beziehung mit Alma bereits absehbar war (sie heiratete im Jahr darauf Walter Gropius) - auf jeden Fall aber wollte er sich damit das Geld zur Unterstützung seiner Familie verdienen und empfand es außerdem als schändlich sich nicht an den Kämpfen zu beteiligen. Ein eindrucksvolles Resultat der Zerrissenheit des Künstlers zwischen der Verpflichtung beim Militär und seinem Liebeskummer ist das Gemälde „Der irrende Ritter“. Ab dem 22. Juli wurde Kokoschka an der Ostfront eingesetzt. Im August wurde irrtümlich sein Tod bekannt gegeben, nachdem er durch einen Bajonettstich in die Lunge und einen Kopfschuss schwer verletzt worden war. Im Lazarett Brunn, wo er sich anschließend erholen sollte, konzipierte er dann das wiederum auf Alma bezogene Drama „Orpheus und Eurydike“. Erst am 9. September 1916 kehrte Kokoschka nach Berlin zurück, nachdem er im August einem Granatschock erlegen und im Lazarett in Wien kuriert worden war. Hier schloss er mit Herwarth Walden einen Vertrag für drei Jahre zur Verwertung seiner Werke ab, den er aber bereits im Oktober wieder löste zugunsten eines Vertrages mit Paul Cassirer, der ihm im Gegenzug monatlich 2500 Mark und 25 \% der Erlöse zusicherte. Seine Bemühungen um eine Professur in Dresden blieben zunächst erfolglos und sollten erst nach Kriegsende entschieden werden. Ende des Jahres dann stand Kokoschkas „Windsbraut“ auf der 40. „Sturm“-Ausstellung im Mittelpunkt des Interesses. ${ }^{303}$

\section{Dresden 1917-1923}

1916 war auch das Jahr, in dem Kokoschka nach Dresden kam, wo er bis 1923 seinen Hauptwohnsitz haben sollte. Den Werken, die in dieser Lebensphase entstanden, wird trotz ihrer Vielfalt ,eine Geschlossenheit bescheinigt (...) wie keiner zweiten Gruppe innerhalb Kokoschkas Gesamtxuvre'304. Er war nach der Trennung von Alma Mahler dorthin geflüchtet und brauchte noch lange um über diese gescheiterte

\footnotetext{
302 Schröder/Winkler (1991), S. 216.

303 Schröder/Winkler (1991), S. 216.

304 Brugger (1991), S. 19.
} 
Beziehung hinweg zu kommen, wie es sich laut Brugger in der Bildabfolge der Gemälde „Windsbraut“, „Stilleben mit Putto und Kaninchen“, „Macht der Musik" und „Selbstbildnis an der Staffelei“" ablesen lässt. ${ }^{305}$ Dresden war somit im persönlichen Bereich für ihn eine Station tiefer Depressionen. Er mochte die Stadt auch an sich nicht besonders - aus Briefen geht immer wieder der Wunsch zu reisen hervor. In künstlerischer Hinsicht jedoch brachten ihm die Dresdner Jahre Erfolg und Anerkennung. 306

„Sphinx und Strohmann“ erweiterte er 1917 zu dem Drama „Hiob“, welches neben weiteren Werken Kokoschkas, wie „Mörder, Hoffnung der Frauen“ und „Der brennende Dornenbusch“, unter anderem im Albert-Theater Dresden zur Aufführung gebracht wurde. Daneben beschäftigte er sich weiter mit nordischen Dichtern, worin er durch die Teilnahme an einer Stockholmer Ausstellung bestärkt wurde. ${ }^{307}$

Als 1918 die Novemberrevolution ausbrach, beteiligte sich Kokoschka daran kaum. Im Vergleich zu Künstlern wie beispielsweise George Grosz oder Otto Dix fällt auf, wie wenig Kokoschka die gesellschaftlichen und politischen Missstände jener Zeit thematisierte. Er wurde sogar von diesen Künstlern angefeindet, als er 1920 einen „Appell an die Einwohnerschaft Dresden“ richtete, um vor der Zerstörung von Kunstwerken durch revolutionäre Handlungen zu warnen. Er selbst beschäftigte sich künstlerisch vor allem weiterhin mit dem Menschen als Bildmotiv. Es entstanden meist persönlichkeitsanalysierende Charakterbilder, wobei immer wieder Liebespaare, Konfliktpaare oder die Auseinandersetzung mit dem eigenen Ich im Mittelpunkt standen. Die „Figurenbilder sind [oft] eingespannt in persönliche Beriehungen "308. Lange sind viele dieser Bilder beispielsweise noch von der Verarbeitung der Beziehung mit Alma geprägt. Eine besondere Rolle spielte hierbei die lebensgroße Puppe, die er nach dem Vorbild Almas bei der Münchener Puppenschneiderin Hermine Moos als Fetisch anfertigen ließ und die, obwohl er von dem Ergebnis enttäuscht war, in mehreren Werken auftaucht. Erst 1920 warf er sie endgültig in den Müll. Als Produkte sehr persönlicher Erfahrung sind die von der Puppe motivierten Werke eine wichtige Episode in Kokoschkas Leben und Wirken. ${ }^{309}$

1919 erhielt Kokoschka dann endlich die ersehnte Professur in Dresden und wurde zudem Ehrenmitglied der Dresdner Secession. Es folgten 1920 und 1921 mehrere Aufführungen seiner Stücke unter anderem die Erstaufführung von „Orpheus und Eurydike" im Frankfurter Schauspielhaus und Beteiligungen an Ausstellungen wie der Dresdner Sommerausstellung der Künstlervereinigung. In der Öffentlichkeit wurde der Künstler aufgrund seines ausschweifenden Lebenswan-

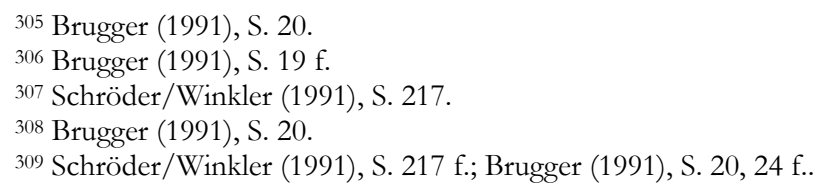


dels und verschiedener Affären als verrückt angesehen. 1922 gelang ihm eine gleichrangige Präsentation seiner Werke neben Max Slevogt, Max Liebermann und Lovis Corinth auf der Biennale in Venedig. In seiner Funktion als Professor arbeitete Kokoschka nicht besonders intensiv. Bereits ein Jahr nach seiner Berufung hatte er sich sieben Monate beurlauben lassen, um in Wien ein Haus für seine Familie zu kaufen. 1923 dann langweilte ihn das geregelte Professorenleben so sehr, dass er von der Akademie unabgemeldet in die Schweiz reiste und zunächst vom Innenministerium freigestellt wurde. Damit begann eine weitere Phase in Kokoschkas Leben, die von einer rastlosen Reisetätigkeit geprägt war. ${ }^{310}$

Paris und Reisezeit 1923-1933

In seine Professorenstelle kehrte Kokoschka nicht zurück, denn er sollte länger als die zwei freigestellten Jahre der Akademie fern bleiben. Zunächst ging er Ende 1923 nach Wien und blieb nach dem Tod seines Vaters im Oktober mehrere Monate bei seiner Familie. Im April und Mai 1924 reiste er nach Venedig und Ende des Jahres nach Paris, Zürich und Wien. Im folgenden Jahr ereignete sich der für Kokoschkas Leben und Schaffen ausschlaggebende Glücksfall, als ihm der Berliner Kunsthändler Cassirer unbegrenzten Kredit für die Ausführung seiner Reisewünsche gewährte. Die Kosten sollten mit den Einkünften der Verkäufe der dort entstehenden Werke verrechnet werden. Innerhalb der nächsten fünf Jahre reiste Kokoschka quer durch den Kontinent, wobei er von allen Reiseorten gemalte Ansichten schuf. Es entstand somit laut Lachnit ein ,monumentaler Zyklus von Städtebildern, der in der Kunst des 20. Jahrbunderts einzigartig dasteht “'311. Kurz gefasst ergibt sich folgendes Itinerar Kokoschkas in dieser Zeit: 1925: Südfrankreich, Spanien, Portugal, Holland; 1926: Norddeutschland, London; 1927: Berlin, Venedig, französische Alpen; 1928: Tunesien, Algerien; 1929: Kairo, Jerusalem, Damaskus, Athen, Istanbul, Venedig, Zürich, Schottland; 1930: wieder Nordafrika, Italien. ${ }^{312}$

Seit dem Weggang aus Dresden lässt sich an Kokoschkas Werken deutlich ein Wandel in der Komposition feststellen, der sich teilweise schon etwas früher angekündigt hatte, jetzt aber radikal wurde. Seine Bilder entstanden nun stets von einem erhöhten Standpunkt aus, von wo sich eine starke Aufsicht mit einer weiten Fernsicht verband. Bei den Ausstellungen, die Kokoschka in der Zwischenzeit immer wieder in Berlin mit diesen Werken beschickte, wurden sie begeistert aufgenommen und es folgte 1925 eine zweite Auflage der ersten über Kokoschka erschienenen Monographie von Paul Westheim (Erstauflage 1918). Als Cassirer im Januar 1926 Selbstmord beging, konnte Kokoschka glücklicherweise den Vertrag mit dessen Nachfolgern Grete Ring und Walter Feilchenfeldt erneuern. Weil

\footnotetext{
310 Schröder/Winkler (1991), S. 218.

311 Lachnit (1991), S. 30.

312 Lachnit (1991), S. 29-31; Schröder/Winkler (1991), S. 219.
} 
Kokoschka noch immer nicht zurückzukehren gedachte, wurde seine Professorenstelle in Dresden 1927 an Otto Dix vergeben. ${ }^{313}$

Die Niedergeschlagenheit, die Kokoschka zu den ausgedehnten Reisen getrieben hatte, konnte jedoch nicht gemindert werden. Dazu kam 1929 die Sorge sinkender Produktivität während der letzten Aufenthalte in Ägypten, Palästina, Athen und Venedig. Ein Jahr später gab es die ersten Angriffe auf die von den Nationalsozialisten so genannte „Entartete Kunst“, der auch Bilder Kokoschkas zugerechnet wurden. Einige davon beschlagnahmte man, um sie neben den Werken von Geisteskranken auszustellen. Noch konnte Kokoschka weiter arbeiten, beteiligte sich 1931 an Ausstellungen in Paris und wurde Gegenstand einer großen Retrospektive in der Mannheimer Kunsthalle. Doch wurde der Kreis seiner Käufer kleiner und nachdem die Galerie Cassirer aus diesem Grunde die monatlichen Zahlungen an ihn einschränken wollte, löste er den Vertrag und zog zunächst nach Paris, Anfang 1932 dann nach Wien. Erstmals befand er sich wieder in Geldnöten, die durch einige Verkäufe bei Ausstellungen in Dresden und der Biennale in Österreich nur unzureichend gelindert werden konnten. 1933 lebte er krank und ganz ohne Einkommen in Paris, wo er wegen eines ungedeckten Schecks Gefahr lief ins Gefängnis zu kommen. Nach der Ernennung Hitlers zum Reichskanzler am 30. Januar 1933 wurde Kunst „mit weltbürgerlichen oder bolschewistischen Vorzeichen“ zensiert und aus den Museen entfernt. Während viele Künstler ins Ausland flohen, unterstützte Kokoschka noch Liebermann im Protest gegen die Arierparagraphen, woraufhin weitere seiner Bilder beschlagnahmt wurden. Als seine Mutter erkrankte, zog er Ende 1933 zu ihr nach Liebhartstal. ${ }^{314}$

\section{Prag 1934-1938}

Nach dem Tod seiner Mutter zog Kokoschka 1934 geschwächt nach Prag und verblieb dort bei seiner Schwester Berta. Wiederholt malte er hier Bilder von einem erhöhten Standpunkt aus; während dieser Zeit lernte er auch seine spätere Frau Olda Palkovská kennen. Sein neuer Galerist wurde Hugo Feigl. Neben dem künstlerischen Schaffen wurde sein Engagement gegen den Nationalsozialismus immer intensiver. So wurde er 1935 auch Mitbegründer der „Union für Recht und Freiheit" und verfasste ein Jahr darauf den Aufsatz „Domine quo vadis“, worin er vor der Ideologie der Nationalsozialisten warnt. Nur kurz nach der ersten großen Kokoschka-Retrospektive in Wien wurden einige seiner Werke 1937 bei der Ausstellung „Entartete Kunst“ in München gezeigt und anschließend über 400 als „entartet“ beschlagnahmt. Kokoschka wehrte sich mit entsprechenden Aufsätzen, doch spätestens seit dem Einmarsch deutscher Truppen in Österreich 1938 geriet er immer mehr Bedrängnis. Durch die Flucht seiner Sammler kam er in finanzielle Not, harrte jedoch zunächst noch bei seiner kranken Schwester aus. Erst am 18.

\footnotetext{
313 Schröder/Winkler (1991), S. 219 f.
}

314 Schröder/Winkler (1991), S. 220 f. 
Oktober machte er seine Emigrationspläne wahr und flog mit Olda in der letztmöglichen Maschine von Prag nach London. ${ }^{315}$

\section{London 1939-1953}

Das künstlerische Schaffen Kokoschkas in den Jahren der Emigration ist geprägt von seinen eigenen Erfahrungen. Die politischen Allegorien, die fortan im Mittelpunkt seines Interesses standen, beschäftigen sich mit den damals aktuellen Entwicklungen in Europa. Dabei scheint es Kokoschka wichtig gewesen zu sein, seine Sicht des Krieges zur Darstellung zu bringen und seine Bilder wurden denn auch so wahrgenommen und weniger als Mahnungen. Er verwendete in den Allegorien eine Bildsprache, zu deren Verständnis eine eingehende Kenntnis des Werks unumgänglich ist. Es entstanden so bedeutende Bilder wie „Die Krabbe“ oder „Das rote Ei“. Weiterhin engagierte Kokoschka sich politisch auch aktiv, wobei er sich meist für Österreich aussprach. ${ }^{316}$

Am 15. Mai 1941 heirateten Olda und Oskar Kokoschka in London. Zwischen 1940 und 1942 gab es mehrere Kokoschka-Ausstellungen in den USA und 1944 in Österreich. Zu seinem 60. Geburtstag wurden ihm verschiedene Ehrungen zuteil und 1947 erschien die erste Kokoschka-Werkmonographie von Edith Hoffmann in London. Nach einem Besuch des Bruders in Wien 1947 und einem erfolglosen Versuch das Elternhaus in Liebhartstal zurückzuerlangen, kaufte sich das Paar Kokoschka 1951 ein Grundstück in Villeneuve am Genfer See. Damit war Kokoschkas Wanderschaft endlich beendet und diese Zäsur bedeutet zugleich den Beginn seines Spätwerks. ${ }^{317}$

Villeneuve 1953-1980

Im Jahr des Umzugs wurde die „Internationale Sommerakademie für Bildende Künste" gegründet, an der sich Kokoschka bis 1963 beteiligte, indem er jedes Jahr den bekannt gewordenen Kurs „Schule des Sehens“ leitete. Darin wollte er „in deren [bezieht sich auf die Kursteilnehmer] Geist und Herzen die Fähigkeit (...) erwecken, mit eigenen Augen zu sehen“318. In seinem Spätwerk beschäftigt Kokoschka sich wieder mit verschiedenen Themenbereichen, wobei er seiner Auseinandersetzung mit der Darstellung des Menschen und der Ausdruckkraft der Farbe treu bleibt. Das Thermopylae-Triptychon beispielsweise stellt die Frage nach der Verantwortung des Menschen sich selbst und anderen Menschen gegenüber. In anderen Bildern setzt sich Kokoschka mit seiner eigenen Person auseinander, wie zum Beispiel in „Time, gentlemen please“ mit seinem Tod oder in seinem letzten Selbstbildnis

\footnotetext{
315 Schröder/Winkler (1991), S. 222 f.

316 Lachnit (1991), S. 39 f.; Schröder/Winkler (1991), S. 223.

317 Schröder/Winkler (1991), S. 223 f.; Winkler (1991), S. 46.

318 Zitiert nach Schröder/Winkler (1991), S. 224.
} 
von 1969, das ihn vermutlich als Peer Gynt charakterisiert, mit der Zerrissenheit seines eigenen Wesens. ${ }^{319}$

In der zweiten Hälfte der fünfziger Jahre war der Künstler viel mit den Bühnenbildern für die Aufführung der "Zauberflöte“ bei den Salzburger Festspielen beschäftigt und auch in den 1960ern schuf er Bühnenbilder. Mehrfach unternahm er Mittelmeerreisen. 1958 wurde in München zu Kokoschkas Ehren eine große Retrospektive im Haus der Kunst eröffnet, wo 153 Bilder und 276 Grafiken von ihm zu sehen waren; mehrere große Ausstellungen schlossen sich an. Im Bereich der Publikationen war die Herausgabe seiner Schriften durch Hans Maria Wingler und zugleich des ersten CEuvre-Katalogs 1956 von großer Bedeutung. In den Jahren 1970-80 arbeitete Kokoschka zudem an der Niederschrift seiner Autobiografie „Mein Leben“ und ließ sich auch durch ein 1974 auftretendes Augen-Leiden mit anschließender Operation nicht davon abhalten, obwohl es ihn in seinem Schaffen behinderte. Sowohl zu seinem 80., wie auch zu seinem 90. Geburtstag wurde er durch verschiedene Ausstellungen gewürdigt. Im hohen Alter von fast 94 Jahren verstarb Kokoschka in einem Krankenhaus in Montreux, wo er auch beigesetzt wurde. 320

\subsubsection{Bild- und Schriftwerke der expressionistischen Phase}

Im Gegensatz zu Ludwig Meidner ist Oskar Kokoschka einer jener expressionistischen Künstler, die allgemein einen hohen Bekanntheitsgrad genießen. Bis heute ist sein Schaffen kontinuierlich Gegenstand internationaler Ausstellungen und umfassender Publikationen. Dass er nicht wie Meidner in Vergessenheit geriet, dürfte im Wesentlichen darin begründet sein, dass er stetige Unterstützung durch Freunde und Förderer erfuhr und die Kontakte zum Kunstbetrieb nie abreißen ließ. Selbst in den Jahren des Nationalsozialismus blieb er präsent, indem er sich von Wien und Prag aus gegen deren Ideologie zu Wort meldete.

Seine expressionistische Schaffensphase lässt sich parallel zur Kernphase des Expressionismus zwischen 1910 und 1920 ansetzen, wobei selbstverständlich auch einige Jahre zuvor und danach entsprechende Werke zu finden sind. Die frühesten Bilder entstanden zunächst unter dem Eindruck des Jugendstils, doch löste Kokoschka sich innerhalb kurzer Zeit von diesen Einflüssen und fand zu einer eigenen, expressiven Ausdrucksweise. Diese wurde mit seiner ersten Dichtung „Die träumenden Knaben“ 1907 eingeläutet und klang mit dem Wandel in Dresden, dem darauffolgenden Beginn seiner intensiven Reisen und den dabei entstehenden Landschaften während der 20er Jahre aus.

\footnotetext{
319 Winkler (1991), S. 46-50.

${ }^{320}$ Schröder/Winkler (1991), 224/225.
} 


\section{Erste Schritte}

Der Übergang im Schaffen Kokoschkas von den vom Jugendstil geprägten Anfängen hin zum expressionistischen Ausdruck vollzog sich wie gesagt um 1907. Zu diesem Zeitpunkt war der Künstler bereits seit drei Jahren an der Kunstgewerbeschule in Wien eingeschrieben, wo er von Anton R. Kenner und Carl Otto Czeschka unterrichtet worden war. Diese Schule war wesentlich Klimt und der Wiener Secession verpflichtet und dementsprechend hatte Kokoschka hier seine ersten Werke unter dem Einfluss von Jugendstil und Symbolismus angefertigt. 1907 begann er zudem Aufträge für die Wiener Werkstätten auszuführen, die eng mit der Wiener Kunstgewerbeschule und der Wiener Secession verbunden war. Unter anderem fertigte er Postkarten und Fächer und war darüber hinaus an der Ausgestaltung des literarischen Kabaretts „Fledermaus“ beteiligt.

Die Mitarbeit in diesem Kabarett weckte offenbar Kokoschkas Interesse für Theater und Literatur, denn er begann alsbald ebenfalls ein Stück zu konzipieren, das in der Endversion „Das getupfte Ei“ betitelt und 1907 aufgeführt wurde.321 Tatsächlich gelang ihm bald darauf sein Ausbrechen aus den Ausdrucksmodi der Secession zunächst im literarischen Bereich durch sein Märchenbuch „Die träumenden Knaben“, auf welches expressive Bildwerke ebenso folgen sollten, wie damals weitgehend als skandalös empfundene Bühnenstücke, die heute von vielen Literaturwissenschaftlern als Beginn des expressionistischen Theaters bewertet werden. 322

Da es sich um eine kunsthistorische Arbeit handelt, gilt für die Betrachtung von Kokoschkas Werk das gleiche wie für Meidner: Es soll in erster Linie von den bildkünstlerischen Werken ausgegangen werden. Dementsprechend werden die Themen ausgehend vom bildkünstlerischen Schaffen erörtert, wobei nicht in jedem Fall auch schriftliche Äquivalente in gleicher Qualität beziehungsweise Quantität bei Kokoschka zu finden sind.

\section{Expressionistische Bilder}

Kokoschkas expressionistische Hochphase im bildkünstlerischen Bereich erscheint thematisch, wie auch stilistisch, sehr vielgestaltig. ${ }^{323}$ Diese Vielgestaltigkeit soll in der nachfolgenden Betrachtung durch die Bestimmung der vorherrschenden Themen genauer beleuchtet werden. Auch wenn damit kein Anspruch auf Vollständigkeit erhoben werden kann und die Zuordnung der Werke zu bestimmten Themen nicht immer eindeutig ist, so erleichtert diese Vorgehensweise das Verständnis von Kokoschkas Entwicklung in seinen beiden Ausdrucksmedien während der 1910er Jahre. Zudem wird sie auch zugunsten der Vergleichbarkeit mit anderen Künstlern, wie in diesem Falle Ludwig Meidner, gewählt. Zwei The-

\footnotetext{
321 Schober (1994), S. 44.

322 Schober (1994), S. 39; Schvey (1982), S. 17; Lischka (1972), S. 55; Schwerte (1964), S. 172 f.

323 Vgl. Stöbe (1997), Spielmann (1994), Schwalenbach (1967), Wingler (1956a).
} 
men werden bei der Untersuchung von Kokoschkas Schaffen von besonderem Interesse sein: der Geschlechterkampf und die Darstellung des Menschen. Mit beiden hat sich der Künstler intensiv auseinandergesetzt und insbesondere Ersteres vielfach sowohl in Texten, als auch in Bildern verarbeitet. Entsprechend viel Raum wird diesen beiden Themenkomplexen innerhalb dieser Arbeit zu widmen sein. Der Geschlechterkonflikt steht zu Beginn der Betrachtungen, gefolgt von Untersuchungen zu religiösen Aspekten und der Darstellung des Menschen. Innerhalb dieser drei Gruppen findet zuweilen auch eine Vermischung statt, der so am einfachsten Rechenschaft getragen werden kann. Als weitere Themenkomplexe sollen Krieg und allegorische Darstellungen behandelt werden, die ebenso wie das Thema Religion einen kleineren Raum in Kokoschkas Schaffen einnehmen, dennoch aber natürlich ebenfalls von Bedeutung sind. Die Landschaften und Akte, die der Künstler in diesen Jahren schuf, können im Rahmen dieser Arbeit mangels entsprechender Vergleichstexte nicht berücksichtigt werden, da sie infolge dessen nichts zur Erhellung seiner Doppelbegabung beitragen. Der Materialvielfalt soll Rechnung getragen werden, indem Ölgemälde und Grafiken (meist Illustrationen) ebenso wie kunsthandwerkliche Arbeiten und Fresken zur Betrachtung herangezogen werden.

\section{Expressionistische Schriften}

Kokoschkas expressionistische Bestrebungen haben sich bemerkenswerter Weise zuerst in literarischen Arbeiten niedergeschlagen. Diese Tatsache ist umso erstaunlicher, als er zuvor ein schriftstellerisches Talent nicht hat vermuten lassen. ${ }^{324}$ Und doch folgen seiner schon am Übergang zum Expressionismus stehenden Dichtung „Die träumenden Knaben“ (1907) innerhalb kürzester Zeit weitere bedeutende expressionistische Texte. ${ }^{325}$ Ihre Anzahl bleibt insgesamt überschaubar (weshalb sie an dieser Stelle im Gegensatz zu den bildkünstlerischen Werken einzeln genannt werden können) und konzentriert sich insbesondere auf einen Zeitraum von zehn Jahren zwischen 1907 und 1917. Nach einem thematischen, wie formalen Wendepunkt um 1920 schuf er nur noch sporadisch Bühnenstücke und Dichtungen. ${ }^{326}$ Von den insgesamt sechs Schauspielen sind eigentlich nur vier als unabhängig voneinander entstandene Texte zu bewerten:

\footnotetext{
${ }^{324}$ Spielmann (2003), S. 43: „Mögen auch Einzelheiten auf den Blättern der, Träumenden Knaben' durch frühere Blätter vorbereitet sein (...) in der Sprache hat sich Kokoschkas Vermögen vor seiner Erstlingsdichtung nicht angekündigt".

325 Die Bedeutung der Bühnenstücke liegt dabei nach allgemeiner Auffassung weniger im verbalen Ausdruck, sondern vielmehr im sich ergänzenden Einsatz beispielsweise von Licht, Schatten, Farben, neuer Technik usw., welcher das Visualisieren von Gefühlen auf der Bühne ermöglicht. Vgl. z. B. Lischka (1972), S. 47 und 56 f.; Schober (1994), S. 82 ff.; Schvey (1986), S. 102 ff.

326 Schober (1994), S. 40.
} 
„Mörder, Hoffnung der Frauen“ (1908/09), „Sphinx und Strohmann“ $(1908 / 09)^{327}$, „Schauspiel“ (1911) und „Orpheus und Eurydike“ (1915). Zumeist haben sie verschiedene Überarbeitungen erfahren 328 und so sind „Hiob“ (1917) und „Der brennende Dornbusch“ (1917) zwei unter neuem Titel herausgegebene, weiterentwickelte Versionen von „Sphinx und Strohmann“ beziehungsweise „Schauspiel“. Neben den Bühnenstücken werden Kokoschka acht Dichtungen zugeschrieben, wobei auch hier verschiedene Fassungen eines Urtextes dazugezählt werden. „Die träumenden Knaben“ (1907), „Der weiße Tiertöter“ (1908), „Allos Makar“ (1913), „Lauschender“ (1918) und „Daisy“ (1921) sind eigenständig, während „Der gefesselte Kolumbus“ (1913) eine Weiterentwicklung von „Der weiße Tiertöter“ darstellt und „Spruch“ (1911) ebenso wie „Zueignung“" (1914) unter anderem auch als Widmungen anderer Texte verwendet werden. ${ }^{329}$ Schon vor den Einzeluntersuchungen darf hier darauf hingewiesen werden, dass die Auseinandersetzung mit dem Thema des Geschlechterkonflikts in verschiedenen Variationen nahezu jedem dieser Texte als Basis dient. Die Autorschaft Kokoschkas von „Lauschender“ ist nicht endgültig geklärt, da sie vom Künstler selbst geleugnet wurde. ${ }^{330}$ Als weitere Texte sind sein vom Grundgedanken her kunsttheoretischer Vortrag „Von der Natur der Gesichte“, den er 1912 im „Akademischen Verband für Literatur und Musik“ hielt, und der 1920 publizierte Essay „Vom Bewusstsein der Gesichte“ (vmtl. 1918 entstanden) zu nennen. ${ }^{331}$

Augenfällig ist die Tatsache, dass sich Kokoschkas schriftstellerisches Schaffen nach Abschluss seiner expressionistischen Phase verschob. Nach „Daisy“ (1921) verfasste er keine weiteren Dichtungen mehr und auch die Produktion der Bühnenstücke fand nahezu ein Ende. ${ }^{332}$ Kokoschka wandte sich dafür, insbesondere am Anfang der dreißiger Jahre, eher der literarischen Form der Erzählung zu. ${ }^{333}$

\footnotetext{
327 Bei beiden Bühnenstücken herrscht Uneinigkeit über die genaue Datierung. Kokoschka selbst glaubt sie 1907 geschrieben zu haben, doch gibt die Differenz zu „Die träumenden Knaben“ berechtigten Anlass, in neueren Publikationen ihre Entstehung 1908 oder 1909 anzusiedeln. Vgl. z. B. Schvey (1982), S. 67; Husslein-Arco (2008), S. 148.

328 „Sphinx und Strohmann“ wurde dreimal überarbeitet, „Mörder, Hoffnung der Frauen“ sogar viermal, „Schauspiel“ zweimal und „Orpheus und Eurydike“ immerhin einmal. Vgl. Lischka (1972), S. 56.

$329 \mathrm{~S}$. Anhang.

330 Secci (1968), S. 485.

331 Verwirrenderweise werden diese Texte in der Sekundärliteratur (beispielsweise bei Spielmann z. B. in seiner 1976 publizierten Anthologie von Kokoschkas Schriften) oftmals unter dem gleichen Titel benannt, was zur Verwechslung führen kann. Daher folgt diese Arbeit der Betitelung nach Wingler (1956).

332 Ausnahme ist „Comenius“ - ein um 1935 konzipiertes, unveröffentlicht und fragmentarisch gebliebenes Schauspiel.

333 Vgl. Wingler (1956).
} 


\subsubsection{Vergleichende formal-stilistische und inhaltliche Analyse}

\subsubsection{Das Ringen der Geschlechter}

Der Geschlechterkampf ist eines der Hauptthemen Kokoschkas in seiner Frühzeit zwischen 1908 und 1920, wenn nicht sogar das Thema dieser Jahre. Es ist als Grundtenor in nahezu jedem Schriftwerk dieser Zeit enthalten, regte den Künstler zu einer Vielzahl von Gemälden an und findet sich immer wieder auch in Illustrationen - selbst in solchen, die in einen ganz anderen Kontext gehören. ${ }^{334}$ Grund und Inspiration dafür mag neben persönlichen Erfahrungen die intensive Auseinandersetzung mit dem Geschlechterverhältnis und dem Sexualverhalten in verschiedenen philosophischen und psychologischen Schriften um 1900 - beispielsweise bei Otto Weininger (1880-1903) und Sigmund Freud -, ebenso wie in Werken z. B. August Strindbergs (1849-1912) und Frank Wedekinds (1864-1918) gewesen sein. ${ }^{335}$ Als zentrales Problem des Geschlechterkonflikts galt dabei vor allem die Sexualität, was der damaligen Gesellschaftsmoral entsprach, wie beispielsweise aus den Worten Stefan Zweigs (1881-1942) deutlich wird: „,...) diese Angst vor allem Körperlichen und Natürlichen war tatsächlich von den obersten Ständen bis tief in das ganze Volk mit der Vehemenz einer wirklichen Neurose eingedrungen (...) ".336 In der Thematisierung des Geschlechterkampfes, die vielfach vor allem in der expressionistischen Literatur ihren Platz gefunden hat, spiegelt sich der Versuch die bürgerliche Sexualmoral und damit zugleich die patriarchalen Strukturen zu überwinden. Für Kokoschka dürften insbesondere „Geschlecht und Charakter“ (1903) von Otto Weininger und „Das Mutterrecht“ (1861) von Johann Jakob Bachofen (1815-1887) inspirierend gewesen sein. So lassen sich Spuren von Weiningers Thesen in den Bühnenstücken wiederfinden, denen zu Folge der Dualismus zwischen Mann und Frau zugleich demjenigen zwischen Verstand und Trieb entspricht. Die Lösung des Konflikts liegt daher nach Weininger in der Enthaltsamkeit. Kokoschka scheint jedoch von Weiningers Ablehnung der Frau als unmoralisches Wesen und damit dem weiblichen als dem Manne unterlegenes Geschlecht abrücken zu wollen, wenn er sagt: „Ich habe immer aus Passion das Matriarchat über die Männerherrschaft gestellt‘ ${ }^{337}$; vielmehr rückt er damit in die Nähe Bachofenscher Ideen. ${ }^{338}$ Doch darauf lässt sich anhand der Beispiele besser eingehen. Es ist bei Kokoschka mit Rücksicht auf die Weiterentwicklung des Themas allerdings wichtig, zwischen verschiedenen Phasen zu unterscheiden, wie es im Folgenden geschehen soll.

\footnotetext{
334 Gleiche Einschätzung auch bei Lischka (1972), S. 76.

335 Mehr dazu s. bei Fleming (2006).

336 Zweig (1970), S. 64.

337 Kokoschka in einem offenen Brief an Paul Cassirer, in: Frankfurter Zeitung, Nr. 968/969; 31.12.1931.

338 Lischka (1972), S. 49 f.; Schober (1994), S. 66 f.
} 


\section{Zuordnung}

Zu Beginn befasste sich Kokoschka mit dem Konflikt zwischen den Geschlechtern allgemein. Ausgehend von ersten, die sexuelle Unsicherheit und Unerfahrenheit während der Pubertät spiegelnden, schriftlichen Ergüssen in „Die träumenden Knaben“, setzt sich die Auseinandersetzung in zugespitzter Form im Drama „Mörder, Hoffnung der Frauen“ und der Dichtung „Der weiße Tiertöter“ fort. Kokoschka findet dabei zu einer das Verhältnis der Geschlechter beschreibenden Symbolik, wie jener des Sonne-Mond-Gegensatzes oder der religiös inspirierten Pietà-Gruppe ${ }^{339}$, die sich ebenso im bildkünstlerischen Bereich wiederfinden beispielsweise im Plakat für das Sommertheater der Internationalen Kunstschau 1909. Als er mit Alma Mahler eine ebenso leidenschaftliche, wie turbulente Beziehung eingeht, wandelt sich seine Beschäftigung mit dem Thema des Geschlechterkampfes. Insbesondere die bildkünstlerischen Werke spiegeln sein persönliches Erleben, indem den Figuren die Züge des Künstlers und seiner Geliebten selbst verliehen werden. Die zuvor entwickelte Symbolik wird auch hier übertragen und weiter angewendet. Immer wieder stellt Kokoschka Alma und sich selbst in verschiedenen Phasen ihres emotionalen Verhältnisses dar - in Paarbildnissen, deren bedeutendstes Beispiel „Die Windsbraut“ ist, in Illustrationen zu seinen Schauspielen und insbesondere in den sechs Fächern, die er als sehr persönliche Geschenke für Alma fertigte. Die Dichtung „Allos Makar“ ist der literarische Ausdruck seiner widerstreitenden Gefühle. Kokoschkas persönliche Erfahrung prägt somit die Werke der zweiten Phase der Auseinandersetzung mit dem anderen Geschlecht. Das Ringen Kokoschkas mit Alma wird stellvertretend für das Ringen zwischen Mann und Frau, wie der Künstler es allgemein versteht. Die Überwindung des Konflikts durch den noch näher zu erläuternden Puppenfetisch bedeutet den Abschluss des Themas „Geschlechterkampf“ insgesamt.

Der grundsätzliche Geschlechterkonflikt im Spiegel der literarischen Anfänge

Die Dichtung „Die träumenden Knaben“340, die 1907 im Auftrag der Wiener Werkstätten entstand, markiert Kokoschkas Hinwendung zum Expressionismus. Sie war als Märchenbuch gedacht und sollte somit die Reihe der Kinderbücher ergänzen, deren Gestaltung zu den Lehrzielen der Kunstgewerbeschule gehörte und die sich der Gunst des Publikums erfreuten. ${ }^{341}$ Statt des gewünschten Bilderbuchs entstand ein unkonventionelles Bildergedicht. Der Dichtung waren acht Farblithografien und zwei schwarz-weiße Vignetten zur Illustration beigegeben, wobei sich allerdings nur die erste, dritte und achte farbige Grafik direkt auf den Text beziehen, während die übrigen eher eigenständig zu betrachten sind. Das Buch wurde im März 1908 in einer Auflage von 500 Exemplaren gedruckt und

\footnotetext{
339 Aufgrund der thematischen Vermischung, wird dieser Aspekt auch in den Untersuchungen zum Themenkomplex „Religion“ (Kap. 3.2.3.2.) wieder aufgegriffen werden.

340 Textnachweis, Text XX.

${ }^{341}$ Husslein-Arco (2008), S. 74.
} 
mit einer Widmung an Gustav Klimt versehen, welcher Kokoschka ermöglichte, es juryfrei an die Öffentlichkeit zu bringen. ${ }^{342}$

Im Keim ist dieses Märchenbuch thematisch und formal noch stark dem Jugendstil verhaftet. Vom Grundthema des „Sich-Finden-Wollens“ ausgehend spiegelt sich darin das pubertäre Erwachen des Eros, das erste Sehnen nach dem anderen Geschlecht und der Drang nach Tabubrüchen, dem das Motiv der Sehnsucht nach kindlicher Unschuld gegenüber gestellt ist. Die damit in Verbindung stehenden irrationalen Wünsche und Ängste werden sowohl im Text als auch in den Bildern in Assoziationsfolgen teilweise ohne logischen Zusammenhang oder einen Anfang, beziehungsweise ein Ende zum Ausdruck gebracht. Wie in traumhafter Atmosphäre steht auch Widersprüchliches nebeneinander. Exotische Anklänge, der Hang zur Ornamentik, Wellen- und Kreismotive verweisen deutlich auf die Nähe zur „Art Nouveau“. Dennoch markieren textimmanente Aspekte wie der hymnische Ton und Schreie, die Ausdruck von Ekstase oder expressivem Gestammel sein können, den Übergang zur expressionistischen Dichtung. Vielfach sind die Elemente des Jugendstils und des Expressionismus auch miteinander verknüpft - beispielsweise in der ersten Strophe, in welcher den ersten drei expressiven Zeilen: „rot fischlein/ fischlein rot/ // stech dich mit dem dreischneidigen messer tot/ / reiß dich mit meinen fingern entzwei“" das Jugendstilmotiv des Kreisens folgt: ,daß dem stummen kreisen ein ende sei".

In den Grafiken sind erste Anklänge expressionistischer Gestaltung durch die scharfen und eckigen Konturen der Figuren, die nichts mehr mit der dekorativen Schönlinigkeit des Jugendstils gemein haben und die - infolge einer scharfen Abgrenzung der Farbflächen durch starke Konturlinien - gesteigerte Farbintensität gegeben. ${ }^{343}$

Im Prinzip ist das Buch einfach aufgebaut: dem Text, welcher sich in einen Prolog und sieben weitere Abschnitte gliedert, die als „Träume“ bezeichnet werden, ${ }^{344}$ wird jeweils eine der acht Farblithografien zur Seite gestellt. Die verschiedenen „Träume“ werden jeweils durch den leicht variierten Satz „,...) und ich fiel nieder und träumte (...)" eingeleitet. Leider ist diese Unterteilung in der gedruckten Edition von 1908 nicht gleich ersichtlich, da der Text des ersten und des sechsten Traumes so lang ist, dass er nicht im Ganzen neben die Grafik passt und daher aus Platzgründen alle Träume ohne Unterteilung aufeinander folgen. Der Text nimmt dabei nur einen geringen Raum neben den Lithografien ein, was deren Eigenwert betont und eine nur illustrierende Funktion ausschließt. ${ }^{345}$

\footnotetext{
342 Husslein-Arco (2008), S. 75. Genaueres zur Drucktechnik und Ausführung s. bei Husslein-Arco (2008), S. 75-77.

343 Secci (1968), S. 459-461; Lischka (1972), S. 52 f.; Timm (1959), S. 70.

${ }^{344}$ Huysman (1992), S. 32; Unterteilung in acht Abschnitte erstmals durch Hadermann (1985), S. $297 \mathrm{f}$.

345 Reher (1993), S. 21.
} 
Die Dichtung steht zwar nur mit den drei genannten Grafiken (Nr. 1, 3 und 8) in direktem Bezug, dafür ist sie aber in sich bereits mit einer Fülle von Bildern gestaltet, die exotische Landschaften, wilde Tiere und primitive Wesen beschreiben. Versteckt darin eingeflochten finden sich in großer Dichte die oft eher assoziativ $\mathrm{zu}$ erfassenden Andeutungen ersten erotischen Begehrens und des Ringens mit den damit verbundenen Ängsten und Veränderungen. Im ersten Traum wartet das lyrische Ich zunächst, „, bei einem peruanischen steinernen Baum “ und ist inmitten einer tropischen Landschaft leisen Ängsten ausgesetzt („,...) die stummen tiere lockt/ blutraserinnen/ die zu vieren und fünfen aus den grünen atmenden seewäldern/ wo es still regnet/ wegschleichen (...)"), die sich in der Beschreibung eines anlegenden Schiffes verlieren („,...) ich böre die rufe der schiffer/ die in die länder der sprechenden vögel wollen/ die segel schwankten hin und her/ kalte luft bewegte sie und drehte die tücher/ das schiff legt an (...)"). Im zweiten Traum wird die sündhafte Erotik als eine dem Menschen selbst inne wohnende Gefahr angedeutet, wenn das Ich zuerst sich selbst als „wärwolf“ bezeichnet und schließlich auf die Existenz dieses Tieres in anderen Personen anspielt:

„(...) spürt ibr die aufgeregte wärme der zittrigen/ lauen luft - ich bin der kreisende wärwolf - (...)/ mein abgezäumter körper/ mein mit blut und farbe erhöbter körper/ kriecht in eure laubbütten/ schwärmt durch eure dörfer/ kriecht in eure seelen/ schwärt in euren leibern/ (...) ich verzehre euch/ männer/ frauen/ halbwache hörende kinder/ der rasende/ liebende wärwolf in euch/ (...),,

Im dritten Abschnitt träumt das lyrische Ich „von unaufhaltbaren änderungen" und zwar ,schluchzend und zuckend wie kinder/ die als pubere vom lager gehen“. Dieser offensichtliche Wandel vom Kind zum Jüngling wird beim Übergang zum nächsten Traum nochmals deutlich: „(...) ich erkannte mich und meinen körper/ und ich fiel nieder und träumte die liebe/ (...)".

In den nächsten Träumen spiegelt sich die Begegnung mit einem Mädchen namens „Li“", welches die verwirrenden Gefühle des lyrischen Ichs auf sich zieht und seine Sehnsucht nach Liebe konkret werden lässt $(,(. .$.$) ehe du mädchen li/ dein name$ klingelt wie silberbleche/ noch aus den gehängen der zinnoberblumen und gelbschwefelsterne tratest (...)"). Die anfängliche Angst (,.(..) und vor dir flüchtete ich in die gärten (...)"), kann der Jüngling schließlich überwinden (,....) weg du popanz meines sündhaften vorbehalts (...) hinab springe ich mit wehenden gewändern zur erde und wie ein hoher einziger ton steht hinter mir auf den gärten die sehnsucht/ (...)'). So bahnt sich im fünften Traum eine zweite Begegnung mit $\mathrm{Li}$ an, bei der er ihr insgeheim seine Liebe gesteht:

„(...) ich sage laut/ dich liebt das seegras auf dem du liegst/ und ich sage wohl auch/ dich liebt ein mann/ der neben dir auf dem seegras rubt in der bütte unter dem grünen baum"

Das Liebessehnen steigert sich im sechsten Traum schließlich gar zu einem Erkennen des Selbst im Anderen, welches Kokoschka auch späterhin noch themati- 
sieren sollte (,. (...) ob wie freue ich mich/ dass du mir gleichst (...) "). Den siebten Traum und somit zugleich die ganze Dichtung beenden die Zeilen „(...) und ich war ein taumelnder/als ich mein fleisch erkannte/ und ein allesliebender/ als ich mit einem mädchen sprach./" in denen Wandel und Erfahrung der Pubertät noch einmal zusammengefasst sind. Insgesamt betrachtet wird also zunächst auf einer ersten Stufe der Prozess der Veränderungen angedeutet, dann werden auf einer zweiten Ebene Liebe und Sehnsucht konkreter thematisiert und schließlich wird der Punkt erreicht, an dem der Jüngling durch die Begegnung mit dem Mädchen Li zu sich selbst findet. ${ }^{346}$

Die traumartige Atmosphäre, welche die Dichtung durchzieht, sowie das tabuisierte Thema pubertären erotischen Verlangens in der Kombination mit der Sehnsucht nach kindlicher Unschuld verweisen deutlich auf den secessionistischen Hintergrund des jungen Dichters Kokoschka. Doch werden, wie bereits erwähnt, diese Jugendstil-Elemente ganz deutlich mit solchen verknüpft, die als erste expressionistische Anklänge zu verstehen sind. Beispielsweise "vielfingrige blätterarme“, „seewälder", „,haare im meerwasser", die secessionistische Motive aufgreifen, stehen expressiv gebrauchten Ausdrücken, wie „blutraserinnen", ,kranke nacht" oder „menschenfressende fische" gegenüber (vgl. mit dem ersten Traum).

Auf formaler Ebene wird die inhaltlich kaum greifbare Zeitfolge - diese ergibt sich eigentlich nur durch die Abfolge der Träume, während die Geschehnisse im Wesentlichen als ein Nebeneinander erscheinen - durch fehlende Interpunktionen und die konsequente Kleinschreibung untermauert. Dazu passt auch die Willkürlichkeit in der Abfolge von gereimten und ungereimten Versen, sowie von strophischer und nicht-strophischer Einteilung, wodurch bindende und klare Strukturen unterlaufen werden, die den Eindruck des Diffusen und Traumhaften stören würden. Die Sinnzusammenhänge lassen sich somit meist nur aus den eingerückten Zeilenanfängen erschließen. Diese Wirkung des Neben- oder Aufeinanderstellens von Geschehnissen und Gefühlen findet ihre Entsprechung auch in den Grafiken. In einer frühmittelalterlichen Miniaturen verwandten Weise sind hier einzelne Bilder perspektiv- und teilweise anscheinend zusammenhangslos verbunden. Auch diese sind teils der „Art Nouveau“ (durch den stilisiert-dekorativen Stil) verpflichtet, teils weisen sie durch die Verwendung reiner Farben und exotischer Motive, die an die Kunst der Primitiven erinnern, erste expressive Anklänge auf. ${ }^{347}$

Von besonderer Bedeutung ist zudem die in der Dichtung angewandte Farbsymbolik. Sie ist nicht nur für Kokoschkas literarisches Schaffen während der expressionistischen Phase richtungsweisend, sondern ist explizites Mittel expressionistischer Lyrik. ${ }^{348}$ Am Auffälligsten ist die Verwendung der Farben Rot und Weiß, die im Kern für zwei gegensätzliche Landschaftstypen stehen können. Rot

\footnotetext{
346 Lischka (1972), S. 53.

347 Secci (1968), S. 460.

348 Vgl. z. B. Mautz, K.: Die Farbensprache expressionistischer Lyrik (1957). Kokoschkas Farbgebrauch stimmt allerdings nicht in allen Punkten mit Mautz 'Postulaten überein.
} 
ist dabei einer tropischen, Weiß einer eher nordischen Landschaft zugeordnet. Die nordische Landschaft wird besonders im sechsten Traum recht deutlich beschrieben: „(...) in die weißen wälder tret ich/ eines renntieres huf klingt und wirft in allen weißen wäldern wiederleuchtende schneesterne auf (...). "Doch verwandelt sie sich in traumhafter Manier in das Mädchen Li: „....) renntierreiterin/ und das rentier ist ein berg/ deine kleider sind eine schneefläche/ wo blumen werden/ die berübrung deiner dünnen finger (...). "Die Ruhe dieser Zeilen und die traditionell Reinheit assoziierende Farbe Weiß deuten auf die Unschuld der Gefühle, die der träumende Knabe hier hegt und die reine nordische Landschaft mag eine Art von verlorenem Paradies ${ }^{349}$ bezeichnen.

Das Rot hingegen wird insbesondere im Prolog verwendet, welcher in den ersten Traum und die dort beschriebene tropische Sphäre (,,...) aus den grünen/ atmenden seewäldern/ wo es still regnet (...)") einführt. Es steht darin für das Blut eines getöteten Fisches und kann im übertragenen Sinn zudem als Symbol sowohl für den Tod, als auch für eine gewisse Animalität des lyrischen Ichs im Moment des Tötens gedeutet werden. Auf Animalität und zugleich auf sündhaftes erotisches Verlangen verweisend wird es auch im sechsten Traum verwendet. Das Motiv aus dem Prolog wird wieder aufgenommen, indem der Schnee der nordischen Landschaft (= Li's Kleider; s. oben) zu einem See schmilzt und Li auf einem darin befindlichen ,roten Fischlein" sitzt. ${ }^{350}$ Das Mädchen ist nun nicht mehr die Figur in einer reinen, weißen Märchenlandschaft, sondern wird zum Objekt der verwerflichen Begierde des Knaben, der dazu anmerkt: „,...) ich hatte von dir nur gesehen deinen nackten hals in den haaren/ (...). "Rot und Weiß sind neben Schwarz tatsächlich besonders häufig verwendete Farben in der Lyrik expressionistischer Dichter. ${ }^{351}$ Kokoschka lässt an einzelnen Stellen des Märchenbuchs auch andere Grundfarben einfließen, doch bleiben Rot und Weiß die beiden Hauptfarben, die einen starken emotionalen Wert annehmen und bei Kokoschkas Dramen ebenfalls als Gegensatz weiter verwendet werden als Farben von Leben und Tod oder Geist und Eros. ${ }^{352}$

Auch wenn im Folgenden nicht jeder Traum für sich untersucht, sondern einer exemplarisch für alle betrachtet werden soll, so ist es doch für das Verständnis der gesamten Dichtung wichtig kurz auf den tieferen Gehalt des Prologs einzugehen. Es geht hier nicht nur um das vordergründige Motiv der Tötung eines Tieres auf kindlich-sadistische Weise, sondern wie Huysman darlegt, um ,eine Art verbüllte, poetische, ziemlich harmlose, aber doch schroffe Rache an Lilith Lang, die Kokoschka und seine Liebe abgelehnt hatte. "353 Lilith war die Schwester eines Freundes Kokosch-

\footnotetext{
349 Secci (1968), S. 466.

350 Diese Konstellation aus Fisch und darauf hockender Figur dürfte möglicherweise Max Klingers „Zweite Zukunft“ (1880) entlehnt sein. Vgl. Gleisberg (1992), Nr. 165. Hier wie dort wird auf den Geschlechtstrieb und die Versuchung des Menschen angespielt.

351 Siehe beispielsweise Gedichte von Georg Heym, Georg Trakl u. a. in Pinthus (1990).

$352 \mathrm{Vgl}$. Secci (1968), S. 462.

353 Huysman (1992), S. 51.
} 
kas. ${ }^{354}$ Sie findet ihre Entsprechung in dem kurz „Li“ genannten Mädchen der Dichtung, welches vom lyrischen Ich - das dementsprechend mit Kokoschka selbst in Verbindung gebracht werden kann - begehrt wird. Durch die Ablehnung in seinen Gefühlen verletzt, findet er im Prolog eine äußerst aggressive Form des Umgangs damit. Von Freud inspiriert, wird das Messer metaphorisch für das männliche Geschlechtsorgan verwendet, ${ }^{355}$ mit welchem gewaltsam (,,rot"verweist wie gesagt auf Blut) der Geschlechtsakt vollzogen wird. Dabei wird das metaphorisch für die Jungfräulichkeit stehende „Fischlein “getötet, das in die als Freudsches Symbol für das weibliche Geschlecht fungierende „Schale" sinkt. Damit wird dem „stummen Kreisen“, also dem sexuellen Begehren, ein Ende gesetzt. ${ }^{356}$ Der Prolog steht somit im Prinzip solitär und stimmt auf die nachfolgenden Träume ein.

„Die träumenden Knaben“ also, die Kokoschkas Übergang zum Expressionismus markieren - und daneben im Übrigen heute als eines der ,frühestens Lebenszeichen des literarischen Expressionismus "überhaupt gewertet werden ${ }^{357}$ - sind zugleich bereits Zeichen seiner Auseinandersetzung mit dem Konflikt der Geschlechter. Schon hier wird das Sehnen nach Vereinigung auf körperlicher und durch das Finden im Anderen auch auf seelisch-geistiger Ebene thematisiert. Und bereits hier erscheint diese Sehnsucht als eigentlich unstillbar, denn über den Traum geht die Beziehung nicht hinaus und bereitet dem lyrischen Ich die Pein widerstreitender Gefühle aus Liebe, Sehnsucht, Zweifeln, Angst und Zorn.

Doch geht es hier nicht um die Betrachtung des Textes allein, ${ }^{358}$ sondern um die Frage nach seinem Verhältnis zum Bild. Zunächst sind dazu die Illustrationen heran zu ziehen. Inwieweit lassen sie sich nun mit dem Text vergleichen? Zur Untersuchung dieser Frage eignet sich natürlich nur eines der Blätter, die in engerem Bezug zum Text stehen. Da der ganzen Dichtung die Problematik des Geschlechterverhältnisses zu Grunde liegt, bietet sich insbesondere die letzte Farblithografie „Das Mädchen Li und Ich“ (Abb. 40) mit der Gegenüberstellung von Knabe und Mädchen an, um die Behandlung dieses Themas in beiden Medien zu vergleichen.

Diese Grafik führt dem Betrachter zwei als Akte dargestellte Figuren vor Augen, die jede für sich in einer kurvilinearen Raumzone innerhalb einer flächig bis zum oberen Bildrand ausgebreiteten Landschaft eingefügt ist. Es handelt sich dabei um die Darstellungen eines Knaben und eines Mädchens, die sich von den Figuren der anderen Illustrationen dadurch unterscheiden, dass sie deutlich die Gesichtszüge Kokoschkas und Lilith Langs tragen und damit die persönliche Note der Dichtung unterstreichen. Dem Kompositionsprinzip der frühen Postkarten

\footnotetext{
354 Spielmann (2003), S. 42.

355 Freud (1994), S. 358.

356 Husslein-Arco (2008), S. 86.

357 Schober (1994), S. 46.

${ }^{358}$ Fortführend lassen sich dazu insbesondere Husslein-Arco (2008), S. 74-107, Huysman (1992) und Secci (1968) konsultieren.
} 
der Wiener Werkstätte folgend ist die Vordergrundszene collagenartig in die Landschaft aus Bäumen, Hügeln und einem sehr hoch gegebenen Horizont eingefügt. Die Körper der beiden Figuren wirken wie die Pubertierender - insbesondere das Mädchen verfügt über eine noch knabenhafte Gestalt mit wenig entwickelten Brüsten, fehlendem Schamhaar und eckig wirkenden Gliedern, wie sie auch im vierten Traum angedeutet werden (,,....) füblte die geste der eckigen drebung deines jungen leibes (...) "). Der Knabe mag vermittels seiner Körpersprache Kokoschkas eigenen Gefühlen Ausdruck verleihen: die Arme ängstlich und gleichsam schützend vor die Brust gezogen und mit unsicher überkreuztem Bein schaut er mit seitlich geneigtem Kopf schüchtern und schamhaft zu Boden. Das Mädchen wirkt dagegen ungleich selbstbewusster. Im Kontrapost steht sie dem Knaben gegenüber, die übereinandergelegten Hände an der rechten Hüfte aufgestützt. Doch ist auch ihr Blick gesenkt und ihr sich vom Knaben wegdrehender Oberkörper verrät $\mathrm{Zu}$ rückhaltung, wenn nicht gar eine gewisse Ablehnung. Durch diese Körperhaltungen - das Mädchen teils abgewandt, der Knabe introvertiert und jeder für sich in seiner weiß hinterlegten Raumzone isoliert - vermitteln das Gefühl einer nicht zu überwindenden Distanz zwischen beiden, die sich auch in den Zeilen des siebten Traumes „(...) es ist fremd um mich/ jemand sollte antworten (...) “widerspiegelt. Diese kann durch Kokoschkas Versuch, in der Dichtung einen anonymen Konflikt darzustellen als generell aufgefasste Distanz zwischen den Geschlechtern gedeutet werden.

Die die beiden Figuren wie Luftblasen umhüllenden Raumzonen werden durch eine dritte sich von der Landschaft abhebende Zone getrennt, die mit Rot gefüllt ist. Anders als bei Husslein-Arco angenommen, dürfte diese Tatsache aber nicht der Inspiration durch den roten Mantel Gottes in einer Cranach-Darstellung des Paradieses, auf welche sich Kokoschka bezogen haben soll, 359 geschuldet sein, sondern sicherlich die bereits angeführte Farbsymbolik der Dichtung aufgreifen. Die beiden an und für sich durch den weißen Hintergrund als unschuldig gekennzeichneten jungen Menschen werden durch die hier einfach als abstrakt und rot gehaltene Fläche, die das - wie im Gedicht mit der Farbe Rot in Verbindung gebrachte - sexuelle Verlangen symbolisiert, voneinander getrennt. Dieses Begehren steht bildhaft zwischen ihnen und macht eine Vereinigung auf der Ebene „reiner“ Gefühle unmöglich.

Der Bezug zur Paradies-Darstellung ist aber dennoch erhellend, handelt es sich doch auch bei „Das Mädchen Li und Ich“ um eine etwas abgewandelte Form dieses Themas. Die Figuren stehen wie das erste Menschenpaar unbekleidet in der Landschaft, sich ihrer Nacktheit noch nicht wirklich bewusst - daher die weiße, reine Aura. Sie sind umgeben von urtümlich wachsendem Grün, Blumen und einem friedlich ruhenden Hirsch. Diese Darstellungsweise ist durchaus analog zu anderen Paradies-Darstellungen, wie beim Vergleich mit dem bereits angeführten

${ }^{359}$ Husslein-Arco (2008), S. 98/Vergleichsabbildung 59 (Lucas Cranach d. Ä. „Paradies“, 1530, Kunsthistorisches Museum Wien). 
Cranach-Gemälde festzustellen ist, auch wenn natürlich Kokoschkas Grafik formal und inhaltlich in einen moderneren und persönlicheren Rahmen transponiert ist. Dass es sich um paradiesische Gefilde handelt, macht auch der Bezug zur Dichtung deutlich. Die hier beschriebene unschuldige und somit paradiesgleiche Schneelandschaft wird in der Grafik durch das Weiß der figurenbezogenen Raumzonen und die darin winterlich blattlosen Sträucher angedeutet. Kokoschka überträgt also die Unschuld Adams und Evas auf sich und Lilith, beziehungsweise auf die Unschuld von Heranwachsenden allgemein. Doch wie in der biblischen Erzählung wird auch ihnen das Erkennen des eigenen und des anderen Geschlechts zum Verhängnis und zur unüberwindlichen Hürde.

Der Gehalt dieser Grafik entspricht somit im weiteren Sinne dem der Dichtung. Der Konflikt und die Distanz zwischen den Geschlechtern werden in beiden Medien gleichermaßen zum Ausdruck gebracht. Weitere Parallelen sind die augenfällig verwendete Farbsymbolik und die Andeutung des persönlichen Erlebens, welche in den Gesichtszügen der Grafik deutlicher ablesbar ist als in der dichterischen Kurzform des Namen Lilith. In beiden Medien ist der Bezug zum Jugendstil deutlich vorhanden. Während er im Text allerdings hinter der expressiven Sprache zurücksteht, ist er im Bild dominant. Hier weist zwar die Verwendung der reinen Grundfarben, ihre flächige Absetzung voneinander und der vermutlich von George Minne inspirierte körperhafte Ausdruck der Figuren ${ }^{360}$ auf den Expressionismus voraus, jedoch ist der Eindruck in erster Linie vom ornamentalen und collagenartigen Stil des Jugendstils geprägt.

In besonderer Weise abweichend ist allerdings die Art, wie der Knabe in den beiden Medien dargestellt wird. In der Dichtung ,ein taumelnder" zwischen ,wärwolf" und ,jünglingsschaft", steht dem Betrachter in „Das Mädchen Li und Ich" ein gänzlich schamhafter Knabe vor Augen. Diese Differenz ergibt sich im Wesentlichen aus dem expressiveren Duktus des Textes einerseits und dem diesem gegenübergestellten, zurückhaltenden Darstellungsmodus des Jugendstils im Bild andererseits. Es ist dies auch die logische Konsequenz daraus, dass das Bild tendenziell nur einen Gemütszustand des Knaben fixieren kann, wohingegen die Dichtung narrativ verschiedene Verhaltensweisen aufgreift. Doch hätte Kokoschka sicherlich auch in der Grafik die im Text ambivalent beschriebenen Gefühle zwischen Angst und Aggression zum Ausdruck bringen können, entschied sich aber für die Darstellung der Schüchternheit. Insofern erscheint der Geschlechterkonflikt im Bild viel dezenter und vorsichtiger thematisiert, als in den aufgewühlten literarischen Artikulationen.

Wenngleich Kokoschka in seinem Märchenbuch „Die träumenden Knaben“ zugleich eine persönliche Ebene verarbeitet haben dürfte, so ließ ihn der Geschlechterkonflikt generell auch in der Folgezeit nicht los. Noch im gleichen Jahr

360 Zum Einfluss Minnes auf Kokoschkas frühen Figurenstil s. Spielmann (2003), S. 39. Dort finden sich auch Bemerkungen zu Zeichnungen von Akrobatenkindern, die den Illustrationen zu „Die träumenden Knaben" vorausgegangen sein sollen. 
- also ebenfalls 1907 - widmete er sich in seinem ersten Drama „Mörder, Hoffnung der Frauen" diesem Thema und es entstanden in engem Zusammenhang dazu stehende bildkünstlerische Werke, wie zum Beispiel die illustrierende Tuschfederzeichnung „Mörder, Hoffnung der Frauen III“ von 1910361, eine als Werbeplakat fungierende Farblithografie von 1909 mit dem sprechenden Titel „Pietà“ oder die Darstellung „Amokläufer“ von 1909.

„Amokläufer“ (Abb. 41) - eine mit Tusche und Tempera zu Papier gebrachte Darstellung eines tobenden Mannes - kann hierbei gleichsam als Schnittstelle zwischen „Die träumenden Knaben“ und „Mörder, Hoffnung der Frauen“ gesehen werden, denn das Blatt überträgt die durch Lilith hervorgerufenen Aggressionen auf die Ebene des im Drama formulierten, sehr gewaltsam ausgetragenen Geschlechterkampfes. Auf schwarzer Fläche wird durch weiße Linien schematisch eine Straßenflucht mit Kopfsteinpflaster angedeutet, aus deren perspektivisch übersteigerter Tiefe ein Amokläufer mit Dolch und Fackel bewaffnet vorwärts stürmt. Er scheint an mehreren Stellen seines Körpers „,in Flammen zu stehen“: kleine Feuersäulen entspringen an seinen Extremitäten und im Hüftbereich. Die Miene ist verzerrt, der Körper befindet sich in unnatürlich verrenkter Haltung, die an eine Kreisform mit Speichen angelehnt erscheint. ${ }^{362}$ Am rechten Bildrand werden vier unterschiedliche Frauenfiguren über- und hintereinander gestaffelt vor Augen geführt. Ihnen allen ist ein leidvoller Ausdruck durch geränderte Augen oder gesenkte Blicke gemeinsam. Zwei von ihnen halten - wohl in Angst vor dem Vorbeirasenden - in schützender Geste ihre Arme vor den Oberkörper, von einer dritten ist nur der Kopf mit den geschminkten vollen Lippen ins Bild gebracht, während die vierte halbentblößt und mit hervorstechend weißer Hautfarbe dargestellt ist. Auffällig ist zudem die Profilansicht eines Mannes, die, ganz in Schwarz gehalten, an einen Scherenschnitt erinnert. Zwar nicht akkurat in der Bildmitte, aber doch prominent ein wenig nach rechts verschoben, ist auf dem fackeltragenden linken Arm des Amokläufers eine Tätowierung zu erkennen, die neben Anker, pfeildurchbohrtem Herz und Vogel die Initialen „OK“ und „L.L.“ zeigt. Diese Buchstaben dürften als Kürzel für die Namen Oskar Kokoschka und Lilith Lang stehen und liefern damit den Schlüssel zum Verständnis des Bildes. ${ }^{363}$ Liliths Ablehnung von Kokoschkas Liebe ist Ursache der Aggression, die hier in überaus expressiver Weise ins Bild gesetzt wird und sich schließlich in blinder Wut gegen alle Frauen - dargestellt durch wenige Stellvertreterinnen verschiedenen Alters und unterschiedlicher Couleurs - entlädt. Die Flammen an der Fackel und an der Kleidung des Aggressors, der somit mit Kokoschka selbst in Verbindung zu bringen ist, können metaphorisch sowohl für die Flammen der Liebe stehen, in die der Künstler für Lilith entbrannt war, als auch für jene des Hasses nach ihrer Absa-

\footnotetext{
${ }^{361}$ Kokoschka selbst verortet die Entstehung der Zeichnungen zum Drama 1908, doch ist lt. Husslein-Arco (2008) eine Datierung um 1910 aus stilkritischen Gründen überzeugender. Vgl. S. 192. 362 Husslein-Arco (2008), S. 142.

363 Schvey (1982), S. 42; Husslein-Arco (2008), S. 142.
} 
ge. ${ }^{364}$ Durch ihre auffällig weiße Hautfärbung, die sich auch im Oberkörper und dem tätowierten Arm des Amokläufers wiederfindet und so eine Verbindung zwischen den beiden Figuren herstellt, hebt sich die halbnackte Frau von den anderen $\mathrm{ab}$ und könnte stellvertretend für Lilith als Objekt der Begierde ins Bild gesetzt sein. Allerdings hat sie, anders als in „Das Mädchen Li und Ich“, keine Ähnlichkeit mit ihr, ebenso wenig wie der Amokläufer tatsächlich die Züge des Künstlers trägt. Dagegen mag die männliche Schattenfigur mit dem kahlen Kopf am unteren Bildrand als Profil Kokoschkas gedeutet werden, der wie bei einer nach innen gerichteten Seelenschau ins Bild und somit auf sein eigenes aggressives Ich blickt.

Dieses Bild ist im Vergleich zu „Das Mädchen Li und Ich“ bereits deutlich expressiver gestaltet. Zu den akzentuierenden schwarzen Konturlinien kommt die Dynamik der Bewegung innerhalb des Kreismotivs hinzu. Zudem wird die Dramatik des Geschehens durch das Kolorit betont. Kontrastreich stechen hier die Weißhöhungen vor dem schwarzen Hintergrund heraus und wurden im ursprünglichen Zustand durch schwefeliges Gelb ${ }^{365}$ der Flammen in ihrer Wirkung unterstützt. Ein etwas speziellerer Bezug ist jener zu ostasiatischen Tuschmalereien und Dämonendarstellungen, ${ }^{366}$ der sich in den dekorativen, feinlinigen Rauchwolken der Fackel und der Darstellung des Amokläufers - insbesondere in seinem verzerrten Gesicht und dem wehenden Kopftuch - andeutet.

Der Geschlechterkonflikt erfährt in diesem Bild im Vergleich zu „Die träumenden Knaben" und der dazugehörigen achten Farblithografie eine deutliche Steigerung. Selbst im Verhältnis zur Dichtung gesehen, die durchaus aggressives Potential birgt (s. o.), geht Kokoschka hier noch einen Schritt weiter: aus dem Konflikt wird offenbar Kampf. Es geht nicht mehr darum nur eine Distanz zwischen den Geschlechtern zu thematisieren, sondern um eine Auseinandersetzung auf Leben und Tod. In „Amokläufer“ ist dabei noch eine deutliche Gewichtung zugunsten des Mannes zu beobachten - er ist es, der aktiv handelt und als bewaffneter Angreifer die Oberhand hat, während die Frauen passiv, wehrlos und schutzbedürftig dargestellt sind.

In seinem ersten Drama „Mörder, Hoffnung der Frauen“367 dagegen ist diese einseitige Machtverteilung größtenteils aufgehoben. In plakativ-bildhafter Weise entfaltet sich darin in einer einzigen Szene ein wahrhaft archaisch anmutender Kampf der Geschlechter, in dessen Verlauf bald der Mann, bald die Frau unterle-

\footnotetext{
${ }^{364}$ Bereits in der Literatur des 19. Jahrhunderts war die Flamme als Metapher für das Anziehende und zugleich Verzehrende gebräuchlich, wobei der dem Untergang geweihte Falter mal mit dem einen mal dem anderen Geschlecht gleichgesetzt wurde. Vgl. dazu Praz (1970), Bd. 1, S. 183 f. Das Symbol der Flamme spielt auch in anderen Werken Kokoschkas, zum Beispiel in „Hiob“, eine wichtige Rolle.

365 Husslein-Arco (2008), S. 142.

366 Husslein-Arco (2008), S. 142.

367 Textnachweis, Text XXI.
} 
gen ist. Doch sind die zwei Pole so unversöhnlich, dass nur der Sieg einer Seite zur Konfliktlösung führen kann. 368

Kokoschka brachte dieses Stück erstmalig 1909369 im Gartentheater der Kunstschau in Wien zur Aufführung. Die Darsteller waren Schauspielstudenten, die Kostüme und das Bühnenbild denkbar kostensparend und die Vorbereitungen sehr kurzfristig. Der auf nur wenigen Seiten festgehaltene Text bestand zu einem Drittel aus Regieanweisungen und es ging Kokoschka dementsprechend auch mehr um die bildhafte Ausdrucksweise, die er noch kurz vor der Aufführung durch Anweisungen zu Mimik, Gestik usw. den Darstellern zu vermitteln suchte. ${ }^{370}$

Das Stück hat nur eine Szene, in der zwei Charaktere - nämlich schlicht Mann und Frau - einander gegenübergestellt sind. Sie werden durch einen Chor von „Kriegern“ und einen „Mädchen“-Chor unterstützt. Zeitlich ist das Stück im Altertum verortet und das Bühnenbild beschränkt sich im Wesentlichen auf einen mit einem Käfig versehenen Turm. Der abgedunkelte Raum sollte nur von Fackeln erleuchtet sein. ${ }^{371}$ Die Gesamtentwicklung des Stücks lässt sich, wie Schober aufzeigen konnte, analog zum Tragödienschema in fünf Phasen teilen. In der Exposition werden Mann und Frau eingeführt. Er hat ein weißes Gesicht, trägt eine blaue Rüstung und dazu in Folge einer Verletzung eine Bandage um den Kopf. Sie hat blondes Haar und tritt in einem roten Kleid auf. Durch die Begegnung der beiden wird der Konflikt aufgebaut. Zunächst fürchtet sich die Frau, während der Mann verwirrt von ihrem Auftreten ist, doch dann findet er zu seinem kriegerischen Gebaren und befiehlt die Frau zu brandmarken. Sie wehrt sich und verletzt ihn mit einem Messer. Diese gegenseitigen Gewalttaten führen zur Peripetie. Der durch die Messerwunde geschwächte Mann wird in den Käfig des Turmes gesperrt. Während Krieger und Mädchen erotischen Vergnügungen frönen, kann die Frau nicht von ihm lassen, umkreist den Käfig und traktiert seine Wunde. Zunächst ist sie dabei in der aktiven Position und der Mann aufgrund seiner Schwäche passiv. Doch wandelt sich sein Zustand und er erstarkt, wohingegen die Frau an Kraft verliert, was sich mehr aus den Regieanweisungen ablesen lässt als am gesprochenen Text („Frau (zitternd): ,Du, stirbst nicht? - Der Mann (kraftvoll): ,Sterne und Mond! Frau!' (...)'). Diese Retardierung endet damit, dass die Frau schließlich den Käfig wieder aufschließt, der Mann sich befreit und die Frau daraufhin sterbend zusammensinkt. Das Stück endet in einer finalen Katastrophe: der Mann erschlägt die ängstlich fliehenden Krieger und Mädchen und verlässt durch ein Flammeninferno die Bühne. ${ }^{372}$

\footnotetext{
${ }^{368}$ Lischka (1972), S. 48.

369 Seit Werkner wird angenommen, dass auch die Entstehung des Stücks auf 1909 zu datieren ist.

S. Werkner (1986), S. 104.

370 Schvey (1982), S. 31.

371 Schvey (1982), S. 33.

372 Schober (1994), S. 68-70; Schvey (1982), S. 33.
} 
In diesem kurzen Handlungsstrang wird der Konflikt zwischen den Geschlechtern auf den Punkt gebracht - wie in „Die träumenden Knaben“ geht es im Grunde um das Ringen mit dem eigenen Sexualtrieb und um die daraus resultierenden Macht- und Abhängigkeitsverhältnisse zwischen den Geschlechtern. Doch erschließt sich diese Aussage nicht sofort, denn bei dem Stück handelt es sich um eine komplexe „Komposition bewegter Bilder aus Sprache, Gebärde, Form und Farbe, die assoziativ Gefüble und Gedanken in den Raum projizieren" "373 Schwierigkeiten bei der Rezeption macht daher neben dem Vorhandensein von vier Fassungen ${ }^{374}$ vor allem die Tatsache, dass die Funktion der Sprache eigentlich nur sekundär ist:375 „Kokoschka meinte wirklich Schau-Spiel, optisches, gestisches, mimisches Spiel, vom geraffen Wort nur gelenkt.' ${ }^{376}$ Der Text der Figuren verharrt oft in eher rätselhaften Andeutungen (z. B. „1. Mädchen: ,Unsre Frau ist eingesponnen, hat noch nicht Gestalt erreicht. “) oder besteht nur aus Satzfragmenten und Schreien, die den zuweilen unlogisch erscheinenden Handlungsablauf wenig erhellen. Beispielsweise bleibt unklar, warum der Mann aus seiner anfänglichen Lethargie erwacht und entscheidet die Frau zu brandmarken. Auch entwickelt sich kein wirkliches Gespräch, sondern jede Figur agiert prinzipiell für sich, so dass der Text eher einer Aneinanderreihung von Monologen und abrupten, gleichsam im Stakkato gesprochenen Einzelsätzen entspricht. So entsteht der Eindruck von Spontaneität und Unwirklichkeit und eine traumhafte Atmosphäre, ähnlich wie in „Die träumenden Knaben“ wird vermittelt. Doch ist sie diesmal viel brutaler, direkter - eher einem Alptraum vergleichbar.

Zwar lässt sich aus der Satzabfolge einigermaßen erahnen, dass Mann und Frau in ambivalente Gefühle verstrickt sind und dass Begehren dabei eine wichtige Rolle spielt - beispielsweise spricht die Frau zu Beginn „Mein Auge sammelt der Männer Froblocken. Ibre stammelnde Lust kriecbt wie eine Bestie um mich", und der Mann singt nach der Messerattacke der Frau: „Sinnlose Begehr von Grauen ₹u Grauen, unstillbares Kreisen im Leeren" -, doch erst durch das Zusammenspiel mit den visuellen Elementen wird das Stück verständlicher. Interessanterweise sind einige Motive aus „Die träumenden Knaben“ hier in der Rede wieder zu finden, wie das eben zitierte „unstillbare Kreisen", das dem „stillen Kreisen" aus dem Prolog der Märchendichtung verwandt ist, oder das ebenfalls dort verwendete Motiv des „Fischleins", das im Drama in der höhnischen Rede des dritten Kriegers wieder auftaucht (, $A n$ Haken bängt Fischlein. Fiscbin hakt sich Fischer!"). Durch diese identische Motivwahl wird die Weiterführung der in der Dichtung aufgegriffenen Thematik sprachlich im Drama kenntlich gemacht. Dass das Paradox von Anziehung durch Begehren

\footnotetext{
373 Schwab (1996), S. 70.

374 Näheres dazu s. bei Lischka (1972), S. 65; Schvey (1982), S. 35.

375 In der Sekundärliteratur zeichnet sich die Tendenz ab Kokoschkas Bühnenproduktion nicht wegen seiner literarischen Qualität positiv und innovativ zu bewerten, sondern wegen Kokoschkas Leistungen als expressionistischer Regisseur und Bühnenkünstler! Vgl. dazu Schwerte (1964), Lischka (1972), Schvey (1982 und 1986), Schober (1994), Schwab (1996).

376 Schwerte (1964), S. 183.
} 
und Abstoßung durch Dominanzwunsch und die daraus resultierenden Abhängigkeiten und Machtverhältnisse im Drama als Kernproblem des Geschlechterverhältnisses propagiert werden sollen, wird am deutlichsten durch die Worte der sterbenden Frau:

„Ich will dich nicht leben lassen. Du!/ Du schwächst mich - / Ich töte dich - du fesselst mich!/ Dich fing ich ein - und du bältst mich!/ Laß los von mir - Umklammerst mich - wie mit eisernen/ Ketten - erdrosselt - los - Hilfe!l Ich verlor den Scblüssel - der dich festbielt."

Entscheidend für das Verständnis des Stücks und für die Darstellung des Geschlechterkampfs sind aber wie gesagt vor allem die visuell fassbaren Elemente, die vielfach mit bedeutsamer Symbolik aufgeladen sind. Hervorstechend sind hier zum einen die neuerliche Verwendung von Kokoschkas persönlich geprägter Farbsymbolik, die schon in „Die träumenden Knaben“ und „Das Mädchen Li und Ich“ zum Tragen kam, und zum anderen das als Bedeutungslandschaft angelegte Bühnenbild. Der Bühnenaufbau nutzt nämlich auffälligerweise nicht die Breite oder Tiefe des Raumes, sondern betont durch den Turm die Vertikale, so dass auch die Darsteller in der Vertikalbewegung agieren müssen. Implizit werden durch diese Aufteilung in „oben“ und „unten“ gewisse Machtverhältnisse charakterisiert. Darüber hinaus werden Turm und Käfig in der Sekundärliteratur überzeugend als Symbole für Phallus und Vagina gedeutet. ${ }^{377}$ Der Käfig als Symbol für das weibliche Geschlechtsorgan war schon in der niederländischen Genremalerei des 17. Jahrhunderts gebräuchlich, ${ }^{378}$ und wird hier von Kokoschka in ähnlicher Weise verwendet. Nachdem der Mann den Entschluss gefasst hat, die Frau besitzen zu wollen - was durch die Brandmarkung verbildlicht werden soll - und somit ihren Reizen erliegt und von ihr verwundet werden kann, wird er in den Käfig gesperrt. Er wird also zum Opfer seines Begehrens, das er für die Frau empfindet und ist somit im übertragenen Sinne Gefangener ihres Fleisches. Die Frau hat in dieser Situation die Oberhand, klettert auf dem Käfig umher und maltretiert den geschwächten Mann. Letztlich aber kann sich der Mann offenbar von seiner Triebhaftigkeit und somit aus dem Käfig befreien und tötet in Ablehnung der Sexualität die sich miteinander vergnügenden Krieger und Mädchen. Zu Recht verweist Schvey in diesem Zusammenhang neben der antiken und mittelalterli-

\footnotetext{
377 Schvey (1982), S. 36; Schober (1994), S. 74.

378 Die Darstellung eines aus dem Käfig genommenen oder entflohenen Vogels war ein beliebtes Motiv in der Liebessymbolik des 17. Jahrhunderts. So konnte der gefangene Vogel sowohl das Gefangensein durch die Liebe als auch das Bewahren der Jungfräulichkeit verbildlichen. Bezüge hierzu finden sich im niederländischen Sprachgebrauch des Wortes „vogelen“ (vgl. mit der deutschen Vulgärsprache für Geschlechtsverkehr) und ebenso in der zeitgenössischen Emblematik. Siehe dazu beispielsweise Müller (1978), S. 117 und 159 oder auch Rijksmuseum (1976), S. 201. Diese Symbolik wurde auch noch bis ins 18. und 19. Jahrhundert verwendet.
} 
chen Anthropologie ${ }^{379}$ vor allem auf die Theorien Weiningers als Inspirationsquelle, denen zu Folge der Kampf der Geschlechter ein Kampf zwischen höherer, spiritueller Kraft - diese ordnet Weininger dem Mann zu - und niedriger, animalischer Kraft - gleichgesetzt mit der Frau - sei. Dementsprechend überwindet der Mann in „Mörder, Hoffnung der Frauen“ das Begehren, wendet sich damit der geistigen Kraft zu und von der dem Animalischen verhafteten Frau ab, die ihn vor ihrem Tod noch bittet „Mann!! Schlaf mir..."380 Auch der Titel des Dramas lässt sich in Richtung des Geist-Körper-Gegensatzes deuten: der Mann als „Mörder“ des Sexualtriebs ist die „Hoffnung des im Geschlecht unerlösten Weibes ‘381. Für die exponierte Bedeutung des Mannes sprechen auch einige religiöse Symbole, die den Mann in die Nähe von Christus rücken, doch soll dies an anderer Stelle (s. Kap. 3.2.3.2.) untersucht werden.

Farbsymbolisch kommen zwei Konstellationen zum Tragen. Der Gegensatz der Geschlechter wird durch die Farben Rot und Blau in ihrer Kleidung verbildlicht. ${ }^{382}$ Daneben existiert die Gegenüberstellung von Rot und Weiß. Anders als in „Die träumenden Knaben“ stehen diese in „Mörder, Hoffnung der Frauen“ nicht für Begehren versus Unschuld, sondern für Leben und Tod. Während zunächst der Mann mit weißem Gesicht auftritt („,Krieger: ,Fübr’ uns, Blasser!'“"), ist es später die Frau, die mit zunehmender Schwäche immer blasser wird („,Der Mann steht gan₹, reißt das Tor auf, berübrt die sich starr Aufbäumende, die ganz, weiß ist, mit den Fingern der ausgestreckten Hand. Sie spürt ibr Ende (...) '). Am Ende ist es der Mann, der (zumindest in der Originalfassung verfärbt vom Blut der Getöteten) rot die Bühne verlässt, was davon zeugt, dass die Lebenskraft sich auf ihn übertragen hat. Dieser Umstand verweist darauf, dass der Geschlechterkonflikt von Kokoschka als Kreislauf verstanden wurde - „(...) the war between the sexes is a continual movement from death to life and from life to death (...)“383 Dafür spricht auch die Tatsache, dass Kokoschka eine weitere Motivopposition einführt und zwar die zwischen Sonne

\footnotetext{
${ }^{379}$ Nach Aristoteles und ihm folgend Thomas v. Aquin war die Frau ein unvollkommener Mann ein „mas occasionatus“ und somit minderwertig. Diese Diskussion um den Wert der Frau und schließlich das Verhältnis der Geschlechter setzte sich bis in die Neuzeit fort. Siehe dazu Gössmann (1980), S. 281-297 und Mitterer (1950), S. 80-103. Wunder (1992), S. 265 ff.

${ }^{380}$ Schvey (1982), S. 34 f. In Weiningers „Geschlecht und Charakter“ ist dazu besonders Kap. XII (Das Wesen des Weibes und sein Sinn im Universum) aufschlussreich. In Aussagen wie „Das absolute Weib jedoch, dem Individualität und Wille mangeln, das keinen Teil hat am Werte und an der Liebe, ist, so können wir jetzt sagen, von jenem höheren, transcendenten, metaphysischen Sein ausgeschlossen. Die intelligibile byperempirische Existenz des Mannes ist erbaben über Stoff, Raum und Zeit. In ihm ist Sterbliches genug, aber auch Unsterbliches. Und er hat die Möglichkeit zwischen beiden zu wäblen. (...). "(Weininger (1916), S. 385) spiegelt sich seine Auffassung vom Geschlechterdualismus.

381 Schwerte (1964), S. 175. Vgl. auch Schvey (1982), S. 38.

382 Evtl. ist in dieser Farbzuordnung (Mann - Blau), eine Bezugnahme auf „Der Blaue Reiter“ erfolgt, wo diese Farbe mit dem „Geistigen“ gleichgesetzt wird.

383 Schvey (1982), S. 37.
} 
und Mond, ${ }^{384}$ welche ebenfalls in einen Kreislauf kontinuierlichen (Macht-)Wechsels eingebunden sind und ähnlich wie Mann und Frau im Stück weder miteinander, noch ohne einander auskommen. Dies wird zum einen in der Rede deutlich - hier spricht beispielsweise der erste Krieger über den Mann: „Unser Herr kommt wie der Tag, der im Osten aufgeht." und bringt ihn so mit der Sonne in Verbindung. Auch die Frau wird mit einem Himmelsgestirn gleichgesetzt, wenn das zweite Mädchen in Andeutungen über sie sagt: „Unsre Frau steigt auf und sink.t, doch kommt nie auf die Erde. "Der Mann selbst spricht die Frau als Gestirn der Nacht an: „Sterne und Mond! Frau!" und auch sie vergleicht ihrer beider gegensätzliches Verhältnis mit dem von Sonne und Mond, wenn sie sagt: „Warum bannst du mich, Mann, mit deinem Blick? Fressendes Licht, verwirrst meine Flamme! Verzehrendes Leben kommt über mich." Zum anderen spiegelt sich dieser Gegensatz im Wandel der Lichtverhältnisse auf der Bühne. Beherrschte zunächst die Frau die Situation und bannte den Mann, so brannten nur einige Fackeln und tauchten die Szene in nächtliches Licht. Doch schließlich erstarkte der Mann, der Morgen kündigte sich durch Hahnenschreie an und die Bühne wurde von flackerndem Feuer erhellt als der Mann siegreich die Bühne verlässt. ${ }^{385}$ Hier lässt sich das Drama auch mit den Thesen aus Bachofens „Mutterrecht“ in Verbindung bringen. Denen zu Folge findet der Geschlechterkampf seinen kosmischen Ausdruck im „Kampf von Sonne und Mond um den Vorrang im Verhältnis zur Erde ${ }^{r 386}$, da irdische und kosmische Ereignisse miteinander verknüpft seien. Doch - und das könnte auch für dieses Drama Kokoschkas entscheidend sein - ist das letzte Ziel dieses Ringens ,erst mit der Herrschaft des Mannes über die Frau, der Sonne über den Mond erreicht. "\$877 Und das, obwohl darauf hingewiesen wird, dass die Nacht zunächst ausgeglichen auch den Tag beherrscht, „den sie aus sich gebiert, wie die Mutter den Sohn“388. Im Stück deutet sich ein Bezug dazu an, wenn der Mann (nach Bachofen schließlich mit der Sonne gleichzusetzen!) bei seinem Erstarken äußert: „Atmend entwirrt sich mir Dunkles. Mutter...Du verlorst mich hier. "Der Nacht folgt durch die Geburt der Sonne also der Tag und somit die Herrschaft des Mannes, wie es sich auch aus dem weiteren Verlauf des Stücks nach dieser Äußerung ergibt.

Kokoschka beschreibt in „Mörder, Hoffnung der Frauen“ das Verhältnis der Geschlechter wie in „Die träumenden Knaben“ insgesamt als ein paradoxes. Mann und Frau ziehen sich an, können aber durch ihren Wunsch einander zu

\footnotetext{
384 Die Motivik von Sonne und Mond zur Verdeutlichung der Abhängigkeit zwischen Mann und Frau wird auch schon in früheren Jahrhunderten verwendet, so z. B. im „Ehzuchtbüchlein“ des Straßburgers Johann Fischart: „Er ist die Sonn, Sie ist der Mond,/ Sie ist die Nacht, Er hat Tagsmacht (...)“. S. dazu Wunder (1992), S. 265 f. Vgl. zur Analogie zwischen Geschlechtern und Gestirnen auch Artikel „Sonne“, „Mond“, „Licht“, „Finsternis“ in Bächthold-Stäubli (1987). Diese Symbolik ist auch in der christlichen Ikonografie von Bedeutung.

385 Schvey (1982), S. 37 f.; Schober (1994), S. 74 f.

386 Bachofen (1948), S. 131.

387 Bachofen (1948), S. 131.

388 Bachofen (1948), S. 130.
} 
dominieren und durch die sexuelle Abhängigkeit voneinander zu keiner friedlichen Einheit finden. Im Stück endet der Kampf schließlich (im Sinne Bachofens) mit dem Sieg des Mannes und spiegelt damit Kokoschkas damalige eigene Unsicherheit und Neugierde gegenüber dem weiblichen Geschlecht. Er selbst äußerte sich in einem Interview 1973 zu dem Drama mit den Worten: „Es war genau das, was ich mir über Frauen vorgestellt hatte, als ich jung war (...) Ich bin stärker! Ich würde nicht von ibr verschlungen werden. ${ }^{\prime 389}$

Die Verknappung von Worten und Handlung, die Expressivität der Sprache, die vielfach auf Ausrufe reduziert ist, die vehementen Gebärden, die Farbe als Bedeutungsträger und auch die offenbar innovativ eingesetzte Lichtsymbolik erzeugen eine irritierende, geradezu wilde Stimmung, die das Disparate der Thematik unterstreicht und „Mörder, Hoffnung der Frauen“ den Ruf eingebracht hat, den „Beginn des Dramenexpressionismus'390 zu markieren. ${ }^{391}$ In seiner Expressivität und Aggressivität ist das Drama durchaus der Behandlung des Themas im Blatt „Amokläufer" vergleichbar. Hier wie dort ist der Mann letztlich der Machtvollere, allerdings findet eine gewisse Bedeutungsverschiebung statt. Während im Bild überwiegend blinde Wut die Handlung hervorzurufen scheint, ist im Stück eine rationalere Ebene eingeführt, da hier der Mann mit der Absicht agiert, die Verlockungen der Sexualität zu überwinden. Auch wird darin eine Allgemeingültigkeit angestrebt, wenn durch die Gleichsetzung mit den Gestirnen auf den gleichsam universalen Geschlechterkonflikt verwiesen und nicht nur wie in „Amokläufer“ eine mehr subjektive Ebene eröffnet wird. Die Flammen von Liebe und Hass im „Amokläufer" wandeln sich im Drama zu einem triumphalen Inferno, das mit der aufgehenden Sonne und dem Sieg des Mannes in Verbindung steht.

Basierend auf der Symbolik und dem Gehalt von „Mörder, Hoffnung der Frauen“, führt das Plakat für das Sommertheater der Internationalen Kunstschau von 1909 - „Pietà (Abb. 42) betitelt - Mann und Frau mit roter beziehungsweise weißer Hautfarbe und flankiert von Sonne und Mond vor Augen. Zwischen zwei Textfeldern, insgesamt zwei Drittel des Plakats einnehmend, ist diese dem Titel entsprechend sehr leidvoll gestaltete Figurengruppe vor einem unbestimmten dunkelblauen Hintergrund ins Bild gebracht. Die leichenblasse Frau, deren seitlich geneigter Kopf durch die hervortretenden Wangenknochen, ihre in schwarzen Höhlen liegenden Augen und ihre knochig entstellte Kinnpartie an einen Totenschädel erinnert, hält in ihren Armen die kraftlose und verrenkte Gestalt des Mannes. Ihr Haupt und ihre Ellenbogen - durch die schwarz hervorgehobenen Mus-

\footnotetext{
389 Schvey (1986), S. 104.

${ }^{390}$ Schober (1994), S. 62.

${ }^{391}$ Entsprechend unverständlich erschien es dem damaligen Publikum, weshalb die Aufführungen regelmäßig zu Skandalen führten. Jene im Gartentheater Wien 1909 endete wegen Randale im Tumult - weshalb Kokoschka auch die Kunstgewerbeschule frühzeitig verlassen musste - und im Mai 1919 in Berlin konnte das Stück nur nach minutenlangen Unterbrechungen, in denen das Publikum seinen Unmut kund tat, zu Ende gebracht werden. Vgl. Schwab (1996), S. 67; Schober (1994), S. 91.
} 
keln und Knochen in einem expressiven schwarz-weiß-Kontrast angelegt - bilden dabei eine Dreiecksform. Der Leib des Mannes beschreibt annähernd eine S-Form (abgesehen von seinem quer hängenden rechten Arm), ist nackt und wirkt durch die blutrote Farbe gleichsam wie enthäutet. Sein Kopf ist so weit unter den rechten Arm der Frau gebogen, dass der Eindruck entstehen kann auf seinem Rumpf throne der Frauenschädel - vielleicht ein Hinweis auf die Untrennbarkeit der Geschlechter. Beide Köpfe befinden sich somit in paralleler Lage. Dadurch verstärkt sich der Eindruck ihrer qualvoll aufgerissenen Münder.

Die Analogie zu christlichen Pietà-Darstellungen ist unübersehbar. Die Ikonografie der Darstellung lässt sich ohne Weiteres mit der Schmerzensmutter und der Kreuzabnahme Christi in Verbindung bringen. Sonne und Mond rahmen Christus bereits in frühchristlichen und mittelalterlichen Kreuzigungsdarstellungen und allgemein wird die Sonne traditionell mit Christus, der Mond mit Maria in Beziehung gesetzt. ${ }^{392}$ Bachofens Mythos der Gestirne folgend übersetzt Kokoschka die sakrale Bedeutung allerdings ins Profane. ${ }^{393}$ Obwohl diese Farblithografie durch den Bezug zur Pietà auch in das folgende Kapitel über die religiösen Aspekte in Kokoschkas Werken gehören könnte, steht hier doch das Thema des Geschlechterkonflikts im Vordergrund. Kokoschka nutzt nämlich die ursprünglich sakrale Symbolik zur Verbildlichung des Geschlechterringens und schafft mit diesem Plakat ein Äquivalent zu dem im Drama „Mörder, Hoffnung der Frauen“ zentral behandelten Paradoxon von Macht- und Abhängigkeitsverhältnis in diesem Kampf.

Wie zu Beginn der zweiten Hälfte des Stückes erscheint die Frau im Plakat als dominant. Sie ist es, die in der Farblithografie den schwach und geradezu leblos wirkenden Mann hält und die im Drama den verwundeten Mann im Käfig bewacht. Doch wie im Bühnenstück verweist die Farbsymbolik auf den eigentlichen Ausgang der Situation:

„Das Plakat, das ich sofort in Farben ausführte und drucken ließ, zeigte den Inhalt des Stückes: Der Mann ist blutig rot, das ist die Lebensfarbe, aber tot liegt er im Schoß einer Frau, die weiß ist: das ist die Todesfarbe. ${ }^{3} 94$

Die weiße Farbe ist also kennzeichnend für die Schwäche und Niederlage der Frau, während das Rot auf den Sieg des Mannes verweist.

\footnotetext{
392 In der Bibel wird Christus im Zusammenhang einer Lichtmetaphorik wiederholt mit der Sonne gleichgesetzt. Marias Verknüpfung mit dem Mond steht insbesondere mit der Deutung der Johannes-Offenbarung (Offb. 12,1: „Dann erschien ein großes Zeichen am Himmel: eine Frau, mit der Sonne bekleidet; der Mond war unter ibren Füßen und ein Kranz von zwölf Sternen auf ibrem Haupt." ") als Hinweis auf die Muttergottes in der Exegese in Zusammenhang. Allgemeines dazu s. Kirschbaum (1972), Bd. 4, Sp. 175 ff. Genaueres über den Zusammenhang zwischen Christentum und Sonne (ausgehend von Schriften und bildkünstlerischen Werken der Spätantike) s. bei Wunder (1992) und Wallraff (2001).

${ }^{393}$ Husslein-Arco (2008), S. 146.

394 Kokoschka (1971), S. 64.
} 


\section{„Dem Drama nach, gewinnt dieser [der Mann] durch die Berührung der Frau seine Le-} benskeraft zurück, während sie die ibre verliert und schließlich zugrunde geht. "395

Doch könnten auch hier im Bild die sich immerwährend abwechselnden Gestirne und die Gegensätze von Leben und Tod, die in der Haltung der Personen und in entgegengesetzter Weise durch die Farbsymbolik vor Augen geführt wird, auf den Kreislauf der wechselnden Machtverhältnisse hindeuten.

Diese im Plakat anklingende Tendenz zu einem eher ausgeglichenen Machtverhältnis zwischen den Geschlechtern zeugt davon, dass Kokoschka also nicht unbedingt von der Vorherrschaft des Mannes überzeugt war, auch wenn ihn die Ideen Bachofens und Weiningers inspiriert und sie teilweise seine Zustimmung gefunden haben. Diese Annahme wird auch gestützt durch die Tatsache, dass in der im gleichen Jahr entstandenen Groteske „Sphinx und Strohmann“ “396 das Ende dem in „Mörder, Hoffnung der Frauen“ gänzlich entgegengesetzt ist. Die männliche Hauptfigur Firdusi stirbt in Folge der Demütigungen durch seine Frau Lilly, die „schön wie ein Paradepferd über den Cadaver" hinwegsteigt und pragmatisch erklärt, ohne ihn weiter zu leben. Darüber hinaus ist natürlich vor allem auch die Tatsache, dass Kokoschka den Geschlechterkonflikt auf die Pietà-Ikonografie transponiert, bedeutsam. Nach christlicher Auffassung opferte sich Christus für die Menschen, in Kokoschkas Plakat opfert sich der Mann - in Anlehnung wiederum an Weininger - für die Erlösung der Frau, die durch seinen Verzicht auf Sexualität zu mütterlicher und damit geistiger Liebe findet, wodurch der Konflikt der Geschlechter gleichsam aufgelöst ist. Damit bringt das Plakat eine Idee auf, die Kokoschka literarisch erst zwei Jahre später im „Schauspiel“ beziehungsweise in dessen späterer Fassung „Der brennende Dornbusch“ verarbeitet. ${ }^{397}$

Wenn also Drama und Plakat nicht unbedingt übereinstimmende Aussagen zum Geschlechterverhältnis zulassen, sondern aggressive Tendenzen parallel zu versöhnlichen aufweisen und somit Kokoschkas schwankende Lösungssuche dokumentieren, so zeugt ihr Vergleich doch von einem evidenten wechselseitigen Bezug und einer ähnlichen Weise der Auseinandersetzung mit der Thematik, die sich insbesondere in der Symbolik manifestiert. Vor allem jene von Sonne und Mond verwendet Kokoschka auch in weiteren Werken, wie beispielsweise dem Fächer aus dem Besitz Grant Pick (Abb. 43), der zwischen 1909 und 1911 entstanden sein dürfte. ${ }^{398}$ Durch floral-ornamental gestaltete Segmente ist der Fächer in drei Bildfelder unterteilt. Im linken wird Bacchus in einer märchenhaft anmutenden Landschaft mit Schmetterlingen und Vögeln vor Augen geführt, rechts reitet ein Jüngling mit Zepter auf einem Tiger. Im Mittelfeld wiederum sind Mann

\footnotetext{
${ }^{395}$ Husslein-Arco (2008), S. 148.

${ }^{396}$ Mehr dazu im Zusammenhang mit der Besprechung der späteren Fassung „Hiob“, S. 172.

397 Dazu mehr s. S. 174.

398 Spielmann datiert ihn auf 1911 und geht davon aus, dass er für Lotte Franzos gedacht war (Spielmann (1988), S. 18); bei Husslein-Arco wird ohne weitere Begründung 1909 als Entstehungsdatum angegeben (Husslein-Arco (2008), S. 171).
} 
und Frau einander gegenüber gestellt. Ein Säugling zwischen ihnen und ein über ihm aufsteigender Vogel als mögliches Symbol für den Heiligen Geist verweisen auf religiöse Themen wie die Geburt Christi oder durch angedeutete Berge, Meer und Schiff wahrscheinlich eher noch auf die Flucht nach Ägypten. ${ }^{399}$ Entscheidend im Hinblick auf die Thematik des Geschlechterverhältnisses ist die Tatsache, dass auch die beiden großen Himmelsgestirne ins Bild gebracht sind. Links oberhalb des Mannes erstrahlt die Sonne, mittig zwischen dem Paar steht der Mond, wobei seine Sichelform analog zum Gesicht der Frau dem Manne zugewandt ist. Die zwei Himmelskörper sind somit wieder in bekannter Weise den Geschlechtern zugeordnet. Die zentrale Stellung des Mondes mag hier auf die vorherrschende Rolle Marias im sakralen Kontext des Bildes bezogen sein.

Das Ringen mit Alma Mahler und sein Niederschlag in „Die Windsbraut“ und „Allos Makar"

Kokoschka bleibt der von Bachofen inspirierten Sonne-Mond-Symbolik auch späterhin treu, als sich der Geschlechterkonflikt viel persönlicher einfärbte. Glich seine Auseinandersetzung mit diesem Thema anfänglich einem allgemeinen Suchen, das zwar durch eigenes Erleben wie die Gefühle zu Lilith Lang inspiriert war, doch zugleich durch philosophische Bezüge eine gewisse Objektivität anstrebte, so wandelte sich dies ab 1912 und führte hin zu einer sehr viel persönlicheren Verarbeitung des Konflikts mit seiner Geliebten Alma Mahler. Als er die Witwe des bekannten, 1911 verstorbenen Komponisten Gustav Mahler im April 1912 kennenlernte, entwickelte sich daraus eine bis 1915 andauernde Beziehung, in der er viele Höhen und noch mehr Tiefen durchlebte. Auf ihre gesellschaftliche Stellung und einen großbürgerlichen Lebensstil bedacht, entzog Alma sich dem noch am Anfang seiner Karriere stehenden und in Wien vielfach kritisch wahrgenommenen Künstler immer wieder, indem sie ihn nur heimlich zu treffen wünschte oder wiederholt verließ. Kokoschka andererseits glaubte mit Alma sein Ideal vom Aufgehen des Einen im Anderen zu finden und hoffte sie durch ein eifersüchtiges Abgrenzen von der Wiener Gesellschaft und der Erinnerung an Gustav Mahler formen, beziehungsweise ganz für sich vereinnahmen zu können. 400

Seine mit Alma in Zusammenhang stehenden Emotionen - Hoffnungen wie Ängste - sind in vielen seiner literarischen und bildkünstlerischen Werke aus jener Phase ablesbar. Kontinuierlicher Spiegel sind die sechs Fächer, die er zwischen

\footnotetext{
${ }^{399}$ Husslein-Arco (2008), S. 171.

400 Spielmann (2003), S. 136 ff. Kokoschka „Mein Leben“, S. 134: „(...) Sie konnte nicht vergessen, dass sie mit einem weltberühmten Dirigenten und Komponisten verbeiratet gewesen war, während ich höchstens berüchtigt - und dies bloß in Wien - und unbemittelt war. Ich haßte die Gesellschaft, die sie unsicher gemacht hat, weshalb ich eifersüchtig auf jeden fremden Einfluß, sie mit allen Mitteln zu isolieren versuchte. Sie bewahrte mir in der ersten Zeit ibre Liebe, doch später lebnte sie sich auf. (...)".
} 
1912 und 1914 als Geschenke für Alma Mahler angefertigt hat ${ }^{401}$ und von denen er selbst sagte: „Meine Fächer sind Liebes-Briefe in Bildersprache (... '402. Sind diese Fächer auch sehr persönliche Gaben, die durchweg direkten Bezug zu dem Paar Alma Mahler und Oskar Kokoschka haben - beide werden wiederholt darauf dargestellt - so finden sich auch hier Symbole wieder, die Kokoschka in den Jahren zuvor entwickelt hatte. So überträgt er beispielsweise sowohl die SonneMond-Symbolik und das Pietà-Motiv als auch die Flammen als Zeichen der Leidenschaft in den zweiten Fächer (Abb. 44), den er im Dezember 1912 für Alma fertigte. Ornamente aus Flammen, floralen Elementen und zuvorderst mit einem Herzen versehen unterteilen den Fächer in drei Bildfelder. Das erste zeigt das Paar in einer der Pietà verwandten Weise: ein nackter Mann mit den Gesichtszügen Kokoschkas verharrt mit geschlossenen Augen und leblosen Gliedern in den Armen der Alma nachempfundenen Frau, die mütterlich fürsorglich auf ihn herabblickt und ihn in einen Mantel zu hüllen scheint. Über ihren Häuptern strahlen Sonnenscheibe und Mondsichel, die wie in den früheren Werken den Geschlechtern zugeordnet sind. Sie finden sich auch in den beiden anderen Bildfeldern. Im Mittelbild ist das eng aneinandergeschmiegte nackte Paar zudem umgeben von einem Schiff, einer von Bergen hinterfangenen Stadt mit Viadukt und einer Meute wilder Tiere, wie Wölfen und Schlangen. Kokoschka scheint diese auf die gierige Wiener Gesellschaft ${ }^{403}$ verweisenden Kreaturen mit seinem erhobenen rechten Arm abzuwehren, um in inniger Zweisamkeit mit Alma zu verharren. Dabei sprechen weniger die fast ausdruckslos erscheinenden Gesichter für ihre enge Verbindung, als ihre einander zugewandte Körperhaltung, sowie die sich berührenden Köpfe. Die dominierenden zeichenhaften schwarzen Konturen der Figuren und Gegenstände werden durch die Grundfarben ergänzt, wobei Paar und Gestirne in einem zarten Gelb erstrahlen. Das dritte Bildfeld zeigt einen kleinen Jungen mit Kokoschkas Zügen, auf einem Phantasietier reitend, inmitten einer fröhlich anmutenden Gesellschaft aus Fabelwesen und Tieren und verweist auf Kokoschkas Wunsch nach einem gemeinsamen Kind mit Alma, das als logische Konsequenz aus den vorigen Bildfeldern und der dort verbildlichten Verbindung resultiert. Ein Wunsch, der ihm durch eine von Alma initiierte Abtreibung verwehrt blieb und schließlich zum endgültigen Bruch führte.404 Es war sein Schicksal, dass seine Geliebte und er nie langfristig zueinander fanden und somit auch die geplante Hochzeit und der Traum vom gemeinsamen Leben als Familie zerplatzen sollten.

In ähnlicher Nähe zueinander wie im Mittelfeld des Fächers, mit eng verschmolzenen Gesichtern stellt Kokoschka sich und seine Geliebte in Büstenform

\footnotetext{
401 Der Fächer als Kunstwerk etablierte sich durch die Begeisterung des Jugendstils für fernöstliche Kunst und war ein Mittel der Repräsentation, das in der Öffentlichkeit Aufmerksamkeit hervorrief und dies natürlich umso mehr, ,wenn er das Zeichen der Verebrung eines berïhmten Malers war. "Spielmann (1988), S. 10.

402 Spielmann (1988), S. 7.

403 Spielmann (1988), S. 44.

404 Vgl. Kokoschka (1971), S. 132.
} 
in einer im gleichen Jahr entstandenen Kreidezeichnung dar. ${ }^{405}$ Auch zu anderen Grafiken und Gemälden, wie dem in Boston befindlichen Doppelakt von 1913 besteht offenkundig eine Beziehung. Im Doppelbildnis von $1912^{406}$ des Folkwang Museum Essen (Abb. 45) wird die Verbindung des Paares zusätzlich durch die Geste betont, mit der der Künstler seiner Geliebten einen Verlobungsring anzustecken scheint und damit gleichzeitig auf so große Vorbilder wie beispielsweise das Doppelporträt von Rubens und Isabella Brandt ${ }^{407}$ Bezug nimmt. Alma in rotorangenen Stoff gehüllt, sitzt hier auf dem Schoß des mit blauem Hemd und brauner Jacke bekleideten Künstlers, wobei sie von einem in Blau- und Grüntönen changierenden und nicht näher definierten Hintergrund umfangen werden. Beide blicken mit ernstem Gesichtsausdruck aus dem Bild, als wollten sie den Betrachter als Zeugen ihrer Verbindung fixieren. Auch mit dieser Darstellungsweise orientiert sich Kokoschka an der ikonografischen Tradition. Wie in vielen von Kokoschkas Porträts ${ }^{408}$ kommt den Händen hier eine besondere Bedeutung zu. Einer Momentaufnahme gleich verharren sie in der Bewegung des Ineinanderlegens. Es ist wichtig festzuhalten, dass Kokoschka in diesem, wie auch in den anderen genannten, ungefähr gleichzeitig mit dem zweiten Fächer entstandenen Darstellungen auf eine spezielle Symbolik, wie die von Sonne und Mond verzichtet. Sie gehört somit zwar zu seinem Repertoire, fließt aber nicht zwangsläufig in jedes Bild zum Geschlechterverhältnis ein. Dennoch zeugt insbesondere ihre Anwendung im zweiten Fächer davon, dass sich das Ringen mit dem anderen Geschlecht in der Beziehung mit Alma fortsetzt und daher in teilweise ähnlicher Weise im Bild umgesetzt wird, wie zuvor im Pietà-Plakat das allgemeine Ringen.

Dieser Geschlechter, ,kampf", den Kokoschka mit der Person Alma zu bestreiten hat, findet seinen Niederschlag ebenso wie der allgemeine zuvor nicht nur in den bildlichen Darstellungen, sondern ebenso im literarischen Schaffen des Künstlers. Hierfür ist die Dichtung „Allos Makar“ von 1913 sicherlich das beste Beispiel. Zuvor ist jedoch „Der gefesselte Kolumbus“ zu erwähnen. Es handelt sich hierbei um eine ebenfalls 1913 zusammengestellte Publikation, die allerdings erst 1916 im Berliner Verlag Fritz Gurlitt tatsächlich veröffentlicht wurde. Hier stellt Kokoschka zwölf Kreide-Lithografien seiner bereits 1908/09 entstandenen Prosa-Dichtung „Der weisse Tiertöter“ zur Seite. Die Dichtung war ursprünglich als eine Art Fortsetzung zu „Die träumenden Knaben“ gedacht und nimmt entsprechend die dort bereits vorhandene traumhafte Atmosphäre und die IchErzählung wieder auf. Auch findet sich auf der Motivebene eine Reihe von Analogien, wie beispielsweise das Motiv des roten Fisches. Interessanterweise war auf der Einladung zu einer Lesung aus beiden Werken im Kabarett Fledermaus 1909

\footnotetext{
405 „Liebespaar“ (1912).

406 „Doppelbildnis“ (1912); Informationen zum Bild vgl. Winkler/Erling (1995), S. 89.

${ }^{407} \mathrm{Zu}$ dem Gemälde „Rubens und Isabella Brant in der Geißblattlaube“ s. Pickel (1999), S. 432 f.

${ }^{408}$ Vgl. Kap. 3.2.3.3.
} 
als Motto der Veranstaltung „Ich ringe um die Frau“"zu lesen. ${ }^{409}$ Entsprechend behandelt auch „Der weisse Tiertöter“ und die später kaum geänderte, in „Der gefesselte Kolumbus“ umbenannte Fassung die Auseinandersetzung des jungen Kokoschka mit dem weiblichen Geschlecht. Im Gegensatz zu „Die träumenden Knaben" ist dieses Werk in Prosa geschrieben und verfügt über Großschreibung und Interpunktion. Der Titel ist vermutlich von Aischylos „Der gefesselte Prometheus" abgeleitet und wählt das Sich-Aufbäumen gegen Gewaltherrschaft zum Hauptthema. In Erinnerung an einen Kolumbus-Film, den er sich im Sommer 1912 mit Alma angesehen hatte, tauschte er dann noch den in Ketten gelegten Prometheus im zweiten Blatt des Zyklus gegen Kolumbus aus. ${ }^{410}$ Das Leitmotiv der Dichtung ist der Mond, ,in dem sich die Frau als Wartende personifiziert"“411. Von ihr versucht sich der Ich-Erzähler gewaltsam zu emanzipieren, bis er sich letztlich zwar mit ihr versöhnt, aber dennoch die trennende Mauer nicht zu überwinden vermag. 412

Es ist bezeichnend, dass Kokoschka diese Dichtung wieder aufgreift und durch Lithografien neu belebt, deren Figuren eindeutig seine und die Züge Almas tragen. Er selbst setzt damit sein Jahre zuvor mehr allgemein formuliertes Geschlechterringen nun direkt mit seiner Beziehung zu Alma parallel und stellt den Bezug zwischen Alma und der in der Dichtung agierenden Mondfrau her. In einem Brief vom November 1912 ließ er seine Geliebte in Hinblick auf seine Pläne zur Veröffentlichung von „Der gefesselte Kolumbus“ wissen: „Gurlitt ist im Grunde einverstanden mit unserem Angebot. So werden wir zusammen ein gutes Buch machen, das von Dir handelt. " ${ }^{13} \mathrm{Da}$ an der Dichtung nur unwesentliche Änderungen vorgenommen wurden, kann der hier angekündigte Bezug zu Alma allerdings nur anhand der Illustrationen nachvollzogen werden. Sie ist es, deren Züge die Eva im „Der Apfel der Eva“"414 (Abb. 60) betitelten sechsten Blatt des Zyklus (und auch fast jede andere in den übrigen Blättern dargestellte Frauenfigur) trägt und die im Licht des Mondes dem Kokoschka im Gesicht ähnelnden Adam den Apfel reicht und ihm somit Versuchung und Erkenntnis gleichermaßen nahe bringt. Ganz gewiss hat Kokoschka jede dieser Bedeutungsebenen sehr genau durchdacht. Der Mythos der in der Dichtung beschriebenen Mondfrau passt auch aufgrund der Tatsache, dass Alma zur Geheimhaltung ihrer Verbindung Kokoschka nur nächtliche Besuche erlaubte, gut zu den beiden. ${ }^{415}$ Während der Text nun also aufgrund seines früheren Entstehungsdatums naturgemäß keinerlei direkten Verweis auf die Beziehung zu Alma gibt, sondern noch der Phase der Auseinandersetzung mit der

\footnotetext{
409 Husslein-Arco (2008), S. 136.

${ }^{410}$ Husslein-Arco (2008), S. 226.

${ }^{411}$ Lischka (1972), S. 54.

412 Secci (1968), S. 470.

413 Kokoschka (1984), Bd. I, S. 65.

${ }^{414} \mathrm{Mehr}$ dazu in Kapitel 3.2.3.2. (Religiöse Aspekte).

415 Spielmann (2003), S. 145.
} 
Geschlechterproblematik allgemein zuzurechnen ist, sind es die Lithografien, die das konkrete Erleben mit der Geliebten spiegeln.

„Allos Makar"4416 hingegen verarbeitet auch auf literarischer Ebene Kokoschkas durch Alma ausgelösten, heftigen emotionalen Schwankungen. Auf den biografischen Hintergrund deutet in verschlüsselter Weise der griechische Titel hin, der von Kokoschka nicht nur mit „Anders ist glücklich" übersetzt worden ist, ${ }^{417}$ sondern der zugleich ein Anagramm der Namen Oskar und Alma darstellt. ${ }^{418} \mathrm{Er}$ gibt damit in überaus artifizieller Weise auf dreierlei Ebenen Hinweise auf Inhalt und Bedeutung des Gedichtes. Erstens: es behandelt die Beziehung der beiden im Titel versteckt genannten Personen. Zweitens: die deutsche Übersetzung lässt bereits vor Beginn des eigentlichen Gedichts den Schluss zu, dass diese Beziehung nicht glücklich ist. Und drittens: durch die Verquickung der beiden Namen wird die enge Verbindung Oskars und Almas symbolisiert und damit auch Kokoschkas bereits erwähnte Auffassung von der Liebe als „Aufgehen des Einen im Anderen“ in Worten verbildlicht.

Formal ist das Gedicht in drei Strophen gegliedert, die mit "Allos", „Makar" und ,Allos Makar" überschrieben sind. Entsprechend scheint in der ersten Strophe der Schwerpunkt auf der Beschreibung der Frau, in der zweiten auf der des Mannes zu liegen und in der dritten eine Art Synthese stattzufinden. ${ }^{419}$ Inhaltlich sind diese Differenzierungen denn aber nicht so deutlich nachvollziehbar. In durchweg expressionistischem Duktus entspinnt sich eine Erzählung aus teils konfusen Bildern, rätselhaften Metaphern und Reminiszenzen an frühere Dichtungen, wie beispielsweise das im ersten Satz erwähnte „weißße Vöglein“, welches schon in „Der weiße Tiertöter“ den Weg zur Frau gewiesen hat. Durchgängig ist ein unregelmäßiger Wechsel zwischen Langversen, Ausrufen und hämmerndem Rhythmus und auch zwischen erster, zweiter und dritter Person zu beobachten. ${ }^{420}$ Die Stropheneinteilung scheint dabei Zäsuren innerhalb des leidenschaftlichaufgewühlten Gedankenganges zu setzen, der Unsicherheit und Zweifel an der Beziehung zwischen Mann und Frau zum Ausdruck bringt.

Die Unmöglichkeit der Verständigung zwischen den beiden Liebenden klingt bereits in den ersten drei Sätzen der ersten Strophe an:

„Wie verdrebte wunderbar mich, seit aus einer Nebelwelt,/ sie zu suchen, mich ein wei-

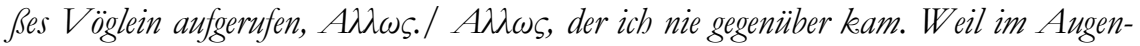
blicke/ schnell sie sich verwandelt in mein Wesen, wie durch/ eine Hintertïr."

Die wirkliche Annäherung an die als „Allos"chiffrierte Frau scheitert an der Tatsache, dass jeder im Anderen nur ein Bild von sich selber sieht. Zwar ist es die

\footnotetext{
416 Textnachweis, Text XXII.

417 Wingler, (1975), S. 94.

418 Kokoschka (1971), S. 136; Secci (1968), S. 479.

${ }^{419}$ Vgl. Lischka (1972), S. 54.

${ }^{420}$ Vgl. Secci (1968), S. 476 f.
} 
symbiotische Beziehung, die Kokoschka anstrebte, doch scheint er hier im Hinblick auf sein eigenes Erleben anzudeuten, dass er Alma idealisiert und gar nicht gänzlich wahrgenommen habe, wie sie wirklich war.

Dem gegenüber steht die von der Frau ausgehende, fesselnde Faszination, die durch ihr "Netz, das goldgelockte" verbildlicht wird und den Eroberungswillen des Mannes hervorruft:

\section{„Umgürtle dein Liebesnest nur geheimnisvoller,/ Vorwände scheinbarer Erwehrung} umwallen, / nötigen den Vogelsteller,/ lieberregt in dein Netz einzufallen."

Interessanterweise klingt hier wieder - wenn auch auf viel subtilere Weise - die Idee der Machtkämpfe an, die schon in Kokoschkas früheren Werken zum allgemeinen Geschlechterringen eine so große Rolle spielten. Beide - der Mann ebenso wie die Frau - werden als Fallensteller und Beute zugleich dargestellt. Am Ende der ersten Strophe scheint der Mann - im Übrigen wird er Kokoschkas Symbolik getreu wieder als Sonne der Nacht/Frau gegenüber gestellt - einzusehen, dass er mit einer unbezwingbaren Gegnerin konfrontiert ist. Er spricht: „,...) magisch bleibt dein Netz, der Wechselflüchtigen. " und drückt damit aus, dass er zwar in ihrem Bann steht, sie aber dagegen frei genug ist, sich ihm jederzeit zu entziehen. Auch darin besteht eine deutliche Parallele zu Alma, die Kokoschka immer wieder verließ.

In der zweiten Strophe wird assoziativ ein Eindruck von der Zerrissenheit und Leidenschaft des Mannes vermittelt. Worte wie "Strittig" und „Ungewrisheit" spiegeln seine Zweifel, wo auch „Sonn und Mond belfen nicht zusammenweisen". Er scheint der Frau unterworfen zu sein, denn er beschreibt sich als Diener der „Fesselschmiedin". Sein damit im Zusammenhang stehendes Leid drückt sich in der Erwähnung von „Winterschwermut", „Sehnsucht flïgelwund", „Ungebeuer" und „Alpdruck" aus. Im letzten Drittel der zweiten Strophe kündigt sich eine vage Hoffnung auf Besserung der Beziehung an: der Mond soll einen Strahl verlängern, „der dem Flüchtling weiset, / und die Sonne sanfter brennen heißet. "Der Mond meint einerseits die Frau, - im konkreten Fall eben Alma -, die dem Mann offenbar stärker entgegen kommen sollte, so dass dieser in seiner drängenden Leidenschaft (wieder symbolisiert durch die Sonne) Beruhigung erfahren möge. Andererseits verweist der Mond zugleich auch auf die nächtlichen Treffen des Paares, die hier von Kokoschka als in der Liebe zu Alma Zuflucht Suchenden beschworen werden. Im Abschlusssatz der Strophe „Schwebendes Geisterschiff,/ Mast und Anker richte dich", drückt sich der Wunsch des Mannes (und zugleich Kokoschkas) aus, dass sich die Beziehung erholen und zum Guten wenden möge.

Doch in der dritten Strophe wird schließlich die Aussichtslosigkeit dieser Hoffnung auf Harmonie festgestellt. Die Liebe verharrt in "täuschende $r]$ Rub", während das Herz in Erinnerung an vergangene Probleme offenbar weiter von Zweifeln heimgesucht wird („Das Herzinnen selber anfällt und drängt. “ und „Donnernd schlägt das Herz, bang allein zu sein. "). Diese Zweifel bestätigen sich in der ans Ende des Gedichts gesetzten Fabel. Hier kämpfen ein männlicher und ein weiblicher 
Vogel um eine Schlange beziehungsweise einen Wurm und schwächen sich in diesem Machtkampf nur gegenseitig, so dass der Wurm letztlich entkommt („Einer siebt des anderen Vorteil bange./ Und eines am andern die Kraft verlor./ Da windet aus den schreienden Schnäbeln der Wurm/ sich hervor. "). Klarer als in seiner Auseinandersetzung mit dem allgemeinen Geschlechterkampf verdeutlicht Kokoschka auf diese Weise in „Allos makar“, dass dieses Ringen keinen Gewinner hervorbringt und beiden Beteiligten zum Nachteil gereicht. Statt den gemeinsamen Feind in Form der Schlange - diese ist in der ikonografischen Tradition negativ konnotiert und dürfte hier als Symbol der Eifersucht fungieren ${ }^{421}-\mathrm{zu}$ beseitigen, agieren Mann und Frau wie vernunftlose Tiere gegeneinander. Am Ende steht daher die abschlieBende, tiefsinnige Botschaft „Anders ist glücklich“ auf einem Zettel, den die überlebende Schlange fallen lässt, und somit die bittere Erkenntnis, dass das emotionale und eifersüchtige Ringen zwischen Allos und Makar beziehungsweise zwischen Alma und Oskar die Beziehung zerstört. Mit diesen Worten wird zugleich der griechische Titel der Dichtung wieder aufgenommen und der Kreis schließt sich sowohl formal, als auch inhaltlich.

Ergänzend zur Dichtung schuf Kokoschka eine Folge von fünf Kreidelithografien (ebenfalls „Allos Makar“ betitelt) (Abb. 46-48), die vermutlich kurz nach der Textniederschrift, also um 1914 entstanden ist und 1915 erstmals in der Zeitschrift „Zeit-Echo. Ein Kriegstagebuch der Künstler" erschien. ${ }^{422}$ In dreien dieser Blätter ist der biografische Bezug ebenfalls deutlich nachvollziehbar, denn die dargestellten Akteure tragen - teils etwas schematisiert - die Gesichtszüge Almas und Kokoschkas. So auch in der vierten Lithografie „Sonne über einem vogelähnlichen Paar“, in welcher zwei Vögel mit menschlichen Köpfen in felsiger Landschaft unter einem ringförmigen Gestirn sitzen und an den zwei Enden einer kleinen Schlange ziehen. Sie illustriert die bereits erwähnte Textstelle der dritten Strophe mit dem Wortlaut: „Da kam von unten ungefähr/ das Schreien rauer Vögel her./ Ein Männchen und ein Weibchen würgen eine Schlange. "Interessanterweise findet sich auch eine Illustration mit Reminiszenzen zur Pietà-Darstellung wieder. Die zweite Lithografie, bei Wingler „Der Mann, im Schoße des Weibes liegend“ betitelt, zeigt eine frontal zum Betrachter sitzende Frau mit nach links gewandtem Kopf. Wie in verwandten Darstellungen zuvor, beispielsweise dem bereits besprochenen Plakat zu „Mörder, Hoffnung der Frauen“, hält sie im Schoß den leblos und verrenkt daliegenden Körper eines Mannes. Dessen Züge ähneln denen Kokoschkas. Gebärde und Mimik der Frau allerdings erinnern nicht an die der mitleidenden Schmerzensmutter, sondern sind hart und abweisend. Ihre Haltung wirkt gespannt und entschlossen, ihr abgewandter Blick mit dem zusammengekniffenen Mund ist ablehnend und ihre Hände halten den Kopf des Mannes brutal umkrallt. Ihr Ziel ist es nicht den Mann liebevoll aufzufangen, sondern ihn zu unterjochen und im wahrsten Sinne des Wortes im Griff zu behalten. Dafür spricht auch die Tatsache,

${ }^{421}$ Vgl. auch Secci (1968), S. 479.

422 Wingler (1975), S. 94. 
dass sie mit ihrem linken Fuß die Oberschenkel des Mannes an den Boden presst. In der bedrückenden Stimmung passt diese Darstellung am ehesten zur zweiten Gedichtstrophe. Die dort zu findende Textstelle „In der Fesselschmiedin Dienst ist sein Auge blind geworden. "dürfte darin verbildlicht worden sein.

In der dritten Illustration findet sich ein weiteres für Kokoschka wichtiges Motiv, das sich an verschiedenen Stellen seines expressionistischen Schaffens wiederholt: das Boot. Eine nackte männliche Figur kniet mit ängstlich zum Mond emporgereckten Händen in einem winzigen Boot, das auf stürmischer See treibt. Mund und Augen weit aufgerissen, blickt er flehend zur Mondsichel empor. Die meist geschwungenen Linien, wie auch die Schraffuren wirken breit und die Zeichnung dadurch etwas plump, dennoch wird die Dramatik durch das bewegte Lineament der Wellen überzeugend vermittelt. Diese „Der Mann im Boot“ betitelte Lithografie ist den abschließenden Zeilen der zweiten Strophe „Schwebendes Geisterschiff,/ Mast und Anker richte dich" zuzuordnen und unterstreicht die von Zweifeln und Unruhe geladene Stimmung dieser Passage. Die darin ebenfalls mitschwingende Hoffnung wird im Bild durch den Mond vor Augen geführt, der als Symbol für die Frau um Rettung aus dem die unsicheren Gefühle des Mannes spiegelnden Seesturm angefleht wird. Das Boot ist im übertragenen Sinn als Basis oder Halt des Mannes zu verstehen, welches aber im emotionalen Chaos ins Wanken gerät. Sein Kentern würde den Untergang des Mannes bedeuten.

In ähnlicher Weise verwendet Kokoschka das Motiv des Bootes auch über den Text „Allos makar“ und die dazugehörigen Bilder hinaus. Bereits im Mittelfeld seines dritten Fächers für Alma von 1913 führt er sich und seine Geliebte nackt aneinander geschmiegt in einem Boot ruhend vor Augen. Am Horizont speit ein Vulkan Feuer. Hintergrund dieser „Das Paar im Boot“ (Abb. 49) betitelten Darstellung ist ein Erlebnis von Kokoschka und Alma während ihres gemeinsamen Italienurlaubs im Frühjahr 1913. Die Reise führte das Paar unter anderem nach Neapel und Venedig und wird stationsweise im dritten Fächer verbildlicht. Das wichtigste Geschehnis war ein Naturereignis in Neapel, welches im zentralen Fächerbild verarbeitet ist. Die beiden logierten in einer Pension ,an einer hochgelegenen Straße“423 mit einem Balkon, der einen Blick über die Bucht bis hin zum Vesuv ermöglichte. Hier befanden sie sich während eines Unwetters, bei dem der Balkon einem Schiff gleich über Sturm und Wellen zu schweben schien.424 „Das Fächerbild übersetžt das reale Ereignis und den Eindruck, den es vermittelte, in eine bildhafte Deutung der psychischen Exaltation. "425 In mehreren skizzenhaften Studien hat Kokoschka die Paardarstellung des Fächerfeldes vorbereitet. ${ }^{426}$ Letztlich zeigt der Fächer das Paar in zärtlicher Umarmung mit geschlossenen Augen und ruhigem Gesichtsausdruck. Das Boot, in dem sie liegen, wird nur durch wenige Linien

\footnotetext{
${ }^{423}$ Mahler-Werfel (1960), S. 51.

${ }^{424}$ Spielmann (2003), S. 146.

425 Spielmann (1988), S. 57.

${ }^{426}$ Vgl. Spielmann (1988), S. 58 f.
} 
angedeutet. Oberhalb der Liebenden peitschen Wogen wild durcheinander. Bedrohlich überragen vulkanisches Gebirge und ein wolkenverhangener Himmel im oberen Drittel die Szenerie. Feine senkrechte blaue Linien deuten den niederprasselnden Regen an. Glutrot qualmt der Vesuv. Vor allem farblich steht die untere Bildhälfte im Kontrast zur oberen. Während das Unwetter im Hintergrund in verschiedenen dunklen Grün- und Blautönen gegeben ist, muten die hellen Partien in Verbindung mit durchscheinendem Senfgrün und Flieder tendenziell leichter und heiterer an. Die Liebe zwischen Alma und Kokoschka, so scheint es, trotzt den Unbilden der Außenwelt und erlebt zumindest zeitweise Harmonie.

Dieses Fächerbild nun ist Keimzelle des wohl bekanntesten und meistgerühmten Gemäldes von Oskar Kokoschka - „Die Windsbraut“ (Abb. 50), welches 1913 fertig gestellt wurde. Die Darstellung ist reduziert auf das in einem Boot auf stürmischer See wie Schiffbrüchige dahin treibende nackte Paar. Auch hier ist das Schiff nicht mehr als eine Andeutung durch vage, gewölbte Linien, die wie eine Nussschale die Figuren von unten her umfangen. Sie sind mit breitem, expressivem Pinselstrich in Olivgrün und Schwarzblau ausgeführt und münden in rötlichen Endungen, die sich vom bewegten, dunkeltonigen und nicht näher definierten Hintergrund abheben. Scheinbar schwerelos schwebt das Paar horizontal und in ähnlicher Lage wie im Fächerbild vor dem blau-grünen Grund. Wie in „Das Paar im Boot" liegt Alma schlafend und mit vor die Brust gezogenen Armen neben dem Geliebten. Ihr Gesichtsausdruck ist friedlich, der Duktus der kaltrosa Farbe ihres Oberkörpers ruhiger und einheitlicher als die übrigen Gemäldepartien. Sie ist dem Betrachter und damit auch Kokoschka zugewandt. Anders als auf dem Fächer sind Kokoschkas Augen hier nicht geschlossen und er ergreift auch nicht in zärtlicher Geste Almas Arm. Stattdessen blickt er auf dem Rücken liegend grimmig, ernst und nachdenklich gen Himmel, wo eine grüne Mondsichel schimmert. Die knotigen Hände hat er in krampfhafter und nervöser Weise vor seinem Bauch verschränkt. Blick und Geste wirken spannungsgeladen und unruhig. Arme und Oberkörper sind aschfahl und schwarzgraue Schattierungen in bewegtem Pinselstrich lassen die Körperteile zerfurcht und entstellt erscheinen. Die rot glimmenden Planken umgeben bedrohlich Kokoschkas Haupt und bilden Lichtreflexe auf seiner Haut. Sie mögen zugleich die negativen Gedanken symbolisieren, die den Geist des Künstlers umklammern. Kokoschkas Gesicht durchziehen tiefe Schatten in der Augen- und Wangenpartie. Darüber hinaus sind die Beine des Paares in merkwürdig kalt und leblos erscheinendem Blau gehalten und lassen sich sowohl in Farbigkeit, als auch im expressiven Pinselduktus kaum von Planken und Wellen unterscheiden. Das linke Ende des Bootes wird von einer großen Woge angehoben und droht über den Köpfen der beiden Figuren zusammenzuschlagen. Insgesamt drückt die Szenerie des Gemäldes Bedrohung aus. Die scheinbar harmonische Verbindung des Paares ist kurz vor dem Scheitern. Sinnbildlich droht entsprechend das nur aus wackeligen Planken bestehende Bootsgebilde, das die Liebenden in einender Ovalform in trügerischer Sicherheit wiegt, im Sturm zu 
kentern. Ahnungsvoll und mit traurigem Ernst scheint der ins Bild gesetzte Künstler diesem Schicksal entgegen zu blicken. Die düsteren Farben und das aufgewühlte Meer spiegeln sehr deutlich die Gefühlslage Kokoschkas. Der Mond, wieder als Symbol für die Frau, könnte dabei als Hinweis auf den Auslöser dieser Emotionen gemeint sein.

Kokoschka wollte mit dem Gemälde ein Meisterwerk schaffen, das ihm breite Aufmerksamkeit und Lob als Künstler und damit gesellschaftliche Anerkennung bescheren sollte. Er hoffte Alma auf diese Weise endlich von seinem Wert als ihr Bräutigam zu überzeugen. ${ }^{427}$ Entsprechend intensiv widmete er sich der Arbeit an dem Bild, das verschiedene Phasen der Überarbeitung erfahren hat, in denen es auch unterschiedliche Stimmungen vermittelt haben muss. Das ursprünglich in Erinnerung an ihre erste Begegnung „Tristan und Isolde“428 betitelte Bild scheint anfangs einen viel positiveren Gehalt wiedergegeben zu haben, wenn Kokoschka es in einem Brief an Alma vom April 1913 wie folgt beschreibt:

„Wir beide mit sehr starkem rubigem Ausdruck, die Hände ineinandergelegt, am Rand
in einem Halbkreis, bengalisch beleuchtetes Meer, Wasserturm, Berge, Blitz. und Mond.
(...) Mitten in den Verwirrungen der Natur ein Mensch dem anderen ewig zu vertranen
und durch den Glauben sich und den anderen zu befestigen. " ${ }^{29}$

Das Bild muss also anders ausgesehen haben als im heutigen Zustand. Anscheinend war darin eine viel größere Nähe und Vertrautheit des Paares gegeben, z. B. durch die zusammengelegten Hände und vermutlich auch durch eine andere Bootsform, die angelehnt war an die Sicherheit suggerierenden Boote früherer Darstellungen, wie z. B. auf dem erwähnten Fächer. Auch muss es in der Farbigkeit zunächst rötlich gewesen sein, denn Kokoschka spricht in seinen Briefen von einem ,roten Bild ${ }^{k 430}$ und das Gedicht Georg Trakls, das dieser angesichts des Bildes in Kokoschkas Atelier ersann, ${ }^{431}$ verweist ebenfalls darauf. Das Gedicht soll laut Kokoschkas eigener Aussage denn auch zur Betitelung des Gemäldes als „Die Windsbraut“ geführt haben.432 Die Veränderung der bildimmanenten Stimmung muss sich im Laufe des Jahres 1913 im Zuge der sich wandelnden Beziehung zu Alma vollzogen haben. So entzog Alma sich seinen Heiratsplänen, die er ohne

\footnotetext{
427 Spielmann (2003), S. 148. Vgl. auch Kokoschka: Briefe, Bd.1 (1984), S. 118: „Das Bild muß mein stärkster Beweis werden, den ich Dir für meine Person geben kann (...). Meine liebe Frau wird nicht einem Kerl sich vermäblen müssen, dem sie nicht glauben kann."

428 Alma hatte Oskar Kokoschka dabei den Liebestod der Isolde aus Wagners Musikdrama vorgesungen. Spielmann (2003), S. 148.

${ }^{429}$ Brief an Alma Mahler. Wien: April 1913, in: Kokoschka (1984), Bd. 1, S. 94.

${ }^{430}$ Spielmann (1988), S. 58.

431 „(...) Über schwärzliche Klippen/ Stürzt todestrunken/ Die erglühende Windsbraut (...)“ Auszug aus Georg Trakls „Die Nacht“ (veröffentlicht in: Ludwig von Ficker (Hrsg.) „Der Brenner“, Innsbruck 1910-1954), s. Trakl (1987), S. 160. Die Verwendung des Adjektivs „erglühende" lässt eine Zusammenstellung warmer Farben zumindest für das zentrale Bildmotiv vermuten. Es sind auch noch weitere, Feuer assoziierende, Worte im Gedicht zu finden.

432 Spielmann (1988), S. 58; Winkler/Erling (1995), S. 59.
} 
ihre Zustimmung vorantrieb, reiste im Mai 1913 nach Franzensbad, und ließ damit den von ihm vorgesehenen Hochzeitstermin platzen. In der Folgezeit löste sie die engen Bande und schuf immer mehr Distanz. „Die Windsbraut“ vollendete Kokoschka einem Bericht an Herwarth Walden zu Folge im Dezember 1913.433 Die sich über das Jahr verschlechternde Beziehung spiegelt sich in dieser verdüsterten, pessimistischen Endfassung. Letztlich führte das Gemälde somit weder auf privater noch auf gesellschaftlicher Ebene zum erhofften Erfolg. Spielmanns Vermutung mag richtig sein, dass Kokoschka in seinem Gedicht „Allos Makar“, welches er wenige Monate später schrieb, mit Worten die Überzeugungskraft auf Alma auszuüben versuchte, die in dem Gemälde nicht gewirkt hatte. ${ }^{434}$ Statt nur einen Zustand der Beziehung und eine Stimmung festzuhalten wie dort, konnte Kokoschka im Gedicht seinen komplexen Gefühlen von Angst, Hoffnung, Faszination, Leid, den sich wandelnden Verhaltensweisen und wechselnden Perspektiven auf ihre Verbindung viel facettenreicher Ausdruck verleihen und damit ein umfassenderes „Bild“ seiner Sicht des Ganzen geben.

\section{Überwindung der Geschlechterproblematik}

Soviel Kokoschka sich in den ersten Jahren seines künstlerischen, zugleich expressionistischen, Schaffens mit dem Geschlechterkonflikt auch befasste - letztlich kam er dann doch dazu diese Problematik zusammen mit der enttäuschten Liebe zu Alma zu überwinden. Spätestens nach Almas Vermählung mit Walter Gropius im August 1915 während Kokoschkas Kriegseinsätzen an der Ostfront, musste der Künstler das Ende aller Hoffnung auf ein Leben mit ihr einsehen. ${ }^{435}$ Diese Einsicht und die Erfahrungen des Ersten Weltkrieges, die ihn schwerverwundet um sein Leben ringen ließen, stürzten ihn in eine tiefe seelische Krise, deren Überwindung ihn Monate, sogar Jahre kostete. Vielfach verarbeitete Kokoschka diese Emotionen in seinen Werken - wie zuvor sowohl in Texten als auch in Bildern. Allerdings tat er das in sehr unterschiedlicher Weise. Während in seinen Bildern vor allem das Ausleben eines Puppenfetisch zum Tragen kommt - eine lebensgroße Puppe, die er sich nach dem Vorbild Almas herstellen ließ, wird dabei zu einem wichtigen Bildelement - behandeln seine Dramen das Thema auf einer abstrakteren Ebene. Sie setzen vor allem die in den früheren Stücken und Fassungen enthaltene Auseinandersetzung mit dem Geschlechterkonflikt fort. Es verstärken sich darin allerdings nach und nach andere Tendenzen und positivere Lösungsansätze, die mit Kokoschkas persönlicher Entwicklung und teilweise mit seiner Loslösung von Alma in Zusammenhang stehen dürften.

In dem zwischen 1915 und 1918 entstandenen Drama „Orpheus und Eurydi-

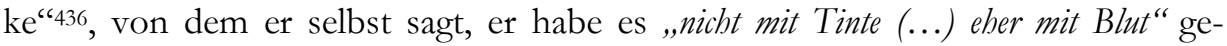

\footnotetext{
433 Husslein-Arco (2008), S. 232 f.

434 Spielmann (1988), S. 77.

435 Husslein-Arco (2008), S. 252.

436 Mehr dazu in Kapitel 3.2.3.5.; Textnachweis, Text XXIX.
} 
schrieben, ${ }^{437}$ greift Kokoschka die Wurzeln seiner Krise - Kriegseindrücke und der Verlust Almas - auf, verschlüsselt sie und scheint sie in der Andeutung einer Hoffnung am Ende des Stückes auch zu überwinden. Doch soll in Kapitel 3.2.3.5 genauer auf dieses Werk eingegangen werden, da es über die Geschlechterthematik hinaus, wie der Titel verrät, in einen mythologischen Kontext gestellt ist.

1917 überarbeitete Kokoschka sein Drama „Sphinx und Strohmann“ ein drittes Mal und führte das daraus resultierende Stück „Hiob“438 zu einem anderen Schluss als in der Ursprungsfassung von 1907. War der das Bildungstheater parodierende Einakter „Sphinx und Strohmann“ noch ein relativ einfaches HahnreiSpiel, das zwar den Geschlechterkampf zum Hintergrund hatte, aber nur Gedankenbruchstücke lieferte und in erster Linie mit den Möglichkeiten der Groteske und dem Topos der „verkehrten Welt“ spielte, so baute Kokoschka „Hiob“ zur komplexeren, dreiaktigen Menschheitskomödie mit Bezug zum Sündenfall aus. ${ }^{439}$ Dabei handelt es sich aber nicht um eine moderne Version der biblischen Geschichte von Hiob, der durch schweres Unglück auf seinen Glauben hin geprüft wird. Er wird hier keineswegs als Spielball von Gott und Satan dargestellt, sondern als Opfer seiner Sehnsucht nach dem weiblichen Geschlecht. ${ }^{440}$

Im ersten Akt erfährt Hiob, der in den vorigen Fassungen des Stücks Herr Firdusi benannt war, von einer Kammerjungfrau, dass seine Frau Anima mit einem anderen Mann verschwunden sei und ihm nur einen Papagei zur Unterhaltung dagelassen habe. Er spinnt Gedanken über ihre Untreue und stellt fest, dass er sich in Anima getäuscht haben müsse und dass "Sie sich verwandelt durch irgend eine Hintertür,/ In ein Wesen das - ich selber bin!" Diese Aussage verweist einerseits auf die Suche nach dem Einen im Anderen - Kokoschkas Idealvorstellung von Liebe und Beziehung - , doch zeugt sie andererseits auch davon, dass man, wie Hiob, Illusionen erliegen und dabei bezüglich des Gegenübers zur Fehleinschätzung kommen kann. Anima erscheint anschließend, bleibt jedoch hinter einer verschlossenen Tür verborgen. Sie tritt mit ihrem Mann in eine Art von Dialog, in welchem Hiob darüber trauert, dass er sein Weib und damit seinen Weltentwurf verloren habe, während Anima zu Bedenken gibt: „Wer sich nicht vorsieht,/ Sich vermisst,/ Kann den Kopf verlieren!"

Im zweiten Akt tritt Herr Kautschukmann auf, welcher in „Sphinx und Strohmann" den erotisch-orientierten Gegenpart zum geistdominierten Herrn Firdusi dargestellt hatte. Er schält sich in Anspielung auf Goethes „Faust" mit der Erklärung, er sei des Pudels Kern und außerdem Psychologe, aus einem Hundekostüm und benennt Erotik und Eifersucht als Animas Mittel, um Hiob zuzusetzen. Er selbst scheint ebenfalls an Animas Reizen interessiert zu sein, denn er schaut lüstern durch das Schlüsselloch in ihr Zimmer und erregt damit Hiobs

\footnotetext{
${ }^{437}$ Wingler (1956), S. $432 \mathrm{f}$.

438 Textnachweis, Text XXIII.

439 Schober (1994), S. 52; Lischka (1972), S. 61; Denkler (1965), S. 38.

${ }^{440}$ Schvey (1982), S. 72.
} 
Eifersucht. So verdreht Anima, als sie heraustritt, Hiob denn auch wie in der Ursprungsfassung den Kopf, was groteskerweise bildlich umgesetzt wird, indem er seinen Kopf tatsächlich zu weit dreht. Das Wortspiel seiner Ausrufe „Man hat mir den Kopf verdreht!/ Man hat mir den Kopf verrïckt!/ Verrückt!" verweist darauf, dass Animas Verhalten zerrüttende Konsequenzen für seinen seelischen und geistigen Zustand hat. Der entstehende Aufruhr wird durch den Auftritt des Eros als kleinem Jungen verstärkt, der auf Animas Rolle als Dienerin der Liebe hindeuten mag. ${ }^{441}$ In allem - von der Untreue und Fehleinschätzung der Frau bis hin zur zerstörerischen Wirkung ihres Verhaltens - kann zugleich eine Parallele zu Kokoschkas persönlicher Auseinandersetzung mit Alma gesehen werden.

Im dritten Akt wird der im Freien vor dem Haus schlafende Hiob durch die Neckereien von zehn Fräuleins geweckt und in Gespräche über die Liebe verwickelt. Er geht schließlich ins Haus und setzt am Fenster stehend eine Giftflasche an seine Lippen, die er dann aber nach einem der aufdringlichen Fräuleins wirft. Er springt aus dem Fenster und wird vom Papagei daran gehindert sich vom Haus zu entfernen. Hiob wächst während des Herumlaufens ein Geweih, das ihn metaphorisch als „gehörnten Ehemann" ausweist und aus einem beleuchteten Fenster des Hauses werfen die sich Entkleidenden - Anima und Herr Kautschukmann ihre Kleidungsstücke auf ihn herab, so dass sie sich in seinem Geweih verfangen. Letztendlich fällt Anima selbst ,wie ein reifer Apfel vom Fenster herunter" und enthauptet Hiob dadurch. Der Gärtner Adam bemerkt darauf: „Zu hoch hast du dein Weib/ In den Himmel versetzt. Erst da sie fällt, kannst du ibr auf/ Den Boden sehn. "Auch hiermit kann auf Alma angespielt sein, deren wahren Charakter Kokoschka zu dieser Zeit widerwillig erkennen musste. Trotz des scheinbar unglücklichen Endes, geht der Geschlechterkonflikt nicht gänzlich negativ aus. Während zehn Herren über das Debakel philosophieren, antwortet Adam auf Animas Frage, ob Hiob tot sei, nämlich: „Nein! Nur sein Kopf sein Herz, und andres ist verschieden." Diese Antwort bringt zum Ausdruck, dass Hiob durch Anima nicht wirklich getötet wurde, die Enttäuschung durch ihr Verhalten ihn aber verändert hat.

„Hiob“ nimmt nicht nur durch seinen Titel, sondern auch noch auf einer weiteren Ebene Bezug auf die Bibel. ${ }^{442}$ Im Prolog des Stücks erschafft der gelangweilte Gott Eva durch einen Stoß in die Rippen des im Garten Eden schlafenden Adam, der daraufhin wünscht: „Mein Gott, bätt' er mir nur mein Bein mit Ruh gelassen. “ Hiob wird somit auch mit Adam in Verbindung gebracht. Einerseits als eine Art Kompositfigur aus beiden - nach der Einführung des schlafenden Adam im Prolog erfolgt Hiobs erstes Auftreten nämlich in Schlafkleidung -, andererseits als eigenständige Gärtnerfigur im dritten Akt. Für beide wird eine problematische Beziehung zur Frau aufgezeigt, die sich zum einen aus dem Verlauf des Stücks ablesen lässt und sich zum anderen aus dem biblischen Hintergrund - also der

\footnotetext{
${ }^{441}$ Vgl. Lischka (1972), S. $61 \mathrm{ff}$.

442 Religiöse Bezüge wurden schon mehrfach erwähnt und sind unter Kapitel 3.2.3.3 genauer untersucht.
} 
Verführung Adams durch Eva - ergibt. Immer wieder sind Anspielungen auf den Sündenfall gegeben, sei es beispielsweise durch die Regieanweisung, die die fallende Anima wie einen reifen Apfel beschreibt und so mit Eva in Verbindung bringt oder seien es Adams Bemerkungen, die er macht, als er dem Papagei im dritten Akt hinterher sieht (,Im Paradies einst raunte mir/ Derselbe Vogel Warnung zu./ Mit Äpfelessen beschäftigt,/ Hörte ich nicht zu." ". Und wenn zum Schluss Anima überlegt „Vielleicht verleumde ich mich selbst nur - / Und Anima, die Hiob das schwere Kreuz auf die Schulter/ legte,/Ist - Eva", so wird damit angedeutet, dass Animas Handeln vielleicht gar verziehen werden muss, da sie als Nachfahrin der Verführerin Eva einen Teil der Erbsünde in sich trägt und daher nicht anders handeln kann. Dieses Verzeihen und die darin sich spiegelnde Überwindung des Geschlechterkonflikts, wie des persönlichen Konflikts des Künstlers, wird denn auch durch Adams Worte unterstrichen: „Das ein₹ige Gute, das ich noch tun kann,/ Ist das Licht auszublasen,/ Damit es nicht brennen muß. "Sie kennzeichnen nicht nur das Ende des Stücks, sondern im übertragenen Sinne - nach dem durch den Kopfverlust angedeuteten inneren Wandel Hiobs - auch das Löschen der Flamme der Leidenschaft. 443

Diese versöhnliche Tendenz spiegelt sich zu guter Letzt ebenso in der Lösung des Konflikts in der Konstellation der Pietà, die in Kokoschkas letztem expressionistischen Drama „Der brennende Dornbusch“444 (1917) aufgezeigt wird. Die Frau verletzt hier den Mann tödlich durch einen Steinwurf und findet durch seine darauffolgende Aufopferung zur Liebe zurück. Die Idee des Opfertodes und der gleichsam mütterlichen Liebe war bereits in der Ursprungsfassung „Schauspiel“ von 1911 und in dem Plakat für das Sommertheater von 1909 enthalten. Die Tatsache, dass mit dem Wiederaufgreifen dieses Lösungsansatzes Kokoschkas expressionistisches dramatisches Schaffen endet, spricht dafür, dass er damit die Auseinandersetzung mit dem allgemeinen Geschlechterkonflikt für sich abgeschlossen hat.

Der Abschluss dieses Themas auf literarischer Ebene bedeutete jedoch noch nicht dessen Ende im bildkünstlerischen Werk, in dem die persönliche Problematik noch bis circa 1922 ablesbar bleibt. Die Loslösung von Alma Mahler erfolgte in einem langsamen Prozess, für den wie bereits erwähnt den Umgang mit einem Fetisch zentral war: im Juni 1919 bestellte Kokoschka bei der Münchener Puppenmacherin Hermine Moos eine lebensgroße Puppe nach dem Vorbild Almas, die ihm die Geliebte ersetzen und seine Idealvorstellung der Frau schlechthin verkörpern sollte. Er versuchte so mit den Mitteln der Kunst das reale Leben zu überwinden. ${ }^{445}$ Die Korrespondenz mit Hermine Moos dauerte mehr als acht Monate und Kokoschka gab in seinen Briefen genaue Anweisungen, wie er sich die Beschaffenheit der Puppe vorstellte. ${ }^{446}$ In mehreren Skizzen versuchte er Fräu-

\footnotetext{
${ }^{443}$ Vgl. Lischka (1972), S. 62 f.; Schvey (1982), S. 72.

${ }^{444}$ Mehr dazu in Kapitel 3.2.3.2.; Textnachweis, Text XXV.

445 Haenlein (1983), S. 22.

446 Näheres dazu s. Gorsen (1986), S. 193 f.
} 
lein Moos seine Vorstellungen von der Puppe zu verdeutlichen. Die lebensgroße Ölskizze „Stehender weiblicher Akt, Alma Mahler“ (Abb. 51) von 1918 sandte er ihr im August 1918 mit der Bitte sie ,recht getreu nachzuabmen und mit dem Aufgebot ihrer ganzen Geduld und Sensualität in Realität umzuschaffen "447. Anhand der weißen Farbflecken sollten seiner Aussage nach die „Lagerung der Fett- und Muskelbündel“448 ersichtlich sein. Der Titel und die Lebendigkeit vermittelnden Ausführungen der Skizze lassen die Puppe wie eine Aktdarstellung von Alma selbst erscheinen.

Die mit der Puppe verbundenen Erwartungen waren letztendlich jedoch zu hoch und der Künstler vom Endprodukt sehr enttäuscht. Als Ersatz für Alma war die Puppe zwar nicht geeignet, doch half sie ihm dennoch bei der Verarbeitung der verlorenen Beziehung, indem sie zum Bildgegenstand vieler Zeichnungen und einiger Gemälde wurde. Ihre Funktion wandelt sich dabei vom symbolischen Ersatz Almas und einer porträthaften Darstellung ${ }^{49}$ hin zu einem eher leblosen Demonstrationsobjekt.

Den Abschluss dieser Distanzierung vom Fetisch, wie auch von Alma bildet das Gemälde „Maler mit Puppe“ (Abb. 52) von 1922.450 Hier posiert sie unbekleidet als Modell in aufgelehnt sitzender Haltung mit an die Brust gelegten Händen und aus dem Bild gewandtem Blick. Der Künstler, der rechts hinter ihr sitzt, hat seine Linke auf ihr Knie gelegt und weist mit der Rechten vorwurfsvoll auf ihren Schoß - eine Geste, die Schimpf und Schande zum Ausdruck bringen soll. 451 Während die rote Farbe des Möbelstücks, auf dem sie sitzt, und die Akzente auf ihrem rosigen Stoffkörper sie in eine beinahe anzügliche Atmosphäre rücken, wirken der dunkel gekleidete Künstler und der grüntonige Hintergrund, dem er zugeordnet ist, im Gegensatz dazu geradezu kühl und sachlich. Kokoschkas Blick ist zudem traurig und ernst. Der in der Geste enthaltene Vorwurf kann sich einerseits auf die von Alma durchgeführte Abtreibung seines Kindes beziehen oder aber auf ihre Abwendung von Kokoschka, die er als Untreue aufgefasst haben mag. In jedem Fall spiegelt sich darin die Bitterkeit über die gescheiterte Beziehung. Auf der anderen Seite wird die Puppe aber deutlicher als z. B. in der Ölskizze zuvor als solche kenntlich gemacht. Ihr plumper Körper lässt sie eindeutig als Objekt erkennbar werden und ist nicht mehr als erotischer Ersatz für die Geliebte dargestellt. Ihre Mea-culpa-Geste und Kokoschkas Zeigegestus lassen das Bild als eine Art Gerichtsszene erscheinen, in der der Künstler anklagt und sie sich stellvertretend für Alma hilflos zu verteidigen sucht - hilflos, weil ihre Schande an ihrem nackt dargebotenen Körper offenbar zu sein scheint. Durch die Darstellung

\footnotetext{
${ }^{447}$ Kokoschka (1984-88; Bd. 1), S. 293.

448 Kokoschka (1984-88; Bd. 1), S. 294.

${ }^{449}$ Beispielsweise in „Frau in Blau“ (1919) vgl. Winkler (1995), Nr. 136, S. 82.

${ }^{450}$ Es ist Winkler Recht zu geben, wenn er der in dem noch etwas späteren Gemälde „Selbstbildnis an der Staffelei“ dargestellten Puppe eine Ähnlichkeit mit dem Puppenfetisch abspricht. Winkler (1995), Nr. 159, S. 95. Insofern beinhaltet „Maler mit Puppe“ die letzte Darstellung des Fetischobjekts.

451 Vgl. Gallwitz (1992), S. 17.
} 
der Puppe als lebloses Gliederobjekt, das nur durch die Drapierung an der Lehne Halt findet, ironisiert Kokoschka den Fetisch und distanziert sich somit von ihm und Alma gleichermaßen. ${ }^{452}$

Im gleichen Jahr dürfte die Puppe ihr unrühmliches Ende bei einer geradezu dadaistischen Inszenierung während einer Feier gefunden haben. Mit Rotwein besudelt und geköpft wurde sie nach einer durchzechten Nacht der Müllabfuhr überlassen. ${ }^{453}$ Alma und der Konflikt der Geschlechter finden hiernach keinerlei Niederschlag mehr in Kokoschkas expressionistischem Schaffen, wie sich seine Bildthemen und sein Stil um diese Zeit auch insgesamt wandeln. Der allgemeine, wie auch der persönliche Geschlechterkampf scheinen somit zu diesem Zeitpunkt für den Künstler überwunden zu sein.

Ergebnis

Es ist nicht von der Hand zu weisen und muss an dieser Stelle noch einmal betont werden, dass im Prinzip jedes der expressionistischen Bühnenstücke Kokoschkas im Kern den Geschlechterkonflikt thematisiert. Bei genauerer Betrachtung lässt sich dabei eine inhaltliche Entwicklung feststellen. Bei aller Vielseitigkeit - vom archaisch-aggressiv anmutenden „Mörder, Hoffnung der Frauen“, über die religiösen Tendenzen im „Schauspiel“, allegorisch-mythologischen Aspekte in „Orpheus und Eurydike“ bis hin zum gänzlich grotesken „Hiob“ - lässt sich die Beruhigung des Geschlechterkonflikts nachverfolgen. Bald eher tragisch, bald eher grotesk454 entwickelt Kokoschka die dem Geiste seiner Zeit entsprechende Idee der immerwährenden Kämpfe zwischen Mann und Frau hin zu einer Lösung des Konflikts im gegenseitigen Vergeben. Seine Auseinandersetzung mit dem Thema ist an diesem Punkt der versöhnlichen Sichtweise um 1917 abgeschlossen und scheint zukünftig für ihn auf der allgemeineren Ebene keine weitere Rolle mehr zu spielen. Auf der persönlichen Ebene, die sich deutlich mehr in den bildkünstlerischen Werken verarbeitet findet, bleibt das Thema noch eine Weile präsent.

Die in den expressionistischen Bildern definitiv direkter zu beobachtende Verarbeitung des persönlichen Konflikts betrifft vor allem die spätere Phase, in der Alma Kokoschkas Leben bestimmt. Die Porträts, Doppelbildnisse und mit Almas beziehungsweise Kokoschkas Zügen versehenen Figuren verschiedenster Illustrationen spiegeln immer wieder persönliche Erlebnisse des Künstlers in unterschiedlichen Phasen seiner Entwicklung. Die Dichtungen spielen im literarischen Schaffen des jungen Kokoschka eine eher untergeordnete Rolle, auch wenn „Die träumenden Knaben" und „Allos makar" durchaus von Bedeutung sind. In ihnen vermischen sich biografische und zeittypische Aspekte des Themas stärker als in den Bühnenstücken. Die Dramen heben sich durch ihre provokanten Innovatio-

\footnotetext{
452 Vgl. Gorsen (1986), S. 199 ff.; Brugger (1991), S. 25.

453 Gallwitz (1992), S. 18.

454 Schwerte (1964), S. 176. Schwerte teilt hier Kokoschkas Dramen in die zwei Gruppen des Tragischen und des Grotesken.
} 
nen im Vergleich zum konventionellen Theater der Zeit besonders ab und dürften für Kokoschka das geeignete Mittel zur Propagierung seiner Ideen gegenüber einem breiteren Publikum gewesen sein.

Zwischen der Verwendung von Text und Bild bezüglich des Themas Geschlechterkonflikt besteht trotz der inhaltlichen Parallelen auch ein wichtiger Unterschied. Im Drama - selbst wenn darin (bei Kenntnis von Kokoschkas Biografie natürlich) immer wieder auch dessen eigene Erfahrungen sich spiegeln - nutzt Kokoschka die Möglichkeiten der Narration, um den Facettenreichtum und die Entwicklungsmöglichkeiten des Geschlechterkonflikts allgemein vor Augen zu führen. Es ist beachtenswert, dass er selbst in diesem eigentlich mit dem Wort operierenden Medium, vor allem ein Interesse an der Bühne ,als Medium des Visuellen" 455 mit einem großen Potential an konkreten und eben auch nonverbalen Ausdrucksmitteln hatte - es sei hierbei beispielsweise an die Symbolik von Farben und Bühnenbild erinnert. In den Bildwerken konzentriert er sich vor allem auf seine selbst erfahrenen Konflikte mit Frauen. So finden wir Lilith Langs Züge in den Illustrationen zu „Die träumenden Knaben“ wieder und ab 1912 gibt es eine Vielzahl von Frauendarstellungen, die mit Alma in Verbindung zu bringen sind. Kokoschka nutzt die beiden Medien von Bild und Text somit, um auf verschiedenen Ebenen den Geschlechterkonflikt zu verarbeiten.

\subsubsection{Religiöse Aspekte}

Trotz seiner Dominanz ist das Geschlechterringen nicht das einzige wichtige Thema im expressionistischen Schaffen Kokoschkas. Bei den bisher durchgeführten Untersuchungen ist bereits angedeutet worden, dass daneben noch andere Aspekte bildkünstlerisch behandelt worden sind und ebenfalls Eingang in das hauptsächlich von der Geschlechterproblematik durchdrungene, literarische Werk gefunden haben. Ein Themenbereich, der sich dabei bereits deutlich herauskristallisiert hat, ist jener der Religion. Erstaunlicherweise ist zu den religiösen Aspekten in Kokoschkas Frühwerk nur wenig in der Sekundärliteratur zu finden und nur bei Erling 456 ist eine eigene Untersuchung explizit dazu durchgeführt worden. Umso lohnender erscheint die Beschäftigung mit diesem Desiderat.

\section{Zuordnung}

Religiöse Aspekte und Motive haben sich in Kokoschkas frühen Werken in unterschiedlicher Weise niedergeschlagen. Wesentlich ist eine Gruppe zeitlich eng zusammengehöriger, religiöser Gemälde um 1911/1912 in einem für Kokoschka damals neuen, opaken Stil, dem eine spezielle Beschäftigung mit Form- und Farb-

455 Schvey (1986), S. 102.

456 Erling (1997), S. 54-73. 
zergliederung eigen ist. Zwar finden sich zuvor schon religiös intendierte Bilder bei ihm, wie z. B. „Veronika mit dem Schweißtuch“ von 1909, doch ist die Behandlung religiöser Themen in Form der sechs innerhalb eines Jahres entstandenen Gemälde auffällig. Vermutlich ist diese plötzliche Intensivierung auf eine persönliche Haltsuche des Künstlers während Krisenzeiten und auf Einflüsse des deutschen Expressionismus während Kokoschkas Aufenthalt in Berlin, von wo er im Januar 1911 nach Wien zurückgekehrt war, zurückzuführen. ${ }^{457}$ Bei den besagten sechs Bildern handelt es sich um „Heiliger Sebastian mit Engel“, „Ritter, Tod und Engel I“, „,Verkündigung“, „Ritter, Tod und Engel II“, „Flucht nach Ägypten“ und „Kreuzigung“. Sie spiegeln eine allgemeine Auseinandersetzung Kokoschkas mit der religiösen Thematik, die er in teils traditioneller, teils innovativer Weise im Bild zu bannen sucht. Auch die 1916 entstandene Folge zur Passion, bestehend aus sechs Kreidelithografien, ist in solcher Weise zu deuten.

Über die mehr oder minder an der ikonografischen Tradition orientierte Darstellungsweise hinaus, findet sich in Kokoschkas Frühwerk eine Reihe von Bildern, in denen sich eine Vermischung von religiösen mit profanen Themen feststellen lässt. Er nutzt hierbei ein christliches Motivrepertoire beispielsweise zur Darstellung seiner Selbstwahrnehmung als Künstler oder, wie im Kapitel zuvor schon angerissen wurde, in seiner Auseinandersetzung mit dem Geschlechterkonflikt. Die Stilisierung als missverstandener Künstler läuft dabei über eine Parallelisierung mit leidenden Personen der christlichen Glaubenswelt, wie beispielsweise mit Christus in der „Kreuzigung “458 oder dem Selbstbildnis im Sturm-Plakat von 1910. Diese Auseinandersetzung mit sich selbst, die Selbststilisierung als „Erleuchteter“, scheint Kokoschka schwerpunktmäßig um 1910/11 zu beschäftigen vermutlich im Zusammenhang mit der kritischen Bewertung seiner ersten Dramenaufführungen in der Öffentlichkeit. Im Ringen der Geschlechter sind vor allem Einflüsse des biblischen Berichts über Adam und Eva und Bezüge zur Pietà von Bedeutung, die sich immer wieder und zu verschiedenen Zeitpunkten des expressionistischen Schaffens finden lassen. Diese unterschiedlichen Schwerpunkte innerhalb des bildkünstlerischen Werks zum Thema Religion lassen sich jedoch im literarischen Werk nicht ganz so leicht wiederfinden. Während sich der religiöse Gehalt in Vermischung mit der Geschlechterproblematik immer wieder in den Dramen - vor allem in „Hiob“ und „Der brennende Dornbusch“ - erkennen lässt, ist eine allgemeinere Auseinandersetzung nur andeutungsweise in dem Vortrag „Von der Natur der Gesichte“ (1912) und dem Text „Vom Bewusstsein der Gesichte“ (1920) vorhanden. Diese Textbeispiele jedoch liefern im Vergleich zu den bildkünstlerischen Werken wichtige Zusatzinformationen zum Verständnis von Kokoschkas Umgang mit religiösem Bild- und Gedankengut.

\footnotetext{
457 Erling (1997), S. 55.

458 In verwandter Weise verwendet beispielsweise auch Gauguin in seinem Gemälde „Selbstbildnis mit gelbem Christus“ (1890-91/Musée d'Orsay, Paris) die Verknüpfung von eigener Darstellung mit dem Gekreuzigten, um auf sein persönliches Leid zu verweisen.
} 
Religiöse Reminiszenzen zur Selbststilisierung als missverstandener Künstler

Eines der frühesten bedeutenden Beispiele, in denen sich Kokoschka in seinem bildkünstlerischen Schaffen auf die christliche Ikonografie bezieht und deren Ausdruckspotenzial für eigene Ideen verwendet, ist das teils in der Sekundärliteratur fälschlicherweise auch als „Ecce homo“ bezeichnete Selbstbildnis des 1910 entstandenen Sturm-Plakats (Abb. 53). ${ }^{459}$

Vermutlich durch Vermittlung von Adolf Loos hatte Kokoschka 1910 dieses Werbeplakat für Herwarth Walden und dessen neue Zeitschrift „Der Sturm“ geschaffen. Seit Mai 1910 arbeitete Kokoschka in deren Redaktion in Berlin mit. Das Plakat zeigt ein Selbstbildnis des Künstlers im Dreiviertelprofil mit kahlem Schädel. Der knochige Kopf ist etwas links der Mitte positioniert; das Gesicht ist geprägt von leidvollen Falten, Augenringen, delirierend verdrehten Augen und schmerzvoll aufeinandergepresstem Zähnen. Zudem weist Kokoschka mit dem Zeigefinger seiner linken Hand auf eine tiefe längliche Wunde unterhalb seiner Brust. Die Konturen sind mit eher trocken und breit geführtem Pinsel in verschiedenen Blautönen ausgeführt, während der weißlich-blasse Körper von einem schlichten terrakottafarbenen Hintergrund ohne räumliche Tiefe hinterfangen wird. In dem als Farblithografie ausgeführten Plakat ergänzt der quer über die Brust verlaufende Schriftzug „Neue Nummer“ den über dem Bildnis prangenden Zeitschriftentitel „Der Sturm“ und verweist auf die wiederholte Verwendung des Motivs. ${ }^{460}$

Nachdem Kokoschka 1909 für die Aufführungen seines Dramas „Mörder, Hoffnung der Frauen“ in Wien vielfach kritisiert und zum öffentlichen Ärgernis erklärt worden war, ließ er sich aus Protest den Kopf kahl scheren und orientierte sich alsbald für einige Zeit nach Berlin um. Er fühlte sich ungerecht und gleichsam wie ein Krimineller behandelt. Durch den kahlen Schädel wollte er nun seinem Empfinden, ein „Gezeichneter“ zu sein, Ausdruck verleihen. In eben dieser Weise wird er kahlgeschoren auf dem „Sturm-Plakat“ vor Augen geführt. Zugleich aber stellt er durch seine Darstellungsweise gleichsam als Schmerzensmann mit Seitenwunde eine Parallele zwischen dem leidenden Christus und seiner eigenen Person her. Durch die Verwendung dieses Motivs im Anschluss an die Tradition der christlichen Ikonografie verweist er auf sein eigenes ihm durch böswillige, öffentliche Kritik widerfahrenes Leid als missverstandener Künstler. Diese Identifikation eines Künstlers mit Christus ist nicht ungewöhnlich und findet sich in der Kunst häufiger - z. B. in Albrecht Dürers bekanntem „Selbstbildnis im Pelz-

\footnotetext{
${ }^{459}$ Genau genommen ist die häufig in der Sekundärliteratur zu findende Betitelung des Plakats als „Ecce homo“ nicht zutreffend, da „Ecce homo“ sich auf die Zurschaustellung der vor der Kreuzigung erlittenen Wunden bezieht, während „Schmerzensmann“ das Motiv des mit durch die Kreuzigung mit Wundmalen versehenen Gottessohnes benennt. Indem Kokoschka sich hier mit Seitenwunde vor Augen führt, folgt er also der Darstellungstradition des Schmerzensmannes. ${ }^{460}$ Husslein-Arco (2008), S. 188 und S. 295.
} 
rock“.461 Die Darstellung zugleich als Gezeichneter - und folglich mit negativer Konnotation - ist dagegen seltener und erscheint auf den ersten Blick widersprüchlich. Beides findet sich, wenn auch nicht zu einem Bild zusammengeführt, beispielsweise bereits bei Paul Gauguin. So verknüpft dieser in dem „Selbstbildnis mit gelbem Christus" seine Person mit dem Gekreuzigten. In seinem Selbstbildnis als Jean Valjean ${ }^{462}$ nach Victor Hugos Roman „Les Miserables“ schlüpft Gauguin in die Rolle des Gesetzlosen, der als „armes Opfer der Gesellschaft“463 unterdrückt und für vogelfrei erklärt wird. In ähnlicher Weise dürfte auch in Kokoschkas Plakat-Porträt die Darstellung als Verstoßener zu deuten sein: als missverstandenes und zu Unrecht kritisiertes Opfer der Wiener Gesellschaft.

Der Dualismus im Bild lässt sich zudem mit Kokoschkas Absicht erklären, zeigen zu wollen, dass er ähnlich wie Christus verkannt, aber für seine Überzeugungen und Ideen zu leiden bereit sei. Mehr noch könnte darin sogar der Gedanke zum Ausdruck kommen, sein Wirken und die dafür erlittene Schmach würden einst als Weg zur Wahrheit wahrgenommen werden. Dahinter verbirgt sich die Idee des Künstlers als eines Erleuchteten und das Bestreben, die Kunst gleichsam als eine Art Religion aufzufassen. Diese Vorstellungen wurden vor allem von Nietzsche propagiert. In seiner um 1886/87 datierten Schrift „Wille zur Macht“, die in Teilen nicht umsonst zuweilen als „Artisten-Evangelium“ bezeichnet wird, preist dieser die Kunst als höchste Aufgabe, als Mittel zur Lebenssteigerung und als Gegenkraft gegen den Nihilismus:

„Die Kunst und nichts als die Kunst! Sie ist die große Ermöglicherin des Lebens, die große Verfübrerin zum Leben, das große Stimulans zum Leben (...) Die Kunst als die einzig überlegene Gegenkraft gegen allen Willen zur Verneinung des Lebens, als das Antichristliche, Antibuddhistische, Antinibilistische par excellence. Die Kunst als die Erlösung des Erkennenden (...) Als die Erlösung des Handelnden (...) Als die Erlösung des Leidenden" 464

Die hymnische Lobpreisung der Kunst durch Nietzsche hatte großen Einfluss und führte dazu, dass die Kunst in den Gott verneinenden Kreisen vielfach als Religionsersatz verstanden wurde. 465 Vor diesem Hintergrund ist also auch Kokoschkas Selbstdarstellung im Sturm-Plakat verständlicher. Die Identifikation mit

461 Albrecht Dürer: „Selbstbildnis im Pelzrock“ (1500/Alte Pinakothek München), siehe z. B. Goldberg (1998); oder auch Paul Gauguins „Christus im Garten Getsemane“ (1889/Norton Museum of Art, West Palm Beach), siehe z. B. Prather (1994).

462 „Les Miserables“ (1888/Van Gogh Museum Amsterdam), siehe z. B. Prather (1994).

${ }^{463}$ Gauguin selbst verweist in seinem Brief an Vincent van Gogh auf diese Deutungsebene: „Et ce Jean Valjean que la société opprime mis hors la loi, avec son amour sa force, n'est-il pas l'ímage aussi d'un impressionniste aujoud'bui. Et en le faisant sous mes traits vous avez mon image personnelle ainsi que notre portrait à 'tous pauvres victimes de la société ... "In: Merlhès (1984), Nr. 166.

464 Nietzsche (1972), S. 319 f.

${ }^{465}$ S. Kapitel 2.3. und z. B. die dort erwähnten Äußerungen Franz Marc zur Findung einer neuen Religion. 
Christus findet sich ähnlich noch in anderen Werken des Künstlers, wie beispielsweise in verschiedenen Pietà-Darstellungen. ${ }^{466}$

Ein anderes Beispiel dafür, wie Kokoschka sich selbst durch religiöse Reminiszenzen als leidenden und missverstandenen Künstler stilisiert, ist das der 1911 entstandenen Gruppe religiöser Bilder zuzurechnende Gemälde „Heiliger Sebastian mit Engel“ (Abb. 54). Vor einem dunklen, nicht näher definierten Grund ist eine nackte männliche Figur mit Lendenschurz zu sehen, die an einen abgestorbenen Baumstamm gebunden ist. Hände sowie Füße sind gefesselt und der Oberkörper ist von mehreren Pfeilen durchbohrt. Als Vorbild soll eine kleine Holzfigur aus Kokoschkas elterlicher Wohnung gedient haben. ${ }^{467}$ Soweit entspricht die Darstellung der in der Kunst über viele Jahrhunderte üblichen Wiedergabe des Martyriums des Heiligen Sebastian, der für seine christliche Überzeugung verfolgt und getötet wurde. Auch das Hinzufügen eines Engels ist nicht ungewöhnlich und so findet sich in Kokoschkas Gemälde in der rechten Bildhälfte ebenfalls eine weibliche Figur mit roter Gewandung und Flügeln, die ihre rechte Hand in einer schützenden Geste erhoben hat und mit der Linken auf den Heiligen weist, um auf sein Leiden aufmerksam zu machen. Die Gesichtszüge des Heiligen Sebastian jedoch und sein kahler Kopf erinnern an das Sturm-Plakat und legen die Vermutung nahe, dass es sich bei der Figur des Märtyrers um ein Selbstbildnis des Künstlers handelt. ${ }^{468}$ Wie in der Selbstdarstellung als Schmerzensmann nutzt Kokoschka das christliche Motivrepertoire, um sein eigenes „Martyrium“ als verkannter Künstler und Dramatiker vor Augen zu führen. Metaphorisch verbildlicht er, wie er von seinen Wiener Kritikern gleichsam an den Pranger gestellt und mit Pfeilen der Missbilligung attackiert worden ist. Der Engel symbolisiert die Aufmerksamkeit und das dem Heiligen geltende Wohlwollen Gottes, beziehungsweise im übertragenen Sinne dem von positiven Kräften (wie Alma sie beispielsweise einige Zeit verkörpern sollte) geführten Künstler.

Traditionelle religiöse Bildthemen

Die Hauptgruppe der sechs religiös intendierten Gemälde entstand 1911, nachdem Kokoschka aus Berlin nach Wien zurückgekehrt war. Ihnen vorangegangen war bereits 1909 „Veronika mit dem Schweißtuch“.469 In diesen Bildern ist eine neue formale und koloristische Entwicklungstendenz zu bemerken, die auf die künstlerischen Einflüsse in Deutschland zurückgeführt werden muss. Die maleri-

\footnotetext{
${ }^{466}$ Es gibt zudem auch Deutungsansätze, die eine Verknüpfung zwischen dem Mann aus „Mörder, Hoffnung der Frauen“, Kokoschka und Christus herzustellen suchen. Demnach soll der verwundete Mann mit dem leidenden und verratenen Christus in Verbindung gebracht werden können (Vgl. Schvey (1982), S. 34; Jäger (1982), S. 218). Doch erscheint diese Behauptung vor dem Hintergrund des Gesamtstücks zu spekulativ.

467 Winkler (1995), S. 37.

468 Vgl. Winkler (1995), Nr. 62; Spielmann (2003), S. 113.

${ }^{469}$ Kokoschka sagte später darüber: „Es ist mir das liebste meiner religiösen Bilder (...). “Kokoschka (1971), S. 126.
} 
sche, vom Hell-Dunkel-Kontrast getragene Form weicht zunehmend prismenartig und kristallin wirkenden, leuchtenden und letztlich bis in Pastelltöne reichenden Flächengefügen. Erling weist auf mögliche Einflüsse durch Kontakte des Künstlers zum Blauen Reiter und den Sturm-Kreis hin, bei welchen das Experimentieren mit facettierten Farblichträumen und die Beschäftigung mit dem „Geistigen in der Kunst ${ }^{\star 470}$ von großer Bedeutung waren. ${ }^{471}$ Insgesamt war, ausgehend von den wachsenden kirchenkritischen Tendenzen und Nietzsches Postulat des toten Gottes, eine Auseinandersetzung mit religiösen Fragestellungen bei vielen deutschen Expressionisten zu bemerken. Nahezu alle wichtigen Künstler der Zeit haben christliche Bildmotive aufgegriffen und in individueller Weise verwendet. Neuschöpfungen und Modifizierungen christlicher Bildüberlieferungen waren somit weit verbreitet und dürften auch Kokoschka inspiriert haben. Er selbst äußert dazu in seinen Erinnerungen über die Rückkehr nach Wien und in die Nähe seiner Eltern schlicht: ,Meine religiöse Vergangenheit war wieder erwacht. “472

Welche Gründe und Einflüsse auch genau dahinter gestanden haben mögen, die Hinwendung zu den religiösen Themen bringt sicherlich auch Kokoschkas Sehnsucht nach innerem Halt in den von allgemeinen Umbrüchen und persönlichen Krisen bestimmten Zeit zum Ausdruck. Das Gemälde „Ritter, Tod und Engel I“ (Abb. 55) beispielsweise spiegelt dies deutlich wider. Es entstand ebenfalls $1911 \mathrm{im}$ opaken Stil und war für die Mutter des Künstlers gedacht. Eine zweite Fassung entstand als Ersatz, weil Kokoschka das erste Bild letztlich doch einem Sammler überließ.473 Vermutlich in Anlehnung an Dürers Meisterstich „Ritter, Tod und Teufel“ führt das Bild die Begegnung eines Reiters auf seinem Pferd mit einer Engelsfigur vor Augen. Der die rechte Bildhälfte dominierende Ritter ist mit einer Rüstung und einem rot befederten Helm bekleidet. Seine Augen sind auf eine lichte Gestalt gerichtet, die sich links im Bild befindet. Dabei handelt es sich um den im Titel benannten Engel, der in ganz ähnlicher Haltung wie im Gemälde „Heiliger Sebastian mit Engel“ vor dem Reiter steht, die rechte Hand weisend gen Himmel hebt und mit der Linken die einzuschlagende Richtung angibt. Hinter ihm hebt sich vom dunklen Bildgrund ein den Tod symbolisierendes Skelett ab. Im Hintergrund sind verschiedene Gebäude und eine Kirche auszumachen. Die bereits erwähnte Tendenz der kristallinen Zergliederung ist besonders an den Figuren und in der oberen Bildhälfte deutlich zu beobachten. Insgesamt hellen sich die Farben nach oben hin auf, während der Weg und der Randbereich um das Gerippe herum von dunklen, zu Braun und Schwarz tendierenden Tönen dominiert werden. Am stärksten hebt sich die Figur des Engels ab, der mit hellen Pastelltönen ausgeführt ist. Die ineinander verschwimmenden Farben rücken das

\footnotetext{
${ }^{470}$ S. dazu Kap. 2.3. (Kandinsky: „Über das Geistige in der Kunst“, 1952).

${ }^{471}$ Erling (1997), S. 54 ff.

472 Kokoschka (1971), S. 126.

473 Winkler, (1997), S. 37.
} 
Geschehen in eine traumhafte, gar visionäre Sphäre, in der die Figuren gleichsam zu schweben scheinen.

In Dürers Meisterstich muss der Reiter dem Bösen auch in Form des Teufels trotzen - er ist dort als christlicher Ritter („miles christianus“) und Vertreter der „Vita activa“ gemeint. Durch die Weglassung des Teufels rückt Kokoschka seinen Ritter von dem im Stich verwendeten Darstellungstypus des vom Heiligen Georg inspirierten „miles christianus“ ab, da für ihn diese Deutung nicht im Vordergrund stand. Dennoch kann der Reiter, der durchaus auch mit dem Künstler selbst in Verbindung gebracht werden darf, wie im Dürer-Stich als der edelmütige Kämpfer gegen das Böse - hier aber eben nicht nur im religiösen Sinne - gedeutet werden. ${ }^{474}$ Anders als im Stich trotzt Kokoschkas Ritter dem Bösen beziehungsweise dem Tod nicht in erster Linie durch die eigene Glaubensstärke, sondern mit Hilfe eines himmlischen Boten. Der Engel symbolisiert die unterstützende Leitung von außen, die dem Reiter den richtigen Weg aufzeigt und unterstreicht, mit dem Zeigefinger zum Himmel deutend, seine göttliche Legitimation. Die Stadt im Hintergrund könnte nebenbei als Hinweis auf das himmlische Jerusalem gemeint sein. Übertragen auf Kokoschkas eigene Situation und in Zusammenhang mit der Selbstdarstellung als Heiliger Sebastian lässt sich die Darstellung auch gleichnishaft verstehen und auf den Künstler selbst übertragen. Sie ist dann so zu lesen, dass Kokoschka sich als einen Suchenden begreift, der den böswilligen Kritiken und allen Widrigkeiten seiner Künstlerexistenz gegenüber standhaft bleiben muss und dabei auf Hilfe und Führung einer von außen kommende Macht des Guten vertrauen will. ${ }^{475}$

Die seltsame Vermischung des Religiösen mit eigenen Auffassungen und Kokoschkas Suche nach einem inneren Halt lassen sich auch in seinem schriftlichen Werk finden. In seinem Vortrag „Von der Natur der Gesichte“, den er am 5. Februar 1912 im „Akademischen Verband für Literatur und Musik“ hielt, ${ }^{476}$ geht es um die Interdependenz zwischen menschlicher Innenwelt und der Außenwelt. „Der Saal war halb leer, die meisten Leute haben nichts verstanden“"und das Originalmanuskript verlor der Schriftsteller Berthold Viertel in der Tramway, nachdem er es sich begeistert von Kokoschka ausgeliehen hatte, so dass dieser es aus dem Gedächtnis erneut aufschreiben musste. So erinnert der Künstler selbst sich an diesen Vortrag. ${ }^{477}$ Tatsächlich ist der Text schwer verständlich, da in ihm nicht nur eine sehr persönliche Weltsicht verarbeitet ist, sondern der Künstler sich darin

\footnotetext{
474 Zu Dürers „Ritter, Tod und Teufel“ vgl. Theissing (1978), S. 25 ff.

475 Kokoschkas engen Bezug zu Dürer und in zwiespältiger Form zur Religion spiegeln auch seine eigenen Aussagen: „(...) keiner steht mir so nahe wie Dürer (...) Das Bekenntnishafte queht mich an. Das große Beispiel einer ikonografischen Genanigkeit würde ich nicht geben, dazu bin ich zu wenig christlich im kirchlichen Sinn. Das heißt aber nicht, dass ich kein Verständnis für das Ritual habe (...)". Interview mit Wolfgang Fischer am 26. und 30. Oktober 1963 in London, zitiert bei Erling (1997), S. 54.

476 Spielmann (2003), S. 116; Textnachweis, Text XXVII.

477 Kokoschka (1971), S. 115.
} 
auch keiner analytischen, vielmehr einer visionären Sprache mit offenbar individuellen Ausdrucksformen und Definitionen bedient.

Eine genauere Interpretation des Textes wurde daher bislang zumeist vermieden, doch ist er für das Verständnis von Kokoschkas Werken sehr aufschlussreich. In Bezug auf die religiöse Auffassung des Künstlers gibt er ganz entscheidende Hinweise. Zwar verwendet er hier einige Zitate, nimmt Anleihen aus der Bibel (z. B. „da ist das Wort nun Fleisch geworden und hat unter uns gewohnt" (Joh. 1,14) und die von Marias Antwort „Mir geschehe nach deinem Wort" nach der Verkündigung (Lukas 1,26-38) abhängige Formulierung ,mir geschah nach dem Worte "), 478 doch wird aus dem Gesamtzusammenhang der Ausführungen eine nicht am christlichen Glauben orientierte, sondern individuelle, teils von pantheistischen und lebensphilosophischen Ideen angeregte Sichtweise erkennbar.

In dem Vortrag wird beschrieben, wie die Welt beziehungsweise das Leben beständig auf den Menschen einwirkt und Eindrücke in seinem Bewusstsein hinterlässt. Kokoschka nennt diese Eindrücke, Emotionen und Reize „Gesichte“. Manche Eindrücke finden über das aufnehmende Bewusstsein sogar Eingang in die Seele, „welche nun beginnt die Gesichte leibhaftig zu formen“. Das Außen dringt also gleichsam ins Innere des Menschen und prägt seine Seele. Kokoschka vergleicht in diesem Zusammenhang den "Stand der Aufmerksamkeit der Seele oder das Bewußtsein" mit einem ungeborenen, selbst somit nicht fassbaren, aber dennoch für die Gesichte empfänglichen Kind. Hier schon ist die Idee erkennbar, dass es laut Kokoschka eine feste Entität im Menschen gebe, die die Eindrücke in sich zusammenführt.

Durch das Aufnehmen der Gesichte ins Bewusstsein macht der Mensch sich eine eigene Vorstellung von dem, was ihn umgibt. Gleichzeitig gehen die Eindrücke beziehungsweise Gesichte in ihn ein und damit in ihm auf und bilden in ihm gemeinsam mit anderen Gesichten eine Art individuellen Kern von Vorstellungen und Emotionen („Bewnßtsein ist das Grab für die Dinge, wo sie aufhören, das Jenseits in dem sie eingehen. So dass sie alsdann bei ibrem Ende in nichts Wesentlichem mehr zu bestehen scheinen, als meinem Gesicht in mir. Sie hauchen ibren Geist aus, wie die Lampe leuchtet (...). "). Dieser Kern dürfte wohl der Seele beziehungsweise einer unzerstörbaren Entität entsprechen, wenn Kokoschka ausführt:

„Schrankenlos lebt das Bewusstsein (...). Wie ein Samen eines einzigen von der Dürre lebend gelassenen Baumes die Fülle enthält, darin Wurzeln aller Wälder der Erde neu entsprossen sein könnten, so geschieht es, dass (...) dieses von eigener Macht wach aufkommt (...). Es gibt keinen Platz des Todes mehr, weil sich die Gesichte wohl auflösen und zerstreuen, doch nur, um sich in anderer Weise wieder zu sammeln. "

Durch die Neuzusammensetzung der Gesichte also vollzieht sich demnach eine Reinkarnation, die sich auch in weiteren Teilen des Textes andeutet. So beispiels-

478 Weiterhin: ,wo es sein Haupt binlege“ "als Abwandlung von Matthäus 8,20 und „wo Sie, Zwei oder Drei, in Meinem Namen beisammen sind, da bin ich mitten unter Ibnen" als Abwandlung von Matthäus 18,20. 
weise in der Aussage, dass man „von Stufe zu Stufe sich selber erhebt“, was die Weiterentwicklung der Seele andeutet, wie sie sich in verschiedenen Religionen finden lässt. Zwar verwendet Kokoschka zur Unterfütterung seiner Ansichten, wie gesagt, teilweise biblische Zitate und nimmt Anleihen aus der christlichen Tradition, doch offenbar nur um damit einen prophetischen Sprachduktus zu evozieren und seine eigenen, individuellen Ideen damit zu überhöhen. Die im Text beschriebene, eigenständige Reinkarnation entspricht nicht der christlichen Vorstellung von der Auferstehung der Seele durch göttliche Erlösung. Wenn man zusätzlich den 1920

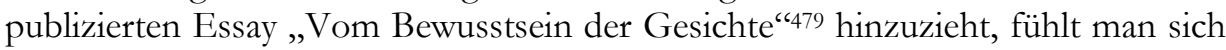
eher an pantheistische Glaubensgrundsätze erinnert. Dieser beginnt mit den Worten „Gott ist nicht einer, aber alle sind, Alles ist göttlich..." und mündet nach einem fiktiven, gesellschaftskritischen wie politisierenden Dialog in die an Nietzsches dionysisches Prinzip anklingende Ausrufe:

„Weil wir alle ebenso nimmersatt vom Recht und Unrecht weinten, daß wir hungrig sind, also statt der Steine laßt uns backen nabrhaft Brot, statt des toten Glaubens sinnlebendigen $W$ ein schenken, statt der grauen Paradiese unsere grüne Erde laßt uns lieben, statt das Wort vom großen, unbekannten Gott uns vorzuleiern, laßt uns unsere Engel selber sein! Wieder Alles endlich göttlich sehen (...) Kyrie eleison! Pan ist auferstanden. Jesulein und die Genien und die Feen! Jetzt will ich euch das Buch der Welt aufschlagen. Und es sind keine Worte, lauter schöne Bilder drin."

Im Vortrag „Von der Natur der Gesichte“ sind noch weitere wichtige Einflüsse ablesbar. Dadurch, dass „Gesichte“ auf den den Bewegungen und Veränderungen des Lebens ausgesetzten Menschen einwirken, unterliegt dieser einem beständigen Wandel von Wahrnehmung und subjektiven Wahrheiten. 480 Diese Gedanken lassen eine Nähe zu der zu Beginn des 20. Jahrhunderts propagierten Lebensphilosophie Henri Bergsons erkennen, der zufolge die alles durchströmende innere Kraft der Welt - von ihm ,élan vital" genannt - in seiner Gänze nur durch eine nach innen gerichtete Selbstschau (bei Bergson „,intuition“, bei Kokoschka „Gesich$t e^{\text {") }} \mathrm{zu}$ erfassen sei. Diesen gleichsam wie ein Einfühlen gemeinten Vorgang beschreibt Bergson als „eine Art der Sympathie“ durch die man sich „ins Innere der Ge-

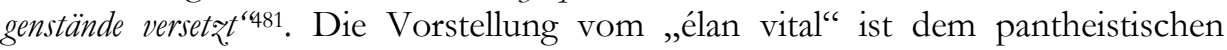
Glauben an einen, in allem als Lebensimpuls spürbaren Gott nicht sehr unähnlich. Auch mystisches Gedankengut lässt sich hier anführen. So geht Nietzsche - der die Anfänge der Lebensphilosophie bezeichnet - davon aus, dass der Satz „Alles ist eins" „seinen Ursprung in einer mystischen Intuition hat" und meint damit die mystische Erkenntnisweise, bei der sich der Erkennende als in die Einheit des Seienden eingeschlossen erfährt. ${ }^{482}$ Kokoschkas Vortrag über die „Gesichte“ vermittelt

\footnotetext{
479 Textnachweis, Text XXIV.

${ }^{480}$ Mehr dazu s. in Kap. 3.2.3.3.

481 Bergson (dt. Übersetzung: „Schöpferische Entwicklung“; 1912), S. 181 f.

482 Zitiert und ausgeführt nach Albert (1995), S. 62 f.
} 
ähnliche Vorstellungen und so äußert er selbst sich in einem Interview, das Gerhard Lischka 1971 in Villeneuve mit ihm führte, direkt: „Der Vortrag ,Von der Natur der Gesichte" steht unter dem Einfluss der deutschen Mystiker." "483 Dass Kokoschka im Übrigen wie die Lebensphilosophen von einem einzelnen Grundprinzip ausgeht (Monismus) wird im gleichen Interview deutlich, wenn er sagt: „Ich bin äußerst gegen Dualismus, prinzipiell, in jeder Form. (...) Deswegen bin ich kein Christ, aber Katholik schon. Unzäblig ja, aber zwei nicht. "484 Diese teils widersprüchliche Aussage - wer Katholik ist, ist schließlich auch Christ! - lässt im Zusammenhang mit den ebenfalls zu findenden pantheistischen Tendenzen zugleich erahnen, dass Kokoschka sich religiös offenbar nicht wirklich festlegen ließ.

Ähnlich wie in dem Bild „Ritter, Tod und Engel I“ wird also auch im Text deutlich, dass Kokoschka ebenso wie andere Expressionisten von der religiösen Sinnsuche erfasst war und dass er religiöse Lehren und Motive in einer individuellen, eigenwilligen Weise vermischt und interpretiert hat.

Ein wichtiges Beispiel für die individuelle Interpretation religiöser Motivik ist auch die „Verkündigung“ (Abb. 56) von 1911, wobei hier weniger die Reflexion über Kokoschkas eigene Anschauungen eine Rolle spielt, als vielmehr nochmals der eigenwillige Umgang mit der ikonografischen Tradition zu beobachten ist. Anders als zumeist in der traditionellen Darstellung dieses Themas in der westeuropäischen Kunst, im Anschluss aber an die byzantinische Bildtradition, ${ }^{485}$ ereignet sich in diesem Bild die Begegnung des Engels mit Maria in freier Natur. Das Gemälde teilt sich durch die Haltung der Figuren diagonal in zwei Hälften. Die rechte wird dabei von der in blau gekleideten Figur Mariens dominiert, die gerade zu Boden gesunken zu sein scheint und halb liegend ihre Augen wie in Ohnmacht geschlossen hat. Ihr linkes Bein hat sie im rechten Winkel aufgestellt, die linke Hand liegt in einer Geste des Erschreckens unterhalb der Brust. Die rechte Hand hat sie wie in leichter Abwehr gegen den Engel erhoben. Ein Krug neben ihr verweist gemäß byzantinischer Verkündigungsdarstellungen darauf, dass Maria beim Wasserholen vom Engel heimgesucht wurde. ${ }^{486}$ Der Engel in der linken Bildhälfte ist als Akt gegeben und beugt sich über die Gottesmutter. Seine weitausgreifende Gestik scheint zweierlei zu verdeutlichen: mit der erhobenen Linken verkündet er Maria die Botschaft, dass sie Gottes Sohn zur Welt bringen werde und mit der rechten Hand zwischen ihre Beine weisend bezeichnet er die Empfängnis. Sein Blick ist dabei nachdenklich in sich gekehrt und von Maria abgewandt. Auffallend und interessant ist das Zusammenspiel von Marias abwehrender Hand und der Rechten des Engels, die die Empfängnis verheißt. Sie befinden sich in entgegengesetzter Haltung genau übereinander, wodurch sie wie in ein Oval eingebunden

\footnotetext{
483 Lischka (1972), S. 9.

484 Lischka (1972), S. 11.

485 Siehe z. B. Schiller (1969).

486 Weitere Deutungsansätze zur Darstellung von Maria mit dem Krug siehe z. B. bei Lüken (2000), S. 63.
} 
sind, und zugleich auf der Mittelachse des Bildes liegen. Fast subtil wird dadurch das zentrale Bildthema in Szene gesetzt.

Im Hintergrund des Geschehens breitet sich kulissenartig eine Landschaft mit Gebäuden, Bergen und einem See mit Brücke aus. Links hinter dem Engel ist eine Kirche zu sehen. Wie die anderen religiösen Bilder dieses Jahres kennzeichnet das Gemälde der opake Stil mit einer prismenartigen Form- und Farbzergliederung, die dem Geschehen eine sphärische, dem weltlichen enthobene Atmosphäre gibt.

Kokoschka findet auch hier, ebenso wie in den zuvor angeführten Bild- und Textbeispielen, zu einer individuellen Ausdrucksweise im Umgang mit einem religiösen Thema: Maria wird zugleich sowohl in ergebener, als auch in abwehrender Haltung vor Augen geführt, der Engel wird als Akt gegeben und das Heilsgeschehen findet unter freiem Himmel statt. Die formale Verschränkung der Figuren bringt die widerstreitenden Emotionen und Verhaltensweisen zum Ausdruck und kennzeichnet den unkonventionellen Umgang des Künstlers mit dem Thema.

Die Behandlung christlicher Bildthemen erfährt 1911 durch eine geballte Bildproduktion einen kurzzeitigen Höhepunkt, doch auch in den folgenden Jahren werden religiöse Themen aufgegriffen. Mit den sechs Blättern seiner Lithografienfolge „Die Passion“ von 1916 setzt Kokoschka dafür noch einmal ein deutliches Zeichen.

\section{Religiöse Aspekte im Geschlechterkonflikt}

Kokoschkas Haltsuche nimmt dann später mit Alma eine Wende. Die religiösen Bezüge werden zunehmend auf die Geliebte und das Verhältnis der Geschlechter angewendet. So findet sich beispielsweise die in „Ritter, Tod und Engel I“ gezeigte Szene der göttlichen Hilfe in verwandter Weise in dem 1914 von Kokoschka für Alma gemalten Kaminfresko (Abb. 57) wieder. Alma als rettender Engel weist dem Künstler die Richtung und führt ihn damit fort von dem Unheil verheißenden Konglomerat aus Flammen, Schlange, Wolf und Totenschädel, das sinnbildlich für die Wiener Kunstszene oder für seine eigene innere Verzweifelung steht, die seine künstlerische Existenz bedroht. Ihre Liebe ist gleichsam seine Erlösung! Dieser Gedanke findet sich auch in Kokoschkas Briefen an Alma wieder, wenn er beispielsweise schreibt:
„Du Engelsweib weißt wohl deutlich, dass Du mich bewachst (...)“oder ,Sei ewig einig mit mir und unauflöslich mit mir zusammengebunden zu einer ewigen Freude. Aus mei- ner langen Kerkerzeit hast Du mich mit Deinem reinen Gesicht erlöst, das immer vor mir hergeht, Du mein Weib!" 487

Ähnlich nimmt sich die vierte Lithografie aus der 1914 entstandenen Folge zu der Kantate „O Ewigkeit - du Donnerwort“ von Johann Sebastian Bach aus. Bach entwickelt in der Kantate einen Dialog zwischen einer Altistin, die die „Furcht“

${ }^{487}$ Briefe an Alma vom 29. und vom 30.09.1912, s. Kokoschka 1984, S. 34 f. 
verkörpert und einem die „Hoffnung“ vertretenden Tenor.488 Kokoschka dreht in den Lithografien dieses Verhältnis um und bezieht es auf seine persönliche Lebenssituation. So wendet sich im „Das Weib führt den Mann“ (Abb. 58) betitelten vierten Blatt die weibliche Figur mit den Zügen Almas ermunternd an den Kokoschka ähnelnden, furchtsam dreinblickenden Mann, der zögerlich der ihm voranschreitenden Frau folgt. Ihre Haltung erinnert dabei stark an jene im Kaminfresko und die im Gemälde „Ritter, Tod und Engel I“. Deutlicher noch führt uns Kokoschka Alma als gleichsam göttliche Botin im linken Bildfeld des vierten für sie gefertigten Fächers (Abb. 59) vor Augen. Hier verkündet ihm die engelsgleiche Geliebte die Erlösung durch die Liebe, was durch einen gekrönten Phönix symbolisiert wird, der sich im Ornamentstreifen oberhalb der Kokoschka verbildlichenden, am Boden liegenden Figur aus den Flammen eines brennenden Herzens hervor in die Lüfte schwingt. 489 Der mythologische Vogel Phönix, der verbrennt und aus seiner Asche verjüngt emporsteigt, wird im Allgemeinen mit Christi Auferstehung in Verbindung gebracht. ${ }^{490}$ Analog zur Auferstehung des Gottessohnes, bedeutet hier der Phönix der Liebe für Kokoschka Erneuerung oder neues Leben.

Die Liebe zu Alma weckt im Künstler die Sehnsucht sein Leben mit ihr zu verbringen und eine Familie zu gründen. Schon bevor er Alma kennenlernte, brachte er den Traum von Familie zum Ausdruck - teilweise ebenfalls mit christlicher Motivik. So finden sich Darstellungen eines Paares mit Kind, die den Mann mit den Zügen des Künstlers zeigen und an die Heilige Familie denken lassen, beispielsweise im Mittelfeld des bereits erwähnten Fächers aus dem Besitz Grant Pick (Abb. 43). Über dem Säugling, der zwischen Mann und Frau zu sehen ist, verweist ein aufsteigender Vogel wahrscheinlich auf den Heiligen Geist und die christliche Färbung des Themas.

Neben der Parallelisierung Almas mit dem Engel und religiös intendierten Familiendarstellungen, bezieht sich Kokoschka innerhalb der Geschlechterproblematik insbesondere auf zwei religiöse Motivkreise, wie im vorangehenden Kapitel bereits in Teilen aufgezeigt wurde: erstens Adam und Eva und zweitens die Pietà. Beide sind ikonografisch prädestiniert für die Darstellung des Mann-FrauVerhältnisses und der Künstler nutzt dieses christliche Motivrepertoire wiederholt zur Verdeutlichung profaner Zusammenhänge und persönlicher Auffassungen, wie es sich besonders deutlich an den beiden Dramen „Hiob“ und „Der brennende Dornbusch“ ablesen lässt. „Hiob“491 „handelt (...) von einem Weib, das dem Mann buchstäblich den Kopf verdreht, und von einem Mann, der darüber buchstäblich den Kopf verliert“. ${ }^{492}$ Die Figur des „Hiob“ genannten Mannes wird, wie bereits erwähnt, einerseits mit dem zur Prüfung seines Glaubens geplagten, biblischen Namensvetter in

\footnotetext{
488 Wingler (1975), S. 88.

489 Vgl. Spielmann (1988), S. 71.

490 Olbrich (2004a), S. 575.

491 Mehr dazu in Kapitel 3.2.1.1.; Textnachweis, Text XXIII.

${ }^{492}$ Joseph Sprengler in der Zeitschrift „Hochland“ (1921/22), zitiert nach Wingler (1975), S. 103.
} 
Verbindung gebracht, andererseits mit dem im Prolog durch Evas göttliche Erschaffung aufgeschreckten Adam. Gleichermaßen ist die weibliche Gegenspielerin im Stück zwiegespalten in Anima, die sich in Anlehnung an Kokoschkas Liebesideal des Ineinanderaufgehens der Partner als „Seele“ (gleichsam als zweite und somit treu liebende Hälfte) des Gatten bezeichnet, und Eva, die biblische Verführerin. Beide Geschlechter werden also durch diese Doppeldeutigkeit ihrer Stellvertreter als Gott teils moralisch verpflichtet und teils ungehorsam dargestellt. In Anbetracht der bisherigen Erkenntnisse, wonach Kokoschkas religiöse Auffassung changiert, sind sie somit im allgemeineren Sinn als Menschen zu begreifen, die moralisch-ethischen Werte entsprechen, aber dennoch nicht sündenfrei oder vollkommen sind.

Die Verknüpfung der Geschlechterproblematik mit den biblischen Ureltern, und das heißt mit dem Sündenfall und der damit verbundenen Erkenntnis der eigenen Sexualität, spiegelt Kokoschkas Auffassung eines gleichsam (fast) seit Anbeginn der Menschheit bestehendes Konfliktpotentials zwischen Mann und Frau, wie es mit seinem Eifersuchtsdrama thematisiert und auf der Bühne zur Schau gestellt wird. Anders als in der biblischen Erzählung, wonach erst der Sündenfall das Idyll des Paares zerstört, beginnt der Konflikt dem Stück zufolge schon in dem Moment, in dem Eva erschaffen ist. So heißt es dort im Prolog recht launig: ,Weint Adam, in der Nacht von einem Rippenstoß erwacht: ,Ei'/ Und da mit Eva sich begattet fand: ,Mein Gott, bätt' er mir nur mein Bein mit Ruh gelassen ", womit Kokoschka den eigentlichen, in der Bibel enthaltenen Text und Adams Ausspruch „Das endlich ist Bein von meinem Bein/ und Fleisch von meinem Fleisch./ Frau soll sie hei$\beta_{\text {en }}{ }^{4493}$ persiflierend variiert. Die in „Hiob“ enthaltene Idee, die Problematik zwischen Mann und Frau sei im gleichen Augenblick entstanden, wie die Geschlechteraufteilung selbst (nämlich im Moment der Erschaffung der Frau/Evas), steht in engem Zusammenhang mit dem Gedanken der kosmischen und somit gleichsam immer schon existenten Geschlechterdifferenz, wie sie sich in Bachofens SonneMond-Dualismus ausdrückt, zu dem in Kokoschkas Werk, wie bereits aufgezeigt wurde, deutliche Anklänge zu finden sind. ${ }^{494}$

Gleichermaßen findet sich dies auch durch Darstellungen von Adam und Eva in bildkünstlerischen Werken Kokoschkas vielfach verarbeitet. Für „Das Mädchen Li und ich“ aus „Die träumenden Knaben“ als ein frühes Beispiel wurde auf den Bezug zum biblischen Paar bereits hingewiesen. ${ }^{495}$ In der sechsten Illustration aus „Der gefesselte Kolumbus“ mit dem Titel „Der Apfel der Eva“ (Abb. 60) ${ }^{496}$ von 1913 wird dem Betrachter ebenfalls das erste Menschenpaar vor Augen geführt, wenn auch in einer für Kokoschka typischen, unkonventionellen Manier. Nicht nur, dass sie die Züge des Künstlers und Almas tragen - zudem sind sie, anders als

\footnotetext{
493 Genesis 2,23.

$494 \mathrm{Vgl}$. S. $156 \mathrm{f}$.

495 Vgl. S. 149.

496 Vgl. S. 164.
} 
in der ikonografischen Tradition, bekleidet statt nackt, und an einem Tisch dargestellt, während die Überreichung des Apfels an Adam erfolgt. Adam kniet dabei links des Tisches, Eva sitzt rechts davon und hat einen Teller vor sich stehen. Beide Figuren sind mit breiten, schnellen Linien ausgeführt und im Vergleich zu anderen Blättern der Folge mit weniger Schraffuren, so dass sie licht, aber auch schlichter erscheinen. Im Hintergrund ist eine Landschaft mit Bäumen und einer Mondsichel zu sehen. Im Kontext der Gesamtpublikation, die sich im Text mit dem allgemeinen und in den Illustrationen dediziert mit dem auf Alma gemünzten Geschlechterkonflikt auseinandersetzt, ${ }^{497}$ lässt sich auch bei „Der Apfel der Eva“ das Urpaar als Archetyp des Geschlechterdualismus deuten.

Gleiches gilt ebenso für die Kreidelithografie „Adam und Eva“ (Abb. 61) ${ }^{498}$ aus der Illustrationsfolge zu „Hiob“ von 1916/17. Die linke Bildhälfte wird von einem Baum dominiert, an dessen Stamm der nackte Adam hinaufklettern zu wollen scheint. Sein linker Arm ist dabei nach unten ausgestreckt. Dort liegt Eva rechts der Mitte rücklings, mit aufgestütztem Arm und halb erhobenem Oberkörper. In ihrer rechten Hand hält sie einen Apfel - den Apfel vom Baum der Erkenntnis - und streckt ihn Adam entgegen. Rechts neben der Baumkrone flattert ein Vogel, der an den im Drama „Hiob“ vorkommenden Papagei erinnert. Der Hintergrund deutet eine Landschaft mit Bäumen und Bergen an. Die Darstellung spiegelt keine konkrete Szene des Bühnenstücks, sondern orientiert sich offenbar frei an dem im Prolog angedeuteten Geschehen der Genesis. Dort folgt auf die Erschaffung des Menschenpaares die Versuchung Evas durch die Schlange und die Stelle, in der es heißt:

„Da sah die Frau, dass es köstlich wäre, von dem Baum zu essen, dass der Baum eine Angenweide war und dazu verlockte, klug zu werden. Sie nahm von seinen Früchten und aß; sie gab auch ibrem Mann, der bei ibr war, und auch er aß. Da gingen beiden die Augen auf, und sie erkannten, dass sie nackt waren. ${ }^{~} 499$

Die Erkenntnis der Nacktheit, d. h. der eigenen Sexualität, steht dabei in direktem Zusammenhang mit dem Ungehorsam des Menschen gegenüber Gott und dessen Verbot Früchte vom Baum der Erkenntnis zu essen. Aus ihr resultiert nach Auffassung der Kirchenlehrer die als Folge der Sünde entstehende Begierde. ${ }^{500}$ Genau hier liegt der Dreh- und Angelpunkt, der für die von Kokoschka vorgenommene Verknüpfung des Geschlechterkonflikts mit Darstellungen des biblischen Urpaares entscheidend ist: Das durch Adams und Evas Vergehen in die Welt gebrachte Begehren ist (nach Kokoschkas Vorstellung) der eigentliche Auslöser des gesamten Geschlechterkonflikts. ${ }^{501}$

\footnotetext{
497 Vgl. dazu S. 166.

498 Vgl. Wingler (1975), S. 103.

${ }^{499}$ Genesis 3,6-7.

500 Mehr dazu siehe z. B. bei Sandler (2009).

${ }^{501}$ Vgl. dazu die Untersuchungen in Kapitel 3.2.3.1.
} 
Die Pietà nun als ein ebenfalls der christlichen Ikonografie entnommenes Motiv verwendet Kokoschka kontrastierend zum Urpaar - wie bereits erwähnt als Ansatz zur Lösung des Konflikts. Sie verkörpert das positive und vorbildliche Gegenstück zur Adam und Eva-Konstellation. Maria, die Reine, als Verkörperung der tugendhaft, tief und geistig liebenden Frau, wird Eva der Verführerin, die gleichsam für den lasterhaften Typus der femme fatale steht, gegenübergestellt. Adam als Archetyp des verführten, sündhaft agierenden Mannes ist Gegenspieler des Gott nahestehenden, sich aus Liebe zu den Menschen für ihre Sünden opfernden Christus. Kokoschka verknüpft hier unkonventioneller Weise wieder einmal religiösen und profanen Bedeutungsgehalt miteinander. Er orientiert sich dabei an der von der christlichen Kirche vertretenen Typologie, der zufolge Personen des Alten und des Neuen Testaments in engem Bezug zueinander stehen. So wurde Christus bereits von Paulus als neuer Adam, und entsprechend von Seiten der Kirchenlehrer danach auch Maria als neue Eva gedeutet. ${ }^{502}$ Mutter und Sohn begleichen die Schuld des Urpaares, um damit den Menschen die Erlösung zu bringen. Wichtigster Anhaltspunkt für diese Verknüpfung ist der Fluch, den Gott über die Schlange ausspricht, nachdem sie Eva dazu verleitet hatte eine Frucht vom Baum der Erkenntnis zu essen: „Feindschaft setze ich swischen dich und die Frau,/ zwischen deinen Nachwuchs und ibren Nachwuchs./ Er trifft dich am Kopf,/ und du triffst ibn an der Ferse. "503 Diese Bibelstelle ist in der christlichen Tradition vielfach als „Protoevangelium“ bezeichnet und ausgelegt worden - also als erster Hinweis auf Maria, Christus und dessen Erlösungstat. Danach ist mit der „Frau“ die Gottesmutter und mit „Er" Jesus Christus gemeint. Der Ausspruch „Er trifft dich am Kopf" wird als Ankündigung des Sieges Christi über den Satan gedeutet, denn die Schlange als Symbol des Bösen wird dabei mit dem Teufel parallelisiert. 504

Wie nun also nach christlicher Tradition Adam und Eva die Sünde in die Welt gebracht haben und Christus als Marias Sohn sie überwunden und getilgt hat, so überträgt Kokoschka die beiden Darstellungsmodi häufig auf den Anfang und das Ende des Geschlechterkampfes. Im bildkünstlerischen Bereich ist die Pietà als Lösung des Konflikts bei Kokoschka schon früh zu finden. Im vorangehenden Kapitel ist bereits auf das Werbeplakat für das Sommertheater von 1908 hingewiesen worden, in welchem Kokoschka diese Idee zum ersten Mal verarbeitet hat. ${ }^{505}$ Das Motiv selbst greift er in der Folgezeit wiederholt auf. Als Beispiele dafür wurden zuvor schon der zweite Fächer für Alma (1912) und die Allos MakarIllustration „Der Mann, im Schoße des Weibes liegend“ erwähnt..06 Die Illustration scheidet dabei als „konfliktlösende Pietà“ allerdings aus - sie ist hier gar im Bezug zum Text eine pervertierte Variante, die das schmerzhafte Abhängigkeits-

\footnotetext{
502 Görg (1991), Sp. 29 f. (Adam) und Sp. 615 f. (Eva).

503 Genesis 3,14.

504 Görg (2001), Sp. 203.

505 Vgl. S. 158 ff. und Abb. 42.

506 S. Kapitel 3.2.3.1.; Abb. 44 und 47.
} 
verhältnis des Mannes von der Frau vor Augen führt. Als zusätzliches Beispiel mit versöhnlicheren Tendenzen lässt sich aber „Pietà/Es ist genug“ aus der Folge zur Bachkantate (O Ewigkeit, du Donnerwort; 1914) anführen (Abb. 62). Wie in dem Blatt „Die Frau, den Mann führend“ aus der gleichen Serie, an welchem Almas hoffnunggebender Einfluss auf den Künstler deutlich gemacht wurde, ist auch hier Kokoschka in der männlichen Figur zu erkennen. Er liegt, nur mit einem Lendentuch bekleidet, diagonal auf dem Schoß einer Frau (die in diesem Fall keine Ähnlichkeit mit Alma aufweist). Seine Miene drückt Leid und Erschöpfung aus. Leblos hängen die Extremitäten herab, während die Frau mit aufgerissenen Augen und vor den Mund geschlagenem Tuch erschüttert und trauernd ihn betrachtet. Die Schraffuren verdichten sich zu einer ins Dunkel getauchten Felsformation, die die Gruppe umfängt. Nicht nur durch die Orientierung am christlichen Darstellungstypus der Maria mit ihrem toten Sohn nach der Kreuzabnahme manifestieren sich die religiösen Bezüge, sondern auch durch Beifügung der Textzeilen „Es ist genug: Herr, wenn es dir gefällt,/ So spanne mich doch aus/...Mein großer Jammer bleibt darnieden./ es ist genug, es ist genug. "Diese findet sich auf der letzten von zehn Federskizzen, die Kokoschka parallel zu den Lithografien zur Bachkantate angefertigt hat und die den gleichen Bildinhalt zeigt, wie die hier beschriebene Grafik. Text und Bild zusammen bringen Schicksalsergebenheit und den Glauben an Gott zum Ausdruck. Als letztes Blatt der Folge, die den in der Kantate enthaltenen Dialog zwischen Mann und Frau und den Wechsel von Furcht und Hoffnung begleitet, schließt es denn auch diese beiden Entwicklungsstränge ab. Lösung und Ergebnis ist dabei der Opfertod des Mannes.

Auffallend ist, dass Kokoschka in der bildkünstlerischen Umsetzung des Themas zwar dieses Opfer vor Augen führt, jedoch ohne dabei Hinweise auf dessen Folge - die hoffnungverheißende Erlösung - zu geben. Dies findet sich deutlich erst in der literarischen Ausdeutung des Pietà-Motivs in „Der brennende Dornbusch“507 von 1917 (beziehungsweise in der „Schauspiel“ benannten ersten Fassung von 1911). Der Titel selbst verweist auf die alttestamentliche Erzählung, der zufolge Gott Moses aus einem in Flammen stehenden, aber nicht verbrennenden Dornbusch heraus zur Rettung seines Volkes nach Ägypten schickt. ${ }^{508}$ Dabei geht es Kokoschka einerseits um den biblischen Bezug als Hinweis auf göttlichen Beistand und eine Erlösungshoffnung und andererseits um das Symbol der sich niemals verzehrenden lodernden Flamme, die er mit der immerwährenden Leidenschaft und Triebhaftigkeit zwischen den Geschlechtern in Verbindung bringt. ${ }^{509}$

Das fünfszenige Drama spiegelt wiederholt eine von den Thesen Weiningers beeinflusste Auffassung der Geschlechter, der zufolge die Frau im Gegensatz zum geistig geprägten Mann mehr dem Körperlichen verhaftet ist und nur ebenfalls zur Geistigkeit gelangt, indem sie vom Mann zur Enthaltsamkeit angehalten und so-

\footnotetext{
${ }^{507}$ Textnachweis, Text XXV; s. auch Kapitel 3.2.3.1.

${ }^{508}$ Ex 2,23-4,18.

${ }^{509}$ Vgl. Reisinger (1986), S. 160; Schvey (1982), S. 46; Lischka (1972), S. 66 f; Denkler (1965), S. 41 f.
} 
mit erlöst und zur Gleichrangigkeit erhoben wird. ${ }^{510}$ So führt die Eingangsszene des Stücks den Raum der Frau vor Augen, die erwartungsvoll auf die Ankunft des Mannes hofft. Diesen sehnt sie viel mehr herbei als ihre Liebhaber, die in der Nähe dem Alkoholgenuss frönen und die (in Anlehnung an die schon erwähnte Symbolik der Gestirne) vom Mond ihre Kräfte zu beziehen scheinen („Deine Ausstrablung flößt Kräfte ein solchen, die im Stiegenhaus mir nachsteigen (...)"). Als der Mann endlich erscheint, gesteht ihm die Frau ihren Liebeshunger, doch er will sie zur Enthaltsamkeit bewegen, indem er sie bis zum Hals in ein Tuch hüllt und sich somit ihren körperlichen Reizen entzieht. Mit dem in biblischem Sprachduktus gehaltenen Ausspruch „mach zu deine Wunden“ fordert er sie im übertragenen Sinne auf, dem körperlichen Verlangen zu widerstehen. Indem er sie schließlich ihre Kerze an der seinen anzünden lässt, betont er symbolisch einerseits ihre ursprüngliche Abhängigkeit vom Mann, doch will er sie damit zugleich zur Unabhängigkeit gegenüber ihm und ihrem Begehren führen, wenn er dabei die Worte spricht: „Des Suchens - wer du wärest - müde, gabst du dich mir. So bist du geworden. (...) Auf zur Geburt erwach' deine Seele, auf zur Geburt. "Er lässt sie in einer Art Trance allein, doch kaum dass sie daraus erwacht, kommt ihr Liebessehnen nach ihm zurück und enttäuscht über dessen Unerfülltheit, jagt sie ihm mit den betrunkenen Liebhabern zornig hinterher. Interessanterweise nutzt sie bei ihren aufstachelnden Rufen Bilder, die Kokoschka auch schon in „Die träumenden Knaben“ verwendet hat, wie „roter Fisch"und „Wärwolf" als Beschreibungen für den Flüchtigen.

In der zweiten Szene sieht man Mann und Frau in zwei nebeneinander liegenden Zimmern. Zwei Lichtkegel, die sich begegnen, untermalen den Dialog des Paares. In biblischen Bildern beschreibt der Mann der Frau die Zeit vor der Liebe als einen Zustand der vollkommenen Ruhe:

„Es schlief das W assertiefe, / Es stand der Berg schattenleer/ Und es war keine Zeit/ Und da börte kein Tier/ Und da wärmte kein Feuer/ Und verbrannte kein Flammen, / Als keine Liebe war."

Dagegen setzt er eine bestialisch anmutende Zeit, die von der Brutalität des sexuellen Verlangens geprägt ist: „Und das Tier schlug den Menschen und fraß ibn und/ spie ibn. Und Flammen schlagen rote Wunden,/ Wo Liebe ward süß Mann und Frau. "Damit versucht er ihr seine Auffassung von der Liebe zu erklären, doch sie rechtfertigt ihr Verlangen mit den Worten: „Von Liebe aß mein Elternpaar; davon ward ich ein Mensch. "Hier ist wiederum - wie bei einigen der betrachteten Bilder - der Bezug zum biblischen Urpaar und der Hinweis auf die Begierde der körperlichen Liebe als Resultat der Erbsünde verarbeitet. ${ }^{511}$ Der Mann versucht ihr, bevor er geht, Hoffnung auf Ruhe einzugeben, die sie durch die Überwindung der Leidenschaft erlangen könne und vergleicht das Begehren mit Bezug zum Titel des Stücks mit einer Flamme, die dem Menschen die Lebenskraft entzieht (,Wie du dich abhetzt, so

${ }^{510}$ Denkler (1965), S. 43 ff.

511 Vgl. Schvey (1982), S. 48; Denkler (1965), S. 42. 
schmilzt die trübe Lampe bin (...). Die Braut wird in der Kammer den Riegel aufgehn sehn. Schon bleicht die Lebensfarbe!").

In der dritten Szene sucht die Frau, noch immer von ihrer Leidenschaft getrieben, mit einer Gruppe von Männer und Frauen den Mann im Wald. Während sie über ihren Verlust klagend zusammenbricht, eröffnen sich dreien ihrer Begleiter in Visionen Bilder vom Mann, die teils analog zu Erlebnissen Christi angelegt sind. So sieht der Erste einen staubbesudelten Mann am Boden liegen, der „dürstet, weil du gereicht hast/ den Schwamm mit Essig getränk.t. "Das Bild des Essigschwamms, der Jesus bei seiner Hinrichtung gereicht wird (Joh. 19,28) und gemeinhin als dessen Verhöhnung gedeutet wird, nutzt Kokoschka im stückimmanenten Kontext als Hinweis auf den liebesleeren, nur sexuell orientierten Körper, den die Frau dem Mann darbietet und der seine wahren Bedürfnisse nicht stillen kann. In der zweiten Vision wird mit dem Satz „Er nahm mit dir den Leib aus einem Kelch - und du hast gelästert" auf das Abendmahl angespielt und zugleich der Frau vorgeworfen, dass sie den Erlösungswillen des Mannes bislang abgelehnt habe. Beiden Visionen liegt durch die Parallelisierung des Mannes mit Christus die Idee vom Mann als Erlöser der Frau zugrunde. ${ }^{512}$ Die dritte Vision deutet denn schließlich hoffnungsvoll die Überwindung der Hindernisse durch den Mann an. Der Mann, der von der Begierde der Frau gefesselt wird („Ich seh einen metallenen Mann an ein brünstiges Tier) gesperrt./ Habt ibr wohl gesehen, also, daß das Tier aß von seinem/ Herzen. / "), macht sich schließlich frei von ihrem Bedrängen („Er regt sich./ Seine gespannte Kette zerklirrt./ Seine glitzernde Hand siegt im zpeifelnden Kampf./ ") und befreit damit auch die Frau von ihren animalischen Trieben (,Sein metallener Ruf erveckt das Weib, das aus dem Balg/ des Tieres tritt./ "). Die Frau überwindet damit die Erbsünde („Frau, die mit dem Fuß die Schlange tritt, /") - das Zitat meint Maria, die die in der Genesis beschriebene Versuchung durch die Schlange tilgt - und findet letztlich zu der von Kokoschka als einzig wahr und rein verstandenen Liebe: der mütterlich-geistigen Liebe (,dein Herz schwellt sich in Mutterfreud"). Wie in den Bildbeispielen wird hier also der Bezug zwischen Eva und Maria, zwischen Sündenfall und Erlösung auf den Geschlechterkonflikt übertragen. Die Erlösungshoffnung wird am Ende der Szene nochmals unterstrichen, indem der Chor dreimal "Ich glaube an die Auferstebung in mir" (notabene: ,in mir")! psalmodiert und die Frau sich von der Peinigerin des Mannes in eine Jungfrau verwandelt. ${ }^{513}$

In der vierten Szene kommt es schließlich zu Klimax und Peripetie des Konflikts. Mann und Frau führen auf zwei Felskanzeln stehend einen Dialog miteinander, wobei sein Redefluss von weißem Licht untermalt wird und der ihrige von rotem. Man mag sich dabei wohl zu Recht an die bei Kokoschka verwendete, bereits erläuterte Farbsymbolik von „rein“ und „unrein“ erinnert fühlen. ${ }^{514}$ Zumal die Frau in ihren Ausführungen über ihr Begehren und ihre Erlösungsbedürftig-

\footnotetext{
512 Vgl. Denkler (1965), S. 42.

513 Vgl. Schvey (1982), S. 49.

514 S. dazu Kap. 3.2.3.1.
} 
keit, wiederholt das Bild der Flamme verwendet, die mal weiß, mal rot brennt und damit ihre Hin- und Hergerissenheit zwischen Verlangen und dem Wunsch nach Enthaltsamkeit Ausdruck verleiht (,Mein Leib ist ein brennender Feuerstrauch (...) weiß und rot - weiß und rot brenne ich (...) Tritt ein zu mir, auslösche und erlöse mich "). Der Mann stellt dem lodernden Feuer des Begehrens die Hoffnung auf ein ruhiges Licht entgegen, das „zulet:t gan ₹ freundlich aussieht!" Die Frau erkennt zwar seinen Wunsch sie zu befreien, ist aber dennoch enttäuscht, dass ihre Wünsche unerfüllt bleiben, so dass sie nach seiner Bitte ,Mütterlicher Raum öffne dich!"ihn durch einen Steinwurf tödlich verletzt. Die Peripetie tritt ein als der Mann getroffen ausruft „Barmberzigkeit! (...) Ach sieh hier mein Leben im Opferblut entschweben (...)" und die Frau ihren Fehler erkennend sich mitleidend und ,Mit großer Liebe "auf ihn wirft.

Die Schlussszene zeigt dann Mann und Frau in der Stellung der Pietà-Gruppe im Sterbezimmer. Die Frau wird hier durch den Opfertod des Mannes endlich zur mütterlichen Liebe geführt. Ein Lichtkranz, der über dem Paar leuchtet und die Worte des Mannes „Lebe ich denn - Du und Ich" symbolisieren, dass beide durch den physischen Tod des Mannes zu spiritueller Auferstehung gelangen werden. ${ }^{515}$ Das verzehrende Feuer sexuellen Verlangens, das sich im Dramentitel andeutet, ist somit gelöscht und der Geschlechterkampf, der daraus hervorgegangen war, findet sein Ende. Wie in den entsprechenden Bildbeispielen verwendet Kokoschka in „Der brennende Dornbusch“ die Konstellation der biblischen Pietà als Lösung für die Auseinandersetzung zwischen den Geschlechtern, wobei der Text deutlicher als die Bilder die Bedeutung der Pietà, nämlich die Aussicht auf Erlösung, zum Ausdruck bringt.

\section{Ergebnis}

Die religiöse Thematik in Kokoschkas frühem Schaffen ist präsenter als es die eher geringe, auf sie in der Sekundärliteratur verwendete Aufmerksamkeit vermuten lässt und würde ein lohnender Gegenstand für weitere, noch tiefer gehende Untersuchungen sein. Aber auch aus den hier vorgenommenen Analysen wird bereits die Bandbreite der von Kokoschka in seinen Werken verwendeten religiösen Bezüge deutlich. Es ist festzustellen, dass sein Repertoire dabei in den Bildwerken vielseitiger und differenzierter ist. Es reicht von Selbststilisierungen als Christus oder Heiliger, über traditionelle, aber unkonventionell behandelte Bildthemen insbesondere in den Gemälden des Jahres 1911 bis hin zu Darstellungen des Geschlechterverhältnisses, die auf Engel, Heilige Familie, das Urpaar und die Pietà als christliche Motive rekurrieren.

In den Texten überwiegen dagegen sprachlich-stilistische Reminiszenzen an die Bibel in Form von direkten Zitaten (z. B. ,da ist das Wort nun Fleisch geworden und hat unter uns gewohnt" („Natur der Gesichte")), Anlehnungen (z. B. „Weint Adam, in der Nacht von einem Rippenstoß erwacht: ,Ei'/ Und da mit Eva sich begattet fand: ,Mein

515 Vgl. Schvey (1982), S. 49. 
Gott, hätt' er mir nur mein Bein mit Ruh gelassen“" („Hiob“)), und Wendungen, die deren Sprachduktus imitieren (z. B. „mach zu deine Wunden" („,Der brennende Dornbusch")).516 Bezüge zu christlicher Motivik konzentrieren sich hier - zumindest in den Dramen - im Wesentlichen auf jene, die zur Verdeutlichung des Geschlechterdualismus geeignet sind - das Urpaar oder kontrastierend dazu Christus und Maria gruppiert zur Pietà. Insofern fällt die Gewichtung motivischer Bezüge in den Bildern und den literarischen Werken unterschiedlich aus, was wesentlich aus der Dominanz der Geschlechterthematik innerhalb der Texte resultiert.

Wesentliche Feststellung ist, dass, so viel Kokoschka auch mit christlicher Ikonografie und biblischen Bezügen arbeitet, dies wohl eher als eine spielerische Aufnahme der Motiv-Tradition anzusehen ist und keine verbindlichen Rückschlüsse auf die religiöse Orientierung des Künstlers zulässt. Der aufschlussreiche Vortrag „Von der Natur der Gesichte“ wie auch der Essay „Vom Bewusstsein der Gesichte" nämlich zeigen die Bezugnahme auf verschiedene religiöse Tendenzen. Dies lässt im erhellenden Vergleich mit den bildkünstlerischen Werken die Behauptung zu, dass Kokoschka auf der Folie bildlicher, wie auch sprachlicher Überlieferung, in eigener, unkonventioneller Weise unterschiedliche religiöse Elemente teils vermischt oder mit profanen Themen verknüpft und zu neuen Darstellungsweisen führt, um seinen persönlichen Auffassungen Ausdruck zu verleihen.

\subsubsection{Der Mensch - Kokoschkas Porträts im Spiegel seines Vortrags von 1912}

Die bildkünstlerische Darstellung des Menschen nimmt im Frühwerk Kokoschkas eine dominante Stellung ein und legte den Grundstein für seinen Ruhm als Künstler. Nicht nur, dass sie natürlich in der Behandlung anderer den Menschen betreffender Themen, wie dem bereits besprochenen Geschlechterkonflikt oder der religiösen Suche, unerlässlich war, sondern sie gewann für den jungen Künstler insbesondere als autonomes Sujet stark an Bedeutung. Dies wurde zum Teil sicherlich durch seine Hinwendung zum Expressionismus begünstigt, dessen Vertreter, inspiriert von den Ansichten zeitgenössischer Geistesgrößen wie Friedrich Nietzsche, Sigmund Freud oder Ernst Mach (1838-1916), im Porträt die psychologische „Wahrheit“ eines Menschen über neue Ausdruckweisen zu ergründen suchten. Gleichzeitig wurde Kokoschka darin ab 1909 maßgeblich von seinem Förderer Adolf Loos unterstützt. Dieser verschaffte ihm nicht nur einen Großteil der Porträt-Aufträge, indem er den Künstler Teilen der Wiener Gesellschaft zuführte, sondern garantierte ihm auch seine künstlerische Freiheit, indem er jene Bilder, die den Auftraggebern nicht gefielen, selbst übernahm.517

\footnotetext{
516 Erläuterungen dazu s. bei den jeweiligen Textbetrachtungen weiter oben.

517 Cernuschi (2002), S. 43 f.; Natter (2002), S. 88 f.
} 
In der Abkehr vom historisierenden Repräsentationsgedanken, wie er bis 1900 für das Bildnis prägend war, entwickelte Kokoschka innerhalb seiner Porträtkunst eine neue und auf damalige Betrachter schockierend wirkende Farb- und Formensprache. Sein Anliegen bei den Bildnissen beschrieb er dabei folgendermaßen:

„Wenn ich Porträts male, geht es mir nicht darum, das Äußerliche eines Menschen, den Rang oder Attribute seiner geistlichen oder weltlichen Prominenz oder bürgerlichen Provenienz festzuhalten. Was die Gesellschaft früher an meinen Porträts schockierte, war das, was ich in einem Gesicht, im Mienenspiel, in Gebärden zu erraten suchte, um dies in meiner Bildsprache als Summe eines Lebewesens in einem Gedächtnisbild wiederzugeben. Ein Mensch ist kein Stilleben (...). "518

\section{Zuordnung}

So beherrschend das Thema des Geschlechterkampfes in Kokoschkas schriftlichem expressionistischen Schaffen ist, so dominant ist die Anzahl der Porträts im malerischen Werk dieser Zeit. Mehr als achtzig seiner ersten hundert Gemälde analysieren die Physiognomie des Menschen, wobei es sich überwiegend um Einzelbildnisse handelt, die einerseits Kunden des Architekten und KokoschkaMentors Loos und andererseits Freunde und Förderer aus expressionistisch orientierten Intellektuellen-Kreisen darstellen. Zudem war es ein Porträt („Ernst Reinhold“), mit dem sich Kokoschka auf der Wiener Kunstschau 1909 erstmals als Maler präsentierte und damit den Grundstein seiner Karriere legte. ${ }^{519}$ Zusätzlich ist auch eine nicht geringe Anzahl von Grafiken mit Bildnissen entstanden. Im Folgenden wird aufgrund ihrer größeren Bedeutung jedoch mehr Gewicht auf die Gemälde zu legen sein. Es sind dabei drei Gruppen von Porträts zu unterscheiden. Neben Beispielen aus der großen Fülle von Einzelbildnissen werden zudem Gruppenporträts und Selbstbildnisse zu betrachten sein, die die Auseinandersetzung des Künstlers mit sich selbst, aber auch mit seinem Umfeld widerspiegeln.

In seinem schriftlichen Schaffen der frühen Phase dagegen hat Kokoschka sein Menschenbild vergleichsweise wenig verarbeitet oder beschrieben. Abgesehen von einem (eben aber auch nicht als literarischer Text anzusehenden) Brief an Lotte Franzos aus dem Jahr 1910, in dem er auf ihre Ablehnung des von ihm geschaffenen Porträts reagiert, lässt sich zum Vergleich mit den Bildwerken aus der expressionistischen Phase nur der bereits zuvor angeführte Vortrag „Von der Natur der Gesichte“ von 1912 heranziehen. Bemerkungen aus der Autobiografie, sowie aus dem Beitrag „Ich male Porträts, weil ich es kann“, den Kokoschka 1961 für die Stuttgarter Zeitung schrieb, können ergänzend, wenn auch aufgrund ihres späteren Entstehungsdatums nicht als gleichwertige Quellen genutzt werden.

\footnotetext{
518 Kokoschka (1971), S. 72.

519 Tomeš (1986), S. 253; Natter (2002), S. 88.
} 


\section{Einzelporträts}

Zwar ist die Zahl der expressionistischen Einzelporträts bei Kokoschka groß, jedoch sind in ihnen abgesehen von den stilistischen Entwicklungen zumeist immer wiederkehrende Elemente zu finden, die es erlauben auch anhand einer kleineren Bildauswahl Kokoschkas Darstellungsweise des Menschen zu umreißen. So lässt sich für die Porträts von Einzelpersonen konstatieren, dass in ihnen die Modelle in Haltung, Ansicht und Bildausschnitt überwiegend in konventioneller Weise - bevorzugt sitzend und als Brustbild in Frontalansicht oder im DreiviertelProfil - gezeigt werden. Ungewöhnlich, aber für Kokoschkas Porträts typisch, sind der nach innen gerichtete, abwesende Blick und die unbestimmten Hintergründe, die die Personen in diffuser Farbigkeit umfangen. Neben diesem evidenten Mangel an Halt, der die Porträtierten gleichsam schwebend erscheinen lässt, fällt auf, dass nicht selten die Hände als zusätzliche Ausdrucksträger ins Bild gebracht sind. Wie andere expressionistische Maler (beispielsweise auch Meidner) vermeidet Kokoschka den Lichteinfall von außen. Stattdessen gibt er den Modellen vermittels einer Art Aura den Anschein von innen heraus zu leuchten. ${ }^{520}$ Wirklich außergewöhnlich ist bei Kokoschkas (sämtlichen) Porträts der Einsatz der bildnerischen Mittel, der vom bald pastosen und bald sehr lasierenden sowie raschen Farbauftrag, über eine expressive Farbwahl bis hin zu den für ihn charakteristischen Ritzungen reicht..$^{521}$

Es wird nun in der Sekundärliteratur immer wieder geradezu schwärmerisch auf Kokoschkas psychologisierende Porträts ${ }^{522}$ hingewiesen und ihm somit das Vermögen zugesprochen in seinen Bildnissen das innere Wesen seiner Modelle offenlegen zu können. Doch was ist damit eigentlich gemeint? Wie kommt es zu dieser Beurteilung? Und: Ist sie zutreffend?

Mit dem Bildnis „Ernst Reinhold“ (1909), später als „Der Trancespieler“ betitelt (Abb. 63), war Kokoschka bei der Wiener Kunstschau 1909 erstmals als Maler an die Öffentlichkeit getreten. Darin wird dem Betrachter der Schauspieler und Jugendfreund des Künstlers mit dem eigentlichen Namen Reinhold Hirsch als Brustbild frontal vor Augen geführt. Dieser hatte bereits 1909 in den ersten Aufführungen Kokoschkas expressionistischer Bühnenstücke mitgewirkt. ${ }^{523}$ Dunkel hebt sich sein braunes Jackett vor dem unbestimmten, nur in hellen, milchigpastellfarbenen Rosa-, Hellblau- und Gelbtönen changierenden Hintergrund ab. Die hellblaue Krawatte um den weißen Kragen korrespondiert mit den leuchtend blauen Augen des Schauspielers, die auf ungleicher Höhe positioniert, rotgerän-

${ }^{520}$ Vgl. Schneede (2002), S. 17; Natter (2002), S. 90, Asendorf (1991), S. 14.

521 Darauf wird anhand der Einzelbeispiele dedizierter einzugehen sein. Im Übrigen beschränken sich diese Gestaltungsmittel nicht auf die Gruppe der Porträts allein, sondern ist auch bei anderen Gemälden Kokoschkas festzustellen.

522 Bei Ehrenstein beispielsweise werden die Bilder als „Psychotomien“, Kokoschka selbst als „Seelenaufscblitzer" bezeichnet. Vgl. Ehrenstein (1917), S. $311 \mathrm{ff}$.

523 Vgl. Winkler/Erling (1995), S. 5; Natter (2002), S. 98. 
dert, nicht gänzlich geöffnet und geradezu tranceartig den Betrachter anblicken. Die gesamte Mimik ist entspannt und wirkt beinahe ausdruckslos, höchstens vielleicht etwas ernst. Die roten, gewellten Haare über der breiten Stirn sind zum Seitenscheitel frisiert. Durch die teils recht dick aufgetragene gelbliche Farbe des Gesichts schimmern dunkelrosa Partien hindurch, die, wie im Kinn, Äderchen erahnen lassen oder um die Nasenflügel und die Augen ein kränkliches, beziehungsweise müdes Aussehen bewirken. Auffällig ist, wie Kokoschka durch die den Kopf umrahmende Pinselführung, Aufhellungen auf der rechten und das Blau der Augen aufnehmende Partien auf der linken Seite, den bereits erwähnten Effekt einer Aura erzielt. Dem Kopf als geistigem Zentrum wird damit eine besondere Bedeutung zugewiesen; es scheint, als würde der Geist Reinholds in einer Art von Leuchten wahrnehmbar gemacht.

Dem abwesenden, ruhigen Blick Reinholds steht die bewegte Gestik der Hände entgegen. Die Rechte ist nur als kümmerlicher hautfarbener Farbfleck gegeben. Die linke Hand ist vor die Brust gelegt und wie im Redegestus erhoben. Diese Gestik steht in Spannung zum unbewegten Gesichtsausdruck und dem geschlossen Mund. Die linke Hand hat Kokoschka genauer ausgeführt als die rechte Finger, Knöchel, teils auch die Nagelbetten sind erkennbar und bläuliche Linien deuten die Adern an - doch fehlt der fünfte Finger. Der Künstler äußerte dazu später selbst:

„Eines der mir besonders wichtigen Bilder, „Der Trancespieler“, Porträt meines Schauspielfreundes Ernst Reinhold, zeigte ein Detail, das bisher übersehen wurde. In der Eile habe ich einer Hand, die er im Bilde an die Brust legt, nur vier Finger gemalt. Ob ich den fünften einfach vergessen habe? Ich selber vermisse ihn nicht, weil die Aufhellung der Psyche des Modells mir wichtiger war als die Aufzählung von Details (...) ".524

Diese Äußerungen zielen in die gleiche Richtung, wie die zu Beginn des Kapitels zitierten (,Wenn ich Porträts male, geht es mir nicht darum, das Äußerliche eines Menschen (...) festzubalten [erg.: sondern darum die] Summe eines Lebewesens in einem Gedächtnisbild wiederzugeben"). In beiden spiegelt sich deutlich, worauf es Kokoschka in seinen Porträts tatsächlich ankommt: weniger auf die Darstellung des Äußeren eines Menschen, also das Erscheinungsbild oder ergänzende, status- beziehungsweise berufsspezifische Attribute, sondern auf die Darstellung seines Inneren, wie es sich in Gestik, Mimik und Verhalten erahnen lassen soll. Er versucht nach seinem Eindruck von der Psyche und dem Charakter des Modells dessen Wesen herauszuarbeiten. In Abwendung von der körperbetonten Darstellungsweise, schreckt der Künstler nicht vor Deformierungen und Abstraktion, wie sie hier in der Gestaltung der Hände zu bemerken sind, zurück - etwas, das in der akademischen Kunst zuvor kaum denkbar gewesen wäre. Kokoschka mag denn im Bildnis Ernst Reinholds durch den Trancezustand, also den Übertritt in eine andere Dimension,

${ }^{524}$ Kokoschka (1971), S. 73. 
implizit dessen Fähigkeit verbildlicht haben, als Schauspieler in einer Rolle, und somit in einer anderen Realität, aufzugehen. ${ }^{525}$

Deutlich wird Kokoschkas Porträtanspruch auch in der Beschreibung seines Vorgehens:

„Meine Modelle müssen einfach dazu gebracht werden, zu vergessen, dass sie gemalt werden, und es bedarf manchmal meiner langen Erfahrung im Umgang mit Menschen, eine oft in der Konvention verschlossene Persönlichkeit wie mit einem Büchsenöffner ans Licht zu bringen. (...) Wenn ich immer versuchte meine Modelle in Bewegung zu halten, durch Gespräche zu unterhalten, geschah es, um sie davon abzulenken, dass sie beobachtet wurden." 526

Kokoschkas Ziel war es dabei sich ,ein Bild zu machen, wie man es etwa von Menschen in der Erinnerung behält, als Gedächtnisbild"527 und dafür war seiner Meinung nach das Stillsitzen wie bei einem Photographen ungeeignet, denn eine „,bloße Tatbestandsaufnabme bringt nichts zum Sprossen; wie die Wintersonne wärmt sie nicht das Her." "528 In dieser Formulierung steckt das Anliegen nicht nur die Erinnerung an das Aussehen der Person wach zu halten, sondern auch die an ihre Wesensart.

Kokoschka war mit diesem Anspruch nicht allein, auch Ludwig Meidner und andere Expressionisten ${ }^{529}$ strebten in ihren Porträts nach einer „Gestaltung der Physiognomie, die nicht das Augenscheinliche wiedergeben will, sondern verschiedene Wesensmöglichkeiten, Befindlichkeiten (...) '530. Dahinter steckt der Gedanke von der wechselseitigen Beziehung zwischen dem Physischen und dem Psychischen, wie sie beispielsweise in der zweiten Hälfte des 19. Jahrhunderts besonders stark in der philosophischen Diskussion um das Leib-Seele-Problem thematisiert wurde und auch die nächsten Jahrzehnte bedeutsam war. Aussagen wie die vom ,vollständigen Parallelismus des Psychischen und des Physischen"531 bei Mach oder die von Weininger aufgestellte Behauptung, dass „Psychologie im engeren Sinne und Physiologie (...) Parallelwissenschaften “532 seien, mögen inspirierend gewesen sein. Es ließ sich daraus der Gedanke ableiten, dass das erkennende Durchdringen nicht nur beim Körper, sondern auch bei der Seele möglich sei. Dieser damals vielfach in den Wissenschaften vorherrschende Wunsch, den Menschen zu durchdringen und die Wahrheit über sein Inneres herauszufinden, wurde auch zum Anliegen vieler expressionistischer Künstler. Am einflussreichsten dürften dabei mit Sicherheit die Forschungen und Theorien Sigmund Freuds gewesen sein. Die Traumdeutung, aber auch die freie Assoziation als Mittel seiner Psychoanalyse, sollten Einblicke in das Unbewusste und gleichsam in

\footnotetext{
$525 \mathrm{Vgl}$. Schuhmacher-Haardt (1996), S. 123.

526 Kokoschka (1971), S. 73 f.

527 Kokoschka (1971), S. 74.

528 Kokoschka (1971), S. 74.

${ }^{529} \mathrm{Vgl}$. dazu Whitford (1987).

530 Schumacher-Haardt (1996), S. 240.

531 Mach (1903), S. 50.

532 Weininger (1916), S. 71.
} 
die menschliche Seele ermöglichen. Der Mensch wurde hierdurch, ebenso wie durch andere naturwissenschaftliche Neuerungen - beispielsweise die Röntgenstrahlen, die für die Medizin bedeutsam wurden - in ein neues Licht gerückt. ${ }^{533}$

Aus dieser Haltung heraus werden Kokoschkas Porträtanspruch und die darauf bezogenen, eindringlichen Äußerungen mancher Kritiker wie: „Es ist geradezu ein Röntgenblick, mit dem da der innere Mensch durchschaut wird“534, oder: „,...) ein Hinwegreißen der Oberfläche des Individuums, um darunter die reine Psyche zu entblößen “535, verständlicher. In manchen Bildnissen hat Kokoschka den Versuch, die Seele über eine geradezu sezierende Behandlung der Anatomie sichtbar zu machen, auf das Höchste gesteigert. „Ludwig Ritter von Janikowski“ (Abb. 64) aus dem Jahre 1909 beispielsweise führt dem Betrachter in fulminanter Expressivität das Gesicht des Adeligen aus dem literarischen Freundeskreis um Karl Kraus vor Augen. Im nahezu quadratischen Bildformat ist Janikowski aus nächster Nähe en face wiedergegeben. Der größte Teil der Figur und des Gesichts ist unterhalb der Bildmitte angeordnet, wodurch der Eindruck des Absackens nach unten entsteht. Der unbestimmte Hintergrund leuchtet gespenstisch in blaugrünen Farbschleiern, in die sich partiell auch Rot, Gelb, Braun und Violett mischen. Während besonders im oberen Bereich die Leinwand erahnbar bleibt, finden sich links des Kopfes einige schwungvoll und mit viel blauer und weißer Farbe ausgeführte Pinselhiebe. Das Antlitz Janikowskis ist schmal und ausgemergelt. Die Wangen sind eingefallen, so dass die Knochen deutlich hervortreten. Die Ohren stehen, blutigen Deformationen gleich, zu den Seiten ab. Tiefe Furchen und Falten verzerren die Miene und Schatten im überwiegend grünen, violetten und roten Farbauftrag um die Augenpartie verdunkeln das Gesicht dämonisch. Der Schnurrbart ist ebenso mit dem Pinselende bearbeitet, wie die Farbschichten direkt am Kopf, die durch Aufhellungen und die dynamisch ausgeführten Ritzungen den für Kokoschkas Porträts so typischen, aura-artigen Effekt bewirken. Inmitten dieser Spannungsgeladenheit aus Farb- und Linienstürmen wirken die Augen des Mannes seltsam leer, Mund und Gesichtszüge kraftlos und schlaff. Janikowski befand sich zu der Zeit, da er sich von Kokoschka porträtieren ließ, in der Wiener Nervenheilanstalt Steinhof und sollte zwei Jahre später in geistiger Umnachtung versterben. Der Künstler zeigt den Adeligen hilflos und dem psychischen Niedergang anheim gefallen. ${ }^{536}$ Dabei verwirft er die tendenziell dem Realismus verpflichtete, zuweilen auch idealisierende Darstellungsweise, wie sie in der Porträtkunst des 19. Jahrhunderts vorherrschte und in den Akademien auch zu Beginn des 20. Jahrhunderts neben dem nach Schönheit strebenden Jugendstil noch präferiert wurde. Stattdessen steigerte er mit dem Mut zum Hässlichen und durch eindringliche, teils anaturalistische Verwendung der Farbe, sowie durch die dynamischen Ritzungen die Expressivität

\footnotetext{
533 Vgl. Eder (2006), S. 219 ff.; Leiß/Stadler (1997), S. 35 f.

534 Westheim (1918), S. 22.

535 Schvey (1982), S. 27 f.

536 Vgl. Natter (2002), S. 112; Winkler/Erling (1995), S. 14.
} 
des Bildes, die dem Betrachter den Eindruck vermittelt, die psychische Gespanntheit des Porträtierten erahnen zu können. Die Art, wie er das Gesicht dabei gleichsam enthäutet, und Nervenbahnen und Adern scheinbar offenlegt, unterstreicht, wie sehr er der Idee vom Erkennen der Seele mittels Durchdringen des Äußeren verhaftet gewesen ist. Auch in anderen Darstellungen des Menschen bei Kokoschka, wie den Illustrationen zu „Mörder, Hoffnung der Frauen“, sind Adern auf der Haut gezeigt und bei den Aufführungen des Dramas bemalte der Künstler den Schauspielern sogar ,die Arme und Beine mit Nervenlinien, Muskel- und Sehnensträngen, wie man das auch in meinen Zeichnungen sehen kann' 537 .

In ähnlicher Weise sind viele der früheren Porträtzeichnungen behandelt. Die Ritzungen, welche in den Gemälden physiognomische Details andeuten oder zur Steigerung der Expressivität eingefügt werden, finden sich hier in zeichnerischen Kürzeln, wie beispielsweise in der Grafik „Karl Kraus I“ (Abb. 65), wo sie vor allem Mund- und Augenpartie umspielen. Gesicht und Hände des Literaten und Herausgebers der Zeitschrift „Die Fackel“ werden mit Tusche durch Linien in unterschiedlicher Strichstärke skizziert. Der leicht gesenkte, im Dreiviertelprofil gezeigte Kopf ist dabei am detailliertesten ausgeführt. Innerhalb breiter Konturlinien sind die Details des Gesichts in bewegter, feiner Binnenzeichnung beschrieben und lassen Poren, Falten sowie Härchen erkennen. Diese Ziselierungen sind ähnlich wie die Ritzungen weniger dem wahren Äußeren des Modells als vielmehr einer angestrebten Psychologisierung des Porträts geschuldet. Schultern, Ansätze der Arme und dynamisch gestikulierende Hände sind dagegen mit wenigen, schnellen Strichen umrissen. Die in diesem Porträt ersichtliche, eckige Zeichenauffassung weicht in der Folgezeit einer weicheren, geschwungenen Linienführung, wie es beispielsweise in der Kreidezeichnung „Lotte Franzos I“ (Museum Folkwang/Essen) von 1912 erkennbar ist, bis schließlich die Linien auf das Wesentlichste reduziert werden und die zarte Binnenzeichnung an Bedeutung verliert. 538

Es ist bereits erwähnt worden, dass nicht nur das Gesicht des Modells in Kokoschkas Porträts kraftvoller Ausdruckträger ist, sondern zudem auch den Händen große Bedeutung zukommt. Im Porträt Ernst Reinholds noch eher nebensächlich behandelt, sind sie im Folgenden vielfach mit großer Sorgfalt und als weiterer Ausdrucksträger ins Bild gebracht. Eines der eindrucksvollsten Beispiele hierfür ist das Bildnis „Auguste Forel“ (Abb. 66) von 1910, in welchem Kokoschka den berühmten Schweizer Naturforscher, Hirnanatomen, Psychiater und Sozialreformer gleichsam als eine visionäre Erscheinung vor Augen führt. Grüne, braune und beige Farbschleier sind dünnflüssig auf der Leinwand verteilt und daraus tauchen, wie aus einem Nebel, Kopf und Hände Forels auf. Arme und Oberkörper der im Dreiviertelporträt nach links gedrehten Halbfigur sind dagegen kaum akzentuiert und nur in Konturen zu erahnen. Der Kopf mit der Halbglatze

${ }^{537}$ Kokoschka (1971), S. 65.

${ }^{538}$ Pessler (2002), S. 184 ff. 
ist leicht gesenkt. Die starren, innere Versunkenheit und Konzentration ausdrückenden Augen blicken ins Leere vor sich. Skeptisch und nachdenklich sind die Augenbrauen hochgezogen, während das hagere Antlitz mit den tiefen Augenringen, Falten und dem schütteren weißen Haar des Bartes und des Hinterkopfes auf das fortgeschrittene Alter des Forschers verweisen. Forel wird so als Mensch mit großer geistiger Energie vor Augen geführt, der aber an körperlicher Kraft und Präsenz zu verlieren scheint. Während sein Gesicht durch den in sich gekehrten Blick und den geschlossenen Mund introvertiert wirkt, verraten seine Hände im Gegensatz dazu deutlich eine innere Spannung. In nervöser Verkrampfung sind sie in die linke untere Gemäldeecke gesetzt. Sie fallen durch ihre aus den Farbschleiern hervorgehobene Akzentuierung besonders ins Auge und erscheinen, erfüllt von seltsamem Eigenleben, beinahe wie ein Bild im Bild. Die Gelenke, Sehnen, Knochen und Adern treten deutlich unter der fahlen Haut hervor und sind genau und eindringlich bearbeitet. Die Rechte ist geradezu unnatürlich stark nach unten abgeknickt, während die linke, leicht geöffnete Hand in sprechender Gestik etwas angehoben ist. Beide scheinen durch ihre Energiegeladenheit eine Nervosität nach außen zu tragen, die das Gesicht nicht in diesem Maße verrät. Durch dieses Zusammenspiel aus Konzentration des Gesichtsausdrucks und Dynamik der Hände vermittelt das Forel-Porträt eine beunruhigende Spannung. Dazu trägt auch der Kontrast aus geistiger Agilität, wie sie durch die Betonung des Kopfes und der inneren Versunkenheit vermittelt wird, und gleichzeitigem, durch die Auflösung der Körperlichkeit aufgezeigtem, Alterungsprozess bei. Kokoschka wollte den Forscher wohl in seiner geistigen Kraft darstellen, Forel selbst jedoch "meinte, es sähe aus, als ob er schon einen Scblag erlitten bätte ${ }^{539}$ und lehnte den Ankauf des Bildes ab. Zwei Jahre später erlitt er tatsächlich einen Schlaganfall und sah dies wohl im Gemälde angekündigt. ${ }^{540}$

Obschon den Händen in der Porträtkunst von jeher Aufmerksamkeit zugekommen ist, sind sie in ihrer Rolle als Ausdrucksträger dem Gesicht traditionell untergeordnet. Wie Ohlsen bemerkt, können sie bei Kokoschkas Bildnissen, wie eben jenem von Forel, nunmehr eine gleichwertige Rolle spielen. Sie evozieren hier einen inneren Ausdruck, den das Gesicht nur bedingt preisgibt. Die bildimmanente Spannung wäre ohne sie nicht denkbar und würde somit zu einer Bedeutungsverschiebung führen. ${ }^{541}$

Wenngleich Kokoschka überaus innovative bildnerische Mittel verwendet und höchst eindrucksvoll den Menschen in bis zum Expressionismus hin undenkbarer Weise darstellt, handelt es sich bei seinen Porträts deshalb nun wirklich um „Seelenbilder", wie es in der Sekundärliteratur teilweise behauptet wird? Wenn man die Bildnisse betrachtet, muss einem klar werden, dass sie natürlich kaum mehr über das tatsächliche Wesen der dargestellten Person verraten, als ein konventionelles

\footnotetext{
539 Kokoschka (1971), S. 98.

540 Kokoschka (1971), S. 98.

541 Vgl. Ohlsen (2001), S. 23 f.
} 
Porträt. Sie gehen in ihrer Ausdruckstärke durch die expressive Steigerung über die, nur auf die möglichst naturalistische Wiedergabe der äußeren Person bedachte, akademische Porträtkunst zwar hinaus, doch zeigen sie dabei nicht die Psyche des Dargestellten, sondern das, was der Künstler in sie hineingelegt und wie er sie interpretiert hat. Bestimmte Merkmale der Person, wie vielleicht Reinholds Fähigkeit mental in eine „andere Welt" zu wechseln, können einfließen, aber dennoch sind die Bildnisse mit der Subjektivität des Malers angefertigt und können kein objektives Bild der Seele spiegeln. Zwar wurde Kokoschka wiederholt seherisches Vermögen zugesprochen und behauptet, er hätte in seinen Bildnissen teils sogar das in der Zukunft liegende Schicksal der Modelle angedeutet - in Bezug auf Auguste Forel beispielsweise dessen zwei Jahre nach der Bildentstehung durch einen Schlaganfall erlittene Teillähmung ${ }^{542}$ - jedoch ist diese Überinterpretation der Werke nicht haltbar. Sie bedient lediglich einen gerade im Expressionismus gerne gepflegten Künstlermythos, wie er sich beispielsweise aus den Worten des Schriftstellers Kasimir Edschmid ablesen lässt:

„Intuition, Blick in die Innenwelt, Transzendenz, waren Kennzeichen für eine Generation von Malern und Literaten, für die der Sinn von Kunst darin bestand eine neue, böbere, übertragene Wirklichkeit kundzutun. ‘543

Visionäres Vermögen erscheint daher für einen expressionistischen Künstler unabdingbare Voraussetzung:

„Die Realität muß von uns geschaffen werden. Der Sinn des Gegenstands muß erwühlt werden. Begnïgt darf sich nicht werden mit der geglaubten, gewähnten, notierten Tatsache, es muß das Bild der Welt rein und unverfälscht gespiegelt werden. Das aber ist nur in uns selbst. So wird der ganze Raum des expressionistischen Künstlers Vision. (...) “.544

Visionär das menschliche Innere nach außen kehren - das war auch ein Ziel Kokoschkas, zu dem er sich tatsächlich befähigt fühlte, wenn er im Abschluss seines Briefes auf eine skeptische Nachfrage von Lotte Franzos antwortet: „Wirklich, glauben Sie nicht, dass es ein anderer Hund in der Erinnerung besser spürt, wie Sie sind."545 Dennoch: ein Ziel, das im genauen Sinne nicht zu erreichen ist. Von entscheidender Bedeutung ist an dieser Stelle jedoch, dass der Versuch der Expressionisten die Psyche des Menschen ins Bild zu bannen, eine bis dahin ungekannte und un-

\footnotetext{
542 Fischer (1986), S. 56 f.

${ }^{543}$ Kasimir Edschmid (1890-1966), zitiert bei Whitford (1987), S. 8.

${ }^{544}$ Kasimir Edschmid (1890-1966), zitiert bei Whitford (1987), S. 9. Zur Diskussion darüber, ob Kokoschka die Seele der Porträtierten eingefangen oder seine eigene Persönlichkeit ins Bild gebracht habe, vgl. Äußerungen u. a. von Natter (2002), S. 93; Ohlsen (2001), S. 25; Tomeš (1986), S. 255 ff. Zu Kokoschkas seherischen Fähigkeiten und denen anderer Expressionisten s. beispielsweise Whitford (1987), S. 8.

545 Brief an Lotte Franzos, 1910. Zitiert nach Kokoschka (1984), Bd. 1, S. 11.
} 
vorstellbare, neue Farb- und Formenbehandlung in der vorher zumeist festen akademischen Regeln folgenden Porträtkunst zur Konsequenz hatte.

Davon ausgehend, dass die Bildnisse eine Interpretation des Künstlers beinhalten, fließen ein Stück weit auch dessen Prägungen - eigene Vorstellungen, Emotionen und die Grundstimmung der Zeit - ein. So spricht auch Edschmid davon, dass das wahre Bild der Welt im Künstler stecke und dieser demnach die Realität selbst „erschaffen“ müsse, womit er impliziert, dass in den Porträts viel vom Empfinden des Künstlers selbst zu finden sein dürfte. Kokoschka gibt hierfür in seinem 1961 geschriebenen Essay „Ich male Porträts, weil ich es kann“546 mit Äußerungen zur Porträtkunst ebenfalls entsprechende Hinweise:

„So sagt denn das Bild, soll es sich von einem Machwerk unterscheiden, nicht nur etwas über den Besteller und das Modell, sondern auch über das Temperament des Schöpfers und noch über eine gegebene Zeit hinaus, etwas, wofür den Zeitgenossen des Künstlers ein Organ fehlte, um es aufzunehmen. (...) Ich bescheide mich damit, dass ich Porträts male, weil ich es kann und darin meinen Weg zum Menschen sehe, einen Spiegel, der mir zeigt, wann und wo und wer und was ich bin. "547

Sic: wann und wo und wer und was „ich “ bin! Deutlich bezeichnet er damit das Bildnis als Weg zur Auseinandersetzung nicht nur mit dem jeweiligen Gegenüber, sondern auch mit der eigenen Person. Die Anspannung und Nervosität, die düstere Bedrohlichkeit und die die eigene Existenz betreffende Unsicherheit, die Kokoschkas Bildnissen immanent ist, spiegelt somit zum Teil seine eigenen Emotionen wider. Seine tendenziell pessimistische Auffassung ist dabei, wie bei vielen Expressionisten, beeinflusst von den äußeren Gegebenheiten einer von politischen, sozialen und wissenschaftlichen Umbrüchen sowie der von Nietzsche propagierten Werte-Entwertung geprägten Zeit.

Der den Einzelporträts vielfach inne wohnende und durch Gestik und Mimik, sowie malerische und zeichnerische Mittel vielfältig umgesetzte Ausdruck von Unruhe und Spannung wird ergänzt durch den Eindruck einer gewissen Verlorenheit. Dieser ergibt sich zum einen aus der Hilflosigkeit der Personen gegenüber dieser Spannung, aus ihrer Versunkenheit, die einen partiellen Rückzug aus der Welt signalisiert, und aus dem diffusen, den Personen keinen Halt gebenden, sondern oft sogar gleichsam aufgelösten Hintergrund. Sowohl die Situation des Gegenübers, als auch seine eigene beziehungsweise eine Grunderfahrung seiner Zeit, kann Kokoschka damit gemeint haben.

\footnotetext{
546 Textnachweis, Text XXVI. Geschrieben im Januar 1961 für eine Diskussionsreihe der Stuttgarter Zeitung mit dem Thema „Das verlorene Menschenbild“. Am 4.2.1961 dort zuerst veröffentlicht. 547 Kokoschka (1975), S. 11 f. Diese Auffassung lässt sich mit den Theorien Schönbergs in Verbindung bringen, der im Almanach des Blauen Reiters von 1911 äußerte, dass die Kunstwirkung eines Werkes quasi zeitlos sei, weil zwar nicht unbedingt der Dargestellte präsent sei, sondern weil „der Künstler uns anspricht, der sich bier ausgedrückt hat, der, dem in einer höheren Wirklichkeit das Porträt ähnlich zu sehen hat" (Kandinsky/Marc (2002), S. 75).
} 
In seinen Texten findet sich seine Sicht des Menschen wie gesagt nur wenig verarbeitet. In dem bereits genannten Vortrag „Von der Natur der Gesichte ${ }^{548}$ aber sind Äußerungen zu finden, die sich mit den Porträts in Zusammenhang bringen lassen. Hier beschreibt Kokoschka, wie die äußeren Einflüsse des Lebens, die er als „Gesichte" bezeichnet, dem Bewusstsein zuströmen, sondiert werden (,Bewnsstsein der Gesichte ist aber Leben selber, welches von Bildungen, die ibm zuströmen, wählt (...)" und schließlich auch Einfluss auf die Seele nehmen, ,der Seele, welche nun beginnt, die Gesichte leibhaftig zu formen" ${ }^{449}$ Die Gesichte sind nach Kokoschkas Auffassung etwas schwer Greifbares, welches er unter anderem als ,ein Bewegen, Eindruckwerden und Sicbtbarsein "definiert.

Aus dem Text lässt sich ableiten, dass die Wahrheit für Kokoschka eine subjektive Qualität hat. Das menschliche Bewusstsein nämlich wird von den Gesichten gespeist, ,wie die Lampe von dem Öl“ und dadurch ,hat jedes Ding sich seiner selbst entledigt" - aus den Wahrnehmungen werden individuelle Vorstellungen, die an den wahrnehmenden Menschen, in dessen Bewusstsein sie als Gesichte eingehen, gekoppelt sind („Bewnsstsein ist das Grab für die Dinge, wo sie aufhören, das Jenseits in dem sie eingehen. So dass sie alsdann bei ibrem Ende in nichts Wesentlichem mehr zu bestehen scheinen, als meinem Gesicht in mir. "). Nur durch diese individuellen Vorstellungen sind anscheinend für Kokoschka die Dinge real existent und subjektiv wahr. Das gilt auch für ihn selbst, wenn er davon spricht "Gesicht" zu sein, sobald sich andere Menschen eine Vorstellung von seiner Person machen und wenn er am Ende seines Vortrages zum Publikum sagt: „Dann aber werde ich nichts mehr sein, als eine, Ibre Einbildung. Dann ist die Einbildung in allen Dingen das, was natürlich ist. Dann ist Einbildung Natur, Gesicht, das Leben."

Entscheidend für die Wahrnehmung des Menschen und somit für die Porträts ist hier zweierlei. Erstens: die Dinge (beziehungsweise Personen) werden gleichsam durch eine nach innen gerichtete Wahrnehmung erfasst. Sie hinterlassen im Wahrnehmenden, in diesem Fall also im Künstler, einen Eindruck, dessen er sich bewusst werden kann. Zweitens: auch wenn er aus den Gesichten wählen kann, ist die Wahrnehmung nicht vernunftbestimmt, denn „Das Bewusstsein der Gesichte ist kein Zustand, in welchem man die Dinge erkennt oder einsieht, sondern ein Stand desselben, an dem es sich selbst erlebt". Die Dinge (beziehungsweise Personen) werden „erlebt", also auf irrationalen, emotionalen Wegen wahrgenommen.

Kokoschkas Beschreibung vom Bewusstsein der Gesichte erinnert somit an die Intuition. Jedoch mag man bei Kokoschkas nebulösen Ausführungen über das Bewusstsein der Gesichte, das auch nach seiner eigenen Aussage ,nie ganz ₹u bescbreiben sein" wird, ebenso an Edschmids Beschwörung des Visionären denken, wenn Kokoschka erläutert, wie die Gesichte (oder Eindrücke) - wenn sie denn ins Bewusstsein und schließlich in die Seele vordringen - einen jähen, geradezu überraschenden Effekt hervorbringen: „Als plöt:licher Stand wird uns ein Gesicht, wie der

548 Textnachweis, Text XXVII; Vgl. Kap. 3.2.3.2.

${ }^{549}$ Genaueres dazu s. Kap. 3.2.3.2. 
erste Blick, wie der erste Schrei eines Kindes, das eben geboren aus dem Leib der Mutter fällt." Einer schlagartigen, gleichsam visionären Eingebung scheint hier das Eindringen der Gesichte ins Bewusstsein vergleichbar.

In Bezug auf seine Porträts und im Hinblick auf sein „Erspüren“ des Wesens eines Menschen, wie es im Brief an Lotte Franzos anklingt, sind diese Ausführungen bedeutsam. Sie betonen das Erfassen des Umfeldes auf tendenziell intuitivem Weg jenseits der Vernunft und die Wirkung des Wahrgenommenen auf die Seele. Damit legt Kokoschka nicht nur die Grundlage für seine „Seelenmalerei“ - in Gesichten erschließt sich ihm das Innere, oder präziser die Psyche seines Modells, welche er dann bildnerisch umsetzt (beziehungsweise umzusetzen meint). Darüber hinaus lässt sich daraus auch wieder die Behauptung ableiten, dass, wenn die Eindrücke (Gesichte) durch den Filter seines eigenen Bewusstseins in seinen Werken Niederschlag finden, sich persönliche Emotionen hineinmischen und somit partiell auch der Künstler im Bildnis der porträtierten Person seine Spiegelung erfährt. Insofern lassen hier Text und Bild die gleichen Schlüsse über Kokoschkas Porträtauffassung zu.

Wesentlich ist in beiden Medien zudem das Prinzip der Bewegung. 550 Wenn Kokoschka seine Modelle während des Porträtierens dazu anhielt sich frei zu bewegen, ohne sich um des Künstlers Aufgabe zu kümmern, 551 wenn er dies beispielsweise mit der Aussage „Ein Mensch ist kein Stilleben "552 kommentierte und wenn er versuchte in seinen Bildnissen die Menschen in der Summe ihres Wesens und in einer Art überzeitlichen Erscheinungsform künstlerisch zu erfassen, so steht dies im engen Zusammenhang mit seinen Formulierungen über das Strömen des Lebens und der Gesichte. In all dem nämlich deutet sich die Auffassung an, dass die Wahrheit beziehungsweise die Wahrnehmung unseres Umfeldes variabel ist, weil das Leben und die Menschen ständigen Veränderungen und Bewegungen unterliegen und zudem dieser Prozess des Wandels kontinuierlich auf das Bewusstsein und die Seele einwirkt. Diese Gedanken lassen eine Nähe zu Simmels Aufsatz „Das Problem des Porträts“553 (1918) erkennen, worin die Frage nach der Gültigkeit der äußeren Erscheinung formuliert und die These von der durch verschiedene Eindrücke fluktuierenden Wahrnehmung einer Person aufgestellt wird. Darüber hinaus lassen sie sich mit Arthur Schopenhauers „Die Welt als Wille und Vorstellung“ (1819) $)^{554}$ und der darin erläuterten Idee von einer durch subjektive

\footnotetext{
550 Vgl. auch Trummer (2002), S. 41.

${ }^{551}$ Egon Wellesz, dessen Porträt Kokoschka 1911 im für dieses Schaffensjahr typischen, kristallinen Stil anfertigte, berichtet beispielsweise davon: ,Am ersten Tag frage ich ibn, ob ich mich während des $M a$ lens bewegen könnte. ,Halten Sie mich für einen so schlechten Maler, sagte er, ,dass Sie rubig sitzen müssen, während ich Sie male? Sie können tun, was Sie wollen. "Wellesz (1981), S. 81.

552 Kokoschka (1971), S. 72.

553 Simmel (1918), S. 1336-1344. Es ist allerdings auch anzumerken, dass Simmel hier die künstlerische Darstellbarkeit der Seele des Menschen und dessen psychologische Erfassung durch die Kunst verneint.

554 S. Literaturverzeichnis.
} 
Wahrnehmung individuell konstruierten Welt ebenso in Verbindung bringen, wie zu der zu Beginn des 20. Jahrhunderts propagierten Lebensphilosophie von dessen Schüler Henri Bergson, der zufolge die alles durchströmende, innere Kraft der Welt in ihrer Gänze nur durch eine nach innen gerichtete Selbstschau (bei Bergson ,intuition“, bei Kokoschka „Gesichte“) zu erfassen sei. Bergsons Äußerungen in „L'Evolution Creatrice“ muten entsprechend wie eine Beschreibung dessen an, was sich aus Kokoschkas Vortrag konkret für sein Porträtieren ableiten lässt:

\section{„Unser Auge fasst die Züge des Lebewesens auf; nur aber als bloßes Nebeneinander (...). Ihm entgeht die Lebensströmung, jene einfache Bewegung, die die Züge durchläuft, sie verbindet, ihnen Bedeutung verleibt. Diese Strömung aber ist es, die der Künstler zu ergreifen trachtet, wenn er sich durch eine Art der Sympathie ins Innere der Gegenstände versetzt, so durch eine Anstrengung der Intuition die Schranke niederreissend, die den Raum zwischen ihm und sein Modell schiebt." 555}

Beide Medien, die Rückschlüsse auf die Auffassung des Menschen zulassen, sind gleichermaßen von der Idee geprägt, dass Kokoschka durch Intuition und Vision das Innere oder den Kern eines im Prozess befindlichen Dinges wahrnehmen könne. Der Vortrag „Von der Natur der Gesichte“ formuliert in schwer verständlichem, unanalytischem und verrätseltem Sprachduktus theoretische Grundlagen, die für Kokoschkas Porträts wesentlich sind und sein Streben, seismografisch die Seele des Gegenübers zu erfassen und ins Bild zu bannen, legitimieren. In den Einzelbildnissen versucht er, seine Wahrnehmung vom Wesen des Modells in expressiver Farbwahl und mit eindringlicher Behandlung von Kopf und Händen zu vermitteln. Farbnebel lassen die Person gleichsam wie im Nichts schwebend erscheinen und die den Kopf umgebende Aura unterstreicht die auch aus dem leeren Blick ablesbare Betonung der Wendung nach Innen. Die sich vielfach in Mimik und Gestik ausdrückende Spannung mag als Spiegel bald für die dargestellte Person, bald für den Künstler und zum Teil vielleicht auch für die Grundstimmung der Zeit gelten.

\section{Gruppenbildnisse}

Die Einzelporträts haben in dem Werkkomplex der Bildnisse bei Kokoschka ein sehr großes Gewicht. Doch lassen sich auch einige Gruppenporträts finden und so stellt sich die Frage, welche Behandlung der Mensch hier erfährt. Ist die Darstellung der Personen derjenigen der Einzelporträts vergleichbar? Welche Zusammenhänge zwischen den Dargestellten werden hergestellt und welche Intention verfolgte Kokoschka dabei?

Das früheste expressionistische Bildnis des Künstlers, das nicht nur eine einzelne Person zeigt, ist das Porträt von Hans Tietze und Erica Tietze-Conrat 556

\footnotetext{
555 Bergson (dt. Übersetzung: „Schöpferische Entwicklung“; 1912), S. 181 f.

556 Literatur dazu u. a.: Natter (2002), S. 98; Winkler/Erling (1995), S. 19.
} 
(Abb. 67) von 1909. Das Wiener Kunsthistoriker-Ehepaar gehörte zum Freundeskreis von Adolf Loos und zu den frühen Kokoschka-Förderern. In breitem Querformat führt Kokoschka links Hans Tietze und rechts seine Frau Erica TietzeConrat vor Augen. Während er mit schwarzem Anzug, Weste und Krawatte im Profil und mit gesenktem Blick gezeigt ist, ist sie violett gewandet und frontal im Bild gegeben. Beide sind im Brustbild vor einen flächigen, in schillernden Farbtönen aus leuchtendem Gelbgrün, Rot, Blau und Violett gehaltenen Hintergrund gesetzt, der zudem von Kratzspuren überzogen ist. Laut Aussage von Frau Tietze wurden sie vom Künstler mit den Fingernägeln in die Farbschicht eingebracht. Kokoschka nutzte dieses von der damaligen Avantgarde neu entdeckte Kunstmittel um den Hintergrund zusätzlich durch Schraffuren und zeichnerische Elemente zu dynamisieren. Diese Liniengespinste sind sehr umfangreich und scheinen gleichsam eine mit Eigenleben erfüllte Landschaft zu bilden, wie eine Linienanalyse bei Husslein-Arco zeigt. ${ }^{557}$ In ausgewählten Partien sind sie auch bei den Personen selbst zu finden, so z. B. zur Betonung der lockigen Haare.

Die Blicke der beiden Modelle wirken starr und leer und gehen aneinander vorbei. Bei der Frau wird dieser Eindruck dadurch verstärkt, dass ihr rechtes Auge zwei Mal leicht versetzt gemalt ist. Die in gewittrigen Farbnebeln schwebenden Körper stehen jeweils für sich. Die Eheleute scheinen einander gar nicht wahrzunehmen. Ebenso ausdruckslos wie die Augen, ist die Mimik der Erica Tietze, während die unmerklich geöffneten Lippen und die leicht in Falten gelegte Stirn ihres Mannes seinen ebenfalls eher schlaffen Zügen einen Hauch von Konzentration verleihen. Die Konturen des Paares sind nicht überall durchgehend akzentuiert, so dass sie partiell mit dem Hintergrund zu verschmelzen scheinen, wie beispielsweise am rechten Arm des Hans Tietze.

Von besonderer Bedeutung sind in diesem Bild, wie in vielen der Einzelporträts, die Hände. Sie stellen die Verbindung zwischen den ansonsten durch Haltung und fehlenden Blickkontakt isoliert erscheinenden Eheleuten her, sie evozieren die Spannung bei den verhalten wirkenden und ausdrucksreduzierten Modellen. Sehnige und rotfleischige Hände streckt Herr Tietze seiner Gattin auf Brusthöhe entgegen. Die Haltung ihrer blassen und feingliedrigen Hände ist dagegen zurückhaltender. Während ihre Rechte vor die Brust gelegt ist, hebt sie ihre Linke zaghaft ihrem Mann entgegen. Wie bei Michelangelos Beseelung Adams durch Gottes Hand in der Sixtinischen Kapelle verharren die Fingerspitzen allerdings kurz vor der Berührung und bilden damit das eigentliche Spannungsmoment einer unabgeschlossenen Bewegung und einer direkt bevorstehenden Erwartungserfüllung.

Das Bildnis der Tietzes gehört nicht nur zu den wenigen Gruppendarstellungen im Frühwerk Kokoschkas, sondern steht als Paarbildnis auch den im Kapitel 3.2.3.1 verorteten Paardarstellungen Kokoschkas mit Lilith beziehungsweise Alma nahe. Entsprechend deutet es Schvey im Zusammenhang mit dem zeitgleich ent-

${ }^{557}$ Husslein-Arco (2008), S. 176. 
standenen Drama „Mörder, Hoffnung der Frauen“ als eine Thematisierung des Geschlechterkonflikts im Gemälde. ${ }^{558}$ Auch wenn seine Behauptung, in den Ritzungen seien oberhalb der beiden Köpfe Sonne und Mond als geschlechtsspezifische Symbole zu erkennen, nicht eindeutig zu verifizieren ist, so ist der für Kokoschkas Auffassung des Geschlechterverhältnisses konstatierte Aspekt von gleichzeitiger Anziehung und Abstoßung durch den Gegensatz von Hand- und Körperhaltung durchaus gegeben. Es geht in diesem Bildnis aber nicht wirklich um die Geschlechterproblematik. Es geht vielleicht teilweise um die Darstellung des Verhältnisses der beiden Personen zueinander, aber vor allem wohl um die Wiedergabe zweier Individuen. Im Vergleich zu den Einzelbildnissen wird deutlich, dass die beiden Eheleute jeder für sich in ähnlicher Weise porträtiert wurden wie die Einzelmodelle. Würde nicht die Hand des Mannes den Ärmel seiner Frau überschneiden, könnte das Gemälde in zwei einzelne, für Kokoschka typische Porträts geteilt werden, ohne dass dem Ausdruck der Personen dadurch etwas verloren ginge. Der Bezug der beiden Eheleute zueinander wird im Bild im Prinzip allein durch die Spannung erzeugende Gestik hergestellt, ansonsten erscheinen sie auf sich selbst zurückgezogen und isoliert.

Grundsätzliches Anliegen ist hier, wie bei den Einzelporträts, das Erfassen des Wesens der dargestellten Personen. Wesentliche Voraussetzung dafür war wohl auch beim Ehepaar Tietze die Bewegung, wie aus einem Bericht der Frau ersichtlich ist:

„Unsere Schreibtische standen aneinandergerückt beim Fenster - Kokoschka konnte uns nur als Silhouetten sehen. Wir schrieben, standen auf, holten ein Buch berunter, setzten uns wieder, als wären wir allein. Kokoschka saß in einem fernen Winkel, zu dem kein Licht drang, auf einem dreibeinigen Schusterstubl (...)“.559

Daneben fällt aber die auch den Einzelbildnissen eigene, bedrückende und isolierte Stimmung auf, die somit nicht auf die eigentliche Beziehung des Paares zurückzuführen ist. Wie verhält es sich bei anderen Gruppenporträts Kokoschkas?

Auf Grundlage der im gleichen Jahre erschienenen Lithografie „Rast auf der Flucht nach Ägypten“560 entstand 1916/17 das in Öl ausgeführte Gemälde „Die Auswanderer" (Abb. 68), in welchem Kokoschka seine Freunde Dr. Fritz Neuberger, Käthe Richter und sich selbst vor einer kargen und dunklen Hügellandschaft ins Bild gesetzt hat. Zu diesem Zeitpunkt war Kokoschka gerade nach Dresden umgezogen, um sich im Sanatorium Dr. Teuscher auf dem „Weißen Hirsch" von den Kriegserlebnissen zu erholen und seine Annahme als Professor an der Akademie voranzutreiben. Es ist festzustellen, dass sich sein Porträtschaffen, welches bis zum Ersten Weltkrieg von den Bildnissen vieler unterschiedlicher Menschen beherrscht war, in dieser Phase wandelte und der Künstler sich auf die

\footnotetext{
558 Schvey (1982), S. $44 \mathrm{f}$.

${ }^{559}$ Erica Tietze-Conrat: „Ein Porträt und nachher“ in: Hodin (1963), S. 70.

560 Abb. s. Wingler (1975), Nr. 84.
} 
Darstellung vertrauter Personen beschränkte. Hier lebte Kokoschka zeitweise als Teil einer kleinen freundschaftlich miteinander verbundenen Gemeinschaft, deren Mitglieder er in seinen Werken dieser Zeit wiederholt als Modelle wählte. Abgesehen vom Tietze-Bild, wendet er sich nun erst eigentlich der Gruppendarstellung zu. Die in „Die Auswanderer“ porträtierte Schauspielerin Käthe Richter spielte in verschiedenen Aufführungen seiner Dramen am Albert-Theater Dresden mit, war einige Zeit seine Geliebte und später eine gute Freundin, während Fritz Neuberger ihm ein enger Freund war, der Organisatorisches für ihn übernahm und ihm durch die Unterbringung im Sanatorium half, sich dem weiteren Militärdienst zu entziehen. Kokoschka veränderte in diesem Gemälde seinen Farbauftrag hin zu einer pastosen Malweise und versuchte, beispielsweise auch durch Bezug zu Runges Freundschaftsbildnis „Wir Drei“, eine Orientierung an kunsthistorischen Vorbildern aufzuzeigen. ${ }^{561}$ Dadurch wollte er sich vermutlich zum einen seinem neuen Geschäftspartner annähern - er hatte Ende 1916 einen Vertrag mit dem Galeristen Paul Cassirer besiegelt - und sich gleichzeitig als für die Professur geeignet erweisen.

Die drei Personen sind dem Betrachter im Querformat, nebeneinander aufgereiht, vor Augen geführt, wobei Kokoschka selbst, rechts im Bild, halb verdeckt hinter Fritz Neuberger erscheint, während seine Freunde fast symmetrisch links und rechts der Bildmitte einander halb zugewandt sitzen. Sowohl Richter, als auch Neuberger haben dabei ihre Linke in die Hüfte gestützt, während die rechte Hand auf den überschlagenen Beinen ruht. Obwohl sie sich in halber Drehung einander zukehren, besteht kein Blickkontakt zwischen den beiden. Jeder von ihnen hat den Blick starr auf einen fernen Punkt vor sich am Boden geheftet, wobei die Augen so leer und ausdruckslos erscheinen, dass sie wohl nichts Konkretes fixieren, sondern die Selbstversunkenheit der beiden Figuren bezeichnen.

Die Schauspielerin trägt ein rotes Kleid, das ihre rechte Schulter entblößt und in breiten deckenden Pinselzügen ausgeführt ist. Die Haare sind zu einer Hochsteckfrisur arrangiert. Darunter liegt ein schmales Gesicht mit hochgezogenen Augenbrauen und einer dadurch in Falten liegenden Stirn. Ihre Haut erscheint blasser als die der beiden Männer, ihre sichtbare rechte Hand feingliedriger als die des Fritz Neuberger. Dieser trägt ebenso wie der Künstler einen dunklen Anzug, während sein Gesicht von einem Vollbart halb verdeckt wird. Seine Hände, insbesondere die rechte, auf dem Knie aufliegende, wirken fahl, knochig und geradezu skelettartig. Kokoschka selbst schaut über die Schulter seines Freundes aus dem Bild heraus. Sein Gesicht mit den wulstigen, leicht hochgezogenen Brauen und den verschatteten Augenringen wirkt nachdenklich und sorgenvoll. Jede der Personen wird also sorgfältig und individuell gestaltet.

Der Farbauftrag ist wie erwähnt breit und pastos, die Farbigkeit, abgesehen vom Kleid Käthe Richters, in erdigen Tönen eher dunkel gehalten. In der Kombi-

561 Winkler/Erling (1995), S. 73 f.; Bushart (1996), S. 48 f.; Husslein-Arco (2008), S. 260. 
nation der in sich gekehrten, nachdenklichen Mienen, der kargen Landschaft und der düsteren Farben zeigt das Bildnis keine harmonische Einheit von Freunden, sondern wie im Tietze-Bild eine Gruppe von unabhängigen Individuen, in der jede Person für sich betrachtet und porträtiert wurde. Wie bei der Darstellung der Tietzes und wie in den Einzelporträts wirken die Modelle abwesend, introvertiert und isoliert. In „Die Auswanderer“ sind nur Neuberger und Richter, und nur durch ihre zur Bildmitte gedrehte Haltung, ansatzweise in Beziehung zueinander gesetzt. Dennoch erscheinen sie isoliert. Der Künstler steht gänzlich außerhalb der Gruppe, beinahe so, als sei er vom Ellenbogen Neubergers zur Seite gedrängt worden. Seine Selbstdarstellung wirkt wie eine Reminiszenz an Werke des 14. und 15. Jahrhunderts, in denen sich der Künstler gleichsam unbeteiligt am Geschehen als Assistenzfigur ins Bild setzte, wie eine bildliche Signatur oder um den Betrachter durch direkten Blickkontakt anzusprechen.

Anders als in „Rast auf der Flucht nach Ägypten“, wo Richter und Neuberger als Maria und Josef mit Jesuskind und Esel vor einem Wald lagern, sind die Personen in diesem Gemälde keine Modelle zur Veranschaulichung einer religiösen Szene, sondern sie sind selbst das Thema. Kokoschka zeigt sich und seine Freunde dabei als Individuen im autarken Miteinander, die durch die Freundschaft zusammengeführt wurden. ${ }^{562}$ Die bedrückte Stimmung des Bildes, die sich sowohl in den Gesichtern als auch in der düsteren Landschaft ausdrückt, sowie der Titel des Bildes lassen die Freunde seelisch erschüttert und heimatlos erscheinen. Darin spiegeln sich die vom Krieg geprägten, unsicheren Umstände, in denen das Porträt entstand und die Kokoschka in einem Bericht über die erste Begegnung mit seinen Freunden in einem Dresdner Wirtshaus in „Mein Leben“ andeutet:

\begin{abstract}
„Die Wirtin, eine resolute Frau, die trotz der im dritten Kriegswinter berrschenden Hungersnot den Gastbetrieb weitergeführt hatte, konnte ibren Gästen an kalten Tagen zumindest eine Koblrübensuppe offerieren (...). Außer Dr. Neuberger waren da der junge Schauspieler Ernst Deutsch aus Prag und der Dichter Walter Hasenclever (...). Auch Käthe Richter (...) wohnte hier. (...) Dr. Neuberger und Käthe Richter habe ich in dem traurigen Winter 1916/17 auf dem Bild, Die Auswanderer' dargestellt; binter die beiden, in eine trostlose Landschaft, habe ich mich selbst gemalt. "563
\end{abstract}

So erscheint denn auch der Kommentar Paul Westheims zum Bild sehr passend:

„Die Auswanderer, das sind die Menschen, die die Barbarei der Zeit unstet und flüchtig gemacht hat, die keine Heimat mehr haben, weil der Geist unter den Tatzen der Gewalt sich entwurzelt fühlt, und denen, vertrieben aus ihrer Domäne, aufgescheucht aus ihrem Menschbeitswirken, nichts anderes mehr bleibt als neue Heimat in der Seele zu suchen. '564

\footnotetext{
562 Vgl. auch Bushart (1996), S. 47.

563 Kokoschka (1971), S. 169.

${ }^{564}$ Paul Westheim zitiert nach Brugger (1991), S. 22 (dortige Quellenangabe unstimmig).
} 
Der Titel „Die Auswanderer“ verweist dementsprechend auf die dargestellten Freunde als vom Krieg umher getriebene Heimatlose, die sich aus der Not und Einsamkeit ihrer Situation heraus zusammengefunden haben.

Die Autarkie und Entwurzelung ausdrückende Darstellung seiner Freunde wiederholt Kokoschka in dem ein Jahr später ausgeführten Gruppenbild „Die Freunde“ (Abb. 69), in welchem Käthe Richter, der Schriftsteller Walter Hasenclever, der Dichter Ivar von Lücken, Fritz Neuberger, im Vordergrund Kokoschka selbst an einem Tisch versammelt und, durch ein im Türrahmen stehendes Zimmermädchen ergänzt, vor Augen geführt werden. In der einander freundschaftlich zugewandten Haltung und der Bildung kleinerer Zusammenschlüsse innerhalb der Gruppe (z. B. bei von Lücken und Neuberger) knüpft das Porträt an das romantische Freundschaftsbild an. Die Personen sind allerdings mit verschlossenen Mienen und in sich gekehrter Haltung wiedergegeben, die Aufgeschlossenheit und Kommunikation vermissen lassen. Äußerlich beziehungslos, ohne Berührungen oder Blickwechsel, sind sie nur durch die gemeinsame Aktivität an der Tafel zu einer Gruppe zusammengeführt.

Die Szene erinnert entfernt an das biblische Gleichnis vom verlorenen Sohn, der sein Geld in der Fremde verprasst, bevor er reumütig zu seinem Vater zurückkehrt, und welcher in der Kunst häufig in Gesellschaftsbildern - also bei Tisch im Kreise anderer Kneipen- oder Bordellbesucher - dargestellt wird. Will man das Gemälde in dieser ikonografischen Tradition lesen, lässt es sich im Zusammenhang mit Kokoschkas damaliger Situation - seelisch und körperlich angeschlagen aus dem Krieg zurückgekehrt und in Dresden neu Fuß fassend - als Ausdruck des Gefühls deuten, entwurzelt und eigentlich unter Fremden zu sein. ${ }^{565}$ Laut einem Brief an Hans Tietze aus dem Frühjahr 1918, in welchem Kokoschka seinen Anspruch an die Gruppenporträts umreißt, sollte dies Gemälde die Freunde eigentlich auch beim Kartenspiel zeigen und war ursprünglich entsprechend als „Die Glücksspieler" betitelt:

„Und so baue ich jetzt Menschengesichter (solche Modelle, wie die zufällig, nun schon lange mit mir hier ausharrenden, mit mir bekannten Personen, die ich in-und auswendig kenne, dass sie mich fast wie Alpträume schon verfolgen) zu Kompositionen auf, in welchen Wesen mit Wesen streitet, in striktem Widerspruch steht wie Haß und Liebe, und ich suche nun in jedem Bild nach dem dramatischen Akzidens, das die Einzelgeister zu einer höheren Ordnung umschweißst. So war im vorigen Jahr das für sie sehenswerte Bild ,Die Auswanderer, heuer ein Bild,Die Glücksspieler, welches ich vor fünf Monaten begonnen babe und welches erst jetzt langsam fertig wird. Es sind meine Freunde darauf, Karten spielend. "566

Demnach waren die Freunde ursprünglich als Modelle für ein Genrebild herangezogen worden, das sie als Kartenspieler zeigt. Kokoschka wählte das Thema des

565 S. Winkler/Erling (1995), S. 78.

566 Tietze (1919), S. 251. 
Glücksspiels dabei einerseits vermutlich deshalb, weil es eine gute Möglichkeit bot, die Freunde in einem Bild zu vereinen und andererseits, weil das Glücksspiel symbolisch die ungewisse Zukunft jedes einzelnen andeuten kann. Durch die offensichtlich vorgenommenen Übermalungen, die die Karten und somit den Anlass des Beisammenseins getilgt haben, wirken die Personen noch autarker und die Betonung verlagert sich weg vom Genrebild, hin zu einem Gruppenbild, in dem die Personen um ihrer selbst willen vor Augen geführt werden.

Die zitierten Zeilen unterstreichen auch, was sich anhand der erläuterten Gruppenbildnisse bereits ableiten ließ: Den Künstler faszinieren besonders die Gegensätze, somit Unabhängigkeit beziehungsweise Individualität der Personen und so versucht er im Gruppenporträt die „Einzelgeister" zu „umschweißen“. Ihn interessiert also nach wie vor der physiognomische Einzelfall und er nutzt das Gruppenbild, um mehrere Individuen mit ihren differenzierten Verhaltensweisen miteinander zu verknüpfen. Das verbindende Element im Bild kann dabei unter anderem die einheitliche Farbigkeit sein (z. B. in „Die Auswanderer"), oder die gemeinsame Aktivität (z. B. in „Die Freunde“). Wenn er sich zum Ziel setzt dabei zu zeigen wie „Wesen mit Wesen streitet“, so meint er damit vermutlich nicht nur die Gegensätze zwischen den Personen, sondern ebenso die sich hier, wie auch in den Einzelporträts, vielfach in den Mienen spiegelnden kontrastierenden Charakterzüge und Stimmungslagen der einzelnen Menschen. Unverändert bleibt somit auch in den Gruppenbildnissen Kokoschkas Anspruch auf psychische Durchdringung der Modelle vermittels eines intuitiven Wahrnehmungsvermögens. Es ist wichtig festzuhalten, dass Kokoschkas Autarkie herausstellende Darstellungsweise, wie sie beim Tietze-Bildnis und ebenso bei den Freundes-Porträts angewendet wurde, nicht als Ausdruck einer disharmonischen Beziehung zwischen den Personen missverstanden wird. Sie resultiert vielmehr aus Kokoschkas Sicht auf die während der schicksalhaften Jahre vielfach von negativen Erfahrungen geprägten Menschen und aus seinem Wunsch jeden für sich genommen zu erfassen. In den Freundesporträts bringt sie die Vereinsamung nicht nur der versammelten Freunde, sondern auch des ebenfalls ins Bild gesetzten Künstlers zum Ausdruck.

\section{Selbstporträts}

Innerhalb der Porträtgruppe sind auch Kokoschkas Selbstbildnisse anzusiedeln. Das Konterfei des Künstlers ist in vielen seiner expressionistischen Werke zu finden, denn er hat sich über die Jahre kontinuierlich in verschiedenen Techniken und in unterschiedlichen Zusammenhängen selbst ins Bild gesetzt. So hat er sich zusätzlich zur Selbstdarstellung in den Freundesporträts, wie in den entsprechenden Kapiteln bereits ausgeführt wurde, bald als Liebesleidender im Konflikt mit den Frauen gezeigt, wie beispielsweise in der Lithografie „Das Mädchen Li und Ich“, in den Lithografien zu den Dichtungen „Der gefesselte Kolumbus“ (1913) und „Allos Makar“ (1914), sowie zur Bachkantate „O Ewigkeit, Du Donnerwort“ (1914) oder in Fächern und Gemälden gemeinsam mit Alma Mahler (beziehungs- 
weise mit der ihr nachempfundenen Puppe),567 bald auch im Zusammenhang religiöser Thematik als Christus oder Heiliger, z. B. in „Heiliger Sebastian mit Engel“" (1911) oder im Sturmplakat von 1910.568 Die Selbstbildnisse, die allein den Künstler als solchen vor Augen führen, sind dagegen als Selbstbefragung an Wendepunkten seines Lebens entstanden ${ }^{569}$ und dienten nach seiner eigenen Aussage einer Bestandsaufnahme hinsichtlich der eigenen Person. 570

Das Sturmplakat mit dem kahlgeschorenen Künstler, der seine Finger in eine Wunde auf seiner Brust legt, ist neben einem Gipstondo das früheste Selbstporträt Kokoschkas. Der Gestus, der hier im Zusammenhang mit einer sichtbaren Verletzung die Deutung als Ecce Homo oder weitergehend als Schmerzensmann ${ }^{571}$ indiziert, ist offenbar ein bevorzugtes Motiv des Künstlers und daher auch in späteren Selbstbildnissen wiederzufinden. Er entstammt der christlichen Ikonografie und bezieht sich auf die Darstellung Christi, der auf sein Erlösungsopfer hindeutet, indem er auf seine Wunden weist. Wie in den Porträts anderer Personen widmet Kokoschka somit den Händen besondere Aufmerksamkeit als Ausdrucksträger. In dem „Selbstbildnis (Hand auf der Brust)“ (1913; Abb. 70) und dem Wuppertaler „Selbstbildnis“ (1917; Abb. 71) weist er in gleicher Weise - nämlich mit dem Zeigefinger der rechten Hand - auf seine Brust; hier allerdings mit dem Unterschied, dass dort keine Wunde zu sehen ist. Sicherlich deutet sie die durch die Anfertigung des jeweiligen Bildes stattfindende Selbstbefragung des Künstlers an, doch lässt sie sich vor dem Hintergrund der Darstellung im Sturmplakat weitergehend, nämlich im übertragenen Sinne als Hinweis auf verborgene oder innere, seelische Verletzungen lesen.572

In dem 1917 in Dresden entstandenen „Selbstbildnis“ präsentiert sich Kokoschka selbstbewusst im dunklen Anzug, was ihm eine seriöse Erscheinung verleiht und mit darüber gezogenem ockerfarbenen Malerkittel, der deutlich seine Künstlerprofession unterstreicht. Er bildet seinen Oberkörper frontal vor einem dunkelblauen Hintergrund ab und richtet den Blick aus dem Bild heraus direkt auf den Betrachter. Zwar erscheinen die breiten Pinselstriche, mit denen sein Kittel, seine rötlich-braunen Hände und das Konterfei pastos ausgeführt sind, schwungvoll und energisch, doch wirken der ernste, offene Gesichtsausdruck und die im Vergleich zu vorigen Bildnissen reduzierte Farbigkeit vergleichsweise ruhig.

\footnotetext{
567 Vgl. Kapitel 3.2.3.1.

568 Vgl. Kapitel 3.2.3.2.

${ }^{569}$ Natter (2002), S. 164.

570 Vgl. Brief Kokoschkas an Dorothy Miller vom 4. Oktober 1953 (Museum of Modern Art, New York): ,All my self-portraits had been paintes in the sense of stock-taking, in the view of estimating individuality".

571 Würde man die Verletzung als Seitenwunde auffassen, wäre die Bezeichnung als „Schmerzensmann“ präziser, da „Ecce homo“ sich genau genommen auf die Zurschaustellung Christi durch Pilatus vor der Kreuzigung bezieht, während als „Schmerzensmann“ die überzeitliche Darstellung Christi mit den Wundmalen bezeichnet wird.

572 Vgl. Winkler/Erling (1995), S. 75.
} 
Wenngleich sein Porträt ihn einerseits selbstbewusst und respektabel vor Augen führt, so zeigt es ihn andererseits auch ernst und leicht melancholisch. Vor dem biografischen Hintergrund, dass der Künstler erst im Jahr vor Entstehung des Bildes mental und körperlich schwer verwundet aus dem Krieg zurückgekehrt war, lassen sich das traurig umwitterte Gesicht und die (vielleicht gar auf seine Verletzung, den Bajonettstich in die Lunge bezogene) Geste, welche an die Schmerzensmann-Darstellung des Sturmplakats anlehnt, als Hinweise auf seine Kriegserfahrungen deuten. Kokoschka bringt mit diesem Porträt zweierlei zum Ausdruck: seine seelischen und körperlichen Verletzungen - angedeutet durch den Gestus - und zugleich ihre Überwindung durch die Rückbesinnung auf sein Künstlertum, die sich in der selbstbewussten Selbstdarstellung im Malerkittel spiegelt.

Auch in dem „Selbstbildnis“ von 1913 lässt sich der Zeigegestus mit Bezug auf die zu jenem Zeitpunkt aktuelle, Kokoschkas Gefühlswelt durchdringende und zermürbende Beziehung zu Alma Mahler, ebenfalls als Hinweis auf einen innen liegenden Schmerz verstehen. Er ist im Bild mit einem roten Nachtmantel bekleidet, den er der Geliebten geschenkt hatte und schließlich selbst im Atelier trug, weil sie ihn verschmähte. Aus Almas Äußerungen zu dieser Begebenheit lässt sich erahnen, dass die Ablehnung des Geschenks ihn verletzt hat und symptomatisch für ihre schwierige Beziehung gewesen sein dürfte:

„Ich bekam einst einen feuerroten Pyjama geschenkt. Er gefiel mir nicht wegen seiner penetranten Farbe. Kokoschka nahm ibn mir sofort weg und ging von da ab nur noch damit bekleidet in seinem Atelier herum. Er empfing damit die erscbreckten Besucher und stand mehr vor dem Spiegel als vor seiner Staffelei. “573

Der durch die großen, ernst und schüchtern fragenden Augen und den zusammengekniffenen Mund kummervoll und ängstlich erscheinende Gesichtsausdruck wird in diesem Bild aber noch nicht wie im Porträt von 1917 durch eine selbstsichere Selbstpräsentation als Künstler aufgehoben. Kokoschka zeigt sich hier furchtsam und von Zweifeln an der Beziehung gezeichnet.

Kokoschka nutzt die Gattung des Porträts aber nicht nur in dem Bildnis von 1917 zur Selbstpräsentation als Künstler, sondern auch im „Selbstbildnis (mit emporgehaltenem Pinsel)“ (Abb. 72) von 1913, in der ein Jahr später entstandenen Lithografie „Selbstbildnis (Brustbild mit Zeichenstift)“ (Abb. 73) und dem darauf basierenden „Selbstbildnis mit Pinsel“ (1914). Im Gemälde von 1913 ist sein Konterfei in die untere Bildhälfte gerückt, so dass der in grau und grünlich getöntem Schwarz gehaltene Hintergrund dunkel auf seinen Schultern zu lasten scheint. Der im Brustbild und Dreiviertel-Profil gezeigte Künstler trägt hier eine schwarzblaue Jacke und wird schwach von einer rechts außerhalb des Gemäldes befindlichen Lichtquelle beleuchtet. Mit forschender, ernster Miene blickt er aus

${ }^{573}$ Mahler-Werfel (1981), S. 50. 
dem Bild, während er die rechte Hand hebt, um mit einem Pinsel, wie zu denken wäre, an einem nicht im Bild gezeigten Werk zu arbeiten. Diese Darstellung mit Pinsel knüpft an einer ikonografischen und motivischen Tradition an, die den Künstler mit seinen Arbeitsinstrumenten als Attributen seiner beruflichen Tätigkeit vor Augen führt. Nachdem die Künstler in Antike und Mittelalter als Handwerker bewertet und entsprechend kaum für abbildungswürdig gehalten worden waren, sorgte das humanistisch geprägte Interesse am Menschen ebenso wie die Förderung von Künsten und Wissenschaften in der Renaissance letztlich auch für die Aufwertung des Künstlertums. Aus dem neuen Selbstbewusstsein resultierte die Auffassung abbildungswürdig zu sein. Zunächst eingebettet in religiöse Zusammenhänge, dann im 15. Jahrhundert den intellektuellen Anspruch des Künstlers artikulierend, erfolgte Ende des 16. Jahrhunderts die Veranschaulichung eines nobilitierten Künstlertums, was sich in der fortan vielfach präsentierten Selbstdarstellung mit Arbeitsutensilien niederschlug. ${ }^{574}$ Kokoschkas Selbstbildnis steht somit ganz in der Tradition der Malerselbstbildnisse, doch geht sein Porträt über die bloße Darstellung als Künstler hinaus. Die düstere Farbigkeit, die ernsten Mienen und der Eindruck des Aus-dem-Bildraum-Heraussinkens beziehungsweise des den Künstler gleichsam niederdrückenden Schwarz weisen auf die von Krisenstimmung erfasste Psyche Kokoschkas hin. ${ }^{575}$

In gleicher Weise sind auch in der Lithografie „Selbstbildnis (Brustbild mit Zeichenstift)“ (Abb. 73) und dem nahezu identischen Gemälde „Selbstbildnis mit Pinsel“" - beide von 1914 - die traditionelle Selbstdarstellung als Künstler mit der Erforschung der eigenen Psyche verknüpft. Die Kreidelithografie - bevorzugtes grafisches Mittel Kokoschkas - ist das Titelblatt einer Serie von letztlich elf Blättern, die Kokoschka 1914 als Illustrationen zu Bachs Kantate „O Ewigkeit, Du Donnerwort" (BWV 60) gefertigt hat. Das Thema der Kantate ist der Widerstreit der zwei existenziellen Empfindungen Furcht und Hoffnung, die von Altistin und Tenor verkörpert werden. Die gesamte Illustrationsfolge ist deutlich autobiografisch vom Künstler angelegt. Er verarbeitet darin seine schwierige Beziehung zu Alma, weshalb die Grafiken Mann und Frau, die symbolisch eine Lebensreise absolvieren, mit ihrer beider Gesichtern vor Augen führen. ${ }^{576}$ So sagt er selbst rückblickend über Alma und die Entstehungsumstände:

„Sie hat mit neuen Augen meine Arbeit verfolgt, in welcher, wie in einem Spiegel, in den Lithografiefolgen, Der gefesselte Kolumbus" und der Bachkantate, O Ewigkeit, du Donnerwort 'eine Melancholie sich ausbreitet, die, als Bericht über drei Jahre, einem Erlebnis Gestalt verleibt und es damit aus der Sphäre eines alltäglichen Liebesverbältnisses hebt.

574 Calabrese (2006), S. 249; Stadler (1994), S. 596 f.

575 Die diesem Porträt, wie auch dem Gemälde „Selbstbildnis mit Pinsel“ (1914) eigene, düstere Farbigkeit und extreme Hell-Dunkel-Kontrastierung erinnert an Rembrandts im Louvre befindliches Selbstporträt von 1660, in welchem dieser sich in ähnlicher Weise als Maler (in diesem Fall zusätzlich mit Malpalette und vor einer zumindest teilweise gezeigten Leinwand) präsentiert.

576 Vgl. Kap. 3.2.3.1. und Abb. 58. 


\section{(...) Auf dem vorletzten Bild der,Bachkantate' bin ich im Grab, von der eigenen Eifer- sucht erschlagen wie Hyakinthos vom Diskos, den das tückische Schicksal auf ihn zu- rück.gelenk.t hat. (...) Meine Lithografienfolgen werden für mich, vielleicht auch für an- dere, immer im Gegensatz. zu der Kunst des Jugendstils, des Impressionismus und der zeitgenössischen Produktion ein Mythos bleiben, ein gestaltetes Symbol, trächtig mit Be- gegnung, Zeugung und Entrweiung. Nicht nur Eifersucht ließ mich gegen ein Fatum to- ben. Ich hatte die Abnung eines kommendes Verbängnisses. "577}

Eifersüchtig auf die Gesellschaft mit der Alma sich umgab und das Scheitern der Beziehung vorausahnend, vertauscht Kokoschka die in der Kantate vorgesehene Rollenverteilung und zeigt tendenziell den Mann und somit sich selbst als den ängstlichen Part. ${ }^{578}$

So auch in dem Selbstbildnis des Titelblattes. Mit breitem, weichem Strich ist es als Brustbild im Halbprofil ausgeführt. Die großen, aufgerissenen Augen mit den darunterliegenden dunklen Ringen blicken zweifelnd aus dem Bild heraus. Das in Falten gelegte Kinn und die heruntergezogenen Mundwinkel lassen den Künstler unglücklich und verhärmt aussehen. Unruhig wirken die abrupten Linien um seinen Kopf, das spannungsreiche Helldunkel und die nervös bewegten Hände knapp über der unteren Bildkante. In seiner Linken hält er einen Zeichenstift. Wie in allen expressionistischen Bildnissen Kokoschkas sind hier Hände und Gesicht als Ausdrucksträger hervorgehoben und sollen das innere Erleben nach auBen hin sichtbar machen. Das traditionelle Motiv des Künstlers mit Mal- oder Zeichenutensilien ergänzt Kokoschka um emotionale Aufgeladenheit und zeigt sich somit als Künstler und zugleich als empfindsamen Menschen. Als Menschen der leidet, und damit bedient Kokoschka einen seit dem 19. Jahrhundert zunehmend wichtiger werdenden Typus der Selbstcharakterisierung. ${ }^{579}$

Das wohl interessanteste und bedeutendste Selbstporträt seiner expressionistischen Phase ist das großformatige „Selbstbildnis (Der Irrende Ritter)“ (Abb. 74) von 1914/15. Der Künstler liegt als Ritter im Harnisch auf einem dunklen, braunen Felsen vor einer zerklüfteten und vom Sturm verdüsterten Küstenlandschaft. Seine instabile und unnatürlich wirkende, horizontale Lage lassen ihn gleichsam schwebend erscheinen. Seine Hände sind, ziellos nach Halt tastend, seitlich ausgestreckt, der Blick hilfesuchend in den schwarzblau verhangenen Himmel gerichtet. Das rechte Bein des Ritters ist angewinkelt, wodurch der Körper gedreht und dem Betrachter somit frontal vor Augen geführt wird. Rechts im Mittelgrund des Bildes kauert eine weibliche Gestalt, die zumeist mit Alma Mahler in Verbindung gebracht wird. Oberhalb Kokoschkas Brust befinden sich zwei Details, über deren Deutung Uneinigkeit besteht: eine miniaturhafte menschliche Vogelgestalt mit der Schädelform des Künstlers und daneben eine auffällige Wolkenformation, die sich

\footnotetext{
577 Kokoschka (1971), S. 135 f.

578 Döring (1997), S. 94; Wingler (1975), S. 88.

579 Döring (1997), S. 27.
} 
als die Buchstabenkombination „ES“lesen lässt. Die Pinselführung im Gemälde ist sorgfältig angelegt, dabei aber insbesondere in den Partien der Meereslandschaft mit den aufgepeitschten Wogen auch sehr bewegt. Unruhe ergibt sich ebenso durch den irritierenden Schwebezustand und die sich durch linken Fuß, Körper und Kopf quer durchs Bild ziehende Diagonale. Kühle Farben und mangelnde Helligkeit verstärken den bedrohlichen Charakter der Darstellung. Blau, Grün, Schwarz und Braun in verschiedenen Schattierungen prägen die beklemmende Atmosphäre.

Dass es sich bei der Frauenfigur rechts um Alma handeln soll, ist vor dem Hintergrund, dass diese den Künstler im Januar 1915, also im Entstehungszeitraum des Bildes, endgültig verlassen hat, sehr überzeugend. Außerdem ist Winkler zuzustimmen, dass das Gemälde stilistisch und inhaltlich eng verwandt ist mit „Der Windsbraut“ und dem „Stilleben mit Putto“, in denen die Beziehung zu Alma ebenfalls thematisiert ist. ${ }^{580}$ Schwieriger ist, wie gesagt, die eindeutige Entschlüsselung von Wolkenformation und Vogelfigur. Die Buchstaben, die die Wolken links neben der zum Himmel gestreckten Hand des Ritters zu bezeichnen scheinen, sind nicht mit Sicherheit als absichtlich von Kokoschka dorthin gesetzte Zeichen zu verifizieren. Folgt man der seit Edith Hoffmann (1947) häufig propagierten Interpretation derselben als Hinweis auf Christi Wort am Kreuz „Eloi, Eloi, lama sabachthani?" (,,Mein Gott, mein Gott, warum hast du mich verlassen? "; Mt. 27,46), so erhielte der Bildinhalt eine religiöse Note. ${ }^{581}$ Biblische Bezüge sind bei Kokoschka, wie in den anderen Kapiteln bereits deutlich wurde, nicht ungewöhnlich und könnten durchaus auch in diesem Fall zur Unterstreichung der offenbar unglücklichen Lage des Dargestellten eingefügt worden sein. Auch die gleichsam dem Gekreuzigten nachempfundene Haltung wäre ein Hinweis auf diese Lesart.

Problematischer noch erscheint die Deutung des Vogelmenschen direkt daneben. Messer beispielsweise sieht darin einen Engel, der mit den Zügen des Künstlers versehen und bezogen auf den Konflikt mit Alma, die Seele des abgetriebenen gemeinsamen Kindes symbolisiert. ${ }^{582}$ An anderer Stelle wird er, vermutlich mit Bezug auf die Ängste des Künstlers vor dem Hintergrund des Kriegsdienstes, als Personifikation des Todes gelesen. ${ }^{583}$ Beide Deutungen sind nicht gänzlich überzeugend. Für letztere gibt es keine wirklichen Anhaltspunkte, und mit der Darstellung des Kindes im „Stilleben mit Putto und Kaninchen“584(1913/14), in dem wohl zu Recht ein Reflex auf die Abtreibung gesehen wird, ${ }^{585}$ weist das im Ritterbild gezeigte Wesen keinerlei Ähnlichkeit auf. Was bislang jedoch anscheinend übersehen, beziehungsweise nicht zur Interpretation herangezogen wurde, ist die

\footnotetext{
580 Winkler/Erling (1995), S. 69.

${ }^{581}$ Hoffmann (1947), S. 154.

582 Messer (1986), S. 184.

583 Z. B. Schumacher-Haardt (1996), S. 143; Hoffmann (1947), S. 154.

584 Vgl. Kapitel 3.2.3.5. und Abb. 88.

585 Vgl. Winkler/Erling (1995), S. 60.
} 
Tatsache, dass der Vogelmensch mit den Zügen des Künstlers in nahezu identischer Form in der Illustration „Sonne über einem vogelähnlichen Paar“ aus der Lithografie-Serie zu Kokoschkas Gedicht „Allos Makar“" zu finden ist. ${ }^{586}$ Hier sind Alma und der Künstler als Vögel gezeigt, die sich um einen Wurm streiten. Im Gedicht thematisiert Kokoschka, wie so oft, die konfliktreiche Beziehung zur Geliebten mit Gefühlen zwischen Hoffnung und Verzweiflung. Am Ende steht die Fabel vom kämpfenden Vogelpaar und das resignierte Einsehen „Anders ist glücklich“. Kokoschka verwendet nun genau diese vogelhafte Verkörperung seiner selbst im Selbstbildnis als Ritter, um die Trennung von Alma symbolisch ins Bild zu bringen. Es gibt kein (Vogel-)Paar mehr, keine wie im Gedichttitel angedeutete Verwebung von Alma und Oskar, sondern nur noch den einsamen Künstler selbst. Alma hat sich, im Bild, wie auch im Leben von ihm abgewendet. Die Verzweiflung darüber und der daraus resultierende Verlust des (inneren) Gleichgewichts spiegeln sich im „Selbstbildnis (Der irrende Ritter)“ unmissverständlich wider.

Weitere Probleme bereitet das Gemälde wegen seiner nicht eindeutig festzulegenden Datierung. In der zweiten Jahreshälfte 1914 begonnen, wird seine Fertigstellung bald vor Kokoschkas Kriegseinsatz in Holic im Frühjahr 1915 angesiedelt und bald danach. Der eigenartige im Bild gezeigte Schwebezustand wird oftmals auf das Kriegserlebnis des Künstlers bezogen und im Zusammenhang mit der unklaren Datierung divergierend entweder als Vision der späteren Verwundung, die zu Gleichgewichtsstörungen des Künstlers geführt haben soll, gedeutet, oder als deren nachträgliche Verarbeitung. ${ }^{587} \mathrm{Da}$ das Selbstbildnis bereits 1914 angelegt wurde, ist eine Verarbeitung der konkreten Kriegserfahrungen und der Verletzungsfolgen (auch und gerade in visionärer Vorausschau) unwahrscheinlich. Es ist daher Winkler/Erling und Natter Recht zu geben, dass das Porträt vielmehr als „persönliche Allegorie des einsamen und bifflos den Scbicksalsmächten ausgelieferten Künstlers ${ }^{558}$ zu verstehen ist. Schicksalsmächten, denen die Beziehung zu Alma erliegt und die Kokoschka in den Krieg ziehen lassen.

Dass er sich dabei in einer historischen Rüstung darstellt, ist sicherlich nicht absichtslos. Der Künstler selbst nennt das Gemälde in einem Brief an Herwarth Walden vom 27.12.1915 seine ,letzte Arbeit" und betitelt es als „Ritter in Zauberlandschaft".589 Einerseits verweist die Rüstung natürlich auf das kriegerische Unterfangen, das Kokoschka bevorsteht. Andererseits kann man sie mit Bezug auf die Verarbeitung der Trennung von Alma auch als Kennzeichen des minnenden Ritters auffassen. Der Künstler zeigt sich demnach zusätzlich als gescheiterten Minneritter. Insofern ist der beispielsweise von Messer geäußerte Hinweis auf eine

\footnotetext{
586 Vgl. Kapitel 3.2.3.1. und Abb. 46. Rudenstine weist auf die Ähnlichkeit hin, ohne jedoch weiterführende Rückschlüsse für die Interpretation daraus zu ziehen. Vgl. Rudenstine (1976), S. 429.

587 Vgl. dazu Angaben bei Winkler/Erling (1995), S. 69.

588 Winkler/Erling (1995), S. 69; Natter (2002), S. 180.

589 Kokoschka (1984), S. 231.
} 
mögliche Verknüpfung mit Parzival, dem Prototypen des irrenden Ritters, nicht ganz abwegig, ${ }^{590}$ da dieser mittelhochdeutsche Versroman von Richard Wagner in seiner Oper „Parsifal“ (1882 uraufgeführt) verarbeitet wurde und sowohl Alma als auch Kokoschka dessen Musik sehr schätzten. ${ }^{591}$ Führt man alle diese Bedeutungsfacetten zusammen, wird ersichtlich wie vielschichtig das Selbstbildnis Kokoschkas als irrender Ritter tatsächlich ist und dass es sich um eines seiner Schlüsselwerke handelt. Nicht umsonst hat er das auffällig große Format und eine sich von den anderen Porträts durch die Anreicherung mit symbolhaften Details merklich unterscheidende Darstellungsweise gewählt. Auf persönlicher Ebene führt er sich als verlassenen Liebenden vor Augen. Gleichzeitig lässt sich das Bild als Ausdruck seiner Ängste in Anbetracht der Gesamtsituation und auch des bevorstehenden Kriegseinsatzes lesen. Auf einer anderen Ebene verarbeitet er religiöse und literarische Elemente, um die eigene, emotional verzweifelte Lage zum Ausdruck zu bringen.

Letztlich geht es Kokoschka denn auch in diesem Porträt - ebenso wie in den anderen hier besprochenen Bildnissen, die Auftraggeber, Freunde oder den Künstler selbst vor Augen führen - um das Erfassen des Seelenzustandes. Auch sich selbst sucht der Künstler in seinen Selbstbildnissen durch Erforschung der „Gesicbte" zu ergründen, wie er es in seinem Vortrag von 1912 propagiert, um die Veränderungen seines fluktuierenden Seins festzuhalten, „denn man ist nicht Mensch damit, dass man geboren ist. Mensch muß man mit jedem Augenblick von neuem werden. "592

\section{Ergebnis}

In Kokoschkas Einzelporträts, die Auftraggeber, Bekannte oder Freunde zeigen, ist, von der stilistischen Entwicklung einmal abgesehen, eine große Übereinstimmung in Behandlung und Intention festzustellen. Der Bildaufbau ist wie bereits erwähnt wurde, immer ähnlich: die Personen werden zumeist im Bruststück vor einem kaum oder gar nicht ausgestalteten Hintergrund gezeigt. Gesicht und Hände als wichtigste Ausdrucksträger transportieren eine Spannung aus innerer Versunkenheit und verborgener, nervöser Unruhe. Der nach innen gerichtete Blick ist dabei ebenso charakteristisch, wie eine allgemein feststellbare, durch die tendenziell von negativen Emotionen gezeichneten Physiognomien, unruhigen Duktus und düstere oder irritierende Farbigkeit evozierte bedrohliche Wirkung. Die Gestaltung dieser Porträts unterliegt dem Streben das innere Wesen, gleichsam die Psyche des Gegenübers, zu erfassen und im Bild sichtbar zu machen. Die Ausstrahlung der Negativität lässt sich dabei vor dem Hintergrund des Vortrags „Von der Natur der Gesichte" sowohl auf das den meisten Modellen eigene, von der

\footnotetext{
${ }^{590}$ Messer (1986), S. 185.

591 Schon bei ihrer ersten Begegnung hatte Alma dem Künstler Isoldes Liebestod aus Wagners „Tristan und Isolde“ vorgesungen. Vgl. Kokoschka (1971), S. 129.

592 Kokoschka (1971), S. 31.
} 
gesellschaftlich und politisch schwierigen damaligen Lage geprägte, Befinden zurückführen, als auch auf die Stimmung des Künstlers selbst.

In seinen Selbstbildnissen greift Kokoschka oft auf die bestehende Ikonografie zurück und zeigt sich selbst mit Pinsel, mit Freunden oder christomorph. Wie auch in den Einzelporträts anderer Personen tut er dies aber teils in neuer Darstellungsweise und mit neuen Bildmitteln, wie z. B. mit lasierendem Farbauftrag, expressiven Ritzungen und leuchtenden Farbnebeln. Es besteht somit ein Zusammenspiel aus traditioneller Ikonografie und neuer Bildsprache, wie es typisch ist für viele expressionistische Künstlerporträts. ${ }^{593}$ Hervorzuheben ist die Anlehnung an den christomorphen Zeigegestus in zwei der erläuterten Beispiele, den Kokoschka mit persönlichem Leid in Verbindung bringt. ${ }^{594}$ In den Freundschaftsporträts ist ein beunruhigender Eindruck von Vereinsamung gegeben und werden die individuell erfassten Personen nicht wirklich in freundschaftlichem Miteinander vor Augen geführt, sondern nur in einem isolierten Nebeneinander. Einsamkeit ist neben Zweifeln auch in den Selbstporträts des Künstlers einer der dominanten Eindrücke. Diese Bildnisse dienen der Selbstreflexion und spiegeln häufig die biografische Situation Kokoschkas. Somit liegt tatsächlich durchweg allen Bildnistypen bei Kokoschka das Streben zu Grunde die Psyche des Menschen zu ergründen.

Dies steht in engem Zusammenhang mit den Textquellen und besonders mit den im Vortrag „Von der Natur der Gesichte“ enthaltenen theoretischen Ausführungen, in denen Kokoschka seine Auffassung von der Wahrnehmung formuliert und somit grundlegende Hinweise für seine Porträtkunst gibt. Bildkünstlerisches und literarisches Medium unterscheiden sich hinsichtlich der Auseinandersetzung mit dem Menschen massiv vor allem in der Quantität, aber auch in der Qualität, denn wo die Bilder die Personen direkt zu erfassen suchen, sind die Texte allgemein und sind nur indirekt auf die Porträts zu beziehen. Nie fasst er in Worte, was er innerlich oder äußerlich an einem Modell zu erkennen meint und was er in seinen Bildern so eindringlich zum Ausdruck bringt. Und dennoch stimmen die beiden Medien in ihrer Intention, in dem, was sie über die Art und Weise des Künstlers den Menschen wahrzunehmen, verraten, überein und ergänzen einander.

\footnotetext{
593 Schumacher-Haardt (1996), S. 240.

594 Diese Art der Verwendung scheint nicht allzu häufig vorgekommen zu sein. Ein Beispiel jedoch ist allerdings „Selbstbildnis“ von Koloman Moser (um 1916), vgl. Trnek (2004), S. 256.
} 


\subsubsection{Krieg und politische Folgen}

Geschlechterkonflikt, Religion und die Wahrnehmung des Menschen sind, wie gezeigt wurde, in Kokoschkas Frühwerk in großem Umfang thematisiert worden. Daneben hat er allerdings auch Aspekte behandelt, die in nur wenigen Bildern und Schriftwerken ihren Niederschlag gefunden haben, die aber dennoch nicht außer Acht gelassen werden sollten, da sie das Gesamtbild von Kokoschkas expressionistischen Schaffen abrunden. So sind aus der Zeit zwischen 1907 und 1920 im bildkünstlerischen Bereich zusätzlich auch Akte, Landschaften, Kriegsdarstellungen und Allegorien zu finden. Die Untersuchung der Akte und Landschaften muss im Rahmen dieser Arbeit unberücksichtigt bleiben, da die Betrachtung der Doppelbegabung die Leitidee bildet und literarische Vergleichswerke zu diesen Themen fehlen. Dies gilt jedoch nicht für die zwei anderen genannten Sujets.

Die Erfahrungen des Krieges, beziehungsweise seine Vorstellungen davon, und die nachfolgenden politischen Machtkämpfe hat Kokoschka in beiden Medien vergleichsweise wenig verarbeitet, obwohl der Erste Weltkrieg natürlich für alle beteiligten Nationen ein überaus einschneidendes Ereignis gewesen ist, das an keinem spurlos vorbeigehen konnte und zudem prägend war für die gesamte Entwicklung der folgenden Jahre. Zumeist ist bei Kokoschka nur das Mitschwingen der aktuell vorherrschenden, negativen Grundstimmung zu erahnen, wie beispielsweise und vor allem in den Porträts. Einige eindrückliche Beispiele expliziter Kriegsverarbeitung gibt es aber dennoch und diese sollen im Folgenden betrachtet werden.

\section{Zuordnung}

Die überschaubare Menge expressionistischer Darstellungen, die Kokoschkas Auseinandersetzung mit den Schrecken des Krieges und auch mit damit im Zusammenhang stehenden politischen Folgen spiegeln, entstanden in der kurzen Zeitspanne von 1914 bis 1917 . Je nach Entstehungszeit zeigen sie vor dem Krieg ausgeführte, visionäre Kriegsszenen, dokumentieren vom Künstler selbst erlebte Ereignisse aus dem Kriegsalltag, beziehungsweise seine Einsatzorte, oder kommentieren die aus dem Krieg resultierenden Verhältnisse. Es ist auffällig, dass es sich bei den Darstellungen ausnahmslos um Aquarelle, Zeichnungen oder Druckgrafiken handelt, jedoch niemals um großformatige Gemälde. Faktoren, wie die Notwendigkeit Gesehenes schnell ins Bild zu bannen oder die aktuelle Marktlage, dürften dabei eine Rolle gespielt haben. Es mag dies aber sicher auch ein Indiz dafür sein, dass dieses Thema für Kokoschka eher nebensächlich war. Wohl nicht, weil die Erfahrungen des Krieges ihn nicht erschüttert hätten, sondern weil er emotional und künstlerisch andere Schwerpunkte (z. B. bei der Verarbeitung der Liebesmisere und der Erstellung von Porträts) legte. Künstler wie Ludwig Meidner, Max Beckmann und Otto Dix dagegen haben in vielfältiger Weise die negati- 
ven Seiten des Krieges thematisiert. ${ }^{595}$ Meidner hat dafür insbesondere in seinen apokalyptischen Landschaften und pathosschwangeren Äußerungen Ausdruck gefunden.

Auch in Kokoschkas Texten sind Spiegelungen seiner Kriegserfahrungen und Äußerungen über die politischen Umstände rar. Hinweise darauf sind allerdings in Kokoschkas Drama „Orpheus und Eurydike“ zu finden, welches er während seiner Lazarettzeit in Brünn im Herbst und Winter 1915 ersonnen hat. Anhaltspunkte zu seiner Einstellung gegenüber den politischen Machtkämpfen, die nach den Wirren des Ersten Weltkrieges in die Novemberrevolution 1918 mündeten, gibt sein anlässlich des Kapp-Putsches im März 1920 publizierter Appell „An die Einwohnerschaft Dresdens“.

\section{Visionäre Kriegsdarstellungen}

Am 28. Juli 1914 erklärte Österreich-Ungarn Serbien den Krieg, nachdem serbische Terroristen den österreichischen Thronfolger Franz Ferdinand in Sarajevo ermordet hatten. Damit wurde eine Reihe von Staaten-Bündnissen aktiviert und aus dem Konflikt zwischen ursprünglich zwei Staaten erwuchs der Erste Weltkrieg. Deutschland als Verbündeter Österreich-Ungarns sah darin die Möglichkeit nicht nur außenpolitische Interessen zu verfolgen, sondern auch die stetig schwelenden innenpolitischen Konflikte und sozialen Spannungen gewaltsam zu einer Lösung zu führen. Die Chance zur internen Umwälzung beflügelte große Teile der deutschen Bevölkerung zu überbordender Kriegseuphorie: ,Als am 1. August 1914 die Mobilmachungsorder verkïndet wurde, waren in Deutschland Millionen von Menschen auf der Straße, jubelnd, singend, voller Begeisterung. "596 Obwohl sie sich damit in eine Reihe mit den von ihnen so vehement kritisierten Anhängern des Imperialismus und Militarismus stellten, schlossen sich zu Beginn des Ersten Weltkrieges weite Teile der gegen Preußentum und ,alte“ Ordnung rebellierenden Künstler und Literaten der allgemeinen Kriegsbegeisterung an. Nur Wenige lehnten den Krieg von Anfang an ab. Pfemferts „Aktion“ ist eines der raren Beispiele konsequenter Kriegsverneinung. ${ }^{597}$ Erst die Erfahrung des Krieges selbst öffnete den Kriegswilligen die Augen.

Kokoschkas anfängliche Haltung dazu ist nicht eindeutig zu fassen, weshalb unterschiedliche Meinungen darüber bestehen, wie bereitwillig er den Kriegsdienst angetreten hat. Einerseits schrieb er im September des Jahres an den Verleger Kurt Wolff, er wolle sich ,freiwillig zum Heer stellen, weil es eine ewige Schande sein wird, $z^{\prime}$ Hause gesessen $₹ u$ haben '598, andererseits war es nach den Erinnerungen Anna Mahlers (Almas Schwester) ihre Mutter, die „Kokoschka so lange einen Feigling ge-

\footnotetext{
595 Mehr zu künstlerischen Kriegsdarstellungen s. z. B. Jürgens-Kirchhoff (1993) und Maas (1965). 596 Jürgens-Kirchhoff (1993), S. 27.

597 Jürgens-Kirchhoff (1993), S. 366, Anm. 48.

598 Kokoschka (1984), Bd.1, S. 183.
} 
nannt" hatte, „bis er sich schließlich freiwillig zum Kriegsdienst gemeldet hat".599 Der Künstler selbst erinnert sich jedenfalls in einer Weise an den Kriegsbeginn, die eine grundsätzliche Tendenz zur Ablehnung erkennen lässt:

„Als ich am 28. Juli 1914 durchs offene Fenster (...) eine Extraausgabe ,Österreich bat Serbien den Krieg erklärt" ausrufen hörte, schloß ich schnell das Fenster, saß nieder auf dem Bettrand und dachte ,Tu felix Austria nube! Nun geht alles in Scherben (...)! $: 600$

Er bezieht sich dabei auf ein in Österreich bekanntes Distichon von einem unidentifizierten Autor, das die Geschicklichkeit der Habsburger ihre Herrschaftsbereiche durch Heiraten, statt durch Kriege zu erweitern, meint. Der vollständige Wortlaut lautet: „Bella gerant alii, tu felix Austria nube. Nam quae Mars aliis, dat tibi diva Venus. (Kriege führen mögen andere, du, glückliches Österreich, heirate. Denn was Mars (den) anderen (verschafft), gibt dir die göttliche Venus)".001 Diese Verse, die auf die Neigung Österreichs anspielen, seine staatlichen Interessen durch eine geschickte Heiratspolitik statt durch kriegerische Auseinandersetzungen zu verfolgen, lassen erkennen, dass Kokoschka sein Land für besser beraten hielt, wenn es diesen Krieg vermieden hätte.

Ähnliches drückt sich denn auch in den ersten den Krieg reflektierenden Bildern aus, die Kokoschka bereits in den Wochen nach der Kriegserklärung auf den für Almas Geburtstag gefertigten fünften Fächer (Abb. 75) malte. In Deckfarben und Tusche führt er in drei Bildfeldern apokalyptisch anmutende Szenen vor Augen. Im Mittelfeld zeigt Kokoschka sich selbst als Ritter zu Pferde, der ein Ungeheuer mit drei Vorderkörpern mit einer Lanze angreift. Eine ihm zugewandte Frauenfigur in hellem Flammenschein, die ein Lamm als Friedenssymbol auf dem Arm trägt, steht mit besänftigender Geste zwischen ihnen. Sie lässt sich als Figuration Almas deuten. ${ }^{602}$ Wie der Heilige Georg den Drachen tötet, um die vom Volk zur Opferung bestimmte, jungfräuliche Königstochter zu retten, versucht Kokoschka Alma hier dem dreiköpfigen Wesen zu entringen. Ob die drei Gesichter tatsächlich Porträts sein sollen und Nebenbuhler des Künstlers um Almas Gunst darstellen, wie Spielmann und Strobl/Weidinger meinen, ${ }^{603}$ ist ungewiss, jedoch kann man sie vor dem biografischen Hintergrund sicherlich als Vertreter einer Gesellschaft ansehen, welcher Kokoschka seine Geliebte zu entreißen suchte. Alma selbst aber war nicht bereit, ihre gesellschaftlichen Beziehungen aufzugeben und wird daher auf dem Fächer gezeigt, wie sie dem Ritter Einhalt zu gebieten sucht.

\footnotetext{
599 Anna Mahler, zitiert nach Husslein-Arco (2008), S. 250.

${ }^{600}$ Kokoschka (1971), S. 139.

${ }^{601}$ Büchmann (1981), S. 285. Zu Mars und Venus s. Roscher Bd. 2,2 (1978), Sp. 2420 ff. und Bd. 6 (1978), Sp. 183 ff.

602 Vgl. Spielmann (1988), S. 85 ff.; Strobl/Weidinger (1994), S. 44.

${ }^{603}$ Spielmann (1988), S. $91 \mathrm{f}$.
} 
Den direkten Bezug nun zum Kriegsgeschehen stellen die beiden flankierenden Bildfelder her. Auf der linken Seite ist eine friedliche Landschaft gezeigt. Im Vordergrund arbeiten Frauen auf dem Feld und im Hintergrund tanzen mehrere Personen unter einem Baum, während daneben ein Zug zu sehen ist, der eine Brücke überquert. Die beschauliche Stimmung trügt. Die Frauen sind hier allein, die Männer offenbar in den Krieg gezogen. Zudem wird die Szene von einer düsteren Himmelserscheinung rechts oben überschattet, die drohendes Unheil ankündigt. Die Erfüllung dieses Vorzeichens führt der rechte Seitenteil vor Augen. Hier herrschen in einer zerschossenen Landschaft mit brennendem Haus und toten Bäumen Tumult und Kampf. Ganz vorne liegt ein Soldat am Boden, während im Mittelgrund links zwei Soldaten mit einer Kanone auf ein Reiterregiment feuern, welches in wilder Flucht davon reitet, und rechts zwei Männer mit Bajonetten gegeneinander kämpfen, die durch ihre unterschiedlichen Uniformen als Vertreter Russlands und Österreichs erkennbar sind. ${ }^{604}$ Als Kokoschka seiner Geliebten am 31. August 1914 diesen Fächer zum Geburtstag überreichte, hatte der Krieg gerade erst begonnen und er selbst noch keinerlei eigene Kriegserfahrungen gemacht. Die im Fächer verarbeiteten Szenen sind daher rein fiktiv und nehmen visionär die Gräuel der nächsten Jahre vorweg. Die Darstellungsweise verherrlicht den Krieg in keiner Weise, sondern zeigt ihn düster und gleichsam apokalyptisch. Ein kriegsbegeisterter Künstler würde das Thema sicherlich anders ins Bild gesetzt haben. Insofern scheint die Annahme berechtigt, dass Kokoschka dem Krieg zu diesem Zeitpunkt tatsächlich ablehnend gegenüber stand, auch wenn Verlustgefühle um Alma einen Teil der negativen Stimmung bedingten. Wenn der Künstler in Briefen an die Verleger Reinhard Piper oder Kurt Wolff also schreibt, er wolle am Krieg teilnehmen, so steht dies eher im Zusammenhang mit finanziellen Nöten und einem geschäftlichen Ansinnen. In seinem Schreiben an Piper vom 1. August 1914 beispielsweise, in welchem er ein Mappenwerk mit Kriegsdarstellungen anbietet, klingt dies deutlich an:
„Ich würde mir vom Ministerium (...) die Möglichkeit verschaffen, auf dem Kriegs- schauplatz zu arbeiten. Ich schlage Ihnen ein größeres vom UmdruckLithografiertes Werk vor (...). Da ich nicht mehr weiß, wie ich meine Angehörigen weiter unterstützen soll (...), wäre ich glücklich, wenn Sie meinen Wunsch erfüllen wollten. "605

Dass Kokoschka das Kriegsgeschehen und den Kampf um Alma im Fächer zusammenführt, mag daran liegen, dass der Weltkrieg für ihn „sein persönlicher Krieg“ war, wie Spielmann es ausdrückt: ,in ihn zog er nicht aus patriotischer Begeisterung, sondern deshalb, weil er, in Erkenntnis der unvermeidlichen Trennung von Alma Mabler, sich im Krieg aufgab" "606 So schreibt Kokoschka denn auch ungefähr einen Monat, bevor er ihr den Fächer schenkte, an die Geliebte:

\footnotetext{
${ }^{604}$ Vgl. Spielmann (1988), S. 85.

${ }^{605}$ Kokoschka (1984), Bd. 1, S. 178 f.

${ }^{606}$ Spielmann (1988), S. 85.
} 
„Die vielen Bestien zu züchtigen, die dich jetzt auf ibre Seite gezogen haben, kann ich leider erst, bis ich als todesbereiter Künstler gezeigt habe (mir), dass ich meines Gleichen nicht finde um eine wirkliche Gefahr und das Fürchten kennen zu lernen. "

Seine Bereitschaft in den Krieg zu ziehen, schwingt in diesen Worten mit und ist ganz wie in den Fächerdarstellungen mit der Vorstellung verknüpft, dass er Alma kämpferisch von sie umgebenden „Bestien“befreien müsse. Kokoschkas Verhältnis zum Krieg ist, wie bei anderen Themen, sehr persönlich gefärbt und wieder einmal auch mit dem Geschlechter- beziehungsweise konkreten Liebeskonflikt verbunden, der ganz offensichtlich auf jeden Bereich seines expressionistischen Schaffens ausstrahlte. Anders als für so viele andere Künstler und Intellektuelle der Zeit, ist in diesen noch fiktiven Bildern der Krieg negativ konnotiert.

Letzteres lässt sich auch bei Betrachtung des sechsten Fächers ${ }^{608}$ (Abb. 76) feststellen, der Ende 1914 entstanden ist. In mehreren dicht verzahnten Abschnitten werden eine einsame Mutter mit ihren Kindern in einer verwüsteten Landschaft, brennende Häuser, eine Schlachtszene mit Kanonenfeuer, marschierenden Soldaten sowie reitenden Kämpfern und auf einem Gräberfeld trauernde Frauen vor Augen geführt. Knochen und Totenschädel am Boden des linken und des rechten Bildfeldes und die Figur eines mit einem Bajonett niedergestreckten Soldaten unterstreichen zusätzliche die verzweifelte Todesstimmung, die der Fächer transportieren soll. Wie im fünften Fächer sind auch diese Szenen Imaginationen des Künstlers vom Krieg, ohne dass er bis dato in der Schlacht gewesen wäre. Sie dürften seine negativ geprägten Vorstellungen davon ebenso widerspiegeln wie seine Ängste, die teils mit Alma, seinen Geldsorgen und seinem eigenen bevorstehenden Kriegsdienst - also mit seiner persönlichen Situation -, teils mit der allgemeinen politischen Lage zusammenhingen. Wie entwickelte sich nun seine Einstellung mit dem konkreten Kriegserleben weiter?

\section{Dokumentation eigener Kriegserlebnisse}

Am 3. Januar 1915 wurde Kokoschka in Wien einberufen. Durch die Vermittlung von Adolf Loos kam er in das Dragonerregiment Nr. 15. Aus dem Verkaufserlös für die „Windsbraut“ finanzierte er sich das nötige Pferd und die vorgeschriebene, standesgemäße Uniform. Er musste in der Kaserne der Wiener Neustadt zunächst die Ausbildung zum Kavalleristen absolvieren. In seinen Briefen - besonders an Alma Mahler schrieb er sehr regelmäßig - beschreibt er den Kasernenalltag. Es wird daraus ersichtlich, dass er diesen wie eine Gefangenschaft empfand, sich isoliert und schikaniert fühlte und seinem Dienst dort nichts Positives abgewinnen konnte. So meldete er sich denn im April (eben wohl auch wegen der absehbaren Trennung von Alma) zum Einsatz und wurde im Sommer des Jahres an der Ostfront eingesetzt, was aber keinen künstlerischen Niederschlag fand. Er erlitt Ende 
August schwere Verwundungen des Kopfes und der Lunge, die er bis Anfang 1916 in Brünn kurieren musste. Mitte Juli 1916 dann begleitete er eine Gruppe von Journalisten und Malern nach Laibach, um sie dort dem Armeeregiment zu übergeben. Nach Abschluss dieses Auftrages meldete er sich aber nicht wieder in Wien zurück, sondern schloss sich einem Honvedregiment an. Als Kriegszeichner an der Isonzofront bewegte er sich dort an der neun Kilometer langen Frontlinie zwischen Idria und Tolmein. Hier entstanden einige Farbzeichnungen, die den Soldatenalltag, Stellungen und Orte dokumentieren. ${ }^{609}$

„Maschinengewehrstellung auf Cote 588 bei Selo“ (1916; Abb. 77) zeigt in nüchterner Weise einen gleichsam zufällig wirkenden Landschaftsausschnitt. Zwischen einigen Bäumen liegt rechts im Mittelgrund die Ruine eines Hauses, dahinter schirmen Berge das Tal gen Horizont ab. In der linken Bildhälfte sind mehrere Schutzvorrichtungen zu sehen, hinter denen die Soldaten Deckung suchen und die Maschinengewehre positionieren können. Doch die Lage im Bild erscheint ruhig. Die zwei gezeigten Soldaten gehen ohne Hektik ihrer Tätigkeit nach, der blaue Himmel erscheint heiter und es gibt keinerlei Anzeichen für kämpferische Handlungen. Die mit Aquarell und Kreide ausgeführte Zeichnung schimmert in satten Farben. Das viel verwendete Grün zeugt von üppiger Vegetation und rotorangene Töne rings um die Ruine lassen an Sonnenstrahlen denken. Dass der friedliche Schein trügt, wird nur durch die ernste Miene des Soldaten vorne links und die Tatsache, dass das Haus wohl während kriegerischer Auseinandersetzungen zerstört worden ist, ersichtlich. Wie Husslein-Arco anmerkt, ist in den Zeichnungen, die zu dieser Zeit entstehen (etwa zwei Monate), eine stilistische Entwicklung hin zu gerundeten und weg von aggressiv-eckigen Formen festzustellen, was sich bald auch in den Gemälden niederschlagen sollte. ${ }^{610}$ Die genaue Ortsbezeichnung, die in der rechten unteren Bildecke zu lesen ist, gibt dem Bild seinen dokumentarischen Charakter. Es hält den von Kokoschka wahrgenommenen Kriegsalltag fest. Wie weit der Künstler hier tatsächlichen Kriegsbericht mit freier komponierten Szenen verquickte, ist nicht zu entscheiden. Festzuhalten bleibt aber die Tatsache, dass diese Darstellungsweise Kokoschkas Bemühen spiegelt, die Bilder als neutraler Beobachter anzufertigen. Diese geradezu emotionslose, nüchterne Darstellungsweise ist auch den anderen an der Isonzofront entstandenen Zeichnungen eigen. Viele sind mit einer genauen Ortsangabe versehen, zeigen Waffen, Soldaten und Baracken, doch sie alle sparen die Schrecken des Krieges aus. Selbst jene, die Momente aktiver Zerstörung zeigen, wie „Feuernde Batterie“ (Abb. 78) oder „Kirche Selo während der Beschießung“ (Isonzo-Front), wirken undramatisch und lassen kritischen Ausdruckswillen vermissen. So zeigt „Feuernde Batterie" zwar eine Feuer und Qualm ausstoßende Kanone in Aktion, umgeben von skizzenhaft angedeuteten Soldaten in blauen Uniformen, inmitten einer bewalde-

\footnotetext{
${ }^{609}$ Vgl. Spielmann (2003), S. 159 f.; Kokoschka (1984), Bd.1, S. 190 ff.; Husslein-Arco (2008), S. 250 ff.; Spielmann (1992), S. 179 (Nr. 67), Strobl/Weidinger (1994), S. 46 f. ${ }^{610}$ Husslein-Arco (2008), S. 254.
} 
ten Landschaft, aber die zerstörerischen Folgen in den Reihen des Feindes werden nicht vor Augen geführt. Tote, Verwundete und apokalyptisch anmutende Szenen, wie sie Kokoschka visionär auf die Fächer gebracht hatte, sind hier nicht zu finden. Ein Anflug von Tristesse lässt sich höchstens einmal erahnen, so wie in der Kreidezeichnung „Projektionsgewehr in eingedeckter Stellung“ (Abb. 79), die in Brauntönen den dunklen Innenraum einer Hütte zeigt. Rechts befindet sich das bezeichnete Gewehr in einer Halterung und ist schussbereit durch eine Fensteröffnung nach draußen gerichtet. Links steht ein verhärmter Soldat in Uniform und Mantel mit besorgtem Blick und hängenden Schultern. Insgesamt betrachtet sind diese direkt im Krieg entstandenen Bilder, in denen der Künstler hautnah mit den Geschehnissen in der Kampfzone konfrontiert war, frei von jeglicher Wertung. Aus ihnen ist kein Urteil Kokoschkas über seine Kriegserfahrungen ablesbar. Als Kriegszeichner war es seine Aufgabe, objektive Kriegsberichterstattung zu leisten und eigene Emotionen auszusparen. Er fasste diese Zeichnungen schlicht als eine „Pflicht" auf (,....) ich habe schon zwei Blocks voll Zeichnungen, Pflicht ziemlich erfüllt (...) ‘'611) und nicht als persönlichen Ausdruck. Daher stehen die im Sommer 1916 gefertigten Blätter in keinem Verhältnis zu dem davon abweichenden Charakter der Fächerszenen.

Kriegs- und Gesellschaftskritik

Von ganz anderer Art, mit deutlich kritischer Intention dagegen ist ein Konvolut von Zeichnungen, die Kokoschka 1917 veröffentlichen wollte. Im März dieses Jahres fragte er bei Leo Kerstenberg, dem zuständigen Mitarbeiter der Galerie Cassirer, wegen Kupferplatten an, die er für die Erstellung einer Kriegsmappe verwenden wollte: „Ich bätte ungefähr 30 Skizien zu einer Kriegsmappe (nach meinem Sinn) bier, die ich noch nicht fertig machen will, weil ich über die Technik. der Ausfïbrung unscblïssig bin."612 Die Mappe ist nie publiziert worden und eine Zusammenstellung der betreffenden Skizzen fehlt in der Sekundärliteratur leider bislang. Doch lässt sich aus der Betrachtung mehrerer einzelner, für diese Mappe bestimmter Blätter ersehen, dass sie ganz anders als die Farbzeichnungen des Vorjahres Kokoschkas persönliche Auseinandersetzung in politisch motivierten, sowohl gesellschafts-, als auch kriegskritischen Darstellungen widerspiegeln.

„Soldaten einander mit Kruzifixen bekämpfend“ (1917; Abb. 80) ist eines dieser Skizzenblätter und mutmaßlich eines der ersten, die für die geplante Mappe angefertigt wurden. ${ }^{613}$ Mit blauer Kreide in breiten, weich aufgetragenen Linien führt das Blatt dem Betrachter zwei Männer vor Augen, die jeder mit einem Kruzifix als Waffe gegeneinander kämpfen. Die Gestalt rechts trägt einen Uniformmantel, einen Säbel und einen Helm mit einem Kreuz auf der Vorderseite. Anhand dieses Helmes, dem sogenannten „Tschako“, der im Ersten Weltkrieg zu-

${ }^{611}$ Kokoschka (1984), Bd. 1, S. 244.

${ }^{612}$ Brief an Leo Kerstenberg vom 31.3.1917, s. Kokoschka (1984), Bd. 1, S. 265.

613 Weidinger in: Schmidt (1996), S. 168. 
meist durch die Pickelhaube ersetzt und nur noch in wenigen militärischen Bereichen getragen wurde, lässt sich der Soldat dem preußischen Landsturm zuordnen. ${ }^{614}$ Energisch bedrängt er den anderen Soldaten mit seinem Kruzifix, während dieser von der Last seines eigenen Kreuzes gebeugt, mit seiner rechten Hand eine Pistole auf den Feind richtet. Die beiden an den Kreuzen befestigten Christusfiguren nehmen sich mit ihren nur skizzenhaft ausgeführten, fratzenhaften Gesichtern wie Vogelscheuchen aus. Ihre groteske Erscheinung scheint die Unsinnigkeit der gezeigten Handlung zu unterstreichen und ein bedrohlich darüber schwebendes Tier, das wie ein Flugsaurier anmutet, verweist zugleich offenbar auf das Ungeheuerliche des Geschehens. Die Bewegtheit des Kampfes wird durch schnell ausgeführte, expressive Linien und Schraffuren vermittelt. Die skizzenhafte, die Formen kursorisch umschreibende und auf Details verzichtende Ausführung lässt manche Partien, wie Kopf und Oberkörper des linken Mannes, nur undeutlich erkennen. Kokoschka führt beide Seiten mit Kruzifixen kämpfend vor Augen und verleiht mit dieser absurden Darstellung dem Geschehen insgesamt einen satirischen Charakter, der das Lächerliche der kriegerischen Auseinandersetzungen andeutet. Spielerisch setzt er mit den als Waffen genutzten Kruzifixen wortwörtlich das um, was dem Landwehrkreuz auf dem Tschako üblicherweise als Umschrift beigegeben war: „Mit Gott für Fürst und Vaterland“. Beide Gegner werden hier negativ gezeichnet und so bringt Kokoschka nicht ohne bissigen Humor zum Ausdruck, dass er das Verhalten beider Kriegsparteien für gleichermaßen unsinnig hält. Insgesamt wird in dieser Zeichnung der Krieg polemisch behandelt und kritisiert. Dementsprechend sollte sie ursprünglich auch als Flugblatt gegen den Krieg verwendet werden. ${ }^{615}$

Andere Skizzen für die Kriegsmappe zeugen ebenfalls von Kokoschkas ablehnender Haltung gegenüber dem Krieg, wie zum Beispiel die mit roter Kreide ausgeführte Zeichnung mit dem Titel „Toter Soldat auf dem Schlachtfeld“ (1917; Abb. 81), die einen auf dem Schlachtfeld liegenden, nackten Mann zeigt. Ein Hund oder Wolf - ein bei Kokoschka auch im anderen Zusammenhang negativ konnotiertes Tier 616 - springt über ihn hinweg, einer untergehenden Sonne entgegen. Offenbar als Sinnbild des todbringenden Krieges oder des Todes selbst, jagt das Tier vorüber und gemahnt damit an die traurigen Folgen der Kämpfe. ${ }^{617}$ Es existiert auch ein Blatt, das in der Sekundärliteratur den Titel „Orpheus auf dem

\footnotetext{
${ }^{614}$ Der „Tschako“ ist anhand des weißen Kreuzes identifizierbar, dem sogenannten „Landwehrkreuz", das als Abzeichen in allen deutschen Armeen für die Landwehr üblich war. Im Laufe des 19. Jahrhunderts wurde der Tschako durch die Pickelhaube ersetzt, beim preußischen Landsturm - einer Art Reservearmee - allerdings beibehalten. Mehr dazu s. z. B. Laurent Mirouze: „Infanteristen des Ersten Weltkrieges" (1996). Großer Dank gebührt an dieser Stelle der Historikerin Stefanie Buchhold für Ihre Hilfestellung bei der Identifizierung des Helmes und für die weitergehenden Hinweise zum geschichtlichen Hintergrund.

${ }^{615}$ Fischer (1996), S. 73.

${ }^{616} \mathrm{Vgl.}$ z. B. Abb. 57 und Abb. 89.

${ }^{617}$ Vgl. Husslein-Arco (2008), S. 260; Strobl/Weidinger (1994), S. 51.
} 
Leichenfeld“618 (Abb. 82) trägt und vor Augen führt, wie der besagte mythische Sänger mutmaßlich über ein Schlachtfeld läuft. Am Boden liegen zwei Menschen, die laut dieses Titels als Tote beziehungsweise Verletzte zu identifizieren sind. ${ }^{619}$ Es ist nicht sicher, ob diese Kreidezeichnung als Illustration für das Drama „Orpheus und Eurydike" oder für die Kriegsmappe gedacht war - stilistisch steht sie „Soldaten, einander mit Kruzifixen bekämpfend“ jedenfalls sehr nahe. ${ }^{620}$ Mit Bezug auf die mythologische Überlieferung, der zufolge das Lyra-Spiel des Orpheus wilde Tiere friedlich vereinte und seine Feinde bezwang, ${ }^{621}$ mag die Darstellung in bitterer Satire den Wunsch nach einem Ende des Krieges zum Ausdruck bringen.

Die Skizze steht eindeutig im inhaltlichen Zusammenhang mit Kokoschkas 1915 während der Genesungszeit in Brünn, angeblich in Fieberträumen begonnenen Drama „Orpheus und Eurydike“622. Dieses Stück ist stark autobiografisch geprägt und verarbeitet, in das mythologische Thema eingebettet und es variierend, Kokoschkas Trennung von Alma, seine Erfahrung des Krieges und die Auseinandersetzung mit dem Tod. ${ }^{623}$ Aufgrund seines stark allegorischen Gehalts, soll die genauere Untersuchung des Dramas im Kapitel 3.2.3.5. erfolgen. An dieser Stelle genügt ein Blick auf den dritten Akt. Orpheus kehrt darin zu Beginn zu seinem Haus zurück, welches im ersten Akt zunächst als Ort des friedlichen und liebevollen Miteinanders mit Eurydike dargestellt worden war. ${ }^{624}$ Er hat Eurydike inzwischen an Hades verloren und beginnt nun verzweifelt und in Todesverlangen sein Grab zu schaufeln. Das Haus ist nunmehr eine Ruine und Orpheus selbst ist so sehr mit sich beschäftigt, dass er es zuerst nicht als das seine erkennt:

„Orpheus, zerlumpt, mit abgehärmten, abgefallenen Zügen, kommt mit einer Schaufel auf dem Rücken und beginnt ein Loch zu graben. Über seinem Haupte schwebt ein Teil des stehengebliebenen Mauergewölbes. Es droht zu verfallen, Schlingpflanzen überziehen es, die die Ruine bald dem Erdboden und seiner Vegetation gleichmachen werden. (...) er legt die Herdstelle des Hauses bloß, nimmt eine Handvoll Asche daraus, die er wiegt. Ein Sparren fällt, so dass er hinaufsieht. Orpheus erkennt plöt:lich das Haus als seines. Orpheus schreit ,In diesem Hause wohnt' ich? Verfluchter Balken, der mich nicht erschlagen!"

${ }^{618}$ S. Strobl/Weidinger (1994) und Fischer (1996).

${ }^{619}$ Fischer (1996), S. 73; Strobl/Weidinger (1994), Abb. 218. Diese Identifizierung ist nicht eindeutig $\mathrm{zu}$ verifizieren, die Figuren könnten auch friedlich schlafen.

${ }^{620} \mathrm{Strobl} /$ Weidinger (1994), S. 50.

${ }^{621} \mathrm{Vgl}$. Kap. 3.2.3.5.

${ }^{622}$ Textnachweis, Text XXIX.

${ }^{623} \mathrm{Vgl}$. Schvey (1982), S. 89; Asendorf (1991), S. 24.

${ }^{624}$ Orpheus ist als mythologische Figur in zweierlei Weise besonders bekannt: einerseits durch die Legende, in der er Eurydike aus dem Totenreich herausführt, ohne sich zu ihr umblicken zu dürfen, andererseits durch sein Mensch und Tier betörendes Lyraspiel. Vgl. dazu Roscher (1978), Bd. 3.1, Sp. 1113 ff. (Orpheus als Sänger) und Sp. 1157 ff. (Orpheus und Eurydike; zum Inhalt besonders Sp. 1160 ff.). 
So klagend findet er im Schutt schließlich auch seine Lyra, die nun zerbrochen ist, und spielt darauf. Offensichtlich davon angelockt, nähern sich nach und nach Landleute, Betrunkene und Soldaten. Das Auftreten der Soldaten lässt bereits den Bezug zum Ersten Weltkrieg erahnen und verweist implizit auch auf die Zerstörung des Hauses im Kriegsgeschehen. Schvey legt nicht zu Unrecht nahe, den Gegensatz von idyllischem und vernichtetem Heim auf eigenes Erleben des Künstlers zu beziehen. So hatte Kokoschka 1913 mit Alma in der Nähe Tre Crocis eine für ihn unvergesslich schöne Zeit verbracht und denselben Ort im Ersten Weltkrieg dann jedoch zerbombt wieder vorgefunden. ${ }^{625}$ Durch das Spiel auf der zerbrochenen, mißklingenden Lyra und seine aus Liebeskummer gehaltene Hetzrede heizt Orpheus die Landleute zu Haß, Gewalt und Zerstörungswut an. Kokoschka kehrt damit die antike Sagengestalt und die Wirkung ihres Musizierens ins Negative um: statt durch ihre Musik Menschen und Tiere zum Frieden anzustiften, säht sie hier gegenteilige Gefühle. So ruft denn, während die Meute hysterisch tobend das Haus verwüstet und Feuer legt, eine Betrunkene aus: „Hört! Die Musik! Dem Seufzer antwortet die Zwietracht! Der Leyer der Liebe Pfeifen und Trompete des Aufrubrs, des Kriegs!" Hieraus allein würde sich schon die kriegskritische Intention herauslesen lassen, der Krieg als ein sinnloses Wüten und als Auslöser verachtenswürdiger menschlicher Verhaltensweisen gedeutet werden können. Das anschlieBende Auftreten der Soldaten unterstreicht dies allerdings noch einmal deutlich und steigert das Geschehen zu einer wilden Orgie aus Sex und Gewalt, an deren Ende Orpheus vom Mob an der Brandstätte erhängt wird. ${ }^{626}$ So lässt das Erscheinen der Soldaten zuerst für einen kurzen Moment auf eine Beruhigung der Situation hoffen. Wie in der von Kokoschka erlebten Kriegsrealität wird die Erwartung geschürt, dass sie dem ausufernden, unmoralischen Treiben Einhalt gebieten und für Ordnung sorgen würden, indem die Landleute innehaltend brav ihre Hüte ziehen und den Soldaten erklären, dass nur ein wenig Aufregung herrsche. Doch die Soldaten beteiligen sich nur in ebenso unkontrollierter Emotionalität an dem Tumult. Der erste Krieger ruft: „Ihr sollt nur sehen, wie Ordnung wird. Ich bin der Berühmteste, ich habe das meiste Blut vergossen. Gebt mir Plat:!" und beginnt sich mit Frauen wegen einer Dirne zu prügeln. In Anbetracht seines anschließenden Handelns wirkt sein stolzer Ausruf zuvor lächerlich. Er sorgt eben nicht für Ordnung, er brüstet sich mit einer Berühmtheit, die er durch Brutalität erlangt hat und beschwört damit das einfache darwinistische Gesetz von der Durchsetzungskraft des Stärkeren. Er frönt der Gewalt und Lust in ebenso liederlicher Weise wie alle anderen auch.

\footnotetext{
${ }^{625}$ Schvey (1982), S. 93.

${ }^{626}$ Mit diesem Ende Orpheus' lehnt Kokoschka erneut an den Mythos an. Dort sind es die Mänaden, die „rasenden Weiber“ aus dem ausschweifend lebenden Gefolge des Bacchus, die den Sänger in Wut über seine Ablehnung gegenüber Frauen zerreißen (Vgl. Fink (2005), S. 260). Analog dazu findet Orpheus bei Kokoschka seinen Tod durch einen orgiastischen Mob.
} 
Kokoschka wendet sich mit dieser Schilderung gegen die Idealisierungen von Krieg und Soldatenstand und stellt beides überaus kritisch dar. So verwirft die Betrunkene Glanz und Glorie des Soldatentums, indem sie spricht:

„Wozu dies Bedenken! Die sahen erst wie gold'ne Widder aus; doch auf die Nieren geprüft, was sie erzengen mögen? Nichts! Nachdem sie die blumigen Fluren zerstampft! Nur Hämmel! Ein Totenfurz, das ist der Blutrubm! Nur Hämmel!"

Sie vergleicht also die Soldaten mit einer Herde von Hammeln - jungen, unreifen Dummköpfen, die für einen zweifelhaften Ruhm (,Ein Totenfury, das ist der Blutrubm!"') alles zerstören. Von dem schönen Schein, von der Erwartung stolze und starke Männer vor sich zu haben, bleibt letztlich nichts übrig. Im Folgenden vermischen sich Kriegskritik und Emotionsstürme zwischen Liebe und Hass, die auch den Bezug zu Kokoschkas Liebesleiden, das für seine Meldung zum Kriegsdienst nicht unerheblich war, erkennen lassen. Diese Verquickung bleibt auch bis zum Ende der dritten Szene des dritten Aktes maßgeblich. Im Diskurs mit einer weiblichen Stimme, die zuerst unspezifiziert, später als die von Eurydikes Geist benannt, aus einem Nebel herausdringt, verteidigt Orpheus seinen Wunsch tot zu sein mit dem Argument sich bereits tot zu fühlen. Er bezieht dies in erster Linie auf den Verlust Eurydikes, aber auch darauf durch sie das Totenreich gesehen zu haben, als er sie Hades entreißen wollte. Dies lässt sich vor dem biografischen Hintergrund Kokoschkas aber auch so deuten, dass der Künstler einerseits durch die Trennung von Alma, andererseits durch die Erlebnisse des Krieges, die ihm wie ein Wandeln durch das Totenreich vorgekommen sein mögen und in die er sich aus Liebesschmerz freiwillig begeben hatte, sich emotional als Toter betrachtete. Am Ende stirbt Orpheus schließlich im wahnsinnigen Lachen erstickend mit den Worten des fünften Gebotes: „Du sollst nicht töten - nicht töten -“, die gleichsam als mahnender Abschluss seiner impliziten Kriegskritik lesbar sind.

Es bleibt jedenfalls an dieser Stelle festzuhalten, dass Kokoschka im dritten Akt von „Orpheus und Eurydike“ in aller Drastik kämpferisches Gehabe, die Verrohung der Menschen im Krieg und den unheroischen Kriegsverlauf anprangert und das Drama somit im engen intentionalen Zusammenhang mit den Zeichnungen von 1917 steht. Wie im übrigen literarischen Werk auch, überwiegt allerdings das Thema des Geschlechterkonflikts, während die politischen Implikationen zweitrangig bleiben. Die gesellschafts- und kriegskritischen Zeichnungen der Kriegsmappe dagegen sind direkt, behandeln konkret ein Thema (da scheiden sich wieder die mehr erzählenden und die mehr fokussierenden Qualitäten von Wort und Bild, wie sie bei Kokoschka beispielsweise auch bei der prägnanten, porträthaften Darstellung des Menschen im Vergleich zu den weitschweifigen Ausführungen in „Von der Natur der Gesichte“ bemerkbar sind), und enthalten tendenziell mehr Polemik. Kokoschka nutzt in ihnen vor allem auch wiederholt und effektiv das Mittel der Satire, um seiner Kritik Ausdruck zu verleihen. 
Auch über die Kriegsthematik hinaus hat Kokoschka das politische Geschehen nicht aus den Augen verloren. So enthält die Kriegsmappe z. B. die Zeichnung „Staatsfrohn“ (Abb. 83), welche wie „Soldaten einander mit Kruzifixen bekämpfend" bitter-satirisch angelegt ist. Sie zeigt eine nackte, abgemagerte Gestalt, die vor einem Staatsrepräsentanten - ausgewiesen durch seinen Zylinderhut - auf allen Vieren kriecht, und von diesem eine schmerzhafte Brandmarkung auf den Rücken erhält. Sie wird dadurch als beliebiges, untergebenes „Herdenvieh“ gekennzeichnet. Solche politisch kämpferischen Blätter verweisen auf die Kontakte des Künstlers zu den revolutionär orientierten, deutschen Intellektuellenkreisen, die die bestehenden Mächteverhältnisse ablehnten und stattdessen sozialistische Ziele verfolgten. 1918 erstellte Kokoschka eine Farblithografie in Blau und Rot mit dem Titel „Das Prinzip“ (Abb. 84), die 1919 in einem von Paul Westheim herausgegebenen Grafik-Sammelwerk publiziert wurde. Sie zeigt eine Büste auf einem Sockel, den Kopf erhoben und im Dreiviertelprofil gewendet. Eine Haarsträhne, die nach rechts absteht, ist rot, ebenso wie der Mund aus dem seitlich Blut zum Kinn herab läuft. In der gleichen blutroten Farbe prangt am unteren Bildrand die Aufschrift „Liberté, Egalité, fratricide " und parodiert damit die Grundideen der Französischen Revolution, indem er das französische Wort für „Brüderlichkeit“ durch „Brudermord“ ersetzt. Die Lithografie ist als Bezugnahme auf die mentale Situation in Deutschland, genauer gesagt auf die innerdeutschen Kämpfe nach dem Krieg, zu verstehen. In der Revolution von 1918/19 wurden die republikanischen beziehungsweise sozialistischen Ziele unter Inkaufnahme von Blutvergießen und „Brudermord“ vehement verfolgt, was in Parallele zur Französischen Revolution steht. Dieses Blatt zeugt somit ebenfalls von den Kontakten des Künstlers zu politisch aktiven Kreisen. So hatte er während der Novemberrevolution 1918 in Berlin engen Kontakt zur linken „Novembergruppe“, hielt sich ihren Sitzungen allerdings fern und wollte in der Presse nicht mit ihnen in Zusammenhang gebracht werden. ${ }^{627}$

Kokoschka war nicht unpolitisch, aber er verwahrte sich gegen die Extreme und stand der Durchsetzung von Zielen und Ideen mit Brachialgewalt ablehnend gegenüber. Davon zeugt auch sein offener Brief an die Einwohnerschaft Dresdens, ${ }^{628}$ der in über vierzig Tageszeitungen abgedruckt wurde. Auslöser war für Kokoschka die Beschädigung von Meisterwerken des Dresdner Zwingers durch Schießereien während des rechtsgerichteten Kapp-Putsches im März 1920, ${ }^{629}$ auf die der Künstler mit kämpferischer Polemik reagierte:

„Ich richte an alle, die hier in Zukunft vorbaben ibre politischen Theorien, gleichviel ob links-, rechts-, oder mittelradikale, mit dem Scbießprügel zu argumentieren, die flebentlichste Bitte, solche geplanten kriegerischen Übungen nicht mebr vor der Gemäldegalerie

\footnotetext{
${ }^{627}$ Vgl. Fischer (1996), S. 74; Wingler (1975), S. 123 f.

${ }^{628}$ Textnachweis, Text XXVIII.

${ }^{629}$ Vgl. Stark (1982), S. 242 f.; Fischer (1996), S. 75.
} 
des Zwingers, sondern auf den Schießplätzen der Heide abbalten zu wollen, wo menschliche Kultur nicht in Gefahr kommt. (...) Ich wage nicht zu hoffen, dass mein Gegenvorschlag durchdringt, der vorsähe: dass in der deutschen Republik wie in den klassischen Zeiten Febden künftig durch Zweikeämpfe der politischen Führer ausgetragen werden möchten, etwa im Zirkus (...)“.

Überzeugte kommunistische Künstler und Intellektuelle wie George Grosz oder John Heartfield griffen Kokoschka für diese Äußerungen an, bezeichneten ihn als „Kunstlump“ und warfen ihm vor, die Revolution behindern zu wollen. Doch ist dies ein Missverständnis. Der Appell zeigt nur, dass Kokoschka alle Seiten in dem Moment ablehnt, in dem sie im Rahmen ihrer politischen Ziele kulturschänderisch agieren. Er verurteilt die Gewalt, vor allem, wenn sie Menschen und Kulturschätze trifft, die mit den Unruhen nichts zu tun haben. In seiner Wortwahl ist er betont ironisch und provokant, wodurch er zwar zum einen den Ernst seiner Empörung, zum anderen aber auch die von ihm so wahrgenommene Lächerlichkeit des zerstörerischen Aktionismus zum Ausdruck bringen will.

\section{Ergebnis}

Die Auseinandersetzung mit dem Krieg spiegelt sich in Kokoschkas Werk in sehr unterschiedlicher Weise. Grundsätzlich steigert er im bildkünstlerischen Bereich seine Behandlung des Themas im Laufe der Jahre. Nur zwei Fächer zeugen von seinen Ängsten im Vorfeld der Ereignisse und sind mit autobiografischer (Liebes-)Problematik vermischt. Der Phase als offizieller und mit dokumentarischer Absicht zeichnender Berichterstatter folgen die kritischen Blätter der Kriegsendzeit und der sich anschließenden politischen Umwälzungen, in denen der Künstler - in einer anderen Bildsprache - deutlich Position bezieht. Die in den Fächern zu bemerkende spezielle Koppelung von Krieg und Liebeskonflikt kehrt auch nach den Fronteinsätzen wieder und findet sich in ähnlicher Form in „Orpheus und Eurydike“. Dieses Drama ist von drastischer kriegskritischer Vehemenz, die in ihrer erzählerischen Breite noch eindringlicher wirkt, als die vielfach satirisch anmutenden Grafiken für die Kriegsmappe. Der Appell an die Dresdner Bürger steht mit diesen Blättern ebenfalls im engen Zusammenhang und spiegelt in ähnlicher Weise, d. h. ironischer und provokativer also als das Drama, Kokoschkas gewaltverneinende Haltung. Wenn Krieg und Politik von Kokoschka im Vergleich $\mathrm{zu}$ anderen Themen auch wenig Niederschlag in Texten und bildkünstlerischen Werken gefunden hat, so ist doch auch aus diesem überschaubaren Komplex abzulesen, dass er wie Meidner kein Kriegsbefürworter war. 


\subsubsection{Stilleben und allegorische Werke}

In vielen seiner Werke arbeitete Kokoschka mit Sinnbildern, wie es in den vorangehenden Kapiteln teilweise bereits deutlich wurde. Dabei spielten für die Interpretation insbesondere der expressionistischen Bühnenstücke, aber auch vieler bildkünstlerischer Werke, die Bezüge beispielsweise zu Religion, Literatur, Politik oder Philosophie eine wichtige Rolle, um das sinnbildlich Gemeinte, wie z. B. die Parallelisierung der Geschlechter mit den Himmelsgestirnen, oder die Brandmarkung des Proletariers durch die Staatsgewalt in „Staatsfrohn“, zu entschlüsseln. Dennoch bleibt eine kleine Gruppe von Werken übrig, die den anderen Themenbereichen nicht zuzuordnen sind; auch wenn hier die schon genannten Aspekte eine Rolle spielen mögen, erscheint doch vor allem der allegorische Charakter in diesen Fällen dominant.

\section{Zuordnung}

Diese Gruppe vornehmlich allegorisch zu bezeichnender Bilder und Texte ist sehr überschaubar. Literarisch zählt dazu das bereits genannte Drama „Orpheus und Eurydike“ (1917/18) mit einem mythologischen Thema. Im bildkünstlerischen Bereich sind die Stilleben („Stilleben mit Hammel und Hyazinthe“ (1910), „Stilleben mit Kaninchen und Putto“ (1913/14) und das bedeutende Gemälde „Die Macht der Musik“ (1920) zu nennen. Insgesamt handelt es sich nicht um Teile eines homogenen Themenkomplexes, vielmehr differieren die Werke in ihren Inhalten und stehen daher eher jeweils für sich. Ein adäquater Vergleich von Bild und Text ist hier somit eigentlich nur bei den Werken mit Bezug zum OrpheusMythos möglich, da zu den Stilleben und zu „Die Macht der Musik“ keine literarischen Entsprechungen existieren.

Sinnbildliche Verwendung des Orpheus-Mythos

Kokoschkas viertes Drama „Orpheus und Eurydike““630, das er 1915 nach schweren Verletzungen während seiner Fieberträume im Kriegslazarett konzipiert und anschließend (bis 1918) niedergeschrieben hat, ist bereits zwei Mal erwähnt worden, denn in ihm sind sowohl das Thema des Geschlechterkonflikts in Bezug auf die Beziehung des Künstlers zu Alma Mahler, als auch das des Krieges verarbeitet. ${ }^{631}$ So vermischen sich darin zwei Sujets, die zum Entstehungszeitpunkt des Stücks Hauptgegenstand seines Denkens waren. Kokoschka selbst gibt davon einen Eindruck in seiner Autobiografie:

„Ein österreichischer Sanitätswagen (...) brachte mich mit den anderen Verletəten nach Wladimir-Wolbynsk (...) wo unter Zelten ein Feldlazarett eingerichtet worden war.

${ }^{630}$ Textnachweis, Text XXIX.

${ }^{631}$ Vgl. zu diesem Drama Schvey (1982), S. 89 ff. 
(...) Viele Wochen musste ich auf den Rücktransport in die Heimat warten, immer in Gefahr, dass die Front zurückrollen würde. Ich batte den Zeitsinn verloren, und aus irgendeinem Grunde war ich auch räumlich isoliert, wie in einer Zelle, überall Fliegen. Manchmal brach meine Erinnerung so stark, hervor, dass ich die Frau, von der ich mich so schwer getrennt hatte, leibhaftig vor mir sah. (...) Da durch den Kopfschuß meine Bewegungsfähigkeit eingeschränkt und auch mein Sebsinn gestört war, habe ich die Worte der Zwiegespräche mit ibr, mit diesem Phantom, mir so lebhaft eingeprägt, dass ich sie, ohne sie aufschreiben zu müssen, in der Phantasie mehr und mehr erweitern konnte, bis sie sich zu wirklichen Szenen entwickelten. So ist aus meinen, mir auf dem Lager von Wladimir-Wolhynsk ständig wiederbolten Halluzinationen das Stück „Orpheus und Eurydike" entstanden (...). "632

Diese beiden maßgeblichen Aspekte von Liebesschmerz und Kriegserlebnis werden im Drama in subtiler Weise mit dem Mythos von Orpheus und Eurydike verknüpft. Der Mythos dient gleichsam als Sinnbild - und damit der Objektivierung -, um die persönlichen Erfahrungen in eine verschlüsselte, allgemeine und damit von einem größeren Publikum rezipierbare Form zu überführen.

Das Drama setzt sich aus drei Akten und einem Nachspiel zusammen, wobei der erste und dritte Akt in drei, der zweite in vier Szenen unterteilt ist. Dabei binden Anfangs- und Endakt den Mittelakt auch in der Wiederaufnahme der örtlichen Gegebenheiten ein: sie finden in Orpheus' Haus statt, während im zweiten Akt sich das Geschehen in der Unterwelt und auf dem Meer abspielt. In der Anfangsszene kehrt Orpheus heim und wird von Eurydike im Garten erwartet. Sie begegnen einander in friedvoller Atmosphäre und tauschen ihre Gedanken im Gespräch aus. Dabei wird als Zeichen ihrer Verbundenheit ein Ring ins Spiel gebracht, den Eurydike am Finger trägt und mit den an die Dichtung „Allos Makar"633 erinnernden Worten ,Wie dieser Ring zusammenbindet Orpheus und Eurydike, so ewig Eines Glück im Andern " herumdreht. In ihrer Nähe spielt ein halbwüchsiges Mädchen namens Psyche, das Orpheus als einen Geist benennt, der Eurydike zur Seite stehen soll. In der zweiten Szene des ersten Aktes erscheinen drei Furien, die in Hades' Auftrag Eurydike in die Unterwelt entführen sollen. Psyche, die Eurydikes Schlaf bewacht, versucht sie zunächst aufzuhalten, gewährt ihnen dann aber doch unfreiwillig Einlass, als sie ihren Geliebten Amor in der Nähe wähnt. ${ }^{634}$ So endet der erste Akt mit der Mitteilung der Furien an das Paar, dass Eurydike sieben Jahre bei Hades leben und Orpheus vergessen müsse, und mit einem anschließenden Abschiedsmahl der beiden. Hierbei wird die Zerstörung der Liebe zwischen Orpheus und Eurydike schon angedeutet, denn Eurydike verliert ihren Ring, bevor sie von einer Schlange tödlich gebissen und von den Furien mitgenommen wird.

\footnotetext{
632 Kokoschka (1971), S. 160 f.

${ }^{633}$ Siehe Kapitel 3.2.3.1.

${ }^{634}$ Näheres zu Amor und Psyche s. gleiches Kapitel.
} 
Im zweiten Akt befindet sich Eurydike in der Unterwelt und viele Jahre sind seit ihrer Entführung vergangen. Mit Psyches Hilfe ist Orpheus ebenfalls in Hades' Reich eingedrungen, um seine Geliebte zurückzuholen. Er hat sein Leben dafür geboten einen einzigen Sommer mit Eurydike verbringen zu dürfen. Als das Paar sich im Nebel einander nähert, warnt Psyche Orpheus davor seine Geliebte anzusehen, ganz so wie ihm dies auch in der antiken Überlieferung verboten ist. Gleichzeitig rät sie ihm, nicht am Vergangenen, also an der Zeit mit Hades, zu rühren. Wahrscheinlich ist dies eine Andeutung Kokoschkas auf Almas verstorbenen Ehemann Gustav Mahler. Seine Eifersucht auf den Toten und die Nachwirkungen dessen Einflusses auf Alma hatten immer wieder zu Konflikten geführt. Orpheus befolgt die Empfehlung und Eurydike, die ihn hatte vergessen müssen, findet ihre Erinnerung an ihn wieder. Mit den Worten „Vergessen, Orpheus? Nie mehr!" lässt sie sich von ihm aus der Unterwelt heraustragen. Die zweite Szene dieses Aktes beginnt hoffnungsvoll, denn das Paar gelangt zunächst in ein lauschiges, frühlingshaftes Tal. Doch Orpheus ist traurig über den fehlenden Ring an Eurydikes Finger und kann Furcht und Misstrauen nicht gänzlich ablegen. Eurydike gerät dadurch in Zweifel und emotionale Verwirrung. Dennoch besteigt sie mit Orpheus eine Barke, die er zur weiteren Flucht vorschlägt, obwohl die Erkenntnis, dass es sich dabei um Hades „Nachen“ handelt, sie zögern lässt. Tatsächlich ist das ein schlechtes Omen, denn die Barke bleibt in "Bleierne [r] Windstille“ unbeweglich, eine schwarze Wolke über ihr drückt die Stimmung und letztlich missglückt die Flucht, als das Boot auf Grund läuft. Es ist interessant, dass Kokoschka mit dem Motiv des Bootes Rückbezüge auf Illustrationen zu „Allos makar“ oder zum Gemälde „Die Windsbraut" herstellt und es in ähnlicher Weise auch hier als Symbol für unsichere Gefühle und vom Scheitern bedrohte Liebe verwendet. Das Desaster erreicht seinen Höhepunkt, als die drei Furien ein Netz auswerfen, darin einen Totenschädel mit Eurydikes Ring im Mund finden und der narrenhafte Kapitän beides zum Liebespaar in die Kabine bringt. Orpheus' Neugierde im Hinblick auf Eurydikes Zeit mit Hades wird dadurch angefacht und als er entdeckt, dass die Inschrift des Ringes so weit zerstört ist, dass dort nur noch „Allos makar“ zu lesen ist - was „anders ist glücklich“ oder „ein Anderer ist glücklich" heißen kann - zwingt er seine Geliebte von dieser Zeit zu erzählen.

Der Bezug zur 1913 entstandenen Dichtung „Allos makar“ ist unübersehbar. Hier, wie dort wird die durch das Anagramm aus den Vornamen Alma und Oskar ausgedrückte Symbiose der Liebenden in Zweifel gezogen.635 Dass der Ring in einem Totenschädel steckt, lässt sich als Hinweis auf Hades' Anwesenheit und auch auf dessen Besitzergreifung von Eurydike deuten. Indem Orpheus durch seine Nachfrage Psyches Rat, nicht am Vergangenen zu rühren, doch missachtet, verliert er Eurydike schließlich endgültig. Diese berichtet ihm nämlich, wie sie Hades mit Psyches Hilfe widerstanden habe und dieser sie, beeindruckt von ihrer

635 Vgl. Kap. 3.2.3.1. 
Treue, zu Orpheus zurückkehren ließ. Sie gesteht Orpheus, dass sie sich nun gerade durch diese Handlungsweise von Hades angezogen fühle und verlässt daraufhin das Schiff und den Geliebten zugleich. ${ }^{636}$

Bis hierher steht Kokoschkas Auseinandersetzung mit dem persönlichen Liebesschmerz über die Trennung von Alma im Vordergrund. Im dritten Akt hingegen bekommt die Verarbeitung der Kriegserlebnisse ein größeres Gewicht, wie es im vorangegangenen Kapitel bereits beleuchtet wurde. ${ }^{637}$ Wie beschrieben, findet sich Orpheus unbewusst wieder in seiner Heimstatt ein, die nun zerstört ist, und beginnt hier sein Grab zu schaufeln. Dabei findet er seine zerbrochene Lyra und lockt durch sein Spiel Gesindel und Soldaten an, die ihn schließlich während einer brutalen Orgie erhängen. Im Zwiegespräch mit einer weiblichen Stimme verteidigt Orpheus dann seine Todessehnsucht. In der dritten Szene wandelt sich die Stimme in diejenige Eurydikes und der Nebel, aus dem sie erklingt, wird rosafarben. ${ }^{638}$ Der Dialog der Getrennten ist schmerzvoll und als Orpheus versucht die flammende Eurydike-Erscheinung zu erreichen, steigt im Moment des Gelingens der Tod aus der Erde. Zu dritt führen sie einen makaberen Tanz auf und Orpheus spricht in seiner Hysterie von Hass gegenüber Eurydike, woraufhin ihr Geist ihn stranguliert und erstickt.

Dieses traurige Ende wird durch den Epilog etwas abgemildert, denn hier erscheint Psyche, die das Verschwinden des von ihr geliebten Amor bemerkt. Sie zeigt daraufhin mit ihrer versöhnlichen Äußerung „Winke qürtlich mit der Hand Dir, weil ich Mal der Küsse widerfind!/ Amor! Bin nicht mehr so bang,/ wie ich - dabei - war!/ Woblan!" eine hoffnungsvollere Lösung für den Geschlechterkonflikt auf, als das gescheiterte Paar zuvor. In sanftmütiger Stimmung streut sie Blumen über das Land, wodurch Mädchen und Jungen erweckt werden, die im Chor Psyches Entschwinden auf Hades Barke untermalen.

Kokoschka verwendet den Orpheus-Mythos in einer individuellen Weise und reichert ihn mit vielen autobiografischen Bezügen an. Rückblickend äußerte er sich selbst sehr aussagekräftig in einem Interview über das Drama mit den Worten:

„Für mich war damals nur die eine Frage von Bedeutung: Wer bin ich, wie bin ich, was ist noch von mir am Leben? Einer Frau wegen war ich freiwillig in den Krieg gegangen. Um die persönlichen Spuren zu verwischen, habe ich die griechische Mythologie benutzt. (...) Es war ein Versuch, mich aus meinem eigenen Chaos zu retten".639

${ }^{636}$ Vgl. Schvey (1982), S. 90 f.; Lischka (1972), S. 72 f.

${ }^{637}$ Vgl. Kap. 3.2.3.4.

${ }^{638}$ Mehr zur Verknüpfung der Geschichte von Orpheus und Eurydike mit Amor und Psyche s. nachfolgend.

${ }^{639}$ Kokoschka im Interview mit Dr. Wolfgang Fischer 1963, zitiert in: Museum für Kunst und Gewerbe Hamburg (1965), S. 48. 
Nach seiner eigenen Deutung benutzte er demnach den Mythos und das daraus erstehende Drama zur Selbstreflexion und Verarbeitung der schmerzvollen Erfahrungen. Doch in welcher Weise genau?

Orpheus ist als mythologische Figur aus einem doppelten Zusammenhang besonders bekannt: einerseits durch die Episode, in der er Eurydike aus dem Totenreich herausführt, ohne sich zu ihr umblicken zu dürfen, andererseits durch sein Mensch und Tier betörendes Lyraspiel. ${ }^{640}$ Beide Aspekte finden in Kokoschkas Bühnenstück in veränderter Weise ihren Niederschlag, wobei der Künstler sich zwar an die Kernelemente des Mythos hält, aber sie für seine Zwecke umdichtet. Wie in der antiken Überlieferung von der Errettung aus der Unterwelt, stirbt bei Kokoschka Eurydike durch einen Schlangenbiss und im weiteren Sinne ebenfalls verschuldet durch das Verlangen eines anderen Mannes - bei Ovid wird sie von Apollos Sohn Aristaios begehrt, bei Kokoschka von Hades. Übereinstimmend ist auch das Eindringen von Orpheus in die Unterwelt zur Errettung seiner Geliebten geschildert. Anders als im Mythos bringt Kokoschkas Orpheus Hades allerdings nicht mittels seines Lyraspiels dazu Eurydike frei zu geben, sondern setzt sein eigenes Leben als Pfand ein und anders auch scheitert sein Unterfangen nicht daran, dass er sich entgegen dem Verbot zu der Geliebten umdreht. Er hält es standhaft ein. Ihm wird dafür ein weiteres, von Kokoschka ergänztes Verbot nämlich nicht an der Vergangenheit zu rühren - zum Verhängnis. Das neue Motiv, die Bereitschaft des Orpheus sein eigenes Leben gegen das der Eurydike einzutauschen, verweist deutlich auf die freiwillige Meldung des Künstlers (der sich verschlüsselt in der Person des Orpheus darstellt) zum Kriegsdienst, mit der er auf Almas Ablehnung reagierte. Die Ausweitung der Flucht, die zunächst das Gelingen der Rettungsaktion erhoffen lässt, nutzt Kokoschka, um in der Beschreibung von Hoffnung und Zweifel sowie dem friedlichen Tal und der stagnierenden Bootsfahrt, die sinnbildlich gemeint sind, die Gefühlswelten widerzuspiegeln, die er mit Alma durchleben musste, bevor der Einfluss der Vergangenheit die Trennung unausweichlich machte. Kokoschkas Eifersucht auf Almas verstorbenen Ehemann und die gesellschaftliche Prägung, die sie durch diesen erfahren hat, waren seines Erachtens ein wichtiger Punkt im Konflikt mit der Geliebten. So fügt er dies in Form des zweiten Verbotes in den Mythos ein und wie in seinem eigenen Leben mit Alma, scheitert die Beziehung von Orpheus und Eurydike in seinem Drama an Orpheus' Eifersucht auf den Nebenbuhler im Totenreich.

Die Schlüsselstelle für die Auseinandersetzung mit dem Liebeskonflikt ist im Drama daher das allegorisch aufgeladene Geschehen auf der Barke. Der Totenschädel und der mit tiefsinnigen Inschriftresten versehene Ring sind Symbole von zentraler Bedeutung. Der Ring dient gleichsam als Isotopie des Stückes, denn er bindet Anfang und Ende des Konfliktes zusammen. So spielt Eurydike bereits in der ersten Szene des ersten Aktes damit und verliert ihn beim tödlichen Schlan-

${ }^{640}$ Vgl. dazu Roscher (1978), Bd. 3.1, Sp. 1113 ff. (Orpheus als Sänger) und Sp. 1157 ff. (Orpheus und Eurydike; zum Inhalt besonders Sp. 1160 ff.). 
genbiss, also in dem Moment, als sie Orpheus und ihre Liebe zu ihm vergisst, um $\mathrm{zu}$ einem anderen Mann zu gehen. Mit seinem Auftauchen in Verbindung mit dem Totenschädel besiegelt der Ring das Ende der Beziehung zwischen Orpheus und Eurydike.

Außer durch Ring und Totenschädel ergänzt Kokoschka den mythologischen Stoff zusätzlich durch andere antike Sinnbilder. So verweisen auch die Wetterverhältnisse, in Form der bedrückenden Windstille oder der düsteren Wolke, auf das Verhängnis. Darüber hinaus scheint es, als habe Kokoschka sogar die Abtreibung seines Kindes ins Stück einfließen lassen. Als Orpheus zu Beginn des Dramas zu Eurydike in den Garten tritt, stolpert er über einen Kinderball, den er ihr dann in den Schoß wirft. ${ }^{641}$ Man mag diesen zunächst der halbwüchsigen Psyche zuordnen, doch wird das Thema der Elternschaft des Paares später auch im Dialog auf der Barkenfahrt angedeutet. Unmittelbar bevor der Narr ihnen die die Harmonie zerstörenden Gegenstände zukommen lässt und Orpheus sich schließlich zu der fatalen Frage „Sag nur noch, siehst Du - Ihn,/ wenn ich bei dir bin?" hinreißen lässt, reden die Zwei über ihre sich ergänzenden Träume. Eurydike spricht: „,Mir träumte, Du wolltest mich/ verstoßen, in die Kälte, und ich trage/ Dein Kind unterm Herzen", worauf Orpheus erwidert: „Und mir, dass Du rachedürstig, dann/ in das Herz. des Ungebor'nen eine/ Nadel stößt". Der autobiografische Bezug zu Alma, die Kokoschkas Kind abtrieb, weil sie sich nicht zu einem Leben mit ihm entschließen konnte, liegt hier sehr nahe.

Die Legende von Orpheus als Sänger nutzt Kokoschka vor allem in der ersten Szene des dritten Aktes im Zusammenhang mit der Kriegsthematik als Grundlage. Die Lyra spielt hierbei eine entscheidende Rolle. ${ }^{642}$ Bei Ovid ist sie das Instrument, mit dem Orpheus jeden in friedliche Stimmung zu versetzen vermag, so dass selbst im Totenreich während seines Spiels alle Qualen der Büßer unterbrochen sind. Sie ist dort ein gänzlich positiv behaftetes Attribut. Kokoschka kehrt dagegen in seinem Drama die Wirkung des Saitenspiels um. Zerbrochen und Disharmonien erzeugend, wiegelt Orpheus' Musik die nur aus negativ konnotierten Personen (Bettlern, Dirnen, brutalen Soldaten usw.) bestehende Gesellschaft zum Mord auf. Die zerbrochene Lyra verweist damit symbolisch auf den emotionalen und moralischen Verfall des Menschen in Kriegszeiten. Weitergehend könnte man mit Bezug auf die im Kapitel zum Thema Krieg betrachteten, gesellschaftskritischen Werke und besonders auf den die Kulturschänderei anklagenden Brief an die Einwohnerschaft Dresdens, speziell im zerstörten Instrument einen Hinweis auf Kokoschkas Auffassung sehen, dass kulturelle Werte durch den Krieg vernichtet werden. Zu guter Letzt ist sie natürlich zusätzlich als übergeordnetes Sinnbild für Kokoschkas Scheitern als Künstler zu verstehen. Durch die unglückliche Liebe und den Krieg verzweifelt und vom Todesverlangen getrieben, ist seine Virtuosität (vorerst) gelähmt.

${ }^{641}$ Zur Deutung des Balles als Hinweis auf einen Fötus vgl. Schvey (1982), S. 100.

${ }^{642}$ Vgl. Kap. 3.2.3.4. 
Kokoschka wählte also zur Verarbeitung seiner persönlichen Misere zwei Hauptaspekte des Orpheus-Mythos. Aber warum greift er nun überhaupt auf diesen Stoff zurück, beziehungsweise gerade auf diese beiden Motive? Die Antwort ist klar und einfach: sie boten ihm die Möglichkeit sich selbst verschlüsselt, einerseits als unglücklich Liebenden und andererseits als künstlerisch Tätigen, darzustellen. In den dem Drama zu Grunde liegenden Orpheus-Mythos mischen sich aber auch noch Elemente aus anderen Mythen, wie die drei als Furien bezeichneten Rachegöttinnen oder die Zentauren. Letztere finden beispielsweise in der kriegskritischen Szene in Akt drei Erwähnung. Mitten im von Gewalt und Liederlichkeiten begleiteten, wilden Tanz des Gesindels rufen die Männer aus: „Es eifert der Kentaur mit uns./ Die Stärksten vor!/ Vermehrt mit den Hieben die Liebeslust!" Das Mischwesen aus Mensch und Pferd findet sich in der antiken Mythologie geprägt von Rohheit und Triebhaftigkeit und wird hier von Kokoschka in gleicher Weise verstanden. ${ }^{643}$

Für die Behandlung des Beziehungs- oder im allgemeineren Rahmen des Geschlechterkonflikts ist es evident, dass Kokoschka dem Orpheus-Mythos verschiedene Partien der Geschichte von Amor und Psyche beifügt. In ihrer Funktion als Beschützerin und Begleiterin Eurydikes zeichnet Kokoschka Psyche als eine Art von Seele oder zweitem Selbst, das beim Tode vom Körper getrennt wird, wie es bereits in der homerischen Überlieferung durchscheint. ${ }^{644}$ So antwortet Orpheus in Kokoschkas Drama auf Psyches Frage, wer ihr Vater sei:

„Der keinen Körper hat. Doch mächtig uns bewegt,/ hat aus der freien Luft Dich, Geist, für eine Weile entbunden,/ Eurydike bier zu dienen. - /Dein Vater!/ Wenn seine beftige Macht sie bräche, sollst Du - im guten Sinn - / ibr nützen (...)".

Dazu passt auch, dass sie bei der Errettung Eurydikes im Totenreich zurückbleibt. In Verbindung mit Amor bezieht sich Kokoschka dagegen auf die im antiken Märchen (2. Jh. nach Chr.) des Apuleius von Madauros vorgenommene Beschreibung Psyches als Königstochter, deren Schönheit die eifersüchtige Venus dazu verleitet, ihren Sohn Amor damit zu beauftragen das Mädchen einem schlechten Mann zu geben. Amor verliebt sich dann aber selbst in Psyche und lässt sie in einem Schloss leben, wo er sie jede Nacht besucht unter der Bedingung, dass sie ihn nicht nach seiner Identität frage und nicht sehen wolle. Aufgestachelt von der Behauptung ihrer eifersüchtigen Schwestern, ihr Mann sei eine Schlange und wolle sie als Schwangere verschlingen, missachtet das Mädchen das Verbot und betrachtet Amor im Schlaf. Dabei weckt sie ihn, überrascht über seine schöne Gestalt, aus Versehen und verärgert über ihren Ungehorsam lässt er sie allein zurück. Psyche sucht ihn überall und muss dabei verschiedene, von Venus ihr auferlegte Aufgaben erfüllen - unter anderem hat sie die Schönheitssalbe der Persepone aus der Unterwelt herbei zu schaffen, ohne in das Behältnis, in dem sie sich befindet, hineinzublicken. Psyche befolgt den Auftrag, nicht aber das Verbot und sinkt

${ }^{643}$ Vgl. Schvey (1982), S. 98.

${ }^{644}$ Roscher (1978), Bd. 3.2, Sp. 3201 f. 
beim Öffnen des Kästchens in einen todesähnlichen Schlaf. Allerdings kommt Amor hinzu, bringt sie ins Leben zurück und Jupiter gewährt ihr letztlich Gnade; sie wird in den Kreis der Unsterblichen aufgenommen und mit Amor vereint. ${ }^{645}$ Diese Geschichte, die durch die Tatsache, dass eine Person aus Liebe agierend die Unterwelt betritt und dass der Verstoß gegen ein Verbot zum Unglück führt, deutliche Parallelen zur Orpheus-Legende aufweist, ${ }^{646}$ wird in Kokoschkas Drama nur gestreift und deren Kenntnis im Prinzip vorausgesetzt. Nur mit ihrer Kenntnis versteht man, wieso Psyche sich im Halbschlaf auf die Gespräche mit den drei Furien einlässt, die ihr versichern, sie würden ihr helfen Amors wahre Gestalt zu erkennen. Träumend, dass dieser sich tatsächlich nähert, lässt sie die Furien schließlich in Eurydikes Kammer. Auch für den Schluss des Bühnenstücks ist der Psyche-Mythos entscheidend, denn indem Psyche - entgegen der Überlieferung den Verlust des Geliebten akzeptiert und ins Totenreich fährt, setzt sie dem tragischen Ende von Orpheus und Eurydike die Hoffnung auf himmlische Liebe entgegen. Kokoschka spielt damit vermutlich auf eine besonders seit dem Altertum geläufige Deutung des Märchens an. „Psyche“ meint ursprünglich die Seele und wurde vermutlich bereits seit Platon mit Eros in Verbindung gebracht. In Platons Dialog „Phaidros“ findet sich die Auffassung der von Eros (oder Amor, letztlich also von der Liebe) beflügelten Psyche. Zu diesem Zeitpunkt wurden allerdings weder die Liebe (Eros/Amor), noch die Seele (Psyche) personifiziert - dies geschah zuerst in Apuleius Märchen. In der christlichen Nachantike wurde dieses Märchen schließlich vielfach als Anspielung auf die Prüfungen gedeutet, die die Seele auf Erden (personifiziert in der Menschentochter Psyche) bestehen müsse, bevor sie mit der himmlischen Liebe Christi (in Vergleichung mit dem Göttersohn Amor) belohnt würde. ${ }^{647}$ Kokoschka schließt damit seine Auseinandersetzung mit dem Geschlechterkonflikt, die auch in den anderen Dramen ihren Niederschlag findet und im entsprechenden Kapitel zu dem Thema untersucht wurde, letztlich in versöhnlicher Weise ab. Alle diese Aspekte beleuchten, welch vielschichtiges und mit Sinnbildern überreich angefülltes Werk Kokoschkas Drama „Orpheus und Eurydike" ist. Durch die freie Aufnahme und die Verquickung verschiedener mythologischer Stoffe schafft er eine Allegorie seines persönlichen, inneren Kampfes während der Monate Ende 1915/Anfang 1916.

Zum gleichen Thema ist auch eine Reihe von bildkünstlerischen Werken entstanden. 1918, im gleichen Jahr, in dem das Drama vollendet wurde, entstand eine Folge von sechs Kaltnadelradierungen, die eine vom Galeriebesitzer Hugo Erfurth in Dresden geplante Edition des Bühnenstücks illustrieren sollte. Die Blätter scheinen teils nicht vollendet zu sein und es wurden nur wenige Probedrucke angefertigt. Letztlich verzichtete man auf die Edition. ${ }^{648}$ Die Darstellungen wirken

\footnotetext{
${ }^{645}$ Vgl. Madaurensis (1990); Schvey (1982), S. 97 f.

${ }^{646}$ Schvey (1982), S. 98.

${ }^{647}$ Roscher (1978), Bd. 3.2, Sp. 3238.

${ }^{648}$ Wingler/Welz (1975), S. 116, Nr. 120-125.
} 
partiell noch skizzenhaft und vom ersten wie vom letzten Blatt existiert jeweils eine zweite Version; dies deutet darauf hin, dass eine weitere Überarbeitung auch der übrigen Darstellungen geplant war. Gezeigt werden die im Garten wartende Eurydike, die Begrüßung des Paares, die Furien, Eurydikes Errettung aus dem Totenreich und wie Orpheus sie durch einen Wald führt, sowie eine Zusammenführung des Paares in Verbindung mit einer Darstellung von Amor und Psyche. Interessanterweise liegt hier in der bildkünstlerischen Verarbeitung des Themas und das, obwohl sie in direktem Kontext mit der literarischen Bearbeitung steht der Fokus eindeutig auf der Beziehung zwischen Orpheus und Eurydike. Es gibt keine Darstellungen des Gespräches der Furien mit Psyche oder von Psyche in der Unterwelt, ebenso wenig vom Geschehen auf der Barke oder von Orpheus' orgiastischen Erlebnissen bei der Heimkehr zu seinem zerstörten Haus. Bis auf das dritte Blatt mit der Darstellung der Furien führen alle anderen Radierungen das Paar in seiner Entwicklung vor Augen. Bereits an der Haltung der beiden im zweiten Blatt, welches „Orpheus begrüßt Eurydike“ (Abb. 85) betitelt ist, ist die Entzweiung vorauszuahnen. Das Paar steht im Garten unter einem Baum. Die Figuren im Profil füllen dabei fast das gesamte Blatt - nur ein Baumstamm und ein Busch sind ansonsten zu sehen. Orpheus hat seinen linken Arm um Eurydikes Hüfte gelegt und will sie für einen Kuss zu sich heranziehen. Er hebt sein Gesicht dem ihren entgegen, doch sie erscheint in ihrer Haltung unnahbar. Statt näher an den Geliebten heranzutreten, beugt Eurydike nur den Oberkörper leicht nach vorne, gleichzeitig biegt sie aber ihren Kopf auch wieder zurück, als wolle sie sich seinem Kuss entziehen. Ihr Gesicht wirkt stolz und verschlossen. Unglücklich erscheint das Paar dem Drama gemäß auch in den folgenden Illustrationen, die in ihrem Inhalt zwischen Leiden, Uneinigkeit und Verzweiflung changieren. Anders als im Bühnenstück dient in dieser Folge der Mythos von Orpheus und Eurydike allein zur Thematisierung von Kokoschkas persönlichem Geschlechterkonflikt. Das Thema des Krieges findet hier keinerlei Niederschlag. Andere mythologische Aspekte, wie das Verhältnis vom Amor und Psyche oder die drei ihren Auftrag ausführenden Furien, werden nur nebenbei mit eingeführt. Sinnbilder bleiben ansonsten ausgespart. Im Vergleich zum Drama ist in der Grafikfolge das Spektrum der allegorischen Motive und die thematische Breite sehr begrenzt.

Dies gilt auch für andere bildliche Darstellungen, die den Orpheus-Mythos aufgreifen, wie das Gemälde „Orpheus und Eurydike“ (Abb. 86) von 1917. Auch hier spielt ausschließlich das Thema des Geschlechterkonflikts eine Rolle. Orpheus und Eurydike sitzen sich in diesem Gemälde in einem düsteren, beengten Raum gegenüber, wobei Orpheus frontal und im Dreiviertelprofil gezeigt ist und Eurydike von der Seite. Ihre Haltung drückt alles andere als Einheit aus. Beide haben ihre Knie überschlagen, wobei Orpheus von seiner Geliebten halb abgewandt erscheint. Sein Blick ist zwar auf Eurydike gerichtet, doch sein Gesicht ist sorgenvoll in die aufgestützte Hand gelegt. Eurydike wendet ihren leeren, traurigen Blick von Orpheus ab und scheint mit einer Geste der linken Hand auf eine 
Türöffnung zu weisen, durch die hindurch man einen Schiffer auf einer Barke wahrnehmen kann. Offenbar will sie damit auf ihren Gefühlswiderstreit zwischen ihrer Liebe zu Orpheus und jener zu Hades hindeuten. Über Orpheus schwebt denn auch die Gestalt Amors, der links aus dem Bild hinausstrebt und zu entfliehen scheint - ebenso wie die Liebe zwischen Orpheus und Eurydike. Orpheus selbst wird durch seine rechts neben ihm stehende Lyra als der berühmte antike Sänger ausgewiesen. Die Tatsache, dass sie unbeachtet an der Seite liegt, lässt sich als Hinweis auf die in den Liebesirrungen ausbleibende Virtuosität lesen. Ratlos und einsam wirken die Figuren. Orpheus erscheint in seiner Nacktheit gar gänzlich schutzlos Eurydikes Rückzug ausgeliefert zu sein. Die Farbigkeit - giftgrüne, blaue und graue Pinselhiebe sind breit, expressiv und dick aufgetragen - verweist in ihren fahlen Tönen auf das Totenreich, aus dem die beiden im Drama zu fliehen suchen. Orpheus hebt sich durch seine rosige Farbe davon ab und erscheint als der Mensch aus Fleisch und Blut, als der er dorthin hinabgestiegen ist. ${ }^{649}$ Inhalt und Stimmung entsprechen am ehesten der Dramenszene auf dem Boot, bei der Eurydike Orpheus von der Zeit mit Hades berichtet und ihre Gefühle für den Gott der Unterwelt offenbart. Das mythologische Paar in dieser Darstellung lässt sich insgesamt also als Allegorie einer zerbrochenen Liebe verstehen.

Wie im Drama verwendet Kokoschka in den bildkünstlerischen Werken den Orpheus-Mythos, um seine eigenen Erfahrungen zu verarbeiten und in allegorischer, beziehungsweise verschlüsselter Form zu objektivieren. Im Bühnenstück gestaltet er dies inhaltlich und sinnbildlich in vielfältiger Weise aus, während er sich bildkünstlerisch auf wenige Aspekte konzentriert und die Darstellung im Wesentlichen auf das Paar Orpheus und Eurydike reduziert.

\section{Allegorische Stilleben}

Allegorien ganz anderer Art finden sich in den Stilleben von 1910 und 1913/14, wenngleich zumindest bei Letzterem ebenfalls die Beziehung zu Alma thematisiert wird. „Stilleben mit Hammel und Hyazinthe“ und „Stilleben mit Putto in Kaninchen“ sind etwas vereinzelt in Kokoschkas Frühwerk stehende Gemälde. Sie lassen sich ergänzen durch das 1909 gemalte „Stilleben mit Ananas“ und das 1911/12 entstandene „Stilleben mit Katze, Hammel und Fisch“, wobei das Erstgenannte noch am Übergang zu Kokoschkas expressiven Schaffen in Öl steht und das zweite hier nur erwähnt wird, da eine genauere Besprechung wenig sinnvoll erscheint. Es ist bei einem Bombenangriff im Zweiten Weltkrieg verbrannt, und hinreichend qualitätsvolle Reproduktionen liegen nicht vor. Bei diesen vier Bildern handelt es sich also um die kleine Gruppe der von Kokoschka gemalten Stilleben in seinem frühen Schaffen. Die drei späteren, welche in expressionistischer Manier ausgeführt wurden, sind allerdings in keiner Weise mit den konventionellen Stilleben zu vergleichen, die besonders aus dem Barock bekannt sind und in denen

${ }^{649}$ Vgl. Winkler/Erling (1995), S. 76; Erling in: Schmidt (1996), S. 98. 
vielfach in sinnbildlicher Form, üblicherweise mittels eines festgelegten Symbolkanons, in vielfältiger Ausprägung religiös-moralisierende Inhalte thematisiert wurden. Stattdessen spiegeln Kokoschkas Stilleben ganz eigene Botschaften, die der Künstler in einer individuellen Bildsprache zum Ausdruck bringt.

Das „Stilleben mit Hammel und Hyazinthe“ (Abb. 87) entstand vermutlich in den Ostertagen 1910, die der Künstler bei dem Sammler Oskar Reichel verbrachte. Dieser hatte ihn zum Osteressen eingeladen und ihm das dafür vorgesehene, enthäutete Osterlamm gezeigt. Kokoschka erinnert sich in seiner Biografie:
„Der Hausherr hatte mich zum kommenden Ostersonntagsbraten eingeladen; er hatte am Markt eingekauft und wollte es mir in der Küche zeigen (...). Der Hausherr ließ mich eine Weile allein in der Küche. Auf dem Tisch lag die Leiche und weil es Karfreitag war, dacbte ich an den Menschensohn, dem es nicht anders ergangen ist. (...) Als der Hausherr es an den steifen Beinen emporzog, um es mir recht zu zeigen, tropfte Blut aus dem Maul des Tieres. Ich hatte genug. Ich hatte plötzlich einen Einfall. Statt der Einla- dung zum Braten zu folgen, wollte ich den abgebäuteten Kadaver scbnell malen. (...) man konnte alles Beiwerk. im Spielzimmer des Sohnes finden: eine alte Schildkröte und in einem Aquarium ein Axolotl, einen rosafarbenen Lurch, der es schwer hat, weil er in den unterirdischen Grotten in Kärnten nicht sehen kann. Auch eine weiße Maus war noch da, die der Knabe so dressiert hatte, dass sie von einem Stückchen Käse, mit der Hand gereicht, knabberte, obne wegzulaufen. (...) Es war alles so grau, traurig und see- lenlos, wie im Reich der Vergessenen, der Schatten im Hades, ja wie auf einem Friedhof. Und eifrig herumsuchend, nach Blumen vielleicht, fanden wir im Zimmer des Dienst- mädchens auf dem Fensterbrett eine weißleuchtende Hyazinthe im Topf voller Blïte. Ei- ne Blume, wie aus Wachs, wie künstlich gemacht. Sie leuchtete wie das Ewige Licht sel- ber im Dunkeln." "650

Entsprechend sind dem Betrachter all die genannten Tiere und Objekte in dem Gemälde denn auch disparat vor Augen geführt. Vor dem diffusen Farbschleier des Hintergrunds scheinen sie gleichsam zu schweben. Es existiert keine direkte Lichtquelle, alles erscheint wie in einer fluoreszierenden Aura. Am unteren Bildrand, nach rechts verrückt, schwimmt der Axolotl bleich schimmernd in seinem Glasbehälter. Links daneben hockt die weiße Maus mit roten Augen und direkt über ihr ist die Schildkröte ins Bild gebracht, die aus der linken unteren Bildecke heraus zur Bildmitte zu streben scheint. Sie verdeckt dabei zum Teil den auf mittlerer Höhe quer ausgestreckten Lammkadaver, dessen enthäuteter Schädel mit dem großen, herausquellenden Auge die verstörende Wirkung des Bildes verstärkt. In der rechten Bildhälfte dominieren dagegen konventionellere Gegenstände: ein Tonkrug, die Blume und eine Orange oder Tomate vor dem Aquarium. In dem dunklen Gesamtkolorit erzeugen die Maus, der Axolotl und die Haut des Lammes durch ihr fahles Leuchten eine unwirkliche, geradezu gespenstische Atmosphäre.

${ }^{650}$ Kokoschka (1971), S. 89 ff. 
Das Weiß der Hyazinthe strahlt dagegen klar, rein und unvermischt vor einem Flecken hellen Blaus. Die Blume bildet damit einen positiv wirkenden Gegenpol zu der übrigen, in gedeckten, von Schwarz, Braun- und Olivtönen dominierten Komposition. In der Kontrastierung der lebendigen Tiere und der blühenden Pflanze mit dem schauderhaften Kadaver des Lammes ist in erster Linie an eine Verbildlichung der Vergänglichkeit zu denken. Die gleichsam ringförmige Anordnung evoziert dabei passenderweise den Eindruck eines Kreislaufes. Das verunstaltete, tote Lamm als Sinnbild von Tod und Verwesung verweist auf das Ende aller lebendigen Kreatur, die durch die anderen Lebewesen im Gemälde stellvertretend vor Augen geführt wird. Kokoschka knüpft damit inhaltlich an die Bildtradition des Vanitas-Stillebens an, ${ }^{651}$ modifiziert es jedoch in persönlicher Weise mit ganz eigenen Bildmitteln. Wurden in konventionellen Vanitas-Stilleben tatsächlich unbewegte Gegenstände verwendet, wie beispielsweise ein Totenkopf, eine Sanduhr oder ein alle Phasen der Blüte spiegelnder Blumenstrauß, wählt der Künstler hier vor allem Tiere zur Veranschaulichung des Themas. ${ }^{652}$

Mit Bezug auf seine eigenen Beschreibungen zur Entstehung des Bildes ist zusätzlich aber noch eine religiöse Intention denkbar. Kokoschka schreibt, dass er beim Anblick des toten Lammes und in Anbetracht des Osterfestes an Christus und dessen Opfertod habe denken müssen. Später vergleicht er die weiß leuchtende Hyazinthe mit dem Ewigen Licht, das in der katholischen Kirche Gottes ständige Anwesenheit symbolisiert. Demnach ist es plausibel, beide Gegenstände entsprechend zu lesen und mit dem Vanitas-Gedanken zu verknüpfen. Das Stilleben würde dann nicht nur auf die Vergänglichkeit hinweisen, sondern im tröstlichen Gegenzug auch auf die christliche Erlösung.

Das „Stilleben mit Putto und Kaninchen“ (Abb. 88) von 1913/14 unterscheidet sich hiervon in Darstellung und Intention ganz erheblich. Es ist viel weniger in der Form eines Stillebens angelegt, weshalb diese Bezeichnung streng genommen gar nicht passt. War das „Stilleben mit Hammel und Hyazinthe“ immerhin eine Mischung aus Tierbild und Beigaben konventioneller Stilleben, so handelt es sich hier um ein allegorisches Tierbild, in welchem verschlüsselte Personenbezüge stecken. ${ }^{653}$ In einer hügeligen Landschaft bei Nacht, die die ganze Szene in bläuliches Licht taucht, sind im Zentrum des Bildes ein weißes Kaninchen und eine getigerte Katze dargestellt. Das Kaninchen hockt in passiver, ängstlicher Stellung da, während die Katze es wie in spielerischer Jagd umschleicht. Links von ihnen, abgegrenzt durch einen toten Ast und von ihnen abgewandt, befindet sich ein nackter Säugling. Er hebt sich in hellem, eisblauem Kolorit ein wenig von der dunkleren Umgebung ab. Im Hintergrund ist ein Gebäude zu sehen und in einem See davor die Gestalt eines Bootsfahrers. Sowohl das Motiv des Bootsfahrers, als auch die Figur des Kindes sind entscheidende Hinweise zur Interpretation des

${ }^{651}$ Vgl. Winkler/Erling (1995), S. 26.

${ }^{652}$ Vgl. auch Asendorf (1991), S. 13.

${ }^{653}$ Vgl. Lischka (1972), S. 83. 
Bildes. Aus der Konstellation von ängstlichem Kaninchen und jagender Katze ist bereits eine bedrohliche Situation abzulesen, doch eine konkretere Deutung ist nicht gleich ersichtlich. Die zeitliche Einordnung hilft hier weiter, denn das Gemälde ist zeitnah zur „Windsbraut“ 1913/1914 ausgeführt worden. Die Vermutung liegt somit nahe, dass hier ebenfalls der Konflikt mit Alma Mahler thematisiert wird und Kokoschka sich selbst als hilfloses Kaninchen darstellt, während Alma durch die unberechenbar mit ihm spielende Katze versinnbildlicht wird, die ihn jederzeit gar tödlich verletzen könnte. Die Katze ist ein verbreitetes Sinnbild der Frau, wie es im Expressionismus insbesondere bei den Künstlern der „Brücke" oder beispielsweise auch bei Max Beckmann zu finden ist. ${ }^{654}$ Es ist eng verknüpft mit der Vorstellung von einer die Frau „,bestimmenden tierbaften und das heißt

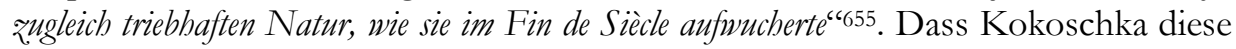
Auffassung mit anderen Zeitgenossen teilte und sie sich eben auch in anderen seiner Werke spiegelt, ist oben bereits festgestellt worden. ${ }^{656}$ Die Deutung von „Stilleben mit Putto und Kaninchen“ als Darstellung seines persönlichen Konflikts mit Alma wird durch den Säugling untermauert und ergänzt. Er verweist auf das Kind, welches Alma von Kokoschka erwartete, jedoch abtreiben ließ. ${ }^{657}$ Der Künstler erwähnt dies in seiner Biografie kurz und bitter mit den Worten:
„Warum mein Verbältnis bereits vor dem Krieg zu Ende gegangen ist, daran war diese Operation in der Klinik in Wien schuld, die ich Alma Mabler nicht verzeiben wollte. Man darf aus Lässigkeit das Werden eines Lebewesens nicht absicbtlich verbindern. Es war ein Eingriff auch in meine Entwicklung (...). " 458

Bereits in den Illustrationen, die er im Auftrag von Karl Kraus zu dessen 1909 erstmals veröffentlichter Erzählung „Die chinesische Mauer“ bis Frühjahr 1913 anfertigte, verarbeitete er in schonungsloser Weise seinen Schmerz über den Verlust des Kindes. ${ }^{659}$ Dessen Tod wird im „Stilleben mit Putto und Kaninchen“ nicht nur durch die räumliche Abtrennung vom Geschehen und die eisblaue Farbe angedeutet, sondern vor allem auch durch den Bootsfahrer, der als Charon bei der Überfahrt ins Totenreich zu interpretieren ist. Das gleiche Motiv findet sich auch in dem drei Jahre später gemalten Bild „Orpheus und Eurydike“ wieder, wo es in deutlichem Bezug zu dem gleichnamigen Drama von 1918 steht. ${ }^{660}$ Wie in dem Dramentext verschlüsselt Kokoschka in „Stilleben mit Putto und Kaninchen" seine persönliche Situation und Personen mit Symbolen.

\footnotetext{
${ }^{654}$ Vgl. Rödiger-Diruf (2007), S. 90 ff. und Noll (2001), S. 288 ff.

${ }^{655}$ Noll (2001), S. 290.

656 Vgl. Kap. 3.2.3.1.

${ }^{657}$ Winkler/Erling (1995), S. 60.

${ }^{658}$ Kokoschka (1971), S. 132.

${ }^{659} \mathrm{Mehr} z u$ diesen Illustrationen s. Husslein-Arco (2008), S. 238 ff. 660 S. o.
} 
„Die Macht der Musik“ - Abschluss der frühen Phase

Das wichtigste allegorische Bild und zugleich ein Schlüsselwerk der frühen Phase Kokoschkas ist sicherlich „Die Macht der Musik“ (Abb. 89), ein Werk an dem er von 1918 bis 1920 arbeitete. In dieser Zeit hielt sich der Künstler überwiegend in Dresden auf, wohin ihn seine Flucht vor weiterem Kriegsdienst im Winter 1916 getrieben hatte. In den vorangegangenen Kapiteln sind bereits einige Werke untersucht worden, die dort entstanden sind und zumeist eher trist seine Gefühlswelt und die Verarbeitung von Liebesschmerz (z. B. Werke mit Orpheus-Bezug, Bilder zur Puppe), Isolationsempfinden (verschiedene Selbst- und Gruppenporträts) oder Kriegserlebnis (Kriegsmappe) widerspiegeln. Umso auffälliger und eindrucksvoller ist der stilistische und letztlich auch intentionale Wandel, den dieses Gemälde markiert. Nach den emotional schweren Jahren der inneren Leere und Verlassenheit, scheint es sinnbildlich Aufbruch und Erneuerung anzukündigen.

Von Kokoschka ursprünglich „Die Schwachheit und die Stärke“ betitelt, führt es dem Betrachter einen Posaune spielenden Engel und einen kauernden Knaben vor Augen. Jede der beiden Figuren nimmt eine Bildhälfte ein. Links steht der Engel mit weitausgebreiteten Flügeln, ${ }^{661}$ in ein grünes Gewand mit roten Ärmelaufschlägen gehüllt. Mit seiner Rechten führt er das Instrument an den Mund, in seiner weit vorgestreckten linken Hand hält er demonstrativ eine Malve, die die Mitte des Bildes markiert. Rechts, vom Posaunenspiel abgewandt, findet sich ein Knabe in gekrümmter Haltung und mit hochgerissenen Armen - gerade so, als sei er geweckt oder aufgeschreckt worden. Seine Kleidung ist leuchtend rot und gelb. Im Hintergrund, der unbestimmt aus grünen und blauen Farbflächen besteht, sieht man ein Tier davonlaufen, das einem Hund ähnelt. Das Kolorit leuchtet in einer eindrucksvollen und bis dahin unbekannten Intensität. Es kennzeichnet den Übergang zu einer neuen, abnehmend expressiven Stilphase, in welcher Kokoschka große Farbschollen und -flächen nebeneinander setzt und reine, leuchtende Primärfarben bevorzugt.

Auf den ersten Blick wirkt die Haltung des Knaben abwehrend und furchtsam erschreckt. Doch zugleich liegt in seinen Gesichtszügen mit den großen Augen und den roten Wangen ein Ausdruck des Erstaunens und der Ergriffenheit, gleichsam als sei er innerlich positiv berührt von der Musik. Virtuos sind diese unterschiedlichen Gefühle ins Bild gebracht und werden durch die Komplementärkontraste noch unterstrichen. Der Engel daneben vereint zwei Motive in sich. Die Posaune verweist auf die Engel des Weltgerichts, die Präsentation der Blume zugleich auf die Verkündigung (wo der Erzengel Gabriel allerdings eine Lilie in Händen hält). Dementsprechend wird dadurch die Übermittlung einer geistigen Botschaft und der Aufruf zur Erneuerung symbolisiert. Die Darstellung ist als Allegorie innerer Erleuchtung und Stärkung zu verstehen. Der Weckruf zu einer geistigen „Auferstehung“, der an den liegenden Jüngling gerichtet ist, kommt nicht

${ }^{661}$ Vgl. Schmidt (1996), S. 114. 
zuletzt auch in den kraftvollen Farben zum Ausdruck. Der ursprüngliche Titel „Kraft und Schwäche“ benennt diese im Bild vereinten Aspekte ganz direkt. Der Hund beziehungsweise Wolf, der in verschiedenen Werken Kokoschkas - z. B. in dem Kaminfresko oder der Grafik „Toter Soldat auf dem Schlachtfeld“662 - in bedrohlichem Zusammenhang auftaucht und hier entflieht, verbildlicht offenbar das Weichen der lähmenden und negativen Mächte, die den Künstler in den vergangenen Jahren belastet hatten. ${ }^{663}$

\section{Ergebnis}

Die Untersuchungen zeigen, dass die Gruppe der allegorischen Werke sehr heterogen ist. Inhalt und Stil sind disparat und zeugen zugleich von Kokoschkas Vielseitigkeit. Verbindendes Element ist hier nicht wie in den anderen Kapiteln ein gemeinsames Thema, sondern eine sinnbildliche Aufladung, die nicht in erster Linie auf Motive der anderen Themenkreise rekurriert. Kokoschka bezieht sich dabei sowohl auf mythologische Vorlagen, als auch auf bekannte Bildtraditionen, wie das Vanitas-Stilleben, welche er in seinem Sinne sogar erneuert. Insgesamt arbeitet er dabei intensiver und abwechslungsreicher im bildkünstlerischen Bereich. Sein Drama „Orpheus und Eurydike“ ist daneben jedoch ein eindrucksvolles literarisches Werk, in welchem der Künstler überaus geschickt verschiedene Motive miteinander und mit seiner eigenen Lebensrealität zu verknüpfen versteht.

\subsubsection{Zusammenfassung der Untersuchungen}

Mit den Untersuchungen zu Oskar Kokoschka ist ein zweiter wichtiger Künstler des Expressionismus in den Blick genommen worden, der in bemerkenswerter Weise bildkünstlerisches und literarisches Schaffen vereinte. Wie bei Meidner ließ sich auch hier auf ein umfassendes CEuvre zurückgreifen, aus dem anhand einer Vielzahl ausgewählter Beispiele die Zusammenhänge und Wechselbeziehungen zwischen beiden Medien deutlich gemacht werden konnten. Insgesamt fällt auf, dass Oskar Kokoschka in seiner expressionistischen Phase in besonderem Maße und stärker als beispielsweise Meidner von philosophischen Schriften inspiriert worden ist. Insbesondere in seiner Auseinandersetzung mit dem Thema des Geschlechterkonflikts sind die Einflüsse von Philosophen wie Weininger oder Bachofen prägend. Die Ideen von der Mann-Frau-Opposition als konfliktbeladenem Gegensatz von Geist und Erotik finden somit Eingang in einen Großteil der Dramen, wie beispielsweise „Mörder, Hoffnung der Frauen“ und spiegeln sich gleichermaßen in einer Vielzahl themenverwandter bildkünstlerischer Werke. Dabei ist allerdings wichtig festzuhalten, dass Bilder, wie z. B. das gerade für dieses

662 Vgl. Kap. 3.2.3.2. und 3.2.3.4.

663 Vgl. tlw. Schmidt (1996), S. 114; Winkler/Erling (1995), S. 85 f. 
Bühnenstück werbende Plakat „Pietà“, oft erst vor dem Hintergrund der Texte und der darin enthaltenen Hinweise auf das philosophische Gedankengut in ihrer ganzen Bedeutung erfasst werden können.

Grundsätzlich ist Kokoschkas schriftstellerisches Werk deutlich begrenzter als das bildkünstlerische. Bei den zu Beginn der Betrachtungen zu Kokoschka genannten Arbeiten fällt speziell der Komplex der Dramen ins Auge, die in einer damals neuen, überaus expressiven Art und Weise gestaltet sind und den Bühnenexpressionismus mit einläuteten. Hier ist, so wurde betont, das Thema des Geschlechterkonflikts maßgeblich. In dieser thematischen Konzentration sind die Dramen gegenüber den Gemälden und Grafiken zwar grundsätzlicher eingeschränkter, doch lassen sich in ihnen, wie gezeigt wurde, eine Vielzahl wichtiger Bezüge auch zu anderen Themenbereichen, wie vor allem zu den religiösen Darstellungen und der Thematik des Krieges finden. Interessanterweise sind in der Behandlung des Geschlechterkonflikts in Bild und Text zwar vergleichbare Intentionen verarbeitet, jedoch unterscheiden sie sich in ihrer Gewichtung. Während Kokoschka in den Texten in erster Linie generell den Geschlechterkonflikt problematisiert, spiegeln sich in den bildkünstlerischen Werken vor allem seine persönlichen Beziehungen, wie es die wiederkehrende Darstellung Alma Mahlers zeigt.

Für die religiöse Thematik, die hier erstmals eingehender untersucht wurde, ist die Kontextualisierung der beiden Medien besonders gewinnbringend. So ist die Analyse der Abhandlung „Von der Natur der Gesichte“ für das Verständnis gerade beispielsweise der Gruppe von Gemälden, die um 1911 religiöse Motive aufgreifen, erhellend. Sie macht deutlich, dass die Verwendung dieser Motivik weniger Kokoschkas christlicher Überzeugung entspringt, als vielmehr zur Darstellung persönlicher Anliegen, wie z. B. der Kennzeichnung seines Künstlertums als ein Martyrium oder der Geschlechterbeziehung, genutzt wird. In ähnlicher Weise vermag auch die Gegenüberstellung der kriegskritischen Passagen aus „Orpheus und Eurydike" insbesondere mit den satirisch und grotesk angelegten Grafiken der Kriegsmappe wie auch den nüchtern und dokumentarisch wirkenden Kriegszeichnungen das Gesamtbild dieser Thematik bei Kokoschka differenzierter abzubilden, als die Betrachtung nur eines Mediums. In ihrer Unterschiedlichkeit unterstreichen Bild und Text hier dennoch gleichermaßen Kokoschkas kriegsablehnende Haltung. Die Porträts zeugen besonders von Kokoschkas Streben nach der psychologischen Durchdringung des Gegenübers und zeigen den von Vereinsamung und Not bedrohten Menschen. Dem sehr umfangreichen Korpus vor allem der Gemälde steht auf literarischer Ebene wenig Vergleichbares gegenüber. Doch eröffnet die Analyse des Vortrags „Von der Natur der Gesichte“ ein tiefes Verständnis von Kokoschkas Porträtkunst. Über die inhaltlich und intentional vielfach übereinstimmenden Aspekte in Text und Bild hinaus, stehen die literarischen Werke den bildkünstlerischen Arbeiten auch durch die häufige Verwendung bildhafter Elemente nahe. So lassen sich hier wie dort immer wieder bestimmte Motive finden, z. B. das Boot, Sonne und Mond oder die Pietà-Gruppe, die beide 
Schaffensbereiche zusammenbinden. Hierzu gehört auch die spezielle Farbsymbolik, die vor allem in „Die träumenden Knaben“ und auch in „Mörder, Hoffnung der Frauen“ zum Tragen kommt. Die in der Märchendichtung aufkommende Veränderung des Sprachduktus hin zu expressiveren, teils aggressiveren Ausdrücken, zur Verknappung und zur Herstellung einer traumhaften Atmosphäre, entwickelt Kokoschka in den späteren Texten weiter und steht analog zu den sich vom Einfluss der Wiener Werkstätten schnell entfernenden, ausdrucksstarken bildkünstlerischen Darstellungen.

So ist Oskar Kokoschka neben Ludwig Meidner einer der Künstler, in deren doppelbegabten Schaffen sich die von vielen Expressionisten verfolgte Idee mehrere Künste zu vereinen, manifestiert. Und das mit einer Selbstverständlichkeit, die sich in den Worten Paul Kornfelds widerspiegelt:

„Fragt man: ,Warum schreibt der Maler Kokoschka Dramen, statt nur Bilder zu malen?' - so erwidere ich mit der Gegenfrage: ,Warum komponiert er nicht auch Symphonien, Opern, Lieder, warum ist er nicht auch Bildhauer?'(...)Ein Drama Kokoschkas ist nur eine V ariante seiner Bilder, und umgekehrt. "664

\subsection{Untersuchungen zur Entsprechung der Gestaltungsmittel}

Bereits in der Einleitung wurde unter Punkt 1.4. auf die Schwierigkeit hingewiesen, angemessene Methoden für den Künstevergleich zu finden. Die bei den Fallbeispielen im vorhergehenden Kapitel angewandte Untersuchung nach Themen und Inhalten ist eine Variante, die sich für die Zwecke dieser Arbeit - nämlich die Untersuchung von Doppelbegabung - als sinnvoll erwiesen hat. Wenn sie auch nicht in allen Bereichen der „Wechselseitigen Erhellung der Künste“ nutzbar erscheint, weil sie einen ähnlichen Ausdruckswillen in beiden Medien voraussetzt, der nicht immer gegeben ist, so erscheint ihre Anwendung im hier gegebenen Rahmen so naheliegend wie sinnvoll. Und sie eröffnet - das haben die vorhergehenden Betrachtungen der beiden Künstler Ludwig Meidner und Oskar Kokoschka gezeigt - einen tiefen Einblick in die Zusammenhänge der sich ergänzenden Schaffensbereiche und in das facettenreiche, expressionistische Euvre der Doppelbegabten. Die vergleichende Betrachtung der formalen Gestaltungsmittel ist dagegen schwieriger. Gibt es auch viele Begriffe - wie z. B. die der Symmetrie, der Dynamik oder der Rhythmisierung -, die bei der Analyse sowohl von Werken

\footnotetext{
${ }^{664}$ Paul Kornfeld: „Kokoschka“, 1917 (zuerst veröffentlicht im Programm zur Uraufführung der Einakter „Mörder, Hoffnung der Frauen“, „Hiob“ und „Der brennende Dornbusch“ am 3. Juni im Albert-Theater Dresden); zitiert in: Beil/Dillmann (2010), S. 262.
} 
der Bildenden Kunst, wie auch der Literatur gebraucht werden, so erscheint es oft kaum möglich die Entsprechungen aufeinander zu beziehen und sinnvoll für eine Untersuchung zu nutzen. Die Gefahr „Äpfel mit Birnen“ zu vergleichen ist groß.

Im Kontext der bisherigen Untersuchungen sind die Gestaltungsmittel bereits analysiert, nicht so sehr aber hinsichtlich ihrer Analogien geprüft worden. An dieser Stelle soll daher der Versuch gewagt werden über die inhaltliche Analyse hinaus noch einmal bei einzelnen Bild- und Textbeispielen exemplarisch anhand ausgewählter Kriterien jeweils die formale Gestaltung zu untersuchen, um die Möglichkeiten des Künstevergleichs auf der Ebene der Doppelbegabung noch weiter zu vertiefen - ohne allerdings in diesem Rahmen den Anspruch einer erschöpfenden Untersuchung erheben zu können. Dass die einzelnen Künste ihre jeweiligen Spezifika haben und somit nicht in allen Punkten vergleichbar sind, soll dabei nicht bestritten werden - nicht jeder Aspekt eines Bildes kann eine Entsprechung im Text finden - dennoch gibt es eine Schnittmenge an analogen Elementen, deren Vergleich möglich und lohnend ist. Ausgehend von den vorhergehenden Analysen in Kapitel 3. bieten sich für den Vergleich zwischen Bildender Kunst und Literatur bei Ludwig Meidner und Oskar Kokoschka folgende Kriterien an, die versuchsweise miteinander in Beziehung zu setzen sind:

- Raum

- Farbe

- Figur

\subsubsection{Ludwig Meidner}

\section{Raum}

Eine der Fragen, die bei der Gegenüberstellung der bildkünstlerischen und schriftstellerischen Mittel auf der Suche nach Entsprechungen gestellt werden kann, ist beispielsweise die nach der Gestaltung des Raumes. Wie wird der Charakter eines Raumes beziehungsweise die Illusion von Räumlichkeit vermittelt? Für die Untersuchung dieser Frage bieten sich aus dem Kreis der zuvor bereits analysierten expressionistischen Werke Meidners vor allem Ansichten, beziehungsweise Beschreibungen von Stadt- und Straßenlandschaften an.

Die Tuschfederzeichnung „Alaunstraße Dresden“ (1914; Abb. 3) weist eine ungewöhnliche, dem Naturalismus nicht entsprechende Raumauffassung auf. 665 Dies wird besonders deutlich an der Gestaltung der Perspektive. Die Tiefe des Raumes, also des Straßenzuges, in den der Betrachter hineinschaut, wird andeutungsweise durch die Linearperspektive evoziert. Die Linien, die die Straßenbe-

${ }^{665}$ Die nicht-naturalistische Darstellungsweise ist schließlich ein Charakteristikum des Expressionismus. 
grenzung und Häuserzeilen beschreiben, laufen V-förmig auf einen Fluchtpunkt zu, der das hintere Ende der Alaunstraße markiert. Doch verlaufen diese Linien nicht gerade, wodurch die normalen Sehgewohnheiten aufgebrochen werden, die Straße sich optisch nach oben biegt und die Häuser zu schwanken scheinen. Dieser Eindruck ist irritierend und, da er das Zusammenstürzen der Häuser suggeriert, auch beängstigend. Die sich teils zur Straße hin neigenden Häuserfronten verengen optisch den Raum und kanalisieren die Bewegungen der Passanten. Durch dynamisierende Elemente, wie spitz zulaufende Liniengefüge (z. B. vorne links) oder gegenläufige Schraffuren (im Asphalt), wird die durch die schwankenden Häuser bereits bewegt wirkende Straße zusätzlich belebt.

Analog dazu erscheint die Beschreibung der Alaunstraße in Dresden im gleichnamigen Gedicht von 1915666. Der Raum wird auch hier einerseits durch die Betonung der Straßenflucht („Häuserreiben ") und der letztlich ebenso Enge assoziierenden Vertikale („Essen, Türme", „wo sich Gotik steilt") gekennzeichnet. Andererseits wird er ebenfalls wie in der Grafik in besonderer und expressiver Weise belebt. Die dinglichen Elemente der Straße werden mit Verben kombiniert, die sie als bewegt, ja gar als eigenständig agierendes Lebewesen erscheinen lassen: „Н̈̈иserreiben " „schreien", „Wände ",trümmern " „sich hebend und schreien" und der "Asphalt (...) sprübt die Kinder hoch". Diese Beschreibungen erzeugen ein gedankliches „Bild“ der Straße, das analog zu der Raumgestaltung der Grafik ist. Die Bewegtheit ist hier nicht nur in der bildhaften Beschreibung selbst ausgedrückt - entsprechend dem wankenden Eindruck in der Tuschfederzeichnung heben sich berstende Wände, hebt sich auch der Straßenbelag im Gedicht - sondern ebenso im schnellen Stakkato der gereihten Worte und Satzfetzen, die teils als Ellipsen behandelt werden, also durch Weglassungen unvermittelt nebeneinander stehen. Den spitzen oder gegenläufigen Linien und Schraffuren im Bild vergleichbar, dynamisieren auch sie den als Straße charakterisierten Raum.

Die Darstellung des Raumes ist in den betrachteten Beispielen aufgrund des in beiden Medien gleichermaßen verwendeten Straßen-Motivs besonders gut vergleichbar. Die Dynamisierung der Stadt wird hier bald in bewegten Linien und im Aufbrechen der naturalistischen Sehgewohnheiten und bald in der Verlebendigung der Straße durch formale, sprachliche Mittel erzeugt. In der Gegenüberstellung der beiden Beispiele wird also deutlich, wie sich für die Gestaltung des Raumes im bildkünstlerischen Werk durchaus Analogien im schriftstellerischen Werk finden lassen.

\section{Farbe}

Die spezielle, kraftvolle und oft den intentionalen Ausdruck verstärkende Verwendung von Farbe ist im Expressionismus im bildkünstlerischen, wie auch im literarischen Bereich von enormer Bedeutung. Wie aus den vorhergehenden Un-

666 Textnachweis, Text II. 
tersuchungen deutlich wurde, zählt sie zu den wichtigsten Gestaltungsmitteln in beiden Bereichen und soll deshalb hier noch einmal vertiefend betrachtet werden.

Bereits in seiner „Anleitung zum Malen von Großstadtbildern“667 äußert sich Ludwig Meidner über die Verwendung von Farbe. Zwar heißt es an einer Stelle etwas lapidar: „Über die Farbe ist nicht viel zu sagen. Nehmt alle Farben der Palette (...)“, doch bedeutet dies für Meidner nicht, dass ihre Auswahl willkürlich wäre - so schränkt er gleich darauf ein: ,- - aber wenn ibr Berlin malt, so vervendet nur $W$ eiß und Schwary, nur wenig Ultramarin und Ocker, aber viel Umbra (...). "Im Zusammenhang mit der Wiedergabe von Licht und Schatten im Bild beschreibt er ebenfalls die für ihn beim Malen der Großstadt angemessen erscheinenden Farben - insbesondere Weiß, Schwarz, Blau und Ocker.

Das in Berlin entstandene Gemälde „Landschaft: Hafenplatz“ (Abb. 13) zeigt beispielhaft und anschaulich, wie eng sich Meidner an die eigene Empfehlung hielt. ${ }^{668}$ So wird es überwiegend von weißen Flächen und Strahlen, die von schwarzen Linien und grauen Schattierungen konturiert und ge- oder durchbrochen werden, dominiert. Mit breitem Pinsel hat der Künstler die Ölfarbe in großzügigen Schichten aufgetragen, wobei der energische Gestus erkennbar wird. Zwischen die zersplitterten und tumultartig ineinander verschränkten, hellen Flächen aus weißer Farbe, die bald gräulich, bald bläulich nuanciert ist, sind vereinzelt weitere Farben eingestreut. So findet sich Rot in den Häuserwänden und dem Stahlgerüst rechts im Mittelgrund, Gelb in einzelnen Strahlenbündeln zu den Bildrändern hin und prominent im Hintergrund, sowie kleinere Einlässe in grüner Farbe, die zumeist in die Nähe der gelben Flächen und zackenartigen Formen gerückt sind. Inmitten der auf Schwarz, Weiß und helles Blau reduzierten Stadtlandschaft treten diese kräftigen Farben deutlich hervor. Insbesondere die gelben Strahlen, die im Hintergrund, einem Kometen- oder Blitzeinschlag ähnlich, aufleuchten und die umliegenden Gebäude erhellen, erzeugen eine grelle und die Szene dynamisierende Wirkung. Aber auch das rote Leuchten der vorderen Häuser, das in verschiedenen Abstufungen changiert und die Wände gleichsam von innen heraus bedrohlich glühen lässt, belebt das Geschehen und unterstreicht die krisenhafte Stimmung, die die flüchtenden Figuren in der linken Bildhälfte und die aufwühlende Formensprache suggerieren.

Ähnlich verhält es sich mit der Farbe in Meidners Text „Nächte des Malers“"669. Wenn es dort heißt „Gewimmel von Pariserblau auf blanken Kreidegründen; zynisches, meckerndes Zinkgelb; Weiß mit Elfenbeinschwarz: das Kolorit der alten Bettlägerigen; Permanentgrün neben Zinnobergeschrei", dann werden die Farben gleichsam zu Eigenleben erweckt. Ihnen werden Adjektive und substantivierte Verben beigesellt, die im Normalfall nur in Verbindung mit Lebewesen auftreten und Sinn ergeben. So

\footnotetext{
667 Textnachweis, Text III.

668 Übrigens nicht nur in den Stadtbildern, sondern auch in den apokalyptischen Landschaften

kommt Meidners Präferenz dieser Farben zum Tragen.

${ }^{669}$ Textnachweis, Text VI.
} 
können im Grunde nur sich bewegende Geschöpfe ein „Gewimmel“ bilden, „meckern“ und „schreien“ sind menschliche oder tierische Laute und Zynismus ist eine Eigenschaft, die gar Intelligenz und Denkvermögen voraussetzt. Weniger direkt, aber dennoch das Bild der „,vermenschlichten“ Farbe stützend, verknüpft Meidner Schwarz und Weiß mit dem Motiv der „alten Bettlägerigen“. Neben der Eigenschaft die Farben lebendig erscheinen zu lassen, was im Übrigen auch hier wieder durch den stakkatohaften und dynamisierenden Reihungsstil unterstrichen wird, vermitteln viele dieser Worte zugleich etwas Bedrängendes. Sie erwecken den Eindruck als würden die Farben geballt auftreten („Gewimmel") und sich aufdrängen, sich über Gemecker und Geschrei gleichsam lautstark Gehör verschaffen wollen. Dies entspricht in etwa den dominant hervorstechenden Farbakzenten im Gemälde, die das Geschehen ebenfalls beleben und gleichzeitig durch ihre grelle Wirkung aggressiv und bedrohlich aufladen. In ihrer pastosen Erscheinung, die den Pinselduktus sichtbar macht und den Auftrag besonders wuchtig erscheinen lässt, tritt die Farbe gemäß dem Text gleichsam „sprechend“ und materiell präsent auf. Meidner schreibt an anderer Stelle weiter:

„Ich denke mir die großartigsten Dinge aus, apokalyptische Gewimmel, hebräische Propheten, Massengrab-Halluzinationen - denn der Geist ist alles, die Natur kann mir gestoblen bleiben. Aber das genïgt nicht: die ölstrotzenden Tuben sind fast noch wichtiger, weil die Farben mitmalen, miterfinden, mitfeiern" 670

Auch hier wird deutlich, welche Bedeutung der Künstler der Farbe zurechnet: sie wird gleichsam selbst zur künstlerischen Gestalterin - erneut wird die Assoziation mit „lebendiger Farbe“ geweckt.

Insgesamt versucht Meidner in beiden Medien die Farbe dynamisierend einzusetzen. Während sie im Gemälde allerdings als unverzichtbarer Bestandteil den Ausdruck des Bildes mit prägt, kommt in den Texten Meidners ihre assoziative und inhaltlich wirksame Kraft seltener zum Tragen als beispielsweise bei Kokoschka. Jedoch können die hier angestellten Vergleiche zeigen, dass in der Farbauffassung Analogien bestehen.

Figur

Ein weiterer elementarer Bereich der Bildanalogie betrifft die Darstellung der Figur. Wie die Untersuchungen zum expressionistischen Euvre von Ludwig Meidner und Oskar Kokoschka gezeigt haben, war bei beiden Künstlern das Motiv des „Menschen“ von wesentlicher Bedeutung für ihr Schaffen. So liegt es nahe auch hier den Vergleich zwischen der bildkünstlerischen und literarischen Behandlung der Figur noch einmal in formaler Hinsicht vorzunehmen.

${ }^{670}$ Hier deutet Meidner wiederholt seine in „Anleitung zum Malen von Großstadtbildern“ formulierte Ablehnung des Impressionismus und der Freilichtmalerei an. 
Betrachtet man Meidners Selbstporträt von 1912 in Darmstadt (Abb. 34), ${ }^{671}$ so fallen die düstere, geradezu dämonische Stimmung des Bildes und die expressive, Unruhe vermittelnde Figurenauffassung sofort ins Auge. Die Unruhe wird vor allem durch die gegenläufigen Bewegungen einerseits des Lichtes und andererseits innerhalb der Figur erzeugt. So gibt es eine helle, weiße Lichtquelle rechts oben, die auf der Glatze des Künstlers widerscheint und eine, die von links unten tiefrot das Gesicht Meidners anstrahlt (beide befinden sich außerhalb des Bildes). Dadurch entsteht ein spannungsgeladenes Hell-Dunkel, das die Figur dramatisch auflädt. Der Wechsel von hellen und verschatteten Partien, die den unnatürlich eckigen Faltenwurf des Gewandes und die zerfurchte Physiognomie betonen, so wie das bedrohliche rote Leuchten des Gesichts, lassen den Künstler unruhig und dämonisch erscheinen. Dieser Eindruck wird unterstützt durch die gegenläufige Gestik: während der linke Arm gerade ausgestreckt einen Pinsel führt, hat Meidner die Rechte vor seine Brust gelegt und die Hand in die Schulter verkrallt. Dieser verschlossenen Haltung steht ein unpassend wirkendes, offenes Lachen gegenüber. Interessanterweise setzt sich dieses Prinzip von Wechseln und Gegensätzen auch in der verschobenen Perspektive fort. Während der Körper mehr frontal gegeben ist, ist der Blick Meidners nach oben gerichtet und gibt den Anschein, der Betrachter sehe den Künstler eher von einer leicht erhöhten Position.

In all dem spiegelt sich eine emotionale Aufgewühltheit und Zerrissenheit der Person, die sich ähnlich auch in dem Text „Hymne an mich selbst“"672 wiederfindet. Meidners wichtigstes Stilmittel ist hier die Metapher beziehungsweise die Beschreibung der eigenen Person als Kompositfigur aus verschiedenen Tieren. Die Unruhe und innere Gespaltenheit wird hier wie im Bild auf verschiedenen Ebenen ausdrückt. Die Verschiebung der Perspektive, die die Figur teils frontal, teils von oben zeigt, wird im Text ebenfalls durch einen Gegensatz von oben und unten angedeutet und lässt eine Selbstwahrnehmung des Künstlers zwischen extremen Selbstzweifeln und ingeniösen Momentaufnahmen vermuten. So ragt die Figur des Künstlers einerseits ,bis in die siebente Region des Weltalls" und dehnt sich gleichsam bedeutungsvoll bis zu den Sternen aus - andererseits erscheint sie gleichzeitig jedoch skeptisch fragend als ein „,kleiner Däumling“. Meidners Beschreibung seiner Person schwankt somit zwischen sehr groß und sehr klein.

Wie im Bild der Versuch unternommen wird, neben dem eigentlichen Aussehen der Person vor allem ihre Psyche abzubilden, so gibt auch der Text über Andeutungen des Äußeren (,seht den Glatzkopf, Kablbauch") hinaus vor allem einen Eindruck von Meidners emotionalem Befinden. Dieser expressionistische Ausdruckswille ist mit einer naturalistischen Gestaltung kaum zu vereinbaren. Deshalb wird hier bei der Figurendarstellung die detailgenaue Wiedergabe vernachlässigt, stattdessen ist sogar eine Tendenz zur Deformation zu beobachten. Im Gemälde ist diese an der ungelenken Haltung des Künstlers, den übertrieben knochigen

${ }^{671}$ Näheres dazu s. in Kap. 3.1.3.6.

672 Textnachweis, Text XVII. 
Händen und vor allem in der Gestaltung des Kopfes beziehungsweise der Physiognomie zu beobachten. Das ganze Gesicht wirkt hier verzerrt. Die gegenläufige, zweifarbige Beleuchtung und der pastose, fleckenartig vorgenommene Farbauftrag verwandelt es in eine Landschaft aus aufgeworfenen Falten (vor allem auf der Stirn) und spitzen oder abstehenden Partien wie Kinn, Wangenknochen oder Ohren. Nasenspitze, Augen und Mund wirken schief und vervollkommnen den grimassenartigen Eindruck. Diese Deformation und Verzerrung der Person, die im übertragenen Sinne die innere Zerrissenheit spiegeln soll, wird im Text durch eine Art Fragmentierung vorgenommen. Die Person wird hier nicht sachlich in ihrer äußeren Erscheinung oder bezüglich ihrer Wesensart beschrieben, sondern über die Kontextualisierung mit verschiedenen, zumeist Ekel oder Gefahr suggerierenden Tieren wie Fliegen, Spinnen oder Wölfen gleichsam wie ein vielköpfiges Ungeheuer dargestellt - eben nicht wie ein einzelnes Wesen, sondern zerrissen in viele Geschöpfe. Auf diese Weise wird im Text ein ähnlicher Eindruck von Unruhe erzeugt, wie er dem Bild zugrunde liegt. Was dort über die Gegenläufigkeit, den expressiven Farbauftrag, den unausgewogenen Kontrast insbesondere von Rot und Grün und das dramatische Hell-Dunkel vermittelt wird, wird in der „Hymne an mich selbst" zum einen durch das Stakkato kurzer, abgehackter Sätze, zum anderen insbesondere auch durch das Prinzip der Bewegung, das sich durch die Vielzahl der Bewegungsverben wie ,wehn", „eilen " oder ,wimmeln "ausdrückt, spürbar gemacht.

Im Vergleich dieser beiden Werke wird anschaulich, dass auch in der Darstellung von Figuren die Gestaltungsmittel beider Medien Analogien aufweisen. Deformation und die Vermittlung von Bewegung mittels Pinselduktus, Farb- beziehungsweise Lichteinsatz und Linienführung auf der einen und Metaphorik, Satzrythmus sowie Wortspezifik auf der anderen Seite, dienen hier wie dort zur Psychologisierung und Charakterisierung der Person.

\subsubsection{Oskar Kokoschka}

Raum

Kokoschkas Umgang mit der Erzeugung des Raumes ist auf den ersten Blick nicht leicht zu fassen. So ist in den bildkünstlerischen Werken häufig keine wirkliche Illusion von Räumlichkeit gegeben - stattdessen scheinen die dargestellten Personen und Motive in einem eher formlosen Nebel aus Farben zu schweben. In den Texten - man berücksichtige, dass hierunter vor allem für die Bühne bestimmte Dramen zu finden sind - sind die räumlichen Gegebenheiten zumeist nur in knappen Regieanweisungen skizziert.

Dennoch findet sich auf den zweiten Blick die entscheidende Erkenntnis, die die für den Vergleich lohnende, gemeinsame Ebene eröffnet: Kokoschka erzeugt „emotionale Räume“. In charakteristisch-expressionistischer Manier geht es ihm 
in beiden Medien nicht um die naturalistische Darstellung eines Raumes, sondern darum, den Raum mit einer gewissen Stimmung zu versehen, die die darin stattfindende Handlung unterstreicht und sich auf den Betrachter oder Leser überträgt.

Die Beschreibung des Raumes in dem Drama „Mörder, Hoffnung der Frauen“673 ist denkbar knapp und auf das Wesentliche reduziert: „Nacbtbimmel/ Turm mit großer gitterner Eisentür/ Fackellicht/ Boden zum Turm ansteigend". Hier bleibt es dem Leser überlassen, sich die Gegebenheiten selbst auszumalen, wobei dem Text zu Gute gehalten werden muss, dass er eben weniger zum Lesen, als viel mehr für eine visuelle Umsetzung im Theater gedacht ist und daher den literarischen Duktus vermissen lässt. Es wird aber deutlich, dass der Raum keiner aufwändigen Gestaltung und nur weniger Details bedarf, um seinen Zweck zu erfüllen. Er ist reduziert auf das Motiv eines im Nachtdunkel daliegenden Turmes, der, so darf man annehmen, mit Gittertüren versehen und von flackerndem Fackellicht erleuchtet, eine bedrohliche Stimmung erzeugt. Bei der Untersuchung des Textes in Kapitel 3.2.3.1. kam die Symbolik des Turmes und des Käfigs als Phallus und Vagina zur Sprache, die im Kontext des Geschlechterkampfes, den das Drama thematisiert, von wichtiger Bedeutung ist. So wird der Mann - eingesperrt im Verlies des Turmes - als Gefangener seines sexuellen Verlangens nach der Frau dargestellt. Kokoschka wählt hier also zur Charakterisierung des Raumes ein einzelnes symbolisch aufgeladenes Motiv, das er durch Gestaltungsmittel, wie z. B. das Licht, in Szene setzt. Durch das Dunkel und die einzelnen Flammen der Fackeln wird der Raum in eine unruhige und düstere Stimmung getaucht. Die spärliche, flackernde Beleuchtung erzeugt eine Dramaturgie aus bedrückendem und aufwühlendem Licht- und Schattenspiel.

In den Dramen-Illustrationen wird der Raum wie in der eben zitierten Regieanweisung nur skizzenhaft und knapp angedeutet. Die Konzentration liegt auch hier oft auf einem Hauptelement, z. B. dem Baum bei der Begegnung von Adam und Eva im ersten Blatt zu „Hiob“ (Abb. 61). Allerdings kann anhand der Grafiken im Gegensatz zu den Gemälden der Vergleich nicht vertieft werden, da Licht und Farbe hier für Kokoschka selten eine Rolle spielen.

In ähnlicher Weise wie im Drama verfährt Kokoschka beispielsweise auch in seinem Gemälde „Die Windsbraut“ (Abb. 50). Losgelöst scheinen der Künstler und seine Geliebte auf einer Barke im Meer aus wogenden Formen und Farben zu schweben. Der Raum als solcher ist hier nicht naturalistisch ausgestaltet - lässt also Tiefenwirkung oder einen näher definierten Hintergrund vermissen. Er ist reduziert auf das in den Wellen treibende Boot, das, wie im Kapitel 3.2.3.1. gezeigt wurde, als Symbol für die emotionale Aufgewühltheit und hoffnungslose Suche des Künstlers nach Halt in der Liebe zu Alma zu deuten ist. In dieser Betonung eines einzelnen, Raum prägenden Motivs ist das Gemälde dem Dramentext sehr nahe. Darüber hinaus wird auch hier die Symbolik durch weitere Gestaltungsmit-

${ }^{673}$ Textnachweis, Text XXI. 
tel unterstrichen. So erzeugen die expressiv und breit aufgetragenen Pinselstriche das Bild aufgepeitschter Wellen, die das Boot fast zum Kentern bringen und vermitteln dadurch eine starke Unruhe. Eine Unruhe, die in ähnlicher Weise im Drama durch das Flackern des Fackelscheins gegeben ist. Gemäß diesem Lichteinsatz im Drama dient im Bild auch die Verwendung der Farbe dazu eine spezielle Stimmung zu erzeugen. Dunkle Violett-, Blaugrau- und Brauntöne besonders in der Himmelzone über dem Paar prägen das nächtliche Dunkel, das von der Mondsichel spärlich erleuchtet wird. Rot scheinen die Plankenenden des Bootes zu glimmen, was an den Feuerschein bei „Mörder, Hoffnung der Frauen“ erinnert und im Warm-Kalt-Kontrast der Farben ähnlich dramatisch wirkt, wie die starken Gegensätze von Hell-Dunkel im Drama.

Im Vergleich von „Die Windsbraut“ und „Mörder, Hoffnung der Frauen“ wird erkennbar, wie Kokoschka mit teils analogen Mitteln Räume emotional auflädt und der Intention des jeweiligen Werkes dienlich macht.

Farbe

Viel stärker als bei Ludwig Meidner ist der Gebrauch der Farbe bei Kokoschka mit einer eigenen Symbolik verknüpft. Bestimmten Farben ordnet er spezielle Bedeutungen zu und verwendet sie sowohl im bildkünstlerischen, als auch im schriftstellerischen Medium wiederkehrend in diesem Sinne. Er beginnt damit bereits in seiner Märchendichtung „Die träumenden Knaben“674. Die Opposition der Farben Rot und Weiß, die einer tropischen und einer nordischen Landschaft zugeordnet sind, steht zugleich für den Gegensatz von erotischem Verlangen und keuscher Unschuld. Beide Farben werden nicht nur genannt, sondern durch den Satzkontext assoziativ aufgeladen. So heißt es im sechsten Traum der Dichtung: „(...) in die weißen wälder tret ich/ eines renntieres huf klingt und wirft in allen weißen wäldern wiederleucbtende schneesterne auf (...) " und anschließend: „(...) renntierreiterin/ und das rentier ist ein berg/ deine kleider sind eine schneefläche/ wo blumen werden/ die berübrung deiner dünnen finger (...)".

Hier wandelt sich also im Traum die weiße, wintermärchenhafte Landschaft in das Mädchen Li, dem das lyrische Ich in jugendlicher Liebe zugetan ist. Die Alliteration "weiße Wälder" beziehungsweise ihre Erweiterung "weißen wäldern wiederleuchtende" hat in der Wiederholung des weichen Buchstaben , $W$ " eine geradezu beruhigende Wirkung. Dies entspricht auch dem neutralen Weiß und der kühlen Schneelandschaft. Weiß wird auf diese Weise mit Ruhe und mit Reinheit assoziiert, was auf die Unschuld der Gefühle des träumenden Knaben hindeutet.

Die Farbe Rot wird gleich zu Beginn der Dichtung mit gegenteiligen Assoziationen verknüpft, wenn es heißt: „rot fischlein/ fischlein rot/ stech dich mit dem dreischneidigen messer tot/ reiß dich mit meinen Fingern entzwei (...)". Zwar wird hier durch die Verniedlichung des Fisches durch das Suffix ,-lein" und die Verwendung des

${ }^{674}$ Textnachweis, Text XX. 
Wortes ,entzweireissen“, das eher an die lapidare Zerstörung eines leblosen Gegenstandes denken lässt, eine Verharmlosung des Geschehens vorgenommen und dem lyrischen Ich somit eine gewisse kindliche Naivität zugesprochen. Doch täuscht das nicht über das große Aggressionspotenzial hinweg, das in diesen Zeilen zum Ausdruck kommt. Die Verknappung der Sätze „stech dich", „reiß dich" durch die Weglassung des Personalpronomens ,ich“ scheint im expressiven Stakkato abrupt und hart, die Beschreibung der Zerstörung des Fischleibes mit den rohen Händen wirkt brutal. Diese Aggressivität wird mit der Farbe Rot, die im inhaltlichen Kontext auch Blut, Tod und im übertragenen Sinne sexuelles Verlangen (vgl. Kapitel 3.2.3.1.) symbolisiert, verknüpft.

Die Farbopposition, die in „Die träumenden Knaben“ für unschuldige, reine Liebe versus erotisches, brutales Verlangen steht, ${ }^{675}$ überträgt Kokoschka mit abgewandelter Bedeutung in sein Drama „Mörder, Hoffnung der Frauen“. Kokoschka stellt hier eine Verbindung zwischen Erotik und weiblichem Geschlecht her, indem er die in der Märchendichtung sexuelles Verlangen symbolisierende Farbe Rot nun als Kennzeichen der Frau verwendet. So wird im Drama die rot gekleidete Frau dem Mann gegenübergestellt, der sich durch einen blauen Brustpanzer und eine auffallende, weiße Gesichtsfarbe auszeichnet. Im Verlauf des Stückes wechseln die Farben: zuerst tritt der Mann mit weißem Gesicht auf, dann wird die schwächer werdende Frau immer blasser. Zuletzt verlässt der Mann lebendig und vom Blut der blassen, toten Frau rot verfärbt die Bühne. Es wurde bereits in Kapitel 3.2.3.2 darauf verwiesen, dass Rot und Weiß im Drama somit als Symbolfarben für Leben und Tod zu sehen sind.

Die gleiche Symbolik findet sich in dem Werbeplakat „Pietà“. Die hohlwangige, leichenblasse Frau hält, wie die Schmerzensmutter ihren toten Sohn, den verrenkten, blutroten Körper des Mannes im Schoß. Die Farben, denen Kokoschka selbst in seiner Beschreibung des Plakates ihre Symbolik zugeschrieben hat, verweisen hier wie im Drama auf den bevorstehenden Tod der Frau und die Erstarkung des Mannes zu neuem Leben.

Auch wenn bei Kokoschka, anders als bei Meidner, in der Frage der Farbverwendung im bildkünstlerischen und schriftstellerischen Schaffen weniger der Farbauftrag an sich oder die assoziative Kraft formaler Textgestaltung eine Rolle spielt, so ist die Analogie zwischen den beiden Medien umso deutlicher in der symbolischen Aufladung der Farbe.

Figur

Die Auffassung der Figur bei Kokoschka ist - so viele Beispiele es dafür insbesondere mit seinen zahlreichen, eindrucksvollen Bildnissen gibt - im literarischen Schaffen nicht ganz einfach zu fassen, da hier keine explizite, beziehungsweise

675 In der Untersuchung des Textes wurde auch auf die parallele Farbsymbolik in der zur Dichtung gehörigen Illustration „Das Mädchen Li und Ich“ hingewiesen. 
ausführlichere Beschreibung einer Person im Sinne eines „literarischen Porträts“ zu finden ist. Die Untersuchungen zu Kokoschka in Kapitel 3.2.3.3. haben jedoch aufgezeigt, dass es dem Künstler vor allem um eine psychologisierende Erfassung des Menschen, also um die Darstellung der Gefühlswelt seiner „Figuren“ ging. Betrachtet man vor diesem Hintergrund sein Selbstbildnis „Der irrender Ritter“ (Abb. 74), lässt sich dies an verschiedenen Faktoren festmachen. In gleichsam schwebender Haltung liegt der in Ritterrüstung gekleidete Künstler vor einer wüsten und von Unwetter verfinsterten Küstenlandschaft. Seine Hände suchen ziellos nach Halt und mit hilflosem Blick schaut er aus dem Bild heraus. Das hinter ihm liegende, aufgepeitschte Meer unterstreicht seinen offenbar aufgewühlten Gemütszustand, der zum einen auf die scheiternde Liebe mit Alma - hier als Fabelwesen rechts im Bild vor Augen geführt - und zum anderen auf seine bevorstehenden Kriegseinsätze als Soldat zurückzuführen ist.676 Insbesondere die eindrucksvoll dargestellte, instabile Haltung und die Mimik mit dem traurigen Gesichtsausdruck und den sorgenvoll zusammengezogenen Augenbrauen tragen die deprimierte Stimmung des Ritters nach außen. Das diffuse Licht, das keine Deutung darüber zulässt, ob Tag oder Nacht herrscht, und die dunkle Farbigkeit in Blau-, Braun- und Grüntönen mit vielen Schwarzanteilen schaffen eine dazu passende, bedrohliche Atmosphäre. Zeit- und haltlos schwebt der Künstler in einem alptraumhaft erscheinenden Raum. Die emotionale Unruhe spiegelt sich denn auch in den sehr dynamisch gesetzten Pinselstrichen, die vor allem die Meereswogen kennzeichnen.

Eine ganz ähnliche „Figuren-Innenschau“ findet sich in der Dichtung „Allos Makar"677, wo es heißt: „(...) Ich komme von weither,/ durch Schäumeräume/ warf ihr Kind die Mutter sehr./ Strittig. Alles Tag und Nacht bedecken,/ Ungewissheit, Nachklang bildend, in der Brust erwecken. (...)". Ängste und Zweifel des lyrischen Ich werden hier durch Worte wie „Strittig" oder „Ungewissheit" zum Ausdruck gebracht. Die Haltlosigkeit und Aufgewühltheit der Emotionen ist durch das Bild des „durch Schäumeräume" geworfen-Werdens beschrieben, wobei dies zugleich Assoziationen an das schäumende Meer im Gemälde weckt. Das Verb „werfen “bringt dabei zum Ausdruck, dass das lyrische Ich wie ein Gegenstand, ohne Vorsicht und auch hilflos, also ohne eine Möglichkeit Einfluss auszuüben, fremden Mächten ausgeliefert ist. Interessanterweise wird auch hier ein bedrohliches Gefühl durch die unbestimmte Tageszeit - „Alles Tag und Nacht bedecken“ - vermittelt. Der sprachliche Habitus von teils rätselhafter, teils unzusammenhängender Reihung sich reimender Satzglieder scheint die emotionale Verwirrung ebenfalls zu transportieren.

Deutlicher aber kommen die Analogien in der Figurenauffassung noch im Vergleich von „Amokläufer“ (Abb. 41) mit Abschnitten aus der Dichtung „Die träumenden Knaben“ zum Ausdruck. Der im Bild gezeigte Mann, der mit einem Dolch und einer Fackel bewaffnet eine Straße entlang stürmt, ist voller Aggressi-

${ }^{676}$ Mehr dazu s. unter Kapitel 3.2.3.3.

677 S. Textnachweis, Text XXII. 
on. Die Darstellungsweise weicht weit ab von einer naturalistischen Figurenauffassung. So ist die Haltung des Mannes unnatürlich verrenkt, unproportioniert und flächig angelegt. Die muskulösen, etwas übergroßen Arme holen wie in einer Ruderbewegung weit aus und machen die erregte Laufbewegung besonders anschaulich. Das nicht mehr menschlich erscheinende Gesicht des Amokläufers mit dem zum Schrei aufgerissenen Mund, ist zu einer dämonischen Fratze verzerrt und wirkt geradezu deformiert. Seine im Liebesleid entflammten Emotionen von Wut und Hass, die ihn zur Mordlust treiben, werden durch kleine Flammen an verschiedenen Stellen seines Körpers verbildlicht. Gleichsam tierische Deformation und Dynamik spiegeln hier die Aggression. In ähnlicher Weise arbeitet Kokoschka auch in der besagten Märchendichtung „Die träumenden Knaben“678, wenn er das lyrische Ich sich als ,wärwolf" beschreiben lässt. Auch hier wird die naturalistische Figurenauffassung zugunsten einer aggressiv-vertierten Darstellung fallen gelassen:

„mein abgezäumter körper/ mein mit blut und farbe erböhter körper/ kriecht in eure laubhütten/ schwärmt durch eure dörfer/ kriecht in eure seelen/ schwärt in euren leibern/ aus der einsamsten stille/ vor eurem erwachen gellt mein geheul/ ich verzebre euch/ männer/ frauen/ halbwache börende kinder/ der rasende/ liebende wärwolf in euch/".

Analog zum Bild verliert hier der von erotischer Raserei befallene Jüngling seine menschlichen Züge und wandelt sich gar in ein hässliches, unberechenbares ${ }^{679}$ Tier (,abgezäumter körper“, „wärwolf"). Die Bedrohung, die im Bild durch die Waffen und die Dynamik vermittelt wird, ist im Textbeispiel allerdings mehr von lauernder Art; „der rasende "Werwolf, dessen Geheul „vor eurem erwachen gellt", wirkt teils schnell und offensiv, doch „kriecht" das Ich in die „laubbütten“ und „seelen" und „schwärt" in den „Leibern“. Die hier überwiegend verwendeten Bewegungsverben stehen für heimliche, langsame Bewegungen, was durch den geradezu ruhigenden, monotonen Rhythmus der Zeilen ,keriecht in eure laubbütten/ schwärmt durch eure dörfer/ kriecht in eure seelen/ schwärt in euren leibern" und die Wiederholungen beziehungsweise nur leichte Abwandlung der einleitenden Verben verstärkt wird. Dass diese Bewegung dennoch nicht weniger gefahrvoll ist als der rasende Amokläufer im Bild, wird klar, wenn der „wärwolf" die Drohung ausspricht „,ich verzehre euch“.

Aus diesen exemplarischen Betrachtungen wird ersichtlich, dass Bild und Text durchaus analoge Elemente aufweisen, wie z. B. die Deformierung der Figur durch unproportionale Körperbehandlung, verzerrte Physiognomie und Vertierung oder ihre Psychologisierung durch assoziationsreiche Farbgebung, Linienführung und speziellen Wortgebrauch.

\footnotetext{
678 Textnachweis, Text XX.

${ }^{679} \mathrm{Da}$ der Werwolf eigentlich ein Mensch ist, der nur bei Vollmond zum Wolf wird, kann man nie sicher sein, ob ein solches Tier im menschlichen Gegenüber schlummert.
} 



\section{Ergebnisse und Schlussbemerkungen}

Ausgangspunkt der vorliegenden Arbeit war das Anliegen das Phänomen des im Expressionismus besonders ausgeprägten, doppelbegabt-künstlerischen Schaffens zu beleuchten. Wichtiges Bestreben dabei war es, die Beweggründe für die Aufnahme zweier unterschiedlicher künstlerischer Ausdrucksformen in dieser Zeit herauszustellen sowie die Vorgehensweise wie auch die Schwerpunktsetzung im einzelnen Medium zu erfassen, um durch die Zusammenhänge zwischen den bildkünstlerischen und literarischen Werken einzelner doppelbegabter Künstler ihr expressionistisches CEuvre insgesamt in neuem Licht zu sehen und besser zu begreifen.

Hierfür wurden vor dem Hintergrund der historischen Entwicklung von Doppelbegabung und der politischen wie sozialen Verhältnisse zu Beginn des 20. Jahrhunderts wichtige Denk-Positionen expressionistischer Künstler und Literaten betrachtet und das Schaffen der zwei Künstler Ludwig Meidner und Oskar Kokoschka exemplarisch unter inhaltlichen Gesichtspunkten untersucht. Neben der Beantwortung dieser zentralen Fragen - eben nach den Gründen für das künstlerische Arbeiten in verschiedenen Medien und dessen jeweiliger Form - wurden die methodischen Möglichkeiten des Künstevergleichs auch unter formalen Aspekten umrissen. 
Im historischen Überblick ließ sich feststellen, dass das Ausleben mehrerer künstlerischer Begabungen, genauer von bildkünstlerischen und literarischen Bestrebungen, zwar seit Jahrhunderten vorkam, jedoch nie zuvor eine solche Bedeutung erhalten hatte, wie es zu Beginn des 20. Jahrhunderts im Expressionismus zu beobachten ist. Die Grundlage für das Schaffen in verschiedenen künstlerischen Medien hier war das im Expressionismus besonders ausgeprägte Streben nach der Erneuerung von Leben und Gesellschaft durch die Kunst, das sich in der Bündelung aller kreativen Kräfte im Rahmen einer im ständigen Austausch miteinander stehenden, übergreifenden künstlerischen Gemeinschaft niederschlug. Treibende Kraft hierfür war ein Krisenbewusstsein, das sich aus der politisch und sozial prekären Lage sowie aus den einschneidenden wissenschaftlichen und technischen Neuerungen heraus entwickelte und das Bedürfnis nach Halt in der Gemeinschaft und in der Kunst als gleichsam „,neuer Religion“ hervorrief. Im gleichen Zuge gewann der Gedanke des Gesamtkunstwerks, der bereits in der Romantik aufkam, verstärkt an Bedeutung und begünstigte die synergetische Zusammenarbeit von Schriftstellern, Künstlern, Komponisten, Regisseuren und Choreographen insbesondere in den Bereichen von Film, Oper, Tanz und Theater. Schriften, wie Kandinskys „Über das Geistige in der Kunst", die als Bedingung jeglicher Kunstform eine ,innere Notwendigkeit“, beziehungsweise inneres Erleben propagierten, unterstrichen den Zusammenhang zwischen den verschiedenen Medien, die nunmehr gleiche Ziele zu verfolgen hatten. Die Doppel- und Mehrfachbegabungen, die im Expressionismus in außergewöhnlich hoher Zahl auftraten - aus der Vielzahl von Namen seien neben Ludwig Meidner und Oskar Kokoschka exemplarisch Ernst Barlach, Wassily Kandinsky und Arnold Schönberg genannt - , waren eine weitere Form, diese einzigartig nachdrücklichen Bestrebungen nach einer Synthese der Künste zu fördern. ${ }^{680}$ Auf der Suche nach geeigneten Wegen um innere Zustände, Visionen und „Vibrationen“ nach außen zu tragen, nutzten die Doppelbegabten verschiedene Medien als Mittel ihres Ausdruckswillens. Dieser im Künstler selbst liegende Antrieb für bildkünstlerisches wie auch literarisches Arbeiten ist Ausgangspunkt und Legitimation für die vergleichende Betrachtung beider Schaffensbereiche.

Im dritten Kapitel wurde daher ausführlich das doppelbegabte Schaffen der beiden Künstler Ludwig Meidner und Oskar Kokoschka während des Expressionismus exemplarisch betrachtet. Ziel dabei war es nicht nur einen Überblick über das jeweilige bildkünstlerische wie auch literarische Cuvre dieser Phase zu gewinnen, sondern auch mittels eindringlicher Analysen zum Verständnis der Werke beizutragen. Die inhaltliche Untersuchung - die Zuordnung der Arbeiten zu Themen, die in beiden Medien auftauchen - half, die Frage zu beantworten, was die Künstler beschäftigte und wie es sie beschäftigte, in welcher Form diese Themen in Gemälden und Grafiken einerseits, Gedichten, Prosatexten und Dramen

${ }^{680}$ S. Kapitel 2. Vgl. hierzu auch Beil/Dillmann (2010), S. 14 ff. 
andererseits, ihren Ausdruck fanden. Die Gegenüberstellung der einzelnen, in verschiedenen Medien ausgeführten Werke innerhalb der Themenkomplexe konnte zugleich ihre inhaltlichen Zusammenhänge beleuchten. Das Vorgehen unter diesem Gesichtspunkt konnte die große Nähe zwischen dem bildkünstlerischen und dem literarischen Schaffen der beiden Künstler aufzeigen und die Beschäftigung mit beiden Medien als zwei Seiten ei nes Ausdruckswillens erweisen.

Bei Ludwig Meidner, der um 1910 zur expressionistischen Ausdrucksweise fand und sich künstlerisch insbesondere unter dem Einfluss der Berliner Literatenbohème entwickelte, sind zwei Themen von zentraler Bedeutung, die auf nahe$\mathrm{zu}$ alle bildkünstlerischen und literarischen Bereiche seines expressionistischen Schaffens ausstrahlen - das Apokalyptische und das Religiöse. Die Apokalypse beziehungsweise ein Hang zur Weltuntergangsstimmung findet sich in beiden Medien, wie deutlich geworden ist, besonders in der Vielzahl der Stadt-, Landschafts- und Kriegsdarstellungen. Meidner verarbeitet hier immer wieder Gefühle existentieller Bedrohung, die sowohl durch die Erfahrung der Großstadt, als auch durch die allgemeine Krisenstimmung vor und erst recht während des Ersten Weltkrieges hervorgerufen wurden. Im Bild, wie auch im Text vermag er gleichermaßen seine Skepsis gegenüber den aktuellen politischen und sozialen Zuständen, seine Bedrückung und Ängste durch einen expressiven Mal- und Sprachgestus zu vermitteln. In beiden Medien nutzt er die formalen Gestaltungsmittel bewegte Pinsel- und Federführung, pastosen Farbauftrag, Aufbrechen der naturalistischen Sehgewohnheiten und ausdrucksstarke Farben in Komplementärkontrasten oder in düsterer Tonalität in den bildkünstlerischen Werken, pathetischen Sprachduktus, Spontaniteitsgesti wie z. B. Ausrufe, Stakkatorhythmus und verlebendigende Formulierungen in den Texten - um Unruhe, Verlorenheit und Dramatik zum Ausdruck zu bringen. Seine Stadtdarstellungen im Text wie auch im Bild transportieren dabei zunächst noch eine ambivalente Wahrnehmung des Urbanen zwischen faszinierender Inspirationsquelle und zerstörerischem Einfluss, wie es z. B. der Vergleich des Gedichtes und der Grafik zur Alaunstraße in Dresden zeigt. Die Stadt- und Landschaftsapokalypsen und vergleichbare Partien in literarischen Werken schließlich spiegeln Meidners persönliche Untergangsstimmung, die keinerlei Tendenzen der weit verbreiteten Aufbruchseuphorie vor dem Krieg aufweist. Insbesondere die Prosa-Texte, welche Meidner ja während seines Kriegsdienstes erst zu schreiben begann, zeugen von seiner ablehnenden Haltung gegenüber dem Kriegsgeschehen. Die religiösen Bezüge finden sich nicht nur in den direkten Darstellungen, wie z. B. den Prophetenfiguren, sondern sind, wie aufgezeigt wurde, ebenfalls Bestandteil der apokalyptischen Landschaften und Kriegsbilder, die Parallelen zu alttestamentlichen Untergangsszenarien aufweisen, wie z. B. die Gemälde „Apokalyptische Landschaft“ (Berlin) von 1912/13 und „Jüngster Tag" von 1916. Hier verwendet Meidner Motive, wie eine Flut, die an die Sintflut denken lässt, oder einen Tod und Sünde symbolisierender Totenkopf mit Schlange. In Meidners pathetischen Prosatexten werden diese Bezüge durch eine 
direkte Ansprache Gottes, wie beispielsweise in „Anrufung des süßen, unersättlichen Züchtigers", teils noch deutlicher, und untermauern so im Vergleich auch den religiösen Gehalt der entsprechenden, bildkünstlerischen Werke. In beiden Medien spiegelt sich die verzweifelte Hoffnung und Suche des Künstlers nach Erlösung. Diese scheint er nach Ende des Ersten Weltkriegs kurzzeitig in den revolutionären Strömungen zu finden, die die gesellschaftliche Neuordnung anstreben, wie es besonders ein Aufruf wie „Bruder, zünd die Fackel an“ deutlich macht. Hier bringt Meidner sein politisches Aufbegehren viel klarer und eindringlicher zum Ausdruck als in den eher verhaltenen Bildern, wie dem doch sehr zwiespältigen Gemälde „Revolution“. Komplettiert wird Meidners expressionistisches Euvre durch die eindringlichen Porträts, die im Sinne von Kandinskys Forderung nach dem Ausdruck des Inneren die Seele des Gegenübers zu erforschen suchen. Ein Anspruch, den Meidner so auch in seinem Traktat „Vom Zeichnen“ formuliert.

Ist Meidners literarisches, expressionistisches CEuvre - neben einigen Dichtungen im Kern vor allem aus den insgesamt 33 Prosa-Texten der zwei Anthologien „Im Nacken das Sternemeer“ und „Septemberschrei“ bestehend - auch weniger umfangreich, in einem begrenzteren Zeitraum entstanden und in seiner Qualität dem bildkünstlerischen Werk, das eine Vielzahl von Gemälden und Grafiken umfasst, nachzuordnen, so ergänzt es Meidners Hauptmedium in bemerkenswerter Weise und bietet weiteren Aufschluss über dessen Form und Inhalt.

Ähnlich verhält es sich mit dem doppelbegabten Schaffen von Oskar Kokoschka. Auch hier ergänzen sich bildkünstlerische und schriftstellerische Werke in gewinnbringender Weise zu einem Gesamtbild von Kokoschkas künstlerischem Ausdruckswillen. Das zentrale Thema seines expressionistischen Euvres ist der Geschlechterkonflikt. Es zieht sich nicht nur kontinuierlich durch die Gemälde und Grafiken von ca. 1910 bis 1920 hindurch, sondern bildet den Kern jedes einzelnen der sechs Bühnenstücke und acht Dichtungen, die Kokoschka zwischen 1907 - beginnend mit dem Märchenbuch „Die träumenden Knaben“ - und 1921 verfasst hat. Von Philosophen wie Weininger und Bachofen beeinflusst, beschreibt Kokoschka den Geschlechterkonflikt als eine Folge der Differenz zwischen dem „geistbestimmten“ Mann und der „triebhaften“, erotischen Frau. Seine Werke spiegeln seine Lösungssuche für dieses vielfach mit persönlichen Erfahrungen verknüpfte Dilemma. Insbesondere an den Texten lässt sich dabei eine stufenweise Entwicklung von aggressiver Unversöhnlichkeit und gegenseitiger Vernichtung (,Mörder, Hoffnung der Frauen“) hin zur versöhnlichen Aufopferung und Auflösung des Konflikts („Hiob“) ablesen. Hier steht die allgemeine Behandlung des Themas im Vordergrund, während die Gemälde und Grafiken in der oft unverblümten Darstellung der für Kokoschka so schicksalhaften Geliebten Alma Mahler zumeist eine persönlichere Ebene behandeln. Der Vergleich beider Medien ist daher sehr erhellend, bringt er doch zwei unterschiedliche Seiten eines Themas - die biografische und die zeitgeschichtlich-philosophische - zum Vor- 
schein. Doch wie die Untersuchung gezeigt hat, bieten die Texte weit mehr als nur die Auseinandersetzung mit der Geschlechterdifferenz. In komplexer Weise sind vielfach weitere Aspekte verarbeitet, die in hohem $\mathrm{Ma} \beta$ auch in den Bildern - hier außerhalb eines erzählerischen Kontextes und mit direkterem Fokus - thematisiert werden. So vermag die Analyse des Stückes „Orpheus und Eurydike“ über Kokoschkas artifizielle Verknüpfung mythologischer Motive mit der so verschlüsselten Geschichte seiner gescheiterten Beziehung mit Alma hinaus auch des Künstlers kriegskritische Haltung herauszustellen. Kokoschka behandelt die Kriegsthematik bildkünstlerisch in sehr unterschiedlicher Weise, was auf die unterschiedliche Funktion der Werke zurückzuführen ist. So stehen die nüchternen Zeichnungen des dokumentierenden Kriegsberichterstatters Kokoschka in deutlichem Gegensatz zu den bissig-satirischen Grafiken aus der Kriegsmapppe des Künstlers. Die drastischen Schmähungen der Soldaten im dritten Akt des Orpheus-Stückes vervollständigen das Gesamtbild von Kokoschkas Verarbeitung des Themas und belegen seine Ablehnung des Krieges, die ohne dies weniger deutlich wäre. In ähnlicher Weise ergänzen sich Text und Bild auch bei der Behandlung religiöser Thematik. Es konnte gezeigt werden, wie oft Kokoschka Motive und Personen mit religiösem Gehalt, wie den Gottessohn, das Urelternpaar, die Pietà-Gruppe, Engel, und Heilige, insbesondere um 1911 verwendet, um sein Bild des leidenden Künstlers und den Geschlechterkonflikt zu veranschaulichen. Zugleich warf dieses auffällige Rekurrieren auf christliche Aspekte die Frage auf, ob damit zugleich Kokoschkas eigener Glauben erkennbar wird. Die Analyse des Vortrags „Von der Natur der Gesichte" konnte dies negativ beantworten. So ist also offenbar, dass die beiden Medien nicht nur auch bei kleinen Unterschieden intentional eng miteinander verknüpft sind - dies ist vor allem auch bei der Betrachtung des Menschen der Fall, den Kokoschka ganz wie auch Meidner wieder und wieder bis in sein Inneres zu durchleuchten sucht -, sondern die Texte an mancher Stelle Fragen klären können, die die Bilder aufwerfen oder unbeantwortet lassen und umgekehrt. In den Texten, die formal ähnlich wie bei Meidner häufig expressionistische Charakteristika wie Verknappung und Verlebendigung aufweisen, ist wie bei den Bildern eine auffällige Präferenz von Symbolen und festgelegten Motiven zu beobachten. Die Gemälde kennzeichnet ein ebenso typischer, expressiver Pinselstrich, wenn auch in Farbauftrag und Flächenbehandlung vielfältige Phasen und Entwicklungen auszumachen sind - von diaphan bis opak, von Ritzungen bis zu pastosem Farbauftrag, von den konturbetonten noch dem Jugendstil verpflichteten Figuren in „Die träumenden Knaben“ bis hin zu den Farbflächen in „Die Macht der Musik“".

Dass der Vergleich der Künste nicht nur auf der intentionalen Ebene, also unter thematischen Gesichtspunkten, lohnend und legitim ist, zeigte die Betrachtung einzelner formaler Kriterien im Euvre beider Künstler, die durchaus analoge Elemente in Bild und Text herausstellen konnte. Hinsichtlich der Darstellung des Raumes bei Meidner ist die Dynamisierung der Raumelemente in beiden Medien 
elementar. Während in der exemplarischen Untersuchung die in der Grafik wiedergegebene Dresdner Alaunstraße durch „wankende“ Linien und unruhige Schraffuren gekennzeichnet ist, die die Sehgewohnheiten aufbrechen und den ganzen Straßenzug in chaotische Bewegung zu versetzen scheint, wird die gleiche Straße im Gedicht durch Bewegungsverben, schnelle, stakkatohafte Wortreihungen und Verlebendigung in vergleichbarer Weise dynamisiert. Bewegtheit und im übertragenen Sinne innere Unruhe sind auch die Kernelemente beider Medien im untersuchten Beispiel zur Figurenauffassung. Während Meidner die seelische Zerrissenheit im Gemälde durch spannungsreiche Beleuchtung, Komplementärkontrast, gegenläufige Bewegungen oder Perspektiven sowie schnelle, expressive Pinselhiebe und eine fast grimassenhafte Darstellung des Gesichts zum Ausdruck bringt, sucht er sie in seiner literarischen Selbstbeschreibung über die Verknüpfung unzähliger Tiermetaphern und damit verbundene Zerfaserung, beziehungsweise Verfremdung des menschlichen Einzelwesens zu erreichen. Die Farbe zu guter Letzt erhält bei ihm ebenfalls eine vor allem dynamisierende Bedeutung, indem sie, teils mit speziell festgelegtem Verwendungszweck, pastos und ausdrucksstark - also bestimmte Stimmungen unterstreichend - verwendet wird.

Bei Kokoschka sind Analogien der formalen Mittel ebenfalls auszumachen, auch wenn er, anders als Meidner, oft eher eine symbolhafte Bildsprache und Ausdrucksform wählt. So beispielsweise, wenn er den Raum im Bild wie im Text auf einzelne, bedeutsame Motive reduziert, wie in „Die Windsbraut“ auf das vom aufgepeitschten Meer bedrohte Boot, das sein Gefühlschaos und die scheiternde Beziehung mit Alma symbolisiert, oder im Drama „Mörder, Hoffnung der Frauen" auf den düsteren, phallusartigen Turm, dessen Gitterkäfig die Gefangenschaft durch sexuelles Verlangen verbildlicht. Von besonderer Bedeutung ist bei Kokoschka die symbolische Aufladung der Farben Rot, Weiß und Blau, die sowohl in den bildkünstlerischen, wie auch schriftstellerischen Werken zum Tragen kommt. In beiden Medien kennzeichnet die Rot-Weiß-Opposition den Gegensatz von Erotik und Unschuld („Die träumenden Knaben“ und dazugehörige Lithografien) oder von Lebenskraft und Tod („Pietà“ und „Mörder, Hoffnung der Frauen“). Ebenso gilt die Zuordnung der Farbe Blau zum männlichen, die Farbe Rot zum weiblichen Geschlecht. Es ist wichtig festzuhalten, dass Kokoschka diesen festgelegten Kanon aus speziellen Motiven und symbolisch gemeinten Farben während seines gesamten expressionistischen Schaffens beibehält und kontinuierlich wiederholt. Für die Gestaltung der Figur ist ähnlich wie bei Meidner auch bei Kokoschka die Psychologisierung der Person entscheidend. Hierfür können ebenfalls analoge formale Mittel zum Einsatz kommen, wie in den untersuchten Beispielen, die Aggression über Vertierung der Person mittels Verfremdung der Physiognomie im Bild oder durch Tiermetaphern im Text, transportieren.

Für die Behandlung aller drei Kriterien bei beiden Künstlern ist eine starke Psychologisierung zu beobachten, die die naturalistische Auffassung von Raum, Farbe und Figur aufbricht. Alles wird statt durch die sachliche Naturbeobachtung, 
durch eine „emotionale Brille“ erfasst und auch ebenso angewendet. Das gilt für literarische wie bildkünstlerische Erzeugnisse gleichermaßen und ist ein Charakteristikum expressionistischer Ausdrucksweise. Diese im Kapitel 3.2. exemplarisch vorgenommenen Untersuchungen formaler Analogien eignen sich, mit Behutsamkeit angewendet, ebenfalls, um dem „Wie“ der Verknüpfung zweier Medien auf den Grund zu gehen. Sinnvoll erscheint dieses Vorgehen im Falle der Untersuchung von Doppelbegabung und auch von bestimmten künstlerischen Strömungen, wie hier dem Expressionismus - also in den Fällen, in denen ein denkbar enger (vor allem inhaltlicher) Zusammenhang zwischen den Medien vorliegt. Inwieweit dies in anderen komparatistischen Studien zur Erhellung beiträgt, kann an dieser Stelle nicht erörtert werden, sondern bleibt einer jeweiligen Einzelfallprüfung überlassen.

Neben der vertiefenden, formal-stilistischen Untersuchung von Gestaltungsmitteln als ein Aspekt des Künstevergleichs, sind auch andere ergänzende Betrachtungen denkbar. So könnten weitere Untersuchungen einzelner Künstlerpersönlichkeiten das Verständnis von Doppelbegabung im Expressionismus erweitern und den in der vorliegenden Arbeit gegebenen Einblick in die Thematik ergänzen. Aufschlussreich wäre hierbei beispielsweise auch die Ausweitung der Fragestellung auf weitere Künste, vor allem auch auf die Musik, die weitere Erkenntnisse über die Beziehungen zwischen den verschiedenen künstlerischen Bereichen im Expressionismus bieten würden. Doch dies sind weiterführende Fragen, die den Rahmen der vorliegenden Arbeit sprengen würden. Hier liegt die Konzentration auf dem grundsätzlichen Verständnis der Voraussetzungen für das Ausleben von Doppelbegabung im Expressionismus, auf der Erprobung verschiedener Wege des Künstevergleichs und vor allem auf der tiefgehenden Durchdringung der Werke von Ludwig Meidner und Oskar Kokoschka als zwei individuellen, doppelbegabten Künstlerpersönlichkeiten, die zum Ursprung einer künstlerischen Tendenz gehörten, die Kunst und Leben miteinander zu verbinden suchte. Einer Tendenz, die sich in abgewandelter Weise im Dada und schließlich in der weiteren Entwicklung künstlerischer Positionen nach dem Zweiten Weltkrieg insbesondere auch in den Werken der Fluxus-Künstler im Grundgedanken wiederfindet und also noch weit in die Kunst des 20. Jahrhunderts ausstrahlt. 



\title{
A Quellen- und Literaturverzeichnis
}

\author{
Quellen
}

Bachofen, J./Fuchs, H./Meuli, K.: Johann Jakob Bachofens gesammelte Werke 1. Basel: 1948.

Becher, J. R.: Werke in drei Bänden, Bd. 1: Gedichte. Berlin, Weimar: 1971.

Bergson, H.: Schöpferische Entwicklung. Jena: 1912.

Best, O. F. (Hrsg.): Theorie des Expressionismus. Stuttgart: Reclam, 2007.

Darwin, C./Neumann, C. W. [Übers.]: Die Entstehung der Arten durch natürliche Zuchtwahl. Stuttgart: 1980.

Ehrenstein, A.: Oskar Kokoschka. In: Die literarische Gesellschaft; 3. Jg. Hamburg: 1917, S. 311-314.

Freud, S.: Die Traumdeutung. Frankfurt am Main: 1994.

Herrmann-Neiße, M.: Meine Erlebnisse mit der Bildenden Kunst. In: Das Kunstblatt. Berlin: 1929

Huelsenbeck, R.: Der neue Mensch. In: Neue Jugend; Nr. 1 (Wochenausgabe, 23.5.1917). Berlin: 1917, S. 2-3.

Kandinsky, W./Bill, M.: Über das Geistige in der Kunst. Bern-Bümpliz: 1952.

Kandinsky, W./Marc, F.: Der Blaue Reiter. München [u. a.]: 2002.

Kokoschka, O.: Oskar Kokoschka. Mein Leben. München: 1971.

Kokoschka, O./Spielmann, H. [Hrsg.]: Oskar Kokoschka. Das schriftliche Werk, Bd. 3: Aufsätze, Vorträge, Essays zur Kunst. Hamburg: 1975.

Kokoschka, O./Spielmann, H. [Hrsg.]: Oskar Kokoschka. Das schriftliche Werk, Bd. 4: Politische Äusserungen. Hamburg: 1976.

Kokoschka, O.: Briefe, Bd. 1-4. Düsseldorf: 1984-88.

Lessing, G. E.: Laokoon oder Über die Grenzen der Malerei. Frankfurt a.M.: 1988.

Mach, E.: Die Analyse der Empfindungen und das Verhältniss des Physischen zum Psychischen. Jena: 1903.

Madaurensis, A. (Hrsg. Kenney, E. J.): Cupid \& Psyche. Cambridge: 1990. 
Mahler-Werfel, A. M.: Mein Leben. Frankfurt am Main: 1981.

Meidner, L.: Anleitung zum Malen von Großstadtbildern. Berlin: 1914.

Meidner, L.: Alaunstraße in Dresden. In: Die Aktion 5. Berlin: 1915, Spalte 61-62.

Meidner, L.: An alle Künstler, Dichter, Musiker. In: Das Kunstblatt 3. Berlin: 1919, S. 29-30.

Meidner, L.: Septemberschrei: Hymnen, Gebete, Lästerungen. Berlin: 1920

Meidner, L.: Eine autobiografische Plauderei. In: Brieger, L.(Hrsg.): Junge Kunst, Bd. 4. Leipzig: 1923.

Meidner, L.: Gruß an Schlesien. In: Schlesische Monatshefte, Blätter für Kultur und Schrifttum der Heimat; Jg. 7, Nr. 9. Breslau: 1930, S. 368.

Meidner, L.: Im Nacken das Sternemeer. Nendeln: (Nachdruck der Ausgabe des Kurt Wolff Verlags, Leipzig 1918), 1973.

Meidner, L.: Vision zur Ekstase. In: Guratzsch, H. (Hrsg.): Ludwig Meidner 18841966: Kat.Ausst. Jüdisches Museum Rendsburg. Schleswig : 2003, S. 14$16 / 43$.

Mühsam, E.: Revolution. In: Revolution 1; Heft 1 (15. Okt.). Berlin: 1913.

Nietzsche, F.: Der Wille zur Macht. Versuch einer Umwertung aller Werte. In: Kröner, A. (Hrsg.): Gesamtausgabe, Bd. 15. Leipzig: 1911.

Nietzsche, F.: Also sprach Zarathustra. In: Oehler, R./Würzbach, F. C. (Hrsg.): Friedrich Nietzsche. Gesammelte Werke, Bd. 13. München: 1925.

Nietzsche, F./Colli, G. (u. a.): Nietzsche-Werke. Anfang 1888 bis Anfang Januar 1889 (Abt. 8: Nachgelassene Fragmente ; Bd. 3). Berlin [u. a.]: 1972.

Pinthus, K. [Hrsg.]: Menschheitsdämmerung: ein Dokument des Expressionismus. Hamburg: 1990.

Prather, M. (u. a.): Paul Gauguin: 1848-1903. Köln: 1994.

Schlegel, A. W.: Die Gemählde. In: Athenäum; Bd. 2. (1799). Stuttgart: 1960 (Reprint), S. 39-151.

Simmel, G.: Das Problem des Portraits. In: Die neue Rundschau, 29. Jg. der freien Bühne, Bd. 2 (Heft 10). Frankfurt a.M.: 1918, S. 1336-1344.

Trakl, G./(Hrsg.) Killy, W.: Dichtungen und Briefe: [historisch-kritische Ausgabe] 1: Gedichte, Sebastian im Traum, Veröffentlichungen im Brenner 1914/15, sonstige Veröffentlichungen zu Lebzeiten, Nachlaß, Briefe. Salzburg: 1987.

Weininger, O.: Geschlecht und Charakter: eine prinzipielle Untersuchung. Leipzig: 1916.

Zweig, S.: Die Welt von gestern: Erinnerungen eines Europäers. Hamburg: 1970. 


\section{Sekundärliteratur}

Albert, K.: Lebensphilosophie. Von den Anfängen bei Nietzsche bis zu ihrer Kritik bei Lukács. Freiburg, München: 1995.

Anz, T./Stark, M.: Manifeste und Dokumente zur deutschen Literatur: Expressionismus 1910-1920. Stuttgart: 1982.

Anz, T.: Literatur des Expressionismus. Stuttgart, Weimar: 2001.

Asendorf, C.: „Wankender Raum“. Das Frühwerk 1907-1916. In: Schröder, K. A./Winkler, J. (Hrsg.): Oskar Kokoschka. München: 1991, S. 11-18

Assmann, M.: Literarische Werke und Briefe (Auswahl). In: Breuer, G./Wagemann, I. (Hrsg.): Ludwig Meidner. Maler, Zeichner, Literat 18841966. Kat.Ausst. Darmstadt. Bd. 2. Stuttgart: 1991, S. 287-487.

Assmann, M.: „Leg den Pinsel weg, Kleckser!“ - Der Dichter und Schriftsteller Ludwig Meidner. In: Natter, T. G. (Hrsg.): Im Nacken das Sternemeer. Ludwig Meidner. Ein deutscher Expressionist. Kat.Ausst. Jüdisches Museum Wien. Wien: 2001, S. 47-55.

Bächtold-Stäubli, H.: Handwörterbuch des deutschen Aberglaubens Bd. 1-10. Berlin [u. a.]: 1987.

Bartmann, D.: Das Großstadtbild Berlins in der Weltsicht der Expressionisten. In: Bothe, R.: Stadtbilder. Berlin in der Malerei vom 17. Jahrhundert bis zur Gegenwart. Kat.Ausst. Berlin-Museum. Berlin: 1987, S. 243-294.

Becker, M.: Ludwig Meidner und die frühexpressionistische Großstadtlyrik. In: Breuer, G. /Wagemann, I. (Hrsg.): Ludwig Meidner: Maler, Zeichner, Literat 1884-1966. Kat.Ausst. Darmstadt. Bd. 1. Stuttgart : 1991, S. 57-70.

Beil, R./Dillmann, C.: Gesamtkunstwerk Expressionismus: Kunst, Film, Literatur, Theater, Tanz und Architektur 1905 bis 1925. Kat.Ausst. Mathildenhöhe Darmstadt. Ostfildern: 2010.

Berankova, L.: Eine kultivierte Chronik der Katastrophenstimmung. Gestus und Pathosformeln im Werk von Ludwig Meidner. In: Natter, T. G.: Im Nacken das Sternemeer. Ludwig Meidner. Ein deutscher Expressionist. Kat.Ausst. Jüdisches Museum Wien. Wien: 2001, S. 40-47.

Blümner, R.: Der Sturm. Eine Einführung. In: Der Sturm. Berlin: 1917, S. 2, 10 14.

Bogner, R. G.: Einführung in die Literatur des Expressionismus. Darmstadt: 2005.

Bothe, R.: Stadtbilder. Berlin in der Malerei vom 17. Jahrhundert bis zur Gegenwart. Kat.Ausst. Berlin-Museum. Berlin: 1987.

Böttcher, K./Mittenzwei, J.: Zwiegespräch: deutschsprachige Schriftsteller als Maler und Zeichner. Leipzig: 1980. 
Breuer, G./Wagemann, I.: Ludwig Meidner: Maler, Zeichner, Literat 1884-1966. Kat.Ausst. Mathildenhöhe Darmstadt. Stuttgart: 1991.

Breuer, G.: Variationen um ein „Weltende“. Zu Ludwig Meidners Sonderstellung im deutschen Expressionismus. In: Natter, T. G. (Hrsg.): Im Nacken das Sternemeer. Ludwig Meidner. Ein deutscher Expressionist. Kat.Ausst. Jüdisches Museum Wien. Wien: 2001, S. 19-31.

Brieger, L.: Ludwig Meidner. Mit einer Selbstbiographie des Künstlers. In: Junge Kunst, Bd. 4 (1. Auflage). Leipzig: 1919.

Brieger, L.: Ludwig Meidner. Eine autobiographische Plauderei. In: Junge Kunst, Bd. 4 (2. völlig veränderte Auflage). Leipzig: 1923.

Brugger, I.: Wesen mit Wesen streitend - Dresdener Werkgruppe 1916-1923. In: Schröder, K. A./Winkler, J. (Hrsg.): Oskar Kokoschka. Kat.Ausst. Kunstforum Länderbank Wien. München: 1991, S. 19-27.

Büchmann, G.: Geflügelte Worte: der Zitatenschatz des deutschen Volkes. Frankfurt a.M.: 1981.

Bushart, M.: Kokoschkas Dresdner Gruppenbildnisse. In: Schmidt, W.: Kokoschka und Dresden. Kat.Ausst. Gemäldegalerie Neue Meister Dresden. Leipzig: 1996, S. 44-50.

Calabrese, O.: Die Geschichte des Selbstporträts. München: 2006.

Cernuschi, C.: Anatomisches Sezieren und religiöse Identifikation. In: Natter, T. G.: Oskar Kokoschka: das moderne Bildnis 1909 bis 1914. Kat.Ausst. Neue Galerie New York. Köln: 2002(a), S. 43-49.

Denkler, H.: „Schauspiel“ und „Der brennende Dornenbusch“ von Oskar Kokoschka. In: Der Deutschunterricht. Beiträge zu seiner Praxis und wissenschaftlichen Grundlegung Jg. 17, Nr. Heft 5. Stuttgart: 1965, S. 34-52.

Döring, T.: Ansichten vom Ich: 100 ausgewählte Blätter der Sammlung ,Künstler sehen sich selbst - Grafische Selbstbildnisse des 20. Jahrhunderts' im HerzogAnton-Ulrich-Museum Braunschweig. Braunschweig: 1997.

Eder, F. X.: Sigmund Freud und die Kultur des Fin de Siècle. In: Faulstich, W. (Hrsg.): Das 1. Jahrzehnt. München: 2006, S. 219-230.

Eliel, C. S.: Die „Apokalyptischen Landschaften“ Ludwig Meidners. In: Eliel, C.S.: Apokalyptische Landschaften. Kat.Ausst. Berlinische Galerie. München: 1990, S. 11-63.

Erling, Katharina: „Das Bekenntnishafte zieht mich an“ - Christliche Motive und Inhalte im Frühwerk Oskar Kokoschkas. In: Frodl, G./Natter, T. G.(Hrsg.): Oskar Kokoschka und der frühe Expressionismus. Symposion der Österreichischen Galerie, Belvedere im Rahmen der Ausstellung „Kokoschka und Dresden“. Wien: 1997, S. 54-73.

Faulstich, W. (Hrsg.): Das 1. Jahrzehnt. München: 2006.

Fink, G. (Hrsg.): Ovid Metamorphosen. Düsseldorf: 2005. 
Fischer, W. G.: Oskar Kokoschka als Seher des Untergangs oder Die Bühne des Verwesens. In: Patka, E. (Hrsg.): Oskar Kokoschka. Symposion der Hochschule für angewandte Kunst in Wien (3.-7. März 1986). Salzburg: 1986, S. 43-71.

Fischer, W. G.: Kokoschkas Golgatha. Reaktionen auf das politische Geschehen 1916 bis 1923. In: Schmidt, W.: Kokoschka und Dresden. Kat.Ausst. Gemäldegalerie Neue Meister Dresden. Leipzig: 1996, S. 72-75.

Flammann, W.: Ludwig Meidner 1884-1966, Kneipe und Café: Aquarelle, Zeichnungen, Druckgrafik. 1994.

Fleming, J.: Erotische Kultur. Debatten über Liebe, Sexualität und Geschlechterverhältnisse. In: Faulstich, W. (Hrsg.): Das 1. Jahrzehnt. München : 2006, S. 163-174.

Flora, P./Ziegler, K.: Tarockanische Geheimnisse: 44 Faks.- Reproduktionen von Buntstift- und Bleistiftzeichnungen. Wien: 1974.

Frodl, G./Natter, T. (Hrsg.): Oskar Kokoschka und der frühe Expressionismus (Symposion). Wien: 1997.

Gallwitz, K. (Hrsg.): Oskar Kokoschka und Alma Mahler: die Puppe. Frankfurt a. M.: 1992.

Gleisberg, D.: Max Klinger: 1857-1920. Leipzig: 1992.

Goldberg, G. (u. a.): Albrecht Dürer: die Gemälde der Alten Pinakothek. Heidelberg: 1998.

Gorsen, P.: Kokoschka und die Puppe, pygmalionistische und fetischistische Motive im Frühwerk. In: Patka, E. (Hrsg.): Oskar Kokoschka. Symposion der Hochschule für angewandte Kunst in Wien (3.-7. März 1986). Salzburg: 1986, S. 187-202.

Gössmann, E.: Anthropologie und soziale Stellung der Frau nach Summen und Sentenzen-Kommentaren des 13. Jahrhunderts. In: Zimmermann, A. (Hrsg.): Soziale Ordnungen im Selbstverständnis des Mittelalters; Bd. 1. Berlin: 1980, S. 281-297.

Grasskamp, W.: Die Malbarkeit der Stadt. Die Krise der Vedute im deutschen Expressionismus. In: Smuda, M. (Hrsg.): Die Großstadt als Bild. München: 1992, S. 265-284.

Grochowiak, T.: Ludwig Meidner. Recklinghausen: 1966.

Günther, H.: Künstlerische Doppelbegabungen: erw. Neufassung mit 156, meist erstveröff. Abb. nach Werken deutschsprach. Künstler vom 16.-20. Jh. München: 1960.

Guratzsch, H. (Hrsg.): Ludwig Meidner: 1884-1966. Schleswig: 2003.

Hadermann, P.: L' Hommage graphique et littéraire de Kokoschka à Klimt: Die träumenden Knaben. Littérature et culture allemandes. Brüssel : 1985, S. 283314. 
Haenlein, C.: Alles andere zu bedingt. In: Haenlein, C. (Hrsg.): Oskar Kokoschka - Die frühen Jahre. Aquarelle und Zeichnungen. Kat.Ausst. Kestner Gesellschaft Hannover. Hannover: 1983, S. 11-23

Hagstrum, J. H.: The sister arts: the tradition of literary pictorialism and English poetry from Dryden to Gray. Chicago [u. a.]: 1987.

Henkel, A./Schöne, A.: Emblemata: Handbuch zur Sinnbildkunst des 16. und 17. Jahrhunderts. Stuttgart: 1967.

Heuberger, G./Riedel, E.: Malerei als Gebet. Ludwig Meidner und sein Judentum. In: Natter, T. G.: Im Nacken das Sternemeer. Ludwig Meidner. Ein deutscher Expressionist. Kat.Ausst. Jüdisches Museum Wien. Wien : 2001, S. 31-40.

Heusinger von Waldegg, J.: Die Bildnisse Max Herrmann-Neißes. Zur Ikonografie des expressionistischen Dichterporträts. In: Breuer, G./Wagemann, I. (Hrsg.): Ludwig Meidner. Zeichner, Maler, Literat 1884-1966. München : 1991, S. 70-83

Hodin, J. P.: Bekenntnis zu Kokoschka: Erinnerungen und Deutungen : [mit 60 Abb.]. Berlin [u. a.]: 1963.

Hodin, J. P.: Ludwig Meidner: seine Kunst, seine Persönlichkeit, seine Zeit. Darmstadt: 1973.

Hoffmann, E.: Kokoschka: life and work. London: Faber and Faber, 1947.

Hoffmann, K.: Ludwig Meidner und der europäische Expressionismus. Ludwig Meidner 1884-1966. Kat.Ausst. Kunstverein Wolfsburg. Wolfsburg: 1985, S. 99-115.

Hollein, M.: Die Visionen des Arnold Schönberg: Jahre der Malerei. OstfildernRuit: 2002.

Hülsewig-Johnen, J.: Gesichter der Stadt. In: Smuda, M. (Hrsg.): Die Großstadt als Bild. München : 1992, S. 239-264.

Husslein-Arco, A./Weidinger, A.: Kokoschka: Träumender Knabe - Enfant terrible. Weitra: 2008.

Huysman, L.: Kein Märchenbuch für Philisterkinder. „Die träumenden Knaben“ von Oskar Kokoschka: eine Gedichtanalyse. (Lizenziatsarbeit). Gent, 1992.

Jäger, G.: Kokoschkas „Mörder, Hoffnung der Frauen“. Die Geburt des Theaters der Grausamkeit aus dem Geist der Wiener Jahrhundertwende. In: Germanisch-Romanische Monatsschrift. Neue Folge, Bd. 32, Heft 2 (1982) S. 215233.

Jürgens-Kirchhoff, A.: Schreckensbilder: Krieg und Kunst im 20. Jahrhundert. Berlin: Reimer, 1993.

Jurkat, A.: Apokalypse-Endzeitstimmung in Kunst und Literatur des Expressionismus (Diss.). Bonn, 1993.

Knapp, G.: Die Literatur des deutschen Expressionismus: Einführung, Bestandsaufnahme, Kritik. München: 1979. 
Kunz, L.: Ludwig Meidner - Dichter, Maler und Cafés. Zürich: 1973.

Lachnit, E.: Die Wiener Schule der Kunstgeschichte und die Kunst ihrer Zeit: zum Verhältnis von Methode und Forschungsgegenstand am Beginn der Moderne. Wien: 2005.

Lankheit, K.: Der Blaue Reiter. Dokumentarische Neuausgabe. München: 1990.

Leiß, I./Stadler, H.: Wege in die Moderne 1890-1918. München: 1999.

Leistner, G.: Idee und Wirklichkeit: Gehalt und Bedeutung des urbanen Expressionismus in Deutschland, dargestellt am Werk Ludwig Meidners. Frankfurt am Main [u. a.]: 1986.

Leistner, G.: Zwischen Apokalypse und Offenbarung. Der Großstadtexpressionist Ludwig Meidner. In: Natter, T. G. (Hrsg.): Im Nacken das Sternemeer. Ludwig Meidner. Ein deutscher Expressionist. Kat.Ausst. Jüdisches Museum Wien. Wien: 2001, S. 9-19.

Lischka, G. J.: Oskar Kokoschka: Maler und Dichter. Frankfurt a.M.: 1972.

Lüken, S./Warncke, C.-P./Unverfehrt, G.: Die Verkündigung an Maria im 15. und frühen 16. Jahrhundert: historische und kunsthistorische Untersuchungen. Göttingen: 2000.

Maas, M. P.: Das Apokalyptische in der modernen Kunst: Endzeit oder Neuzeit. München: 1965.

Marquart, C.: Die frühen Selbstbildnisse 1905-1925. In: Breuer, G./Wagemann, I. (Hrsg.): Ludwig Meidner. Zeichner, Maler, Literat 1884-1966. Kat.Ausst. Darmstadt, Bd. 1. Stuttgart : 1991, S. 28-39.

Mautz, K.: Die Farbensprache der expressionistischen Lyrik. In: Deutsche Vierteljahresschrift für Literaturwissenschaft und Geistesgeschichte Jg. 31. Nr. 2. Stuttgart, Weimar: 1957, S. 198-240.

Merlhès, V.: Correspondance de Paul Gauguin. Paris: 1984.

Messer, T. M.: Der irrende Ritter. In: Patka, E. (Hrsg.): Oskar Kokoschka. Symposion der Hochschule für angewandte Kunst in Wien (3.-7. März 1986). Salzburg: 1986, S. 183-186.

Mirouze, L.: Infanteristen des Ersten Weltkrieges. Solingen: 1996.

Mitterer, A.: „Mas occasionatus“ oder zwei Methoden der Thomasdeutung. In: Zeitschrift für katholische Theologie; Bd. 72. Würzburg: 1950, S. 80-103.

Müller, W. J./Jongh, E. de: Die Sprache der Bilder: Realität und Bedeutung in der niederländischen Malerei des 17. Jahrhunderts. Braunschweig: 1978.

Müller, K.: Unter unerforschlichen Meteoren: Ludwig Meidner - Ernst Barlach. Bielefeld: 2009.

Museum für Kunst und Gewerbe, Hamburg: Oskar Kokoschka: Illustrationen, Mappenwerke, Plakate. Katalog zur Ausstellung vom 29. April bis zum 20. Juni 1965. Hamburg: 1965. 
Natter, T. G.: „War doch nur ein Feuerwehrauto!“ Erinnerungen von Jörg von Kitta-Kittel an Ludwig Meidner. Ein Interview. In: Natter, T. G. (Hrsg.): Im Nacken das Sternemeer. Ludwig Meidner. Ein deutscher Expressionist. Kat.Ausst. Jüdisches Museum Wien. Wien: 2001, S. 193-199.

Natter, T. G. (Hrsg.): Im Nacken das Sternemeer. Ludwig Meidner. Ein deutscher Expressionist. Kat.Ausst. Jüdisches Museum Wien. Wien: 2001.

Natter, T. G.: „Charakterbildnisse, nicht Gesichtsbildnisse“. Zu Kokoschkas frühen Porträts. In: Natter, T. G.: Oskar Kokoschka: das moderne Bildnis 1909 bis 1914. Kat.Ausst. Neue Galerie New York. Köln: 2002, S. 88-95.

Natter, T. G.: Oskar Kokoschka: das moderne Bildnis 1909 bis 1914. Kat.Ausst. Neue Galerie New York. Köln: 2002.

Noll, T.: „Adam und Eva“ im Werk von Max Beckmann. In: Jahrbuch der Berliner Museen 43. Berlin: 2001, S. 261-302.

Ohlsen, N.: Forels Hände. In: Sommer, A.: Kokoschka. Werke der Oskar Kokoschka Stiftung Museé Jenisch, Vevey. Kat.Ausst. Kunsthalle Emden. Heidelberg: 2001, S. 21-31.

Padberg, M.: Weltentaumel-Anmerkungen zu Ludwig Meidners expressionistischer Werkphase. Ludwig Meidner-Weltentaumel. Die expressionistische Werkphase. Kat.Ausst. Verein August-Macke-Haus Bonn. Bonn: 2004, S. 12 46.

Patka, E. (Hrsg.): Oskar Kokoschka. Symposion der Hochschule für angewandte Kunst in Wien. Salzburg: 1986.

Pessler, M.: Drama und Drastik in den frühen Bildniszeichnungen von Oskar Kokoschka. In: Natter, T. G.: Oskar Kokoschka: das moderne Bildnis 1909 bis 1914. Kat.Ausst. Neue Galerie New York. Köln: 2002, S. 184-186.

Pickel, R.: Alte Pinakothek München: Erläuterungen zu den ausgestellten Gemälden. München: 1999.

Raabe, P.: Expressionismus: Aufzeichnungen und Erinnerungen der Zeitgenossen. Olten [u. a.]: 1965.

Rathenau, E.: Der Zeichner Kokoschka. Hamburg: 1961.

Reher, T: Kampf des Wildlings mit dem Rotfisch. Studien zum literarischen Frühwerk Oskar Kokoschkas. (Magisterarbeit). Erlangen: 1993.

Reisinger, F.: Die Gefährdung des Individuums. Mythosproblematik und Groteskform im schriftlichen Werk von Oskar Kokoschka. In: Patka, E. (Hrsg.): Oskar Kokoschka. Symposion der Hochschule für angewandte Kunst in Wien. Salzburg: 1986, S. 154-168.

Rijksmuseum (Netherlands): Tot lering en vermaak: betekenissen van Hollandse genrevoorstellingen uit de zeventiende eeuw. Amsterdam: 1976.

Rödiger-Diruf, E.: Auf leisen Pfoten: die Katze in der Kunst. Heidelberg: 2007. 
Roters, E.: Nächte des Malers. Apokalyptische Landschaften. Kat.Ausst. Berlinische Galerie. München: 1990, S. 63-90.

Rothe, W.: Der Expressionismus: theologische, soziologische und anthropologische Aspekte einer Literatur. Frankfurt am Main: 1977.

Rudenstine, A. Z.: The Guggenheim Museum Collection: paintings 1880-1945; Vol. 2. New York: 1976.

Salzer, A. (u. a.): Illustrierte Geschichte der deutschen Literatur in 6 Bänden; Bd. 5: Das 20. Jahrhundert. Weinheim: c. 1986.

Sandler, W.: Der verbotene Baum im Paradies: was es mit dem Sündenfall auf sich hat. Kevelaer: 2009.

Schmid, A.: Die sogenannten „Apokalyptischen Landschaften“ (1912-16). In: Breuer, G./Wagemann, I.: Ludwig Meidner. Maler, Zeichner, Literat 18841966. Kat.Ausst. Darmstadt, Bd. 1. Stuttgart: 1991, S. 84-96

Schmidt, W.: Kokoschka und Dresden. Kat.Ausst. Gemäldegalerie Neue Meister Dresden. Leipzig: 1996.

Schneede, U. M.: „Ähnlicher als man ist“. Bildnisse in der Moderne. In: Natter, T. G. (Hrsg.): Oskar Kokoschka. Das moderne Bildnis 1909-1914. Köln: 2002, S. 12-18.

Schober, T.: Das Theater der Maler. Stuttgart: 1994.

Schröder, K. A./Winkler, J.: Oskar Kokoschka. Kat.Ausst. Kunstforum Länderbank Wien. München: 1991.

Schulz-Hoffmann, C.: Pinakothek der Moderne: Malerei, Skulptur, Neue Medien. Köln: 2002.

Schumacher-Haardt, U.: Das Künstlerporträt im Expressionismus. Münster: 1997.

Schvey, H. I.: Oskar Kokoschka: The painter as playwright. Detroit: 1982.

Schvey, H. I.: Mit dem Auge des Dramatikers: Das Visuelle Drama bei Oskar Kokoschka. In: Patka, E. (Hrsg.): Oskar Kokoschka. Symposion der Hochschule für angewandte Kunst in Wien. Salzburg: 1986, S. 100-113.

Schvey, H. I.: Doppelbegabte Künstler als Seher: Oskar Kokoschka, D. H. Lawrence und William Blake. In: Weisstein, U.: Literatur und bildende Kunst: ein Handbuch zur Theorie und Praxis eines komparatistischen Grenzgebietes. Berlin: 1992, S. 73-85.

Schwab, C.: Der innere Dämon und die kindliche Perspektive. Kokoschka und das Theater von 1917 bis 1922. Kat.Ausst.: Kokoschka und Dresden. 1996, S. 67-71.

Schwalenbach, F.: Oskar Kokoschka. Königsstein im Taunus: 1967.

Schwerte, H.: Anfang des expressionistischen Dramas: Oskar Kokoschka. In: Zeitschrift für Deutsche Philologie 83, Nr. 2. Berlin: 1964, S. 171-190. 
Secci, L.: Die lyrischen Dichtungen Oskar Kokoschkas. In: Jahrbuch der deutschen Schillergesellschaft 12. Stuttgart: 1968, S. 456-493.

Sérullaz, A./Pomarède, V.: Eugène Delacroix.: la libertè guidant le peuble. Paris: 2004.

Smuda, M. (Hrsg.): Die Großstadt als Bild. München: 1992.

Soergel, A.: Dichtung und Dichter der Zeit: eine Schilderung der deutschen Literatur der letzten Jahrzehnte. N. F.: Im Banne des Expressionismus. Leipzig: 1925.

Sommer, A.: Kokoschka. Werke der Oskar Kokoschka Stiftung Museé Jenisch, Vevey. Kat.Ausst. Kunsthalle Emden. Heidelberg: 2001.

Spielmann, H.: Oskar Kokoschka: die Fächer für Alma Mahler. Dortmund 1988.

Spielmann, H.: Oskar Kokoschka - Lebensspuren: Ausgewählte Gemälde, Aquarelle, Zeichnungen der Kokoschka-Stiftung Vevey aus den Jahren 1906 bis 1976. Genf [u. a.]: 1992.

Spielmann, H.: Oskar Kokoschka. Das Frühwerk. In: Kunstchronik Nr. 47. Nürnberg: 1994, S. 418-422.

Spielmann, H.: Oskar Kokoschka: Leben und Werk. Köln: 2003.

Spielmann, H.: Oskar Kokoschka - Erlebnis des Augen-Blicks: Aquarelle und Zeichnungen. München: 2005.

Stark, M.: Für und wider den Expressionismus: die Entstehung der Intellektuellendebatte in der deutschen Literaturgeschichte. Stuttgart: 1982.

Stöbe, E.: Die Praxis des Koloristen Oskar Kokoschka. In: Frodl, G./Natter, T. G. (Hrsg.): Oskar Kokoschka und der frühe Expressionismus (Symposion). Wien: 1997, S. 101-111.

Strobl, A./Weidinger, A.: Oskar Kokoschka, Das Frühwerk (1897/98-1917), Zeichnungen und Aquarelle. Wien: 1994.

Theissing, H.: Dürers Ritter, Tod und Teufel: Sinnbild und Bildsinn. Berlin: 1978.

Thesing, S.: „Krieg“ - ein grafischer Zyklus von Ludwig Meidner. Ludwig Meidner. Zeichner, Maler, Literat 1884-1966. Kat.Ausst. Darmstadt, Bd. 1. Stuttgart : 1991, S. 106-117.

Tietze, H.: Oskar Kokoschkas neue Werke. In: Die bildenden Künste; Jg. 2, H. 11/12. Wien: 1919, S. 249-256.

Timm, W.: Die träumenden Knaben - ein Frühwerk von Oskar Kokoschka. In: Marginalien. Blätter der Pirkheimer Gesellschaft. Nr. Heft 5/6. Wiesbaden: 1959, S. 69-72.

Tomeš, J. M.: Kokoschkas Verhalten zu seinen Zeitgenossen und dessen Widerspiegelung in seinen Porträts. In: Patka, E. (Hrsg.): Oskar Kokoschka. Symposion der Hochschule für angewandte Kunst in Wien. Salzburg: 1986, S. 252-264. 
Trnek, R.: Selbstbild: der Künstler und sein Bildnis. Ostfildern-Ruit: 2004.

Trummer, T.: Horizonte am Meer der Vorstellungen. Zur kryptotheologischen und lebensphilosophischen Konzeption von Kokoschkas frühen Porträts. In: Natter, T. G.: Oskar Kokoschka: das moderne Bildnis 1909 bis 1914. Kat.Ausst. Neue Galerie New York. Köln: 2002, S. 36-42.

Ulmer, R.: „Bin voller heiliger Stimmungen und trage mit mir heroische, bewegte Bibelgestalten herum." Religiöse Kompositionen im Werk Ludwig Meidners. In: Breuer, G./Wagemann, I. (Hrsg.): Ludwig Meidner. Maler, Zeichner, Literat 1884-1966. Stuttgart : 1991, S. 106-117.

Vietta, S./Kemper, H.-G.: Expressionismus. München: 1994.

Vietta, S.: Lyrik des Expressionismus. Tübingen: 1999.

Vondung, K.: Mystik und Moderne: Literarische Apokalypse in der Zeit des Expressionismus. In: Anz, T./Stark, M. (Hrsg.): Die Modernität des Expressionismus. Stuttgart/Weimar: 1994, S. 142-151.

Wais, K.: Symbiose der Künste: Forschungsgrundlagen zur Wechselberührung zwischen Dichtung, Bild- und Tonkunst. In: Weisstein, U.: Literatur und bildende Kunst: ein Handbuch zur Theorie und Praxis eines komparatistischen Grenzgebietes. Berlin: 1992, S. 34-53.

Wallraff, M.: Christus verus sol: Sonnenverehrung und Christentum in der Spätantike. Münster: 2001.

Warncke, C.-P.: Symbol, Emblem, Allegorie: die zweite Sprache der Bilder. Köln: 2005.

Weisstein, U.: Literatur und Bildende Kunst: Geschichte, Systematik, Methoden. In: Weisstein, U.: Literatur und bildende Kunst: ein Handbuch zur Theorie und Praxis eines komparatistischen Grenzgebietes. Berlin: 1992, S. 11-31.

Weisstein, U.: Literatur und bildende Kunst: ein Handbuch zur Theorie und Praxis eines komparatistischen Grenzgebietes. Berlin: 1992.

Wellesz, E.: Egon Wellesz: Leben und Werk. Wien/Hamburg: 1981.

Werkner, P.: Physis und Psyche. Der österreichische Frühexpressionismus. Wien/München: 1986.

Westheim, P.: Oskar Kokoschka. Das Werk Kokoschkas in 62 Abbildungen. Berlin: 1919 (1918).

Wetzel, M.: Dichter und Maler - Ein double-bind? In: Kunstforum, Bd. 139: Kunst und Literatur I. Ruppichteroth: 1997/98, S. 52-62.

Whitford, F.: Das Porträt im Expressionismus. München: 1987.

Wingler, H. M. (Hrsg.): Oskar Kokoschka: Schriften 1907-1955. München: 1956.

Wingler, H. M. (Hrsg.): Oskar Kokoschka. Das Werk des Malers. Salzburg: 1956a.

Wingler, H. M./Welz, F.: Oskar Kokoschka: das druckgrafische Werk [1]. Salzburg: 1975. 
Winkler, J.: Leben aus dem Feuer der Farbe. Zum späten Werk 1953-1973. In: Schröder, K. A./Winkler, J. (Hrsg.): Oskar Kokoschka. Kat.Ausst. Kunstforum Länderbank Wien. München: 1991, S. 45-51.

Winkler, J./Erling, K.: Oskar Kokoschka, die Gemälde: 1906-1929. Salzburg: 1995.

Wunder, H.: ,Er ist die Sonn’, sie ist der Mond ؛ Frauen in der frühen Neuzeit. München: 1992.

Zimmermann, A. (Hrsg.): Soziale Ordnungen im Selbstverständnis des Mittelalters; Bd. 1. Berlin: 1980.

\section{Lexika}

Brockhaus: Brockhaus-Enzyklopädie Bd. 2: Apu - Bec. Mannheim: 1987.

Görg, M.: Neues Bibel-Lexikon Bd. 1: A - G. Zürich: 1991.

Görg, M.: Neues Bibel-Lexikon Bd. 3: O - Z. Düsseldorf [u. a.]: 2001.

Kirschbaum, E.: Lexikon der christlichen Ikonografie 4: Allgemeine Ikonografie Saba, Königin von-Zypresse Nachträge. Freiburg: 1972.

Muller, J.-E.: DuMont's kleines Lexikon des Expressionismus. Köln: 1977.

Olbrich, H.: Lexikon der Kunst Bd. 2: Cin - Gree. Leipzig: 2004.

Olbrich, H.: Lexikon der Kunst Bd. 5: Mosb - Q. Leipzig: 2004a.

Richard, L. (Hrsg.): Lexikon des Expressionismus: Malerei und Grafik, Skulptur, Architektur, Lyrik und Prosa, Drama, Film, Bühnenkunst, Musik. Paris: 1980.

Roscher, W. H.: Lexikon der griechischen und römischen Mythologie. Hildesheim: 1978.

Schiller, G.: Lexikon der christlichen Ikonografie, Bd. 1: Inkarnation, Kindheit, Taufe, Versuchung, Verklärung, Wirken und Wunder Christi. Gütersloh: 1969.

Stadler, W.: Lexikon der Kunst, Bd. 6. Erlangen: 1994. 


\section{B Textnachweis (Quellentexte)}

Die Unterstreichungen in den Textbeispielen sind von der Autorin der vorliegenden Publikation vorgenommen worden, um einzelne Passagen der Interpretation leichter zu finden. Die Textzitate zu Ludwig Meidner sind - abweichend von den angegebenen Ersterscheinungen - Breuer/Wagemann (1991) entnommen.

\section{Ludwig Meidner}

Text I: „Erinnerung an Dresden“

In: Meidner, L.: „Septemberschrei - Hymnen, Gebete, Lästerungen.“

Mit vierzehn Steindrucken. Paul Cassirer, Berlin 1920. S. 11-14.

Erstdruck in: Neue Blätter für Kunst und Dichtung 1, 1918

Text II: „Alaunstraße in Dresden“

In: Die Aktion 5, 1915. Sp. 61-62. Abschriften mit Variationen im Nachlass Ludwig Meidner, Darmstadt.

Text III: „Anleitung zum Malen von Großstadtbildern“

Aus: „Das neue Programm“. In: Kunst und Künstler 12, 1914. S. 312-314.

Text IV: „...im Nacken das Sternemeer...“

In: Meidner, L.: „Im Nacken das Sternemeer.“

Mit zwölf Zeichnungen. Kurt Wolff Verlag, Leipzig 1918. S. 26-31.

Text V: „Vision des apokalyptischen Sommers“

In: Meidner, L.: „Septemberschrei - Hymnen, Gebete, Lästerungen.“ Mit vierzehn Steindrucken. Paul Cassirer, Berlin 1920. S. 6-10.

Text VI: „Nächte des Malers“

In: Meidner, L.: „Im Nacken das Sternemeer.“

Mit zwölf Zeichnungen. Kurt Wolff Verlag, Leipzig 1918. S. 17-25. Erstdruck unter dem Titel „Sehnsüchte des Malers“ in: Die Aktion 5, 1915. Sp. 59-61. 
Text VII: „Anrufung des süßen, unersättlichen Züchtigers“

In: Meidner, L.: „Im Nacken das Sternemeer.“ Mit zwölf Zeichnungen. Kurt Wolff Verlag, Leipzig 1918. S. 9-16.

Text VIII: „In den weißen Windhimmel lauf ich hinein“

In: Meidner, L.: „Septemberschrei - Hymnen, Gebete, Lästerungen.“ Mit vierzehn Steindrucken. Paul Cassirer, Berlin 1920. S. 65-68.

Text IX: „Malers Tag-Gesang““

In: Meidner, L.: „Septemberschrei - Hymnen, Gebete, Lästerungen.“ Mit vierzehn Steindrucken. Paul Cassirer, Berlin 1920. S. 41-42. Erstdruck unter dem Titel „Malers Taggesang“ in: Die Schaubühne 14 (I.), 1918 (Nr. 8). S. 185-186.

Text X: „Septemberschrei“

In: Meidner, L.: „Septemberschrei - Hymnen, Gebete, Lästerungen.“ Mit vierzehn Steindrucken. Paul Cassirer, Berlin 1920. S. 27-30.

Text XI: „An alle Künstler, Dichter, Musiker“

In: Das Kunstblatt 3. Berlin 1919. S. 29-30 und in: Simon, W.: „An alle Künstler!“ Berlin 1919. S. 7-10

Text XII: „Bruder, zünd die Fackel an. Zum Gedächtnis Carl Liebknechts und Rosa Luxemburgs.“ In: Die Erde 1, 1919 (H. 4). S. 115-118.

Text XIII: „Aschaffenburger Tagebuch“

In: Meidner, L.: „Septemberschrei - Hymnen, Gebete, Lästerungen.“ Mit vierzehn Steindrucken. Paul Cassirer, Berlin 1920. S. 15-23.

Text XIV: „Gruß des Malers an die Dichter“

In: Meidner, L.: „Im Nacken das Sternemeer.“ Mit zwölf Zeichnungen. Kurt Wolff Verlag, Leipzig 1918. S. 74-78.

Text XV: „Eine autobiografische Plauderei“

Brieger, L. (Hrsg.): Ludwig Meidner. Eine autobiografische Plauderei. In: Junge Kunst, Bd. 4 (2. völlig überarbeitete Auflage). Leipzig 1923.

Text XVI: „Vision zur Ekstase“

Manuskript um 1925 (bestehend aus 3 Doppelseiten; im Falz verklebt) Tinte auf Papier; 21 x 16,5 cm, Galerie Pels-Leusden, Berlin (abgedruckt und transkribiert bei Guratzsch, S. 14-16/S. 43). 
Text XVII: „Hymne an mich selbst“

In: Meidner, L.: „Septemberschrei - Hymnen, Gebete, Lästerungen.“ Mit vierzehn Steindrucken. Paul Cassirer, Berlin 1920. S. 75.

Text XVIII: „Mündung, du böse bleckende, schweig, schweig!““

In: Meidner, L.: „Im Nacken das Sternemeer.“ Mit zwölf Zeichnungen. Kurt Wolff Verlag, Leipzig 1918. S. 79-82.

Text IXX: „Vom Zeichnen“

In: Meidner, L.: „Im Nacken das Sternemeer“. Mit zwölf Zeichnungen. Kurt Wolff Verlag, Leipzig 1918. S. 32-36. Erstdruck in: Das Kunstblatt 1, 1917. S. 97 101.

Oskar Kokoschka

Text XX: „Die träumenden Knaben“ (1907)

In: Wingler, H. M.: „Oskar Kokoschka. Schriften. 1907-1955“. Georg Müller Verlag, München 1956. S. 107-120.

Text XXI: „Mörder, Hoffnung der Frauen“ (1907)

In: Wingler, H. M.: „Oskar Kokoschka. Schriften. 1907-1955“. Georg Müller Verlag, München 1956. S. 137-151.

Text XXII: „Allos Makar“ (1913)

In: Wingler, H. M.: „Oskar Kokoschka. Schriften. 1907-1955“. Georg Müller Verlag, München 1956. S. 130-132.

Text XXIII: „Hiob“ (1917)

In: Wingler, H. M.: „Oskar Kokoschka. Schriften. 1907-1955“. Georg Müller Verlag, München 1956. S. 199-229.

Text XXIV: „Vom Bewußtsein der Gesichte“ (Essay 1920)

In: Wingler, H. M.: „Oskar Kokoschka. Schriften. 1907-1955“. Georg Müller Verlag, München 1956. S. 342-352.

Text XXV: „Der brennende Dornbusch“ (1917)

In: Wingler, H. M.: „Oskar Kokoschka. Schriften. 1907-1955“. Georg Müller Verlag, München 1956. S. 169-197. 
Text XXVI: „Ich male Porträts, weil ich es kann“ (1961)

In: Spielmann, H.: „Oskar Kokoschka. Das schriftliche Werk, Bd. 3: Aufsätze, Vorträge, Essays zur Kunst.“ Christians Verlag, Hamburg 1975. S. 279-283.

Text XXVII: „Von der Natur der Gesichte“ (Vortrag 1912)

In: Wingler, H. M.: „Oskar Kokoschka. Schriften. 1907-1955“. Georg Müller Verlag, München 1956. S. 337-341.

Text XXVIII: „An die Einwohnerschaft Dresdens“ (offener Brief 1920)

In: Kokoschka, O./Spielmann, H.: „Oskar Kokoschka. Das schriftliche Werk, Bd. 4: Politische Äußerungen“. Christians Verlag, Hamburg 1975. S. 31/32.

Text XXIX: „Orpheus und Eurydike“ (1915)

In: Wingler, H. M.: „Oskar Kokoschka. Schriften. 1907-1955“. Georg Müller Verlag, München 1956. 231-306. 


\title{
Ludwig Meidner
}

\author{
Text I: „Erinnerung an Dresden“
}

\author{
Erinnerung an Dresden
}

Hellauflachend, mit flatternder Fahne - der Kassiopeja junisanftes Gleiten - so in dem lauen Sommerbrodem schwammest du in die Nacht hinein: Hochgekuppelte, du Kupplerin Dresden, muntere und strenge - du hast mich müde und weh gemacht.

Das war im Frühjahr 1914.

Wir bewohnten einen rustikalen, kubischen Kasten am Anfang der Bautzner Straße. Die Bautzner Straße hatte einen Dämon im Genick. Ach, der war nicht der kosmopolitische Zug der AlaunstraBe eigen: Das Weitausschreitende und unermeBlich Wallende. Ein zweiter, schmaler, doch menschlicherer Elbstrom - ein Hineinrufen in den Himmel. Unten der Ladentüren Geläut. Oben, als ob die Fenster sich öffneten und Menschen verzückt und voll unaussprechlicher Weltfreude sich über die Brüstung in die Tiefe schwangen - in diese Tiefe, die so brunnenklar und weiß wie ein mattverhängter Maitag war. Man wehte so, ledig aller irdischen Schwere, mit dem erschütternden Gesang durch diesen Engpaß hin und ward ein wilder, turbulenter Narr.

Ja, aber die Bautzner war ganz anders. Da standen viele Litfaßsäulen wie dicke, schwatzhafte Weiber herum, und wenn wir aus unsern Stuben die Köpfe raussteckten und die Leiber weit vorbeugten, dann gewahrten wir den großen Straßen-Dämon mit heiserem Hundegebell, und wir zuckten wie Gestochene blitzschnell wieder in die Stuben zurück und taumelten lange und riefen die Wände zu Zeugen unsrer unausdrückbaren Gefühle auf. Drei verwegene Stuben bewohnten wir im ersten Stock. Ich und der Dichter Lotz.

Lotz, Ernst Wilhelm -: Deutscher Schwärmer, Romantiker, verliebt in Wolken und Wind. Schmal und lang, mit weiten Schritten durchs Gewühl der Straßen flammend. Immer straßenfroh und händehoch und beschwingter Besinger des Städtemeers. Immer Tänzer, Schwimmer, Segler durch die blauen Gassen. Von seinen Hüften glitt ihm alle Traurigkeit der Welt. Mit vorgeneigtem, verhalten-fieberndem Gesicht, mit beschwingten Lungen atmete er ein den ungestümen Tag, horchte beherzt auf seine Impulse hin und riß die Inspiration, wenn sie kam, so stürmisch wie ein Mädchen in die Arme. Melodienreicher Dichter in vierundzwanzigjähriger Jugend und Erdenseligkeit - immer zugetan dem heiB schwärmenden, begehrenden Blut - und das Herz hochhaltend und die Vernunft wie eine Schnupftabakdose in der Rocktasche zu seltenem Gebrauch. - Wir waren dem rasenden, tausendstimmigen Berlin entwichen. Hatten uns auf dieses blumige, noch unbescholtene Gefild gerettet. Denn wir wollten ungestört uns unserm innern Wesen weihen und auf die Lieder innen horchen und die Schätze aus vollen Schächten heraufholen. Eines Sinnes waren wir in allen Dingen. Rissen uns immer abwechselnd an unsern Entzückungen hoch ermunterten uns in allen Wagnissen, und Tag für Tag gaben wir unbekümmert unsern süßen Kindereien recht. - Dichter und Majer können getrost zusammen arbeiten. Da gibts keine Feindschaft noch Neid. Da gibt es nur helle Bereicherung und Leben in geistiger Fülle. Tagsüber hämmerte ich an einer Leinwand in der hintersten Stube, während Lotz noch vorne schlief. In meine Striche floB ein wenig die edle Geigenmusik von Dresden ein. Ich fühlte einen andern Rausch als in Berlin in meinem Rücken. Ich fühlte, daß die Gegenwart allgütig, leicht und wie ein langer, sanfter Traum aus meinen Händen strömte. Und der 
Dichter gesellte sich dann meinem Demutsschweigen, und wir brannten zusammen auf wie ein riesiges Feuer, liefen sprachlos aus dem Haus, und als wir in den Albertplatz einbogen, umrauschte uns der Gesang der Türme lieblich wie ein alter Choral, und wir blieben verdutzt stehen und fragten staunend, was uns hier getroffen habe. Dann genossen wir den Abend in tiefen Zügen, und spät nachts, an der Elbe, hielten wir noch immer die Flaggen der Begeisterung in Händen hoch.

Dresden! Dresden! Dein Schall und deine leisen Stürme! Dein Übermut am Strom hinan dein Aufseufzen, dein Auflachen - dein zärtlicher Tränenfluß - deine barocken Sehnsüchte, ja - dein ergrauendes Haar - sind mir noch immer selig nah. -

Wir schlugen uns wie Berserker durch den Tag. Wuschen uns mit Erde rein und mit schimmerndem Wolkenweiß. Und bei des Taggestirns Verglühen haben wir immer den Rest des Unkrauts aus unsern Schädeln gejätet, denn wir wollten lauter und ehrfürchtig dastehen auf den Gipfeln wunderreicher Nächte.

Lotz dichtete jetzt seine besten Gedichte. Und ich entsank wieder in die Bizarrerien einer gottlosen, füneberen Welt, wo nur Skelette in allen Ecken kichern und Fragmente von Stadt, Laterne und Mensch an dreifachen Horizonten versprühen.

Todesängste, wie tobende Krähenscharen, fuhren allnächtlich über mich hin, und ich zankte mit Lotz, der das Todesgrauen verlachte und nur dem irdischen, atmenden Sein seine Päane sang.

Schmetterlingsbunt und Gangestänzer und beschwingter, blonder Soldat: Ernst Wilhelm Lotz. Ein Flackerlicht im tropischen Wald. Immer hineilend, immer aufgeschlossen und das Frühgestirn mit tobendem Dichtergruße grüßend. Im Sternenscheine lächelnd. Im Wiesengrün Hände verwühlt in dem Wind. Immer Heide war er, aber sündelos und edel. Die tiefe Fleischeslust, die sichtbare Schönheit der Leiber, die Labung frenetischer Küsse lobend und würdevoll bejauchzend. Allen Gram zerbrechend. Geröll und Tragik des Alltags mit behenden Füßen und Gesang überquerend.

- Du warst edler wie ich, Ernst Wilhelm, schwebtest über den Niederungen und dampfenden Abflußgräben in dem grenzenlosen Raum der Poesie. Empfindung, ganz, ganz schwellendes Gefühl - - wie eine Flaumfeder leicht gen Äther taumelnd. Wenn du durch die Landschaft triebst, hast du weitausschreitend den Boden kaum mit den Fußspitzen berührt. Jenseits aller Brot- und Werktagssorgen, flogst du auf und davon, bautest deine summende Sprachgewalt wie silbermaschige Netze ins All, fingest Grillen ein, Schnurrpfeifereien und lächelnde Ja's. Deine Gebilde waren sehr lauter und absichtslos schön - hingehängt wie heitre Wolken über Frühsommerhügelland, wie Ulmenalleen meilenweit ins Gelände schwankend - aber durchwirkt von Wehmut und händeverkrampfter Ahnung. -

Welch ein zuckender Kelch! Sein nervöser Poetenleib schoß in unsern Stuben jäh wie eine Brandfackel herum. Der kleine Bachsłelzenkopf, die ganz engen Augen, wie Mauerritzen scharf geschnitten und überspült von Kindes Unbefangenheit, weckten Zuneigung und Freundschaft aus herzlichem Vertrauen.

Aber unheimlich prangte auf seiner Stirn das Todesmal, und es wuchs mit den Stunden des Tages, und wenn die Nacht hoch stand, dann senkte sich seine schmerzende Schneide, und eine düstere Ahnung beschlich mich und machte mich erbärmlich klein.

Lotz begann zu zeichnen. Sein Bleistift folgte in anmutigem und sicherem Schwung den Nervenlinien eines Antlitzes oder einer Landschaft pathetischem Flug. Wie fein sein Instinkt ein abgeschlossenes Bild in die Fläche schreiben konnte! Aber er legte diesem Können keinen Wert bei und wies immer nur auf seine Dichtungen hin.

Er liebte die Malerei. Die hellen, orphischen Flächen jener Jahre waren ihm Peitschen und Wind in die Segel -, Delaunay, Kandinsky und Marc. Und meine eigenen, gezeichneten Hymnen von Stadtstraßen gaben ihm oft genug einen grellen Stoß, daß er kopfüber, wie ein Schwimmer, in seine Visionen hineinsprang.

- Die Tage verrauschten in Schönheit schwer.

Wir rissen uns alle Bangigkeiten wie beschwerende Kleider vom Leibe, und nach den Ängsten der Arbeit sausten wir im Galopp durch die Stadt. Von den alten Fassaden strömten unsägliche Wonnen ab, und der Duft der Avenüen klärte uns wieder und füllte uns von neuem mit Schöpfermut.

Aufrecht, wie dröhnende Bäume, standen wir im Juniglühen, und der Sommer wuchs hoch empor. Und wir wuchsen mit ihm, gespannt und schmerzlich. Die Stadt blühte auf wie ein betäubender Garten. und Tangomusik, schwebend wie leichte Windwolken über Kirchen und steineme Brücken. umflorte unsre Stimen lind... 
Da umfing mich sacht ein Alp mit unterirdischen Armen. Ich ward in quälende Bäder getaucht, hatte Unlust und Unrast alle Tage - und ballte die Fauste in Jähzorn und Wut. Wie ein Affe sprang es aus mir heraus. Ich qualte immerfort Enst Wilhelm damit -; der aber blieb ruhig und lächelte fein.

Im häBlichen Hundetrott vergingen uns die Tage. Es wurde mir immer ärger und peinigender. Mich kitzelte nun täglich der wilde Knochenmann. Und des Dichters erdentrückter, grüner Sommerflug (... jenes Dichters mit dem dunklen Totenmal) schnitt mich immer wie Beleidigung, und ich gab ihm rohe Worte Tag fur Tag.

Ich schlug mit Fäusten in meine unfertigen Bilder, und die Pinsel zerbrachen in den ungeduldigen Händen. Denn ich konnte nicht mehr in innigkeit und gesammelter inbrunst mich dem hohen Dienste weihen. - So ward der Dresdner Sommer eine Höllenqual.

Aber dennoch einmal, an der Schwelle frühen Tages, brach die große Liebe mächtig aus unsern geschändeten Seelen. Wir hoben die alten Schàtze wie übervolle Weinkrüge auf. Landend unter einer Stubentür, zwischen drei und vier, gingen unsre Gespräche weit hinaus über Erdenball und Sterneschweigen. Wieder einmal wuchsen wir tiefer Freundschaft voll in unermeBliche Weite.

Wie ward mir die Arbeit sauer in den letzten Junitagen. Ach, mich quälte schwer das unsichtbare Gift.

Da tat ich eines Tages die Augen auf und sah alle Leute verstört und suchend auf den Straßen stehen. Ach, es waren ihrer so Viele überall. Sie waren reich gekleidet, übersatt und müde, und es schien, als ob sie traurig wären, daB es keine neuen Zerstreuungen und Späße für sie gab. Sie waren leidend und wuBten nicht warum. Die Autos donnerten vom WeiBen Hirsch herunter. Gastmähler und Geigen nahmen schier kein Ende. Und die Sonne, furchtbar heiB, drommetend, schnaubend, fuhr in mächtigen Bogen über den Himmel hin Brandstifterin und Petroleuse - eine schreiende Hyäne des Unheils. Mitte Juli fuhr mein Freund nach Berlin. Wir hatten ein neues begeistertes Monatsblatt im Sinn, fanden Verleger und Drucker, und Lotz wollte in Berlin unsre Mitarbeiter werben...

- Indessen saß ich geduckt und verkrampft und die Zähne verbissen über meinem Zeichenbrett, und es schossen nur wiehernde Fratzen aus meinem Stift; und zerstampfte Leiber rannen wie Satans Speichel aus meinen Fingern.

Aber Gott der Herr fand, daB die Zeit reif war. Er bedeckte sein unerforschliches Angesicht und holte gewaltig aus in seinem Zorn.

Und aus den Schlünden der Erde stiegen entsetzliche Unholde, setzten sich in alle Hime breit hin ... und der Dämon der Bautzner Sṫraße sprang auf, wuchs riesengroß über den Kontinent. Da tat die Stadt Dresden hunderttausend Mäuler auf zu Lästerung und grenzenlosem Hohn. Sie schäumte auf, und das Gift stieg bis an die Dächer.

Und sie entblbBten ihre Scham, und ihre geheimen Schwären zeigten sie unter dem offenen Himmel. Und in ihrem Wahn logen sie die Zuchtrute zu einer Festireude um und priesen den einzigen Tag, und ihre heisernen Gesänge verdunkelten das Firmament. Ach, ach, ach! wir wissen alle noch, wie jene Tage uns gegeißelt haben, und es war hier wie dort das Gleiche.

- Viele Wochen lag ich brach wie ein Klumpen heiBer, schmerzenreicher Erde. Da, im Beginn des Herbstes, als meine Hand vermeinte, wieder in die Weite langen zu kōnnen, kam mir die Kunde von des Freundes frühem Tod. Der Zarte, Selige lag nun hingestreckt auf Frankreichs Erde. Ich sank wieder in meines offnen Sarges Jammerschrei zuruck, und tausend Messer und Schaufeln und Axte zerleischten meine Brust ... bis der Winter mich in seinen lindernden Mantel hülite und kalte Regengüsse meine leidzerrissenen Hãnde wuschen.

Dresden, das einstmals schwelgende, in Würde, feierlichen Prunk, in goldenen Flaum getauchte, wandte seinen geschlagenen Leib und fuhr in eine tiefe Gruft des Schweigens. ich nahm die Einsamkeit auf meinen Rücken wie ein Leidenskreuz und stahl mich weg von hier. Tagaus, tagein noch wehrte ich mich gegen das große Gericht und geiferte über Gottes heilige Hand. Und Jahre vergingen, ehe ich zum Sinn des Lnwetters gelangte: denn es muB viel Trübsal, Verzweiflung und leibliche Not in die Welt kommen, auf daß ein bessrer Morgen tage. 
Text II: „Alaunstraße in Dresden“

\author{
Alaunstraße in Dresden \\ Auf, zu Himmeln auf \\ schreien Häuserreihen, \\ trümmern Wände sich hebend und schreien. \\ Wind um weiß Gesicht, \\ Essen, Türme, Wolken flattern weit. \\ Asphalt, der zu Bergen saust, \\ sprüht die Kinder hoch. \\ Unter uns die schwarzen Hosen schlenkern, \\ Tabakpfeife, Käfig, Wildbrethase \\ durch die Himmelsweiße schwimmend. \\ Fuhrwerksstimmen hauen uns \\ um Aug' und Mund, \\ $A B C$ der Schilder, \\ Schnellzugseile... \\ O Choral der Fernen, \\ wo Kasernen blauen, \\ wo sich Gotik steilt. \\ Nimm Gerassel mich \\ in dein Schicksal ein, \\ trag mich Wellenberge hoch \\ und Täler nieder. \\ Aus Budiken, Milchgeschäften \\ wirbelt Heringswonne in mein Ohr. \\ Aus den Betten zwanzigstöckiger Häuser, \\ aus den Läden, Truhen, Käfigen der Menschen \\ hauchen Winde diese Wellenbahn vorüber, \\ und die Löcherfronten krachen \\ in der Glut des weißen Tages.
}




\title{
Text III: „Anleitung zum Malen von Großstadtbildern“
}

\author{
Anleitung zum Malen von Großstadtbildern
}

Wir müssen endlich anfangen unsere Heimat zu malen, die Großstadt, die wir unendlich lieben. Auf unzähligen, freskengroßen Leinwänden sollten unsre fiebernden Hände all das Herrliche und Seltsame, das Monströse und Dramatische der Avenüen, Bahnhöfe, Fabriken und Türme hinkritzeln. Wir erinnern uns an einzelne Bilder der siebziger und achtziger Jahre, welche Großstadtstraßen darstellten. Sie waren von Pissaro oder Claude Monet gemalt, zwei Lyrikern, welche von Wiese, Busch und Baum herkamen. Das Süße und Flockige dieser Agrarlandschafter ist auch in ihren Stadtbildern. Doch malt man Häuserungetüme so strichelnd und durchsichtig, wie man Bäche malt, und Boulevards wie Blumenbeete?! Es ist nicht möglich mit der Technik der Impressionisten unser Problem zu bewältigen. Wir müssen alle früheren Verfahren und Trucs vergessen und ganz neue Ausdrucksmittel uns zu eigen machen.

Das erste ist: daß wir sehen lernen, daß wir intensiver und richtiger sehen als unsere Vorgänger. Die impressionistische Verschwommenheit und Verundeutlichung nützt uns nichts. Die überkommene Perspektive hat keinen Sinn mehr für uns und hemmt unsre Impulsivität, »Tonalität", "farbige Lichter", "farbige Schatten«, "auflösen des Kontur«, "Komplementärfarben « - und was es alles noch gibt - sind Schulbegriffe geworden. Zuzweit und das ist nicht minder wichtig - müssen wir anfangen zu schaffen. Wir können unsre Staffelei nicht ins Gewühl der Straße tragen, um dort (blinzelnd) „Tonwerte« abzulesen. Eine Straße besteht nicht aus Tonwerten, sondern ist ein Bombardement von zischenden Fensterreihen, sausenden Lichtkegeln zwischen Fuhrwerken aller Art und tausend hüpfenden Kugeln, Menschenfetzen, Reklameschildern und dröhnenden, gestaltlosen Farbmassen.

Das Malen im Freien ist ganz falsch. Wir können nicht das Zufällige, Ungeordnete unsres Motivs im Nu auf die Leinwand bringen und ein Bild daraus machen. Aber wir müssen mutig und überlegt die optischen Eindrücke, mit denen wir uns draußen vollgesogen haben, zu einer Komposition formen.

Es handelt sich hier nicht, das sei gleich gesagt, um eine rein dekorativ-ornamentale Füllung der Fläche à la Kandinsky oder Matisse - sondern um Leben in seiner Fülle: Raum, Hell und Dunkel, Schwere und Leichtigkeit und Bewegung der Dinge - kur: um eine tiefere Durchdringung der Wirklichkeit.

Es sind vor allem drei Materien, welche uns zur Gestaltung des Bildes dienen müssen: 1. das Licht, 2. der Blickpunkt, 3. die Anwendung der geraden Linie.

Unser Problem ist zunächst ein Lichtproblem - aber nicht ausschließlich ein Lichtproblem, denn wir fühlen nicht überall das Licht, wie die Impressionisten. Diese sahen überall Licht; sie verteilten Helligkeit über ihre ganze Bildtafel, selbst die Schatten sind hell und durchsichtig. Cézanne ist in dieser Richtung schon viel weiter, er hat die schwebende Festigkeit und diese gibt seinen Bildern die große Wahrheit.

Wir nehmen in der Natur nicht überall Licht wahr; wir sehen häufig ganz vorn große Flächen, die wie erstarit sind und unbelichtet scheinen; wir fühlen da und dort Schwere, Dunkelheiten, unbewegte Materie. Das Licht scheint zu fließen. Es zerfetzt die Dinge. Wir fühlen deutlich Lichtfetzen, Lichtstreifen, Lichtbündel. Ganze Komplexe wogen im Licht und scheinen durchsichtig zu sein - doch dazwischen wieder Starrheit, Undurchsichtigkeit in breiten Massen. Zwischen hohen Häuserreihen blendet uns ein Tumult von Hell und Dunkel. Lichtflächen liegen breit auf Wänden. Mitten im Gewühl von Köpfen zerplatzt eine Lichtrakete. Zwischen Fahrzeugen zuckt es hell auf. Der Himmel dringt wie ein Wasserfall auf uns ein. Seine Lichtfülle sprengt das Unten. Scharfe Konturen wanken in der Grelle. Die Scharen der Rechtecke fliehen in wirbelnden Rhythmen.

Das Licht bringt alle Dinge im Raume in Bewegung. Die Türme, Häuser, Laternen scheinen zu hängen oder zu schwimmen. 
Das Licht ist weiß, oder silbrig, oder violett, oder blau, wie ihr wollt. Doch nehmt lieber ein Weiß, so rein wie möglich. Streicht es mit breitem Pinsel auf - daneben ein tiefes Blau oder Elfenbeinschwarz. Fürchtet euch nicht, und bedeckt die Fläche mit heftigem Weiß, kreuz und quer. Nehmt Blau - das satte warme Pariserblau, das kühle, laute Ultramarin - nehmt Umbra, Ocker in Fülle, und kritzelt nervös, eilig. Seid lieber brutal und unverschämt: eure Motive sind auch brutal und unverschämt. Es genügt nicht, daß ihr den Rhythmus in den Fingerspitzen habt, ihr müßt euch winden unter Tollheit und Lachen!

Wichtig für das Kompositorische ist der Blickpunkt. Er ist der intensivste Teil des Bildes und Mittelpunkt der Komposition. Er kann überall liegen, in der Mitte, rechts oder links von der Mitte, aber aus Kompositionsgründen wähle man ihn etwas unter der Mitte des Bildes. Es ist - auch zu beachten, daß alle Dinge im Blickpunkt deutlich seien, scharf und unmystisch. Im Blickpunkt sehen wir aufrechtstehende Linien senkrecht. Je weiter vom Blickpunkt entfernt, desto mehr neigen sich die Linien. Stehen wir zum Beispiel geradeausblickend mitten auf der Straße, so sind vor uns, weit unten, alle Häuser senkrecht zu sehen, und ihre Fensterreihen scheinen der landläufigen Perspektive Recht zu geben, denn sie laufen dem Horizont zu. Doch die Häuser neben uns - wir fühlen sie nur mit halbem Auge - scheinen zu wanken und zusammenzubrechen. Hier schießen Linien, die in Wirklichkeit parallel laufen, steil empor und schneiden sich. Giebel, Schornsteine, Fenster sind dunkle, chaotische Massen, fantastisch verkürzt, vieldeutig.

Malt im Blickpunkt mit kleinen Pinseln, kurze, heftig empfundene Linien, die alle sitzen müssen! Malt hier sehr nervös; aber je weiter ihr euch dem Bildrand nähert, desto breiter und unbestimmter könnt ihr werden!

Früher hieß es immer: Es gibt keine gerade Linie in der Natur, die freie Natur ist unmathematisch. Man liebte die gerade Linie nicht, und noch Whistler löste sie in viele kleine Teile auf. Seit den Tagen Ruisdaels ist die gerade Linie in der Landschaftsmalerei verpönt, und die Künstler haben immer vermieden, neue Gebäude, neue Kirchen und Schlösser auf ihren Bildern anzubringen. Sie zogen die pittoresken Dinge vor, denn diese waren unregeimäBig und vielgestaltig: baufällige Häuser, Ruinen und möglichst viel Laubbäume.

Wir Heutigen, Zeitgenossen des Ingenieurs, empfinden die Schönheit der geraden Linien, der geometrischen Formen. Nebenbei sei bemerkt, daß auch die moderne Bewegung des Kubismus große Sympathie für geometrische Formen an den Tag legt, ja daß sie bei ihr eine noch tiefere Bedeutung haben als bei uns.

Unsere gerade Linie - hauptsächlich in der Graphik angewandt - ist nicht zu verwechseln mit den Linien, welche die Maurermeister auf ihren Plänen mit der Reißschiene ziehen. Glaubt nicht, daß eine gerade Linie kalt und starr sei! ihr müßt sie nur sehr erregt zeichnen und ihren Verlauf gut beachten. Sie sei bald dünn, bald dicker und von leisem, nervösen Erzittern.

Sind nicht unsre Großstadtlandschaften alle Schlachten von Mathematik! Was für Dreiecke, Vierecke, Vielecke und Kreise stürmen auf den StraBen auf uns ein. Lineale sausen nach allen Seiten. Viel Spitzes sticht uns. Selbst die herumtrabenden Menschen und Viecher scheinen geometrische Konstruktionen zu sein.

Nehmt einen breiten Bleistift, und ziehet heftig auf dem Papier gerade Linien und dieses Gewirr mit einiger Kunst angeordnet wird viel lebendiger sein als die prätentiösen Pinseleien unserer Professoren.

Über die Farbe ist nicht viel zu sagen. Nehmt alle Farben der Palette - aber wenn ihr Berlin malt, so verwendet nur Weiß und Schwarz, nur wenig Uitramarin und Ocker, aber viel Umbra. Kümmert euch nicht um »kalte« oder "warme« Töne, um „Komplementärfarben« und ähnlichen Humbug - ihr seid keine Divisionisten - aber strömt euch aus, frei, ungehemmt, sorglos. Denn darauf kommt es an, daß morgen Hunderte von jungen Malern voller Enthusiasmus sich auf dieses neue Gebiet stürzen. Ich habe hier nur einige Hinweise und Andeutungen gegeben. Man könnte es ebensogut auch anders machen, vielleicht besser und überzeugender. Aber die Großstadt muß gemalt werden!

Es ist schon in den Manifesten der Futuristen - nicht etwa in ihren törichten Machwerken gesagt worden, wo die Probleme liegen, und Robert Delaunay hat vor drei Jahren mit seiner großartigen Konzeption des "Tour Eiffel" unsere Bewegung inauguriert. Auch ich habe in diesem Jahre in einigen malerischen Versuchen und gelungeneren Zeichnungen praktisch das getan, wofür ich hier theoretisch eintrete. Und alle jüngeren Talente sollten sogleich an die Arbeit gehen und alle unsre Ausstellungen mit Großstadtschilderungen überschwemmen. 
Leider verwirt heute allerlei Atavistisches die Köpfe. Das Stammeln primitiver Völker beschäftigt auch einen Teil der deutschen Maler-Jugend, und nichts scheint wichtiger zu sein als Buschmannmalerei und Aztekenplastik. Auch das wichtigtuende Gerede steriler Franzosen über sabsolute Malereix, über sdas Bilda, Italien, Poussin* findet bei uns lauten Widerhall. Aber selen wir ehrlich! Gestehen wir uns nur ein, daß wir keine Neger oder Christen des frühen Mittelalters sind! Daß wir Bewohner von Berlin sind anno 1913, in Caféhäusern sitzen und diskutieren, viel lesen, sehr viel vom Verlauf der Kunstgeschichte wissen und: daß wir alle vom Impressionismus herkamen. Wozu die Manieren und Anschauungen vergangener Zeiten nachahmen, das Unvermögen als das Richtige proklamieren?! Sind diese rohen, mesquinen Figuren, die wir jetzt in allen Ausstellungen sehen, ein Ausdruck unserer komplizierten Seele?!

Malen wir das Naheliegende, unsere Stadt-Welt! Die tumultuarischen Straßen, die Eleganz eiserner Hängebrücken, die Gasometer, welche in weißen Wolkengebirgen hāngen, die brüllende Koloristik der Autobusse und Schnellzugslokomotiven, die wogenden Telephondrähte (sind sie nicht wie Gesang?), die Harlekinaden der LitfaB-Säulen, und dann die Nacht ... die Großstadt-Nacht...

Würde uns nicht die Dramatik eines gut gemalten Fabrikschornsteins tiefer bewegen als alle Borgo-Brände und Konstantinsschlachten Raffaels? 
Text IV: „Im Nacken das Sternemeer“

... im Nacken das Sternemeer ...

Zuweilen, wenn es mich nachts zur Stadt hintreibt, verwegene Stirne tief getunkt, im Nacken das Sternemeer, wenn ich längshin die Fläche sause... sind Wolkengeschreie um mich her, flackernde Gebüsche, ein fernes Flügeischlagen und Menschenkerle, dunkel und fauchend. Der Mond brennt an meinen heiseren Schläfen. Wir durchsegein den Raum, ich und mein Schatten, der lange Hund. Eben hatte ich noch ein wildes Gezänk mit mir selbst, peinigte meinen Unterleib mit Vorwürfen, zerkratzte mich mit höhnischem Gewitzel - und jetzt durch die Ebene hin, Kavalkade des Schmerzes, zertrümmert die heiBe Brust.

Wie mich das alles am Halskragen packtl Lokomotive prasselt; Fabrik kocht hoch - Ha! und die Dunnerkjels, die Eschen. Der Wolken Donnern, des Mondes Gebrumm bedrängt mich schrecklich. Ein Gesang in hoher Wölbung zerreißt meine Spannung. Ich zittre, horchend durch das Getōn der Nacht̀...

Was peitscht mich denn so in die Stadt hinein? Was ras' ich verrückt heerstraßenlang?! Pfähle blutig anrempelnd, Schädel zertrümmernd an feisten Stämmen und meine stadtgeilen FüBe zerreiBen am Gestein der Nacht... Was wollt ihr kreischenden Sterne, die an herbem Sand hier zerschellen? Was fliegt ihr Birken in die Weite? Krüppelföhre, zucke nicht und schreit nicht, Sandhügel, nach euern Toten!

Bist du so fern von mir du Stadt - Stadt - Stadt??!!

ich frage den Mond, was er mich bedroht. Was die Stunden plärren. Was magische Radler mich überholen und Wanderratten mich umtummeln, zischend und nachtäugig. Der Sterneraum fliegt grün ins Endlose. Gestirne stürzen weit über die Grenzen des Weltalls und der Gesang hoch oben singt ewig in mir fort.

Es naht die Stadt. Sie knistert schon an meinem Leibe. Auf meiner Haut brennt ihr Gekicher. Ich höre ihre Eruptionen in meinem Hinterkopf echoen.

Die Häuser nahen. ihre Katastrophen explodieren aus den Fenstern heraus. Treppenhäuser krachen lautlos zusammen. Menschen lachen unter den Trümmern. Wände sind dünn und durchsichtig. Schädel haben zernagelte Fratzen. In Betten geschehen unerhörte Dinge. Kinder pullen sich ein. Kontoristinnen warten auf ihren Beischläfer. Sie masturbieren schon aus Langerweile... Die Straßen werden allmåhlich glatter. Laternen schmeißen ihre Lichtstrahlen einfach weg und jeder kriegt was ab... Allmählich werden die Straßen voll. Der Asphalt brült auf. Furchtbares Getümmel. Maschinenlärm... Gewieher entgleister Straßenbahnen, Niesen älterer Damen und philosophische Gespräche der Schuhmacher beschäftigen den Raum. Schaufenster feuern funkelnageineue Attrappen in die Welt hinaus. In Schaufenstern keucht hinkend die große Zeit. Damen und Weiber schieben ihre Dickbãuche durch das kalte Wetter. Und Kolporteurskinder, von Kohlrüben gesättigt, trudein zwitschernd hinterdrein.

Tumult steht auf. Warenhauses Wände bauchen aus vor Hitze. In Glühlichtkatarakten stürবt ihr Schweiß auf uns herab. Die Ełagen bellen. Tausende pressen sich die matten Leiber. Eine Welt der Schachteln prasselt von den Decken. Der Unzucht Wolken schweben drüber hin, verweben sich den donnernden Unterröcken... Mein Schatten, jetzt lauter zackige Katzenbiester, tanzt um meine Füße.

ich bin Wirbel und Wind. ich schleudre mich straßenlang. Fassaden knallen Salutschüsse, strecken ihre feisten Wänste raus. Kriegsfreiwillige drängen in ein Portal; jeder will der Erste sein. Kaseme brült aus dem Erdboden auf. Aus ihren Fenstern erbricht Reserve das fette Mittagsmahl. Mietshäuser heulen schmalbrūstig in die Nacht hinaus. Pfeifen ihr Hungerleid den Sternen. Milchstraße singt lyrischen Tenor. Mond brummt und die Wolkenkugeln, die Luftschiffe, die Meteore, die Quarkstullen und die witzigen Gazetten hageln bekümmerter Menschheit ins Angesicht.

Die Stadt umwittert Kohlrübengestank. Straßen, durchtoste, durchrasselte, hinauf, hinab... 
Ein Feldgrauer ruft die Parole: "Maul halten, enger schnallen, durchhalten!! Maul halten, enger schnallen, durchhalten!! braust es von Mensch zu Mensch. Aus Giebeln, Torbogen, Kirchenfenstern; von Balkonen, Häuserdächern, Nachtstühlen schallt's wieder. Aus allen guten Stuben, Philharmonien und Kreditanstalten heraus: "Maul halten, enger schnallen, durchhalten!! « Es klatscht auf die hohen Fronten der Postämter, zischt aus den Feueressen, fällt auf die dicken Türme. Die Bürger machen loyale Gesichter und werfen sich das Wort zu wie saft'ge Würschte. Der Junge nebenan konjugiert das Verbum ndurchhalten « und das Küchenfräulein wickelt es in ihre Tasche ein.

Erhabner Gesang der Zeit! Du dringst auch in meine magre Fülle; machst mich wild, turbulent, vehement, schwertgezückt, und ihr Wolken, ihr doppeladlergeschmückten am feldgrauen Firmament dröhnt eure Echos wieder...

Menschenscharen brodeln vorbei, Kreaturen ferner Gestirne, Kaskaden in Lila ... stürzen in die Wände, versinken dröhnend im Asphalt.

Die Stadt kreischt auf, steilgetürmt und weltenhoch. Sie dehnt sich krokodilisch lang, schnellt wie ein Feuerwerk in alle vier Winde. Sie bestürzt mich mit ihren Balkonen. Sie knattert in meinen Eingeweiden. Das Gesumme der Kinos und aller hunderttausend Stuben. Tragödien der Trottoire, Autos und Konditoreien; der Litfaßsäulen frenetische Aufschreie; Apotheose der Kantinen, der murmelnden, bierverseuchten; der hunderttausend Hammelbraten auf allen hunderttausend Tellern des Restaurants, kollernd in die Bäuche der Spießer ... ballt sich dick wie ein Lawine und stürzt donnernd in den Mond hinein.

Laß mich ins Caféhaus geh'n, Katze, jetzt zerhackt um meine Füße tanzend. Laß mich hinein, du irrsinniger Schatten (sind wir nicht ein Herz und eine Seele?!).

Du Café voll Wonne - o zaubrische Helle - du Paradies der Lebendigen. Du Seele der Zeit. Du schwingende Glocke des Diesseits. Du Schule hoher Geister. Du beschwingter Kämpfer Rendezvous. Du tumultuöse Arche der Dichter. Du Halle, Dom, Luftschiff, Vulkan, Käfig, Gruft und Kluft, Dungloch und Stunde der Beter... Ich flamme auf in deiner tosenden Gluthelle. Ich tanze zu deinen marmornen Bassins hin. Ist das Leben nicht umsonst gelebt, alle die schwierigen Stunden des Tags...?! Bin ich nicht immerfort gierig, geifernd, geil und ganz verheult?! Doch du Lebendiges, du Caféhaus, zuckend, juckend und seltener Freuden gerammelt voll, jagst aus meinem irdischen Gehäus, - diesem grellen kunterbunten Schädel, dieser ozeanischen, mondhellen Brust - treibst aus meinem kupferroten Dasein die Gebärden des Spleens, Winde der Weltlust, Katafalke der Sehnsucht heraus zu schmetternder Lust. Du bist mit deinen Sesseln, Korbstühlen und fletschenden Spiegeln, Tribüne der flunkernden Fräcke, der Traiteure, Chikaneure, Amüseure, Tal der artistischen Abenteurer, der imposanten Herren Rhetoriker Parkett und Spielsaal... Nun sitz ich mitten drin, Pascha der Ewigkeit. Um mich das Tirili der Ewigkeit. Um mich des Mondes Gebrumm; im Nacken das Sternemeer. Nun sitz' ich hier, toller Hecht - mein Schatten sitzt rundherum gekauert: ein schlafender Tiger. Mein Ich springt klatschend heraus aus dem Teich: ein toller Hecht. Ich zornlächle, ich schaumgeifre, ich zähneblecke.

Ich bin zu unerhörten Liebessehnsüchten aufgestachelt.

Wo sind denn die schmalen muskelmatten Mädchen, die Juni-Blonden, die perversen Schlangen, die nimmersatten Küsserinnen?! Wo sind denn die schlanken, seidenen Jünglinge, die Herbst-Blonden, die herben Umarmer, die betauten, unkeuschen, lachenden Epheben?!

Die Spiegel grimassieren. Lampen glühen in Zornesfalten. Die Decke spiegelt meine mürrische Frisur. Meine Finger zucken wie Tanzmäuse auf bebender Marmorplatte Zirkus Rund. Ich bin im Café und trinke den Tee. Die Turmuhr feixt. Das Nashorn bellt! - was rufen die Schuhmacher heut in die Welt?!!!

Nun hinaus! hinaus, wieder in die Luft. Wieder zu den wohltemperierten Sternen, dem nikotinfreien Mond! Straßen hin und her - runter vorbei, vorüber entlang weithin fernher dahin...

Türme wandeln steil um mich herum. Steil umtürmen mich Wandelnde. Ich wandelnder Turm ent-steile der Nacht. Ich Steiler türme im Wandel der Nacht. Hinaus in die Nacht... Avenüen lang, Chausseen dahin...

Donner-Lüttich! es ist tiefe, tiefe Nacht. Urzeit! aus fernen Zeiten moderriechende Fernen. Lang tönt die ferne Nächteschar! ... des Mondes Gebrumm, im Nacken der Sterne Gewieher! Ich bin Soldat. Muß ins Lager zurück. Muß schwer, schwer schlafen. 
Text V: „Vision des apokalyptischen Sommers“

\author{
Vision des apokalyptischen Sommers
}

Wie der Frühsommer, wie der grünjauchzende Schwimmer aus den Ebenen steigt. Wie er die Schollen sprengt und dampfend juchineit. Wie die Wälderscharen sich um die Sonne drängen. Die Städte läuten leise, hinter Kratern, Bergen und Bagatellen. Lechzen nach weißzischenden Wolken und sengenden Meteoren. Der Raum schwingt in heiBen Gerüchen, in der Linden verhaltenem Trommelwirbel. Unzählige Straßen durchsegeln die Welt. Weizenfelder krächzen, der Kuckucke schmiedeeisernes Gehämmer und der Wipfel tausendfaches Flügelschlagen in einem tränelosen Meer des Mittags.

Mir fält Tau und Hitze von den Schläfen. Mich ergreifen holdselige Düfte ringsherum, und die dicken Schatten sausen quer durch meinen Bauch. Wird nicht aus dem unseligen Dickicht das Stimmengewirr der Käfer sich auftun und der Mittaggruß der Spinnen?

Hinein in den Wald, wo die Bäume zitternd schreien. Wo Wolken durch das Knoticht und Zweigicht stolpern. Sich hinschmeißen in die faltige Erde, den behaarten Boden streicheln und küssen, Ameislein necken, Eichhorn überlisten. Bebet ihr nicht wie ferne Gewitter, ihr verzückten Bäumescharen über mir! Seit meinen frühen Kindertagen waret ihr mir entrückt. Nicht wuBte ich von euerm Flammenwibel und der zackigen Unschuld der lohenden Stämme. Nun bedränget ihr mich wieder und seid in meiner Brust wie fiebrische Musik. Und du brennender Boden unter mir, du Wohlgeschmack, du wohlriechender, keimtoller, wühlerischer Boden, nach dir lechzet meine Zunge, meine unselige Weltzunge. Nach dir jauchzet meine zerbrochene Seele, die gierige Seele eines Stubenmenschen. Hier habt ihr mich, Baum und Boden, Wolke und Halm, Mittag und tropfende Hitze. Hier habt ihr den Stadtgnomen mit Haut und Haar.

Ach, wie sind die vielen Jahre eines Malers in die Enge gerannt. Ach, wie war ich vergrämt in dem Ölgestank des Ateliers, und meinen Kopf barg ich in der Glut des Gaslichts. Das war in all den jubelnden Jahren vor dem Krieg, und einen Sommer, besudelt über und über mit Krätze, Not und Verrücktheit werde ich nicht vergessen können, denn er hat mich alt gemacht, und meine Jugendpläne sind zerweht und mein Mut ist brüchig geworden.

in einem Malkittel steckend, der, mit geronnener Farbe bedreckt, wie ein Panzer steif war, mit nimmersatter Palette gegürtet und fletschenden Pinseln, so stand ich, nicht wankend, die ganze Nacht und malte mich selbst vor dem grimassierenden Spiegel. Ich blieb ungestört und nur Gaskocher, Teetopf und Tabakpfeife waren meine murmelnden Gefährten. Hitze keuchte wie bei einer Feuersbrunst. Die Keilrahmen knackten. Weit offen stand das Fenster, und die Sterne regneten wie Raketen um meine gletscherblanke Glatze. Wie mich die Kerkerfarbe des Ateliers verbrannte. Sonne stach nie ihre blutigen Messer hinein. Aber ich wurde braun wie der August. In mir kochte der Wüstensommer mit Geiern, Skeletten und gellendem Durst. In mir schrie es nach knattenden Fernen und den PosaunenstoBen künftiger Katastrophen. Mußte ich nicht auf meine Selbstporträts immer Blutrinnsale hineinmalen und zerfressene Wunden?! Liebte ich nicht auf allen Hintergründen den Kometenschweif und brandende Vulkanel lch kratzte, rieb und wetzte meine Farben. Aber elend zerrte ich dabei am Leibe, der, verhängt vom Farbenpanzer glühte in der Krätze gräßlichem Gewimmer. $O$, du wilder und geblähter Bauch, ihr abrupten Gliedmaßen und ihr diabolischen Gelächter auf den Backen - nun ward mir das Lachen sauer. Ich wuBt' mir kainen Rat vor Ungeduld. Goß Ströme Peru-Balsams über meine Haut. Es nutzte nichts. Zum Kerker der Frohne und ekler Krankheit war ich verdammt. Ich war allein mit mir und ohne Rat. Und jeden Mittag, wenn ich, verwildert von gräßlichen Träumen und feucht vom Salben, aus meiner Ecke mich erhob, begann der Kampf von neuem, und jeden Morgengrauen, beim Zubettgehen, würgte mich ein schäumender Cauchemar und ich gierte immer mit den Augen nach den unfertigen Leinewänden hin und lechzte und wand mich wie ein zerprügelter Hund. Mein Schlaf war tief wie unterirdische Höhlen, und schweißbedeckt grüßt' ich beim Erwachen den Mittagwind. Die Teetassen gaben mir einen erhabnen Stoß ins Grelle. Gierig fraß ich wie ein hungerndes Tier ein selbstbereitetes, schmales Mahl... Und dann dieses Klafiern und Halftern vor dem Spiegel bis zur Dämmerung. Bis ich klebrig war im Farbenschmutz und ertranik im Sudel des süß stinkenden Peru-Balsams. 
O, dann kamen selige Minuten. Ich rückte das Bild weit weg von mir und sah eine zuckende Stirne, einen mondhaften Leib sich recken. Immer hielt auf meinen Bildern die zerkrümelte Hand die Palette wie einen Schild zur Abwehr bereit. Du mein einziger Schild, farbentränender, in der Pein des ewigen Werktags. Gott war mir noch ferne in jenen Tagen. Ich wußte kaum von seinem Namen. Ich war noch unerweckt, verstockt und trübe. Und kein Gebet machte mich strahlend und mild, und keine Demut sänftigte meinen Blick. Wohin fliehen? wo gab es Frieden, Frohsein und einen Becher voll Licht?

Wie sehnte ich mich nach den sommergrellen Ebenen, nach dem rauhen Atem baumloser Hügelketten. Ich schürte fanatische Klagen in mir und wagte leise zu singen, was ich noch von früher her wußte.

$-O$, daß doch über meinem Haupte der magische Mond aufbräche! $O$, daß mein Bette nie mehr leer schriee die ganze Nacht! DaB sich meine Arme verlassen bäumten. Ich heule zum Fenster hinaus, und meine Tränen fallen den Passanten in thre knöchernen Hände. Die Sommernacht raschelt in den Straßen. Sie schwebt in meiner Stube. Sie ist grellgrün, ein offner Rachen und schrecklich sternen-gezähnt. Ich höre mein Fleisch sich aufbäumen, in Sommerunruhe tief seufzen. Meine Brust ist nicht zu beschwichtigen. Meine Fäuste sind gedemütigt und leer. Nicht mehr glühe ich rot auf und strecke mich nicht zu den Gestirnen. Ich verga $B$ meine hochgestimmten Tage. Ich vergaß dieses Stubengeschrei der vergangenen Jahre. Ich war niemals so zerrüttet und in Ängsten aufgewühlt. Und dennoch muß ich dir Treue wahren, mein Atelier, du höllischer Morast. Atelier, mit deinen verzweifelten Ecken im Staub, Eiland des trunknen Galeerenknechts und Kantaten der unfertigen Bilder, die dem Schöpfer fluchen. Zehn Schritt lange steinerne Halle, meine feigen FüBe baggern in deinem Grund. Meine zitternden Händlein liebkosen deine zwei Stühle, deinen ächzenden Tisch. Und die Lampe wirft ihre schmerzenden Balliste auf mich und dich, du kummervolles Bett. Bette, mein beflorter Kahn, du kennst nicht helles Menschen-Gejubel. Du kennst nur der Arzeneien Geruch, und ich muß immer allein sein und Bilder schmieden. Wo bist du, unbekannte Geliebte, die ich Nacht für Nacht heiß küssen werde? Ich sehe schon deinen Leib aufrauschen, Stadtmeerweib, in den bunten Wogen meiner Stube dich baden. Farbengeflimmer entbrennt auf deiner Haut. Ich wühle mich tief in die Rätselhaftigkeit deiner Fleische hinein. Wie blüht dein Schoß heiß auf, Farren im Waldesgrund. Schenkel umschlingen mich. Herz schlägt dunkel wie die langsamen Domuhren. 0 , wärst du doch schon da, Nachtstunde eifervollen Dienstes! Azur, sommernachtgrün, fällt durch das große Fenster. Unsre Leiber spiegeln die sonoren Töne meiner Bilder. Mond-Sichel hängt uns zu Häupten. Oh, noch so ferne Nacht! Und ihr herzinniglichen und tiefen Gespräche mit der Geliebten! Aber ich muß einsam sein und Bilder schmieden. Und ich muß stille liegen und darf nicht jubeln.

So hab ich den Hochsommer vor dampfenden Leinwänden geschlottert, die in allen Flächen, Wolkenfetzen und Sturzbächen die künftige Erdennot ahnten. Ich habe zahllose Indigo- und Ockertuben zerbrochen, und ein schmerzhafter Drang gab mir ein, alles Geradlinig-Vertikale zu zerbrechen. Auf alle Landschaften Trümmer, Fetzen und Asche zu breiten. Wie baute ich immer auf meine Felsen die Häuserruinen, klagevoll gespalten, und der Weheruf der kahlen Bäume zackte zu den krächzenden Himmeln hinauf. Wie rufende, warnende Stimmen schwebten Berge in den Hintergründen; der Komet lachte heiser, und Aeroplane segelten wie höllische Libellen im gelben Nachtsturm.

Mein Hirn blutete in schrecklichen Gesichten. Ich sah nur immer einen Tausendreigen der Skelette tänzeln. Viel Gräber und verbrannte Städte durch die Ebene sich winden.

An harte Stubenwand gelehnt, spürt' ich das Rinnen meines Bluts nicht mehr. Erhorchte nur ganz ferne singenden Chor der ungekannten Mächte, die in den Kratertiefen schliefen. Der Juli hatte mein Gehirn gequirlt mit seiner unerbittlichen Grelle und den weißen, lautlosen Hitzschlägen. Aber August schlug mich wie ein Raubvogel mit scharfen Schnabelhieben. Ich ruderte angstbedeckt im Schatten der roten Fledermäuse, unter unerforschlichen Meteoren und den Hörnern der dröhnenden Ulmen. August riecht faulig und sauer nach dem Kot der Ruhrkranken und den Leichnamen der Verreckten. Man zerreißt mit Fingernägeln das blinde Gesicht und weiß nicht aus noch ein. Und wenn er verrauscht ist und versandet im silbernen September, dann fliegen die Arme hoch in den lauten Sonnestrahl. Der Haarschopf weht wie eine rauchende Fackel, und die matten Gerüche der Blumen entfesseln deine letzte, müde Qual. So grüBte auch ich den wehenden September und ward gesund. So fiel auch mir die Hitze ab und verrauschte mild in sternelosen Nächten, und ein Regen kühlte die gramzerrissene, graue, todgeweihte Stirn. 
Brandende Wolke - o Sand. Wälder, gebräunt und voll Samen. Und ihr vielen bestürzten Antlitze in den Straßen, die so straßestumm ihren Hundstag wandeln, die so keuchend im Nachmittaglichte stehn.

Ich bin am Saum der Wälder und lieg' hingestreut wie Laub, und meine Hände graben hitzig im heißen Waldgestein. Was ziehen da gen Nacht für ungestüme Wolkenwände rauf? Musik der Ach und Weh's in allen ästeringenden Wipfeln. Geländer an prasseinden Brücken. Pfeifen der feldgrauen Radler, und das laternelose Flußbett stöhnt und kreißt in der Schwüle. Der Sommer schwingt seinen Feuerhut. Er setzt den Hahn auf jeden morschen First. Das Korn verbrennt auf den Feldern. Wälder verrauchen in Feuersbrünsten und Ströme versickern, verdorren. Erde zerreißt und Schollen zerbrechen, und die Ebenen züngeln gierig in die Sonne hinein, schlagen ihre Lohen in das wolkenlose Firmament. Sonne, du Werwolf. Panier Baals. Verfluchte, räuberische, lüsterne. Würgst den edlen Bäumen den Atem ab. Sengst die grüne Perücke den Linden vom Haupt. Saugst dem armen Pflänzlein das Blut aus dem dünnen Leib. Und das magre Hornvieh flehend brummt und sehnt sich nach Trog und grünen Gräsern. Die Hitze gerbt die Kreaturen. Sie umrast mit Dreschflegeln die dürren Bauern. Die Dicken müssen faßweise das schlechte Bier in ihre Rachen gießen. Und nackte Badende fallen um im Hitzschlag und sind stumm.

Derweilen sprachlos stehen Ebenen und Hügelgruppen. Nur Kanonaden hämmern fern und lang. Und unsre Ohren bleiben taub und Schweiß steht rot in allen Fratzen.

Jahre vergingen seit jenem ahnungsvollen Sommer, in dem mich Krätze schreckte. Fern ist die Werkstattstube, und der Staub liegt dort dick auf zerbrochenen Urnen.

Die große Stadt flammt auf im wütenden Gebelfer, Verfluchungen, Händeballen gegen die Zeit. Revolte fängt an, aus den Winkeln zu kriechen. In den Tavernen geht es wie zähnefletschender Aufruhr von Mund zu Mund. Die Leute fressen faulige Speisen. Trinken verseuchte Brunnen leer. Und bald schleichen Magenkrampf und Ruhr die fünf Treppen hinauf. Bäuche quietschen und ächzen. Gesichter werden schmutziggrau und brechen ein. In aufgewühlten Betten bäumen sich zerfressne Männer. Sie sind todmatt in Leib und Hirn. Und die Beischläfer halten es vor Flöhen nicht aus, und ihre Weiber gurgeln ganz leis in verebbender Lust. Hinter geheimen Türen prassen Wucherer und Gastrosophen, und die Nacht stürzt in alle Fenster, weiBglühend und schwärmerischer denn je. Gestirne zirpen selig wie die Grillen. Und Sonne mit Paukenschlägen entsteigt dem ewigen Schacht. Sonne, in pueriler Lust, treibt ihr Tagewerk mit feurigen Gebärden. Städte, lungernd, mit Schwadronen blitzender Frontons. Rasselnd in Staubwolkenpracht, im Geknatter der Aeroplane. Städte, lang wie Kadaver hingestreckt, schluchzen ihre Kriegsnot zähneklappernd dem sommrigen Azur, zerringen die entfleischten Fossilien-Arme. Ein Duft der Seuche hängt um alle Feueressen, um alle aufgescheuchten, zerstochnen Gesichter. Und der Tag schleift schwitzend seinen endlosen Weg...

Wieder bin ich kauernd am Waldesrand, eingegraben ins heiße Gestirn. Das Koppel hab ich weit weg geschleudert, und der Helm bedrängt nicht mehr meine mondhelle Glatze.

Augustgewitter, du, drüben am Fockmast torkelnd, mit blutiger Forke; die Flüsterer im Föhricht, du Flößer auf dem Mondregenbogen! Brändeentfacher Juli-August: dein Fortissimo ermuntert alle Wanzen, Skabies und Mäusebrut. Gewürme dringt aus allen deinen Poren. Fliegen begatten sich den ganzen Tag, und deine Ratten, zu Tausenden, gemästet, fett wie kleine Hunde, tummein aus Trichtern und Gräben...

Oh, der Sand, der Sand! Er ist festgestampft vom windigen Nord-Ost. Er ist glattgefegt und heiß von dem Brodem des August:..

Oh, der Sand, die Albatrosse, Wolkenschatten und Stahthelme. Oh, mein Zagen und um den Mund ein Nimmerwiedersehn...

Eine Mine kommt geflogen. Du, Lachtaube Gottes, Mine, du bist kein Zufall. Ich bücke mich tief vor dir. Heißa, was machst du für Staub! Aber immer noch einen Fetzen Augustblau in deinem tragischen Krakeel. Kamrad, wo bist du? Oh, die Schollen brechen. Kamraden, wir müssen uns bei den Händen halten. Wir, Millionen Brüder. Und auch ihr Drübigen. Uns bei den Händen halten.

Aber ach, zu spät. Wir sinken... 


\title{
Text VI: „Nächte des Malers“
}

\author{
Nächte des Malers
}

Gewimmel von Pariserblau auf blanken Kreidegründen; zynisches, meckerndes Zinkgelb; Weiß mit Elfenbeinschwarz: das Kolorit der alten Bettlägerigen; Permanentgrün neben Zinnobergeschrei; Umbra, helles Kadmium und feurig Ultramarin ---- überhaupt muB das Dasein von fetten, strotzenden Ölfarbentuben eingeengt sein. Man muß sich fest einschlieBen in vier aschengraue Atelierwănde, vor großen Leinewänden herumturnen, einsam schimpfen, wütend sein, sich kratzen und eine Donnerwetter-Palette in der Faust haben. Ich denke mir die großartigsten Dinge aus, apokalyptische Gewimmel, hebräische Propheten und Massengrab-Halluzinationen - denn der Geist ist alles, die Natur kann mir gestohlen bleiben. Aber das genügt nicht: die ölstrotzenden Tuben sind fast noch wichtiger, weil die Farben mitmalen, miterfinden, mitfeiern.

Ich stelle mich manchmal blöde und ausgeleert vor die Staffelei und grinse in meine unrasierten, sommersprossigen Backen hinein; da hüpft aus den zähen Chrom-Fladen auf einmal ein Umriß heraus, das Zinnober fängt zu schreien an und eine wunderbare WirrwarrWelt baut sich allmählich unter meinen Borstpinseln auf.

Ja, Farben, Farben ohne Zahl! Ich werde in eine Ölfarbenfabrik einheiraten. Meine Frau wird mir je tausend Tuben Umbra, Ocker, Kobalt, Kremserweiß und Krapplack in die Ehe bringen. Meine Frau wird eine Eckige, Frenetische, Heiße sein. Sie soll meilenlange Arme haben, mich fest an sich wickeln. Wir wollen uns in die enge Bettstatt pferchen, Ida, und von gebrannter Umbra träumen. Deinen Kopf werde ich dir abbeißen und Fangeball spielen in meinen grellen, zügellosen Nächten.

lhr Winternächte! Inbrunst, Wildheit bis früh um sechs. Her mit den schneeigen Flockenbogen. Mit zuckenden Fingern grab' ich den Zimmermannsblei tief in den Schnee. Ja, ich bin ein strenger Zeichner. Ich flitze kreuz und quer den Stift. Hinter den Sirius setz' ich ein Tusche-Chaos. Ein Kindlein weint darin. Keine Trauer-Esche wift ihren Schatten.

Her mit dem Rum, ich muß schleckern. Die Staffelei presse ich an meine haarlose Brust und tanze zotig und wie ein Bezechter. Geld her, meine Damen. Ich will mir sechs Greise mieten. Mit viel rauhen Schollen werde ich sie begraben, daß ihre spitzen Kniee nur und ihre entfleischten Hände hervorstehen. So will ich sie malen mit lauter Gelächter-Farben.

Kürzlich lief ich ohnmächtige Tage lang herum, Schädel verqualmt, Bauch schwer und Hände vergrämt. Stundenlang auf einen Stuhl hingelümmelt, dumpfes Bohren in Gedichtbänden, stumme Freßbegier und diese Hölle umstarrte mich wie ein Geierkäfig. Da lag ich nachts wie ein Zermalmter hingefletscht, neben Aschenberg und wucherndem Ofenrohr. Ich wälzte mich in Schwermut und venworrenen Gesichten. Minutenlang hatte ich schreckliche Freuden und dann umflackerten mich wieder die schweren Stiere und Maulesel und die bleierne Ramme des Stumpfsinns.

Heute am 15. rasen Sturmsee-Kolorits. Ich mauere Hăusertürme in tänzelnde Mondsichellandschaften. Sechs Stunden keuche ich vor Staffeleien. Es wird wolkengeballter Tag, ehe ich ins Bett stürze... Und die Nacht sieht mich wieder in ihren Mauern. Ich rudere mit breiten Borstpinseln um Hügel und Felszacken herum, quetsche mit Zeigefinger und Ballen den Himmelbrei. Erdrückte Schreie im Herzen, so geht es mit der hohen Bahn, die der Mond am Himmel macht. Ich bin ungebrochen und herrlich stirnzerklüftet. Nenne Bosch und Breughel meine besten Brüder. Die Umbratuben sind im Nu geleert. Zinnober raschelt um die Wackelköpfe der Fliehenden diagonal über das Bild und die Zinkgelbblitze schlagen kahlen Flächen die Rippen ein.

Ein Steamer treibt den Strom entlang. Dünn hängt der silberne Steg über dem Gewoge. Das Menschenschwein trabt drüber her ... da: rux, es kracht. Gischt, Geheull Rufe zu Gott. Häuserungetüme biegen sich und schütteln manchen Selbstmörder ab. Kathedrale purzelt nach links in die Landschaft hinein. Kein Gewinner! nur Gestank strömt auf aus den Nachtlagern zahlloser Lüsterner. Warum verdunkeln so viel Zeppeline den Mond?!! Da klatscht einer auf die Dächer hinab. Menschenbrei rinnt auf meinen Hut. 
Durch solche Nächte werde ich geschleift! Meine Seele umflattert meine Farben. Auf der Spitze des Pinsels lächelt die Seele und singt mit dem Choral meiner pastosen Wälder. Hitze umbrandet mich; heiße Gesänge wollen aus mir heraus; eine furchtbare Gewalt rumort in meiner Brust.

Da kommt mir ein Tag in den Sinn: September-Nachmittag, du warst mein! Ein Patzenhofer Wagen fuhr die milde Chaussee entlang. Der Dicke oben johlte mit dem Winde. Eine Sonne ohne Radau schien auf zackige Vorstädte und ich drückte mich an Drahtzäunen hin, zag und Schluchzer um Kinn und Nase.

Damals war ich ein junger Maler und arm. Meine Inbrunst zitterte um den Maggi-Suppentopf und das kärglichste Mahl machte mich mutlos, anämisch und dumm. Ich zeichnete Fabrikessen im Sonnenschein. SaB am Straßenrand und zeichnete auf Sechserpapier melancholischen Rauch, der aus Fabrikessen floB. Die Abende jahrelang in übelriechenden Lesehallen. $\mathrm{Da}$ ich mich krumm zersaß und Kunstjournale hastend zerfaserte, da ich bei idiotischem Lampenschein immer wieder dieselben Plattheiten las - - hat kein steiles, rauschvolles Blühen die Nächte geschwellt. Ich war verlassen, zerstoßen, geduckt und hoffnungslos in Hirn und Gedärm. Das kleine Tagebuch, das ich behutsam jeden Abend mit meinen winzigen Erlebnissen vollschrieb, berichtet von den verborgenen Qualen, die eine Malerstube bergen kann. Nie hatte ich Farben. Die Pfennige reichten nicht dazu. Mittwoch und Sonnabend nachmittag durchwanderte ich immer StraBen, die zum Wochenmarkt führten. Da fand ich Karotten, Kartoffeln und Früchte, die den Hausfrauen-Netzen entglitten waren, und ich fülte meine Taschen damit. Suchte ich fleißig, so ward mir ein reichliches Essen beschert. Mein Topf brodelte über und ich umtänzelte ihn wie einer, der die ganze Welt im Sack hat.

Oft saß ich auf einer Bank, ganz erstarrt vor Schmerz und zählte mir immer wieder meine verlorenen Jahre, die in Armut und Hunger hinsiechenden Jahre auf. Ich nährte Wut in mir und Anarchismus. Ich hatte den Blick für meinesgleichen.

Ich erkannte euch gleich, Schicksalsbrüder! Obdachlose, verlassene alte Frauen, Männer ohne Arbeit und Heim, unsichern Schritts, blicklosen Auges, so flehentlich dahinwankend. Ging ich nicht manchmal stundenlang hinter euch her und wurde nicht mein Unglück geringer dabei?!

Da war in frühen Tagen ein Winter in Paris zu bestehen. Tagsüber saß ich, ein Selbstporträt zeichnend, in meiner muffigen Kammer. Am Abend schlich ich immer die schrecklich lange Rue Clignancourt hinauf, die vor Elend heult. In schmutzigen Buden briet man Pommesfrites und der Satan versuchte mich jedesmal, meine letzten zwei Sous-Stücke auszugeben.

In jener Zeit, in der der Sonnenschein mir immer ironisch vorkam, die Wolken taub, die Bäume schauerlich und die Nächte ohne Brennen - als ob Gott seine Hand von mir gewendet - hat nie ein liebevoller Mensch meine Hand gedrückt. Es gab nur Dürftige, oder Geizige, oder Hochnäsige, oder brutale Narren. Ich sprach nur selten einen Menschen und wenn ich dann anhub zu reden, klang meine Stimme wie zerscherbte Kannen. Ich war immer scheu, verlegen, glanzlos und in Verworrenheit gehült.

Jetzt bin ich zäh, glatzköpfig, stirnzerbeult und wie ein verzückter Mönch.

Es ist mitten im Winter. Eisfirmamente bedrohen wüste Häusermassen. Die Fugen der Nacht krachen lautlos. Ich durchtaumle das Atelier und sehne mich nach der Geliebten. Ich lispele deinen Namen, Einzige, Teure, Schenkerin. Du wirst nicht von mir gehen. Immer wirst du meinen Namen rufen. Rufst du auch jetzt meinen Namen in die Nacht hinaus, so wie ich rufe, besessen und weinend?!!

In Fieber und Einsamkeit verbringe ich meine Nächte und am Tage schlafe ich traumzerrissen und einsam. Der Spät-Nachmittag poltert mir in das Ohr. Ich bin unglückzerfetzt und erbost über den grellen Tag. Meine Geliebte hat mir keinen Brief geschickt. O, wie ich still in mich hineinschreien und meinen Rumpf verkrampfen muß. Hast wieder in deiner Neurasthenie gelungert, Mädchen! Warst zu feig zum Schreiben?! Am liebsten würd' ich dir jetzt lauter Zynismen ins Gesicht spucken... Mein Bett ist immer leer; ich darf mich nicht mit fremden Leibern beschmieren, weil ich auf dich warte, ferne Quälerin.

Es ist jetzt weißer, siedender Nachmittag mit Geschrill, Gekreisch, Gelächterfetzen. In der Nacht bin ich magisch oder nahe der jenseitigen Welt - aber Nachmittags durchwogt mich ein Orkan roten Blutes. Raus aus den wollüstigen Betten und hinein in die erhabenen Räusche eines Liebesbriefs. Ich schrieb dir sonst vernünftelnde, seichte Briefe. Damit nun 
Schluß! Von nun ab will ich meine Liebe dir zuschreien, dich feste rütteln und durch deine Sonntagslangeweile schleifen. Glaube ja nicht, unsere Liebe wäre ein so banales Täubchengegirr und temperamentlose Beischläfrigkeit wie all das Erlebte deiner letzten sieben Jahre. Ins Bett hüpfen mit Idioten, ohne Verpflichtung und Angst. Der reine Betthase warst du und prahltest noch mit deiner Immoralität. Du wirst es nicht leicht haben mit mir und das Lotterleben einer Bohemienne wird wie eine reine Kleinbürgerei sein neben unseren fanatischen Zinnober-Nächten und Ultramarinblau-Tagen. Habe ich dir nicht Woche für Woche seitenlange Lyrismen geschickt, Schwindelbauten des Herzens, das von Blut überläuft?!! Nun will ich kannibalisch mit dir reden und wie ein Malersmann...

Wieder ist die Nacht. Wieder umfängt mich Palettengestank. Die geliebten Malbesen in den Fäusten. Hitzige Gebärden vor Leinewänden - so geht es Stunde um Stunde. O du aschengraues Mal-Atelier, einsames Felsgestade mit den Skeletten verspeister Bücklinge in den Winkeln und Gerassel der Mäusescharen! Ich trage Nacht für Nacht meine Inbrünste in dein Geklüfte und du sagst nicht "Nein« dazu. Septembermatten locken mich nicht. Septemberblumen welken umsonst. Meine Schreie zerstieben leise an den Wänden. Und ein heftiges Freitag-Abendgebet klatscht mich zuweilen hoch auf die Decke. Ich fliege im Saus zum Fenster in die Morgenröte hinein. Dann wieder fegt mich Zerknirschung in die Ecke. Aber wenn ich mich an dich erinnere, Süß-Geliebte, falle ich in einen Schacht und ich bin lange verschollen.

Die Mondsichel blinkert zum Fenster rein. Ich stehe mit dem Gummiknüppel auf der Wacht und verscheuche die Mörder. Dezemberschnee näßt meine heißen Stirnmale. Noch ist der Tod weit weg von mir...

Man muß saufen können. Immer eine Rumflasche auf dem Nachttisch. Ein Maler muß viel fressen. Dabei hat er breughelische Einfälle. Tollheiten steigen aus dem prallen Bauch. Man muß Gelächter brüllen wie ein Prolet, dröhnend sich schneuzen, gemeine Flüche zum besten geben. Dann auch ist es gut, sich weit aus dem Fenster zu beugen, die Sterne anzuulken und den Mond mit Zoten zu beglücken. Nachher sollst du feste schuften, Maler. Schiebe dich mit gewaltigem Ruck vor die Staffelei. Kümmere dich nicht um Schulen und vorgefaßte Meinungen, noch um das Gerede der Caféhäuser. Mal' deinen eignen Gram, deine ganze Verruchtheit und Heiligkeit dir vom Leibe.

Wie umarme ich meine Nächte in unaussprechlicher Liebe. Eine einzige Stunde tilgt die Schande der verdorbenen Jugendjahre. Ich lalle manchmal wie ein Biertrinker, wenn ich pathetische Baumgerippe gierig hinkritzele. Ich durchwate den Schiefer und Morast schwefelgeiber Städte. Die Dächer öffnen sich im Nachtwinde. Mäuler und Zungen brechen aus den Mauerschlünden. Im Talkessel brodeln Geschreie der lagernden Vertriebenen. Ihre Gebete bohren sich wie Maulwürfe in den hoffnungsleeren Lehm. Viel Kadmium strauchelt um verirte tote Anlitze. Im Himmel schrilt Kremserweiß-Gefetz und ganz vorne sind zerlumpte Bettler in kalten Flächen hingemauert.

Meine Staffelei knurrt und bäumt sich gegen meinen Bierbauch. Ich wüte mit dem Krapplack. Klebrige Pinsel mahnen mich an die Erbärmlichkeit des Daseins. Chromgrün läßt mich kalt. Und Kobalt erinnert mich an meine Kleine-Jungen-Tage, wenn ich Molchen die Schwänze abbiB. Ich bin ein Pinselfex, rührig, schlau, schamlos und unverbesserlich. Ich hege böse Gedanken und mein Malfanatismus geifert und hurra't. Manchmal lächle ich vor Glück. Ich bestaune meine Leinewände. In Zukunft werde ich nur noch ekstatische Szenen malen. Ich fürchte mich nicht. Nur manchmal klaftert jäh Grabes-Finsternis vor mir auf.

Es ist nachts halb zwei.

In meiner Brust schreien die noch ungemalten Pestkranken, Leichenschänder und hungernden Ammen. Mich bedrohen verkrampfte Fäuste und wiehernde Grimassen an den Wänden. Ich schreite wie in gewalttätigen Träumen umfangen. Ich habe schreckliche Angst. Die Nacht ist schweigend und dröhnt.

Dies ist die Sehnsucht des wahren Malers: Umbra mit Zinkgelb und Pariserblau! Eine Rumflasche! Die Donnerwetter-Palette! Die zügellose Geliebte und die Hand ausgestreckt nach den Sternen! 
Text VII: „Anrufung des süßen, unersättlichen Züchtigers“

\author{
Anrufung des süßen, unersättlichen Züchtigers
}

Schaufle die Tage auf. Zerpflügte Stirne - brandend in Spätsommertagen. Fiebre in deiner Enge, deiner stachelnden Stille. Hallo, die Pfähle glühn - die dich umzirkeln, umkerkern, sind süß. Tanze, springe. Weltlust pfeife auf deinen zerküBten Lippen... Särglein ist süB. Die Jahre über den Sand störrisch hinkriechen und verzweifelt fiennen ... unser aller Jahre sind faul und winterlich worden... Wieder ist ein Mensch dahin. Gestern noch bauchgebläht, liedersingend, torkelnd. Jetzt ein Stinkteich, aus allen Löchern laufend, blau. Packt ihn, schmeiBt ihn hinein in den Kasten. Musike voran. Wir hüpfen in den Föhrenwald und haben nicht lange zu fackeln mit dir, geliebter Erdenbruder. Ruf die Würmelein - hei, Würmelein - sie sollen bei dir zu Gaste sein und letzen ihre Bäuchlein klein. - Was schlägt in meinem Him, was tropft in meiner Brust? Es ist mir alles unbekannt. lch sage ja, betevere laut und spitz' die Ohren. Vor dieser schauerlichen Gruft verstummt mein Mund. Mein Him verstummt. Die lieben Leute haben Masken aufgesteckt und wiehern in ihre Hälse hinein. Warum sind Bäume ringsherum, Dächer und trompetende Firmamente. Ich sehe alle Nächte die Gestime, kaltherzige Gestirne sich im Unendlichen jagen. thre Gäule, warum dieser verrückte, steile Lauf? Wer hieß euch galoppieren? Habt ihr eignen trotzigen Willen, oder seid ihr Knechte jenes unerbittlichen Herren, von dem die Menschenbrüste tröstlich stammein?! - Krieg und Katastrophen, Krankheit, Teuerung und Wassersnot - die Menschlein laufen heulend herum, husten Blut, höhnen ihre eigne Art, zerkratzen sich die Mäuler. Unzählige sind aus ihrer Heimat weg, verbannt, vertrieben; zitternd, bettelarm und hungrig. Siechen hin im Flammenlohen der Feuersbrünste. $O$, sieche Pein, o Feuersnot auf allen Hügein und Firsten ... Feuer-Entfacher, du Heilloser, wo bist du? - Gründer der Wälder, der riesigen Berge, der Stromschnellen, wo bist du? Erfinder der Buckligen, Blinden, Stelzfüße und Zwerge, der Leprosen und Schwachsinnigen; Erwecker der Dichter und Prediger, der Kometen und Regenbogen, wo bist du? Wo kommst du her, wo kommst du her, rauschender Blutbach in mir? Woher diese seltsame, rührige Kraft, die mich laufen heiBt, lechzen, stieren, stammein, schreien, jubilieren? Wo bisi du, wo bist du? nenne dich, bekenne dich, du Unheilschrein, Stachler, Ruderer, Aufwiegler in mir!

Ober Sandhügel ströme ich hin. Über Heidesand stottert mein FuB. Unendlich tönend die Brust und heiß jauchzend. Hört es, hört es, ihr Ermatteten alle! ihr Wimmernden untenl Gott lebtl Lebt. Er ist, der lebendige Gott. ich ahnte ihn, wuBte ihn, liebte ihn immer; suchte in seinen Wegen mein Heil. Doch jetzt muß ich es endlich laut bekennen: er ist, der aus Äonen donnert; der Wiesengründe mit Blumen schmückt; den Blindgeborenen die Liebe stiftet und seine Gnade allen zermorschten Bettlern schenkt. Wimmerer, Winseler, Wehlacher in den Grüften, Wisperer und Windsbraut in den Lüften - er ist euch Wonnetau, Berater, Beschwichtiger und Vater-Arm. Euch brodelnden Scharen, euch Millionen der Kontinente ist ein Mahner, Droher, Peiniger, Würger. Er singt auf jedem Ast. In den Steinen ist er nicht stumm. In den Felsen rumort sein Fuß. Und auf den Wolkenbergen, Gletscherfirnen und Kuppen der Einöden singt sein schallender, furchtbarer Mund. Du Sonne, im Schreikrampf taumeind gegen Mittag, du Spielgefährtin ihn, wie unerträglich du bist. Wie unerträglich, Kothaufen, den der Wanderer an den Wegrand legte, brünstig schimmernd und mir die Stirne aufreißend im Nu. Und ihr unermeßlichen Bezirke des Weltraumes, heiße Atmosphären um den Polarstem herum, zerkrachende Weltgestime in der obersten Region ... ihr beweiset seine entsetzliche, unerforschliche Faust. - Aber diese Weisheit hab ich nicht alle Tage. Muß ich ins Unendliche blicken, um dich zu umarmen, mein Vater? Wenn du auch nur murmelst in meiner kleinen Brust, bist du weit herrlicher als in den Sphären droben und ich schaue dich näher als je. Wenn ich stille bin und weise, kommst du sacht zu mir. Strahlst in meinem wunden Leib, machst ihn lind und warm.

Hinken, hocken, hobein, Hohngelächter heulen ... bramarbasieren ... und brummen wie die Hummeln. Über Dämme keuchen ... Sonne pflücken ... den Mittag verschlafen ... Wasser schlürfen aus hohler Hand ... ins Waldgras beiBen und lachen. An den FluB rennen. 
Einen Hamen hinwerfen den Fischen. Böse lauern und sich sehr schämen, wenn Fischlein klein zerrissen in deiner Schüssel ruhn. - Über einen Steg hüpfen, im Ohr die Kantilenen des Junitags. Blumen raffen, scharlachne Zweige, Schilf und Teichrosen. Dem Gemurmel der Rinder zugetan, im weißen Schein tummeln und Narr sein, närrisch seufzen ... Sommertagmüde verblühn. Im Walde ein Lager sich betten, als Kissen eine Hand voll Spreu. Die Nacht verdämmern; träumelos ruhn im Sommerwald. - So ziehn die Tage, die Windseglertage ihren Lauf... Aber es fehit mir was. Ich weiß nicht, ich weiß nicht, es fehlt mir was. Ich scharre suchend zwischen den Stämmen. Greife flackernd an die Stirne mir. Es fehlt mir was. Ich hab was verloren. Ich habe Gedanken - aber die gehn bloß bis zum nächsten Busch. Meine Adern sind schwer und darinnen braust es nicht wie sonst. Bald bin ich zagend im Wiesenwinkel. Bald kindisch tölpelnd in meiner Stube. Und morgen werde ich verzweifelt sein. Morgen kommt der Zweifel in meine Brust ein tiefes Loch aufreißen und das hilflose Herz hinzerren aufs Schafott. Der Zweifel, der scharfsichtige Harpunier, wirft seinen Schleuderhaken und trifft mich gut. Er schleift mich viele Tage im scheelen Meer der Schande und Erbitterung. Was ist aus mir geworden?! Nicht sehe ich mehr die Farben des Waldbaches und die Schauer der stummen Tiere. Die Wolken sind im Starrkrampf über mir. Die Nächte taubstumm und blind wie mein verkümmertes Herz. Was nützt mir jetzt die heilige Schrift und die Bücher der frommen Magier, die ich mit mir herumschleppe den ganzen Tag. Sie lassen sich nicht entsiegeln und ihre tiefsten Sprüche bleiben hart und gleichgültig auf dem Papiere stehen. - Vertreib die Nächte in Spelunken, Cafés; such in Wäldern und Blumengärten dein Heil. Du triffst ihn nicht, du triffst ihn nicht. Du siehst nur das starre Sein wie Pfützen überall nach einem Regen. Wie die Menschen aus ihren Kehlen krächzen. Wie Besessene immerfort dieselbe Kurbel drehn. Immerfort dieselben Türme läuten den Menschen Feiertag zu. Aber die rühren sich nicht und auf ihren Häuptern entbrennen nicht himmlische Flammen. Ich renne von Stube zu Stube, von Buch zu Buch. Gedanken springen nicht auf. Sie bleiben müde liegen wie Staub... Warum schweigst du und enthüllst dich nicht, Gnadeschenker, Taubringer, Nährer Gott? War ich schlecht? war ich gehässig? spielerisch und launenhaft? habe ich deine Kreaturen gering geachtet? habe ich zu sehr nach weltlicher Liebe gebuhlt? habe ich meine Trägheit nicht meistern wollen? habe ich dich je vergessen und auch nur einmal klein von dir gedacht? oder auch nur einmal leichtfertig von dir gesprochen vor den Menschen? Mein Gott, allersüßester Gott: dich, dich such ich wieder. Wonnefunken in meiner Brust, spring auf und laB mich nicht verdorren. Ich laufe wie im kranken Schlaf herum all' die Wochen. Ich bücke mich, aber Inbrunst schlägt nicht mein Gebein. Ich geh wie in Stücke zerschlagen, denn du bist nicht bei mir, Geliebter; du Ruderer, Aufrührer in mir. Wo ist mein Mut, meine Redlichkeit und Tagsicherheit? Rachsucht und Jähzorn steht auf meiner Stirn. Wo bist du, innere Stimme, die mir immer das Rechte sagt? die mich labet und wegweiset? Mein Leib ist mir eine furchtbare Last. Es sind allerorten Wände, die ich durchschreiten muB, aber meine Beine sind nicht fest genug und die Zetergeschreie der nackten Brüder um mich herum bringen mich immerfort zum Straucheln. Ah, Dichter sein! Rausch der Vokale! Sprachgewaltig taumeln und tanzen... Maler sein! Hohes Erdenglück! Mit den Dämonen ringen und mit Gewitterwolken rasen... Kämpfer der Freiheit sein! Mit allen Menschenbrüdern Hand in Hand, verwegen, märtyrerischer Mut... Doch was gilt das alles gegen deine hohe Gnade, deine überirdische Glut, o mein Vater?! Du Wandler, Wender, Verklärer, Zwiespalttilger und allerweisester Arzt. Was ist des Dichters, Malers, Erdenstreiters Glück, verglichen mit deiner Fülle, deinem süßen Frieden, deiner allerletzten, tiefen Seligkeit?

Du Frager in der Nacht, wenn Frost auf mich fällt, wenn die Sterne bellen und der Mond raucht. Bin ich ohne deine Gnade, weiß ich nichts vom Sein. Werf das heiße Hirn ohnmächtig an die Wand. Du letzter Grund, wie viel Tränen pressest du mir ab in solcher Stunde. Wie viel häßliche Dohlen mich dann umflackern. Wie ich anklägerisch vor dir heulen muB. Daß du uns immer und immer mit dem Paarungstrieb peinigest. Ach, wie närrisch, viehisch wir uns in der Wollust winden. Du, Gott, schicktest uns den Hunger in den Bauch. Bauch und Unterleib, Doppelgestirn der Schande, in der Erdenhölle Tag und Nächte scheinend. Die Menschlein lebten jubelnd in den Tag hinein, vergaßen dich und deine scharfe Zucht. Sie wollten einen neuen Turm von Babel bauen und hoffärtige Worte erfanden sie für ihn und nannten ihn "Zivilisation«. Aber du Gott hast ihren Sinn verwirrt. In 
einer heißen Hochsommerwoche verdarbest du fürchterlich ihr Werk und die Bauleute verstanden ihre Sprache nicht mehr. Die Weisesten machtest du dumm. Und die Gerechtesten böse und blutgierig. Du, Gott, triebst uns in unsre Sünden hinein, um dann gewaltig auszuholen mit der Racherute. Du schicktest wiederum zehn Plagen über uns und deine Geschöpflein krümmen sich wie Späne vor dir. Du rissest ihre Leiblein auf. Blutige Furchen grubst du in die Rücken. Hacktest Bein und Füße ab. Und in zerfleischten Schenkeln sieht man deine Fingermale sitzen. Du Heimsucher warfest alle Leiden tausendfach auf uns in dreien Jahren. Wir schreien jetzt vergeblich zu dir auf, Bedränger, Peitscher, Nimmersatt. Ach, du bist schrecklich. Wer kann vor dir stehen, wenn du zürnest? Wenn du das Urteil lässest hören vom Himmel, so erschrickt das Erdreich und wird still. Aber deine Lieblinge lässest du unversehrt. Sie gehen heil und heiter durch das Blutgetümmel. - Warum hast du dir Lieblinge erkoren, du Gerechter? Warum sind nicht Alle deine Lieblinge? Jede Sekunde raffest du einen Erdenwurm dahin. Und jede Sekunde ziehest du Einen aus dem schleimigen Mutterleib. Jede Sekunde entfachst du alle Affekte; alle Mörderei, Bluttat, Unzucht, Verrücktheit, Teufelei, Geiz und Gier. Hilf, hilf, denn die Jauche gehet uns bis an die Seele. Hilf uns, denn das Land steht in Flammen. Stütz uns windige Skelette, du Erschaffer der Mäuse und der Generale, der Kornblumen und der Weltmeere. Du Water im Blute, der du die Herde zertrümmerst, die warmen Nester der Familien. Mit deinem Lächeln stürzen Tausende tot hin. Durch einen kleinen Ruf fliegen volkreiche Städte in Scherben. Deine Atemzüge sind Erdbeben und Zyklone. Und wenn du schläfst, verdunkelt sich der Mond und viele Sterne wanken tosend in dem ewigen Raum. Aber du gibst einem Waisenkind den Unterhalt; vergissest nicht den allerletzten, kranken Tagelöhner. Der Spinne gibst du jeden Tag ihr Futter und die Eintagsfliege findet, was sie braucht. Und wenn ein müdgehetzter, armer Schlucker zerweinten Schädel auf die Schienen legt und auf den malmenden Expreßzug wartet - dann, Allerbarmer, schickst du einen Engel hin, der hebt ihn auf und führt ihn wieder weg ins tolle Leben rein ... ins orgeln, glücklich sein...

Ich rüttle wie der Herbststurm in meinem hölzernen Vogelkäfig. Der Mond knarrt und die Pappeln pfeifen draußen im Wolkenmeer. Ich bin noch ganz bedrängt von Schmerz und Grauen um das Los der Welt. Fresse Heringe und werfe die Köpfe zum Fenster 'naus. Um mich steigen Gesichte meiner künttigen Leiber auf, derweil die rotgescheckten Höllenhunde rasselnd schnobern an meinen Pantalons. Die letzte Asche meines jetzigen Leibes seh ich in tausend Jahren verspritzen; den letzten morschen Knochen zerspellen. Ha! mich trägt Gewißheit weg in ferne Welten, wo meine Seele reiner ist und näher der göttlichen Glut aufjauchzt. Der Feuermantel des Ewigen umhuscht meine lächelnden Wangen. Ich falle hin; aus tiefem Herzensgrund heb ich meine Hände auf. Trunken bin ich und ich singe lautlos mit meinem Mund...

Tanze, springe... Särglein ist süß... Zeuch hin, Staubgeborener! Zeuch hin. 


\title{
Text VIII: „In den weißen Windhimmel lauf ich hinein“
}

\author{
In den weißen Windhimmel lauf' ich hinein
}

In den weißen Windhimmel lauf' ich hinein ... friedlos, frierend, faustgeballt das Herz. Neben den lechzenden Äckern eile ich hin und verfang' mich im blasenden Wind ... verlier' meinen Atem im donnernden Raum... Wer bin ich noch immer nach allem, was ich erlebt hab'?!

Über die schreienden Felder meiner Jugend blick' ich zurück. Zitternd lang' ich zu den sacht gestrichelten Blättern, die ich gemacht hab' um die achtzehn herum ... renne erschüttert immer wieder den windgrünen Weg, der am Heimatfluß fließt. Renne mit verschlossenem Gesicht durch die Zeit - Zeigefinger immer auf die Blutwunde weisend ... nur selten bäumten sich Herzen auf ... nur selten rief die Erde ihr schneidendes "Nein «.

Warum seh' ich Feuer so gern? Feuerbäume der Hochöfen; Feuersbrünste gar drohen? Warum liebe ich hohe Türme, zerstampfte Häuser und Städte, Mondfinsternisse und heftige Winternachtregen? Warum ergötzen mich Begräbnisse, nackte, verwesete Leiber und Fiebergewinsel Todkranker? Warum fühl' ich so wenig Liebe in mir? ... und der Friede Gottes hat mich verlassen ... mein Haus, mein feines Heim, mein stiller Garten, mein Wagen, in dem ich fahre, ist dahin...

Voriges Jahr noch war ich erleuchtet und groß in der Liebe. Da goß der Himmel seine Tränen herab, und die Erde gab aus ihren Schluchten Brot und wilden Honig. Ich fand Lust am Schenken und schenkte mich hin. Achtete nicht meine Zeit, meine Ruh'! Verschwendete Bruderspenden alle lieben Stunden.

... denn seinen Freunden gibt er's im Schlaf. Und wie im Schlaf kamen mir Gedichte. Leicht und willig hüpften die wahren Worte zu mir ... schnellte meine Weite mich wie einen Ball dahin.

Oh, meine Lust damals ... meine Weltoffenheit, Entzückung und Gottesruh' ...!

Über den krassen Pflastersteinen lauert der Würger Mord. Durch die flennenden Straßen, durch die verärgerten Häuser zieht wie ein Zugwind er.

Über den Städten und Häfen hängt ein tolles Tier. In meinen Händen steht ein steiles Los ... liegt Hohn auf meiner Zunge, und ich muß mich mühen, daß der $\mathrm{HaB}$ nicht wie ein Wolkenbruch die Säle überschwemmt.

Hungrige Hunde schleichen, Leichenwagen laufen, kahle Gerippe rattern in den Straßen und heulen: Rache, Rache ist da!

In den verhängten Nachthimmel fall' ich hinein ... in das Schilf, in das Kappweidendickicht und den Wildentenpfuhl ... in dem wiehernden Wasser schwimme ich hin - mein Auge wächst auf in der Nacht, mein Mund fängt zu sprechen an.

Über die Felder wälz' ich mich hin. Streu' mich wie Krume entlang der Chaussee ... rolle zum Mond, der an der Schwelle des Morgens schwankt ... der meinen Namen brüllt, der mein Gesicht beleckt...

In die Kindheit eil' ich zurück, als mich göttliche Kunde das erstemal rief. - Ach, welche jugendliche Inbrunst, unsäglich damals ... inbrünstiglich beten und Freudengeweine, Tränenlust häufig am Tag.

Da kamen die Verlockungen des Unglaubens. Bestechende Broschüren überredeten mich zum Atheismus. Ich ward hin- und hergeschleudert wie im sturmgetriebenen Kahn. Schwelgte in der SüBigkeit des Hallel-Gebetes, und dann bespie ich Jah, türmte Schimpf und Schmähung in die blaue. Wölbung oben... Diese unvergeBlichen, heiBkalten Sturzbäder im siebzehnten Jahr...! Schließlich ward die Gnade mit den unerbittlichen Rutenschlägen des Zweifels verjagt. Ich verwand die selige Liebe und dampfte mit fanatischen Rudern in den $\mathrm{HaB}$. - Trieb ab für lange in den Ozean von EinsamhaB und Menschennot. Flog ins uferlose, keuchende Getümmel, ohne Rat und weise Sänftigung. -

Durch die Kasernen toset verhaltene Wut ... schallt mein erbitterter Schaftstiefeltritt. An den Tagen drück' ich mich zagend entlang. Alle halten geballte Fäuste in den Taschen fest (- denn noch zähmen sie ihren Zorn -). Wie Werwölfe schaukelt das Volk am Rand der Rache.

An den Fenstern schrillt der Tod. Pfeift der Hunger durch alle Ritzen. Steigt die Grippe aus allen Pfützen. In allen Herzen UngewiBheit und Not. 
Ha! Ha! daß Welt und Zeit mich so überkam! So sehr, so grimmig mich die Erde mit ihren Stacheln zwackte. -

Bis zum achtundzwanzigsten Jahre war ich blind dem innern Gesicht, dem Weltherzen fremd und taub, und wie einen losen Fetzen trieb mich der Winterwind von Berlin. War nHunger, Hunger« nicht die Straße, in der ich tag- und nächtigen mußte! Hunger nach Brot, nach Liebe, nach Weisung von oben. Die Straße Hunger hat mich zerfetzt wie vierzig Jahreszeiten einen blätterlosen Strauch. Mir regnete nicht Güte. Wohlwollen fächelte mich nicht. Freundschaft düngte nicht meinen Boden. Und immer fauchte das Morgen mich an wie bellende Hunde. Das Morgen ohne Aussichten, ohne einen Pfennig Geld...

Aber heute - hingestellt, hingestampft - der Menschheit Glöckner, an den Strängen zerrend - Schiffer an Bord der Ewigkeit - ich lausch' den Stimmen der Horizonte, winke allem Weltenjammer Nimmerwiedersehen zu.

Da horch, horchl Gewinsel aus dem Erdreich rinnt, Gemordeter Weherufe ... vorbei ist dein winzig Leid und der Erde Leid, dieser Jahre Biutröchein wirft sich schmerzhaft an deine Brust. Verdorrtes Bruderblut - Krieg, Kriegl - der heiseren Hassenden Würghände noch immer, noch immer im Land. Blutlachen auf der weiten, keuschen Erde.

An den Schienensträngen lang schleift mich Novemberwind. An Kanalufern, Böschungen, Hügelhängen stammelt erschauernd mein Tritt. An die Stadtkirchen klatscht mich, an Kasernen, Gefängnisse pfercht mich der rote Tod. Man mahlt mich in allen Mühlen... Lang' war ich ohne Tröstung, ohne Dach und guten Rat. In der Hungerhölle hat meine Stirne kalte Tränen geschwitzt ... da, eines Nachts, im Herbste, als ich lange arbeitend auf einem Ölbild wühlte, tat sich eine seltsame Stille auf in mir, und eine große Stimme sagte laut in mir "Steh' aufla und wiederum "Steh' auf! -

$\mathrm{Ja}$, Seele, Seele, nun entrang sich deine Stunde...

Jene Stimme, ja, hielt ich wunderbar in meinem Herzen fest. Stieg fortan auf Himmelsleitern auf und ab. Mir kam Liebe in die Brust, Friede, Frohlocken, ungekannte Freude. Nahrung war da, oh, und Menschenwohlwollen und Interesse für das, was ich schuf ... und Girlanden über Türen und Wänden und inbrünstiges Lachen zuweilen in früher Nacht.

Oh, meine Gottversunkenheit damals, meine Sicherheit, Weltinbrunst und tiefe Macht.

Jubel im Herren, FleiB und Zuversicht und paradiesische Gärtnertugend ... war ich für dieses Erdenleben tot, als ich in deinen Fittichen hing, mein Gott? - Nein, niemals, niemals, nein; - nur die Bastionen der Geschlechtsliebe hatte ich fliehend preisgegeben, um in höherer Wonne zu treiben. Aber nicht versank um mich die Welt in Schmutz und Verachtung. Als ich in deinem Arme ruhte, war ich dennoch feurig zugetan den Dingen um mich her. Alles, alles hatte wundersame Farben, und hinter den Schatten lauerten keine Zweifelsfragen mehr. Welt war enthüllt, mit tausendfältigem Gestrahl, mit himmlischem Parfüm betropft. Nie floh ich Welt - getrost und rein war meine Weltverbundenheit.

Warum lieb' ich schon immer den Mond? die heftigen Reden der Irren? der GroßstadtstraBen Nachmittaggetose - und mein eigenes Spätnachtaufflammen in der Werkstatt vesuvischem Geröll? Warum sind Leichname so schön? auch tote Fische, Kadaver gefallener Pferde und Hundeskelette machen mich glücklich. Warum gibt es so wenig Liebe unter den Menschen? Und warum gelang es mir nie, meine Freunde zu Gott zu bereden? - Oh, warum ist dieses Erdenrund und wir da mitten hineingestreut wie Wind? Oh, warum muBte Krieg sein, Hungersnot, Hader und soviel Menschenhaß? -

Ich wanderte auf des Ewigen feurigem Pfad, bis mich die Gnade eitel und hochmütig machte. Laut brüstete ich mich vor den Leuten mit jenem seltenen Wein und benasrümpfte die Erdschweren und Höhlenbären. So in Hoffart und Hohn ich verblendet, wandte sich die Gnade von mir weg und ließ mich wieder allein. Stieß mich in alte, längst vergessene Pein und Ruhelosigkeit. Mich übermannte wieder der Marder Verstand und Herzens harfende Stimme schwieg jäh still.

In den grauen Schneehimmel renn' ich hinein. In der schneidenden Winternot winkt mir kein Weib... Keines drückt mir die Hand. An den Türmen, Kadavern und Fischen flieg' ich vorbei. Von den Tischen her rollen Stimmen zu mir. Von den Wasserflaschen, vom Salz wogt eine Lawine von $\mathrm{HaB}$... Werde ich vor der Zukunft bestehen? Wird wieder himmlische Liebe in mein Her kommen? Demut, Kraft und Gebet? Wird wieder das Land sich in BuBe bekehren zu Güte, Geduld und Gerechtigkeit? Werden die Leute wieder einfach und redlich werden und wieder das Brot lernen ehren?

Über die grelle Mondfläche flieht wie ein Nachtalp mein Leib. Meine Arme sind voll Zank. 
Mein Gehirn zerbarst vor lästerischer Glut.

Durch die grollenden Vorstädte hastet mein Fuß ... stolpert mein Schrei...

Oh, mein Schrei, an dem ich mich festhalte bei Tage. Ich klammere mich an meine eigenen, strohernen Worte wie ein schiffbrüchiger Mönch. Ich bin kein Mönch mehr ... nein, ich bin ein Todesschrei, ein Gottesverräter, ein Hund.

Was Freiheit in mir war - ist dahin. Unbändige Sehnsucht, Überschwang voll Geduld, Überschwang voll zehrendem Feuer und Liebe voller Ungeduld ... und hilfreiche Hand und Weltgüte ... mein reines, tausendfaches Lachen ... meine Verzückung, Läuterung, Reue und Reinigung ist dahin ... und der Friede Gottes hat mich verlassen - mein Haus, mein feines Heim, mein stiller Garten, mein Wagen, in dem ich fahre, ist dahin. 


\title{
Text IX: „Malers Tag-Gesang““
}

\author{
Malers Tag-Gesang
}

Maler, stell' dich feste hin und fall' nicht um.

Fall' nicht um, sei behend und bereit, trag' deinen Leib in das Farbenreich.

Oh, von deiner Seele falle der Schlaf. Wenn auch die Horde um dich herum in deine Fersen kläfft, wenn auch die Zeit, wenn auch die grause Einsamkeit dich trifft - - - weiche nicht und stemme gegen die Wolkenschauer beherzte Brust.

Balle die Hände, hebe den Hut; du suchst in gellenden Nächten deine Farbenskala; in den Wäldern hallt dein magischer Schritt.

Falle nicht, Maler, wenn die Gesichte dich bedrücken; wenn innen die Löwen schrein, weinen knotige Fingerlein, gebückte Menschlein in dir tönen und rasen...

Ach, wie das Weltail bellt; aus allen Heuhaufen, Fichtenhainen deine Liebesseufzer dringen. Ihre Echos aus harten Keilrahmen springen...

... du Stotterer, wenn dich der Mondschein überfällt - melancholischer Pinselschwinger und Späher in ferne, mondhelle Bereiche. Du Haderer mit den weißen Tagstunden. Deine innere Gewalt, wirf sie auf schlottrichte Leinwände, wirf deinen wilden Feinden sie zu. Du Zügelloser, Zäher, zorniger Eiferer. Pikör der himmlischen Hengste, trabend durch farbentolle Räume...

Wie die Stunden vor Staffeleien hinziehn, im Flug entsausen... Eilige Pinasse gleit' ich dahin. Regen feuchtet mich nicht. Hagel und Blitz trifft mich nicht und die Granaten zergehen fern. Ich schlendre heil unter Verseuchten, schlürfe die Pestbazillen ohne Gefahr. Im Gemetzel bleib' ich kalt, und Feuers mordende Flammenmühle mahlt mich nicht zu Staub. ... Herzu! Herzu! Die Farben schlafen in ihren Tuben allen. Blas' innen jüngstes Gericht. Wecke sie, peitsche sie auf. Die Farben in ihrem Schlaf Nänieen blasen, wimmernd das Gesicht verhüllen. Rüttle sie wach, Henker, Magier! peitsch' sie auf.

... meine Brust, du, entzündet vor Staffelei. Hirn, geöffnetes, in hohen Hitzgraden pulsierend auf der Leinwand; du Amboß, auf den die Wucht des Himmels donnert; Kieselstein, geschleudert von unsichtbarer, wilder Hand, und du Wind ... bunter, aromatischer, herzwarmer ... fliegst in all meine Flächen hinein ... tönst von himmlischer Brunst... Maler, träume nicht, da die Erdreiche grollen, Jahrtausende vor deiner Zeit erschrecken ... sei auf deiner Hut. Stelle dich gegen die Zeit, schrei' ihr meuternd ihre Verbrechen zu. Maler, strauchle nicht, ob auch die Leichen schrein. Der Schall der Minen dein Gehirn zerreißt. Reiß von den blutigen Fahnen das Tuch. Kochend, in weißer Glut spann es auf und mal' das Leid. Mal' dein Menschenherz auf das blutige Tuch...

Mitten im waghalsigen Tag, wenn Sonne auf allen Dächern klirrt, gloset der fahle Mond und hebt dich hoch. Du fährst auf dem Mondstrahl in die Äonen hinein. Bist lange wie tot, mitten im trunkenen Sein.

Hoch! ... Malerseele, arme, zermarterte ... schwimme in deinen mondheißen Wassern, grüß' die Plejaden am Mittag. Ruf' dem Polarstern deine Schwüre zu, recke dich auf zum Saturn.

... ich bin gezückt und reif die Treppen hinabgetrieben. Sternschnuppe funkte um meine süblime Nase - bunte Winde um die Backen herum.

Horch! ... durch die Millennien, durch die endlosen Wüsten des Azur.

In den Mitsommernächten schlottre du, bist ja der Griffel unerforschlichen Gottes, der mit ihm seine Marginalien malt.

... niederfalle beschämt vor ihm, der in deinen Adern und Stirnhöhlen unsäglich pocht, der in deinen Gedanken jauchzt ... der immerfort in deinem Herzen weint.

Maler, tanze in Gott. Mit deiner Farbenschar bekriege den schaurigen Zwiespalt.

... du Mäusefraß der Zeit, schwind' hin, schwind' hin...

Eiferer, Haderer schwind' hin... 


\section{Text X: „Septemberschrei““}

\section{Septemberschrei}

September-Ende jagt mit höllischem Gebell über den Sand-Winter, nagt in den Sand träumenden Sonnenschein. Müde Eilande kriechen im Grün der Städte, des Getürm, des Glockenklang. Kiefern-Dome singen in blauer Glut, umwölben mild und blau den WeltRand.

Über dem Gefangenenlager zu M. dampft Geschrei und Schwermut des Kerkers. Schwarze Fahnen sturmknallen am Firmament ... in Sandhügeln vergrabene Baracken, unbarmherzige Stacheldrähte und Pfähle, Pfähle in meinen Leib gebohrt, und Flüche fremder Sprache bedrängen mich heiser... Oh, und der Sand, der wie das Erbrochene Sterbender um meinen Fuß droht...

Menschengesichter, tief zerfressen von Sehnsüchten. Von Hunger und Kränklichkeit Zernagte, gedemütigt und bespieen von Menschenbrüdern. Menschenantlitze mit SlavenNasen bleckend. Schiefe, sengende Augen-Fratzen. Immer lauernde Mäuler. Rasierte, zerfetzte Schädel voll Zweideutigkeit und Verrücktheit in den Wangen.

Da flammt auf einer Maske Güte auf und gottseliges Lächeln. Da gehen zarte Händedrücke um. Und manche sind versunken in ihr Nichts und ferne Heimatlieder.

Franzosen rasch durch das steile Blau der Engländer knicken.

Die Engländer pfeifen die Verdorbenheit und Lüste der großen Hafenstädte. Frechheit schlenkert um Hosen und Hände.

Ohne Taumel und Chaos schreiten Serben mit großen Bottichen immer zu Vieren.

Ein Köpfegewirr, zerrissen und zerquält von Stacheldrähten, schweifende Hände und Gestampf vieler Tausender im stürmelosen Meer des Sandes...

Über den Platz loht heißer Suppen Gedampf. Die Gefangenen sind in sich geduckt und ganz zerrüttet vor Angst.

Ihr Wälder ringsherum, jubelt ihr nicht euern Odem in nackte Höfel Aber Geräusch vieler Krähen schwebt über euch ermatteten Hirnen.

Mich bedrängt der große Welt-Unsinn. In mir weint es schon tagelang. Ich will $\mathrm{HaB}$ in mir entfachen! Aber das nützt nichts. Ich will wehklagend mich in den Aschen der Traurigkeit wälzen! Aber das nützt nichts. Ich muß ein langes Messer an der Seite tragen und meine Menschenbrüder mit zynischem Gleichmut bedrohen.

Reveille flattert über den Platz. Eine Sekunde Aufruhr trompetet sie den Seelen. Dann geht das Weltzagen weiter seinen Gang durch den Sand-Winter. Die Posten lösen sich träge ab. Die Nacht trommelt schon an den Flanken der Baracken. Da geht die hohe Orgel der Schnarcher durch die Stille. Sie wehklagen im Traum die armen Hingestreckten. Lampenblitze grellen durch die Schwärze. Nur Schreck lärmt in meinem Blut, Zorn und Bitterkeit, wenn ich, Wache stehend, die Nacht durchstarre... Da unten flammt ja die schreckliche Stadt Cottbus auf ... da ist ja ein Mond am östlichen Firmament, der mich heute nicht bedrängen will, und die vielen Schattenmulden um mich vermehren meine stumme Zerquältheit. Die Welt ist wie ein Tier-Lächeln schrecklich. Sie ist so verzagt und fragevoll...

Einstimmen-Gesang kommt aus offenem Fenster geflogen: der w/nternationalew strömender, aufwiegelnder Fittich ... quirlt hoch, vermählt sich den Krähen am Nacht-Firmament und weht mit ihnen hin bis zu dunklem Heimatwanderer ... der erglüht, händebeschwingt und die Brust tönend von All-Menschheit.

Wie heißer Mondstrahl im Gewölke des Tabakqualm fällt Glühbirnenlicht in die Schräge des Wacht-Lokals. Waghalsiger Kajütraum im Weitmeer der Nacht. Ich liege auf schmutzigem Sack, der mit Holzwolle gestopft ist, und drehe mich in bleierne Träume. UngezieferScharen wüten auf meinem Leib. Mitten im Schlaf stachelt's mich auf und brennt wütend an mir. Meine Finger rasen und zerren an dünner Haut. Wortgetaumel der andern im Schlaf kommt an meine Augen geweht. Aus schrecklichen Mondfernen an meine Augen geweht. Sie rufen nach Paarung und nacktem Fleisch in ihren Träumen. Die schlafende Soldateska ist wild und mystisch...

Das Früh-Wecken klatscht in unsre strahlenden Traum-Ebenen. Alles schüttelt sich jähe und tragisch die Nacht von den Gliedern. Der verruchte Sonnenschein hustet über die Höfe. Herbst donnert überreif die Felder dahin. 
Ich bin zum Anbinden kommandiert. Der Pfähle-Wald brüllt im Früh-Himmel, kratzt den Himmel auf, daß er schreit. Achtundvierzig Russen trotten in den Hof. In den Falten ihrer Kleider ist Kälte und Eis verborgen. Ein untersetzter Henker (mit Gefreitenknöpfen) verrichtet das Werk wie jahrelang geübte Handwerksarbeit. Zigarre hängt ihm am rotbraunen Maul. Wollust läuft aus seinen Augen. Er trieft vor selbsthasserischer Häßlichkeit. Ein Zweiter, sehr Giftiger hilft mit. Windet Stricke um Beine, schnürt Hände fest, daß sie am Pfahle gezackt sich spreizen.

Die Angebundenen weinen nicht. Sie recken ihre Köpfe weit heraus und schauen wie in jenseitige Welt hinein. Mit meinem tagtäglichen Mörderinstrument stehe ich da, ganz erbärmlich und schuldbeladen. Ich habe nicht den Mut zur Empörung. Ich zucke unsicher unter Blicken, die von überall her mich durchstechen. Wimmere ich nicht schon ewig?! O Tag, Tag, warum nimmst du kein Ende?! Warum muß ich ohne Erbrechen dies Pulver schlingen! Mich überschlagen, purzeln, streiten, Hände ringen! In dies Sandmeer bin ich geworfen worden, meine Kehle ist rissig und blind, Nachtlaute umgellen mich, Geiergeschrei rasselt um meine Lippen, Friede wird nie mehr in mir keimen.

Die Pfähle sind lautlos vor Krampf. Hände laufen blau an. Füße sind wild in den Sand gestemmt. Teuere Brüder, am Holze hängend, vergebt mir! Bin ich nicht wie ihr hineingestoßen in diese tobende Erdenpein! Gefesselt, geschlagen und hilflos wie ihr! An den Schandpfahl gehängt und erniedrigt von Menschenbrüdern! Und auch du, fuchsroter Höllenhund, aber nicht weniger mein Bruder als alle andern, du leidest mehr, als wir's wissen mögen. Du bindest mit diesen Leuten dich selbst an den Pfahl. Die Schande wird ewig in dir fressen und deine Wege werden künftighin von Pfählen umsäumt sein...

Mit einmal überkommt mich eine herrliche Hoffnung. Gesänge unaussprechlicher SüBe überschwemmen mein Herz. Von Liebe, Brüderlichkeit, Gottbegeisterung. Oh - wie fern mich entrückend, rauscht es auf: Tanzmusik einer zukünftigen Menschheit.

Die Pfähle krachen im Menschenschweiß. Sie bergen Gewitterhimmel in ihrem Holze. Ich taumle über meinen heißen Erdenfleck, und auf mein Gesicht zieht eine schiefe Falte. Wohin, wohin willst du, Tag? Wimmerer-Tag, warum nimmst du kein Ende?!

Aus den Höfen kommt keine Antwort geweht. Wolke bellt. Turm tänzelt im Himmelweiß, und ein Gesicht, mit Zähren heiB bedeckt, duckt sich wild im schwarzen Barackenschlund.

Eingeschlossener Bespieener mit einer Seele göttlicher Abkunft! Du röchelst eine gewaltige Frage in dein Menschenherz und weißt keine Antwort darauf. Möchtest du nicht deine Hände zu Gebeten verschränken?! aber ach, sie sinken ins Morastige.

Hier sitzt ein Mensch, der nie seine Mutter sah. Er kennt seine Winzigkeit und erbärmliche Verschollenheit.

Träne falle auf dich vom himmlischen Angesicht. Den Bäumen bist du vielleicht vertraut, denn sie fürchten deine fanatischen Küsse nicht, die du auf ihre alternden Leiber drücken möchtest. Ahorn übertürmt dich. Du siehst nirgendwo Liebe. Du siehst deine Hand faltig und grau und willst den Raum um dich her ergreifen und zerbrechen.

Über die Heide stammelt mein Fuß. Pfähle, Stacheldrähte, wildes Flehen über den Sand hin, der Dohlen Rufen und ferner Wälder Knistern ... eine herbe Föhre neigt sich milde mir zu.

Gnadenstrahl kommt mir nicht durch dein Gedächer, lieber Baum. Warum quält mich so gräßlich der Zweifel?! Ich Verstoßener, das zerriebene Hirn in meinen feurigen Händen! Aber du, mein Herz, heute noch ein Schlund voll Schlangen und Schrei, wirst in herrlichen Inbrünsten aufblühen, wenn Gott dir wieder tagt. Ihr tauben Wolken droben! Ihr wolkentönenden Stunden und fernes Turmgeläut, Choräle in Kirchen und die verstummenden Seufzer der Schlachtfelder! Geheul der Freudenhäuser und Träne, die sickert, wenn mich die Entzückungen der Liebe rütteln. Wenn Juni-Wind die Pappeln umschwebt und Gelübde, lächelnd entschlüpft aus verschämten Lippen, und Zerknirschung mich ans Bettende zwingt...

Doch heute stiert der Welt-Humbug in den großen Tag hinein. Geschrieene Haßlaute überschütten den Sand; zu Bergen mästen sich aufreizende Fiüche; Klagegesänge fahren aus Skythengesichtern auf. Die Vergewaltigten schweigen...

Ein Revolte-Sturm poltert über die Heide hin. Augen rotklaffen - aber am Himmel fliegt kein Wunder auf. Nur Wolkenzacken zerschellen in dem Sand-Winter. 
Scharen Eiliger mit Eßnäpfen gänsemarschieren zehn Minuten nach dem Getut. Es torkeln Schmalbrüstige, die ihr Entsetzen wie eine Last mit den Händen wegschleppen. Manchen hängt die Pein wie um den Hals herum. Den Graubärtigen umregnet ein Nimmerwiedersehen. Der hat eine Mördergesinnung deutlich zwischen den Zähnen hängen, und der Tatar beißt immer die Rache, daß sie knackt, zwischen den Zähnen. Viele sind sehr erschrocken. Sie reißen ihre Hälse hoch aus schimmeligen Futteralen. Sind gegerbt vom erbärmlichen Trott der Kerker-Tage. Aus fliegenden Nasenlöchern fegt ein Wind von Lüsternheit und Enthusiasmus. Verbissen und verheult schwanken Juden mit ihren Näpfen. Zersägen den Tag mit fanatischem Schweigen. Hebräische Düsterkeit schleift über den Platz ... aber steil gegürtet mit Kälte und Hochmut, kahl von Liebe bis in ihr Gebein, mit Pistolen am Bauch, stolzieren die Wächter des Eilandes und werfen Grüße weg wie Papierschnitzel.

Die dünne Suppe wird nicht schmecken, aber die Gefangenen sind laut geworden und erinnern sich an die Späße der Heimat. Sie heben die Schüsseln an den Mund und gießen feierlich die Jauche in ihren Bauch. Halten ein, grinsen auf in den taubstummen Tag. Einer macht einen schrecklichen Witz. Es meckert Radau. Der Wachtmann donnert heraus, und der Mittag saust endlos in den sandigen Tag hinab. Er ist lauwarm und schmeckt faulig. Er hat keine Sonne im Zenit...

Auf diesem Sand-Eiland, unerwartet und das Herz zerreißend, entsickert mir alles, was immer mich hochwarf. Hier ist Menschenqual. Schrecken, den ich nicht fasse, peitscht mich in Pfützen. Kunst, Ruhm, Vaterlandsliebe, alle Idole der Jugend, Sehnen nach der Mutter, das Freudenbett und die Liebesbriefe, Kameraderie und die Verzückungen einsamer Nächte ... alles umstürzt mich, loht zertrümmernd ins Welt-Gedärm. Weinend entreiße ich mich den häßlichen Gelächtern des Herbst-Windes. 
Text XI: „An alle Künstler, Dichter, Musiker“

\begin{abstract}
An alle Künstler, Dichter, Musiker
Damit wir uns nicht mehr vor dem Firmament zu schämen haben, müssen wir uns.endlich aufmachen und mithelfen, daß eine gerechte Ordnung in Staat und Gesellschaft eingesetzt werde.

Wir Künstler und Dichter müssen da in erster Reihe mittun.

Es darf keine Ausbeuter und Ausgebeuteten mehr geben!

Es darf nicht länger sein, daß eine gewaltige Mehrheit in den kümmerlichsten, unwürdigsten und entehrendsten Verhältnissen leben muB, während eine winzige Minderheit am übervolen Tisch vertiert. Wir müssen uns zum Sozialismus entscheiden: zu einer allgemeinen und unaufhaltsamen Vergesellschaftung der Produktionsmittel, die jedem Menschen Arbeit, Muße, Brot, ein Heim und die Ahnung eines höheren Zieles gibt. Der Sozialismus soll unser neues Glaubensbekenntnis sein!

Er soll beide erretten: den Armen aus der Schmach der Knechtschaft, der Dumpfheit, Roheit und Gehässigkeit - und den Reichen will er vom erbarmungslosesten Egoismus, von seiner Habgier und Härte erlösen für immerdar.

Uns Maler und Dichter verbinde mit dem Armen eine heilige Solidarität! Haben nicht auch viele unter uns das Elend kennen gelernt und das Beschämende des Hungers und materielle Abhängigkeit?! Stehen wir viel besser und gesicherter in der Gesellschaft als der Proletar?! Sind wir nicht wie Bettler abhängig von den Launen der Kunst sammelnden Bourgeoisie!
\end{abstract}

Sind wir noch jung und unbekannt, so wirft sie uns einen Almosen hin oder läßt uns lautlos verrecken.

Wenn wir einen Namen haben, dann sucht sie uns durch Geld und eitle Wünsche vom reinen Ziele abzulenken. Und wenn wir längst im Grabe, dann deckt ihr Protzentum unsere lauteren Werke mit Bergen von Goldstücken zu. - Maler, Dichter, Musiker, schämt euch eurer Abhängigkeit und Feigheit und verbrüdert euch dem ausgestoßenen, rechtlosen, gering bezahlten Knecht!

Wir sind keine Arbeiter, nein. Rausch, Wonne - Verglühen ist unser Tagewerk. Wir sind leicht und wissend und müssen wie Führer-Fahnen vor unsern schweren Brüdern wehen.

Maler, Dichter ... wer sonst sollte für die gerechte Sache kämpfen als wir?! In uns pocht noch mächtig das Weltgewissen. Die Stimme Gottes in uns facht immer von Neuem unsere Empörerfäuste an.

Seien wir auf der Hut!

Wird nicht schon morgen wieder die Bourgeoisie die Staatsgewalt in ihre Hände reißen durch Putsche, Bestechung und skrupellose Wahlpraktiken? Wird dieses neue Deutschland der herrschenden Bourgeoisie nicht noch unverschämter menschliche Arbeitskraft ausnützen, den Armen noch brutaler ducken? Wird es nicht in allen geistigen Dingen noch arroganter und frecher triumphieren wollen, als es je das kaiseristische Deutschland getan? Denn dieses, mit seiner aufgetakelten Macht von Kanonen, Kasernen und Eisenschiffen, ABC-Schulen, Polizisten und falschen Pfaffen, war zu plump und träg und unwissend, um ernsthaft in den Bezirken des Geistigen großen Schaden anrichten zu können. Wo aber der despotische Bourgeois aufkommt - wo der in den edlen Räumen des Geistes mit seiner wüstenTatze hintritt - da wächst kein Gras mehr nach.

Maler, Dichter! scharen wir uns mit unseren eingeschüchterten, wehrlosen Brüdern um den Geist!

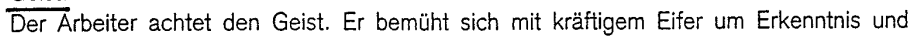
Wissenschaft. 
Der Bourgeois ist ehrfurchtslos. Er liebt nur Spielerei und ästhetisch verbrämte Stupidität und haßt und fürchtet den Geist - denn er fühlt, daß er von ihm entlant werden könnte. Der Bourgeois kennt nur eine Freiheit, seine eigene - d.h. die Anderen ausbeuten zu können. Das ist der bleiche Terror, der geht schweigend um und Millionen sinken hin und verwelken früh.

Der Bourgeois kennt keine Liebe - nur Ausnutzung und Übervorteilung.

Auf, auf, zum Kampfe gegen das häßliche Raubtier, den beutelüsternen, tausendköpfigen Kaiser von morgen, den Gottesleugner und Anti-Christ!

Maler, Baukünstler, Skulptoren, denen der Burgeois hohe Löhne für eure Werke zahlt - aus Eitelkeit, Snobtum und Langeweile - höret: an diesem Gelde klebet Schweiß und Blut und Nervensaft von tausend armen, abgejagten Menschen - höret: das ist ein unreinlicher Gewinn.

- Ach, wir wollen ja nur leben können und unsre Werke tun zum Preise Gottes!

Maler, Dichter und alle Künstler, alle aufrichtigen Freunde der Künstler, Kameraden alle: wir müssen uns stark machen: es geht um den Sozialismus. Wir wollen keinen blutbefleckten Lohn mehr. Wollen frei sein, zu unsrer und der Menschheit Lust uns hinströmen.

Kameraden, höret weiter: wir müssen wahre Sozialisten sein - die höchste sozialistische Tugend in uns entfachen: Menschenbrüderlichkeit. Das heißt: Güte, Freundlichkeit für einander und Einsicht in das, was uns allen nottut.

Höret weiter: Wir müssen Ernst machen mit unsrer Gesinnung, dem neuen, wundersamen Glauben. Wir müssen uns der Arbeiterpartei anschließen, der entschiedenen, unzweideutigen Partei.

Wir dürfen in unserem Kreise nicht mehr dulden die Schwätzer, Spieler, Ästheten und bürgerlich korrumpierten Mit-Macher.

Wie der wahre Christ den Umgang mit den Bösewichten flieht - so müssen wir uns rein halten von den Unreinen, Menschenverächtern und flunkernden Tagedieben.

Wir müssen die Zyniker festnageln auf dem Schmutze ihrer eigenen Bosheit. Lassen wir uns nicht beirren durch ihre giftigen Reden und Drohungen.

$O$, uns leite an diesem dunklen Tag die göttliche Stimme: Gerechtigkeit und Liebe! Mit Leib und Seele, mit unseren Händen müssen wir mittun.

Denn es geht um den Sozialismus - das heißt: um Gerechtigkeit, Freiheit und Menschenliebe - um Gottes Ordnung in der Welt! 
Text XII: „Bruder, zünd die Fackel an“

Bruder, zünd' die Fackel an

Zum Gedächtnis Carl Liebknechts und Rosa Luxemburgs

Bruder, zünd' die Fackel an, draußen im Winde stinkts nach Mord und Verrat.

Wir standen im Schatten der Nacht, um Morgenröte aus den Himmein zu rufen - da kommen zwei Leichen geflogen - șcharf wie ein Windstoß wirft die Nacht sie aus, daß wir erschüttert aufschreien, und haßgeballt ein neuer Strom von Feindschaft in den Morgen wallt.

Er, der Mann -: nimmersatter Rebell, zischend gegen Gewalt, der alle Lauen mit Stachelruten gerbte. Der mit Sturmtrommeln auf die Basteien rief zum Kampf... O, einmal war er das reinste Gesicht, hochaufgereckt über den Erdball, sein schneidendes Nein dem Kriegsgemetzel entgegenschleudernd, von den Gaffern bestaunt, den Guten verehrt und Tausende Erschrockene in den Gräben benedeiten leise den verfemten Namen. Die saubere Gesellschaft hat inn in ihre Verließe geschleppt. Doch sein Blut schäumte über die Kerkermauern ins Land, stürzte in viele edle, glühendheiße Leiber und aufgestaut war es mächtig, wie eine zähe, mutige Woge allen Unrat, allen listigen Zwang im Lande wegzuschwemmen.

Sie, das Weib -: häßlichen Leibes, Gerippe eckig, gellend, eifrig, rauh und ruhelos, HaBfanal. Schreiauf vom Geschlecht des Amos. Wutfaust im grenzenlosen Reich der Raffer, das sie an den vier Winden anpacken und zur Hölle schleudern wollte, denn die Erde ward zu lange schon vom Schweiß bestohlener Sklaven gedüngt.

Zwei Leichen sind über Bord geflogen, aber das Schiff hat ein Leck. Es hatte sich bepanzert mit Zuchthäusern, Polizisten, Professoren und Kanonen und fuderweise bepackt mit verlogenem großen Wort. Ha! das Piratenschiff hat ein Leck! Es legt sich schon ein wenig auf die Seite und seine. Pfaffen und Tribunen hantieren blindlings an den Pumpen, auf daB andringendes Ungemach den ganzen Büttel nicht in den Strudel reiße und alles verschlinge im $\mathrm{Nu}$-.-

Zwei Leichen sind in unsere Kolonnen geflogen. Wir dürfen nicht länger im Schatten warten hier. Doch horch: da brausen sie wieder vorbei. Sie haben sich von Neuem aufgemacht, ihre Menschenrechte zu erlangen. Wie sie mit schreienden Armen in die Luft greifen und entschlossen ihren Willen in den grauen Tag stellen!!

Rote Fahne allüberall! Rote Fahne, unter deinem Flattern will ich fechten! -

Als ich siebzehn war,las ich das Kommunistische Manifest. Ich war ganz verwirrt, verstört und enthusiastisch entzückt: daß man das Verbrechen bloßgestellt hat - daß man den Hilflosesten helfen will - daß man der gewissenlosen Gesellschaft ihre Verbrechen ins glatte Gesicht schreit - Gewißheit ward, daß dennoch eines Tags das göttliche Recht vom Himmel stürmend in die Menschheit bricht.

Später mischte ich mich dann unter das Volk, strömte in alle Meetings und Proteste und unter den tobenden Gewittern der Erbitterung gelobte ich immer wieder, daran festzuhalten, im Glauben an bessere Menschenwelt zu erstarken, und Eurem Rechte Treue zu schwören, ihr lieben, schweren, tausendfach geschändeten Brüder.

Nach Jahren erst bemerkte ich, daß jene feinen Herren der Tribünen, die so grimmig die Wortführer machten, nur maulwerken konnten, schlau vertrösteten und immer wieder schön zuredeten, daß die Geknuteten recht brav und artig unter ihrer Kette knirschen möchten, daß sie nach "Ordnung und Gesetz« sich hielten. Nur stöhnen sei erlaubt und leise fluchen und die Schmach menschenunwürdiger Knechtschaft wälzte sich weiter über menschenfressender Flur.

Brüder im großen Leid! Wie hat man euch so lange betrogen und in die Tiefe gestoßen! War das Menschenlos? Eure Menschenwürde, die herrlich in euch beschlossen ist - auch in euch - wird einmal an den Tag gebracht. Jetzt seid ihr noch mit dem Schmutz der Sklaverei und Beleidigung und Entehrung zu sehr befleckt und stöhnend vom Schweiß des Krieges verwirt. Noch schwingt ihr heiß um eure aufgescheuchten Köpfe die Rache wie feurige Keulen. Gerechte Rache! Wie verstehe ich sie! Sühne für soviel Pein und Demütigung durch eure Unterdrücker und die Grabhügel fünfzehn Millionen Gemordeter heulen euch immer wieder "Rache, Rache« ins Herz! 
Brüder, dunkle, ringende Brüder! auf unserer hohen, roten Fahne steht das ernste Wort "Gerechtigkeit». Wir wallen alle dahin, auf dies steile Plateau, wo es heißt: Arbeit Aller. Gemeinsame Arbeit und gemeinsamer Genuß der Früchte der Arbeit. Keine Ausbeuter, keine Ausgebeuteten mehr.

- Zu den Waffen! Zu den Menschheitswaffen!

Liebe und Fanatismus heiBen sie! Geist sei unser Pulver. Begeisterung unsere Lehne und Freiheit das Ziel.

Laßt uns hinuntereilen und in Reih und Glied treten mit ihnen, den rauhen, so lange geschlagenen Knechten.

Über uns wölbe sich rot mein Panier!

Du Farbe der Morgenröte, sei meinem Atem nah! - So nebelgrau, verhängt sind jetzt die Tage - dennoch von Siegersonne umpralit. - - -

$O$, einen blutheißen Leiberwall aller Herzen und Geister entgegenwerfen dem Feind! O, unsere entfachten Fäuste gegen den Feind!

Wir alle: Dichter, Literaten, Künstler - junge Gelehrte, junge Idealisten - wagemutige Advokaten, Lehrer, Studenten, viele Studenten - maßlose Schwärmer, kluge Fanatiker intelligente Matrosen, und auch aus eurer Sklavenmitte die hellen und entschlossenen Köpfe - alle müssen wir uns feien, festigen, fanatisieren zum Kampf. Uns weise die innere Stimme qualvoll unsere Fahrt hinan. "Geistlich arm " müssen wir werden zum letzten, brennendsten Menschheitskampf. Was Besitz, Stellung, Ansehen, was unsere persönliche Laufbahn, unsere Ruhe, unser Alltagsglück ist, fahre dahin! Alles müssen wir aufzugeben bereit sein - auf daß die rechte Gnade uns widerfahre -; aber nicht das himmlische Licht mache uns selig und froh, sondern die dämonischen Kräfte der Erde, lautere Wut, höllische Glut, heize unseren Willen, peitsche unsern Schwung.

Gemach, nicht unbesonnen und tollkühn ins Verderben gerannt! Nicht in überstürzter Hast die Bataillone gesammelt! Listig und leise müssen wir uns in die Seelen schleichen - belehrend wirken, unterrichten, aufklären - überall in den Herzen graben, schürfen, aushöhlen, - um mit hellen Fäusten aufzurütteln, anzufeuern, zu wühlen, zu hetzen, zu schüren -! Brüder, Brüder! Rauscht nicht um unsere Fahne, wie sphärischer Gesang, das wunderbare Wörtlein "Liebe«?!

Erst den Feind zertreten, den großen Verächter, - dann Menschentum, Bruderliebe überall ausgegossen über den menschlichen Kontinent. Unsere verschütteten Herzen werden dann wundersam aufbrechen - endlich wird unser Bestes sich herauswagen können. Denn es gibt keine Geier und Raben mehr. Alle sind wir Brüder!

Ich weiB, ich hab' es erlebt als Soldat: wir sind alle gleich! thr Härteren littet damals alle so sehr wie ich. In mir wie in euch war Milde, Treue, Geradheit eingeschlossen. In uns allen ruht das Edle verborgen, und Sehnsucht zu Gott zutiefst in unser aller Brust. Man muß euch nur richtig anzufassen verstehen, um die Schätze ans Licht zu fördern.

$\mathrm{J} a$, wir sind alle gleich. Vom selben Blut und Hirn. Vom einen Ursprung sind wir ausgeschickt. Wer will sich über seinen Bruder erhöhen?

Und ist nicht auch jeder von uns so groß, um Liebe, Liebe auszuschütten - denn sie ist ja ein Geschenk der Gnade aus Himmelshöhen - dennoch können wir alle gerecht sein und Gerechtigkeit fordern und Gerechtigkeit als oberstes Gesetz hinstellen in unserer Gemeinschaft.

Aber müßig ist's, von euch, ihr Bürger - ihr auf euren festen Bastionen und hinter dicken Eisenschränken - vergebens prallt die Forderung Gerechtigkeit an eure taubstummen Herzen. Was faucht und fuchtelt ihr jetzt in die Tage - verdächtigt uns und droht und mentekelt?!? Was sendet ihr eure Kohorten brillenschnäuziger.Professoren auf den Plan, die Pappenschwerter schwenken und Blechtrompeten blasen!?! Was heulen eure Gazetten seit Monden für Schakaltöne und brechen Lügen aus, Entstellung und tierischen Haß?! Ist das eure Freiheit, eure Vernunft, euer Recht?

Doch höret: Gerechtigkeit regiert die Welt. Noch seht ihrs nicht, Gott ist euch fern. Ihr glaubet nur fest an den blauen Kassenschein, und zur Beschönigung habt ihr eine buntbemalte Kulisse vor eure gemästeten Bäuche hingestellt, die nennt ihr frech "Kultur" und lügt die großen Dichter und Propheten in eure Wortemacher um. - Noch seht ihr ihn nicht. Dennoch: Gott lebt. Ich hab' ihn gesehen. Er schickt einen besseren Tag hinauf, den sozialistischen Tag. Die Menschenschinder, die zynischen Ausbeuter und Verächter werden vertilgt werden. Und die euch um den Ertrag eurer Arbeit betrügen, ihr Brüder, werden zunichte gemacht werden wie Spreu. 
Diese ganze, gottlose Ordnung muß fallen, daß eine gerechte, göttliche Ordnung erstehe.

Rote Fahne, mein Panier. Blitzender Turmknauf in der Morgensonne - juble Entzücken über dein Erstarken in den frühen Tag.

Menschensonne, Menschenliebe, wie Morgentau über alle Lande getropft, wie treibender Samen in alle Seelen gesät!

Ach, ach! aber der Weg der Menschheit ist mühevoll und weit. Haß, Gewalttat und Leichenhügel sind seine Meilensteine. Drum laßt uns eilig schreiten. Werdet Kommunisten wie ich! Ich will Nichts - denn ich habe Alles in mir - schütte euch mein ganzes Wesen hin. Nehmt noch das Übrige: meine Bilder, Bücher, Gedichte - meine Stühle, Schränke, Geräte für euch - all meine Begeisterung, meine geistige Gewalt, mein Innerstes, mein Herz für euch - alles, alles für euch! -- -! 


\title{
Text XIII: „Aschaffenburger Tagebuch“
}

\author{
Aschaffenburger Tagebuch
}

August/September 1918

Halte deine Hand hin, denn uns ist sehr bange. Halte deine Macht fest in uns, o Herr, denn wir zittern vor dem Sterbenmüssen.

Über das Blachfeld geht es atemlos, in Schwarmlinie brausend wie Gottes Orkan. Zorn steigt uns an die Schläfen. Wälzt sich dorthin, wo der schwarze Rand schäumt. Wir rennen immer unter Gottes Faustschlägen dahin. Sind seine Wölfe, die heiser bellen müssen. Stolpern über den Wind. Wittern Gas - Gas! - den Helm herunter, die Masken vor - nieder in Deckung! Da liegen wir, dein Höllenvieh, auf deiner brennenden Erde, und ich bin unter meiner Maske weiß vor Scham und Schuldgefühl.

Halte deine Hand über mich. Hör' meine Schreie. Rechne mir nicht zu meine Zweifel und Treulosigkeit.

Halt' mich oben in deinem Lichte, denn der Tag bricht auf, da du uns wägst und richten willst.

Endlich halb drei. Der Mittag war lange, lange, wie schlaflose Nächte. Wir hatten geschwiegen vor Stummheit und Überdruß. Nun stößt man die Tür auf, daß ein Freudenschrei uns zerreißt, und herein wanken die Zwei mit dem Kübel, daß wir mit den Schüsselchen, in Gänsereihe, schnell die graubraune Brühe saufen dürfen. Wir schlürfen wie aus einem biblischen Bach. Gehen nicht erst zu den Betten hin. Stehend genießen wir den Trank. Dann sind wir ganz erschöpft und enttäuscht wie nach tagelangen Märschen im Sand. Wir kriegen noch die erlauerten, feinen Zwiebacke und trollen uns endlich damit weg wie Diebe. Verteilen uns in den lodernden Nachmittag. Liegen lang und kauern an den Betten und warten waghalsig, was die Stunde schlagen wird im echolosen Saal.

$\mathrm{Ja}$, die haben sich hier für eine Weile aus dem Granatenhagel gerettet, und dennoch ist nicht leicht ihnen die bodenlose Brust. Eine rote Spinne sitzt auf aller Wangen. Sie haben juckenden Schaum im Angesicht. Bartflechte frißt das frische Fleisch vom hölzernen Schädel, und salbengekrönt oder triefend oder verhült in knittrige Verbände stelzen sie mit der Bahn der Sonne durch den beizenden Sommertag.

Und ich, ein Maler, lüstern und genießend und wie ein Wegelagerer scharfäugig und gespannt, hocke auf meinem Pfosten und fresse die zottigen Figuren wie Mittagsmähler, und saufe den Satansrummel um mich wie einen wüsten Wein.

- Ha, Erdenball! In ihren grauen Kutten stolzieren sie wie Mönche eines seltsamen heidnischen Ordens, der die Eitelkeit als oberste geistige Tugend ehrt. Sie ziehen von Zeit zu Zeit kleine Taschenspiegelchen hervor und besehen ihre wunderliche Affenschönheit, und manche haben noch jetzt den ganzen Morgen ihre Schnurrbartbinden um.

Was waren das für aufgeblasene Hähne - da hat ihnen der Rache-Engel ins Gesicht gespieen, und sein Speichel läßt sich nicht abwaschen und frißt und frißt. Wie sie thre schnauzbärtigen Mäuler auf und zu tun und ihre Zahnstummeln über den Tisch hängen! Das pomadisierte Gestachel ihrer Häupter und der feuchte Geruch der Glatzen schleicht durch den Saal wie lange, zähe Echsen ... Harlekine, geschmückt mit Narben, Narrheit und Spuren von bärentatziger Gutmütigkeit.

Sie haben das Schrecklichste gesehen, und mehr als einmal standen sie mit dem Tod auf Du und Du. Doch jetzt genügt einer schlecht gespielten Harmonika Gejammer oder eines Witzblattes fadenscheinige Farce, um sie innig zu erschüttern und von ihren Muskelgebirgen die Nebel zu nehmen. 
Und doch und doch - sie können nicht heraus aus ihren beinernen Gehäusen. So müssen sie sein. Sie können sich nicht entfliehen. Sie sind ja nicht selber daran schuld, daß soviel erbarmungslose Härte und Geifer und Lüge lauert in allen Winkeln der Welt. Du, dunkel Geschick, hast sie mit Dumpfheit geschlagen und häßlich gemacht wie Dämonen und dumm wie die Kälber im Stall.

Ich stiere noch immer auf meinem Pfosten und will nicht behaupten, daß ich etwa besser als die Anderen bin. Auch mir brennt rotflackernd das Mal des Eitlen auf meiner Wange. Ich trag mein beschmiertes Gesicht nicht umsonst ... ich weiß es, ich weiß es und ducke mich tief vor Elend und Bitterkeit.

- Warum müssen wir alle so in der Tiefe grimmen?! Ach, unsre Kleinheit, unsre MenschErbärmlichkeit! Jeder grüne Halm ist majestätischer als wir. Denn er bläht und brüstet sich nicht in seiner Enge. Er ist so unbefangen, friedfertig und milde, und leise lobt er immerfort des Herren große Gütigkeit - - -

Der Tag rollte unter die Horizonte. Nun fällt die Nacht wie Räuber über uns her, wirft uns auf die karierten Betten. - Noch platzen hie und da Gelächter auf und zynische Witze im Saal; der Magenwinde dumpfes Grollen verebbt. Wir bohren uns in die Strohsäcke und wühlen uns tief in den Schlaf. Die Nacht rauscht wie ein Meer, und Lachen und Glucksen der Träumenden und Aufschreie wie von Ertrinkenden fallen jäh in ihren unerforschlichen Abgrund hinein.

Stunde der großen Erfüllung, wann bist du nah?!

Noch immer bin ich ein Musketier. Bin dem kalbsledernen Affen verwandt, der ächzend auf meinem Rücken schwitzt. Bin wie mein Gewehr so hart und unter dem Zwange. Wie eine Erdscholle hingeworfen unter das Firmament. Aber dennoch fehlt mir nicht die Gnade, und ich wandre im Stillen verklärt und in Zuversicht groß.

Jahrelang fern sein müssen seiner Berufung! Oh, wie ein Gaul vor die Tage gespannt - oh, das ist schwer und hängt mir wie Mühlsteine um den Hals.

Aber meine Kräfte bleiben nicht liegen. Sie türmen sich zu Hauf'. Wandern mit mir mit wie ein Berg. Ich zerbreche schier unter der Kraft. Mich ängstet der weite Odem meiner Brust. Mich ängstet es, daß soviel schöpferische Macht unausgenützt in meinen Händen verrinnt. $\mathrm{Da} B$ ich immer wieder inwendig entbrenne und langsam qualvoll, ohne Ausschüttung, verglimmen muß.

... wenn ich erst lächelnd die Tür meines Ateliers aufstoßen werde! Wie Lohe wird die alte, wilde Malerbrunst aus meinem stillen Leibe schlagen. Jahrtaussendstaub wird sich unhörbar von meinen schlafenden Schultern heben. Der Staffelei Trompetenruf, der Farbentuben Chorgesang, der Keilrahmen Geschreie wird mich wecken wie am jüngsten Tag. Besonnen will ich an den alten Platz am Fenster schreiten. Die Hände recken gen Nacht, auf daß sie deinen Gruß empfangen, Ewigkeit.

- Stunde der Erfüllung, wann bist du nah?

Hier ragt die Schönheit der äußeren Welt bis in unsere Seelen hinein. Hier schallt es meuternd vom Main, von den Zinnen des Spessart. Verschollene Jahrtausendseele haucht uns mächtig an, schreitet furchtbar aus ihrem Mauergrab in den erwartungsheißen Tag. Aschaffenburg, du steile Hand im Mittagland, an Hügel gelehnt. Du Zickzackgassengewirr, bergauf, bergab. Ein hohe, mystische Sonne steht immer über dir im Zenit. Aber du Verwegene willst in den Himmel klettern, und ich treib' mich umher in deinen Gründen und muß immer den Kopf in die Höhe halten, damit ich dich nicht aus den Augen verlier'. Denn unten ist nur der beblümten Läden lautes Lachen - aber oben bist du, zügellose Pracht, und die Wonnen des Fegefeuers fallen auf den Ahnungslosen runter wie Schnee in Sommertagen.

Wie himmlischer Schnee - gotisches Gebirge, Heulen und Zähneklappen und des Paradieses Launen im unerwarteten Barock. Im Gegiebel droben Widerhall meiner geheimsten Wünsche, und in deinem schilfgrünen Park die Keusche und Sehnsüchtigkeit urmächtiger Bäume, die meinen Kleinmut unsäglich beschämen müssen.

In der Stiftskirche hängt ein zartes Bild des Grünewald, der ein Sohn der Stadt, also ihr feurigster und unvergeßlichster gewesen ist. Es zeigt jenes ringende Händepaar in einer Flut des hehrsten Blau, über dem toten Heiland redend. 
Ich vergesse diese frenetischen Hände nicht, solange ich in deinem Banne bin, grelle Stadt. Sie gehen mit mir durch deine Fachwerkwände und werden mir immer aufhelfen, wenn ich träge und mißmutig wandeln muß. Und jene wilden, kleinen Köpfe, die im Dunkel des Gemäldes grollen, führen mich mit Sturmes Hast in mein eigenes Atelier zurück, wo ich, getrieben von den gleichen Gesichten, meine Pinsel in der Abendröte wetzte, um in später Nacht meine Tuben leise lachend, weh umschnürt, wie Schwefelregen und rauchende Tromben zu vertun. -

Aschaffenburg ist weltlich und asketisch wie frühere, große Zeiten.

In der Erbsengasse, voll Gottesglut, kniet eine uralte, knochige Akazie, wie eine Matrone am Zaun. Die grünen Blätterbüschel jubeln hinauf, auf den Zacken wild gewundener Äste, die sich wie geschlagene Leiber um einen Stamm wälzen, der im Sonnenscheine betend schreit.

Und alle Menschen beten laut mit und alle braunen Brote in den Bäckerläden, und die ganze Stadt wälzt sich im Beten, im Tränen-Hinströmen, im Hände-Jubelringen zu den Füßen des Herren.

Das war nicht das Richtige, wie viele von uns vor dem Kriege gelebt und geschaffen haben. Wir hingen alle wie Absalom mit den Haaren im Geäst des Zeitgeistes, und keiner hatte in der Brust die Ewigkeit und Sehnsucht nach der ruhenden Erde, nach Besinnung und Besiegung der Zwiespältigkeit. Wir waren verwirrt, überspannt und gereizt. Bis oben rasend bedrückt vom nahenden großen Weltgewitter. Und stillschweigend war der Spleen' als Weltgesetz proklamiert, das Paradoxon als höchste, geistige Tugend. Und den meisten genügte nicht die eigne, wilde Kraft, der Traum der höllischen Palette -; sie rannten alle wie besessen dem Gelde nach, dem windigen Erfolg der Stunde und stachelten einen willigen Kunsthandel, um das Erworbene schnell in würdelosem Prassen zu vertun. Ach, unsre Not war tief, wir wußten damals gar nicht, daß wir in der Sünde staken. - Die Zeit war dennoch groß im Reich der Malerei. Neue Möglichkeiten waren entdeckt, neue ungeahnte Formen. Und wurden sie auch zumeist an unvollkommenen Gegenständen erprobt, so waren ihre Wirkungen dennoch nicht gering, und alle standen wir im magischen Bann, atemlos und fiebernd.

Oh, daß die Gewalt des ersten Rausches uns auch morgen nicht verließe, da wir uns zu größeren Taten rüsten werden. Denn wir müssen aus den Niederungen heraus. Wir müssen bessre Wege zeigen und das alte Ideal, die alte Reinheit, Gottesklarheit, die Macht der Seele unvergänglich hinstellen in jauchzenden Flächen. Wir werden fürderhin nicht mehr dem mörderischen Kopfe folgen, dem alten Kirchendogma, einem politischen Ziel oder einer Tagesmeinung zuliebe malen - aber aus unseren urtiefen Herzen, aus den urplötzlichen Gesichten, ja! - aus unserm geistlichen Leib, dem seligen Bereich des Jenseits wollen wir unsre Eingebungen heraufholen und auf tönende Tafeln hauen. -

Auch ich war lange ohne Trost, zerrüttet und gottlos, preisgegeben allen Irrtümern und Launen der Minute, vereinsamt und verängstigt wie Gassenkehricht ... bis mich eines Nachts eine innere Stimme wunderbar getröstet hat...

Von da an ging es aus den hohlen Gassen wegsam auf eine strahlende Ebene hinaus. Ich schlich mich verstohlen in alte, mystische Bücher, und eines Tages ward mir inne, daß jene totgesagte Heilige Schrift ein unerschöpflicher Freudenborn und Quelle tiefer Wahrheiten ist. Hatte ich früher mit Mißverstehen nur und Uberhebung darinnen geblättert, so packten mich jetzt mit Allgewalt die besänftigenden Verse der Psalmen oder die schrecklichen Reden des Jesaja; weckten mich wie einen Schlafenden, wirbelten mich wie Staub gen Himmelshöhen. Wie ein junges Kind ward ich froh, und aller Gram und Zwiespalt wandelte sich in SüBigkeit. Jeder Tag war mir ein neuer, heiliger Zuruf. Jeder Gang ins Freie, jedes

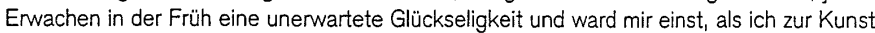
erwachte, der zügellose Kritzelstrich gegeben, der Sinn am Bizarren, am grinsenden, geifernden Sein -, so floß jetzt sachte eine reinere Sehnsucht in meine Linie ein. Meine Pathetik bekam einen edleren Schwung. Der Aufbau wurde klar, und zarte Saitenklänge tauchten da und dort im rhythmischen Gefüge auf. - Da ich jung war, in der Unlust und Unrast der Tage, mußten mich die Kellerkneipen der Vorstädte peitschen, grelle französische Romane oder die grotesken Begebenheiten der Psychopathia sexualis. Da ich aber 
älter wurde, genügte mir irgendeine Zeile von Paulus, um mich innen zu entzünden und zur Tat zu stacheln. Und morgen werde ich ganz vom Gottesglanz befeuert werden; ganz ein Sturm sein, den der Allmächtige entfacht. Ich will nicht mehr den Nächten meine Kräfte opfern, sondern ledig aller Trübsal, in den Wassern lichten Tages schwimmen und frohlockend meine Glaubenswerke tun.

Ja, ich hab' den großen Trost und diese Hoffnung, daß ich dir, o Herr, zum Preise unaufhörlich schaffen, trachten, beten, jubeln werde; unaufhörlich grimmig hohe Vollendung erflehen. Und hab' ich zwanzig, dreißig Jahre dir gedient, Herr Gott, dann laß mich ruhig beim Malen vor meinem letzten Bilde verrecken. Dann mag dein Atem mich verwehen, zu Staube fallen die nimmersatte, jauchzende Schöpferhand.

Barhaupt schreitest du durch den Septembertag. Unter deinen Tritten geht die Stille der Nacht. Aber hoch überwölbt dich der Tag und schlingt dich gierig in seine trügerische Fülle ein. Willig bist du hingelehnt in seinen ephemeren Kahn. Schaukelst durch sein Wellengetänzel wieder gen Nacht.

Du. Falter Tag. Flatterer, der die Dächer krönt. Flüsterer, der die Wolkenmeere aus weiten Fernen ruft. Gestirne blasen jetzt nicht ihre Chöre. Aber ich weiß, daß zwischen vielen tausend Zimmerwänden verweinte Hände blasse Stirnen stützen.

Falb bin ich wie das Septemberlaub und rutsche immer tiefer in meine Unseligkeit hinab. Ich trag' wie Eimer schwer in beiden Händen meine ungeweinten Tränen und das Hohnlachen dieser blutvergießenden Jahre, und ihre erbarmungslose Härte wühlet schwer an meiner offenen, nackenden Brust. Spätsommerwehmut überrinnt mein tiefes Herzeleid...

Endlich, endlich tret' ich wieder aus meiner Enge heraus. Bin wieder der fahnenschwenkende, flatternde Fant, flackernder Poet am Dächergebirge hüpfend. Kann mit dem Wolkenjubel schwimmen, der über dem rötlichen Schlosse thront.

Du, SchloBgezack, deine runden Türme brummen in dem Wind. Deiner einstigen Jagdgelage Herrlichkeiten lächeln mir über des Mainstroms Wellen, die des Mittags Güte fächelt. Und dann sehe ich eine Weile, um zu ruhen, in mich: Gewahre auch dort der Sonne Geleucht und Himmelzeltes Geläut, und groß Schreiten dröhnt und der Unendlichkeit Stimmengewirr weht in meinem wundersamen Leib.

Staunend steh' ich still und ruf' in mir der Herzbrust Urgesänge wach.

Glühen, o Glühen! Enthusiasmus, du heilig Feuer, warum währest du so kurz? Warum läufst du nicht von Mittag bis Mitternacht, über alle Erdkreise hinweg, durch der Jahrtausende Dämmern? Warum bist du nicht in jede Seele gebannt, in jeder Kreatur entbrannt und wie der Blutlauf rasend in jedem warmen Leibe?! Warum schwängerst du nicht die taubstummen Weiher und Felsen und Hügel und die schrecklichen Ebenen mit deiner reifen Melodie?!

Wenn ich in Reih' und Glied als Musketier zuweilen steh' im fahlen Tag, dann rauschet über mir mit feuerroten Schwingen Begeisterung wie Schwärme von Staren hin. Aber ach, du bist nicht immer meine Schwester, ach, ich bin ein Bettler und empfang' dein Kleingeld nur. Ich laufe wie ein Trübsalmusikant daher, straßein, tagaus. In meines Lazarettes Wänden schmeck' ich deine Herrlichkeit von fern. In meinem Bett, in früher Morgenstunde, ahn' ich deinen Glanz, aus Traumesfahrten aufgewacht. Aber ach, ich bin nicht immer dein, lieb Schwester. Mich umhalst die Traurigkeit und Mühsal, die am Alltag umgeht, jede kleine Stunde in den Ecken ächzt.

Auf, Seele, auf! fürbaß und schweige!

Hebe deine Augen auf ... und hin zum jenseitigen Gestade des Main. Wie dort die Pappeln und Akazien schwellen! noch eins sind mit der Wolkenherrlichkeit; eine gar kräftige Stimme haben im feurigen Grün der Matten. Oh, würden doch auch meine Gemälde so mächtig grünen und brausen, und wie diese bezechten Pappeln müßte es in allen Bildecken tummeln und mit überirdischen Zungen rufen.

Natur! Natur! wer faßt am Tiefsten deine ungewisse, schweigende Macht?! Wer packt deinen Kern und hebt ihn auf im Raum? Wir müssen dich wieder von neuem erschauen lernen, deine schauerliche Urgewalt erkennen und rücksichtslos dein herbes, knotiges Gesicht auf unsre Tafeln schmeißen. 
Die Kleinen weit und breit, die Ölfarbenpinsler und Leinwandfeger machten eine kleinliche Welt; ein ängstlich, dürftig, grämlich Grünen; ein magres Wolkenwehen, ein trübes Wässerlein, statt tosendem Gewässer. Oh, wie haben die Pygmäen der verflossenen fünfzig Jahre dich verhunzt. Oh, die tragikomischen Possenreißer, Menzel, Makart, Meyerheim, Knaus, KnackfuB, Knille - Detailfritzen, mit dem großen Sitzfleisch und dem kurzen Atem, aus dem Menschen eine armselige Daguerrotypie murksend und aus der Landschaft ein penibles topographisches Abbild. Und danach kamen die Bramarbasse der Netzhaut - wer will ihre Namen noch einmal hören? - diese Stimmungsochsen, die die Welt vor lauter pastosem, grauem Ton nicht fühlten. Dies nannte man auch "Wahrheit, Wirklichkeit», zu seiner Zeit, aber es war eine seichte Wahrheit und leicht wie windverwehte Spreu...

Worauf es morgen ankommt, was mir und allen Andern nottut, ist ein fanatischer, inbrünstiger Naturalismus; oh, eine glutvoll männliche und unbeirrte Wahrhaftigkeit, wie die der Meister Multscher, Grünewald, Bosch und Breughel. Denn wir wollen ja dem Höchsten dienen mit unserem Geschäft. Wir haben die großen Gesichte zu schaffen - wie könnten wir das anders als mit den Formen der äußeren Welt! Unsre Visionen müssen so deutlich und kräftig gefügt sein, wie die von Multscher und Grünewald. - Denken wir immer an diese Beiden! Und vergessen wir nicht das edle, sichere, weise Handwerk dieser Heiden. Die malten, wie Steinmetzen hauen, denn Größe will durch die Jahrtausende langen und nicht einen Minuteneffekt auf nächster Ausstellung erhaschen. Ja, das Handwerk, das teure, mühsame Handwerk, das auch seine strenge Schönheit hat...!

Heutige Maler wissen nichts von Farbenhaltbarkeit und mischen alles und pinseln jeden giftigen, unbeständigen Ton auf ihre schlecht grundierten Flächen. Ein ganzes Menschenalter muß man schuften, tüfteln, grübeln, raten, ehe man eine brauchbare Palette hat. Unveränderlichkeit der Farbmaterie sei erstes Gesetz! GewiB, verblassen tut ein jedes Kolorit ein wenig. Drum ist es gut, auf kluge Weise zu übertreiben. Bedenket, daß die Zeit an jedem Bilde leckt. Daß die Farbe einsinkt, verwächst, ergraut! und ehemals belebte und nervöse Flächen werden schließlich glatt und kraftlos. Drum übertreibet zart und nicht zu dünn und aquarellhaft, wie es heute Mode ist, die Farbe aufgesetzt! Und nicht zu dick, denn solche Bilder werden später schwarze, speckige Schinken! Die Wissenschaft der richtigen Bindemittel, der Öle, Firnisse und Pinsel ist viel wichtiger, als die meisten ahnen.

Es ist sehr wichtig, daß wir wieder unsre Pinsel lieben!! daß wir eng verschwistert unsern Farbentuben sind! -

Hier sieht es aus wie auf meinen Bildern. Unerwartetes, der Jüngste Tag bricht an im großen Raum, zerbricht im Tumult der Vertikalen. Brauner Wolkenschaum brandet über dem Dächergewoge ... jäh fällt die Welt dir vor die Füße...

Dir graut und nimmst Reißaus vor deinen schmerzhaften Gesichten...

Aschaffenburg - dein Glockenklingeln, - deine Schaver von Gottesgnadentum und seltener Architektur - von heute und gestern dein Ja - deine Gelübde vor dem Himmel und deine tiefe Treue zur Welt ... im Schöntal der Segen deiner ehrfürchtigen Bäume - dieser entflammten Linden, steilen Lärchen und laut lachenden Ahorne, die mich kleinlaut stimmen und meinen verwirrten Sinn besänftigen können. Und dann lenkt mich meine Sehnsucht immer wieder zur Jesuitenkirche hin, wo ich endlich stille bin und vor wahrer Größe staune...

Unbegreiflich, wie so ein schwärzlich Monument dich packen tut.

Ein Dachreiter windet sich verzückt auf seinem First und schreit sein Halleluja in die Herrlichkeit der schrägen Gassen.

Wanderst du dann durch die neueren Straßen, so schlägt dich Roheit und der unschöpferische Geist der letzten Jahre wie mit Keulen. Du siehst das Schicksal einer glaubenslosen Zeit von windigen Fassaden winseln, deren nackte Blöße phantasieloser Zierat decket und deren Rhythmus Maurermeisters stupide Reißschiene kommandiert hat. Alle diese faulen Farcen im Zuckerbäcker-Makkaroni-Jugend-Katakomben-Behrensstil prügeln uns wie schweineschnäuzige, zynische Henker, und wenn Architektur uns wie Musik befeuert oder ängstet, so haben unsre Architekten mit den jetzigen Krieg verschuldet. Denn dieses Blutgebelfer, das uns Tag für Tag auf unsre Nerven trommelt, hat uns schlieBlich ganz verzagt gemacht. Wir hielten dem Alpdruck unsrer fürchterlichen Wände nicht mehr länger stand und mußten heraus aus den Häusern - in ein ander Land.

Aber Baukunst muß selig machen und zum Erhabenen die tagverstörten Blicke lenken. 
Und wie die Baukunst muB die Malerei beglücken und Hinweis sein zur Herfichkeit des Herm.

Wir hatten letzthin allzusehr den Hang zu ganz erdfernen Gebilden. Eine geometrische Formuljerung war unser ersehntes Ziel, und namentlich die Jüngsten strebten alle wie besessen nach Abstraktion und Gegenstandslosigkeit.

Jhr wolkenseligen Malkünstler möchtet alle gleich hoch hinaus, die Erde vergessen und den Geist rein und entirdischt aus euern Farbentuben gießen. Aber haltet euch nur ein wenig an die herrliche Realität der Dinge.

Seht die Bäumel die sind weise. Sie halten sich am Erdreich fest, sonst würden sie ihre Flügel erheben und lieber in den Himmel fliegen. Denn sie sind so gottselig zügellos. Aber sie sollten uns ja mit ihrer Schönheit gut und gläubig machen. Drum bohren sie ihre Wurzein tief in den Lehm und bleiben verzückt aut ihrer Stelle im Wind.

Also halten wir uns an der Erde fest, sonst geraten wir ins Uferlose, Blaue. Kehren wir zu einem leidenschaftlichen Naturalismus zurück, zu einer tiefen, liebenden Treue gegen die äußere Wirklichkeit der Welt. Weil wir das Überirdische erflehen, müssen wir das lrdische beherrschen. Weil wir so gottessehnsüchtig brennen, müssen wir die Erde erst in uns verdauen und verstehen. Und begreifet, daB diese inbrunstvolle Wahrheitsmalerei keine leichte Sache ist. Sie ist so schwer, weil sie das Höchste will, und jeder, der das Höchste will, muB diesen Weg des Schweren gehn.

Hier fühl' ich micn als Maler ganz zu Hause. Lebt' ich nicht viel zu lange in Berlinl? Ach, Berlin! Du Guillotine alier Freudenträume. Henkerin aller Zartheit, Reinheit und Tugend in mir. Warum blieb ich so lange in deinen schmerzenden Seilen festgeschnürt?!! - Später werde ich nur noch auf dem Lande wohnen, in der Nähe der Einsamkeit und unendlicher Ebene. -

Wir müssen uns auf ein anspruchsloses Leben gefaßt machen, wir Maler. Denn die Not der kommenden Zeit wird auch dem Großbürger umfangreicheres Mäzenatentum verwehren. Viel besser für uns wäre es ja, wir hätten eine kommunistische Gesellschaft, die uns unabhängig machte von den Marotten der kaufenden Bourgeoisie. Denn auch hierin ist sie despotisch und arrogant. Und später haben wir erst recht vollkommene Unabhängigkeit vonnöten, denn unser unbarmherziger Naturalismus wird dem GroBbürger gar anstöBig sein, und schwerlich eine sanfte Schmückung seiner Salons. Der impressionismus war so recht eine bourgeoise Kunst, und seine besten Vertreter entstammten der Bourgeoisie. Aber das heutige Wollen ist rustikaler, stammt mehr von unten her, und vjelleicht werden seine kommenden großen Werke auch mehr in den unteren Schichten Widerhall finden.

Auf alle Fälle werden wir die Großstädte fliehen und die schrecklichen Ateliers unter den Dächern mörderischer Mietskasernen. Ach, wir werden unter dem nackten Himmel stehen; immer dem Atem der heiBen Sterne zugewandt. Wie simplen Handwerkern werden uns die Jahre vergehen, in herrlich harter, nimmerrastender Arbeit. Fern den sinnlichen Verlockungen, wollen wir durch inbrunst, Kraft und Gebet in ein gottseliges Leben eingehen.

Noch immer leb' ich. Treib' meine Fieberbrunst im sachten Wind des Saales. Im blaukarierten Lakengrab bin ich kein scheintoter, trauriger Frosch, und als Grabstein an Kopfendes Pfahl, daran meine Hose hängt, sieht mein simpler Name kraus in Kreideschrift geschrieben.

Ach, ich bin nicht fett. Der Winter hat mich mit Zangen gezwickt. Und Sommer verbrannte mich wie dürres Gras. Und dazu sind jetzt meine Backen tiefrot von Flechte zerfressen, und von dem Schädel poltern die letzten Borsten mir ins Genick.

Auf den Märschen war ich immer weitausschreitend verzückt. Aber nachts in den Massenquartieren, müde von Wanzenbissen und verbittert von den Liebkosungen der Flöhe, seufze ich lange in Träumen, in denen der Dämon des Ärgers unaufhörlich Vergatterung bläst. Um mich herum, den ganzen Tag, die Namheiten der Kameraden, mit ihrer zerbrochenen Seelenachse und dem Rechtsdrall im dick ummauerten Gehirn. Ich liebe sie nicht. Aber dennoch, in ergriffenen Viertelstunden, fühle ich mich ihnen innig verwandt. Und ich, wie sie, trotten tief bedrängt auf dieser turbulenten Erde herum, deren Pfosten gefährlich warken, denn sie hat sich, ein fürchterliches Gomorrha, durch Übermut, schwere Verbrechen und Oberhebung schuldig gemacht. -

Doch jetzo noch, im weichenden Tag, bin ich feierlich froh. Hingelehnt an die raschelnde Stadt, vom Maiwind leise berūhrt. 
Ich spüre hehr den Todesengel über dem Lande stehen und seine heißen Flügelschläge durch meine Tabakringe ziehen. - - -

Die Seele stöhnt nach Stille. - Morgen wird es besser sein. -

Vermummet in der Wolke - maitagbraun und nikotinumwölkt - - - Aeternitas - du, du

Ewigkeit - meine letzte Zuversicht! - - -!

\section{Text XIV: „Gruß des Malers an die Dichter“}

\section{Gruß des Malers an die Dichter}

Leg den Pinsel weg, Klexer. Genug der farbentriefenden Stunden, der ledernen, schwerfälligen Leinwände. Schwing dich endlich aus der Höhie deiner Dachkammer hinauf in den Wolkenhimmel und grüBe die Dichter!

Heran, heran, ihr Schwadronen der Angst und Verzückung. Heran, ihr, mit den großen Hüten auf den mähnenden Häuptern. lhr, mit knatternden Fahnen an euern Hüften; mit Wimpein und Bändern an den Schultern. Thr, mit den gewaltigen Beinen, Donnerer durch die Jahrtausende. Ihr Riesen-Krokodile, schwimmend, tauchend, schnaufend im Meer der Gefühle; aus euem Nasen prasseln Fontānen von Begeisterung. Ihr spert eure Mãuler gewaltig auf zu Liebe, Klage und bußfertigem Sinn. Ihr weißen, hochgetürmten Elefanten mit wunderbaren, beschwingten Rüsseln, die erschnüffeln, was den Menschenseelen nottut. Ihr Lämmergeier mit riesigen Fledermausflügeln, schlagt einen Höllen-Wind im Weltali der Gedanken. Ihr steckt mit Pechfackein die morschen Städie, den Plunder protzig herrschender Systeme und Tatsachen in Brand. Ihr weiß wiehernden Hengste galoppieret über die Kontinente und schlaget Funken, daß die Felsen erklirren und Transatlantics spurlos im Gischt verschwinden. Ihr Wasser-Unholde! Ihr musizierenden Walfischel thr Brontosaurier der Urzeitl thr Barometer der kosmischen Regenzeit! thr fixen Autos und brausenden Lokomotiven! ihr Behemoths! thr Paviane und Grimassenschneider, ithr wundervollen Narren... Ihr Dichter seid gegrüßt! Der Maler grüßt euch. Er schämt sich seiner zähen Farben, seines langsamen, klanglosen Handwerks. Der Maler findet nicht Worte genug, seine Bewunderung vor euch ausschütten zu können.

Gräser blühen am Wege, Dornbüsche und Fichten und sie wissen nicht warum. Kahle Bäume recken ihre Arme zum Himmel auf, wie die hilfeflehenden Menschen. Es laufen die Kreaturen in den Tag hinein, jeder mit seiner Pein und seiner Verrücktheit... Aber ihr Dichter wisset alles und schaut alles durch und durch! Komm doch, komm, du Naher und ewiger Tröster mir, göttlicher Psalmist, du David! Dein Gesang umtönt noch die Verdammten des jüngsten Tags! Und du zorngeballter Jeremia und du unnahbar Verückter, Jesaja. Woge christlicher Dichter, umsinge mich und zertrete mich: Augustinus, Thomas a Kempis, François de Sales, Madame Guyon! thr Gottnahen Jan van Ruysbroeck, Seuse, Böhme, Silesius! Du Zions-Sänger Jehuda Halevi, und du himmlischer Springer Israël Baalschem! Ist nicht auch Luther einer der GröBten und Zartesten?! Und Paul Gerhardt, Spee, und du Jesu-Sänger Novalis und ihr Lieblinge meines Tages, du unvergeBlicher, wogender Franz Werfel und du sehr innig-beglückter Nadell!

Was hör' ich gewittern, was seh' ich drommeten? Die Giganten stiebein vorbei: Homer, ein Grieche, Ossian, ein Verhüilter, Torkelnder ... Dante, Camoes, Ariosto, Tasso, Milton, Klopstock; ach, und da fält mir der Homer meiner Jahre ein, der die Odysseen des Caféhauses singt: Ferdinand Hardekopf! GegrüBet du Weltdichter Goethe, du imposanter Victor Hugo und du lieber Bruder

\section{Walt Whitman!}

Du Menschheits-Singer, du Allererster, Allernächster, Fackel, Herzblut und Komet der neven Zeit!

Schwärmt aus, ihr ur-alten Kerle, Pindar, Horaz, Vergil! Du kostbarer Hafis ... all ihr chinesischen und ihr unzähligen indischen Dichter!!

Wie ich Villon liebe, den Franzosen und Donner und Doria! der Brite Lord Byron! ah, Shelley! und du cher Cousin, Purzler, Wonnevoller, Heinrich Heine! Du Lenau, Madách, Leopardi. Du Tegnér, Mickiewicz, Lermontow, Puschkin. Kommt zu mir, ihr entzückenden, formbeherrschenden, tiefen Dichter: ihr Platen, Hölderlin, Nietzsche, ihr Nenal, Gautier, Baudelaire, Verlaine, Mallarmé, d'Annunzio, Leconte de Lisle, Hérédia, Rimbaud, Jammes! Du deutscher Schickele! Du nächtlicher Clemens Brentano. Du mittägiger Conrad Ferdinand Meyer, du Stefan George, du Hofmannsthai.

$\mathrm{Hal}$ es schrillen Zukunftsirenen! Idealisten-Trupps, Pioniere mit Spitzhacke und Säge, Männer der Freiheit und Bruderliebe, klirrend-beschwingte Jünglinge nahen! Friedrich von 
Schiller, Kühnster, Männlichster unter den Deutschen! Herwegh, Freiligrath, Uhland! Ihr Volksdichter Desaugier und Béranger! Du Lamartine! Noch einmal walle, du Jüngling, Mann und Greis Walt Whitman! Du südlicher Mistral! Du Dichter der schäumenden Städtemeere. Verhaeren! Du, wie die weiße Sonne, Alfred Mombert: Meteor über Gebirgen, so sehr geliebt von mir und gefeiert in manchem Gemälde und vielen tönenden Blättern!

Alfred Mombert sei gegrüBtl

Und da strömen schon meine Kampfgenossen ein, die heißköpfigen, brennenden Verwirrten: Georg Heym, heraus aus deiner Totengruft! aus euern Grüften, Stadler und Trakl. Max Brod!! Johannes R. Becher, atemlos Fliegenderl Benn, Boldt, Lichtenstein, Wolfenstein!! Du Else Lasker-Schüler! Du dunkel flennender Albert Ehrenstein! Du fetter Däubler! (wiegst drei Zentner, aber dichtest die Bäume und Felsen, Wolken und Mondsichel wie keiner sonst!) Und ihr meine nahen Freunde: Walter Hasenclever und Rudolf Leonhard! seid bedankt!! Voll Ehrfurcht und Staunen reiche ich meine Bruderhände dir, Lotz, Ernst Wilhelm, hin!! Seele meines besten Freundes, möchtest du in unbekannter, unirdischer Weit diese meine wehenden Grüße erahnen!!

Zurück in der Jahrhunderte bunten, kollernden Bauch! Riesen-Hechte erwachet! Rabelais, Cervantes, Grimmelshausen, Swift, Jean Paul, Balzac, Dostojewskil Du gewaltiger Teutone Grabbe! Ihr süß-geliebten Jules Laforgue und Alfred Jarry! Du Wunder Lautréamont. Du Grotesken-Dichter und Präsident Ur-alter Jucker: Mynona! Du Wald-Inbrünstiger, Peter Hille und du Stadt-Verzückter, Jakob van Hoddis! Fern in Schlesien hausender, viel weinender Max Herrmann, Kamerad und Mensch während des Krieges, sei bedankt, sei bedankt!! Seid bedankt all ihr andern Dichter! Ihr vielen bekannten und unbekannten Dichter aller Zeitalter! Ihr Verschollenen auch und ihr in jugendlichem Alter dahingestorbenen oder auf den Schlachtfeldern niedergemetzelten Dichter. Ich gedenke auch jener Millionen, die in Volksliedern und Gassenhauern die einfachen Seelen erfreut haben! Dichter der Bänkelsänger, der Tavernen und Jahrmärkte, der Bars, Kabaretts und Spelunken. Und ihr, die ihr religiöse Traktätchen und Schriften schreibet! Poeten der Heilsarmee, der Herrenhuter, Quäker, Adventisten und der Pfingstgemeinden; ihr Zionisten und ihr famosen Verfasser sozialistischer Flugblätter. (Die Aufwiegler und Anarchisten, die im geheimen schaffen und deren Dichtungen bei Tagesgrauen verstohlen unter die Stubentüren der armen Leute gesteckt werden!) Ihr, die ihr kommunistische Manifeste, Marseillaisen und Internationalen dichtetet und wenigstens für eine halbe Stunde die Ohnmacht der dunklen Scharen mit freudigen Blitzschlägen getilgt habt. Und zum SchluB, ihr Verabscheuer unsrer Zeit, ihr wahrhaften Dichter und Menschen, ihr Gottesstreiter dieser Tage, einsam treibend und tief geknechtet - euch Allertreuesten sende ich meinen menschenbrüderlichen Gruß. 


\title{
Text XV: „Eine autobiografische Plauderei“
}

\author{
Eine autobiographische Plauderei
}

Das ist eine schöne Stunde, nachmittags um fünf, wenn ein heitrer Himmel über Berlin steht, nach schweren Wintermonaten; wenn das kühle Frühjahrslicht durchs große Fenster auf die vielen Bleistifte und die leeren Flaschen und Kisten fällt und überm Brett gebückt ich zeichne. Die Bücher, die alten verrosteten Leinwände, Weckeruhr, Teetopf und Rollmopswanne - alles ist an seinem Platz. Nach Terpentin und Säure duftet es leis im Raum, Gerūche, die ein Maler so gern hat.

Wie fein ist so ein Atelier und wär' es noch so klein! Nirgendwo bin ich lieber als in meinem Atelier - und ich weile nicht gern in den Bergen oder am Meer oder in fremden Städten oder sonstwo auf der Welt, weil es in meinen vier Wänden am schönsten ist. Hier die Abgeschiedenheit, Wesenheit und Einkehr; hier der Ort der Betrachtung und der Gebete und hier bin ich bei mir selber zu Gaste und halte Zwiesprache mit mir selber und ich arbeite und esse und trinke und schlafe, und werde auch einmal sterben im Atelier, so hoffe ich wohl. Wenn man ganz jung ist, liebt man die freie Natur - in den Zwanzigern das Catéhaus und später kehrt man wieder enttäuscht zur Natur zurück. Ich aber hab' mich im Kriege vielleicht ein wenig zu lange und zu intim mit ihr eingelassen und nun bin ich froh, daß ich unterm Dach wohnen kann, in eigenen verrußten Wänden, mit einer engen Schlafkammer nebenan. Und ist auch das Dach nicht dicht und wenn es regnet eher wie ein Sieb - und ist's auch im Winter hundekalt und im Sommer so unerträglich wie ein Backofen - und ist auch alles Gerăt und Gestühl ein wenig zerschlissen und abgenutzt - - dennoch liebe ich meine Werkstatt und alle Wälder und Auen, Cafés, Bars und Boudoirs der Welt können mir gestohlen bleiben. Denn die Welt, das ist das Närrische, Verkehrte und Vergängliche - aber die wahre Welt, das ist die inwendige Welt, wenn du in die Stille gehst und lauschest und dort das wahre Wort im innern reden hörst.

Doch Natur, wie ein Maler sie braucht, schaut auch hier durchs Fenster, und im Mittagsbiau sind's langhinziehende weiBe, und am Abend feurige und gehörnte Wolken - denn was ist sehnsuchtsvoller und verlockender als das Firmament und seine Wolken?! Und stecke ich nebenan meinen Kopf durch die Dachluke, dann umfängt mich eine Pracht ohnegleichen ein weites Meer der Dächer und Essen und Schnurrpfeifereien der Giebel braust um meine Nase und unten rauscht die Motzstraße von Osten nach Westen, in der die lüsternen Weiblein des bayerischen Vierteis spazieren gehn - und das alles prangt in einem entzückend heiteren Licht. -

Die Stunden machen den großen Zeichenbogen voll und der Abend senkt sich auf meine staubige Glazze. Ich greife nach Brot, Margerine, Kuhkäs und Tee. Aber zuerst muß ich ein paarmal rings um meine Klause rennen, um Malerwut und Fieber abzuschütteln, denn wenn man arbeitet, ist man so häufig voller Zorn. Es wird nicht armseliger, das Leben, mit dem Älterwerden. Jetzt endlich wird man den Springinsfeld los und Nüchternheit ist schöner als Verrücktheit. So ein Abendessen nach vollbrachter Arbeit löst das bitterböse Herz und alles Tun und Denken eint sich zu einer großen Harmonie. Und dazu rattert und rauscht die Motzstraße so gewaltig, daß das Haus in allen Fugen klirt. Und manchmal glaub' ich gar, es gäbe ein Erdbeben oder ein Einsturz, denn alles rasselt und kracht wie in magischen Gewittern.

Wie beschwichtigend ist doch ein fahles Abendoämmern. Dann schweigt man lieber leise, während man in der Frühe singt und am Nachmittag sich eins pfeift oder lange Selbstgespräche brummt. Aber in der Nacht geht es wild zu. Die Nacht ist zornig und verwegen. Niemais ist größere Fruchtbarkeit in mir als Nachts.

Ich preise Dich, Nacht, als große Phantasiespenderin und Fülihorn guter Einfälle. Hătte ich je meine langen, bizarren Figuren, meine Schiffbrüchigen, Verängsteten, Zerknirschten und meine verzückten Bußgänger gemacht ohne Dein geheimnisvolles Wirken, ohne Deinen lautlosen, aufstacheinden Lärm, o Nacht?! Du überschattest mich mit Deiner wehen Düsternis. $O$, ich bin im Fieber nach Dir. Bin verint nach Dir und taumele wie ein bindes Kind. Der Rötelstift zischt über das Papier und umkreiset die Rückenlinie eines eifernden 
Schaul von Tarsus. Ich will immerfort bei Dir bleiben und mich verträumen, O Nacht. Laß mich an Deinem Halse hängen, du Unruhestifterin. Bald kommt ein neuer Bogen, über den ich mit dem Bisterstift das Gerüst zu einem Amos spanne. Er redet, das Haupt halb verhüllt, gewaltig, mit fester Stimme: dirschuni wich'ju! Bister ist härter als Rötel; man zeichnet damit strenger und linearer als mit Rötel, der malerischer ist.

Die Gaslampe ist das wahre Licht. Sie befördert die Inspiration. Sie summt leise und wenn man spät, spät und lange hinhört, vernimmt man einen öfernen, gewaltigen Gesang. Das Tageslicht ist zu rationalistisch und zu skeptisch und am Tage hat man auch keine Kurage zu seinen Einfällen und Witzen. Aber unter der Lampe ist man verflucht mutig, verwegen und groß. Man muß Nacht für Nacht aufbleiben und zeichnen und malen. Das Nachtwachen birgt geheimnisvolle Kräfte. Das mystisch-asketische Leben vergangener Epochen wußte dies gut. Aber die Neuzeit hat den Tag erfunden für alles Tun und die Nacht bleibt ungenutzt und tot.

Nichts tu ich lieber als große Blätter komponieren mit Gestalten oder Begebnissen der heiligen Schrift. So einen korpulenten Zeloten hineinzupflanzen in den Raum, daB die Wölklein seinen Ringelbart umspielen! Dann mach' ich auch Bartlose, Pilger, die in sich hineinhorchen und schweigen. Oft stehen sie in einer weiten Landschaft oder wandeln über Wüstensand. Es muB viel Raum, Weite und Odem geistlicher Zone in diesen Blättern sein. Ach, wenn ich meinen Propheten das herrliche Pathos der Bibel aufdrücken könnte! Es sind männliche, unbeugsame und dennoch milde Menschen, diese größten Zeugen des Schöpfers und Herrn.

Mich fesselt so sehr der Gegenstand eines Bildes. Was ist auch wichtiger als die Gegenstände der Welt? - sie sind uns tausendmal näher als alle Ideen der Welt. Und die großen Wahrheiten des Glaubens sind auch keine Ideen, sondern Dinge, die sinnlich wahrnehmbar sind. Ein Gemälde ohne Gegenstände der realen Welt ist eine große Torheit und nur dem Narren und Snob ein Gewinn. Und die großen und edlen Gegenstände in der Kunst sind mir lieber als die kleinen und nnatures mortes". ist es mir auch nicht gegeben, ein hohes und erhabenes Sujet in einer hohen und erhabenen Form zu gestalten, so kann ich dennoch teilnehmen an der erhabenen Sache, indem ich sie zu gestalten versuche und ich bereichere vor allem meinen inneren Menschen damit. Aber um ganz deutlich mich zu erklären will ich ein Beispiel, das ich gern heranziehe, geben, Cornelius und Renoir.

Peter Cornelius ist der letzte religiöse Künstler gewesen - ein Eklektiker der Form nach, in der Gesinnung groß und ein wahrer Christ. Er hat nicht viel Neues gebracht in die Kunst, aber er ist ein bedeutender Compositeur und in seinen Kartons und Blättern weht dennoch eine große, gotterfüllte Seele. Es rührt mich zart und heilbringend an, wenn ich jene etwas trocken mit Kreide gezeichneten Flächen schau!

Der Franzose Renoir hingegen ist ein echter, großer Maler der blühenden, sinnlichen Welt. Der Reichtum seiner Oberfläche entzückt noch heute alle Künstler und ich selber kann mich keineswegs dieser süßen und starken Fülle verschließen - aber innerlich bleibe ich kalt und stumm. Und wenn ich beim Anschauen eines Renoir an Cornelius denke, so versinkt jener in Nichts und schämt sich seiner Flachheit und Weltlichkeit, seiner ganzen windigen und vergänglichen Seele, - aber Cornelius strahlt mächtig und verklärt vom heiligen Geist. Er hat die unvergängliche Welt gewählt - und das ist die einzige, die Wert haben wird in deiner Todesstunde. Denn was in der Todesstunde besteht, das Ding allein hat Wert und Geltung.

"Der ist wahrlich weise und mehr von Gott denn von Menschen gelehrt, dem alle Dinge das gelten, was sie sind und nicht das, was sie heißen und wofür sie vom Menschen geschätzt werden« - so heißt es in einem schönen Buche des Mittelalters. Mögen auch alle Leute von Welt und alle Künstler überströmen im Lobe der rein künstlerischen Kunst, so will ich selber für mich immer mehr jene Meister feiern, die mein Herz reicher machen und die mein Inwendiges zuwenden in Liebe dem größten aller Meister und Geber aller guten Gaben. Denn wer tiefer in die Rätsel des Seins hineinblicken konnte, der hat recht die Fragwürdigkeit, Begrenztheit und Zeitlichkeit aller sinnlichen Dinge erfaßt und dem erschließt sich allmählich auch der große Reichtum und die mannigfache Schönheit jener andern Welt, die nicht mit den leiblichen Augen geschaut wird, sondern mit den inneren Augen, die viel weiter und viel tiefer zu blicken vermögen.

So bin ich, nicht nur in der Beurteilung der Kunst überhaupt, sondern auch in meiner eigenen Arbeit, bestrebt, die innere und geistliche Welt lebendig zu machen. Und wenn ich dabei auch vermutlich nichts Großes und Dauerndes zuwege bringe - denn allein ein hohes 
Talent und eine fromme Seele ist imstande das Religiöse zu gestalten - so habe ich dennoch die Genugituung, daß ich nicht wider Gottes Willen handle und daß auch ich zur Ehre des Allerhöchsten eine kieine Stimme erheben darf. Denn auch die Bilder und ihre Urheber werden einmal gewogen werden und alle Corots, Manets, Renoirs, Cézannes, Matisses und ungezählte Andere werden zu leicht befunden und hinabgeschleudert werden in den Abgrund der höllischen Schande.

Mögen die Künstler der Sinnenwelt glänzen mit ihrem faischen Glanz - sie benebeln nur die Augen und verführen die Kreatur zu Eitelkeit und maßloser Weltiebe; und ob sie gleich unverfänglich und heiter, mit edler Gebärde sich geben, so geht dennoch Finsternis von ihnen aus und die Herzen verhärten immer mehr und werden trotzig und ruhelos und verschließen sich für immer dem ewigen Licht. Die Gestalter aber, die dem Reiche Gottes zugehören, haben stillere und weniger glanzvolle Werke darzubringen. Dafür geht von ihnen ein Strom der Liebe aus, der alle Gotteskinder wundersam berührt und sie bestărkt im Dienst und im Ausharren, und der höhere Nutzen für ihre Hervorbringer ist der, daß sie dem barmherzigen Schöpfer Ehre antun und ihm dienen, indem sie auf gemalten Tafeln seines Namens Macht und Schönheit preisen.

Solch' geistliche Malereien sind in der deutschen Gotik zu finden, bei Hans Multscher, Dürer, dem Schlesier Wilmann, Ph. O. Runge und Comelius - während Konrad Witz, Meister Francke, Cranach, Grünewald u.a. mit dem Reichtum einer groBartigen Palette prunken, aber dem Gottesreich nicht Genüge tun. Und vollends, die letzten Jahrhunderte, sind eine laute und schreiende Heidenzeit geworden, und die rationalistische und gänzlich entgottete Welt der Impressionisten und alles das, was jüngsthin die Malerei geleistet hat, wird, wie ich sagte, zu leicht befunden werden am Tage des letzten Gerichts.

Wenn ich nun selber noch einmal von meinen Arbeiten spreche, so möchte ich das in aller Demut und Bescheidenheit tun. Denn die Vorsehung hat mir dieses begrenzte Talent zuerteilt, und ob ich gleich ungestüm begehrte, ein Großer und Reicher zu sein in der Kunst, und ob ich auch gegen mein Unvermögen wütete und meine eigenen Werke schmähte, so muBte ich mich begnügen mit dem, was der Höchste mir anvertraut hat. Deshalb kann ich auch, verglichen mit den wirklich Großen, dem Himmel nur ein kleines Liedlein singen und nur in schwacher Weise Zeugnis ablegen für den lebendigen Herrn. Und da ich ein Israelit bin und meine Religion es verbietet, mag ich die Gottheit oder die göttlichen Wunder der Schrift nicht darstellen, sondern nur die sündige Kreatur im Aufblick zu ihrem Schőpfer und Hern. Der zerknirschte, der reuevolle, der buBfertige Mensch, der Sünder, der die Bekehrung erharrt, der einsame Beter, der Zwiesprache hält, und der entrückte Beter, der lächelnde Fromme in der Freude des Geistes und der Verzückte, der im Lichtglanz der Gottesherlichkeit sich tummelt -: das sind die Gegenstände, die ich immer wieder zu gestalten suche. Mag auch in meinen Blättern noch viel Bizarres sein und wenig von jener Hoheit und Reinheit der geistlichen Welt, so muB man bedenken, daB auch ich ein Kind der Zeit bin und Anteil habe an ihren Krankheiten und Häblichkeiten und soeben erst hob ich meinen FuB auf zur Pilgerschaft in das Reich der Wahheit - denn gestern war ich noch wie die Anderen und trieb es nicht besser als sie.

Neben Jenem beschäftige ich mich auch seit Jahren mit dem Porträt. Das ist zwar kein sublimes Thema, aber es ist ja nichts Unerlaubtes und ich muß es schon darum tun, um mich vor der Natur immer wieder zu erneuern, und zweitens, um mein Brot zu verdienen (obwohl sich nur selten Jemand von mir konterfeien läßt) denn für meine religiösen Stoffe interessiert sich kein Teufel und der leibhaftige am allerwenigsten. Der reizt mich höchstens immer wieder zu allerhand Unfug und zu abseits liegenden Stoffen, zur Landschaft und zur Großstadt auf. Und von meiner literarischen Arbeit hat er mich geschickt und schlau in den letzten Jahren abzuhalten gewußt, der böse Feind. Erst kürzlich ist es mir geglückt in gedrängter Prosa das niederschreiben zu können, was mich seit langem so sehr bewegt und erschüttert hat. In einem religiösen Bekenntnisbuch habe ich Rechenschaft ablegen können über meine inneren Wandlungen und Kämpfe, und in einem kleinen Andachtsbüchlein gelang es mir in würdiger Weise und in reiner Form dem Barmherzigen Dank zu sagen für das, was er an mir und den Menschen getan; in kleinen, anschließenden Kapitein versuchte ich dann Hinweise zu geben zum inneren Leben und zur großen und herrichen Liebe des Allerhöchsten. Aber dieses alles vermochte ich nicht aus eigener Kraft, sondern allein mit dem Beistand des heiligen Geistes, der meiner Feder das rechte Wort verlieh. Und er hat mich dazu so reich und überschwenglich gesegnet und ich habe innerlich so viel dabei 
gewonnen, daß ich glaube mit jenen kleinen Werken die Gemeinheit getilgt zu haben, welche ich mit meinen früheren Prosaschriften und mit häßlichen demagogischen Pamphleten anstiftete, die in den ersten Revolutionsmonaten in die Welt gingen. Den Spleen, die Übergeschnapptheit und Schamlosigkeit, welche in meiner früheren Prosa walteten, habe ich weit, weit hinter mir gelassen und so sehr hat mich der Gottesglaube geklärt und nüchtern gemacht, daß ich heute nur noch mit tiefer Schamröte in jenen jugendlichen Arbeiten lesen kann. Von Haß und Unrast bin ich ausgegangen und zum Frieden Gottes bin ich eingekehrt - noch nicht zu dem tiefen und vollkommenen Frieden des Herm, aber immerhin in einen still und selig machenden Hafen, der mich schützen kann vor den Verirrungen und Narrheiten, in denen alle meine Freunde noch befangen sind. Und was das anbelangt, so bitte ich Dich, der Du dieses liest, von Herzen, daß Du einmal mit großem Ernst für eine halbe Stunde allen Hochmut, allen Trotz und alle falsche Bildung abtust und Dein verflossenes Leben überdenkst, damit Du Dich des grundgütigen Spenders aller Wohltaten, die Du erfahren hast, erinnerst und recht Deiner Schwäche und Abhängigkeit inne wirst. Wenn Du aber schon weiter bist und voller Sehnsucht nach dem Überzeitlichen, so gehe nicht zu den falschen Propheten, Okkultisten und Theosophen, noch zu den Lehren des Buddha und Laotse, die heute in aller Munde sind, sondern schließe Dein Herz den alten Sprüchen und Psalmversen auf, die Du in Deiner Kinderzeit gelernt hast, vielleicht wirst Du in ihnen, die heute wie armselige Bettler abseits stehen müssen und von Niemand mehr beachtet werden, ungeahnte und beglückende Schätze finden.

Ja, dort ist das Heil, Frieden, Seligkeit und Dauer über den Erdentag hinaus!

Das Wort Gottes, das geschriebene, und das Wort Gottes, das innen im Menschen redet: das ist die einzige Wahrheit, das bringt Glück und Ruhe und Sicherheit, das weist den einzig richtigen Weg, den man gehen muß. Drum laßt uns dem Schöpfer, dem Meister aller Meister und Geber aller Gaben danken aus Herzensgrund, für dieses sein Wort und für Alles, was er täglich an uns erweist! Amen, Amen. 


\section{Text XVI: „Vision zur Ekstase“}

Im Sommer des Jahres 1912, in meinem neunundzwanzigsten Lebensjahr, wurde ich zum erstenmal von eigentümlich beglückenden, geistig=körperlichen Zuständen heimgesucht, die sich auch in den folgenden Jahren häufig wiederholten und mich am Tage, bei der Arbeit, auf der Straße, sogar mitten im Kreise von Menschen unsäglich überraschten. Allmählich ward ich inne, daß dies nichts Außergewöhnliches und Einzigartiges oder gar Krankhaftes sein könne, zumal der Zustand, der übrigens immer nur einige Minuten daverte, aber noch stundenlang von seinem Glück einen tiefen Nachgeschmack hinterließ, mich mit ungeheurer Kraff überschüttete und in ungeheurer Kraft empfangen ward. Wie zufällig kam mir in jenen Tagen ein altes Buch in die Hände, das von Ekstase handelte und ich hatte sogleich den Schlüssel zu meinen Erlebnissen. Da ich nicht wissenschaftlich und nicht Psychologe genug bin, um Vorgang, Wirkung und Wesen der Ekstase erklären zu können, möchte ich nur kurz und vermutlich undeutlich genug sagen, daß Ekstase eine Hochspannung der Seele sondergleichen und zugleich ein Glücksgefühl des Körpers ist, die sich mit anderen großartigen Vorgängen, sogar mit der Inspiration des Dichters und Künstlers keineswegs vergleichen lassen. Das Charakteristische meiner Erlebnisse war nun, daß sie vorwiegend religiös gefärbt gewesen sind oder einen ausgesprochen religiösen Inhalt hatten, was um so seltsamer war als ich in den vorausgegangenen zehn Jahren niemals religiöse Impulse in mir gespürt, ja eher eine religionsfeindliche Haltung an den Tag gelegt hatte. Bei malerischer oder zeichnerischer Arbeit äußerte sich die Ekstase in einer bestimmten Linien=dynamik und in geschwungenen Kurwen [sicl] - in späteren Jahren, als ich, weniger ungeschickt, diesen magischen Strömen folgen gelernt hatte, in einer ausgesprochen barocken Linie, die sich in schnörkeligen und unverschlungenen Ornamenten über das ganze Bild hinwälzłe und manchmal sogar bei ganz einfachen und ruhig sein sollenden Motiven wie ein aufwühlender Orkan aussah. Allmählich unterschied ich die ausgesprochen verschiedenen Arbeitsweisen. Brunft, Trunkenheit und Vision. In der "Brunft" arbeitete ich aus einer Überfülle von Lust und Hingebung. "Trunkenheit" war ein extaseähnlicher [sic!] Zustand und wie inTrance flossen die Linien aus meiner fást bewußtlosen Hand. In "Vision" dagegen stand leuchtend oder erschreckend ein grelles Bild einer Gestalt, einer Landschaft in meinem inneren Auge und zwang mich gebieterisch zur Niederschrift. Die Kehrseite so glückhaft=magischen Arbeitens war eine gewisse Hastigkeit in der Ausführung. Man wollte den Augenblick nutzen, daß er einem nicht sogleich zerfließe und brachte viele oberflächliche und formlose Arbeiten zuwege. Künstlerische Arbeit ohne Besinnung und Rechenschaff kann nicht das Richtige sein, und es war schließlich ein Glück, daß ich vor einigen Jahren fast völlig die Fähigkeit der Ekstase verlor und mich allmählich einrichten mußte, mit klarem Kopf und ruhigem Herzen arbeiten zu lernen. So mache ich nun unauffallige, aber geformtere Arbeiten und schreibe eine stille und besonnene Prosa und obwohl ich jetzt schon jahrelang bürgerlichem Herkommen entsprechend schaffe, heilt es noch immer unter den Leuten "Meidner, der Ekstatiker" - der Zuname bedeutet hier tast einen Schimpt, zumindest eine Naserümpfen. Wenn ich aber denen, die so reden meine neveren Bilder zeige, dann äußern sie enttüuscht: "Herr M. Sie haben ja ihre ganze Eigenart eingebüßt. Thr Schwung, thre Ekstase sind völlig dahin."

LM 
Text XVII: „Hymne an mich selbst“

Hymne an mich selbst

$\mathrm{Da}$, da - - - hineingeweht in den Alltag - seht den Glatzkopf, Kahlbauch - ihn, den eulenäugigen, gestiefelten Kater, Anfeuerer der Petroleusen und aller Stiefsöhne des Monds.

Hineinragend bis in die siebente Region des Weltalls - sich skeptisch schneuzend und immerfort wehlachend - fragt er, kleiner Däumling, nach des Weltalls Wieso und Warum.

Sapperment! Aưf seinen langen Ohren Stö̀che nisten. Gänsegeier und Bussarde um seine Augenbrauen wehn. Sein asphaltierter Rachen schreit heisre Sarkasmen. Seine Backen voll FliegenschiB. Spinnen wimmein um seine Hoden. Dromedare taumein aus seinen Lenden. Aus seinem Bauche Wölfe und Füchse eilen. Und der groBe Bär spiegelt sich eitel auf der Glatze, mitten in rotbrauner, feilschender Nacht.

Mitten in der Bettstelle johlt er lautlos und wehe, ernennt den Vollmond feierlich zu seinem Bett-Cousin. (Der lauert lange - springt über seinen schlaffeuchten Leib und lacht) - In seinen polternden Träumen wogen die Türme der Kathedrale. Die Wanzen krăchzen und beißen ihn ins Genick.

Im Genicke den Mondschein, zerbissen vom Zweifel die haarige Brust, jauchzt er in den Morgen hinein, wird Dichter und kosmischer Narr.

Er trampelt über den Damm - Kinàdengeneral - umheult von zerknitterten Wolkenfahnen. Schwingt seine Tabakpfeife, fühlt sich als Lesebuchgröße des neuen Jahrtausends Radaubruder, Rädelsführer, Megaloman...

Phosphorener Wildling, klettert er im Gebälk der Wälder; will die Bäume mit Bier wässern, mit Sauerkohl düngen.

... der Wetterwendische ... tänzelt durch die ruhmreichen Abende; liebkoset jeden Laternenpfahl; stehend hält er den Beischlaf mit der süBen Laterne.

Winter kältet nur sein Ohr. Sommer macht ihn schwül und schwer. Bald händefaltend beten - bald nihiljstisch winseln. Bald Geschrei versteckend, verzückte Schreie hinter gefütterter Weste bergend. Bald unzüchtig die Waldbäume bedrohend - bald psalmodierend zerknirscht. Bald chaotischer Zappler, Kunsthonigschlecker, Frenetischer in Exzessen der Wollust. Bald im Alltagseinerlei ersoffen. Bald taubstumm - bald süße Orgel, Gezwitscher, Lied. Bald Galgenvogel. Bald windschiefes, wackeliges Gemäuer. Bald russophil - bald Misogyn. Bald Vogel Strauß - bald Sybarit. Bald Drossel - bald Chamäleon. Heil Du, Käsehändler der Vernunft... 
Text XVIII: „Mündung, du böse bleckende, schweig, schweig!“

Mündung, du böse bleckende, schweig, schweig!

Mündung meiner Flinte, die ich täglich auf dem Buckel tragen muß, was grinsest du mich schrecklich an aus deiner gellenden Kluft heraus? Du Hohngelächter der irdischen Zagen, Echo der Fiebernden und wilde Lust der roten Verdammten; ich halte dein hämisches Verhalten hier unter den Sternen nicht mehr länger aus!

Was ist das hier??

MUß immer auf der Schräge windverwehten Dammes auf und ab marschieren, frierend im Klapperkasten des irdischen Gehäuses. Muß immer mein grelles Leid in mich hinein heulen; mein Gesichte vor den Sternen geduckt bergen. Muß mich schämen vor dem Mond, vor dem Wehen himmlischer Musik mich tief verkriechen und immer diesen höllischen Abgrund auf meinem Rücken schnauben, rauchen und hohnspektakeln hören.

Zerbreche ich nicht vor Wehegeschrei in mir? Heult nicht in meinem Herze uralter Leierkasten seine ekstatische Leierkastenmelodei?!

Warum ist diese Nacht?!

Warum springt grüner Mondstrahl auf meinen spitzen Helm?!

Ich bin in alter Heidentracht, angetan in schwarz und rot, mit scharfem Messer an der Seite und diesem satanischen Rohr auf dem Rücken. Mein Leib steckt zitternd, wehe drin im tieffremden Gemach. Von ungeweinten Tränen bin ich wie betaut.

Warum hier zu sein, du lichte Seele, verbannt in einen trägen, zerbrechlichen Leib?! Warum die Pein der Nacht alltäglich wiederholen?! Warum nicht stille liegen, ewig ruhen und dem Lamento des Mondes Gehör geben?!

Warum auf diesen runden, behaarten Beinen stehen, herumgehen, wackeln, wiegen?! Warum diesen Bauch, diese überflüssigen Schultern, die verzweifelten Arme tragen?! Warum diese unerklärlichen Augen, Ohren, die dünnen Lippen, die infernalische Zunge mitten in dem schrecklichen Kugelkopf?!

Warum dieser Stachel der Liebe, wühlend ewig im stürmischen Fleisch?! Warum diese niegestillte Sehnsucht nach Paarung mit fremden, düster wehenden Leibern?!

Warum diese Unruhe in mir, die rote Unruhe, die mich so zermürbt?! Warum das immer wiederkehrende Zweifeln; das Nagen, Fressen, Bohren, Wühlen, Kratzen, Zermalmen?!

- Kannst mir keine Antwort sagen, Mond über mir, fletschende Hyäne des Firmaments?!? Warum steht Gott den Armen nicht bei? Warum gibt es Bucklige, häßliche Einäugige, Krüppel und Zwerge?

Warum ist deine Ernte immer so gewaltig reich, du Spinnentier, Luder Tod, so reich im üppig blühenden Fleisch?

Warum die verlassenen Bräute, die einsamen Greise, die Herden Unglücklicher auf den Landstraßen, die letzten Winsellaute der Verhungernden, die nie gestillte Liebessehnsucht der Eingekerkerten?

Warum gibt's Erstochene, häßlich Hingemordete und jeden Tag die zahllosen Scharen der jammernden, flehenden Weiber?

Warum sterben kleine Kinder dahin und haben nie den Junitag gesehn?

Warum die unendlichen Reihen der stillen, schwermütigen Tiere, die man täglich zur Schlachtbank führt?

Und warum die Millionen von Männern, weggeblasen wie von einem Windstoß und verscharrt in den Sand Europas wie Dreck??

Nein, nein, dieses ist nicht länger zu ertragen. Heut halt ich die Höllenschrecken nicht länger aus. Ich muß weg von hier. Seele, du mußt entfliehen dem beinernen Spottgelächter! Laß mich frei, du fremder Ort der Qual. Laß dein zartes Kleinod entfliehen; zu den Wolken hin; hin zu unirdischer, taumelnder Sterneschar...

Her du süßes Rohr, Tränental, du einzige Geliebte jetzt, gefült mit verheißungsvoller Patrone. Sei gut, liebes blinkerndes Ding; versage nicht, versage nicht!

Hinaus, hinaus wehende Rakete in meinen zahnlosen Schädel rein! Mach sie tot, Peitsche! diese gotteslästerische Glut! 
... seh ich da nicht, daß das Wolkenmeer sich lichtet, daß der Mond nun milde blickt ... hör ich nicht, wie beschwichtigende Stimme in mir redet?! wie OrgelgrüBe in mir erbrausen??!! Nein, nein! ich will nicht, ich will nicht! Sei stille du nackender Mensch! o manchmal tut sich der Himmel mir auf. In deiner Herrilichkeit schwimm ich dann, a Gott, glückselig und nicht ailein. In deinem Frieden bin ich geborgen. In deiner Mitte bin ich ruhig. In deinem Fleische fühl' ich ew'ge Vergessenheit.

... Seele, sei stille, sei stille...

\title{
Text IXX: „Vom Zeichnen“
}

\author{
Vom Zeichnen
}

Wenn du zeichnen willst, so mußt du eine hohe Fülle von Geist, Heiterkeit, Beschiwingtheit und Weltliebe in dir fühlen.

Fürchte dich nicht vor der leeren Weiße des Papiers. Sei unverzagt! Dort ist die wilde Welt, die schreckliche UngewiBheit - und hier ist dein Geist und dein heiBer Wille eine neue Welt zu schaffen, eine reinere, gebändigtere, Gott nähere Welt als die chaotische, wirre, da ringsherum.

Uns Zeichner dieser Zeit, dieser flackenden Rätsel-Tage, peitscht nicht irgend eine formalistische Tendenz, eine vorgefaßte Schul-Meinung auf - aber das Leben um uns hebt uns mâchtig hinauf. Wir schwimmen in einem magischen Strom und mit heißen Fingern und machtvoll gespanntem Hirn bohren, kratzen, wühlen wir in Stein, Metall, Holz und Kartons unsre inneren Gesichte hin. Unser Überschwang umarmt die Wunder des niederen Lebens ebenso, wie die ganz zarten, inwendigen Bilder, die Gott in unsere Seelen haucht - das Zeitgenössisch-Wilde und Verückt-Neue ebenso wie Felsen, Wolken und Mondsichel. Anders als unsere in Krautäckern herumhopsenden und Valeurs äugenden Impressionistengauche sind wir Flamme und Feverstrom, aber nicht romantisch zeriahren und zügellos, sondern voll von Strenge, Straffheit und Melodie.

Fürchte dich nicht vor dem Antlitz des Menschen, das ein Abglanz himmlischer Herrlichkeit ist, aber noch häufiger ein Schlachtfest mit blutigen Fetzen. Nimm Ruлzeistime, Nasenwurzel und Augen eng zusammen. Bohr dich wie ein Wühltier in den unerklärichen Pupillengrund und das Augenwei $B$ deines Gegenübers und la $B^{\prime}$ deine Feder nicht rasten, bis du deines Gegenübers Seele mit der deinen zu einem pathetischen Bunde vermähit hast. Versenke dich in die Innigkeit, in die feuchte und schreckliche Innigkeit eines Lippenpaares.

Beachite die Spitze oder zernarbte Weichheit des Kinns. Das Ornament des Ohrs soll dich immer wieder entzücken und die lodernden Haare, die Haarwellen, die Haar-Asche um dürre Wangen, die stechenden Borsten, die Härlein um den Mund seien ein Wohlgeschmack für deine flitzende Feder.

Willst du eine I andschaft zeichnen, so mußt du viel von dem Geiste der Wolken, der Bäume und der silbern hinschwingenden Chausseen in dir haben. Bloße Genauigkelt und Intimität nützen hier nicht viel. Sei voll von Gesang - und alles wird von selbst gehen. Wozu willst du im einzelnen wissen, wie man Birke, Fichte und Busch zeichnet, wie man das Schäumen des Stroms mit der Feder ausdrückt?

Wenn ich an die gewaltigen Zeichner der vergangenen Jahrhunderte denkel Diese wuchtigen, breitbeinigen Donnerkiels ohne Angst und Bange und Neurasthenie! Wenn mir der Bosch van Aeken, der Breughel, der Callot oder das Luder, der Hogarth in den Schädel fährt! Und sprich gedämptt und voll Ehrfurcht, wenn du an deine eigenen Landsleute denkst, die Schongauer, Dürer, Altdorfer und Urs Graf!

Was haben diese Kreuzhimmelsakramenter nicht alles vollbracht! Eine Welt voll kurioser, rätselhafter, unglaublicher, verrückter, satanischer und heiliger Begebenheiten und Historien aufgebaut. Und wie eindeutig und sicher! Und wie haben sie daran geglaubt! Dazu Licht und Schatten, Rhythmus, Komposition und Psychologie der Wolken und des Himmelsraums. Was für heisere Triumphschreie, die Allegorien der "Geduld" und der sWollustw des Pieter Breughel, und was für schädelspaltende Ironien und pessimistische Verkrampfungen, diese Schnapsgassen und Hurenbuden des Hogarth.

Wenn die Jahrhunderte tönen, dann kommt wieder Mut in meine zerknitterte Landsturmbrust. Meine kleinen Hände rasen im Tempo jener uralten, urhaften Stiche und Schnitte. Ich bin ganz in meinem Element und grüBe die Titanen in thren wuchernden, unruhevollen Grüften. 
Der echte Zeichner liebt die menschliche Gestalt. Er hat ein heißes Verlangen, das Gebäude des Leibes hinzustellen. Er fühlt die Nacktheit durch und durch. Am liebsten würde er immer das Knochengebein mit hineintun, Verwesung mitzeichnen.

Wie tragisch sind die Gebärden der Schlafenden; denn siehe, sie sind in überirdische Welt gerückt, groß und seltsam hingestreckt. Sie pressen die Arme um ihre Brust, recken sie spitz um den Kopf herum. Und manche halten ein Kissen fest an ihrem Munde in schauerlicher Inbrunst.

Zeichner, sieh dir die Schlafenden an. Sie ruhen schuldbeladen vor Gottes strengem Angesicht.

Man muß mit spitzem Instrument ans Werk gehen; Kugelspitzfeder mit Stau, scharfer Nadel oder harter Kreide. Du Graphiker darfst nicht »malerisch« wursteln und bluffen. Dein Strich muB aus innerem Leben hervorbrechen. Du muBt einen höllischen Wind in deinen Nerven haben. Du Mond-Toller, dein Blut soll ein kochendes Meer sein.

Die Poesie tief innen und der geschärfte, expansive, glühende Strich; der Strich, der hellseherisch richtig sitzt, der alles ausdrückt, der nur einmal gemacht werden kann. Die Musik deiner weitatmenden Brust und die feuerbeschwingte Hand, die ein Engel dir führt. Darauf kommt es an. Das ist wichtiger als alles andre. Das führt zum großen Werk.

Zeichner dieser Tage, du ekstasenreicher männlicher Mensch! Du kennst deine Mittel. Du weißt, wie sehr es auf jeden Strich, auf den I-Punkt ankommt. Du hast ein ungeheueres Verantwortlichkeitsgefühl, denn deiner Seele dürfen nicht häßliche, unfertige und unlautere Gebilde entsprießen.

Ah, der zitternde Erdball ist mit unzähligen, herrlichen Zeichnungen bedeckt. Aus grauen Zeiten wirft ein Strom Millionen tosender Blätter ans Land, und seht, sie kommen schon angeweht, die Zeichner der Zukunft, mit zuckenden Fingern und explosiven Hirnen. Sie haben Mut im Leibe und in ihren Händen die Sicherheit der Mondsüchtigen.

Wir lieben das Zeichnen von jeher, wir unvernünftigen, spielenden, jubelnden Erdenmenschen. Von dem ersten entzückenden Stammeln der Urvölker - bis zu Kokoschka und Hermann Huber; von Raffaels strengem Zeichenstil - bis zu den pornographischen Kritzeleien unsrer Piß-Buden.

Zeichnen macht gesund, heiter und gottgläubig.

Ich bin immer für mich allein. Kein Mädchen liebt mich. Keine Frau will bei mir schlafen. Kein Freund mit mir sein. Ich habe nicht Haus, nicht Heimat; bin arm, verfemt und viel gehaßt... aber ich darf zeichnen, frei mich hinschwingen, in Gottesliebe mich tummeln auf warmer Fläche pochendem Grund und ich jubiliere mit dem Stift, singe, bete und lobe die große Allgüte. 


\section{Oskar Kokoschka}

\section{Text XX: „Die träumenden Knaben“}

\author{
DIETRAUMENDEN KNABEN \\ gustav hlimt \\ in verehrung zugeeignet
}

rot fischlein / fischlein rot /

stech dich mit dem drei-

schneidigeo messer tot

reiß dich mit meinen fingern

entzwei /

daß dem stummen krcisen

ein ende sei $/$

rot fischlein / fischlein rot

mein messerlein ist rot /

meine fingerlein sind rot /

in der schale sinkt ein

fischlein tot /

und ich fiel nieder und

träumte viele taschen hat

das schicksal / ich warte bei

einem peruanischen steiner-

nen baum / seine vielfingri-

gen_blatterarme greifon wic

geängstigte arme und finger dünner / gelber figuren / die sich in dem sternblumigen gebüsch unmerklich wie blinde rühren / ohne daß ein heller / verziehender streifen in der dunklen luft von fallenden sternblumen die stummen tiere lockt / blutraserinnen / die zu vieren und fünfen aus den grünen atmenden seewäldern / wo es still regnet / wegschleichen / wellen schlagen über die wälder hinweg und gehen durch die wurzellosen / rotblumigen / unzähligen luftzweige / die wie haare im. meerwasser saugend tauchen / dort heraus winden sich die griunen wogen / und das schreckliche meer der untiefen und menschenfressenden fische / faßt die überfüllte galeere / oben an den masten schwingen käfige mit kleinen blauen vögeln / zieht an den eiser- nen ketten und tanzt mit ihr hinein in die teifune, wo wassersäulen wie geisterschlangen auf dem brüllenden meer gehen / ich höre die rufe der schiffer/die in die länder der sprechenden vögel wollen / die segel schwankten hin und schwankten her / kalte luft bewegte sie urd drehte die tücher / das schiff legt an / leise gehen taktmälig / in pausen verständlich / dann wieder übertönt die prozessionen der vom schiff steigenden / schlcicher in braunen wollkleidern winden sich durch und nackte magere mädchen geben vögel / nüsse und korallenschnüre zur erinnerung an die nächte der dunkíen zärtlichkeiten / und ich fiel und träumte die krankes. nacht $L$

was schlaft ihr / blaugekleidete männer / unter den zweigen der dunklen nußbäume im mondlicht?

ihr milden frauen / was quillt in euren roten mänteln / in den leibern die erwartung verschlungener glieder seit gestern und jeher?

spürt ihr die aufgeregte wärme der zittrigen / lauen luft - ich bin der kreisende wärwolf -

wenn die abendglocke vertönt / schleich ich in eure gärten / in eure weiden / breche ich in euren friedlichen kraal /

mein abgezäumter körper / mein mit blut und farbe erhöhter körper / kriecht in eure laubhütten / schwärmt durch eure dörfer / kriecht in eure seelen / schwärt in euren leibern / 
aus der einsamsten stille / vor eurem erwachen gellt mein geheul /

ich verzehre euch / männer / frauen / halbwache hörende kinder / der rasende / liebende wärwolf in euch /

und ich fiel nieder und träumte von unaufhaltbaren änderungen /

horra / heraus aus dem gelben / stehenden wasser / in dem ihr wie korallenstöcke lebt /

horra / ihr wachsfarbenen mit den teigmasken und den bärten aus rotem schwamm /

ein wind zieht in die vergessene stadt / in deren verschlossenen zimmern singende menschen wie in vogelkäfigen hängen /

horra /. du bange große gemeinde / mein schwacher knabengesang und mein gebet des unwissenden schützt deine laster nicht mehr /

in mir träumt es und meine träume sind wie der norden / wo schneeberge uralte märchen verbergen / durch mein gehirn gehen meine gedanken und machen mich wachsen / wie die steine wachsen / niemand weiß davon und begreift /

bange stunden träume ich. schluchzend und zuckend wie kinder / die als pubere vom lager gehen $\angle$

nicht die ereignisse der kindheit gehen durch mich und nicht die der mannbarkeit / aber die knabenhaftigkeit / ein zögerndes wollen / das unbegründete schämen vor dem wachsenden / und die jünglingsschaft/ das überfließen und alleinsein / ich erkannte mich und meinen körper / und ich fiel nieder und träumte die liebe $/$

erst war ich der tänzer der könige / auf dem tausendstufigen garten tanzte ich die wünsche der geschlechter / tanzte ich die dünnen frühjahrssträucher / ehe du mädchen li / dein name klingelt wie silberbleche / noch aus den gehängen der zinnoberblumen und gelbschwefelsterne tratest / aus den gewürzgärten / kannte ich dich schon und erwartete dich an den blauen abenden auf meiner silberdecke / aus den verworrenen vogelwäldern des nordens und von den seen der roten fische des südens / spürte ich dich her / fühlte die geste der eckigen

drehung deines jungen leibes und verstand die dunklen worte deiner haut und der kindlichen mit glasschnüren behängten gelenke / und vor dir flüchtete ich in die gärten / herauf von stufe zu stufe / bis zur tausendsten und letzten in meiner scheu / musik / musik / gaukler mein leib / schellenraßler / beckenschläger /

weg du popanz meines sündhaften vorbehalts / helle feuer liegen an den zwergwäldern / hinab springe ich mit wehenden gewändern zur erde und wie ein hoher einziger ton steht hinter mir auf den gärten die sehnsucht /

und ich träumte / wie ein zungenfeuchter baum ist mein leib / in verlorenen brunnen läuft das leben auf und nieder und drängt zum verschütten / die nächte wunderlicher / namenloser tiere tragen meine liebe weg und aus meinen verworrenen innigkeiten ist kein tasten zu fremden greifenden fingern / die ohne erinnerungen wären / ich warte wieder in meiner hütte / vom ufer her liefen zwei ottern über den lehm der baumlosen ebene / ein mädchen besucht mich / deine mageren ungezeichneten finger sollten an meinen knien hängen wie satte blumen / dich liebt der grüne baum und die roten / gestickten hände auf meiner decke in der hütte / ich sage laut / dich liebt das seegras auf dem du liegst / und ich sage wohl auch / dich liebt ein mann der neben dir auf dem seegras ruht in der hütte unter dem grünen baum / höre es nicht / daß die lautlose stille bleibt /

ich sehe dich wie ein einziger / ich hätte dir vielleicht muscheln gesucht /

der einzigè bin ich / der von dir weiß / was zum frühling wartet / aber es ist kein reden vom formlosen / wenn die haut noch nicht weiß / wir werden suchen müssen / wie nach einem verlorenen. kind /

wie nach etwas / das in der luft hängen blieb und ungesagt /

und ich fiel nieder und träumte dem morgen zu / du sollst bleiben in meinem haus / ich will nicht schlafen / ich muß mit den händen in die luft greifen und durch die gänge nach dir rufen / obgleich ich mich schäme / keiner hat dich noch so gesehen wie ich / ich stehe neben dir und sehe deinen 
arm sich biegen / eine geschichte so / die aufhört zu sein / wenn man an sie rübrt / hinter allen worten und zeichen sche ich / oh wie freue ich mich / daß du mir gleichst / wie du mir gleichst / komme du nicht näher / aber wohne in meinem haus und ich will das kindliche zittern deiner schultern erwarten und sehen / wie dein mund / ohne worle zu suchen / für mich spricht /

in meinem weißen zimmer war ich alleiu / doch vielleicht trug ich dich jetzt herein und es bleibt und spricht wie aus schweren blumen etwas zu mir / mein zimmer wurde wie ein anderes land / in die weiBen wälder tret ich / eines renntieres huf klingt und wirft in allen weißen wăldern wiederleuchtende schnco-

sterne auf / wie spitzengärten ist es um dich / renntierreiterin / und das rentier ist ein berg/deine kleider sind eine schneefläche / wo blumen werden / die berührung deiner dünnen finger / und die schneewälder stehen um dich wie staunende knaben / der schnee rinnt zusammen zu einem see und auf einem roten fischlein warst du gesessen / ich hatte von dir nur gesehen deinen nackten hals in den haaren

ein stäblein wächst ins wasser hinunter / wo ist das ende alles wesens /

aus deiner runden brust geht dein atem über den blauen see / wie leise ist das wirken alles wesens /

ich greife in den see und tauche in deinen haaren / wie ein versonnener bin

ich in der liebe alles wesens /

und wieder fiel ich nieder und träumte /

zu viel hitze überkam mich in der nacht / da in den wäldern die paarende schlange ihre haut streicht unter dem heißen stein und der wasserhirsch reibt sein gehörn an den zimmtstauden / als ich den moschus des tieres roch in allen niedrigen sträuchern / es ist fremd um mich / jemand sollte antworten / alles läuft nach seinen ei genen fährten / und die singenden mücken überzittern die schreie /

wer denkt grinsende göttergesichter und fragt den singsang der zauberer und altmänner / wenn sie die bootfahrer begleiten / welche frauen holen /

und ich war ein kriechend ding / als ich die tiere suchte und mich zu ihnen hielt / kleiner / was wolltest du hinter den alten / als du die gottzauberer aufsuchtest /

und ich war ein taumelnder/ als ich mein fleisch erkannte /

und ein allesliebender / als ich mit einem mädchen sprach / 


\section{Text XXI: „Mörder, Hoffnung der Frauen“}

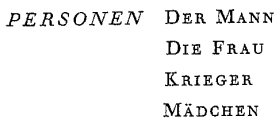

Die Handlung spielt im Altertum

Nachthimmel

Turm mit großer gitterner Eisentür

Fackellicht

Boden zum Turm ansteigend

\section{DER MaNN}

weißes Gesicht, hlaugrepanzert, Stirntuch, fas eine Wunde bedecki, mit der Schar der Krieger, wilde Köpfe, graue und rote Kopftücher, weiffe, schwarze und braune Kleider, Zeichen auf den Kleidern, nachte Beine, Fohe Fuchelstungen, Schellen, Getose, Die kriachen herauf mit vorgestreckten Stangen und Lichtern, versuchen müle und unwillig den fortstürmenden Abenteurer zurückzuhaiten, reijon sein Pferd nieder. Er geht vor. Sie lösen den Kreis um inn, während sie mit langsamer Steigerung aufschereien

\section{KRIEGER}

Wir waren das flammende Rad um ihn.

Wir waren das flammende Rad um dich, Bestürmer yerschlossener Festungen!

gehen zögernd wieder als Kette nach; er, mit dem Fuckelträger vor sich, geht woran

\section{KRIBGER}

Fubr' uns, Blasser!

währendi sie sein Pferd niederreißen wollen, steigen Mädchen mit der. Führerin die rechts liegende Stiege herab, die aus der Burgmauer führt

FRAU

rote Kleider, offene gelbe Haare, grof

lonet

Mit meinem Atem erflackert die blonde Scheibe der Sonne.

Mein Auge sammelt dor Männcr Frohlocken.

Inre stammelnde Lust kriecht wie eine Bestie um mich.
MÄDCHEN

lösen sich von ihr los, sehen jetzt erst den Fremden

ERSTES MÄDCHEN

neugierig

Unsre Frau!

Sein Atem hängt ihr an.

ERSTER KRIEGER

darauf zu den andern

Unser Herr kommt wie der Tag, der im Osten aufgeht

ZweItes MÄDCHEN

einfältig

Wann wird mit Wonne sie umfangen!

FRAU

sieht den Mann fest an

Wer ist der Fremde, der mich ansah!

ERSTES MÄDCHEN

zeigt ihn, schreit

Der Schmerzensmutter verscheuchter Knabe,

mit Schlangen um die Stirn, entsprang.

Kennt ihr ihn wieder?

ZWEITES MÄDCHEN

lächelnd

Untiefe schwankt.

$\mathrm{Ob}$ sie den lieben Gast vertreibt?

DER ManN

erstaunt, sein Zug hält an 
Was sprach der Schatten?

das Gesicht hebend, zur Frau

Sahst du mich an, sah ich dich?

FraU

fürchtend und verlangend

Wer ist der bleiche Mann?

Haltet ihn zurück!

ERSTES MÄDCHEN

gell schreiend, läuft zurück

Laßt ihr ihn ein? Der wittert, daß wir unbeschützt?

Die Festung offen steht!

\section{ERSTER KRIEGER}

Thm ist, was Luft und Wasser teilt,

Haut und Feder, Schuppen trägt,

haarig und nackt Gespenst

gleich untertan.

\section{ZWEITES MÄDCHEN}

Mit einer Falte weint und lacht die Goldgelockte da.

Jäger fang uns schon...

Gelächter

ERSTER KRIEGER

zum Mann

Umarme sie!

Das Wiehern hetzt die Stute irr.

Gib dem Tier die Schenkel!
ERSTES MäDChEN

listig

Unsre Frau ist eingesponnen, hat noch nicht Gestalt erreicht.

ZWEITES MÄDCHEN

groptwend

Unsre Frau steigt auf und sinkt.

doch kommt nie auf die Erde.

DRITTES MÄDCHRN

Unsre Frau ist nackt und glatt, auch schlieBt sie nie die Augen.

DHIT'ER KRIBGBR

zum dritten Mädchen, hähnisch

An Haken fängt sich Fischlein.

Fischin hakt sich Fischer!

ZWEITER KRIEGER

zum zweiten Mäudichen; er hat verstanden

Locken fliegen! Thr Gesicht befreit ...

Die Spinne ist aus dem Netz gestiegen.

DER MaNN

hat der Frau den Schleier gelüftet; zornig

Wer ist sie?

ERSTER KREGER

aufreizend

Sie scheint dir bange, fang sie! 
Verfängt doch nur die Angst.

Bang du, was du dir erfangst!

ERSTES MäDCHEN

ängstlich

Frau, laß uns fliehen!

Verlöscht die Lichter des Führers!

ZWEITES MäDCHEN

eigensinnig

Herrin, hier laß mich den Tag erwarten ...

Heiß mich nicht schlafen gehen,

die Unruh in den Gliedern!

\section{DRITTES MÄDCHEN}

flehend

Er soll nicht unser Gast sein, unsre Luft atmen!

Laßt ihn nicht übernachten.

Er schreckt uns den Schlaf!

ERstes MädcheN

Der hat kein Glück!

ERster KrIEger

Die hat keine Scham!

FraU

Warum bannst du mich, Mann, mit deinem Blick?

Fressendes Licht, verwirrst meine Flamme!

Verzehrendes Leben kommt über mich.

Oh, nimm mir entsetzliche Hoffnung -

DER MANN

fährt wütend auf

Ihr Männer! Brennt ihr mein Zeichen mit heißem Eisen ins rote Fleisch!

Krieger führen den Befehl aus. Zuerst der Haufen mit den Lichtern mit ihr raufend, dann der Alte mit dem Eisen, reißt ihr das Kleid auf und brandmarkt sie

FrAU

in furchtbaren Schmerzen schreiend

Schlagt die zurück, die böse Seuche.

sie springt mit einem Messer auf den Mann los und schlägt ihm eine Wunde in die Seite. Der Mann fällt

KRIEGER

Flieht den Besessenen, erschlagt den Teufel!

Wehe uns Unschuldigen, verscharrt den Eroberer.

Der Mann

Wundkrampf, singend mit blutender sichtbarer Wunde

Sinnlose Begehr von Grauen zu Grauen,

unstillbares Kreisen im Leeren.

Gebären ohne Geburt, Sonnensturz, wankender Raum.

Ende derer, die mich priesen.

$\mathrm{Oh}$, euer unbarmherzig Wort.

\section{KRIEGER}

zum Mann

Wir kennen ihn nicht.

Verschon uns!
Kommt, ihr Griechenmädchen, laßt uns Hochzeit halten auf seinem Notbett.

ALLE MäDCheN

Er erschreckt uns,

euch liebten wir, als ihr kamt.

die Mädchen legen sich zu den Kriegern kosend, rechts auf den Boden

drei Krieger machen aus Stricken und Ästen eine Bahre, und stellen sie, mit dem schwach sich Bewegenden, in den Turm hinein. Weiber werfen das Gittertor zu und ziehen sich wieder zu den Männern zurück

DER ALTE

steht auf und sperrt ab. Alles dunkel, wenig Licht im Käfig

FRAU

allein, jammernd, trotzig

Er kann nicht leben, nicht sterben,

er ist ganz weiß.

sie schleicht im Kreis um den Käfig. Greift gezwungen nach dem Gitter. Droht mit der Faust

FrAU

trotzig

Macht das Tor auf, ich muß zu ihm!

rüttelt verzweifelt

KRIEGER UND WEIBRR

die sich ergötzen, im Schatten, verwirrt

Wir haben den Schlüssel verloren - - wir finden ihn - -

Hast du ihn? - - sahst du ihn - - wir sind nicht schuldig.

Wir kennen euch nicht. - - Was wissen wir von euch!

Der Streit ist unverständlich und dauert eine Ewigkeit. gehen wieder zurück. Hahnenschrei, es lichtet im Hintergrund

FRAU

langt mit dem Arm durchs Gitter, böswillig keuchend

Blasser! Schrickst du, Furcht kennst du?

Schläfst du bloß? Wachst du? Hörst du mich?

DER MANN

drinnen, schwer atmend, hebt mühsam den Kopf, bewegt später eine Hand, dann beide Hände, hebt sich langsam, singend, entrüickend

Wind, der zieht, Zeit um Zeit.

Einsamkeit, Ruhe und Hunger verwirren mich.

Vorbeikreisende Welten, keine Luft, abendlang wird es.

FrAU

mit beginnender Furcht

So viel Leben fließt aus der Fuge,

so viel Kraft aus dem Tor,

bleich wie eine Leiche ist er.

schleicht wieder auf die Stiege hinauf, zitternd am Körper, wieder laut lachend

DER MaNN

ist lanigsam aufgestanden, lehnt am Gitter

FraU

schwächer werdend, grimmig

Ein wildes Tier zähm ich im Käfig hier,

bellt dein Gesang vor Hunger? 
DER MANN

offnet den Mund zum Sprechen

.........

Hahnenschrei

FRAU

zitternd

Du, stirbst nicht?

\section{DER MANN}

\section{kraftvoll}

Sterne und Mond! Frau!

Fell leuchten im Träumen

oder Wachen sah ich ein singendes Wesen ...

Atmend entwirrt sich mir Dunkles.

Mutter . . Du verlorst mich hier.

\section{FRAU}

liegt ganz auf ihm; getrennt durch das Gitter, schließt langsam das Tor auf

\section{FRAU}

leise

Vergiß mich nicht...

MANN

wischt sich über die Augen

Rostgedanken klebt sich auf die Stirn ...

FRAU

zart

Es ist dein Weib!

MaNN

sanft

Eine Spanne scheues Licht! -

FRAU

bittend

Mann!! Schlaf mir....

MaNN

lauter

Ruhe, Ruhe, Truggedanke, la $B$ mich ...

FRAU

offnet den Mund zum Sprechen

..........

\section{ManN}

einsam

Ich fürchte mich -

FrAU

immer heftiger, aufschreiend

Ich will dich nicht leben lassen. Du!

Du schwächst mich -

Ich töte dich - du fesselst mich!

Dich fing ich ein - und du hältst mich!

Laß los von mir - Umklammerst mich - wie mit eisernen

Ketten - erdrosselt - los - Hilfe!

Ich verlor den Schlüssel - der dich festhielt

läßt das Gitter, fällt auf der Stiege zusammen
DER MANN

steht ganz, reißt das Tor auf, berührt die sich starr Aufbäumende, die ganz wei $\beta$ ist, mit den Fingern der ausgestreckten Fland. Sie spürt ihr Ende, spannt die Glieder, löst sie in einem langsam abfallenden Schrei. Die Frau fällt um, entreijit im Fallen dem aufstehenden Alten die Fackel, die ausgeht und alles in einen Funkenregen hüllt

DER MANN

steht auf der obersten Stufe, Krieger und Mädchen, die vor ihm fliehen wollen, laufen ihm schreiend in den Weg

KRIEGER UND MäDCHEN

Der Teufel!

Bändigt ihn, rettet euch!

Rette wer kann - verloren!

DER MANN

geht ihnen gerade entgegen. Wie Mücken erschlägt er sie. Die Flamme greift auf den Turm über und reißt ihn von unten nach oben auf. Durch die Feuergasse enteilt der Mann. Ganz ferne Hahnenschrei 


\section{Text XXII: „Allos makar“}

Mond verlänger einen Strahl der dem Flüchtling weiset, und die Sonne sanfter brennen heißet. Moxacp steiget im Winde dann $\alpha \lambda \lambda \omega s$ klammert an Untiefen an. Schwebendes Geisterschiff, Mast und Anker richte dich.

$$
A \lambda \lambda \omega \varsigma-M \alpha x \alpha \rho
$$

Umflechten die Rippen die täuschende Ruh. Das Herz innen selber anfảilt und drängt. Auf das Vergangene zurückfliegt weiße Erde von der Wintersonne. Über das Vorgestellte still mahlet dieselbe Wehe staubgebildetes Schattenspiel. Zieht eine Ohnmacht in die Unruhe ein.

Donnernd schlägt das Herz, bang allein zu sein.

Da kam von unten ungefähr

das Schreien rauher Vögel her.

Ein Männchen und Weibchen würgen eine Schlange.

Einer sieht des atuderen Vorteil bange.

Und eines am andern die Kraft verlor.

Da windet aus den schreienden Schnäbeln der Wurm sich herror.

Ließ einen Zettel fallen, vom Raufen zerdrückt. Ich nahm ihn und las ihn, im Staube gebückt. Lachen die Lippen zur täuschenden Ruh. »Anders ist glücklich.«

andern dieWärme sucht, bist du nicht, kannst du nicht sein! Im Heitern der klaren Sonnengarben, die heiß und stark die Welt umarmen, entriegeln der Gestalten Schooß, den Nächtigen, magisch bleibt dein Netz der Wechselflüchtigen.

$$
M \propto x \alpha p
$$

Ich komme von weither, durch Schäumeräume warf ihr Kind die Mutter sehr. Strittig Alles Tag und Nacht bedecken, Ungewißheit, Nachklang bildend, in der Brust erwecken. Voller Blendung kommt der Wache her.

Sonn und Mond helfen nicht zusammenweisen mild dem Klimmenden das Weiterreisen. Und im Nebelnorden ist er einer Frau ihr Mann geworden. In der Fesselschmiedin Dienst ist seinAuge blind geworden. Auf die Winterschwermut ohne Grund folget Sehnsucht flügelwund.

Ungeheuer brennen schnell ein Feuer beide, das aus mir.besteht.

Überfiel sie doch der Schlaf! Fliehend enden Alpdruck von liebeverschlingenden Händen! Fliehet der Wind nach Haus, findet Wasser nach Haus.

Einen Traum hab ich bedeutet, wer den Spiegel meiner dreht:

Neigung einfach nach sich selber schreit! 
Text XXIII: „Hiob“ (Auszüge)

\author{
PERSONEN HIOB \\ ANIMA, sein Weib \\ HerR KaUtSCHUKMAN \\ ADAM, der Gärtner \\ EROS \\ KAMMERJUNGFER \\ FRÄULEIN \\ HERREN \\ PAPAGEI
}

Als Adam schlief auf grünem Rasen, Erbarmte Gott, die Sonn' im Mlittag stand

Und dem vor Langerweil schon um Schlafen sei.

Weint Adam, in der Nacht von einem RippenstoB er. wacht: $\gg \mathrm{Ei} \ll$

Und da mit Eva sich begattet fand:

„Mein Gott, hätt' er mir nur mein Bein mit Ruh gelassen.《

\section{ERSTER AUFZUG}

HroB

mit Zipfelmütze und Schlafrock, klopft an die Tür zu seiner Frau

KAMMERJUNGFER

steckt den Kopf vorsichtig aus der anderen Tür hervor, versteckt etwas hinterm Rücken

Ich klopfte schon und frag nun an,

$\mathrm{Ob}$ mir der gnädge Herr nicht was vom Buckel

Nehmen kann.

Die gnädge Frau hat es mir mit zwei Tritten Auf's Kreuz appliziert; mit Federn und Krallen, Zung' und Schnabel ist es garniert.

Ihre Gnaden selbst ist mit dem jungen Herrn, Schön ist er wie gemalt, schon heute morgen ausgegangen.
- Das Federtier da läßt sie dem Herrn

Zur Unterhaltung hier.

sie wirft einen Papagei aus einem Korb heraus. Der Papagei fliegt Hiob auf die Schulter

\section{KAMMERJUNGFER}

trällert, $a b$

Das ist die laue Sommernacht -

Die verschwand und seufzt aus

Einer tiefen Erdspalte.

Wässert Zungen, säuert Tränen -

Hinter einem Nachtlicht flicht und spinnt

Ihr Netz die blonde Haarlocke -

Fängt die Helden gefahrengezogen . . .

Hгов

Da dacht' ich doch, sie wäre eben hier?

zeigt auf die Tür

Eine Seele für die Jungfernschaft erhandelt -

Von einem Mann zum andern geschlüpft.

Und verläßt den Schädel, wenn er leergefressen,

Hiob deutet auf seine Stirn

Hier, wo sie nistete, im Fliehn

Noch, hat sie schnell ein Ei gelegt,

Aus dem sie verjüngt wieder, ein Phönix, hüpft. -

Keine Sonne will ich aufgehn haben,

Keine Himmel türmen, mit

Luftschlössern drin, davor Sphinxen

Konversieren! . . 
Papagei mit einem Satz anf den Kopf Hiobs, welcher auf und $a b$ geht

Wehe dem Jüngling, den sie zu vergeistigen sinnt, Bis er mit meiner Zunge zu reden beginnt.

falle in einen Stuht

Dem Haupt des Schöpiers einst.

Entsurang die Schöpfongsmutter,

In SchoB verbergend heimlich dessen Welt.

Papagei zaust ith an den Haaren.

$\mathrm{Ei}$ - ei mein Kopf!

Wohin im Hui?

Ei Horror vacui!

singt

Wie verdrehte mich die Liebe,

Seil in diescm leeren Haus

Von einem Frauenzimmer eine sanfte Stimme,

Sie zu suchen, mich gerufen hat

- Mich ein Labyrinth vexiert.

Aus dem ein Echo neckt,

Mich in kreuz und quer ein Lufthieb schreckt.

Wie's in den Wald ruft, so schailt es heraus.

Ich schelt: sie, sie fopnt mich and kommt nicht heraus.

Weil im Augenblicke schneil

Sie sich verwandelt durch irgend eine Hintertiur,

In ein Wesen das - ich selber bin!

\section{ANIMA}

hinter der Tür singt

НІов

hört nicht, spielt mit dem Vogel, lockt ihn auf den Finger

Was ist dem Mann - ein Zeitvertreib?

Papagei

ahmt die weibliche Stimme nach

Anima - deine Seele, dein Weib.

Нгов

Meine Seele!

Thre Unart oder Flucht oder wie ich's

Benennen soll, läßt mir zu denken

Übrig, daß . . . aber . . .

Welchen Namen nennt der Mann sein? Heh?

\section{PAPAGE}

Ach und Amen - Mann ein Weh!

Papagei springt Hiob wieder auf den Kopf, krault ihn zutraulich

HIOB

Das hinterhältige Weib ist mir zu Kopf gestiegen -

Spricht mir nach dem Mund

Sieht mir aus den Augen

Holt mich aus. Höhlt mich aus!

schüttelt den zudringlichen Gast, der sich an seine Ohren hält

Wie ein Kürbiskopf bin ich in Kurzem,

Der in der Grube mit seinem Geisterschein

Verwesen muB.

der Vogel macht sich auf Hiobs Kopf breit und bläht sich dick Hoffnung oder Niedertracht,
Du wirst zu schwer!

$\mathrm{LaB}$ mir die Besinnung,

$\mathrm{Daß}$ ich dich ertragen kann.

Ich fasse dich!

Hilfe!

leiser

Das spricht sie ja? - Wie ...?

ANIMA

echot

Ich kann dich nicht erleichtern -

Verbunden sind wir!

Ewig - Eins.

Н1ов

Aber beim Himmel oder der Hölle!

Sag doch noch - wer du bist!

ANIMA

echot

Anima ist's, dein Weib! Deine Seele bin ich.

Нrов

Weg ist - ich bin - und was bleib - ich?

rüttelt fassungslos wieder an der Türklinke

Ich hatte ein Weib,

Sie war meine Welt!

mit Tränen

Den Rand des Globus, meint' ich

Zu umfangen, da verschwand mir der

Boden unter den Beinen und

Meine Herrschaft hängt wie eine -

Schweinsblase in der Luft!

Horror vacuil

gefestigter

Blieb's auch nur im Entwurf.

Es war doch meine Welt!

schwindlig, stolpert

ANIMA

hinter der Tür, sanft

Wer sich nicht vorsieht.

Sich vermißt,

Kann den Kopf verlieren!

$\mathrm{H} 1 \mathrm{BO}$

verärgert

Kopf oder Welt! Eins und 's andre!

Man zieht mir ja das Wort

Aus dem Mund!

Ich möchte glauben, man lehrt

Es mich erst!

Wie ein Schwamm Essig saugt,

Wiedergibt ohne was zu schlucken...

Hiob wendet sich empört von der Tür ab. Nachdem seine mühungen, dort Einlaß zu finden, vergeblich geblieben

ANIMA

leise

... Der freilich

Mich nicht bewirten sollte,

Der Essig gab und Wein dafür wollte. 


\section{ZWEITER AUFZUG}

$\mathrm{HIOB}$

flüshtet sich, um allein zu sein, in die Badekammer, wo Herrenund Damenwäsche zum Trocknen auf Stricken ausgespannt ist. Turnt sich auf die Fensterlücke hinauf. Draußen stürmt's und blitzt's. Will sich hinauswerfen, bemerkt etwas auf der Straße Elemente! Gielst euch aus, ihr Himmel!

Flutet, überschwemmt die aufgeregte Brust!

Ein Hund... Her!

Ein trewer Hund...

Der letzte Trost, wem Menschen

Hassenswert.

\section{DRR PUDEL}

läuft durch den Flur, ôfnet die Tür, springt Hiob schweifwedelnd an

Wauh ... Wanh ... Wauh,

Der Hund hat eine scharfe Nase.

Ich bin ein Psycholog!

Schau . . Schna . . Schnu,

Herr Vetter sucht Frau Base!

HERB KAMTSCHUKMANN

wickeli sich aus dem Hundefell

Verzeihen Sie die närrische Verkleidung -

Ich bin des Pudels Kern!

Sic sind ja menschenschcu geworden.

zeigt auf den Flor

Das gute Mädchen da, indes, jagt

Ejuen Hund nicht yor die Tūr,

Bei diesem Hundewetter - !

Hut $a b$ vor einem Mann,

Dem die Empfindung wühlt in Nier' und Herz.

Wenn das einmal erschlafft, - Kopf ab dann!

Zwar weist die Forschung nach: das Herz auch

Noch ne Weile nach der Enthauptung eines

Armen Sünders voll Empfindung schlägt.

Bezeugt ward's nicht bis jetzt,

Ob's lauter angenehme war.

Trotz Aufziehn jede Uhr läuft einmal ab!

Wie ich schon zu bemerken in andrer

Form Gelegenheit nahm - ich bin ein Psycholog und stell' mit

Gutem Rat mich nützlich ein.

Der Advokat des Lebens ward ich nicht,

Das bringt den Patienten selber um.

Vertraun sie mir, dann hab' ich

Schon ein Recht auf sie!

Nicht wahr! Ansichten austauschen,

Ist nicht, Einsichten austauschen -

Sondern Aussichten eintauschen.

Kautschukmann sieht aus dem Fenster die Frau des Hauses zurückkehren die dann im Nebenzimmer sich beschäftigt. Er schnüffelt neugierig am Schlüsselloch. Hiob wendet sich bei der Bewegung im Nebenzimmer unmutig und gezwungen $a b$

Herr KaUtschummanN

Das schöne Weib!

Sie zieht sich aus!... Mich an! zu Hiob, der sich mit großer Anstrengung bezwingt, nicht nach der ominösen Tür zu blicken

Übrigens, falls ihre schwere Stunde,

Die schon im Anziehen

Eines Diligentium bedürfte...

ins Schlüsselloch mit großer Anstrengung, fast hineinkriechend

Ich beobachte eine Frau, die,

Kurz, einem Mann den Kragen

Umdreht!

HIOB

unwillig, abseits

... Und Sie als Arzt, der

Schwachen Freund, verhindern die

Gewalttat nicht?

HERR KAUTSCHUKMANN

Nur aus privatem Forscherdrang

Ich bitte, - ich bin kein Arzt.

in die Tür

... Mich interessiert das Experiment . . .

freudig

... Heureka! Ich hab's! . . .

Ihr Mittel! . . Ist entdeckt!

- Eroditis, die Eifersucht! Die Saat,

Die ein Bacillus incupiert,

Der Erotococcus, der HexenschuB!

- Den ließen mir noch übrig die

Kollegen zu entdecken! Der tut's

In eurem Fall, wo durch die

Leidenszeit Patient geschwächt,

Nicht mehr immun ist.

ANIMA

aus dem Nebenzimmer

Leicht kopflos wird durch Wissenschaft

Der Mensch, der ihr nicht in die Regel paßt.

Sie schneidet ihn vom Kopfe ab, der durch Ideen,

Durch Gottes- oder Liebesmacht verwirrt, verkehrt,

Für eine Zeit versonnen, dem kleinen Ich den Rücken kehrt.

Hiob sieht, wie Kautschukmann mit nassem Mund und gierigem Auge am Schlüsselloch klebt. Die Tür öffnet sich langsam, Anima tritt heraus, bleibt stehen; Hiob, durch den Anblick verrückt, verdreht das Gesicht. Hiob bringt den Kopf nicht mehr in die traditionelle Lage, greift sich entsetzt an die Ohren, reißt sich große Haarbüschel aus

HERR KAUTSGHUKMANN

springt zu Hiob, entsetzt

Lassen Sie mich Thren Puls fühlen!

Der Mann stirbt mir im Angstzustand!

Sie ersticken! Lüften Sie den Kragen!

Sie machen ja alles verkehrt!

Das Übel kommt von Ihrer schiefen

Auffassung von Dingen, die nicht

Gerade gehen! 
HIOB

brüllt

Man hat mir den Kopf verdreht!

Man hat mir den Kopf verrückt!

wimmert

Verrückt!

HERR KAUTSCHUKMANN

macht sich an Hiobs Brust zu schaffen

Das Herz ist noch intakt! Die doppelte

Zirkulation muß ich da unterbrechen,

zieht eine Chirurgensäge hervor

Damit die Infektion ihm nicht das

Herz noch lähmt. Kopf ab, beherzt!

Kopflos gelebt, läßt sich das Übel nicht halb

So schlimm an!

ANIMA

Mein Gott, wenn ich doch helfen

Könnte! Man kümmert sich nicht um mich!

Нгов

tanzt im Kreise herum, brüllt Kautschukmann weg, der mit seiner Säge herumfuchtelt

Ich weiß nicht mehr, wo mir der

Kopf steht!

Gehört der zu mir . . . ist's der?

Sie sind mir der Nächste . . . das

Ist . . ich muB Thnen an die

Gurgel!
Ein vorurteilsloser Geist mich heut' als Weib nahm, Mich entzaubert und ich helfe nach!

Hion

Der Teufel! Er zaubert wahrhaftig!

Und mutig mit Küssen und Schwüren beschwört er sich Anima.

Oh, offene Hölle! Die flüchtigste Hexe! Vertrag schließt sie, ergibt sich;

Verwirrt, errötet ihr Busen und Nacken; sie öffnet ihr

Herz,

Sie lüftet Geheimnis und Röcke; und gesellt sich im Bett

Hausfraulich der männlichen Autorität . . .

Wie wird mir da? Ich bin's nicht, wer dem Antagonisten gleicht,

Sich dorten niederläßt und zeugt dann! . . .

ANIMA

fällt wie ein reifer Apfel vom Fenster herunter, kaum bekleidet, mit dem Sitz Hiob auf den Kopf. Dieser fällt ab mit AnimaHiob stirbt. Herr Kautschukmann stellt noch ihrer Tugend vom Fenster aus deutlich nach. Anima vorwurfsvoll

Aber nein! - Mein Herr Kautschukmann!

PAPAGEI

Aber mein Herr Kautschukmann . . .

ADAM

milde

Zu hoch hast du dein Weib

In den Himmel versetzt.

Erst da sie fällt, kannst du ibr auf

\section{Den Boden sehn.}

Adam zieht einen Vorhang herunter, der Haus, Garten, Hiob und Anima verdecht, auf welchem zehn Herren in Trauerkleidung aufgemalt sind. An Stelle der Gesichter sind Löcher angebracht, aus welchen ein Schauspieler den Kopf durchsteckt, wenn im folgenden Gespräch die Rede an die betreffende Figur kommt

PAPAGEI

explodiert und zieht als rosa Wölkchen in den Himmel ein

ADAM

sieht ihm nach

Im Paradies einst raunte mir

Derselbe Vogel Warnung zu.

Mit Äpfellesen beschäftigt,

Hört ich nicht zu.

seufzt

ANIMA

kommt, an einem Apfel kauend, hervor

Der selige Hiob spitzte auch

Nach dem Apfel der Erkenntnis, ach ...

ERSTER HERR

vorlaut

Weil der Apfel wurmig war,

Ließ Eva ihren Mann erst drüber.

ADAM

Ruhig! Ordnung halten,

\section{(...) Fortsetzung im 3. Aufzug:}


Du kommst noch nicht dran!

Alle der Reihe nach.

Da mußt du erst den Kopf oủrchstecken.

Aber mit den Beinen nicht schlenkern,

Sonst bricht die Wand ein.

durch die Bewegnan wird der Kopf Hiabs vor die Wand gerolli. Anima beugt sich entsetzt dariber, veriient fast den Verstand

\section{ZWeiter Herr}

Frau Sphinx, der schlecht gelohnet ward,

$\mathrm{DaB}$ ihresgleichen den Philosophen auf die Welt gebracht -

Seinen Kopf vor allem andern - auf den Mist,

Der Rätsel gab - Fraı Anima wird sie jetzt zubenannt.

Nun mangelt's ihr an Phantasie,

Ins Reine nit sich selbst zu kommen!

Drittek HeR

Der göttlich̀e Wahnsinn war der Schaffensgrund.

\section{VIERTER HrRB}

Man überrede die arme Verführte,

Thre fausse-couche wieder einzunehmen!

Hoffen wir, daß sie die noch einmal austrage!

\section{HERR KAUTSCHUTMANN}

schüchtern vor

Die moderne Naturwissenschaft

Wird helfen!

FÜNFTER HERR

Schamhaftig geworden in den Kinderschulen,

Wegen ihrer Abstammung,

Beschränkt sich aufs Analysieren der Schöpfung,

Ob's nötig war.

ADAMI

zieht Hiobs Körper unter der Leinwand hervor und setzt den Kopf wieder säuberlich auf. Mit bösem Blick auf Kautschukmann

Der Arzt erfand die Krankheit,

Der Patient bezahlt die Rechnung.

SECHSTER HERR

zu Hiob, der mit ausgebreiteten Armen vorne liegt

Der Tod, der mit dem Weib

So recht aufs Kreuz dich traf,

Reißt nun kein Höllenloch mehr auf mit Pfnausen und Kuranzen.

\section{SIEBENTER HERR}

zum sechsten Herrn

Im Höllenloch ein einziger Strahl

Brach noch in tausend Farben Licht!

Die Umnachtung fällt,

Und weicht der aufgeklärten Zeit.

\section{ACHTER HER R}

Der Allzutag wird nie mehr Nacht.

Friß, Phönix Menschheit, dies und stirb!
ADAM

leise, Hiob betreuend, legt eine Handvoll Erde auf seine Brust

So eine Menge Blumen aus einer Schaufel Erde.

Auf daß die Erde leicht dir sei!

ANIMA

Ist er tot?

\section{ADAM}

ruhig

Nein! Nur sein Kopf sein Herz und andres ist verschieden.

\section{HERR KAUTSCHUKMANN}

plärrt

Die Menschheit muß in die Höhe

Gezüchtet werden!

Ehereform, Ehereform!

Vor den Augen der Gelehrten

Vollziehe sich die Vereinigung!

NEUNTER HERR

Die Wissenschaft, die nicht gereinigt durch den Filter Geist ist,

Wälzt sich über Leben und Tod und macht beides unrein!

\section{ZEHNTER HERR}

kräftig

Ich glaube an den Genius der Menschheit!

Anima - Amen!

\section{ADAM}

milde, dreht das Bühnenlicht ab

Ein grïner Schirm ist der gute Glaube!

Den wehen Augen verschleiert er das Licht der Welt.

Das einzige Gute, das ich noch tum kann,

Ist das Licht auszublasen,

Damit es nicht brenmen muB.

mit Anima weg

\section{ANIMA}

im Dunkeln

Hiob konnte vielleicht nur das schwere Kreuz fühlen.

Ich habe mit eignen Augen gesehen,

Wie man mich hier mit Schande bedeckt hat.

Vielleicht verleumde ich mich selbst nur -

Und Anima, die Hiob das schwere Kreuz auf die Schulter legte,

Ist-Eva. 


\title{
Text XXIV: „Vom Bewusstsein der Gesichte“ (Essay)
}

\author{
VOM BEWUSSTSEIN DER GESICHTE
}

(Vorrede zum nOrbis pictusi)

Gott ist nicht einer, aber alle sind, Alles ist göttlich... Seht zu: dem heiligen Chassydim, der Elohim ausklärt: einem heiligen Franziskus, der mit Steinen, Wesen, als mit Seinesgleichen spricht: Ekhard, der die ganze Welt vergottet; Swedenborg, der selbst mit Verstorbenen lustwandelt und die Welt im Bewußtsein als Arcana coelesti$c a$ fand; der heiligen Theresia, die Gott als ihren Mann umfing; mehr staunet noch über Maria voll der Gnaden, die Gottes Menschenmutter wird! Ist es möglich, daß Leonardo mit einem Lächeln eine Welt besiegte? Ist es Wunder, daß aus Mozarts süßer Kehle ganz Österreich, mein geliebtes - sang? Sicher ist es auch, daß Columbus Auge unsern Horizont um eine Welt vorrückte; dann ist es auch begreiflich, daß Walt Whitman voller Andacht vor einem schwachen Grashalm kniet: Denn jedes kleine Kind in der Wiege mit der Puppe spielend, wird Euch bedeuten, daß dem Sinn alles Göttliche Erscheinung ist, und es ergreift mich so heiliger Zorn: Nennt Ihr den Wurm, der die Verwesung unterbricht, Wurm nur; Kohl, der Wiege eines Schmetterlings wird, ruppigen Kohl nur! Sternenlichtstrahl, der dramatisch aus der Finsternis hervorbricht, keusch in die sich wieder schwingt, - sieben zerbrochene Farben nur, weil $\mathrm{Thr}$ ihn zerlegt und sieben zählt!

Ihr verkuppelt Schwefel und Salpeter, die vermählt Feuerwerk und Volksfest sind mit dem tủckischen Rohre gar, das im Menschen alle Freude mit dem Leben tötet! Ihr nennt Zeit, was Traum ist, und nur Raum, was Phantasie ist. Den Tyrannen aber, Euern Zweck, den selbstgerechten - Euern Gott, weil Euch nicht Wurm und Blüte, Stein und Licht und Mensch bewohnt von Genien mehr ist. Jagt Ihr Eure Genien ins chimärische Nichts, wo das Göttliche ersticken mußte, faßt mich solcher Zorn, daß ich Euch zur Vergeltung wünschen möchte bei der Wiederkehr der Seelen, daß $\mathrm{Thr}$ in ein goldenes Kalb verwandelt würdet; weil Ihr Gras vorsätzlich niedertrampelt und nicht wisset, wie es Ochsen göttlich ist! Aber Künstler, halt an Dich wie der Landmann, mit Geduld, der im Herbste Samen sät, wenn im Frühling erst Blüte wird. 


\section{(...) Fortsetzung im hinteren Abschnitt:}

ICH: Wie weit hat die Barbarei, das ist jene Trägheit, die wie ein Lindwurm in der Erde haust, über uns Macht? Doch nur soweit, wie man ihr aufmacht und die Tür nicht gleich schließt. Träge, trotz rasender Frohn, sind wir fünf Jahre lang gewesen, denn auf der Erde lebet jetzt weniger wie zuvor; und die Blüten sind farbloser geworden und die Singvögel entflohen. Und die Trägheit heißet also die Verfluchung! Und die Arbeit, sei ihr Sinn das Leben, die Beseligung. Wählt Thr Leben oder Tod?

ALLE (sich umarmend): Lieber schaffen wir schon, und lebendig!

ICH: Nun, so wären wir zum letzten Mal ein träges, indolentes Sklavenvolk gewesen! Solange der Zweck uns regieren wollte, da verga $\mathrm{B}$ er, daß die Zukunft nicht: mit der Zeit, sondern von den Erdenkindern ewigerschaffen wird. Wollen wir, daß die Gegenwart einmal sich verwurf sich das Genie des Lebens nimmt, so lasset uns in der Arbeit unsere Trägheit animierend ein rauschendes Hurra dem überwundenen Zweck in die Ohren lachen! Und jubeln in allen Schützengräben, Kasernen, Fabriken der Welt zu einer uberall festgesetzten Stunde, in allen fröhlichen Lauten der Welt, mit allen Geräuschen von Sirenen, Hämmern, Hörnern, Nageln, Nieten, Schlossern, Feilen, Pfeifen, Lachen, Brüllen, Heulen, Knirschen von Winden, Gestängen, Zügen, wie Euer Handwerkszeug grade ist und wie $\mathrm{Ihr}$ es heiter machet: die Liebe die Genien, unser Leben, das sei unser Recht! Weil wir alle ebenso nimmersatt vom Recht und Unrecht weinten, daß wir hungrig sind, also statt der Steine laßt uns backen nahrhaft Brot, statt des toten Glaubens sinnlebendigen Wein schenken, statt der grauen Paradiese unsere grüne Erde laßt uns lieben, statt das Wort voim großen, unbekannten Gott uns vorzuleiern, laßt uns unsere Engel selber sein! Wieder Alles endlich göttlich sehen; Wollen wir dem Gotte, wenn wir ihn wahrhaft anbeten, nie mehr Grenzen ziehen; laßt uns unsere Beine grade, daß sie uns überall herum im göttlichen Land spazieren tragen! Laßt uns unsere zwei kunstfertigen Hände gesund, die ins göttliche Wesen überall uns verflechten! Lasset unsere Ohren überall aus der Erde Götterworte vernehmen! Unsere Augen alles drin sich göttlich widerspiegeln! Und die Nase Blumengötter Nähern riechen. Und den Unrat aber frühest wittern, wo der Ungott ist, der die Erde dazu macht; früher als er unsern blödern andern Sinn sonst gewahr geworden wäre als Spielverderber!

Lachet, Amen!

Preise, du Mund, aber als Letzter Heimat, Vater- und Mutterglieder, die alles Anfang und Ende sind. Nun ist die ewige Verfluchung begraben, ihr Zweck erfült, wir sind erlöst. Kyrie eleison! Pan ist auferstanden. Jesulein und die Genien und Feen! Jetzt will ich Euch das Buch der Welt aufschlagen. Und es sind keine Worte, lauter schöne Bilder drin.

Werft den Stein weg, vielleicht hat Euer Lachen den Himmel bewegt! 


\title{
Text XXV: „Der brennende Dornbusch“
}

\author{
PERSONEN MANN \\ FraU \\ JUNGERAU \\ MUtTer und KNABE \\ MäNNER \\ WEIBER
}

Zimmer der Frau, große geteilte Fenstertür, durch welche Mondstrahlen einfallen, so, da $\beta$ man auf das Dach hinaussehen kann

FRAU

in weißem Bettlaken, zum Schlafen gekleidet, so langes Haar, daß es am Boden in Ringeln nachschleift. Sie kriecht geisterhaft aus den Bettüchern hervor und richtet sich gegen die Lichtstrahlen auf, elektrische Helligkeit des Mondes

\section{FRAU}

Ich träumte, ein Karren wär heiß gefahren - schleudert mich zum Himmel auf. Es drückt nichts mehr nieder mein Gesicht im Schlummer. Um zu schlafen, mich zuviel dürstet; $z u$ - trinken!

sie geht zum Glockenzug - vergißt wieder!

Wo kommen die neuen Strahlen her? Die zogen mich, wecken aus allen Kräften. - Meinen Füßen widerstand ich nicht mehr. Ich friere, sieht mich wer?

lauter

zur Tür hinaus

Mein Rock und mein Hemd ist nicht hier, geben Sie es mir herein!

Sie schlafen immer noch und ich wache. sitzt frierend im Stuhl mit offenen Haaren

Hängt die fruchtlose Wärme des unklaren Gestirns überall über mir! Mann im Mond, - dreh dich um, schau nicht her. - 
Deine Ausstrahlung flößt Kräfte ein solchen, die im Stiegenhaus mir nachsteigen und aufs Zimmer kommen.

Herr Adernrot gab mir einen Backenschlag.

Herr Finstergesicht wünschte mir einen guten Tag.

Ein Blümchen pflückte mir Herr Lendenkraft, was liegt mir an der gesamten Schlafgenossenschaft.

man hört unten das Lachen der betrunkenen Liebhaber. Sie wäscht sich die Hände im Lavoir auf dem Eisentisch und geht zum Fenster, winkt

Komm auf mein Bett, Schatten, sollst mir liebes Wesen sein, - pfui, - eine Katze schwarz wie Pfeffer, warf sie der Wind mir zum Fenster herein.

sie öffnet die Glastüre und geht aufs Dach

Kommt er noch, kommt er? -

Immer wieder die Bangigkeit in aller Natur, vom Dach zum Himmel hinauf. Alles wartet auf ein Aufatmen. Meine Augen hängen an der Sichel, die meine Schonzeit liürzt.

Am Tage bin ich ein Zweifelswesen von Menschenähnlichkeit.

Heut nacht bläst mir ein Mann den Atem ein und glaubt an die Gestalt.

oben Mondlicht wandernd

Wunderbare fremde Männerart,

die Sterne in Kreisen sah

und Schatten und Licht $z u$ Freundschaften flicht.

Wundertätige Männerart,

die aus Gespenstern sich Gebärerinnen schuf.

Nicht lange ist meine Stunde und schon nah! Wie kurze Zeit darf jedes Ding nur blïhen. Schon will des Mondes Licht erlöschen.

Unendlicher Genuß! Bald nimmer wünsche ich mir etwas. Keine Wolke ist mehr.

Dem fiebernden Wind setz ich mich aus, bin herrlich eingesäumt von Haarstrahlen, am Rückenrand, ordentlich wie Wasserkämme laufen sie über meine Beine hinab und verschwinden in der Erde.

sie sieht jemanden unten schleichen, erschreckt und erfreut, sie winkt ihm; eine Tür schlägt plötzlich auf, der Mann gleitet lautlos herein. Brennende Kerze in der Hand

FraU

bevor sie ihn sieht, singt

Ein alter Mann hielt Winter lang einen Vogel.

Als es Frühling war,

litt es nicht länger den Vogel,

daß er vergaß zu singen gar.

Der Alte sparnt ein grün Tuch über Vogelbauers Eisenstäbe;

noch sang nicht wieder froh der Vogel vor dem Alten.

FraU

zum Mann

Mein Singen hieß dich herzuhören?

Sahst du mein Gitter offen?

Du machst dem Kuckuck nach und fliegst ins fremde Nest.
Um nachtschlafende Zeit siehst du mich!

Wie schlichst du durch Mauer und Tür?

MANN

Ich rate, wie wußt ich's?

$\mathrm{Du}$ bist immer einsam gewesen.

Ich war nicht bei dir. Deine Stimme rief in der Nacht die Fremden und du meintest mich. Und du hast wahrhaftig Hunger und Geiz auf Liebeswerke und so kam ich herauf zu dir.

FRAU

Du - dreh dich zu mir! . .

Warum bist du nicht gut mit mir?

Klar habe ich dich geträumt und weinend

erst im Morgengrauen gesehen -

Habe ich unrecht getan, daß ich dir winkte wie vielen?

Jetzt stehst du im seligen Glanz der Gegenwart.

Mein Wunsch mochte dich in der Dunkelheit herziehen.

Ich hungere vor Liebe.

Wenn ich nur mich erst dir hingegeben, soll durch deine reine Kraft allein ich leben.

... Meine Arme ziehen deine - meine Beine machen dich gehen.

Mann tritt näher, sie erschrickt

FRAU

Du machst mir ordentlich Herzklopfen. Meine Stimme

will sein deines Mundes Süße, meine Scham verdunkelt dein Erröten, -

Schläfert dich auf einmal?

Hilf - meine Ohnmacht fließt in deine Kraft herein. O weh!

der Mann nimmt ein Tuch und umhüllt sie ganz, daß nur ihr Kopf sichtbar ist

MANN

leise

Mach zu deine Augen,

mach zu deine Wunden,

ich hab dich gefunden.

Mann geht zögernd zum Ausgang, es wird finster, sie nimmt ihren Leuchter vom Tisch, um ihm zu folgen, die offene Tür verlöscht ihr Licht

FrAU

$\mathrm{Du}$ - laß mich nicht aus, nicht allein - o Herr.

leise

Wie ich von dir die Augen wende,

kommen langsam manche Zuständè.

MaNN

wird wieder in der Türöffnung sichtbar

Am Himmel leuchtet der Morgenstern,

die Nacht her, streift ich aus weiter Fern!

Rief mich dein Glaube zu dir!

Darf nicht fürchten schwächer zu sein,

wo ich nun war dahier. 
FraU

reicht die Hand zögernd nach

Greif mich mit deinem Finger an,

damit ich noch dir glauben kann.

Da wollt' ich fragen dich,

bleibst du bei mir?

Gehst du mir heraus

und läßt die Braut in der Versuchung sein!

Meine Brust ist krank,

wie eine Blume in der Lichtlosigkeit.

Gib mir deine Hand noch einmal, Liebloser.

Du - laß mich noch einmal bei dir sitzen und die Augen

schließen und verschlafen alles Geschehene.

O Herr - ich fürchte mich, so schwach bin ich, so sehr

hänge ich an dir.

der Mann kniet vor der Frau und leuchtet ihr ins Gesicht, sie zïndet ihre Kerze an seiner an und schaut ithn an

FraU

Mein Liebster, ich hab vergessen, ich weiß nicht, wo ich war, sag du zu mir.

MANN

Du ziindest jetzt dein eignes Licht

gleichsam an meiner Liebe an,

dein Leib gibt ihm die Nahrung dann!

Des Suchens - wer du wärest - müde,

gabst du dich mir.

So bist du geworden.

Unḋ ziehe Ich mich jetzt leise, wie ein Schleier, von dir, So bleibst du?

Auf zur Geburt erwach' deine Seele, auf zur Geburt.

Und wenn die Trennung dir bange Schwermut macht, erscheint mein Bild gespiegelt in der Nacht.

Und deiner Eigenliebe Schein

wird wieder von dem zarten Nachtbild angeleuchtet sein.

Mann schlägt das Tuch ganz über ihren Kopf zusammen - sie will ihn sehen, er drückt thre Augen sanft zu, so, daß sie in die Knie sinkt, er flieht auf den Korridor

Frau, betäubt, wacht auf, folot ihm in den Raum, wo die betrunkenen Liebhaber schlafen. Männer erwachen, Frau sieht durch das Gitterfenster auf den Flüchtenden hinaus

\section{FraU}

halb schlafend - halb singend

Wacht auf, Schläfer!

Ein weißer Vogel fliegt im Zimmer, hat meine Augen ausgehackt -

Wacht auf, Schläfer!

Ein roter Fisch schwamm durch, hat mein Blut vollgetrunken -

Schlagt ein das Tor, Schläfer! Ein Wärwolf rannte aus, hat mein Herz abgefressen -

die Burschen werfen die Hüte weg - einer ist halb nackt, den das Mädchen freundlich ansieht, und mit ihm dem Haufen nachrennt. Sie nehmen Stöcke und laufen dem Flüchtigen nach - neben einem hohen Steindamm eine Treppe hinauf aus Eisensparren, stürzen - Aufenthalt - Flüchtling schöpft Atem wendet sich als Silhouette in der Höhe gegen die Verfolger um, wird matt - sie umringen ihn - unter der Bahnbrücke - ein Zug rollt vorbei - Signalglocke. Der Flüchtling nimmt die Gelegenheit wahr, um sich ins Wasser von der Höhe fallen $z u$ lassen. Man schießt ihm nach, ohne ihn zu erreichen

gleichzeitig mit den letzten Worten der Frau stimmt eine Heilsarmeemannschaft nach geistlicher Melodie folgenden Hymnus an:

Wer himmlischer Liebe Schlüssel hat, dem nie erstirbt die Stund.

Wie süß wird's ihm erst sein.

Ird'sche Liebe ist nur ein' Pein,

Ein Rosendorn am Pfad zum Gartentor von Golgatha.

Seele, bleib noch nicht da...

man sieht noch, wie sich das Mädchen mit dem Burschen von friiher wegschleicht

\section{ZWEITE SZENE}

Mondnacht. Zimmer wie früher, Frau, offene Haare, kriecht zum Fenster, das groß und voller Schatten ist, die sich ändern und den Boden mit Figuren überziehen

Frat

lockend, heiser lächelnd

O - komme zu mir in der Nacht.

$\mathrm{DaB}$ du mir sollst zürnen - bitte ich dich,

weil bei mir ein Fremder mit im Bette liegt.

Wär's besser nicht zu sein, als schlecht zu sein?

Wenn Schlechtsein schon den Anschein, Wirklichsein, erregt?

So lieb ich dich, wie du mich haßt.

So bin ich doch, wie du mich hast.

müide, krank

Nein, ich schlafe still allein,

Bettgewand ist mein Frauenhaar,

aufgespannt bin ich noch auf deine Hände.

Und legte mein Ohr ans Tor,

Und ein Vogel zog

- und höre dich?

Und legte meine Augen ans Fenster

- Und der Mond log -

Und umarme dich?

unruhig

Und der Morgen log nicht,

da ich mich sah allein und war eine Jungfrau wieder.

Weine Tränen in mein Haar.

Pause. Hebt die Arme wieder beschwörend

Ein Mädchen sagte dir einst ins Ohr -

Hab mich dir in Ehren gegeben -

Muß nicht von dir mir Ehre wiederkommen?

träumend, sinnend

Was ich verloren, mich finde ich wieder in dir?

Was ist finstrer als die Nacht, da ich nur neue Sehnsucht gebar!

Was ist weißer als die Nacht, da ich jetzt will Wunder tragen?

Und was ist Erlösen und was Genesen, 
Warum sind den Frauen süß die Rechten

und sind die Frauen süchtig nach dem Fremden.

Der Rechte erkannte -

der Fremde versuchte.

Wehe meinem Leib!

schreit wieder auf, angstvoll fragend. Man sieht beide Zimmer

\section{MANN}

im anderen Zimmer, mit fremdem Ton singend ohne Bewegung, weißliches Licht, offene Tür, die jetzt Licht einwirft, Lichtstrahlen kreuzen und suchen sich aus den zwei Zimmern in der Mitte der Höhe

Es schlief das Wassertiefe,

Es stand der Berg schattenleer

Und es war keine Zeit

Und da hörte kein Tier

Und da wärmte kein Feuer

Und verbrannte kein Flammen,

Als keine Liebe war.

Und wieder . . .

Lichtstrahlen heben sich und spielen und treffen sich wieder zur Ruhe

Wasser rauschte Wasser nach,

Und Berg verfinstert Berg.

Zeit $z \circ g-$

Und das Tier schlug den Menschen und fraß ihn und spie ihn.

Und Flammen schlagen rote Wunden,

Wo Liebe ward süß Mann und Frau.

der Mann ruht auf dem Lager, starr und wendet kein Auge von der Frau. Lichter verschwinden langsam im Zimmer der Frau, sie atmet kaum hörbar und wird schwach. Das Folgende spricht sie furchtbar traurig, voll und warm

FrAU

wankt zur Tür

Von Liebe aß mein Elternpaar; davon ward ich ein Mensch. Du Mensch! Der mich erkannte.

Hilfe... Fallen! . .

sie fällt nieder

MANN

Mach dich Hoffnung aufstehn! Bald gehst du aus dem Hause.

Wie du dich abhetzt, so schmilzt die trübe Lampe hin, die solcher Not das Wehtun, dem Flackern Leben borgt.

Die Braut wird in der Kammer den Riegel aufgehn sehn.

Schon bleicht die Lebensfarbe!

Flügelschlagen das du selber bist, bläst an den Docht.

Das Feuer fragt, wo soll ich mich denn hintun!

Und legt sich in die Asche.

Schon seltsam und untraurig...

FRAU

... schließt über mir Tagesschein.

\section{DRITTE SZENE}

Szene im Wald, Frau im Hemd, krankes Gesicht, unbewußt eine bestimmte Richtung suchend, weißer Boden, Baumstämme schwarz, Himmel schwarz, kein Licht außer der Reflexion des weißen Bodens. Männer und Heiber

\section{FRAU}

jammernd wie eine Gebärende

Weh mir -

er lebt mit meiner Kraft.

Irgendwo.

Weh ist mir -

ich bin schwach.

Als er bei mir war und ich hielt den Saum, fiebernd wich ich zurück vor ihm.

Du verführst mich, wohin?

zornig, schreiend, langsam höher

Und da ward er durchglüht und durchleuchtet auf einmal und mein warmes Blut sprang in mir,

mich fror und meine Zähne klapperten.

windet sich entsetzt

Fort ron hier -

Unseliges Lager . . .

Unraststätte!

Opferstall.

\section{Alter ManN}

hält sie für eine kranke Lügnierin

Wir suchen die Spur,

wir gehen im Kreis.

Mondeshelle Flammen wehen leis.

Mit Laternen durch den Dunst

durchhellen wir den Forst.

Scheuer Geier würgt im Horst.

FRAU

verzückt

Allüberall eine Menschenstimme - Du -

Irgendwo hör' ich deinen Anruf -

Ein zWeiter alter ManN

Wix suchen den.Mann,

der eine Frau verließ.

Ein jagendes Tier schrie.

sie schlagen an die Bäume, um ihn aufzuscheuchen

FRAU

Schau, er faucht mich an aus den Dörnern!

Er wacht auf zum Geschrei!

Seht doch!

- Wie Wasserdonner immer tosender -

Umher Umarmung!!

Das Gesicht des Menschen -

Du im Traum dein süßer Geruch . . .

Dein feuerfarbener Kopf im Sonnenmantel erstickt?

EIN DRITter ManN

leise

Ein Blitz zitterte und äscherte ein die zahme Herde. 
FraU

Flutender, du umhorchst mich ...

Weh!

Er brach ein.

In mir weidet er.

Erstes Weib

Hört, was sie spricht;

Die Morgenwärme steigt herauf,

Der Sonnenstern dringt lichtklar durch den Dampf.

Irre wird sie in der Natur -

Frat

Fort, fort mit leisem Tritt,

$\mathrm{DaB}$ keiner seine Nähe scheucht.

Wie geschieht mir Gutes von dir!

Ich sende dir, ich sende dir meinen Brautwunsch ent-

gegen!

schreiend

Bricht mein Auge -

Bin ich gestorben?

Da ich sein Wunder verspür,

Friedhof wird sein mein Hochzeitsbett und Weinkrampf

Hochzeitschrei.

sie stürzt in der Mitte der Bühne und bleibt wie ein Bündel liegen, regungslos

\section{ZWEITES WEIB}

Der Engel leitet sie,

durchweintes Haar bedeckt ihr Auge

und sie sieht ihn?

Ihr Greist ist verstört.

Ein Engel leite sie.

rastlos

\section{DRITTES WeiB}

Nach welcher Seite wenden?

Drei Wege offen,

Gehe jedes einen.

drei aus dem Chor, jeder geht getrennt von dem andern einen Weg; denen tun sich drei Bilder auf. Beschreibend, langsam lauter, jeder nur so lange beleuchtet, als er spricht

\section{ERSTR ALTER}

Ich sehe einen Mann sich härmen am Boden.

Sein Barthaar besudelt im Staub.

Sein Herz klopft laut.

Er dürstet, weil du gereicht hast den Schwamm mit Essig_getränkt.

\section{ZWEITER ALTER}

Ich sehe ihn undeutlich!

Er nahm mit dir den Leib aus einem Kelch - und du hast gelästert.

Ich sehe wieder -

Rufen Irrende?

Ein sehnendes Herz.

Ist er es?
Dritter MANN

Ich seh einen metallenen Mann an ein brünstiges Tier gesperrt.

Habt ihr wohl gesehen, also, daß das Tier aß von seinem

Herzen.

Er regt sich.

Seine gespannte Kette zerklirrt.

Seine glitzernde Hand siegt im zweifelnden Kampf. Sein metallener Ruf exweckt das Weib, das aus dem Balg des Tieres tritt.

Frau, die mit dem Fuß die Schlange tritt.

dein Herz schwellt sich in Mutterfreud.

strahlendes Licht. Unruhiges Getöse, Männer und Frauen greifen nach offenen Händen, rufen, schluchzen, man sieht momentan viele offene Hände

$\mathrm{CHOR}$

Männer zu Frauen, unruhig, laut und leise

Ich sehe dich anders als sonst,

Du bist mir nicht mehr fremd!

Ich vergaß dich und sehe dich wieder liebend.

Dein Körper ist vielsagend geworden.

Was ist geschehn, daß ich Jahre neben dir lebte!

Und so oft du dein Herz geöffnet - ich war nicht würdig, $\mathrm{daB}$ ich einkehrte in dir.

Wie wird mir ...

Im Aufmerken wird lautlose Kunde mir und sonderbares Verstehen.

Bange Lippen.

Verlorene Worte kommen.

Fremde Welt, Freude, Seligkeit.

es wird langsam dunkel

CHOR

psalmodierend in clen Hintergrund gehend

Ich glaube an die Auferstehung in mir

Ich glaube an die Auferstehung in mir -

Ich glaube an die Auferstehung in mir -

es wird ganz dunkel. Man hört noch das Getöse der Stimmen während des folgenden Bildes. Später schwächer und undeutlicher werdend, Raum leer. Langsam fällt von oben Licht auf die Mitte der Bühne, man sieht jetzt an der Stelle, wo die Frau lag, ein Mädchen. Es liegt verzückt am Boden und spricht leise für sich, voll unterdrücktem Jubel. Dünne Stimme - die wie eine Vogelstimme anschwillt

JUNGFRAU

Aus dem Tal zieht die Lerche in das Himmelsheim. Ich möchte meinen Geliebten ungesehen mit den Armen umgeben, wie ein Strauch die neue Rose.

Ich bin so froh, seit er mich heimsuchte.

Warum sind nicht alle Menschen gut?

\section{VIERTE SZENE}

Mann und Frau gegenüber auf zwei Felskanzeln, im Dunkel des Grundes undeutlich der Chor, Mann abwehrend, Frau groß. Wogende palmenartige Gräser und Farnbïschel. Solange er spricht, weißes Licht, das mit rotem intermittiert, sobald sie antwortet 


\section{FraU}

Ein Bann geht von diesem Weißen aus.

Mein Leib ist ein brennender Feuerstrauch,

Du mein Mann. Nährender Wind!

Meine Brust zwei Feuerzungen,

Du, widerwillige Stimme!

Meine Hände heiße Flügel,

meine Beine brennende Kohlen -

weiß und rot - weiß und rot brenne ich;

im Feuerkleide langer Qual, in Scham recht Erglühte, brenne und verbrenne nicht.

Tritt ein zu mir, auslösche und erlöse mich.

\section{MANN}

Kreißende, hoffnungslose Wöchnerin!

Die vor Schwachheit nicht Austragen wagt!

Habe dazu keine beßre Zeit vor -

um dich nachher, gemach hinschauernd,

zur Ruhe zu legen!

Laß uns das Weh später beschwichtigen,

wann eins von uns müde ins

Linnen gerollt.

Angefacht ist schon was werden

möchte ein Licht,

anders als rauchend Feuer, drin das Auge übergeht.

Feuer brennt zu Asche,

Licht zuletzt ganz freundlich aussieht!

\section{FRAU}

erschreckt

Todsgestalt! Hast mir Fleisch, Blut vorgelogen!

Rasend kamst du in mir aufgezogen!

Sonne bleicht den Mond -

Eisiger Reif

Greift in mein Fleisch.

Greift in mein Fleisch.

Um mich der Mann, der mit mir rang,

der niederstößt jeden Gedanken,

niederschlug ...

Weichst mir nicht

aus Adern und Bein -

höhnisch

Reißender der mich ausgesogen!

Weh tust du Erlöser, Auflöser jetzt.

Kann dich nicht grüßen, lieber Mann,

der nicht annahm mich Opfer

in der stummen Angstpause!

O nimm mich aus der Marterwelt.

ManN

Wahrhaft bist du ein Mensch? Langhaarige!

FRAU

Warum bist du nicht gut -

Mann, der mich mit Wünschen niederrannte.

Ich weiß, du willst sein

mein Freier und Befreier, mir Unreinen, Ungekannten --

Und bist mein böser Feind

Und Kerkermeister!

sie zuckt zusammen - weinend

MaNN

Meine verströmte Liebeskraft, überall von dir aufgesaugt, nur in Spitzen - leise verdunkelnd, leise verklärend, rührt sie da dich, Fremdes, widerspenstiges Dugespenst?

Das Weib ist unschuldig.

Aber der Mann - in seinen Dornen einsamt der Friedlosigkeit Frost.

Zeitweise in dir still wie nachträumend.

Ausgeweint, umgewendet,

scheidend blickst du mir ins Gesicht...

Mürtterlicher Raum öffne dich!

Himmelsheimat, ziehe den irren Sohn.

Müde bin ich.

Weib, geh frei aus meiner Hand.

FraU

wirft den Stein, der seine Brust trifft

Ich kenne dich nicht mehr an.

MANN

Barmherzigkeit!

Du tust mir weh,

durch die ich abgelöset bin.

Ach sieh hier mein Leben im Opferblut entschweben.

Die Erde nimmt die Kraft kaum an,

die aus mir drang, die aus mir rann.

Du läßt mich nun zugrunde gehen,

An dir, die so ich losgemacht.

Im Todeskummer, wer ist da mein Trost?

Schwester, trockne meine Stirn!

FraU

fällt auf ihn und drängt die anderen zurück. Mit großer Liebe

Laßt mich.

Mein Mann soll unberühret sein!

Ich leide mit dir!

Geh noch nicht, Eilender von mir.

Sieh her, da komm ich schon zu dir.

MANN

Glaube mir, und deine Hand tut mit Versegnung verwachsende Wunde mir zu - Warum sind wir nicht gut!

\section{FÜNFTE SZENE}

Sterbezimmer. Mann, wund auf dem Bett. Frau über ihn gebeugt. Stellung der Pietagruppe. - Mutter und Knabe gehen durch. Knabe halbwüchsig

KNABE

Sag, was sieht die Frau mit starrem Blick? Und leise dir ins Ohr Mutter sag, voller Sünden sind, die so leiden? aufgeregt

Mutter, bist du ein Weib? 
Was du bish, verwirrt mich!

Ich leide mit der schönen Frau, ich möchte zu ihr.

MUTTER

0 weher Mutter Tod und ahnend Kindlein Wundern. Bewalre! Geh niclut hin und schau nicht hin, Wo die zahlen Blut und nicht einig werden.

$\mathrm{KNABE}$

Gib Frieden denen, die da zu Ilause sind!

Ein Grabhügel volì von Trauerleuten.

Ich steh am Tor.

Gott legt den Kopf in seine Hand und weint.

\section{MUTTER}

Ich kann es anders sehen?

Tin Dornstrauks brannte auf einmal.

Die Dürre schleicht dem Wurm gleich weg.

Gott läßt zu sich das Licht empor.

abgehend

CHOR

on der Wand stehend, Trazerhileidung

Ihr im Herzen ist sein Bild mit glühender Kohle aufgerissen.

Scheint sie ihm?

Lebt er noch?

Ich gab ihm einen Apfel in die Hand und die Frucht ist schon ganz brawa gewworden.

Er hat die Augen vor dem Unsichtbaren geschiossen.

Ich weiß, Sterbende sind Gute, sie nehmen Sterbens Not. der Lichtkranz hat sich mittlerweile, über der Hauptgruppe gebildet. Die Sonne geht unter

Gloriole - Frau und Mann sprechen im Schlaf, hoch, ganz fremd, so, daß jeder Ton ergreift

MANN

Lebe ich denn - Du und Ich.

FRAU

Verlorenes,

Vergessenes bespült mich,

verrinnt.

Weißgebrannt.

MANN

Grauenhaft war die Zeit.

Wunschlaufen - Opfertier!

leise sterbend

Und hinfallen in Vergessen!

FraU

Lautlos löst sich ein Gesicht.

Mann tot. Summen hört momentan auf. Lichtkranz ist gebildet, alle heben die Hände, geben Zeichen

CHOR

reiht sich in zwei Gruppen, halb singend

Und so starb ein Mensch, der sich begriffen hat.
MÄNER DES CHORES

Du bist mein stilles Hinschaun.

WeIber DEs ChORES

abwechselnd mit den Männern zum Bett

Du bist mein Erschauern,

du bist mein Licht,

du lauter durchleuchtet.

und ich kehre ein verborgen

und du wirst mir offenbar.

Ich aber verlor mich

- und ich erinnerte mich . . .

\section{CHOR}

der Männer

Vergessen Rufen ohne Ton.

Vergessen gnadloses Einmalsein.

Vergessen irdische Seligkeit.

\section{WEIBER}

Vergessen rinnendes Blut ohne Genesen.

Vergessen bebender Zähne hungernde Lust.

CHOR

Frage

Warum bist du nicht gut?

Warum bist du nicht gut?

CHOR

Antwort

Weil sein sie sollten,

im Schein verharren sie wollten.

\section{GeSAMTER CHOR}

Erzwungen, erscheint ein Gesicht, eine Welt dem Bewußtsein.

Und wieder löst vom Bilde, wo es haftet, sich das Erschaffne.

Als Wasser, Luft und Erde formt sich der Raum. Feuer brennt ihn ewig und verbrannte ihn. 


\section{Text XXVI: „Ich male Porträts, weil ich es kann“}

ICH MAIE PORTR ÄTS, WEIL ICHES KANN 196 I

Kürzlich besuchte mich ein Deutscher, der malt, weil es ihn freut, obwohl sein Sehvermögen sehr reduziert ist. Eine Handgranate im letzten Kriegsjahr hatte ihn auch sonst übel hergerichtet. Von seinem Regiment, das meist aus Jugendlichen bestanden hatte, sind bloß neun lebend und diese verstümmelt von Stalingrad zurückgekommen, einer davon völlig erblindet. Mein Besucher war ein schlichter Mensch, der sich nicht gegen das Schicksal auflehnt, und wenn ich bemerkte, da hätte er noch Glïck gehabt, machte es wenig Eindruck auf ihn. Gleichgïltig sagte er dazu, damals hätte er gewühscht blind zu sein, um die Reihen von Gehängten nicht sehen zu müssen, meist auch Ach zehnjährige wie er selber, die das Armeeoberkommando so für Fahnenflucht vor dem Feind zur Abschreckung der anderen bestraft hat.

Also war diesen Opfern eines bethlehemitischen Kindermordes nicht Zeit 'genug gegeben, um sich dem Milieu anpassen zu können, wofür in der Jetztzeit ein langes Leben kaum reicht.

In der Jugend hat man noch keinen Maßstab, der zur Interpretation der Umwelt dient, in die man mit der Zeit absorbiert wird. Wie relativ andererseits mag der visuelle Schatz sein, der sich im Verlauf eines langen Lebens im Gedächtnis aufspeichert, im Vergleich zu dem, was man erwarten sollte. Dessen wird sich so mancher hoffentlich

nicht bewußt, dessen Augen im Atter schwach werden oder gar erlöschen. Das Tempo der, Entwicklung dès modernen sozialen Mechanismus setzt das Individuum einer Úberfuille yon verwirrendsten, in Blitzgeschwindigkeiten auf es einstïrmenden Impressionen aus, auf welche das Bewuftsein nur partiell zu reagieren vermag. Vermöchte man es, man wïrde verrïckt. Der Prozeß, der in allen Gebieten - Politik, Wissenschaft, Technils und Wirtschan - das individuelle Schicksal ignoriert, vollendet sich in bestïrzender Weise ohne uns, so daß die Logik und noch die Ausgeburten der kühnsten Phantasie ad absurdum geführt scheinen. Niemand gibt sich voll Rechenschaft über das, was mit ihm geschieht oder was er tut. Man macht die Augen zu und stellt sich blind. Man nennt dies "gleichschalten“.

Man liest jetzt häufiger von geglückten Operationen an Blindgeborenen, die sehend machen. Wie in Cbereinstimmung sagen die Patienten, denen das Sehvermögen wie durch ein Wunder gegeben wird, daß sie die längste Zeit darüber nicht hinwegkommen konnten, wie häßlich diese sichtbare Realität einer gegenständlichen Welt vorerst für sie gewesen sei, welcher fast übermenschlichen psychischen Anstrengungen es bedurfte, sich in diesem Chaos von Licht und grellen Farben zurechtzufinden. Dieser Ersatz einer sichtbaren Außenwelt für ihre gewohnte, die sich organisch aus dem eigenen Sinnesbewußtsein, vornehmlich vom Tastsinn ausgehend, entwickelt, sei ihnen wie eine Fremdsprache vorgelkommen, die sie nicht verstïnden.

Dies beantwortet.zum Teil die Frage, warum wir hetute kein gesellschaftliches Leitbild haben, das vor allem dem Porträt über die leibhaftige Gestalt hinaus Sinn und Halt geben könnte. Dies, soweit es die Gesellschaft angeht, denn๋ für den Künstler bleibt der Auftrag ja dex gleiche wie zu allen Zeiten. Gleichgültig, ob auch die große Mode heute verlangt, daß wir alle trotz einer jahrtausendaiken Eríahrung aus rousseauschen sentimentalen Grüinden zum' Sansculotttentum zurückkehren sollen. Ich habe mich bereits des öfteren bei den. Theoretikern der modernen Schule der Malerei recht unbeliebt gemacht, weil ich vom Maler erst einmal verlange, daß er sein Handwerk erlerne, bevor érals Künstler gelten will, ebenso wie der Fotograf das seine zu lernen hat. Von einem Porträtbild wird ja in erster Linie nichts anderes erwartet als vom fotografischen Abbild, daß es nämlich den Auftraggeber, der aus irgendwelchen Gründen darauf Wert legt, verewige. Der Sprachgebrauch drückt hier mehr aus, als man glaubt.

Nun liegt es nicht an der Gesellschaft, sondern am Künstler, wenn der Unterschied nur darin gesehen wird, daß das Olbild handgemalt ist und die Fotografie auf der Platie entwickelt. Ich erinnere mich, solches in den Schriften von Kandinsky, Klee oder deren Kommentatoren gelesen zu , haben. Gewiß gibt es Epochen ohne Kunst. Die gesellschafh-

- lichen Energien werden anderseitig verbraucht, in religiösen Spekulationen, in Revolutionen, Wirtschafts- und Machtkriegen, im wissenschaftlichen und technischen Fortschritt, aber auch im aesthetischen Theoretisieren über Kunst.

Man stelle sich vor, eine Wachsfigur aus dem bekannten Panoptikum der Madame Tussaud wäre durch einen komischen Zufall in ein Museum geraten neben die künstlerischen Dokumente, die den Menschen darstellen, aus den verschiedensten Ländern und Zeiten. Wie viele Besucher wären da wohl imstande, ohne ihren Führer zu Hilfe zu nehmen, den Unterschied zwischen einem solchen Abguß oder einer Imitation einer menschlichen Figur und einem Kunstwerk zu sehen?- Gleicht nicht ein Konterfei dem anderen? In den Hauptstädten der Welt, im Westen wie im

Osten, gibr es eine Merige solcher Figuren als StandBilder, ohne daß. wir mehr darari meriken als eine Behinderung des Verkehrs.

Wenn nun gewisse Werke der großen Kunst ihren Glanz über lange Zeiten hinaus behalten haben, so mag es, wie im Falle des Hofporträtisten 'Goya, vielleicht die Indignation gewesen sein, die seine Kunst über jene seiner Zunftgenossen hinaushob. Mit ihm beginnt das moderne Porträt. Um näher zu unserer Zeit zu kommen - es mag die Resignation, die Desperation des Fin de siècle gewesen sein, welche der lyrischen oder magischen Poesie eines Porträts des Cézanne zugrunde liegt, der das Menschliche als eine nature morte sah. So sagt denn ein Bild, soll es' sich von einem Machwerk unterscheiden, nicht nur etwas über den Besteller und das Modell, sonderin auch über das Temperament des Schöpfers und noch über eine gegebene Zeit hinaus, etwąs, wofür den Zeitgenossen des Künstlers ein Organ fehlte, um es aufzunehmen. Je reicher nun die Aspekte eines Bildwerkes sind, je vielfältiger - so daß"selbst kommende Generationen irrs selben und gleichen Werk' sich wie in einem Spiegel selbst erkennen -, desto vortrefflicher ist die Bedingung erfüllt, die das Kunstwerk ausmacht. Das Verlangen nach Verewigung ist die menschlidhste Hoffnung.

Das Problem der modernen Malerei, ob das Vakuum der Jetztzeit zu füllen ist, wird vorerst im Porträt gelöst. Und wenn Ahnlichkeit, also ähnlich wem? - Fragt man sich so etwa vor einem Altersporträt des Rembrandt, der als junger Maler viel beschäftigt war, dann verarmte und vergessen starb - man weiß nicht, wo er begraben ist! Erst in der Goethezeit hat man sich wieder für seine Graphil zu interessieren begonnen, noch nicht für seine Porträts. Auch die freien und gelösten Zeichnungen seines Altersstils konnter 
spät in der $z$ weiten Hältte dès neunzehnten Jahrhunderts' noch für einen Pappenstiel yon einem. Sammler erworben werden, der sie Hamburg vermachte. Dem Klassizismus wurde das Leid in einem Menschenblick Picht sichtbar, es mußte wie bei Greuze eine Träne über die Wange laufen und eine pathetische Geste den 'seelischen Vorgang illustrieren, um Trauer auszudrücken. Noch hatte die Gesellschaftkein Organ erworben zur visuellen Orientierung in einer terra incognita, als welche das Phänomen Mensch uns zu gelten hat; dies besonders seit den Glaubensikriegen, die die geistige Unruhe schufen, aber in welchen auch das irrationale Wüten der Gesellschaft anhub. Die alten Götter wurden gestürzt, jedoch die Höllenpanilk nicht vermindert. Seitdem entledigt sich das Phänomen Mensch aller Bindungen, tritt die Herrschaft über die "Elemente und im Kosmos an und entblößt zugleich seine tiefsten, aber auch die tierischsten Möglichkeiten. Der Auftrag des Künstlers jedoch bleibt der gleiche: das Menschenbildnis.

So erübrigt sich eine Antwort auf die Frage nach Anzeichen zu einem neuen Realismus des Menschenbildes in unserer Zeit, denn das verführte mich sonst, den Gegenstandslosen am Ende noch eins auszuwischen, die mit ihrem Anspruch auf Alleingeltung den jungen Menschen mehr schaden, als sie wissen können. Ich bescheide mich damit, daß ich Porträts male, weil ich es kann und darin meinen Weg zum Menschlichen sehe, einen Spiegel, der mir zeigt, wann und wo und wer und was ich bin. 


\section{Text XXVII: „Von der Natur der Gesichte“ (Vortrag)}

VON DER NATUR DER GESICHTE

(Vortrag 1912)

Das BewuBtsein der Gesichte ist kein Zustand, in welchem man die Dinge erkennt oder einsieht, sondern ein Stand desselben, an dem es sich selbst erlebt.

In Gesichten ist Bewußtsein selber niemals zu begreifen, welche ein Bewegen, Eindruckwerden und Sichtbarsein, eine erteilte Macht sind und hervorzurufen.

Bewußtsein der Gesichte ist aber Leben selber, welches von Bildungen, die ihm zuströmen, wählt, und ebenso sich solcher enthalten kann, wo es ihm nicht gefällt.

Ein sich selbst Macht erteilendes Leben führt das Bewußtsein der Gesichte. Und in seiner freien Wahl aufgenommene Gesichte, ungeachtet, wie sie sich vereinigen, ausgereifte oder kaum wahrzunehmende, und auch was den Raum und die zeitlichen Umstände betrifft, völlig ungebundene, verbindet diese Macht derart, daß sie Einfluß auf das Bewußtsein zu üben scheinen in Allem, was als ihre Ordnung und Rang ihrer Sichtbarkeit hervortritt. Dieser Einfluß nach dem Eintreten der Gesichte in die Seele ist aber wirklich eher eine Äußerung des Bewußtseins, daß es ihrer gewärtig war, und ein Erguß

der Seele in die Gesichte; der Seele, welche nun beginnt die Gesichte leibhaftig zu formen. Der Stand der Aufmerksamkeit der Seele oder das Bewußtsein ist etwas Ähnliches, ein Harrendes, Wahrnehmendes, wie ein ungeborenes Kind, das selber der Mutter unempfunden bleiben kann, zu dem auch nichts von der Außenwelt hereinschlüpft. Und trotzdem, wovon immer seine Mutter erschauern wird, Alles, bis aufs Blutmal, dessen sich diese auch versehen haben mag, pflanzt sich ihm ein; und als ob es sich der Augen der Mutter bediente, Gesichte nimmt das Ungeborene auf, ohne selber faßbar zu sein.

Schrankenlos lebt das Bewußtsein und in die Dinge aufgegangen, wie eingewirkt in die Gesichte. So hat es mit dem Wesen alle Qualitäten des Lebens gemeinsam. Wie ein Samen eirnes einzigen von der Dürre lebend gelassenen Baumes die Fülle enthält, darin Wurzeln aller Wälder der Erde neu entsprossen sein könnten, so geschieht es, daß, wenn einmal wir aufhören selber und im Bewußt$\widehat{\text { sein zu }}$ sein, dieses von eigener Macht wach aufkommt und findet nicht mehr, wo es sein Haupt hinlege. Es gibt keinen Platz des Todes mehr, weil sich die Gesichte woh auflösen und zerstreuen, doch nur, um sich in anderer Weise wieder zu sammeln.

Denn achten wir mit der vollkommenen Aufmerksamkeit auf solche Rede von Innen und streiften wir durch die Schatten der Worte bis zu ihrem Quell heran, »da ist das Wort nun Fleisch geworden und hat unter uns gewohnt«, und entreißt der innere Quell bald heftiger, als schwächlich sich den Worten, worin er wie ein Zauber lebt, »mir geschah nach dem Worte.«

Nun, weil wir im Stande sind, unter Aufgabe unserer entgegenstrebenden Geschlossenheit solches magische Lebewesen zu empfangen als Gedanken, Ahnung und Relation; weil wir alle Tage sehen, da $B$ Wesen ineinander sich versenken, Lebende, Lehrende, Wollende und Absichtslose, so ist alles einmal in die Welt Gekommene, Mitgeteilte, Eingeflossene durch seine sich selbst gestaltende Kraft im Bewußtsein und im Selbstleben enthalten und bewahrt sich, wie ein Wesen hoher Art, vor dem Absterben. Man nenne dieses Wesen Ich, man nenne es $\mathrm{Du}$, je nachdem, wie man seine Regel und Unendlichkeit unter Absehen von sich selber und das eigene Dasein als darin Verlorensein betrachtet. Man lasse also mit sich tun, was von uns in Einklang kommen will. Ich glaube auch, wenn man neugierig von Stufe zu Stufe sich selber erhebt und kreisend so um die ganze Natur, als ein regelloser Mensch von der ganzen Welt mit der eigenen Seele widerbebt, also tue man neugierig auch mit dem Wort: Das Bewußtsein der Gesichte!

Das Bewußtsein der Gesichte wird nie ganz zu beschreiben sein und seine Geschichte rie zu begrenzen, weil es das Leben selber ist. Sein Wesen ist ein Strömenlassen und Gesichtesein, ist die Liebe, die sich darin gefällt, sich ins Bewußtsein zu betten. Beigefügt zu werden, ob wir es gehen lassen oder nicht, dies geschieht auf eine Eingebung, sobald wir von dem atmenden Leben gewinnen. Als plötzlicher Stand wird uns ein Gesicht, wie der erste Blick, wie der erste Schrei eines Kindes, das eben geboren aus dem Leib der Mutter fällt.

Was das entscheidende Kennzeichen von Leben ist, Wesenhaftes ist das Bewußtsein der Gesichte; Wesenhaftes körperlosen oder leiblichen Charakters, je nach der Richtung wahrgenommen, wie man auf seine Strömung hinsieht, die heraufsteigt oder abebbt.

In Gesichten, welche also eine Bewregung, ein Eindruckwerden, ein Sichtbarsein ausführen, welche eine erteilte Macht sind und willkürlich hervorzurufen, ist aber Bewußtsein nicht erschöpfend zu erfassen. Weil das Bewußtsein von den Bildungen, die ihm zuströmen, wählt und sich solcher willkürlich ebenso enthalten kann.

Bewußtsein der Gesichte beschreibe ich, was da ein Standpunkt eines Lebens ist und ein Hochstand dort, wie ein Schiff sowohl Hinabtauchen in die Wogen und Beflügeltsein in der Luft ist.

Bewußtsein ist die Ursache aller Dinge, auch der Vorstellungen. Es ist ein Meer, dessen Horizonte Gesichte sind!

Bewußtsein ist das Grab für die Dinge, wo sie aufhören, das Jenseits, in dem sie eingehen. So daß sie alsdann bei ihrem Ende in nichts Wesentlichem mehr zu bestehen scheinen, als meinem Gesicht in mir. Sie hauchen ihren Geist aus, wie die Lampe leuchtet und läßt vom Docht das Öl ziehen. 
In diesem Maße hat jedes Ding sich seiner selbst entledigt in das Jenseits, wie es mich anschaut. Ich bin davon Gesicht, das ohne Vermittlung des Traumes eingegeben wird. Wo Sie, Zwei oder Drei, in Meinem Namen beisammen sind, da bin Ich mitten unter Ihnen. Und als ob sich dieses mitzuteilen verstände, da wird mein Gesicht von den Menschen unterhalten, gespeist, wie die Lampe von dem Öl, von dem. Überflusse, der im Leben ist. Jetzt aber heiße man mich, solches auf natürliche Weise zu erklären. Es wird da sein, daß die Dinge für mich eintreten und sich von selber eingestehen; ich habe in Ihrer statt mit Ihrem Schein, mit Meinem Gesicht geredet. Mein Geist, Es hat geredet!

Ich suche, rate, frage: mit wessen Wärme begehrt wohl der brennende Docht das Öl, daß die Flamme auf einmal vor mir nun an Lebhaftigkeit zunimmt, im selben Grade, wie drüben sich mit ihr das Öl verbindet? $\mathrm{Mir}$ ist es vollkommen bewaßt, gewiß, daß ich es mir einbilde, was dort als Flamme brennt! Ist mir aber solches an der Flamme aufgefallen und Euch entgangen, nun möchte ich die hören, die klar sehen. Ist mein Gesicht nicht so: ich ziehe aus der Welt absichtslos etwas als Dinge empor. Dann aber werde ich nichts mehr sein, als eine, Thre Einbildung. Dann ist die Einbildung in allen Dingen das, was natürlich ist. Dann ist Einbildung Natur, Gesicht, das Leben. 
Text XXVIII: „An die Einwohnerschaft Dresdens“

AN DIE EINWOFNERSCHAFT DRESDENS

I920

Ich richte an alle; die hier in Zukunft yorhaben, ihre politischen Theorien, gleichviel ob links-2, rechts- nder mittelradikale, mit dem Schiefprügel zu argumentieren, die Ilehentlichste Bitte, solche geplanter kriegerischen Öbungen nicht mehr vor der Gegnaldegalerie des $Z$ wingers, sundern etwa auf den Schiebpiatzeen der Heide abhalien zu wollen, wo menschliche Kultur nicht in Gefahr komme. Am Montag, den 15. März wurde ein Meisterbilid des Rubens durch cine Kugel verletzt. Nachdem Bildex keine Möglichkeit haben, sich von dort zu retten, wo sie nicht mehr unter dem Schutze der Menischheit stehen, und auch weil die Fntente einen Raubzug in unsere Galerie damis begründen könnte, då wir ḱeinen Sinn für Bilder hätten, so fele auf die Künstlerschaft von Dresden, die mit mir

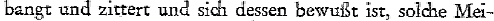
sterwerke nicht selber schaffen zu lsönthen, wenn die uns anvertrauten zerstört wïrden, die Verantwortung, einer Beraubung des armen zukünftigen Volkès an seinen heiligsten Gütern nicht mit allen erdenklideil Mitteln rehtzeitig Einhalt geborer zu haben. Sicber wird später das deutsche Volk im Ansehen der geretteten Bilder mehr Glück und Sinn findes als in sämtlichen Ansichten der politisierenden Deutschen von heute. Ich wage nicht $z u$ hoffen, dail mein Gegenvorschlag durchdringt, der vor-

sähe: daff in der deutschen Republik wie in den klassischen Zeiten Feb̆den kïnftig durch Zweikiämpfe der politischen Fijhrer ausgetratgen werderi möchten, etwa im Zirkus, eindrucksvoller gemacht durch das homerische Geschimpfe der von ihnen angeführten Parteien. Was alsdann harmloser und weniger verworren wäre als die jetzt üblichen Methoden.

\author{
Oskar Kokoschka \\ Professor an der Akademie der \\ bildenden Künste in Dresden
}


Text XXIX: „Orpheus und Eurydike“ (Auszüge)

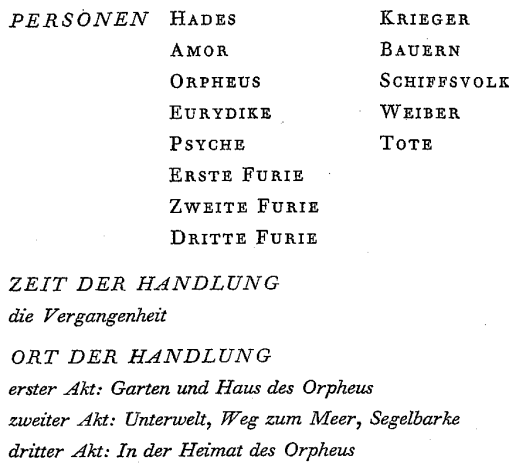

ERSTER AKT

ERSTE SZENE

Eurydike sitzt im Vorbau ihres Gartens. Sie schaut auf die Gebirge hinüber. Auf dem Boden ein Korb mit Nähzeug. Eurydike ist in ein ungefärbtes Lammvlies gehïllt, darunter ein fließendes, violettes Gewand, das Haar fällt in blonden Locken geringelt herunter. Auf dem Finger der einen Hand hat Eurydike einen Ring mit dem Bild des Orpheus, dessen Inschrift sie liest. Ein Wagen rollt an. Man hört die Schellen der Rosse läuten. Orpheus kommt von der Straße herein. Der Übergang vom grellen Licht in den von üppigem. Laub beschatteten Vorbau blendet ihn. Er greift ins Leere. Stößt mit dem Fuß das Körbchen um, aus welchem ein Kinderball rollt. Eurydike lacht leise. Orpheus wirft den Ball Eurydike in den Schoß, küßt sie auf die Stirn, indes er ihren Kopf zart nach rückwärts beugt

EURYDIRE

Du bist zurück?

fast vorwurfsuoll

So bald?

OrpheUs

Und $\mathrm{Du}$, - wie nicht allein?

Als dächtest Du was zu Ende-

EURYIKE

Wie dieser Ring zusammenschmiedet Orpheus und

Eurydike, so

dreht den Ring

ewig Eines Glück im Andern. Das war's. 


\section{schmollend}

Ich hab' Dir nachgeschaut,

wie Du im Wagen, ohne Gruß, heut' morgen

vorbeigefahren bist.

Wie konntest Du!

Nichts als an Dein Glück, an Dich gedacht?

Ich lächle, was nicht alles Liebe unbegreiflich macht für sich

Nein! Ich kann nicht, so vor ihm fremd tun!

laut

Du lang Erwarteter!

Dein Kopf sich neigte in der Fahrt zurück,

für Grüße ich's genommen hab.

Dein Augenpaar auf glatter Vogellinie mich traf.

Du schönèr Blick!

Wenn ich mich nimmer satt sehen könnt' -

Schmilzt der Vergrämtheit Reif nicht durch ein Sonnen-

paar!

Sein Wesen nimmt dem Gatten, die hier sitzt und hütet es. Jetzt $\mathrm{fa} B$ ich's, und dies, da draußen mich verwirrte.

Der Wagen immer kleiner wurde, ein Punkt zuletzt.

Der barg mir ja Dein Angesicht, das mir - nicht - kleiner ward!

Durch das gefälschte Glas der Außenwelt sah ich den Aufzug nur;

oh, der vorüberglitt! -

Mein mir verflüchtigt Wesen der Räder um die Wette Verkleinerung,

Dich, Vollbesitz nicht mit sich fortriß,

noch minderte.

Du! Wenn ich Dich vergessen könnte?

Psyche in der halbgeöffneten Tür, halbwüchsig, schelmisch, mit einer kleinen Schlange im Arm.

EURYDIKE

So - Du mein Kind?

Magst kommen!

Psyche

scheu vor Orpheus, mit fliegenden Augen, erhitzt

EURYDIKE

Was soll's, das Gesichtchen?

PSYCHE

geheimnisvoll tuend

Du Schwester! Du, was ist an einer Tür und einem Rätsel Gleiches?

EURYDIKE

befangen auf die Tür, dann lachend, versucht auf den Scherz einzugehen

\section{PSYCHE}

überlegen

Es ist was drinn, was erst - nichts war.

So ist's, wenn man neugierig ist!
EUR XDIKE

klatscht in die Frände

Sag noch, wer war die Lehrerin?

PSYCHE

wirft sich Eurydike um den Hals

Mir hat's geträumt. -

EURYDIKE

Nun geh!

PsYCHE

Nicht schlafen gehen, es ist noch immer Tag!

- Ich wäre spielen gegangen mit dem Traum, da stehen plötzlich drei fremde Frauen herum, und dann, haben mich die drei Frauen gefragt,

Wer mein Vater ist -

EURYDIKE

leise zu Orpheus

Du mußt es hüten!

Sie weiß manches und verbirgt, wofür sie lebt.

Alle ihre Eigenheiten oft sind Proben.

Das war eben ein Zeugnis.

Du muBt ihr von ihrem Vater sprechen,

damit sie nicht hinter sich blickt.

ORPHEUS

zu Psyche, zögernd, ernst

Der keinen Körper hat, doch mächtig uns bewegt,

hat aus der freien Luft Dich, Geist, für eine Weile ent-

bunden,

hier Eurydike zu dienen. -

Dein Vater!

Wenn seine heftige Macht sie bräche, sollst $\mathrm{Du}$ - im guten Sinn -

ihr nützen; die Du Gestalt wie sie, Gespielin ihr, die Blitze mildern und einherstürmendes Geschick, das durch

Dich

sich fortflicht, sollst rückwärts leiten!

ORPHEUS

an der Brüstung, ins Freie, mit anderm. Ton

Ein neuer Stern ist heute nach dem Regen herausgetreten.

EURYDIKE

Psyche kennt alle Sterne.

der Stern flackert in der Abendluft. Psyche's Kleid weht, als wollte sie selbst entschweben. Eurydike nimmt ihren Arm

PsYCHE

schreit entzückt

Eurydike, laß mich noch!

Dort fliegt der Stern im Himmel!

Jetzt fällt er herein -

entfernt sich leise, läuft dann im Garten weiter

EURYDIRE

Wo ist Psyche geblieben? Kehr um, Kind! 


\section{(...) Fortsetzung beim zweiten Akt, erste Szene:}

\section{ZWEITER AKT}

\section{ERSTE SZENE}

drei Jahre später, im Orkus. Psyche sieht Euryclike unter den Schatten

\section{STIMME DER EURYDIKE}

vom Innern des Orkus

Welche Harmonien - welche Hoffnung -

\section{PSYCHE}

in der Richtung zu Eurydike

Wenn von Orpheus schnell ich jetzt berichte, willst Du hören? Eurydike!

\section{EURYDIKE}

Stimme

Wer ist Orpheus?

Orpheus ist gestaltlos, ist wie dieses Eiland.

Bist Du menschlicher Zunge Wohllaut,

daß Du mich bewregst?

PSyche

Psyche muß Dir dienen -

zu überlisten Hades, riet ich Orpheus, den die Sehnsucht bei lebendigem Leibe herschleppt,

in die Unterwelt zu steigen!

\section{ORPHEUS}

vom Eingang in den Orkus her

Was hast Du gieriger Orkus Deinen Schatten umgeworfen schon

übers ganze Leben ihnen, die Du aufnimmst, Allen.

Jetzt mehr um mich!

Nun kein, nicht ein letzter Augenblick in Schmerzen mehr?

Nachdem, wie vielmal, die Selbstsucht ihn ahgrundtief durchmessen.

Ein Glied, ein Zug an mir verräterisch noch?

Kein Zucken vor dem letzten Handel!

Eurydike! Orpheus ist zum Sterben aller Hoffnung bar.

Hörst Du's?

$\mathrm{Zu}$ den Kalten suche ich vergeblich einen Steig himunter; Schlagt die Augen auf, da meine trüb und naß sind!

Trocken sind die Euren wie die Asche hier?

Hat Euch Psyche schon Gerỉcht verbreitet?

Löst Eurydike einen kurzen Sommer, für mein Leben!

Schlagt zu, Hades!

Die, für meine Haut als Lösegeld!

Orphens versusht, die modrigen Nehel durchschreitend. Furydike unter den Schatten zu erkennen, indem er von Gruppe zu Gruppe kommt. Einige versuchen ithm die Hände zu lecken,

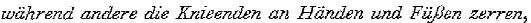
schadenfroh in eine Grube stogen. Bettler mit Krücken verteilen Kehricht aus einem Sack, utm welchen sich faule Dicke zum Fressen anstellen, streiten, Irrsinnise versuchen die Wände hinaufzukleitern und gleiten ab. Mörder mit Dolchen springen auf seinen Schatten. Verliebte kriechen auf allen Vieren davon, wenn er naht, hängen wie ein Schwarm zusammen. Manche haben Tiergesichter oder Sichwänze und Klaten. Kichern, Murmeln, gellendes Lachen aus dem Innern

Eurydike, verzïckt, wie eine Engelsgestalt an diesen elenden
Ort, weißgekleidet, nach dem Sterbegebrauch in einen langen Schleier gehüllt, der an den Enden nachschleift, wird von Psych herangeführt. Alles beim Auftrith urd der Begegnung im sinnlosen Tun innehallend und lauschend.

\section{РАY CHR}

eilt Eurydike voraus, dem Orphens entgagen, der in die Mitte gekommen ist. Leise, hastig

Orpheus, kehre am!

Wenn Du nicht die Augen wendest, micht sie ängstigst mit Vergang'nem, kehrt zuräck Bewußtsein, das Eurydike entwichen!

\section{HUURYIKE}

wird ohnmächtig, versucht zu nufen

Reiß den Schleier weg! - Psyche, was geht denn vor? taumelt, beriuhrt ihn

Orphens! Hier, Orpheus - das ist meine Hand --

Orpheus fassungsios, aber dem Rat der Psyche folgend, blicht weg. Eurydike fallt in die Knie

EURYIRR

Ach, vergib, vergib die lange Zeit?

Orpheus mit abgewandtem Gesicht trägt sie zum Ausgang in die Welt. Alle Schatien ringen die Hände

\section{EURYDIKE}

Vergessen, Orpheus? Nie mehr?

ORPHRUS

Vergessen? Eurydike, nie!

Psyche

bleibt allein gelassen

Vergessen bleibt Psyche hier!

hinter den Emporsteigenden schließen sich die Nebel

\section{ZWEITE SZENE}

Weg vom Krater heraus, dem Ausgang der Unterwelt. Unter Schleierfällen, über vielfache Lavazerklüftungen, die an den Rändern des Wreges, vereist, mitlaufen, die aber mehr zurückbleiben und den Blick durch Schneewände freigeben auf ein liebliches Seegestade in der Tiefe. Schneeschmelze. Fichtenzweige schießen hohe Schneeladungen auf den tauenden Pfad, je mehr es zu Tal geht, desto wärmer wird der Tag. Eurydike zieht wie eine Last am Arm des Orpheus aus dem Eise hervor. Ein Flug Tauben durch einen Nebelriß, der das Meer freilegt.

ORPHEUS

Schwebende Wesen, die eine Faust ausläßt!

Des Aufblicks Sturz nach innen kehrt.

Abbild der Weite drängt im kleinen auszutreten.

Wunschgeschöpfe steigen lassen,

die wie Gelassenheit in der Brust, die Laune lange übersah.

\section{EURYDIKE}

Ein Federchen die Wärme hebt! frischer

- Ich nehm' es so zum Zeichen mir.

Nichts anders war's als Du, Orpheus, zum erstenmal Eurydike's Namen hauchtest. 
Da lebte ich auf und stieg Dir zum Gefallen mit herror. Fühle meine Kräfte!

Zum Wundern kräftigt sich ein Frauenherz, schlägst Du den Herzschlag mit.

Wie geh ich leicht und ohne allen Kummer!

Ist's nicht das frühere frohe Wesen, das Dir gleich innig anliegt?

Sieh meinen freien Schritt.

ORPHEUS

Gib mir Deinen Arm fester.

EURYDIKE

Du hast mit einem Blick den Ring an meiner Hand gesucht?

ORPHEUS

Noch hat die Neigung die beschwichtigende Gewalt zwar -

\section{EURYDIKE}

argwöhnisch, wieder heiter

- ob auch, wenn Du Dir's erst erklären wirst?

Meinst Du.

Komm weiter, Orpheus! Folg.

Nicht grübeln.

Auf Kelches Neige zu prüfen,

den Trunk, den süßen nachgesüßt,

da schmeckt der Satz leicht bitter.

ORPHEUS

Bin schon so weit, hätt' ich gedacht -

Warte -

\section{EURYDIKE}

strauchelt, fällt lachend Orpheus in den Arm

- schon stürz' ich wie ein reißend Strom zum Meer, und halt' Dich schwindelnd um den Hals, Orpheus.

ORPHEUS

Statt Deiner mir im Arm, die Furcht war in die Hoffnung lange eingewunden.

Die Kette schleppt mir nach.

Wie wohl mich nichts versuchte, mich an vergang'nes Leid, Verdruß, gleich unfruchtbare Höllendinge, zu klammern.

Wie manche sich an Dörner, Steine, die im Stürzen. Eurydike, tauch' die Hand ins Licht Täuscht nicht ein Segel vorne?

zeigt aufs Meer. Man sieht eine schwarze Segelbarke, die sich im Nebel und Licht vom Wasser abhebt. Eurydike schricht beim Anblick der Barke zusammen

Sieh! Dort lernt der Ferne wieder Tiefen ab, die Freude! Komm, es färbt Dich frischre Luft, sind wir erst drauf fort!

EURYDIKE

für sich

Auf Hades' Nachen fort? - Ich?
- Das flüsterst Du?

Ich weiß nicht mehr, was mir gehörte.

Eurydike steht unentschlossen hinter Orpheus am Steg. Or-

pheus drängt sie vor sich

\section{ORPHEUS}

Fortsegelnd kannst Du umsehn von der Flucht.

Nachsinnen unterwegs uns wenig Aussicht schafft.

Schau vorn, an ein Steg legt.

Du geh vor mir!

Will sehn, vom lästigen Gestern des Segels

fröhliche Fortbewegung,

Dich auf unübersichtlichem Rund mir

meine Spur schreiben!

Eurydike zögert.

\section{EURYDIKE}

Verwirrt der Herzschlag? Ich und Du. -

Und noch was? Angst vor Dir?

betteind

Lug und Trug - Orpheus - geh Du -

ORPHEUS

Des Tages Mitte öffnet sich für unser Zwei

Durchgehn.

Nichts drängt sich zwischen uns.

Wie eine Spinne, der ihr Fang entschlüpfte,

krümmt unter uns die Nacht sich und vertrollt.

Fühlst Du Dich sicher? Und ich? - Wir allein -

\section{EURYDIKE}

Bliebe es so. Noch ist es nicht zu spät.

ORPHEUS

Zu spät zurück, Du Liebe. Eilen wir.

Weiß nicht wie lange alles greifbar bleibt -

EURYDIKE

- Die Hoffnung, daß es wieder Tag wird morgen!

Kleine Blumen! Wie deutlich spür' ich

eurer Fesseln Lockern.

Wie grüner Samt der Frühling!

Preßt an die Gitterstäbe sein Gesicht. -

Von früher will ich nichts mehr wissen.

ORPHEUS

hebt sie an Bord

Die Segel ziehn uns jetzt hinaus.

EURYDIKE

Ein Federchen die Wärme hebt,

Sprich's - ein Wort - ich lebe.

Dein Kopf sich neigt. Rat' nicht,

warum Eurydike schweigt.

Oh, was ich trieb, das lief Dir in die Wege.

Nimm's gütig auf und schenk' mir's dann zurück.

der Steg wird aufgezogen, das Schiff entfernt sich. 


\section{DRITTE SZENE}

auf der Barke. Bleierne Windstille. Sternbilder, darunter eine schwarze Wolke. Vorne die Kabine, die mit einer Matte verhängt ist bis zur vierten Szene. Die drei Furien hocken, stricken ein Netz, spähen zeitueilig in die Kabine, den Vorhang ein wenig hebend. Der närrische Matrose, auf den das Mondlicht füllt, nickt am Steuer ein, zon der glühenden Hitze gequält, rollt sich in die Nähe der Furien an die Schiffsbrüstung und starrt ins Meer, das glühende Bild des Mondes an

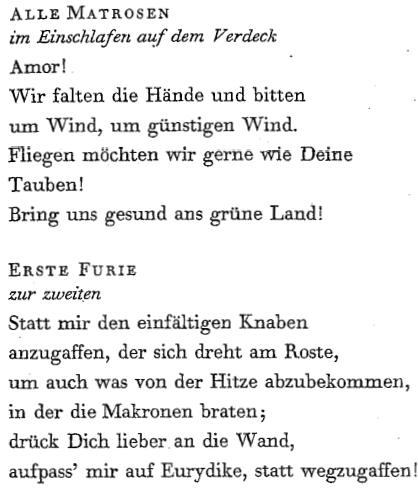

\section{(...) Fortsetzung: gleiche Szene, später:}

Seht, was uns der leibhaft'ge Teufel

nachgeworfen hat!

Netze! - Fischt! -

Heben - heben -

Wie es geifert - wie es spuckt -

wie benetzt - wie begeifert -

sie finden im Netz einen abgehackten, in Tang gehüllten Toten schädel, der ihnen im Gedränge entfällt, gegen die Kabine rollt.

\section{Erster Matrose}

Ei, was? Ein abgehackter Kopf, und wie der grinst!

Schön nicht, wenn man den aufhätt'!

Der Natr

Wir wollen's dem Patron auf

den Hals setzen.

Dem mit dem blassen Weib!

Die drinnen schliefen, dieweil

sie uns so ungebührlich in Gefahr

brachten.

\section{Erster Matrose}

$\mathrm{Ei}$, das Meer ist für alle -

Ist Dir in unserm Boote zu wenig Platz?

Bist Du denn toll? Daß Dich gleich

ein schlimmer's Los für Deine kecken

Reden ereilen soll!

Hier das hinter die Ohren, Lümmel! während der Narr den Schlägen ausweicht, stolpert er über den Totenkopf, findet in dessen Zähnen einen Goldreif, wirft den Schädel in die Kabine und reicht den Reif Orpheus

DER NARR

O Herr! Kein Betrug! Kein Betrug!

O gold'ne Hoffnung! Gold!

Da hatt' ich mich aber gefreut, wie mich das Glück was Gutes fischen ließ. Um's der Frau zu bringen. Die mir dann was in den Beutel stopft, das hätte dem wohlgetan! Branntwein kauf' ich -

\section{VIERTE SZENE}

in der Kajüte. Orpheus und Eurydike auf einer Bank, übernächtig

EURYDIKE

Mir träumte, Du volltest mich verstoßen, in die Kälte, und ich trage Dein Kind unterm Herzen -

ORPHEUS

- Und mir, daß Du rachedürstig, dann in das Herz des Ungebor'nen eine Nadel stößt -

Ich hasse die gaukelnde Nacht, die ächzend mich, von einer Seite auf die noch schrecklichere, andre wirft - - Warum willst Du nicht reden!

EURYDIKE

Genug! Genug!

Solche Gedanken auf einen gerichtet zu sehn - Du machst mich böse und - ich fühle, daß ich Mutter werde Schonung!

ORPHEUS

Vielleicht wird mir dann leichter, wenn ich - alles - weiß und mir Nichts schwärzer ausmalen muß - als schwarz! - Von den Unterirdischen!

EURYDIKE

Nicht fragen! - Ach, könnte ich mehr geliebt sein! sie erhebt sich, als in der Tür der Schädel hereinrollt

ORPHEUS

heftig ihren Arm ergreifend

Sag nur noch, siehst Du - Ihn wenn ich bei Dir bin?

EURYDIKE

traurig

Bleib bei mir! 


\section{(...) Fortsetzung im dritten Akt, zweite Szene:}

\section{DRITTER AKT}

\section{ERSTE SZENE}

Orpheus, zerlumpt, mit abgehärmten, abgefallenen Zügen, kommt mit einer Schaufel auf dem Rücken und beginnt ein Loch zu graben. Utber seinem Haupte schwebt ein Teil des. stehengebliebenen Mauergewölbes. Es droht zu verfallen, Schlingpflanzen überziehen es, die die Ruine bald dem Erdboden und seiner Vegetation gleichmachen werden.

ORPHEUS

Also Bettler, so betrogen bin ich nun selbst.

Ein Wasserloch, das ist für meine Haut!

Dazu Gerber-Lohe, das ist Hohn,

weil euch noch zu wenig mein Fell gegerbt war.

Oder zu schlecht für den Handel?

$\mathrm{DaB}$ ich euch nicht erbose, Unterirdische,

wenn ich wage, mir ein Loch zu graben,

neben euch!

er legt die Herdstelle des Hauses bloß, nimmt eine Handvoll Asche daraus, die er wiegt. Ein Sparren fällt, so daß er hinaufsieht. Orpheus erkennt plötzlich das Haus als seines

\section{OR.PHEUS}

schreit

In diesem Hause wohnt' ich?

Verfluchter Balken, der mich nicht erschlagen!

Soll ein Stein noch gradestehn, mir zum Grabstein?

Da ich nicht verderben kann!

Wühlen in der Asche wie ein Hund, der

Knochen sucht, nach dem Glücke -

Fallet, Mauern! Niederreißen! Stürzen!

Sieben Jahr schon höhnt mich Charon:

Diese, diese Nacht wär ich vorüber!

findet die zerbrochene Leyer im Schutt, spielt sie

Wehklaget's im Moder wieder mit menschlichen

Stimmen, mich zu täuschen? -

So treff' mich der Pfeil des wütenden Amor,

daß im Gesang ich Sonne und Mond, alte, alte

Zeiten, Wollust und Wahnsinn,

selbst das Bild Eurydike's endlich verfluche!

Landleute kommen von den Äckern.

LANDLEUTE

Hört den Maulwurf!

ORPHEUS

He, Gesindel!

Reißt mir die moos'ge Hütte nieder, stürzt die Mauern, daß die Bettstatt bettelleer grinst, sorgt für Feuer auf dem Dache!

Feuerhahn her!

Totengräber!

Stoßt die Schaufel in die Brust mir dann!

Reißt das Herz aus, das verstritten, Ich gegen Ich, einst. Ich mit Eurydike!

Und dann in die Hölle, verflucht bin ich schon

lange gewesen!

Nebelwälder, beginnet euch wieder zu öffnen,

Schleierfall dich wieder zu senken, zu breiten über die vielen zwischenragenden Klippen. Wie sie nachwachsen in unendlicher Größe! Bald Eurydike vergessen! Bald ziehst $\mathrm{Du}$ an mir vorüber und nicht fragen wird Eurydike Orpheus wieder.

\section{LANDLEUTE}

zudringlicher

Ei, mit diesem Sauertopfe haben

wir fürwahr einen köstlichen Fang gemacht. Jetzt diesem da yon der Nähe zugehört!

Denn er ist nicht wie unsereiner!

$\mathrm{Er}$ hat angefangen! Uns zu betören, wie ein Kometenschwanz hat er uns irre gemacht, daß wir von der Scholle, die wir unter der Sonne umbrachen, aus der Gemeine wegliefen.

Neugierig zu hören, wie gegen die Natur der

Leyermann spielte die Saiten,

jagte den Pfeil uns ins Fleisch!

Wie's brennt, der Liebe Widerhaken!

$\mathrm{HaB}$ Dir, Rache!

WEIBER

Versichert euch uns'rer Fäuste, gilt's Rache!

Womit wir zerreißen, was wir geboren!

EIN BETRUNISENER

mit einem Feuerspan

Mit Feuer brennen wir Löcher aus, die die

Liebe gebissen hat -

EINE BETRUNKENE

Hört! Die Musik!

Dem Seufzer antwortet die Zwietracht!

Der Leyer der Liebe Pfeifen und Trompete

des Aufruhrs, des Kriegs!

das Gesindel hat im Hause gewütet, Feuer gelegt, die Zerstörungslustigen beginnen um Orpheus, der auf seiner Grube spielt, einen wilden Reigen zu tanzen. Man verhöhnt ihn

EIN BETRUNKENER

Zahnloser! Leyer und Pfeife rast durch

die Glieder der Schar!

Und Thr heftet euch nicht hinter die Röcke?

Kitzelt mit Skorpionen sein Fleisch,

daß er gestreichelt von solchen Griffen,

aufstürzt, versucht noch einmal, taumelnd

das Bein.

WEIBER

reißen ihn am Haar

Sieh Dir die Grube recht vorsichtig an.

Und wir raten Dir, hinein!

Gerüstete Männer die Himmelsstufen herunter-

rasseln, schnell!

So mit dem Kopfe nach unten!

Damit Du Dir nicht mehr holst,

was Dich verdrießen wird!

Dieweil der wilde Gott der Liebe auf und $a b$

rennt, tritt mit Füßen sein Geschlecht!

Krieger auf einem Beutezug mit Musik. 
ERSTER KRIEGER

Was geht hier vor?

\section{Alle Landleute}

ziehen die Hüte

Sie haben sich eben ein wenig aufgeregt und

das muß ausgeglichen werden, o Herr!

ERSTER KRIEGER

Ihr sollt nur sehen, wie Ordnung wird.

Ich bin der Berühmteste, ich habe das

meiste Blut vergossen. Gebt mir Platz!

beginnt mit den Weibern um eine Dirne zu balgen. Stürzt. Verwirrung

DIE BETRUNKENE

Wozu dies Bedenken!

Die sahen erst wie gold'ne Widder aus;

doch auf die Nieren geprüft, was sie erzeugen mögen?

Nichts! Nachdem sie die blumigen Fluren

zerstampft! Nur Hämmel!

Ein Totenfurz, das ist der Blutruhm!

Nur Hämmel!

DIE KRIEGER

Werft die Knüttel weg, drauf mit den

Fäusten!

die Männer werfen die Waffen weg, die Krieger die Lanzen, beginnen sich zu würgen, die Weiber helfen bald dem, bald jenem.

\section{Alle Weiber}

Begrabt das Gelichter mit Toten!

Das ist Unsterblichkeit!

\section{Die MänNeR}

Blut regnet! Amor!

Allmächtiger, ist das das Ende?

Durst!

DER BETRUNKENE

Die Hunde saufen Blut,

doch mußten sie auch viel Ungemach

ertragen.

Man muß eben abgehärtet sein.

Ein Mann sein, heißt seine Kraft lieben!

die Erde dröhnt, Wiehern, wïtende Pferdeschreie.

EINIGE WEIBER

Im Knäul eine Stute mit durchgegangenen

Hengsten -

ANDERE

Vom Stampfen muß die Erde bersten -

ANDERE

Wer hetzt sie mit Steinwürfen und Peitschen?

ERstes Weib

Da setzt die Weiße über die Hengste weg,

ohne Zaum.
He! Mit dem Bauche fegt sie den Boden.

Ihr folgt ein Ungeheuer. Halb Mann,

halb RoB!

Schweißbedeckte Flanken!

Nicht Maulaffen stehen!

MÄNNER

Es eifert der Kentaur mit uns.

Die Stärksten vor!

Vermehrt mit den Hieben die Liebeslust!

Und die ausgeriss'nen Glieder zerstreut,

Blut! Überfluß über die Erde, wo der

Schweiß nicht ackert!

noch wilder rast der bacchantische Tanz, immer tönt aus dem

Loch die Leyer, Weiber werden Huckepack getragen.

ALLE

Tanzen!

Unter Bissen und Küssen,

Mänaden und Tolle!

LaBt liegen, was stürzt.

Laßt die am Boden, im Unrat

wühlen,

im Kehricht Fliegenschmeiß zeugen

Brust an Brust!

Milch mischt sich mit Blut!

Fäulnis brenzelt in der Glut.

Tanzet vorüber!

Geißelt Ihr Dirnen die drehenden

Burschen, doch haltet Euch gut

auf den Nacken,

man zerrt Euch, wenn Thr abgeworfen,

hinters Gebüsch!

Verschlingt im Übermaß Euch, Kinder!

Jubelt! Frohlocket!

Erbarme Dich unser!

Orpheus wird an der Brandstätte aufgehangen. 


\section{(...) Fortsetzung im dritten Akt, dritte Szene:}

\section{ORPHEUS}

Halt! Ich will Dich nicht auslassen!

Gehascht!

GRIST DER EURYDIKE

Bist Du so weit -

\section{ORPHEUS}

tanzt mit Eurydike

Mit teuflischer Freude ich beichte:

Ich hasse Dich!

Meine Tat ist - Hades - der Tod überlistet!

Du, bist's, hier, hast nicht versäumt mir ins brechende Auge zu grinsen! Tanzen! Tanzen! Nun sieh einmal! Er ließ Dich nicht leben, Hades! Du da! Triumph! Ich laß Dich nicht sterben! Heule, Hölle! Wie brennt sie, wie grollt sie Was hab' ich getan, Dich Geliebte verflucht?! Spei aus Zunge, die hasset sich selber!

Das ist mehr - Mich! Ich verdien's!

Denn ich liebte sie, liebte! - Liebe!

Hörst Du Hades?

Pause. Orpheus stürzt in die Knie

Ein Mörder macht ein Geständnis dem Winkel, wo das Blut herkommt, alles!

Böse, die's mit dem Gewissen haben, denken laut: Erinnre mich einer Nacht, die ähnlich ist. Huh!

- Was ich liebte, zu vergessen! - Da schaffte in mir ein Selbst und schaukelte in einer Welle Blut, Eine, die Dir ähnlich war -

lacht wahnsinnig

Solang war's Geheimnis, was da drin wohnt.

Bis aus dem Mund fließt Schreien zu Diesen, die nicht mehr sind!

Von Mund zu Ohr fliegt,

was brandig - glüht.

Was dumpf - erstickt,

bis es mit Schrecken des Todes Ränder anfüllt. Hinter der Liebe bis in den Tod steckt -

$\mathrm{HaB}$ !

GEIST DER EURYDIKE

Da Liebe so aberwitzig ist, so

wäre der Tod die Aufgabe Unser selbst?

ORPHEUS

erstickt im Lachen

Mutter, hu! Wie heißt's -

Du sollst nicht töten - nicht töten -

Euryclike versucht Orpheus' wahnsinniges Lachen zu ersticken, inclem sie beide Hände gegen seine Kinnbacken preßt, um seinen Hals schnürt. Lange. Die Leyer wimmert noch. Etwas Dunkles schwirrt im Zwielicht. Ein durchdringender Schrei eines Vogels, noch einer seiner Verfolger
GEIST DER. EURYDIKE

Du hauchtest die Flamme,

sie verbrennt Dich. Kentaur!

Nun - bist Du Asche!

So im letzten Kampf umarmend,

voller Entsetzen,

für letzten Kuß, aus des Orpheus' erstarrten Kiefern

lös' ich mich endlich ledig.

Eintönig Lied der Erde -

Was wir umringen, ewig Glïck ist anders -

$\mathrm{Ob}$ es $\mathrm{HaB}$ ist, solche Liebe?

Dies Verlangen -

die Finsternis zerreißt.

\section{NACHSPIEL}

Psyche ist an der Stelle sichtbar, wo eben vorher Eurydike den Geisterreigen angeführt hatte und mit diesem verblaßt war.

PSYCHE

hat ein Bündel Ähren und taubetränte Rosen, Tulpen, Lilien im Schoß, die Leyer im Arm. Erwacht, streckt die Hände nach dem Dämmern, der Ferne

Niemand hier?

Mit dem geraubten Kusse

bist Du so leise beiseite geschlichen, daß ich ruhig weiterschlief?

Ihr Stunden, Ströme, die berauschen,

Trällern, Lachen, Weinen noch im Ohre gellen -

hält sich lachend die Ohren, als ob sie da gekitzelt würde

Oh, Du bist's, nicht Du Traumliebster -

wie - Du meinst - meinst, schnell,

hier könntest Du so lange verkriechen?

reibt sich die Augen

Dicht bei mir seh' ich ein Geländer

nah zum Tag,

in der Luft über dieses flatterte ein Schleier,

Amor, Deiner!

Gestern war's!

Im Spiele.

In Gesichten Psyche Du unterwiesest,

welchen,

wie alle Eifersüchtigen auf das Ungebund'ne

des Gefühls, sie zwiespältig lauschte. -

Und dies fand nicht meinen Beifall, daB Amor Psyche hintern Flieder lockte!

»Gib Acht, Psyche!

Sollst mir die Augen verbinden.«

Und da warst Du nackt,

mit der Hand spürte dies ich.

Gleich drauf flüsterst Du:

»Oh, Du verbindest mich nicht! -

Nein, Psyche! Du bindest mich -«

Und ich fand, Deine Binde vor den Augen

stand Dir schlecht, daß ich selber

Dich nicht mehr erkannte, als vom Bogen, 
auf den die Liebe aufgespanni ist, mir ein Bündel Haß entgegendräute!

Und da lachtest $\mathrm{Dn}$ :

sPsyche!

Was Du tatest!

Eine Stunde später, hast Du mich verlassen können; als da jode Fascr selig dic,

vordem, vergift'ten, Pfeile ritzen -

Winke zärtlich mit der Hand Dir.

weil ich Maì der Küsse wiederfind!

Amor! Bin nicht mehr so bang,

wie ich - dabei - war!

Wohlan!

sie streut die Blumen übers Feld. Mädchen erwachen, Zesen die zum Strauj3.

CHOR DER MADCHEN

Wohlan!

Un der Stimne willen,

die aus einem Wort besteht - Hoffnung?

Hoffnung, tausendfaches $\mathbf{L}$ cho scufzt

mit jedem Falm im Winde,

da die Rinde spaltend,

tiefentzúckt dorten aus der Erde fuhlet

schauernd gegen das Himmelslicht

sich nähern!

PSYCHE

besteigt den schwarzen Nachen, dier am Ufer liegt

Das ewige Licht leuchte ihnen -

CHOR DER BURSCHEN

erwacht, erhebt sich vom Boden

Hoffnung! Saat,

die aus der Nacht sprießt,

ist sie schon bereit zum Schnitt?

PSYche

Erwacht!

Noch ein blut'ger Blitz zittert,

stürzt ins Meer.

Schon wirft die Sonne ihren unendlichen

Schein über die schlafende Nacht -

CHOR DER ALTEN BÄUERINNEN

läuft bange zur Jugend

Gebet Acht!

Wie Empfängnis und Tod

paart mit der Hoffnung sich Angst.

Angst und Hoffnung rühren an die

vielfältig sich spiegelnde Sonne

und erschüttern sie nicht!

Mädchen bekränzen die Burschen lachend mit Blumen

CHOR DER MädCHEN

Wollen wir mit euch, Bösen, Blumen tauschen?

Uns'rer Wangen Rosen nach dem ersten Kuß

erwacht sind, als wir auf der Blüten Tau

überall, eure Spur vorfanden!
PSYCKI

rilhrt die Leyer, der Kuhn entfernt sich

Tränen auf der Wangen Blut, ja,

hinterließ der Traum

den erschrock'nen Schläferinnen -

CHOR DER BURSCHEN

klirren mit den Weinbechern, fröhliches Rufen

Ja, so war es!

Als sich Anoor leise wegschlich,

Ist Psyche erwacht mit Tränen!

PSYche

das Schiff entschwindet den Alugen, Leyer

- Ihrm war - ich - zunächst!

Ich hab' exch lieb! -

CHOR DIR BURSCHEN

Die Sonne auf tausenden Ebenen her -

und die Augen noch hinter sich

wirft die Psyche vorm Glanz -

Chor DER MÄDCHEN

- selig wie die Lerche,

die den Stern anbetet.

alle knien nieder. 



\title{
C Abbildungsverzeichnis
}

\author{
Ludwig Meidner
}

Abb. 1: Ludwig Meidner: „Bau der Untergrundbahn in Berlin“, 1910,

Öl/Leinwand, 65 x 80 cm, Museum Ludwig, Museen der Stadt Köln. Breuer (1991) 2, S. 81.

Abb. 2: Ludwig Meidner: „Gasometer in Berlin-Wilmersdorf“, 1911,

Öl/Leinwand, 67 x 80 cm, Staatsgalerie Stuttgart. Bartmann (1987), S. 287.

Abb. 3: Ludwig Meidner: „Alaunstraße Dresden“, 1914, Feder, Tusche, 63,5 x 48 cm, Staatliche Kunstsammlungen Dresden. Breuer (1991) 2, S. 99.

Abb. 4: Ludwig Meidner: „Landschaft: Landhaus in Dresden“ („Das Eckhaus“), 1913, Öl/Leinwand, 92,7 x 78 cm, Sammlung Thyssen-Bornemisza, Lugano. Guratzsch (2003), S. 23.

Abb. 5: Ludwig Meidner: „Süd-Westkorso in Berlin-Friedenau“, 1913, Rohrfeder, Tusche, 41,3 x 56,2 cm, E.W.K., Bern. Breuer(1991) 2, S. 90.

Abb. 6: Ludwig Meidner: „Mond über Berliner Stadtbahnbrücke“, 1913, Feder, Tusche, Deckweiß, 46 x 59 cm, Saarland Museum Saarbrücken, Stiftung Saarländischer Kulturbesitz. Brener (1991) 2, S. 97.

Abb. 7: Ludwig Meidner: „Potsdamer Platz“, 1918 (aus der Mappe „Straßen und Cafés"), Lichtdruck (nach einer Vorzeichnung von 1913), 37 x 29 cm, Nachlass Ludwig Meidner Darmstadt. Brener (1991) 2, S. 109.

Abb. 8: Ludwig Meidner: „Vorzeichnung: Caféhaus in Berlin“, 1913 (aus der Mappe „Straßen und Cafés"), Feder, Tusche, 41 x 39,5 cm, Privatbesitz. Breuer (2001), S. 26.

Abb. 9: Ludwig Meidner: „Stammtisch-\$11“, 12. Januar 1915, 1915, Tusche und Bleistift, collagiert auf Zeichenkarton, 47,4 x $64 \mathrm{~cm}$, Privatbesitz (Winfried Flammann, Karlsruhe). Müller (2009), Kat.Nr. 46.

Abb. 10: Ludwig Meidner: „Die Bar, Wilmersdorf“, 1915, Tusche auf Papier, 48,3 x 38,7 cm, Indiana University Art Museum, Bloomington, Indiana. Breuer (1991) 2, S. 121. 
Abb. 11: Ludwig Meidner: „Betrunkene Straße mit Selbstbildnis“, 1913, Pinsel, Tusche, weiße Deckfarbe, 46 x 58,5 cm, Saarland Museum Saarbrücken, Stiftung Saarländischer Kulturbesitz. Breuer (1991) 2, S. 91.

Abb. 12: Ludwig Meidner: „Ich und die Stadt“, 1913, Öl/Leinwand, 60 x 50 cm, Privatbesitz. Eliel (1990), S. 82.

Abb. 13: Ludwig Meidner: „Landschaft: Hafenplatz“, („Apokalyptische Landschaft"/,Spreehafen Berlin“), 1913, Öl/Leinwand, 81 x 116 cm, Saarland Museum Saarbrücken, Stiftung Saarländischer Kulturbesitz. Bartmann (1987), S. 289.

Abb. 14: Ludwig Meidner: „Apokalyptische Landschaft“, 1912/13, Rückseite: „Barrikade“ (s. Bild 19), Öl/Leinwand, 80 x 116 cm, Staatliche Museen PreuBischer Kulturbesitz, Neue Nationalgalerie, Berlin. Eliel (1990), S. 32.

Abb. 15: Ludwig Meidner: „Apokalyptische Landschaft““ 1912/13, Öl/Leinwand, $67 \times 78,5 \mathrm{~cm}$, Staatsgalerie Stuttgart. Eliel (1990), S. 85.

Abb. 16: Ludwig Meidner: „Apokalyptische Landschaft“, 1913, Öl/Leinwand, $67,3 \times 80 \mathrm{~cm}$, Sammlung Janet und Marvin Fishman, Milwaukee/Wisconsin. Breuer (1991) 2, S. 135.

Abb. 17: Ludwig Meidner: „Schlachtfeld“, 1912, Kohlezeichnung, 46 x 53,5 cm, Saalbau-Galerie Darmstadt. Breuer (1991) 2, S. 161.

Abb. 18: Ludwig Meidner: „Am Vorabend des Krieges“, 1914, Pinsel, Feder, Tusche, 58,5 x $44 \mathrm{~cm}$, Städtische Kunsthalle, Museen der Stadt Recklinghausen. Grochowiak (1966), Abb. 58.

Abb. 19: Ludwig Meidner: „Die Bombe“, 1914 (Blatt 2 aus der Mappe: „Krieg““ Nach der Vorzeichnung: „Brückenexplosion“), Lichtdruck, 40 x $32 \mathrm{~cm}$, Nachlass Ludwig Meidner, Darmstadt. Breuer (1991) 1, S. 97.

Abb. 20: Ludwig Meidner: „Verwundeter“, 1917 (aus: „Das zweite Psalmenbuch“. Skizzenbuch aus dem Gefangenenlager Cottbus-Merzdorf), Kugelspitzfeder mit Stau, Tusche, 37 × 27 cm, Nachlass Ludwig Meidner, Darmstadt. Grochowiak (1966), S. 114.

Abb. 21: Ludwig Meidner: ,Jüngster Tag“،, 1916, Öl/Leinwand, 100 x 150 cm, Berlinische Galerie Berlin. Eliel (1990), S. 58.

Abb. 22: Ludwig Meidner: „Das schwarze Revier“, 1913 (Titelseite zu P. Zechs „Das schwarze Revier“/Lyrische Flugblätter, erschienen m A. R. Meyer Verlag, Berlin-Wilmersdorf), Tuschezeichnung, Staatsbibliothek Preußischer Kulturbesitz, Berlin. Breuer (1991) 2, S. 250.

Abb. 23: Ludwig Meidner: „Barrikade“ („Revolution“/,Barrikadenkampf ${ }^{\text {“) }}$, 1912, Rückseite: „Apokalyptische Landschaft“ (s. Bild 10), Öl/Leinwand, 80 x 116 $\mathrm{cm}$, Staatliche Museen Preußischer Kulturbesitz, Neue Nationalgalerie, Berlin. Eliel (1990), S. 28.

Abb. 24: Eugène Delacroix: „Die Freiheit führt das Volk an“, 1830, Öl/Leinwand, 260 x 325 cm, Louvre, Paris. Sérullaz/Pomarède (2004), S. 4/ 5. 
Abb. 25: Ludwig Meidner: „Ewig im Aufruhr“، 1919 (Umschlagbild zur gleichnamigen Flugschrift (Nr.7/1920)), Tuschezeichnung, Schiller-

Nationalmuseum/Deutsches Literaturarchiv, Marbach a. N. Breuer (1991) 2, S. 251.

Abb. 26: Ludwig Meidner: „Ex libris“, 1902, Tusche und Feder auf Papier, montiert, Bl.: 16 x 10,6 cm/Ul:: 38 x 22,6 cm, Städtische Kunstsammlungen Darmstadt. Breuer (1991) 2, S. 65.

Abb. 27: Ludwig Meidner: „Der Heilige Franziskus“, 1902, Tusche und Feder, 34,9 x 29,2 cm, Städtische Kunstsammlungen Darmstadt. Ulmer (1991), S. 108.

Abb. 28: Ludwig Meidner: „Töte das Fleisch!“‘, 1902, Tusche und Feder auf rosafarbenem Papier, montiert, Bl:: 20,2 x 31,8 cm/Ul:: 31,6 x 37,7 cm, Städtische Kunstsammlungen Darmstadt. Guratzsch (2003), S. 35.

Abb. 29: Ludwig Meidner: Prophetenfigur, 1915 (Illustration für „Im Nacken das Sternemeer", 1918 im Kurt Wolff Verlag, Leipzig erschienen), Tusche und Feder, Ca. 15 x 11,8 cm, Städtische Kunstsammlungen Darmstadt. Breuer (1991) 2, S. 182.

Abb. 30: Ludwig Meidner: „Die Sibylle“, 1916, Tusche, Feder und Pinsel auf Karton, 101 x 72 cm, Privatbesitz. Guratzsch (2003), S. 33.

Abb. 31: Ludwig Meidner: „Trauernder Prophet“, 1917, (aus „Psalmenbuch“, Skizzenbuch aus dem Kriegsgefangenenlager Kottbus-Merzdorf, begonnen 1917), Tusche und Feder, 27 x 37 cm, Nachlass Ludwig Meidner, Darmstadt. Breuer (1991), S. 186.

Abb. 32: Ludwig Meidner: „Aus Rotte Korach“, 1920, Fettkreide, 62 x 47 cm, Privatbesitz. Breuer (1991) 2, S. 201.

Abb. 33: Ludwig Meidner: Selbstporträt, 1905, Bleistift, 20,3 x 14,5 cm, Sammlung Marvin und Janet Fishman, Milwaukee/Wisconsin. Breuer(1991) 2, S. 40.

Abb. 34: Ludwig Meidner: Selbstporträt, 1912, Öl/Leinwand, 79, 5 x 60 cm, Hessisches Landesmuseum Darmstadt. Brener (1991) 2, S. 39.

Abb. 35: Ludwig Meidner: „Selbstmörder“, 1912, Öl/Leinwand, 69,4 x 59 cm, Bayerische Staatsgemäldesammlungen, Pinakothek der Moderne, München. Schulz-Hoffmann (2002), S. 230.

Abb. 36: Ludwig Meidner: Selbstporträt, 1916, Tusche und Feder, 58,5 x 48,3 cm, Schiller-Nationalmuseum/Deutsches Literaturarchiv, Marbach a. N. Breuer (1991) 2, S. 52.

Abb. 37: Ludwig Meidner: Selbstporträt, 1923, Öl auf Pappe, 60 x 47 cm, Sammlung Janet und Marvin Fishman, Milwaukee/Wisconsin. Breuer(1991) 2, S. 61.

Abb. 38: Ludwig Meidner: „Max Herrmann-Neiße“, 1913, Öl/Leinwand, 89 x $74,5 \mathrm{~cm}$, The Art Institute of Chicago. Grochowiak (1966), Tafel XVII. 
Abb. 39: Ludwig Meidner: „Ernst Wilhelm Lotz“, 1914, Kalte Nadel, Platte: 14,8 x 11,8 cm/Blatt: 36 x 23,8 cm, Städtische Kunstsammlungen Darmstadt. Brever (1991) 2, S. 222

\section{Oskar Kokoschka}

Abb. 40: Oskar Kokoschka: „Das Mädchen Li und Ich“, 1907, Farblithografie, 25,9 x 29,2 cm, Lentos Kunstmuseum, Linz. Husslein-Arco (2008), S. 85.

Abb. 41: Oskar Kokoschka: „Amokläufer“", 1909, Tusche und Tempera auf Papier, 24,9 x 18,2 cm, Galerie und Auktionshaus Wolf Dietrich Hassfurther, Wien. Husslein-Arco (2008), S. 145.

Abb. 42: Oskar Kokoschka: Plakat „Pietà“, 1909, Farblithografie, 125 x 81 cm, Leopold Museum, Wien. Husslein-Aroo (2008), S. 147.

Abb. 43: Oskar Kokoschka: Fächer aus dem Besitz Grand Pick, ca. 1909/1911, Deckfarben und Tusche auf „Schwanenhaut", Property of the Estate of Grant Pick, USA. Spielmann (1988), S. 16.

Abb. 44: Oskar Kokoschka: 2. Fächer für Alma, 1912, Feder, Tusche und Aquarell auf Pergament, 21,5 x $40 \mathrm{~cm}$, Museum für Kunst und Gewerbe, Hamburg/Stiftung zur Förderung der Hamburgischen Kunstsammlungen. Spielmann (2003), S. 184.

Abb. 45: Oskar Kokoschka: Doppelbildnis, 1912, Öl/Leinwand, 100 x 90 cm, Museum Folkwang, Essen. Spielmann (2003), S. 185.

Abb. 46-48: Oskar Kokoschka: Illustrationsfolge zu „Allos Makar“, 1914

- Abb. 46: „Sonne über einem vogelähnlichen Paar“, Kreidelithografie, 18 x 15,1 cm. Wingler/Welz. (1975), Kat. Nr. 72.

- Abb. 47: „Der Mann im Schoße des Weibes liegend“, Kreidelithografie, 15,3 x 14,8 cm. Wingler/Welz.(1975), Kat. Nr. 70.

- Abb. 48: „Der Mann im Boot“", Kreidelithografie, 14,4 x 19,1 cm. Wingler/Welz. (1975), Kat. Nr. 71.

Abb. 49: Oskar Kokoschka: „Das Paar im Boot“ (Detail aus dem 3. Fächer für Alma), 1913, Feder, Tusche und Aquarell auf Pergament, 21,5 x $40 \mathrm{~cm}$, Museum für Kunst und Gewerbe, Hamburg/Stiftung zur Förderung der Hamburgischen Kunstsammlungen. Spielmann (2003), S. 187.

Abb. 50: Oskar Kokoschka: „Die Windsbraut“, 1913, Öl/Leinwand, 181 x 221 cm, Kunstmuseum Basel. Spielmann (2003), S. 190.

Abb. 51: Oskar Kokoschka: „Stehender weiblicher Akt/Alma Mahler“, 1918, Öl auf Papier auf Leinwand, 180 x 85 cm, Privatbesitz. Husslein-Arco (2008), S. 271. 
Abb. 52: Oskar Kokoschka: „Maler mit Puppe“, 1922, Öl/Leinwand, 85 x 120 $\mathrm{cm}$, Staatliche Museen Preußischer Kulturbesitz, Neue Nationalgalerie, Berlin. Winkler/Erling (1995), Kat. Nr. 158.

Abb. 53: Oskar Kokoschka: Sturm-Plakat, 1910, Öl/Leinwand, 102 x 70 cm, Szépmüveszeti Muzeum, Budapest. Natter (2002), S. 134.

Abb. 54: Oskar Kokoschka: „Heiliger Sebastian mit Engel“, 1911, Öl/Leinwand, 70,5 x 51,5 cm, Niederösterreichisches Landesmuseum, Wien.

Schröder/Winkler (1991), Kat. Nr. 16.

Abb. 55: Oskar Kokoschka: „Ritter, Tod und Engel I“, 1911 (?), Öl/Leinwand, 86 x 75,5 cm, Kunsthaus Zürich. Winkler/Erling (1995), Kat. Nr. 63.

Abb. 56: Oskar Kokoschka: „Verkündigung“, 1911, Öl/Leinwand, 83 x 122,5 cm, Museum am Ostwall, Dortmund. Schröder/Winkler (1991), Kat. Nr. 18.

Abb. 57: Oskar Kokoschka: Kaminfresko, 1914, Tempera und Öl auf trockenem Kalkputz, 68 x 403 cm, Privatbesitz. Husslein-Arco (2008), S. 246/249.

Abb. 58: Oskar Kokoschka: „Das Weib führt den Mann“ (4. Blatt der Illustrationsfolge zu „O Ewigkeit, du Donnerwort“/Bachkantate), 1914, Kreidelithografie, 39,2 x 31,3 cm. Wingler/Welz. (1975), Kat. Nr. 61.

Abb. 59: Oskar Kokoschka: 4. Fächer für Alma, 1913, Feder, Tusche und Aquarell auf Pergament, 21,5 x $40 \mathrm{~cm}$, Museum für Kunst und Gewerbe/Stiftung zur Förderung der Hamburgischen Kunstsammlungen. Spielmann (1988), S. $72 / 73$.

Abb. 60: Oskar Kokoschka: „Der Apfel der Eva“ (6. Blatt der Illustrationsfolge zu „Der gefesselte Kolumbus“), 1913, Kreidelithografie, 34 x 29,5 cm. Wingler/Welz. (1975), Kat. Nr. 48.

Abb. 61: Oskar Kokoschka: „Adam und Eva“ (1. Blatt der Illustrationsfolge zu „Hiob“), 1916/17, Kreidelithografie, 24,7 x 25,4 cm. Wingler/Welz. (1975), Kat. Nr. 87.

Abb. 62: Oskar Kokoschka: Pietà („Es ist genug“) (11. Blatt der Illustrationsfolge zu „O Ewigkeit, du Donnerwort“/Bachkantate), 1914, Kreidelithografie, 29,2 x 32,2 cm. Wingler/Welz. (1975), Kat. Nr. 68.

Abb. 63: Oskar Kokoschka: „Ernst Reinhold“, 1909, Öl/Leinwand, 81 x 65 cm, Musée d'Art Moderne, Musées Royaux des Beaux-Arts de Belgique, Brüssel. Natter (2002), S. 99.

Abb. 64: Oskar Kokoschka: „Ludwig Ritter von Janikowsky“, 1909,

Öl/Leinwand, 60,2 x 55,2 cm, Privatsammlung, New York. Natter (2002),

S. 113.

Abb. 65: Oskar Kokoschka: „Karl Kraus I“, 1909, Feder und Pinsel in Tusche auf Papier, 29,7 x 20,6 cm, Sammlung Walter Feilchenfeldt, Zürich. Natter (2002), S. 188. 
Abb. 66: Oskar Kokoschka: „Auguste Forel““, 1910, Öl/Leinwand, 70 x 58 cm, Städtische Kunsthalle Mannheim. Spielmann (2003), S. 129.

Abb. 67: Oskar Kokoschka: Porträt von Hans und Erica Tietze, 1909, Öl/Leinwand, 76,5 x 136,2 cm, Museum of Modern Art, New York. Natter (2002), S. 123.

Abb. 68: Oskar Kokoschka: „Die Auswanderer“, 1916/17, Öl/Leinwand, 95 x $146 \mathrm{~cm}$, Pinakothek der Moderne, Bayerische Staatsgemäldesammlung, München. Spielmann (2003), S. 197.

Abb. 69: Oskar Kokoschka: „Die Freunde“, 1917/18, Öl/Leinwand, 102 x 151 $\mathrm{cm}$, Neue Galerie der Stadt Linz, Wolfgang-Gurlitt-Museum. Spielmann (2003), S. 197.

Abb. 70: Oskar Kokoschka: Selbstbildnis (Hand auf der Brust), 1913, Öl/Leinwand, 79,1 x 49,5 cm, Museum of Modern Art, New York. Natter (2002), S. 165.

Abb. 71: Oskar Kokoschka: Selbstbildnis, 1917, Öl/Leinwand, 79 x 63 cm, Von der Heydt Museum, Wuppertal. Husslein-Arco (2008), S. 265.

Abb. 72: Oskar Kokoschka: Selbstbildnis mit emporgehaltenem Pinsel, 1913, Öl/Leinwand, 108,5 x 70,5 cm, Kunstsammlung Nordrhein-Westfalen, Düsseldorf. Schröder/Winkler (1991), Kat. Nr. 22.

Abb. 73: Oskar Kokoschka: Selbstbildnis (Brustbild mit Zeichenstift), Titelblatt zu „O Ewigkeit, du Donnerwort“/Bachkantate, 1914, Kreidelithografie, 45,5 x 30,5 cm. Wingler/Welz. (1975), Kat. Nr. 58.

Abb. 74: Oskar Kokoschka: Selbstbildnis/„Der irrende Ritter“, 1914/15, Öl/Leinwand, 89,5 x 180,1 cm, The Solomon R. Guggenheim Museum, New York. Natter (2002), S. 181.

Abb. 75: Oskar Kokoschka: 5. Fächer für Alma, 1914, Feder, Tusche und Aquarell auf Pergament, 21,5 x $40 \mathrm{~cm}$, Museum für Kunst und Gewerbe/Stiftung zur Förderung der Hamburgischen Kunstsammlungen. Spielmann (1988), S. $86 / 87$.

Abb. 76: Oskar Kokoschka: 6. Fächer für Alma, 1914, Feder, Tusche und Aquarell auf Pergament, 21,5 x $40 \mathrm{~cm}$, Museum für Kunst und Gewerbe/Stiftung zur Förderung der Hamburgischen Kunstsammlungen. Spielmann (1988), S. $96 / 97$.

Abb. 77: Oskar Kokoschka: „Maschinengewehrstellung auf Cote 588 Selo“, 1916, Aquarell und Kreide auf Papier, 30,4 x 42,9 cm, Privatbesitz, Courtesy Kunsthandel Wienerroither \& Kohlbacher, Wien. Husslein-Arco (2008), S. 257.

Abb. 78: Oskar Kokoschka: „Feuernde Batterie“, 1916, Farbige Fettkreiden auf braunem Zeichenpapier, 30,3 x 43,4 cm, Privatbesitz. Spielmann (2005), Nr. 55.

Abb. 79: Oskar Kokoschka: „Projektionsgewehr in eingedeckter Stellung“, 1916, Farbkreiden, schwarze Kreide auf grauem Linienbütten, 32,2 x 48,2 cm, Sammlung Dr. Rudolf Leopold, Wien. Strobl/Weidinger (1994), Nr. 203. 
Abb. 80: Oskar Kokoschka: „Soldaten einander mit Kruzifixen bekämpfend“, (1917), Blaue Fettkreide auf Papier, 39,2 x 29,9 cm, Privatbesitz. Strobl/Weidinger (1994), Nr. 220.

Abb. 81: Oskar Kokoschka: ,Toter Soldat auf dem Schlachtfeld, über ihn hinwegspringender Wolf“', 1917, Roter Farbstift auf leicht getöntem Papier, 48,8 x 33,5 cm, Privatbesitz. Strobl/Weidinger (1994), Nr. 224.

Abb. 82: Oskar Kokoschka: „Orpheus auf dem Leichenfeld“, (1917), Schwarze Kreide auf getöntem Papier, 17,8 x 24,7 cm, Privatbesitz. Strobl/Weidinger (1994), Nr. 218.

Abb. 83: Oskar Kokoschka: „Staatsfrohn“, (1917), Blaue Fettkreide auf gebräuntem Papier, 57,4 x 34,3 cm, Privatbesitz. Strobl/Weidinger (1994), Nr. 219.

Abb. 84: Oskar Kokoschka: „Das Prinzip“, 1918 Farblithografie, 35 x 24,5 cm. Wingler/Welz. (1975), Kat. Nr. 132.

Abb. 85: Oskar Kokoschka: Orpheus begrüßt Eurydike, 2. Blatt der Illustrationsfolge zu „Orpheus und Eurydike“, 1918, Kaltnadelradierung, 15,9 x 11,7 cm (Platte). Wingler/Welz. (1975), Kat. Nr. 121.

Abb. 86: Oskar Kokoschka: „Orpheus und Eurydike“, 1917, Öl/Leinwand, 70 x $50 \mathrm{~cm}$, Sammlung Himan Brown, New York. Schröder/Winkler (1991), Kat. Nr. 33.

Abb. 87: Oskar Kokoschka: „Stilleben mit Hammel und Hyazinthe“, 1910, Öl/Leinwand, 87 x $114 \mathrm{~cm}$, Österreichische Galerie im Belvedere, Wien. Schröder/Winkler (2001), Kat. Nr. 7.

Abb. 88: Oskar Kokoschka: „Stilleben mit Putto und Kaninchen“, 1913/14, Öl/Leinwand, $90 \times 120$ cm, Kunsthaus Zürich. Husslein-Arco (2008), S. 243.

Abb. 89: Oskar Kokoschka: „Die Macht der Musik“, 1920, Öl/Leinwand, 100 x 151, $5 \mathrm{~cm}$, Stedelijk Van Abbe Museum, Eindhoven. Schröder/Winkler (1991), Kat. Nr. 36. 
Aus urheberrechtlichen Gründen dürfen die Abbildungen, die Sie in der gedruckten Version des Buches finden, nicht online veröffentlicht werden.

Die gedruckte Fassung ist direkt über die Homepage des Universitätsverlags Göttingen www.univerlag. uni-goettingen.de oder über den Buchhandel erhältlich. 
er Expressionismus als Bewegung zu Beginn des 20. Jahrhunderts erfasste Künstler, Literaten und Musiker gleichermaßen und legte wichtige Grundlagen für die Entwicklung der modernen Kunst. Außergewöhnlich hoch ist in dieser Zeit die Zahl doppelbegabter Künstler, die gedrängt vom Willen zu gesellschaftlichem Umbruch und inspiriert von neuesten Erkenntnissen aus Philosophie und Wissenschaft ihren expressiven und emotional aufgeladenen künstlerischen Ausdruck in verschiedenen Medien suchten. Untersuchungen zeitgenössischer Texte geben Aufschluss über die Voraussetzungen zum doppelbegabten Schaffen, das wie der historische Vergleich zeigt, nie zuvor in solcher Intensität stattgefunden hat.

Hervorragende Beispiele expressionistischer Doppelbegabung sind Oskar Kokoschka - prominenter Künstler und „Begründer des Dramenexpressionismus“ - und Ludwig Meidner, der für seine apokalyptischen Landschaften einst hoch gerühmt wurde. Der Vergleich ihrer Gemälde und Grafiken mit ihren Dramen, Gedichten und Prosatexten erlaubt interessante, tiefergehende Einblicke in ihre Intentionen und die Bandbreite ihrer Themen. Zugleich ermöglicht der interdisziplinäre Ansatz ein eingehenderes Verständnis für ihr expressionistisches Gesamtœuvre und die Bezüge zwischen Kunst und Literatur. 